\author{
UNIVERSIDADE DE SÃO PAULO \\ ESCOLA DE ENGENHARIA DE SÃO CARLOS \\ CENTRO DE RECURSOS HÍDRICOS E ESTUDOS AMBIENTAIS \\ PROGRAMA DE PÓS GRADUAÇÃO EM CIÊNCIAS DA ENGENHARIA AMBIENTAL
}

ANTONIO KLEDSON LEAL SILVA

\begin{abstract}
IMPACTO DA EXPANSÃO DA PALMA DE ÓLEO SOBRE O ESCOAMENTO SUPERFICIAL E PRODUÇÃO DE SEDIMENTOS NAS SUB-BACIAS HIDROGRÁFICAS NÃO MONITORADAS DOS RIOS BUJARU E MARIQUITA NO NORDESTE DO ESTADO DO PARÁ, AMAZÔNIA ORIENTAL.
\end{abstract}

São Carlos 

ANTONIO KLEDSON LEAL SILVA

\section{IMPACTO DA EXPANSÃO DA PALMA DE ÓLEO SOBRE O ESCOAMENTO SUPERFICIAL E PRODUÇÃO DE SEDIMENTOS NAS SUB-BACIAS HIDROGRÁFICAS NÃO MONITORADAS DOS RIOS BUJARU E MARIQUITA NO NORDESTE DO ESTADO DO PARÁ, AMAZÔNIA ORIENTAL.}

Tese apresentada à Escola de Engenharia e São Carlos, Universidade de São Paulo, como parte dos requisitos para obtenção do título de Doutor em Ciências da Engenharia Ambiental.

Orientador: Prof. Dr. Silvio Crestana

São Carlos 
AUTORIZO A REPRODUÇÃO TOTAL OU PARCIAL DESTE TRABALHO, POR QUALQUER MEIO CONVENCIONAL OU ELETRÔNICO, PARA FINS DE ESTUDO E PESQUISA, DESDE QUE CITADA A FONTE.

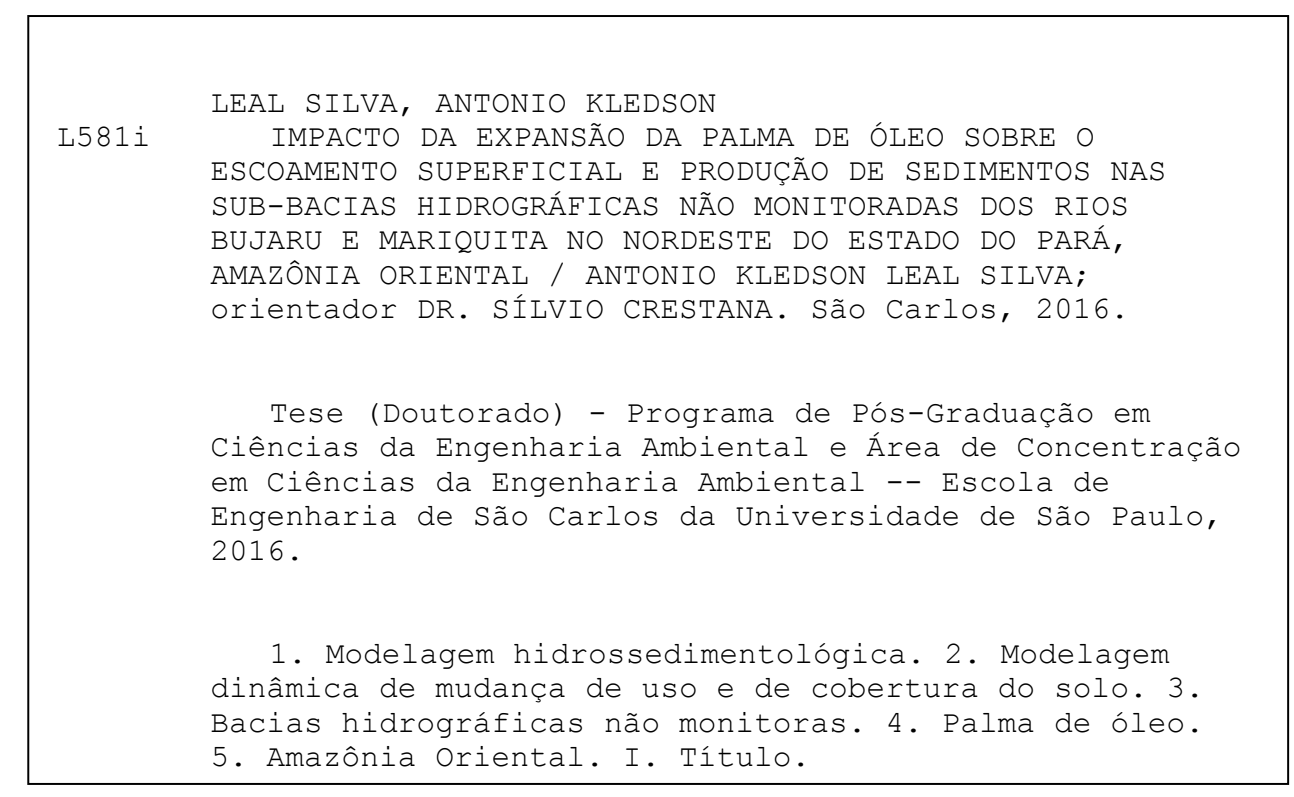




\section{FOLHA DE JULGAMENTO}

Candidato: Engenheiro ANTONIO KLEDSON LEAL SILVA.

Título da tese: "Impacto da expansão da palma de óleo sobre o escoamento superficial e produção de sedimentos nas sub-bacias hidrográficas não monitoradas dos rios Bujaru e Mariquita no nordeste do estado do Pará, Amazônia Oriental".

Data da defesa: 27/04/2016

\section{Comissão Julgadora:}

Prof. Dr. Silvio Crestana

(Orientador)

(EMBRAPA Instrumentação)

Prof. Associado Frederico Fabio Mauad

(Escola de Engenharia de São Carlos/EESC)

Prof. Dr. Adriano Marlisom Leão de Sousa

(Universidade Federal Rural da Amazônia/UFRA)

Dra. Luciana de Souza Soler

(Instituto Nacional de Pesquisas Espaciais/INPE)

Dr. Sandro Eduardo Marschhausen Pereira

(EMBRAPA Meio Ambiente)

\section{Resultado:}
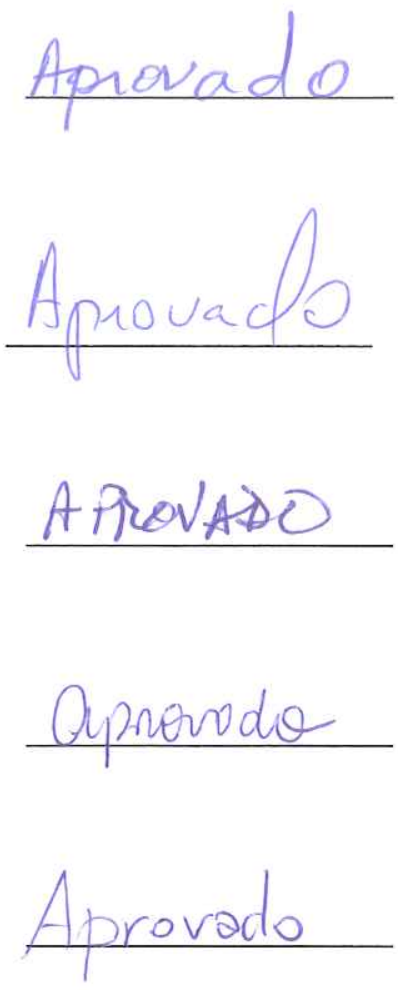

Coordenador do Programa de Pós-Graduação em Ciências da Engenharia Ambiental:

Prof. Associado Frederico Fabio Mauad

Presidente da Comissão de Pós-Graduação:

Prof. Associado Paulo César Lima Segantine 



\section{DEDICATÓRIA}

À família que faço parte: meu pai Antonio, minha mãe Terezinha, meus irmãos, Klebson e Katiúcia, aos meus sobrinhos Victor, Henrique e Malu e à minha cunhada Mayara!

À minha futura família, que se iniciará com a Ana Paula, minha futura companheira, e amor da minha vida, e vem crescer com os nossos filhos e agradeço também aos seus familiares!

Aos amigos, pois somos eternamente responsáveis por aquilo que cativamos! 



\section{AGRADECIMENTOS}

Grato a Força Superior, nosso Pai Criador, Deus do Universo por esta bela oportunidade de evolução pessoal. Que os frutos deste trabalho sejam compartilhados de maneira bondosa, responsável e desinteressada com meus irmãos!

Aos meus Pais, Antonio das Neves Silva e Terezinha Leal Silva pela vida e pelo fiel apoio neste momento inspirador de nossas vidas! Se venci... Sou fruto da glória de vocês!

Agradecimento especial ao meu querido orientador, Dr. Sílvio Crestana, que me concedeu a oportunidade, ferramentas e o incentivo necessários ao desenvolvimento deste trabalho durante esta jornada. Dentre todos os ensinamentos advindos de sua experiência de vida, a de que eu posso ser algo a mais, crescer um tanto a mais, ir além do imaginável e se superar constantemente sempre estarão vivos em minha memória! Quero que deste trabalho surja uma boa amizade, enriquecida pelo respeito e pela confiança, pois essa é a melhor forma que posso retribuir a sua paciência, compreensão e dedicação.

Aos meus irmãos pelo apoio, carinho e pensamento positivo! Essa vitória é de vocês também!

À minha futura companheira Ana Paula, que sempre esteve em meus pensamentos quando traçados os objetivos desta jornada! Que a luz de Deus se mostre nesta vitória a você.

À Universidade de São Paulo, que através do Centro de Recursos Hídricos e Estudos Ambientais da Escola de Engenharia de São Carlos me concedeu esta oportunidade de continuar minha caminhada profissional numa excelente instituição de ensino, a qual me sinto honrado e privilegiado por ter vivenciado estes quatro anos de curso na Pós Graduação em Ciências da Engenharia Ambiental.

À Universidade Federal do Sul e Sudeste do Pará (UNIFESSPA), em especial às Graduações em Educação do Campo, que fiz parte, e em Biologia, atualmente como docente, pelo auxílio em colaborarem com minha formação através da minha liberação. 
Ao Dr. Adriano Marlyson Leão de Sousa, professor pesquisador da Universidade Federal Rural da Amazônia (UFRA), por todas as orientações, apoio aos trabalhos de campo e ensinamentos técnicos com o Modelo SWAT, mas também pela amizade, receptividade e motivação! Que nossa convivência seja razão para uma longa amizade!

Ao Dr. Sandro Eduardo Marschhausen Pereira, Analista da Embrapa Meio Ambiente, pela disponibilização na transmissão desinteressada dos conhecimentos com o CLUE-S e no apoio técnico com o desenvolvimento da tese e com a prática com - ArcGis. Guardo um profundo respeito e amizade pela pessoa que o senhor se mostrou ser.

Ao Dr. Adriano Venturieri, pesquisador da Embrapa Amazônia Oriental, pela disponibilização de dados espacializados das áreas plantadas com palma de óleo no estado do Pará e pelo apoio técnico com os dados geográficos utilizados na tese.

À Dra. Débora Marcondes Bastos Pereira Milori, pesquisadora da Embrapa Instrumentação Agropecuária pelo suporte e orientação dado ao desenvolvimento das atividades com o estudo de estoque carbono relativos a bolsa de doutorado vinculada ao Projeto REDE PECUS, que também financiou as análises de carbono.

Ao M.Sc. Hildo Giuseppe Garcia Caldas Nunes e a M. Sc. Joyse Tatiane Souza dos Santos, os quais foram professores, companheiros e amigos durante toda a jornada da tese. Grato por todo apoio com o modelo SWAT e com os SIG's. Contem comigo!

À Dra. Lucietta Guerreiro Martorano, pela gentil receptividade em seu meio de trabalho, pelo financiamento do trabalho de campo para os estudos de estoque de carbono na Amazônia, através do financiamento do Projeto ROBIN, bem como por todas as orientações com o estudo de dinâmica espacial e com a palma de óleo.

Ao Dr. Steel Silva Vasconcelos, pesquisador da Embrapa Amazônia Oriental e meu orientador da Dissertação de Mestrado, pelo apoio técnico e de campo para os trabalhos de estudo de estoque de carbono em áreas de palma de óleo na Amazônia. Reafirmo minha gratidão pela sua consideração e pela amizade meu nobre amigo.

Ao Dr. Rubens Cardoso da Silva e ao Dr. Guillaume Xavier Rousseau, pela orientação no Trabalho de Conclusão do Curso de Engenharia Ambiental no ano de 2006. Sou grato pelo apoio, confiança e auxílio para que eu chegasse até este momento. 
À Dra. Luciana de Souza Soler, do Instituto Nacional de Pesquisas Espaciais, pela gentil orientação no aprimoramento dos trabalhos com os dados de entrada, nas análises estatísticas, calibração e melhor entendimento dos resultados do Modelo CLUE-S. Sinto uma sincera gratidão por todo seu auxílio e disponibilidade mesmo em momentos de dificuldade.

Ao Dr. Raghavan Srinivasan, pequisador da Texas A\&M University (Departments of Ecosystem Sciences and Management and Biological and Agricultural Engineering / Spatial Sciences Laboratory), pelo aceite para desenvolvimento do doutorado sanduiche nos Estados Unidos, bem como por toda receptividade, suporte, imprescindíveis orientações que elevaram a qualidade e credibilidade dos resultados da tese. Sou extremamente grato ao senhor!

Ao Dr. Francisco Assad, da Embrapa Informática pela atenção e disponibilização dos dados climáticos.

Agradecimento especial aos amigos e colegas de trabalho da Faculdade de Ciências da Saúde e Biológicas Clarissa Mendes Knoechelmann, Alessandra Rezende e André Picolli pelo apoio com a liberação das atividades da UNIFESSPA para concluir o doutoramento. Sou muito grato pelo auxílio!

Ao M. Sc. João Marcos Villela, grande amigo e irmão, por todo auxílio com os trabalhos iniciais da tese, pelo companheirismo, pela fundamental disponibilidade no treinamento com o software de calibração SWAT-CUP. Um dos passes mais valorizados do mercado do futebol mundial!

Ao Dr. Alessandro Carioca, pela gentil colaboração com o fornecimento de dados preliminares de evapotranspiração real em áreas de plantio de palma de óleo no município de Moju (Pará), os quais auxiliaram consideravelmente na discussão da tese.

Ao Dr. Antonio Ramalho Filho, por ter nos auxiliado gentilmente com o fornecimento dos dados do Zoneamento Agroecológico da Palma de Óleo para as áreas desmatadas na Amazônia.

Ao M. Sc. Ulisses Guimarães, do Centro Gestor e Operacional do Sistema de Proteção da Amazônia (Censipam), por todo auxílio no desvendamento das soluções necessárias aos problemas de percurso no aprendizado dos trabalhos com os modelos, 
com os dados de entrada e com os SIG's. Amigo de graduação que tenho grande estima e gratidão!

Ao M.Sc. Moacir Azevedo Valente, pesquisador aposentado da Embrapa Amazônia Oriental, pelo auxílio no planejamento das coletas de solos e na classificação dos mesmo.

À Dra. Caroline Galharte pelo grande auxílio no processo de seleção de ingresso no doutorado, carinhosa receptividade na Embrapa Istrumentação e pelo auxílio conceitual inicial com o modelo CLUE-S. Pessoa de paz que tenho respeito pela força de vontade e objetivo positivo de vida.

À Dra. Danielle Bressiane pela amizade em São Carlos e por todos os ensinamentos pacientes e dicas importantes com o modelo SWAT. Simplesmente uma profissional brilhante.

Ao M. Sc. Waldomiro Barioni Júnior, da Embrapa Pecuária Sudeste, pelo gentil auxílio e orientação nos métodos estatísticos.

À Dra. Aline Segnine, que contribuiu diretamente com entendimento e prática do método de análise de estoque de carbono na Embrapa Instrumentação.

À M Sc. Saime Rodrigues, por todo seu empenho no trabalho de campo com solo, nas atividades do laboratório e análise dos dados de carbono na Embrapa Amazônia Oriental, pelo apoio com sua energia positiva e por todo auxílio minha jovem amiga.

Agradecimento a Dra. Valéria Pinheiro, que além de grande amiga, teve fundamental participação na descrição das características geológicas e geomorfológicas das nossas bacias hidrográficas.

Aos Doutores Cláudio Blanco e Francisco Pessoa, da Universidade Federal do Pará, e ao Dr. Pedro Rolim, do Censipam, pelo auxílio teórico e metodológico com o método de regionalização de vazão.

A minha amiga Dra. Ângela Fushita, da Universidade Federal de São Carlos pelos excelentes ensinamentos sobre os sistemas de informação geográficas, pelo auxílio com o banco de dados da tese e pela amizade sincera. 
Ao Instituo Nacional de Meteorologia (INMET), Núcleo de Brasilia e ao Núcleo de Belém do Pará, na pessoa do senhor Francisco Sandim pelo excelente atendimento e fornecimento dos dados das estações climáticas automáticas.

Ao M. Sc. Vinícios Oliveira pelo grande apoio e ensinamentos durante a temporada de estudos na Texas A \& M University (USA). Grato pelo auxílio meu amigo.

Agradecimento ao importante financiamento da bolsa de estudos de doutorado pela Coordenação de Aperfeiçoamento de Pessoal de Nível Superior (CAPES) e da bolsa de doutorado sanduíche pelo Conselho Nacional de Desenvolvimento Científico e Tecnológico (CNPq). 

Mestre, fazei que eu procure mais consolar do que ser consolado, compreender do que ser compreendido, amar do que ser amado. Pois é dando que se recebe, é perdoando que se é perdoado, é morrendo que se vive para a vida eterna.

(Oração de São Francisco) 



\section{RESUMO}

SILVA, A. K. L. (2016). Impacto da expansão da palma de óleo sobre o escoamento superficial e produção de sedimentos nas sub-bacias hidrográficas não monitoradas dos rios Bujaru e Mariquita no nordeste do estado do Pará, Amazônia Oriental. Tese (Doutorado) - Escola de Engenharia de São Carlos, Universidade de São Paulo, São Carlos, 2016.

Atualmente, uma atividade que se tornou estratégica a nível nacional é o cultivo de espécies oleaginosas para o mercado alimentício e energético, em especial o plantio da palma de óleo (dendê) na região nordeste do estado do Pará, na Amazônia oriental. Esta cultura, assim como tem apresentado benefícios, como fixação do homem no campo, recuperação de áreas degradadas e redução da perda de solo, também tem apresentado riscos de ordem social e ambiental, como possíveis expropriações de terras e aumento do desmatamento e empobrecimento da diversidade ecológica. Mas se conhece pouco ainda dos impactos da expansão dessa cultura sobre o balanço hídrico e processos erosivos. Por isso, este trabalho estimou os impactos da expansão da cultura da palma de óleo na dinâmica de mudança de uso e cobertura da terra, bem como no escoamento superficial e na produção de sedimentos. Para isto, aplicou-se o modelo hidrossedimentológico Soil and Water Assessment Tool (SWAT) e o modelo de dinâmica espacial Conversion of Land Use and its Effects at Small region extent (CLUES) sobre as sub-bacias não monitoradas dos rios Bujaru (SBRB) e Mariquita (SBRM), com calibração do SWAT realizada a partir da técnica de regionalização de vazão por regressão não linear e medições em campo com o molinete hidrométrico. A princípio, as equações de regressão se apresentaram eficientes nas estimativas de dados de vazão para as sub-bacias, fundamentadas no bom resultado da calibração e validação sobre as estações reais. Nas áreas de palma de óleo, o modelo foi capaz de estimar com bom grau de eficiência a evapotranspiração nestas Unidades de Resposta Hidrológica da SBRB $(1089,2 \mathrm{~mm})$ e da SBRM $(1093,1 \mathrm{~mm})$, em relação a literatura e medidas em torre de monitoramento micrometeorológico. O modelo CLUE-S foi capaz de integralizar as variáveis explanatórias com as demandas agregadas e as características de elasticidade com o objetivo de gerar cenários futuros de uso e cobertura da terra, bem como modelar a palma de óleo nas sub-bacias, identificando as variáveis biofísicas como as principais forçantes de mudança de uso e cobertura da terra. As estimativas de escoamento superficial e produção de sedimentos apontaram para uma redução na SBRB e um aumento na SBRM entre os cenários de 2008, 2013 e o cenário projetado com o CLUE-S para 2023 em especial por razão da grande variação das áreas de vegetação secundária. As áreas de Palma de Óleo tiveram menor escoamento superficial e produção de sedimentos médio mensal do período mais chuvoso em ambas sub-bacias e em todos os cenários em relação as áreas de Agricultura Geral e Pastagem. Os resultados também mostraram a boa capacidade do uso integrado dos modelos SWAT e CLUE-S na geração de dados que contribuem para a análise do impacto ambiental da expansão da palma de óleo na região nordeste do 
estado do Pará, sendo também importante para o planejamento e gestão ambiental rural em bacias hidrográficas não monitoradas na Amazônia Oriental, pois demonstra a eficiência do método em proporcionar 0 aumento dos conhecimentos do comportamento hidrológico destas bacias em relação a dinâmica espacial de uso e cobertura do solo.

Palavras-chave: Modelagem hidrossedimentológica, Modelagem dinâmica de mudança de uso e cobertura da terra, Bacias hidrográficas não monitoras, Palma de óleo, Amazônia Oriental. 


\begin{abstract}
SILVA, A. K. L. (2016). Impact of oil palm spreading over runoff and sediment yield on Bujaru and Mariquita ungauged river-basins in Northeast Pará, Brazil, Eastern Amazon. Doctoral Thesis - São Carlos School of Engineering, University of São Paulo at São Carlos, 2016.
\end{abstract}

Nowadays, oilseed production for food and energy has become a strategic activity at national level in Brazil, particularly oil palm crops located in the Northeast of Pará State, Eastern Amazon. Oil palm crops have shown benefits such as keeping farmers on the land, recovering degraded areas and reducing soil loss. Conversely, it may also increase social and environmental risks linked to land tenure instability and land expropriation, deforestation and biodiversity losses. In such context, there is still a lack of knowledge concerning the impacts of such crop on the local water balance and erosion processes. Thus, this research estimated the impacts of increasing oil palm crops on land use and land cover change dynamics, as well as on runoff and soil erosion processes. To do so, it was applied the Soil and Water Assessment Tool (SWAT) and the spatial explicit framework Conversion of Land Use and its Effects at Small region extent (CLUE-S) over two ungauged sub-basins of Bujaru (SBRB) and Mariquita (SBRM) rivers. SWAT calibration was done by the regionalization streamflow method that adopts nonlinear regression and field measurements using a current meter. Initially, regression equations were effective in streamflow data estimation for the subbasins, this was based on effective calibration and validation results upon real stations. In the oil palm crop areas, the SWAT modeling was able to successfully estimate evapotranspiration on both hydrologic response unit of SBRB $(1089,2 \mathrm{~mm})$ and SBRM $(1093,1 \mathrm{~mm})$ when compared to the literature and measures in micrometeorological monitoring tower. When applying CLUE-S model it was capable to integrate explanatory variables to scenario demands and elasticity parameters determining land use/cover change. Such integration allowed modelling oil palm spatial-temporal dynamics in current and future scenario demands within the two sub-basins SBRB and SBRM, as well as the identification of biophysical variables as the core drivers of land use/cover change. Runoff and sediment yield pointed out towards a decline in SBRB and an increase in SBRM in the current scenario between 2008 and 2013, as well as in the future scenario modelled using CLUE-S land use/cover change maps for 2023, particularly because of a large variation in the dynamics of secondary vegetation between the two sub-basins. Oil palm areas had smaller monthly average runoff and sediment yield in the rainiest period in both sub-basins and in current and future scenarios regarding agriculture and pasture areas. The results also show a suitable capability of integration between SWAT and CLUE-S models when generating data that contribute to the analysis of environmental impact of oil palm expansion in the Northeast of Para State. Such contribution is also relevant to the rural environmental planning and management in ungauged river-basins in Eastern Amazon, since the results found here demonstrate the efficiency of the method in providing an improved knowledge of the 
hydrological behavior of these basins concerning land use and land cover changes dynamics.

Key words: Hydrossedimentological modeling, Land use and cover change modeling, Ungauged watersheds, Oil palm and Eastern Amazon. 


\section{LISTA DE FIGURAS}

Figura 1: Componentes do balanço hídrico simulados nas sub-bacias do SWAT ....... 19

Figura 2: Mapa conceitual do percurso metodológico da tese .....................................43

Figura 3: Mapa de localização das sub-bacias dos rios Bujaru e Mariquita .................. 44

Figura 4: Média do acumulado mensal de longo período da série de 2003 a 2014 das estações da ANA (SBRM - 248001 / 248003 / 248006; SBRB - 148009 / 247003 / 148017)

Figura 5: Localização das sub-bacias dos rios Bujaru e Mariquita sobre as classes de aptidão edafoclimáticas do Zoneamento Agroecológico da Palma de Óleo para o estado do Pará. 46

Figura 1: Localização da Fazenda Ipiranga. 52

Figura 7: Fotografias dos usos e coberturas da terra e dos trabalhos de coleta e análise dos solos da Fazenda Ipiranga. Onde: A - Plantio de palma de óleo; B - Sistema Agroflorestal; C - Pastagem; D - Remanescente florestal; E - Vegetação secundária; F Abertura da trincheira; $\mathrm{G}$ - Perfil da trincheira aberta; $\mathrm{H}$ - Coleta de solo para análise de fertilidade; I - Amostra indeformada para análise da densidade; J - Pesagem da densidade; K - Entrevista com o proprietário; L - Equipe de trabalho. 281

Figura 8: Fluxograma de comandos do SWAT para cada HRU ...................................55

Figura 9: Processo de funcionamento do Modelo SWAT na Interface SIG ...................75

Figura 10: Equipamento de medição da velocidade do fluxo de água que passa por uma sessão do rio

Figura 11: Cálculo da meia seção e verificação da área de influência de cada vertical84 Figura 12: Distribuição das estações reais e sintéticas utilizadas na regionalização de vazão

Figura 13: Distribuição dos polígonos de Thiessen e das estações utilizadas na

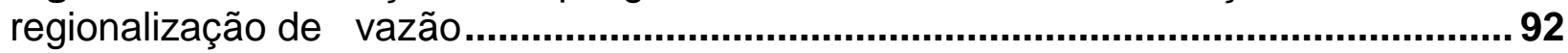

Figura 14: Área da porção média da bacia do rio Capim modelada com o SWAT........97

Figura 15: Procedimento de análise da dinâmica espacial através do CLUE-S..........103

Figura 16: Visão geral do fluxo de informações dentro do modelo CLUE-S ...............104

Figura 17: llustração de uma transição hipotética de mudança de uso e cobertura do

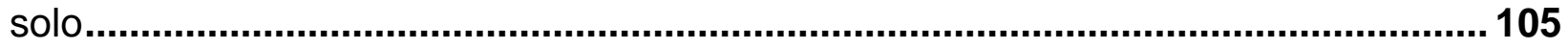

Figura 18: Exemplo de matriz de conversão utilizada no modelo CLUE-S ................. 106

Figura 19: Fluxograma do módulo de alocação do modelo CLUE-S............................108

Figura 20: Exemplo de formato de um arquivo 'alloc.reg' utilizado na tese .................116

Figura 21: Exemplo de arquivos 'allow.txt' utilizado na tese.......................................116 
Figura 22: Exemplo de resultado da regressão logística efetuada pelo SPSS............109

Figura 23: Mapa de uso e cobertura de 2008 para a sub-bacia do rio Bujaru............ 127

Figura 24: Mapa de uso e cobertura de 2008 para a sub-bacia do rio Mariquita ....... 128

Figura 25: Mapas de uso e cobertura de 2013 para a sub-bacia do rio Bujaru ........... 129

Figura 26: Mapas de uso e cobertura de 2013 para a sub-bacia do rio Mariquita...... 130

Figura 27: Mapas de uso e cobertura de 2000 e 2004 para a sub-bacia do rio Bujaru 131

Figura 28: Mapas de uso e cobertura de 2000 e 2004 para a sub-bacia do rio Mariquita

Figura 29: Gráfico de mudança de uso e cobertura da terra entre os anos de 2000, 2004, 2008 e 2013 na sub-bacia do rio Bujaru. 133

Figura 30: Gráfico de mudança de uso e cobertura da terra entre os anos de 2000, 2004, 2008 e 2013 na sub-bacia do rio Mariquita

Figura 31: Mapa de uso e cobertura do ano de 2010 para a porção média da bacia do

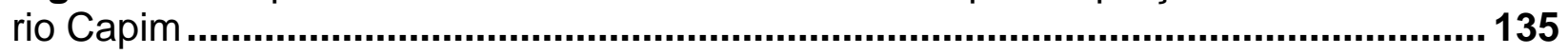

Figura 32: Modelo digital de elevação do terreno da sub-bacia do rio Bujaru .............137

Figura 33: Modelo digital de elevação do terreno da sub-bacia do rio Mariquita.........138

Figura 34: Modelo digital de elevação do terreno da porção média da bacia do rio

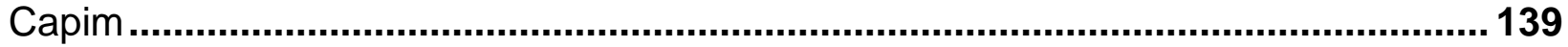

Figura 35: Mapa de solos da sub-bacia do rio Bujaru ................................................ 140

Figura 36: Mapa de solos da sub-bacia do rio Mariquita ..........................................141

Figura 37: Mapa de solos da porção média da bacia do rio Capim..............................142

Figura 38: Interface do módulo Watershed Delineator do ArcSWAT 2009.................. 143

Figura 39: Sub-bacias e hidrografia delineadas pelo modelo SWAT para a sub-bacia

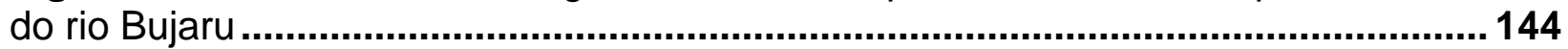

Figura 40: Sub-bacias e hidrografia delineadas pelo modelo SWAT para a sub-bacia

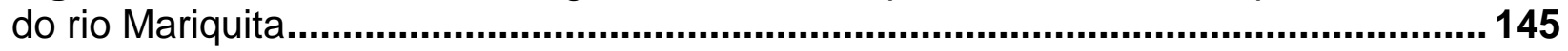

Figura 41: Sub-bacias e hidrografia delineadas pelo modelo SWAT para a porção média da bacia do rio Capim ................................................................................... 146

Figura 42: Módulo Weather Data Definition............................................................ 149

Figura 43: Vazões observadas e vazões simuladas da regionalização da vazão média mensal de longo período das 4 estações reais ........................................................154

Figura 44: Diagrama de dispersão das vazões médias mensais de longo período observadas (Q_Obs) e simuladas (Q_Sim) através das equações de regionalização para o período de 2003 a 2014 nas Estações Badajós (A), Fazenda Maringá (B), Bom Jardim (C) e Vila Capoeira (D) 155 
Figura 45: Vazões médias mensais simuladas e regionalizadas em comparação com a precipitação para a modelagem com condições iniciais da sub-bacia do rio Bujaru. Sendo PRECIPmm a precipitação, Q_Regional a vazão regionalizada, Q_Sim_PT a vazão mensal simulada com Preistley-Taylor, e Q_Sim_PM a vazão mensal simulada com Penman-Monteith 161

Figura 46: Vazões médias mensais de longo período simuladas e regionalizadas em condições iniciais para a sub-bacia do rio Bujaru entre os anos de 2006 a 2014. Sendo Q_Regional a vazão regionalizada, Q_Sim_PT a vazão mensal simulada com PreistleyTaylor e Q_Sim_PM a vazão mensal simulada com Penman-Monteith 162

Figura 47: Diagrama de dispersão das vazões médias mensais regionalizadas e simuladas (sem calibração) para o período de 2006 a 2014 na sub-bacia do rio Bujaru. A - Modelo com Preistley-Taylor; B - Modelo com Penman-Monteith

162

Figura 48: Vazões médias mensais simuladas e regionalizadas em comparação com a precipitação para a modelagem com condições iniciais da sub-bacia do rio Mariquita. Sendo PRECIPmm a precipitação, Q_Regional a vazão regionalizada, Q_Sim_PT a vazão mensal simulada com Preistley-Taylor, e Q_Sim_PM a vazão mensal simulada com Penman-Monteith 164

Figura 49: Vazões médias mensais de longo período simuladas e regionalizadas em condições iniciais para a sub-bacia do rio Mariquita entre os anos de 2006 a 2014. Sendo Q_Regional a vazão regionalizada, Q_Sim_PT a vazão mensal simulada com Preistley-Taylor e Q_Sim_PM a vazão mensal simulada com Penman-Monteith ........ 165

Figura 50: Diagrama de dispersão das vazões médias mensais regionalizadas e simuladas (sem calibração) para o período de 2006 a 2014 na sub-bacia do rio Mariquita. A - Modelo com Preistley-Taylor; B - Modelo com Penman-Monteith ........ 165

Figura 51: Vazões médias mensais simuladas (Q_Sim_PT é a vazão mensal simulada com Preistley-Taylor) e observadas (Q_Observada) em comparação com a precipitação (PRECIPmm) para a modelagem com condições iniciais da porção média da bacia do rio Capim

167

Figura 52: Diagrama de dispersão das vazões médias mensais observadas e simuladas (sem calibração) para o período de 2006 a 2014 na porção média da bacia

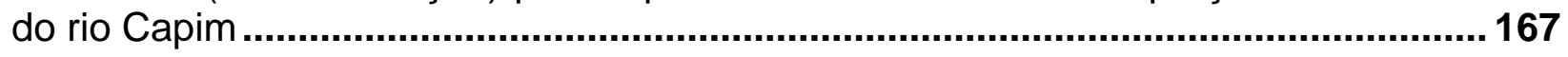

Figura 53: Resultado da análise de sensibilidade dos parâmetros do SWAT para a subbacia do rio Bujaru . 170

Figura 54: Resultado da análise de sensibilidade dos parâmetros do SWAT para a subbacia do rio Mariquita 171

Figura 55: Vazões médias mensais simuladas calibradas (Q_Sim_PT é a vazão mensal simulada com Preistley-Taylor) e observadas (Q_Observada) em comparação com a precipitação (PRECIPmm) para o período de calibração (2006-2010) e validação (2011-2014) da porção média da bacia do rio Capim 175

Figura 56: Diagrama de dispersão das vazões médias mensais observadas e simuladas calibradas para o período de 2006 a 2014 na porção média da bacia do rio Capim 
Figura 57: Comparação entre as vazões médias mensais simuladas calibradas diretamente com a regionalização (Q_Sim_PT), simuladas calibradas através dos parâmetros calibrados da porção média da bacia do rio Capim, vazões regionalizadas (Q_Regional) e a precipitação (PRECIPmm) para o período de calibração (2006-2010) e validação (2011-2014) da sub-bacia do rio Bujaru

Figura 58: Vazões médias mensais de longo período simuladas calibradas (Q_Sim_PT_Cal4) e Regionalizadas (Q_Regional) para a sub-bacia do rio Bujaru entre os anos de 2006 a 2014

179

Figura 59: Diagrama de dispersão das vazões médias mensais regionalizadas e simuladas calibradas para o período de 2006 a 2014 na sub-bacia do rio Bujaru. A Calibração direta com a regionalização; B - Calibração com transferência de parâmetros 179

Figura 60: Comparação entre as vazões médias mensais simuladas calibradas diretamente com a regionalização (Q_Sim_PT), simuladas calibradas através dos parâmetros calibrados da porção média da bacia do rio Capim, vazões regionalizadas (Q_Regional) e a precipitação (PRECIPmm) para o período de calibração (2006-2010) e validação (2011-2014) da sub-bacia do rio Mariquita.

181

Figura 61: Vazões médias mensais de longo período simuladas calibradas (Q_Sim_PT_Cal2) e Regionalizadas (Q_Regional) para a sub-bacia do rio Mariquita entre os anos de 2006 a 2014 181

Figura 62: Diagrama de dispersão das vazões médias mensais regionalizadas e simuladas calibradas para o período de 2006 a 2014 na sub-bacia do rio Mariquita. A Calibração direta com a regionalização; B - Calibração com transferência de parâmetros 182

Figura 63: Perfis delineados nos exutoríos das sub-bacias dos rios Bujaru e Mariquita para medição de vazão com molinete hidrométrico 283

Figuras 64: Mapas de distribuição da densidade populacional rural e da renda mensal familiar para as sub-bacias dos rios Bujaru e Mariquita. 193

Figuras 65: Mapas de distância euclidiana e logarítmica a hidrografias para as subbacias dos rios Bujaru e Mariquita 195

Figuras 66: Mapas de distância euclidiana e logarítmica a hidrovias para as sub-bacias dos rios Bujaru e Mariquita.

196

Figuras 67: Mapas de distância euclidiana e logarítmica a portos para as sub-bacias dos rios Bujaru e Mariquita.

Figuras 68: Mapas de distância euclidiana e logarítmica a rodovias para as sub-bacias dos rios Bujaru e Mariquita. 198

Figuras 69: Mapas de distância euclidiana e logarítmica as usinas para as sub-bacias dos rios Bujaru e Mariquita.

199

Figuras 70: Localização das usinas de extração do óleo de palma em relação às subbacias dos rios Bujaru e Mariquita 200 
Figuras 71: Mapas de custo da distância as usinas de extração do óleo de palma para as sub-bacias dos rios Bujaru e Mariquita

Figuras 72: Mapas de restrição de converção de 2008 e 2013 para as sub-bacias dos rios Bujaru e Mariquita 206

Figura 73: Correlação bivariável entre a classe palma de óleo e as variáveis explanatórias para o ano de 2013. 209

Figura 74: Correlação bivariável entre a classe agricultura geral e as variáveis explanatórias para o ano de 2013.

Figura 75: Correlação bivariável entre a classe pastagem e as variáveis explanatórias para o ano de 2013 284

Figura 76: Correlação bivariável entre a classe Remanescente Florestal e as variáveis explanatórias para o ano de 2013. 284

Figura 77: Correlação bivariável entre a classe vegetação secundária e as variáveis explanatórias para o ano de 2013. 285

Figura 78: Mapa de probabilidade de alocação da palma de óleo na sub-bacia do rio Bujaru 285

Figura 79: Mapa de probabilidade de alocação da palma de óleo na sub-bacia do rio Mariquita. 286

Figura 80: Mapa real (esquerda) e mapa da etapa de calibração (direita) do CLUE-S para a sub-bacia do rio Bujaru 218

Figura 81: Mapa real (esquerda) e mapa da etapa de calibração (direita) do CLUE-S para a sub-bacia do rio Mariquita. 220

Figura 82: Mapa da projeção para 2023 com o CLUE-S das sub-bacias dos rios Bujaru e Mariquita. 222

Figura 83: Distribuiação na sub-bacia do rio Bujaru do escoamento superficial (mm) e da produção de sedimentos (t/ha) para os modelos de 2008, 2013 e 2023. 228

Figura 84: Comparação da variação temporal do escoamento superficial total mensal médio $(\mathrm{mm})$ nos três modelos da sub-bacia do rio Bujaru

229

Figura 85: Comparação da variação temporal da produção de sedimentos total mensal média (t/ha) nos três modelos da sub-bacia do rio Bujaru 229

Figura 86: Distribuição na sub-bacia do rio Mariquita do escoamento superficial ( $\mathrm{mm}$ ) e da produção de sedimentos (t/ha) para os modelos de 2008, 2013 e 2023. 232

Figura 87: Comparação da variação temporal do escoamento superficial total mensal médio $(\mathrm{mm})$ nos três modelos da sub-bacia do rio Mariquita. 233

Figura 88: Comparação da variação temporal da produção de sedimentos total mensal média ( $\mathrm{t} / \mathrm{ha}$ ) nos três modelos da sub-bacia do rio Mariquita. 233

Figura 89: Escamento superficial e produção de sedimentos nas 19 sub-bacias do rio Bujaru 237 
Figura 90: Escoamento superficial e produção de sedimentos nas 11 sub-bacias do rio

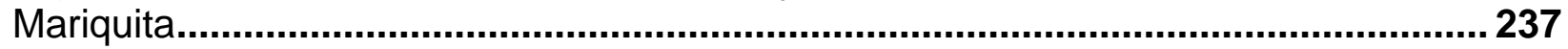




\section{LISTA DE QUADROS}

Quadro 1: Variedades de LATOSSOLO AMARELO Distrófico (LAd) encontradas nas

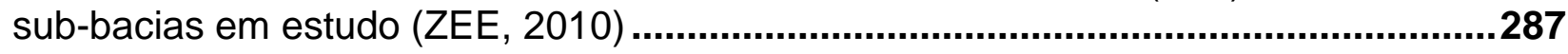

Quadro 2: Reclassificação dos usos e coberturas da terra do Projeto TerraClass 2008 para as áreas das sub-bacias dos rios Bujaru e Mariquita ............................................. 126

Quadro 3: Origem do dados utilizados nas simulações com CLUE-S para as subBacias dos rios Bujaru e Mariquita ............................................................................ 192 


\section{LISTA DE TABELAS}

Tabela 1: Resumo das áreas das classes do Zoneamento Agroecológico da Palma de Óleo nas áreas desmatadas da Amazônia Legal com adoção dos níveis de manejo B (nível tecnológico médio) e C (alto nível tecnológico)

Tabela 2: Principais agroindústrias de extração de óleo de palma presentes no estado

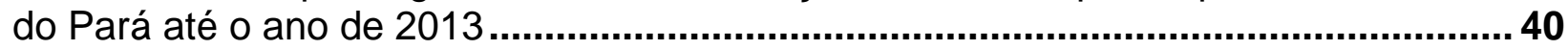

Tabela 3: Municípios de localização da sub-bacia do rio Bujaru (SBRB) ...................... 44

Tabela 4: Municípios de localização da sub-bacia do rio Mariquita (SBRM) .................46 46

Tabela 5: Relação de cenas do satélite RapidEye utilizadas e suas datas ...................49 49

Tabela 6: Código, nome, localização e usos e séries das estações de precipitação (ANA) e de dados climáticos (INMET) disponíveis utilizados na tese ............................78

Tabela 7: Estações fluviométricas e características morfoclimáticas das bacias

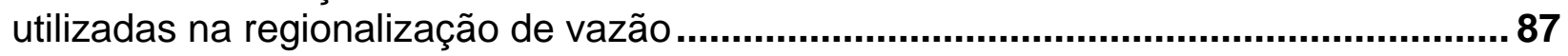

Tabela 8: Arquivo de parâmetros principais ('main.1') …...........................................117

Tabela 9: Tabela de contingência adaptada para a tese .........................................122

Tabela 10: Índice Kappa e o correspondente desempenho da classificação .............. 123

Tabela 11: Distribuição de áreas para cada uso e cobertura da terra segundo reclassificação do TerraClass no ano de 2008 para a sub-bacia do rio Bujaru em

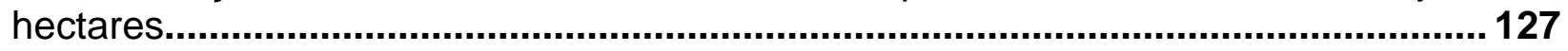

Tabela 12: Distribuição de áreas para cada uso e cobertura da terra segundo reclassificação do TerraClass no ano de 2008 para a sub-bacia do rio Mariquita em hectares.

128

Tabela 13: Distribuição de áreas para cada uso e cobertura do mapa de 2013 para a sub-bacia do rio Bujaru em hectares .................................................................. 130

Tabela 14: Distribuição de áreas para cada uso e cobertura do mapa de 2013 para a sub-bacia do rio Mariquita em hectares....................................................................... 131

Tabela 15: Dinâmica da mudança do uso e cobertura da terra na sub-bacia do rio Bujaru entre os anos de 2000, 2004, 2008 e 2013.................................................. 133

Tabela 16: Dinâmica da mudança do uso e cobertura da terra na sub-bacia do rio Mariquita entre os anos de 2000, 2004, 2008 e 2013 ................................................... 134

Tabela 17: Distribuição de áreas para cada uso e cobertura do mapa de 2010 para a porção média da bacia do rio Capim em hectares ..................................................... 136

Tabela 18: Classes de uso e cobertura representadas no SWAT .............................147

Tabela 19: Classes de rampa e suas respectivas representatividades de área para a sub-bacia do rio Bujaru 
Tabela 20: Classes de rampa e suas respectivas representatividades de área para a sub-bacia do rio Mariquita

Tabela 21: Classes de rampa e suas respectivas representatividades de área para a porção média da bacia do rio Capim.

Tabela 22: Parâmetros climáticos inseridos na WGN_user INMET_A202, localizada no município de Castanhal, PA, calculados a partir da série de 2003 a 2014 149

Tabela 23: Parâmetros climáticos inseridos na WGN_user INMET_A213, localizada no município de Tomé-Açu, PA, calculados a partir da série de 2008 a 2014 149

Tabela 24: Parâmetros climáticos inseridos na WGN_user INMET_A212, localizada no município de Paragominas, PA, calculados a partir da série de 2008 a 2014. 150

Tabela 25: Parâmetros das camadas de solo utilizadas nas simulações com o SWAT 151

Tabela 26: Parâmetros adaptados a região de estudo relativos às culturas do SWAT 151

Tabela 27: Parâmetros adaptados à região de estudo relativos ao Módulo de Manejo do SWAT. 153

Tabela 28: Resultados dos índices de acertos da regionalização da vazão média de longo período sobre as bacias monitoradas em estudo 154

Tabela 29: Coeficientes de regressão e estatísticas das equações finais para estimativa da Regionalização da Vazão Média Mensal de Longo Período das 4 estações reais de monitoamento fluviométrico. 282

Tabela 30: Coeficientes de regressão e estatísticas das equações finais para estimativa da Regionalização da Vazão Média Mensal de Longo Período das subbacias dos rios Bujaru e Mariquita 156

Tabela 31: Avaliação da eficiência da simulação inicial usando Preistley-Taylor e Penman-Monteith para as sub-bacias dos rios Bujaru e Mariquita e para a porção média da bacia rio Capim. 163

Tabela 32: Parâmetros, descrições e ranges iniciais da análise de sensibilidade e calibração utilizados em todas as bacias estudadas. 169

Tabela 33: Valores de $t$-stat e $P$-Value obtidos pela análise de sensibilidade dos parâmetros para a sub-bacia do rio Bujaru 170

Tabela 34: Valores de $t$-stat e $P$-Value obtidos pela análise de sensibilidade dos parâmetros para a sub-bacia do rio Mariquita 171

Tabela 35: Listagem dos 9 parâmetros selecionados de acorda com a demanda de ajuste dos modelos das sub-bacias dos rios Bujaru e Mariquita. 172

Tabela 36: Parâmetros, métodos, intervalos e valores resultantes da calibração para a porção média da bacia do rio Capim. 174

Tabela 37: Avaliação da eficiência das simulações calibradas diretamente com a vazão regionalizada e calibradas com os parâmetros transferidos do modelo calibrado da 
porção média da bacia do rio Capim paras as sub-bacias não monitoradas dos rios Bujaru e Mariquita e da simulação para a porção média da bacia do rio Capim ..........176

Tabela 38: Classificação do desempenho para as estatísticas NSE, PBIAS e RSR

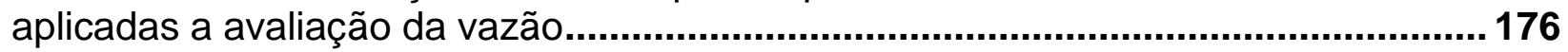

Tabela 39: Parâmetros, métodos, intervalos e valores resultantes da calibração para a sub-bacia do rio Bujaru 178

Tabela 40: Avaliação da eficiência das simulações calibradas diretamente com a vazão regionalizada e calibrada com os parâmetros transferidos do modelo calibrado da porção média da bacia do rio Capim paras as sub-bacias dos rios Bujaru e Mariquita

Tabela 41: Parâmetros, métodos, intervalos e valores resultantes da calibração para a sub-bacia do rio Mariquita. 180

Tabela 42: Balanço hídrico da sub-bacia do rio Bujaru calibrado com a regionalização de vazão. 183

Tabela 43: Balanço hídrico da sub-bacia do rio Bujaru calibrado com os parâmetros da porção média da bacia do rio Capim. 184

Tabela 44: Balanço hídrico da sub-bacia do rio Mariquita calibrado com a regionalização de vazão.

Tabela 45: Balanço hídrico da sub-bacia do rio Mariquita calibrado com os parâmetros da porção média da bacia do rio Capim 185

Tabela 46: Resultados da medição da vazão nos perfis dos exutórios das sub-bacias dos rios Bujaru e Mariquita 186

Tabela 47: Precipitação (PCP), evapotranspiração potencial (PET) e evapotranpiração real (ET) médias mensais interanuais paras as sub-bacias não monitoradas dos rios Bujaru e Mariquita e para a porção média da bacia monitorada do rio Capim. 187

Tabela 48: Evapotranpiração real (ET) mensal de 2006 a 2014 em comparação as medidas mensais da Torre Micrometeorológica do município de Moju para a sub-bacia do rio Bujaru.

188

Tabela 49: Evapotranpiração real (ET) mensal de 2006 a 2014 em comparação as medidas mensais da Torre Micrometeorológica do município de Moju para a sub-bacia do rio Mariquita. 188

Tabela 50: Uso e cobertura da terra para os anos de 2008 e 2013 para a sub-bacia do rio Bujaru

190

Tabela 51: Uso e cobertura da terra para os anos de 2008 e 2013 para a sub-bacia do rio Mariquita. 190

Tabela 52: Demanda por uso entre os anos de 2008 e 2013 para a sub-bacia do rio Bujaru, considerando 6 classes de uso e de cobertura da terra, com as áreas em hectares e valores múltiplos de 1 ha (pixel de $100 \mathrm{~m}$ ) 202 
Tabela 53: Demanda por uso entre os anos de 2008 e 2013 para a sub-bacia do rio Mariquita, considerando 6 classes de uso e de cobertura da terra, com as áreas em hectares e valores múltiplos de 1 ha (pixel de $100 \mathrm{~m}$ )

Tabela 54: Demanda por área para projeção de 2013 e 2023 para a sub-bacia do rio Bujaru, considerando 6 classes de uso e de cobertura da terra, com as áreas em hectares e valores múltiplos de 1 ha (pixel de $100 \mathrm{~m}$ ) 203

Tabela 55: Demanda por área para projeção de 2013 e 2023 para a sub-bacia do rio Mariquita, considerando 6 classes de uso e de cobertura da terra, com as áreas em hectares e valores múltiplos de 1 ha (pixel de $100 \mathrm{~m}$ ) .................................................. 204

Tabela 56: Lista de fatores exploratórios para a sub-bacia do rio Bujaru .................... 205

Tabela 57: Lista de fatores exploratórios para a sub-bacia do rio Mariquita................ 205

Tabela 58: Matriz de conversão adotada para a calibração do modelo de 2008 para 2013 em ambas sub-bacias dos rios Buajru e Mariquita. 207

Tabela 59: Matriz de conversão adotada para nas simulações de projeção de 2013 a 2023 em ambas sub-bacias dos rios Buajru e Mariquita. 207

Tabela 60: Resultados da regressão logística do melhor modelo de calibração (20082013) para a sub-bacia do rio Bujaru 213

Tabela 61: Resultados da regressão logística do melhor modelo de calibração (20082013) para a sub-bacia do rio Mariquita 214

Tabela 62: Parâmetros principais dos modelos na calibração e projeção ...................216

Tabela 63: Frequência de acerto na calibração do melhor modelo para a sub-bacia do rio Bujaru 218

Tabela 64: Tabelas de contigência para o teste estatistico dos resultados da palma de óleo na sub-bacia do rio Bujaru 219

Tabela 65: Resultados dos índices de acurácia global e kappa paras as sub-bacias 219

Tabela 66: Frequência de acerto na calibração do melhor modelo para a sub-bacia do rio Mariquita. 220

Tabela 67: Tabelas de contigência para o teste estatístico dos resultados da palma de óleo na sub-bacia do rio Mariquita 221

Tabela 68: Uso e cobertura da terra para os três períodos de modelagem 225

Tabela 69: Escoamento superficial e produção de sedimentos nas 19 sub-bacias do rio Bujaru 230

Tabela 70: Escoamento superficial e produção de sedimentos nas 11 sub-bacias do rio Mariquita.

Tabela 71: Média anual de longo período do escoamento superficial (Escoa) e da produção de sedimentos (Sedim) entre os anos de 2006 e 2014 para a sub-bacia do rio Bujaru nos três anos de uso e cobertura da terra por declividade 
Tabela 72: Média anual de longo período do escoamento superficial (Escoa) e da produção de sedimentos (Sedim) entre os anos de 2006 e 2014 para a sub-bacia do rio Mariquita nos três anos de uso e cobertura da terra por declividade

Tabela 73: Média e soma anual de longo período do escoamento superficial e da produção de sedimentos entre todos os meses e entre os meses mais chuvosos dos anos de 2006 e 2014 para a sub-bacia do rio Bujaru nos três anos de uso e cobertura

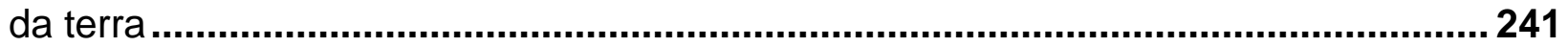

Tabela 74: Média e soma anual de longo período do escoamento superficial e da produção de sedimentos entre todos os meses e entre os meses mais chuvosos dos anos de 2006 e 2014 para a sub-bacia do rio Mariquita nos três anos de uso e cobertura da terra. 


\section{LISTA DE ABREVIATURAS E SIGLAS}

\begin{tabular}{|c|c|}
\hline AGRL & Agricultura geral \\
\hline ANA & Agência Nacional de Água \\
\hline ArcSWAT & Interface SWAT com o SIG ArcGis \\
\hline ARS & Agricultural Research Service \\
\hline CLUE-S & Conversion of Land Use and its Effects at Small region extent \\
\hline FAO & Food and Agriculture Organization of the United Nations \\
\hline FFC & PLINTOSSOLO PÉTRICO Concrecionário \\
\hline FRSE_RF & Remanescente florestal \\
\hline FRSE_VS & Vegetação secundária \\
\hline GXbd & GLEISSOLO HÁPLICO Distrófico \\
\hline HRU & Unidades de Resposta Hidrológicas / hydrologic response units \\
\hline INMET & Instituto Nacional de Meteorologia \\
\hline IPCC & Intergovernmental Panel on Climate Change \\
\hline LAd1B & LATOSSOLO AMARELO Distrófico de Bujaru \\
\hline LAd1M & LATOSSOLO AMARELO Distrófico de Mariquita \\
\hline MDE & Modelo digital de elevação do terreno \\
\hline MUSLE & Equação Universal da Perda de Solos Modificada \\
\hline NSE & Coeficiente de Nash-Sutcliffe \\
\hline OILP & Palma de óleo \\
\hline OUTROS & Classes Água e Área Urbana somadas \\
\hline PAST & Pastagem \\
\hline PBIAS & Percentual de tendências \\
\hline PVAd & ARGISSOLO VERMELHO-AMARELO Distrófico \\
\hline QMMLP & Vazão média mensal de longo período \\
\hline $\mathrm{R}^{2}$ & Coeficiente de determinação \\
\hline RSR & $\begin{array}{l}\text { Razão entre a raiz quadrada da média com o desvio padrão dos } \\
\text { dados observados }\end{array}$ \\
\hline SBRB & Sub-bacia do rio Bujaru \\
\hline SBRM & Sub-bacia do rio Mariquita \\
\hline SIG & Sistemas de informação geográfica \\
\hline
\end{tabular}




$\begin{array}{ll}\text { SRTM } & \text { Shuttle Radar Topography Mission } \\ \text { SWAT } & \text { Soil and Water Assessment Tool } \\ \text { SWAT-CUP } & \text { Software de calibração do SWAT } \\ \text { USDA } & \text { United States Department of Agriculture } \\ \text { USGS } & \text { United States Geological Survey } \\ \text { USLE } & \text { Equação Universal da Perda de Solos } \\ \text { WGN_user } & \text { Weather Generator } \\ \text { ZAE-Palma } & \text { Zoneamento Agroecológico da Palma de Óleo } \\ \text { ZEE-PA } & \text { Zoneamento Ecológico Econômico do estado do Pará }\end{array}$




\section{SUMÁRIO}

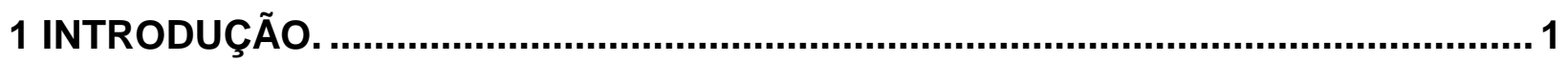

2 HIPÓTESES.................................................................................................... 5

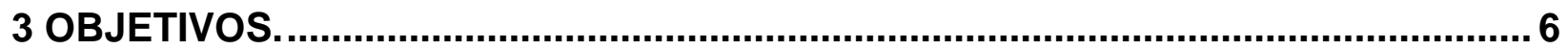

3.1 OBJETIVO GERAL.

3.2 OBJETIVOS ESPECÍFICOS.

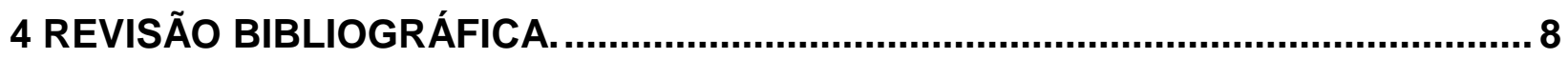

4.1 DINÂMICA DE MUDANÇA DE USO E COBERTURA DA TERRA E OS SEUS IMPACTOS AMBIENTAIS SOBRE O ESCOAMENTO SUPERFICIAL E PERDA DE SOLO. 8

4.2 MODELAGEM AMBIENTAL COMO FERRAMENTA DE GESTÃO E PLANEJAMENTO AMBIENTAL DE BACIAS HIDROGRÁFICAS NÃO MONITORADAS.

4.2.1 Sistemas de Informação Geográfica aplicados a caracterização e análise ecossistêmica. ...................................................................................................15

4.2.2 Modelagem hidrossedimentológica utilizando o modelo SWAT (Soil and Water Assessment Tool)..............................................................................16

4.2.3 Modelagem dinâmica utilizando o modelo CLUE-S (Conversion of land use and its effects at small regional extent. .......................................................25

4.2.4 Regionalização de vazão para sub-bacias não monitoradas...................32 4.3 ESTUDO DE CASO: ÁREAS SOB A EXPANSÃO DA PALMA DE ÓLEO NO NORDESTE PARAENSE.

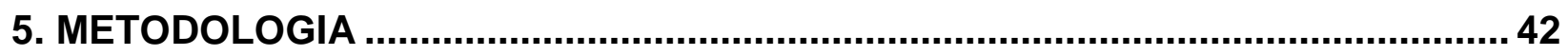

5.1. ÁREA DE ESTUDO. 42

5.2. LEVANTAMENTO DE DADOS E MAPEAMENTO DO USO E COBERTURA DA TERRA $\begin{array}{ll}\text { NAS SUB-BACIAS. } & 47\end{array}$

5.2.1 Classificação semiautomática das imagens do LandSat.........................47

5.2.2 Avaliação da exatidão do Mapeamento ...................................................49

5.3 PRINCIPAIS CARACTERÍSTICAS GEOLÓGICAS E GEOMORFOLÓGICAS DAS SUBBACIAS DOS RIOS BUJARU E MARIQUITA E DO COMPLEXO HIDROGRÁFICO GUAMÁCAPIM NO NORDESTE DO ESTADO DO PARÁ. $\quad 50$

5.4 CARACTERIZAÇÃO DO SOLO EM ALGUNS PERFIS NA FAZENDA IPIRANGA. 5.5 SOIL AND WATER ASSESSMENT TOOL (SWAT). 53

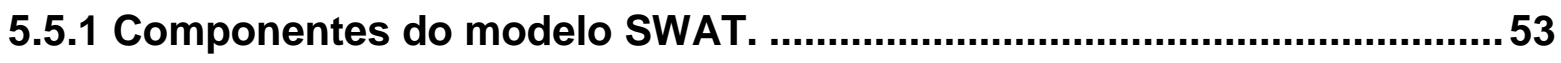

5.5.2 Banco de dados de entrada do modelo SWAT......................................... 74

5.5.3 Medidas diretas de vazão em campo utilizando o molinete hidrométrico ou correntômetro de hélice. 
5.5.4 Estimativas de vazão através da regionalização de vazão das bacias

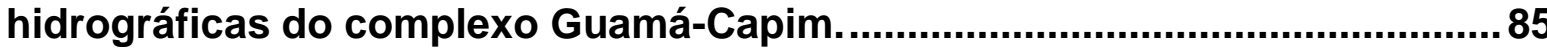

5.5.5 Análise de sensibilidade, calibração e validação. ...................................94

5.5.6 Transferência dos parâmetros calibrados da modelagem da porção

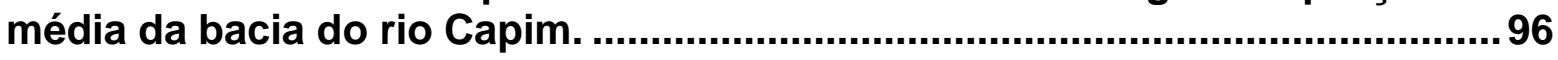

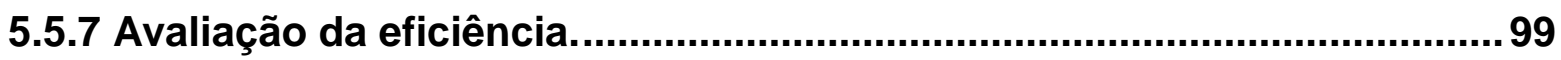

5.5.8 Simulações hidrológicas por períodos e cenário. ..................................101 5.6 MODELAGEM DINÂMICA DE MUDANÇA DE USO E COBERTURA DA TERRA UTILIZANDO O MODELO CLUE-S.

5.6.1. Componentes do modelo CLUE-S.........................................................103

5.6.2 Banco de dados de Entrada do modelo CLUE-S. .................................. 109

5.6.3 Procedimentos da modelagem dinâmica com o CLUE-S.......................110

5.6.4 Verificação do acerto dos resultados da calibração do modelo. ...........121

5.7 SISTEMAS COMPUTACIONAIS UTILIZADOS NA TESE 123

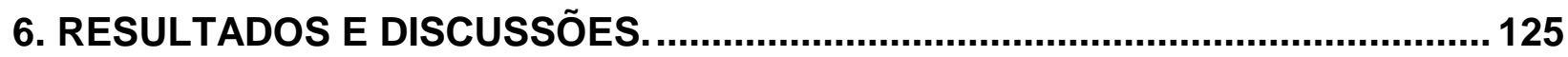

6.1. MAPAS DE USO E COBERTURA DA TERRA NAS SUB-BACIAS. 125

6.1.1 Mapa de uso e cobertura da terra de 2008. .........................................125

6.1.2. Mapas classificados para os anos de 2000, 2004 e 2013.....................129

6.1.3. Descrição das Mudanças de uso e cobertura de 2000 a 2013.............. 132

6.1.4 Mapa de uso e cobertura da terra do ano de 2010 utilizado na modelagem da porção média do rio Capim...........................................................................135

6.2. MODELO DIGITAL DE ELEVAÇÃO DO TERRENO (MDE). 136

6.3 MAPA PEDOLÓGICO. 139

6.4. RESULTADOS DA APLICAÇÃO DO MODELO SWAT. 142

6.4.1 Delineamento automático das bacias. ...................................................... 142

6.4.2 Unidades de Resposta Hidrológica - HRU's. ..........................................146

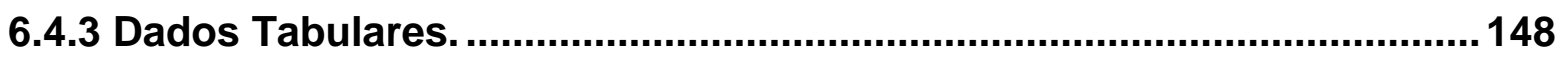

6.4.4 Resultados da regionalização de vazão................................................153

6.4.5. Resultados dos experimentos de simulações com o SWAT. ................159

6.5 RESULTADOS DAS SIMULAÇÕES COM O MODELO CLUE-S 190

6.5.1 Identificação do uso e cobertura de cada sub-bacia............................190

6.5.2 Identificação dos Fatores exploratórios e Aquisição de arquivos digitais. 191

6.5.3 Identificação das demandas de mudança de uso e cobertura para cada sub-bacia. 202

6.5.4 Preparo dos arquivos para uso no modelo. ...........................................204

6.5.5 Análise dos fatores exploratórios do estudo de caso............................208

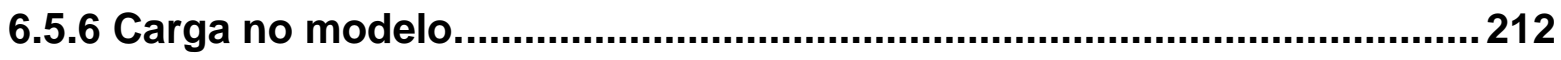


6.5.7 Ajustes do modelo de calibração 2008 - 2013 e projeção 2013 - 2023. 215 6.6 EXPERIMENTO 3: ANÁLISE DE CENÁRIOS E INTEGRAÇÃO SWAT E CLUE-S. 223

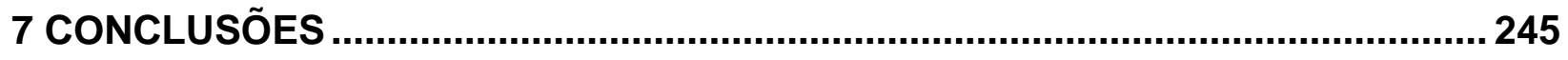

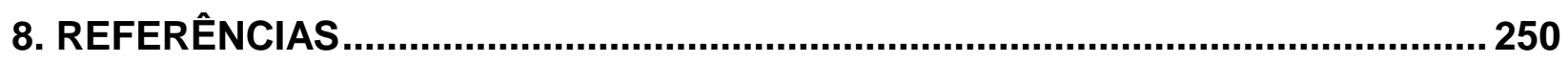

APÊNDICE A - Informações extras do modelo SWAT............................................281

APÊNDICE B - Informações extras do modelo CLUE-S.........................................284

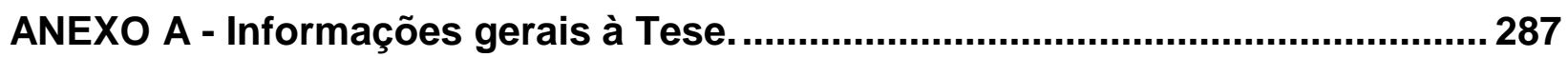





\section{INTRODUÇÃO.}

A região amazônica brasileira, em especial a região nordeste do estado do Pará, passou por um processo de desenvolvimento econômico acelerado, o qual foi oriundo do Programa de Integração Nacional e sequenciais incentivos ao desenvolvimento de atividades agropecuárias, extrativismo e mineração (BECKER, 2005). No entanto, pouco se planejou para a realização da ocupação desses territórios, o que ocasionou o desenvolvimento de um complexo mosaico de usos e ocupação do solo formado por ecossistemas de floresta primária e sucessional, áreas degradadas e desmatadas, agropecuária, mineração, indústrias diversas, unidades de conservação ambiental, reservas indígenas, assentamentos rurais, agricultura familiar e ocupação urbana (LIMA, 2005), os quais trouxeram uma série de impactos ambientais e socioeconômicos oriundos, especialmente, da falta de planejamento do uso do solo e de gestão dos recursos naturais.

Como consequência do manejo incorreto do solo e dá água, alguns desequilíbrios ecossistêmicos podem ser destacados, em especial as alterações do regime de escoamento superficial e intensificação de processos erosivos (YANG et al. 2009). A perda de solo pode causar problemas de nível local como a redução de fertilidade, a criação de voçorocas, obstrução de nascentes, além de problemas de ordem regional como a contaminação dos recursos hídricos e o assoreamento de rios e reservatórios (FILIZOLA et al., 2011). Hernani et al. (2002) identificam os processos erosivos como a principal razão da degradação do solo em regiões tropicais, em especial no Brasil, mas também apontam a influência da erosão em processos catastróficos como inundações e longos períodos de estiagem. Dessa forma, é necessário pensar mecanismos adequados para construção de sistemas de manejo conservacionistas que permitam a redução de processos erosivos, assim como outras formas de degradação dos recursos naturais, bem como os efeitos a curto, médio e longo prazo. Mas para que seja possível prevenir e remediar problemas dessa natureza

é necessário adotar medidas em acordo com a legislação ambiental, que forneçam embasamento técnico e científico, ampliando o manejo integrado de bacias 
hidrográficas, substituindo técnicas de manejo convencionais por modelos que contribuam diretamente para a conservação do solo, da água e na melhoria da qualidade de vida do produtor rural (WISCHMEIER; SMITH, 1978; GUERRA; BOTELHO, 1996, HERNANI et al., 2002; GUERRA, 2005; GUIMARÃES et al., 2012).

Atualmente, uma atividade que se tornou estratégica a nível nacional é o cultivo de espécies oleaginosas para o mercado alimentício e energético, em especial o plantio da palma de óleo de dendê na região nordeste do estado do Pará. Para subsidiar o desenvolvimento desta cultura em regiões desmatadas da Amazônia, o governo federal encomendou a realização do Zoneamento Agroecológico do Dendezeiro (RAMALHO FILHO, 2010), o que demonstra as intenções governamentais em identificar as áreas mais favoráveis ao desenvolvimento dessa atividade. Hoje, os plantios de palma de óleo têm se expandido pelo mundo, pois o óleo extraído dessa planta é amplamente utilizado no mundo pelas indústrias de alimentos, cosméticos e agora com forte objetivo para a produção de biocombustíveis (BECKER, 2010).

A produção da palma de óleo apresenta muitas vantagens no Brasil, destacando as condições biofísicas ideais na Amazônia, forte interesse econômico pelos seus produtos, tecnologia disponível, elevada capacidade de ofertar emprego a população próxima aos plantios e políticas públicas de financiamento e incentivos fiscais (BECKER, 2010). Porém, também apresenta riscos, sejam eles de ordem socioeconômica, através da imposição de regras de produção pelas grandes empresas nos contratos com os pequenos agricultores e possíveis expropriações de terras, assim como de ordem ambiental, os quais são os mais discutidos devido à possibilidade da expansão da palma de óleo provocar o aumento do desmatamento e empobrecimento da diversidade ecológica (BUTLER; LAURENCE, 2009). Mas também é importante destacar que a expansão da cultura da Palma de óleo na Amazônia tem sido vista como um benefício à fixação do homem no campo, à recuperação de áreas degradadas, à redução da perda de solo por processos erosivos e como grande potencial para produzir biodiesel (HOMMA, et al., 2000).

Todos esses agroecossistemas utilizam e influenciam diretamente na qualidade dos recursos naturais solo e água. Devido a grande importância, em especial, dos recursos hídricos como base de sustentação da vida de maneira geral, a Política 
Nacional dos Recursos Hídricos definiu a Bacia Hidrográfica como sua Unidade Básica de Planejamento Territorial (BRASIL, 1997), reconhecendo a importância dos recursos hídricos para a sociedade e meio ambiente como um todo. Assim, consolida-se esta unidade como território favorável ao planejamento integrado do uso e ocupação do solo focando no desenvolvimento sustentável, constituindo um sistema adequado aos estudos e avaliações de impactos ambientais das atividades antrópicas (TUNDISI, J.G.; STRASKRABA, 1995; SOUZA; FERNANDES, 2000).

A modelagem ambiental tem se mostrado uma importante ferramenta no estudo de impactos ambientais das mudanças da paisagem de curta e longa duração (SINGH; WOOLHISER, 2002; DOUGLAS-MANKIN et al., 2010), contribuindo diretamente na tomada de decisões e no planejamento estratégico do território (ROCHA et al., 2012). A aplicação do modelo hidrossedimentológico SWAT (Soil and Water Assessment Tool), em especial, fornece a possibilidade de se avaliar o impacto dos diferentes usos do solo, bem como de sua dinâmica, no escoamento superficial e na produção de sedimentos (DEBELE et al. 2008). Isso é possível por razão do SWAT ser um modelo hidrológico contínuo no tempo, com embasamento físico, construído para estimar diariamente a vazão e predizer possíveis perdas de solo e nutrientes em bacias complexas com diferentes usos do solo, características pedológicas e de manejo (ARNOLD et al., 1998; ZHANG et al. 2009). Conjuntamente ao SWAT, o uso do arcabouço CLUE-S (Conversion of Land Use and its Effects at Small Region Extent) nos possibilita avaliar a dinâmica de uso e cobertura do solo e simular cenários baseados na competição entre classes de uso em escala local e até mesmo regional (VERBURG et al., 2002). O desenvolvimento de cenários tem se tornado uma ferramenta útil e poderosa para compreender os impactos das mudanças de uso e cobertura da terra, permitindo a avaliação de um provável ambiente futuro e a buscar alternativas de gestão diferenciadas (VERBURG et al., 2006b). Com isso, a análise de cenários com o uso de modelos pode dar suporte ao planejamento das políticas de uso do solo (VERBURG et al., 2004).

Tendo em vista a importância de estudar a influência de diferentes cenários de uso e ocupação do solo sobre os processos hídricos e erosivos, a fim de contribuir com trabalhos de promoção da conservação dos recursos hídricos, conservação do solo e 
no planejamento territorial, o presente trabalho aplicou a modelagem ambiental nas sub-bacias não monitoradas dos rios Bujaru e Mariquita, região nordeste do estado do Pará, Amazônia Oriental, com o objetivo de estimar o impacto da expansão da palma de óleo sobre o escoamento superficial e produção de sedimentos. Especificamente, avaliou-se a calibração do modelo SWAT, tendo como base as séries de dados de vazão regionalizadas de bacias monitoradas para as sub-bacias não monitoradas, comparando esses resultados com medidas em campo de vazão na sub-bacia não monitorada para o ano de 2014. Compararam-se, também, os resultados da evapotranspiração do modelo com resultados da literatura e dados de campo. Por fim, verificaram-se as diferentes produções de escoamento superficial e de sedimentos entre os diferentes usos e coberturas da terra presentes na modelagem do período com pouca ou nenhuma área plantada com a cultura da palma de óleo (2008), com forte expansão desta cultura (2013) e em cenário futuro (2023). 


\section{HIPÓTESES.}

1. As ferramentas de análise e monitoramento ambiental utilizadas no presente estudo são capazes de trabalhar em conjunto para subsidiar estudos dos impactos ambientais da palma de óleo na Região nordeste do estado do Pará.

2. As diferentes dinâmicas de uso e cobertura do solo apresentam a palma de óleo como uma cultura com boas possibilidades de responder positivamente à redução do escoamento superficial e da produção de sedimentos. 


\section{OBJETIVOS.}

\subsection{OBJETIVO GERAL.}

Estimar o impacto da expansão da cultura da palma de óleo sobre a dinâmica de mudança de uso e cobertura da terra nas sub-bacias não monitoradas dos rios Bujaru, afluente do rio Guamá, e Mariquita, afluente do rio Acará-Mirim, na região nordeste do estado do Pará, avaliando os efeitos sobre os aspectos hidrossedimentológicos em escala espacial e temporal.

\subsection{OBJETIVOS ESPECÍFICOS.}

1. Levantar dados e sistematizar as informações que viabilizem a aplicação dos modelos CLUE-S (Conversion of Land Use and its Effects at Small Regional Extent) e SWAT (Soil and Water Assessment Tool);

2. Aplicar duas técnicas alternativas de calibração do modelo SWAT para bacias não monitoradas dos rios Bujaru e Mariquita: sendo a primeira fundamentada na regionalização de vazão em conjunto com medidas em campo de vazão com molinete hidrométrico; e a segunda através da transferência de parâmetros da calibração da bacia do rio Capim;

3. Elaborar cenários de uso e ocupação do solo para estas sub-bacias, fundamentados no estudo de forçantes de mudança espacial e temporal do uso e cobertura do solo, através da aplicação do Modelo CLUE-S; 
4. Estimar o escoamento superficial e o transporte de sedimentos nas sub-bacias dos rios Bujaru e Mariquita através da aplicação do Modelo SWAT em função do uso e ocupação da terra atual e dos cenários gerados a partir do CLUE-S;

5. Analisar a contribuição dos resultados dos modelos para o diagnóstico e monitoramento ambiental, visando o planejamento e gestão ambiental e agrícola das sub-bacias em estudo. 


\section{REVISÃO BIBLIOGRÁFICA.}

\subsection{DINÂMICA DE MUDANÇA DE USO E COBERTURA DA TERRA E OS SEUS IMPACTOS AMBIENTAIS SOBRE O ESCOAMENTO SUPERFICIAL E PERDA DE SOLO.}

Os diferentes sistemas de uso e cobertura da terra são complexos e operam na interface de múltiplos sistemas sociais e ecológicos (VERBURG et al., 2002), o que propõe o desafio multidisciplinar de correlacionar diferentes áreas de estudo, como a socioeconomia, as ciências políticas e do meio biofísico para se buscar realizar a simulação das mudanças do uso e cobertura da terra. No entanto, a análise integrada de sistemas de uso da terra, aspectos sociais e ecológicos nos levam a trabalhar uma série de conceitos que conectam direta ou indiretamente esses fatores. VERBURG et al. (2002) explicam que essa conectividade implica que não podemos compreender o uso da terra em um determinado local por apenas estudar as características de determinada localidade, mas sim, as suas relações com os locais circunvizinhos ou ainda mais distantes, podendo ser tão importante quanto às condições no local em si.

Na presente tese, se utilizará constantemente o termo "uso e cobertura da terra", por isso é importante entender que os termos "uso" e "cobertura" não são sinônimos, sendo importante a compreensão correta de seus significados, os quais são constantemente aplicados em estudos de mudanças de uso e cobertura do solo (BRIASSOULIS, 1999). Dessa forma, é importante saber que a cobertura da terra representa o estado biofísico da superfície e da subsuperfície imediata do solo (Ex.: áreas agrícolas, florestas e água), enquanto que o uso da terra corresponde à maneira e o objetivo pelo qual os atributos biofísicos são manipulados (TURNER et al. 1995 ${ }^{1}$ apud BRIASSOULIS, 1999).

\footnotetext{
1 - TURNER, B.L. II; SKOLE, D.L.; SANDERSON, S.; FISCHER, G.; FRESCO, L.O.; LEEMANS, R. Landuse and land-cover change. Science/Research Plan. Stockholm e Geneva: IGBP Report, n. 35 e HDP Report, n. 7, 1995. 132 p.
} 
O estudo das mudanças nos padrões de uso e cobertura da terra é de reconhecido interesse de todos os setores em geral da sociedade, devido aos impactos ambientais e socioeconômicos dessas mudanças do nível local ao global, como os aspectos de degradação dos recursos hídricos e de mudanças climáticas (AGUIAR, A., 2003). Assim, estudar os processos que influenciam direta e indiretamente as mudanças de uso e cobertura da terra, sejam estes de escalas locais, regionais ou globais, bem como os seus reais impactos é fundamental para saber se as consequências são ou serão negativas ou positivas, permitindo assim agir de maneira a prevenir e/ou mitigar possíveis impactos e promover a sustentabilidade do desenvolvimento (BRIASSOULIS, 1999; AGUIAR, A., 2003).

As mudanças no uso e na cobertura da terra são resultados da interação de vários processos (VERBURG et al., 2002), os quais são influenciados por uma ou mais variáveis que agem como fatores determinantes nas ações dos agentes e das mudanças envolvidas no processo, tais como: fatores demográficos, econômicos, tecnológicos, políticos e institucionais, culturais e fatores biofísicos (TURNER et al., 1995 apud VERBURG et al., 2002). A definição e escolha dessas variáveis, também denominadas de forçantes de mudanças (driving forces), para o estudo de mudança espacial é uma das mais importantes etapas desse tipo de estudo, sendo a dinâmica de mudança influenciada por fatores políticos, culturais, infraestruturais, sociais, econômicos e de mercados, desde escalas locais até globais (LAMBIN et al., 2001).

De maneira geral, a modelagem espacial dos sistemas exige uma série de características, as quais serão base do desenvolvimento do presente estudo, onde podemos destacar: 1. a análise multiescalar entre as variáveis dependentes e as forçantes de mudança; 2 . especial atenção as forçantes analisadas; 3 . entendimento de que o conceito de sistema pressupõe resiliência e estabilidade, logo algumas forçantes podem não apresentar o resultado esperado; 4. e o modelo deve permitir interações entre os aspectos locais, e permitir feedbacks com níveis organizacionais mais elevados (VERBURG et al., 2002; VERBURG et al., 2004; VERBURG; OVERMARS, 2007). Dentro deste contexto, VERBURG et al. (2002) reforçam a importância de se buscar compreender o conceito de conectividade dos sistemas de uso e cobertura da terra, uma vez que processos biofísicos, como o transporte de sedimentos, são 
resultados de processo erosivos, e estes, por sua vez, são resultados de uma combinação de fatores edafoclimáticos com os movimentos antrópicos no espaço. Da mesma forma, a degradação do solo em um determinado local pode impulsionar o desmatamento em outras regiões.

As mudanças de uso e cobertura da terra, seja qual for a magnitude espacial e temporal, sujeitam os ecossistemas a um determinando grau de impacto ambiental. Porém, quanto menor o nível de planejamento e a qualidade da tecnologia aplicada no manejo dos recursos naturais, maior pode ser o impacto negativo das ações antrópicas. Como principais impactos desta ação, podem-se destacar impactos no clima, atmosfera e estratosfera, com alterações na temperatura e regime de chuvas; sobre os recursos hídricos, como contaminação da água por nutrientes e pesticidas; impactos sobre o solo, como aumento de processos erosivos e salinização; sobre os ecossistemas, como perda de biodiversidade e propagação de pragas; e por fim, impactos sobre a saúde e segurança humana, como a escassez de recursos hídricos e aumento de doença de vinculação hídrica (BRIASSOULIS, 2004).

Dentre diversos problemas ambientais que estão sujeitos a acontecerem conforme o cenário de uso e ocupação da terra aplicado ao território, podemos destacar a alteração do ciclo hidrológico, em especial sobre o escoamento superficial, bem como as respectivas consequências sobre o transporte de sedimentos através do processo de erosão. Vários trabalhos têm descrito e discutido a relação desses dois fluxos ecossistêmicos, de maneira a descrever diferentes métodos de estimativa, simulações, bem como suas causas e efeitos no território brasileiro (MACHADO; VETORAZZI, 2003; BALTOKOSKI et al., 2010; LELIS et al., 2012; ARAGÃO et al., 2013; MARCHIORO et al., 2014; CREECH et al., 2015).

O processo erosivo do solo é função de um arranjo de fatores, sendo eles as características da precipitação pluviomátrica, declividade, capacidade de absorção de água pelo mesmo, resistência do solo à erosão e das características da cobertura do vegetal (BERTONI; LOMBARDI NETO, 1999). Esse arranjo de fatores que irá determinar a intensidade do fluxo ecossistêmico denominado de escoamento superficial, que corresponde ao excesso não infiltrado da precipitação após saturação 
das camadas mais profundas e superficiais do solo pela água da precipitação (TUCCl, 2013).

A erosão é um processo de desprendimento e arraste acelerado das partículas do solo causado pela água e pelo vento, sendo este fenômeno um dos principais fatores do empobrecimento dos solos (BERTONI; LOMBARDI NETO, 1999). O mecanismo de erosão se inicia com o impacto das gotas da precipitação que desprendem as partículas de areia, ocorrendo primeiramente o transporte destas por salpicamento e em seguida são transportadas pelo fluxo turbulento do escoamento superficial (BERTONI; LOMBARDI NETO, 1999; GUERRA, 1999).

Basicamente, temos quatro formas de erosão: a laminar, em sulco, ravinas e as voçorocas (RIO GRANDE DO SUL, 1985; GUERRA, 1999). A erosão laminar é uma forma de erosão cuja água da precipitação escoa em uma camada fina e paralela uniformemente a todo o solo, como uma lâmina. O efeito laminar é lento, mas com o tempo começam a aparecer no solo pedras, raízes das plantas, sendo assim perdido o solo mais superficial e também o mais rico em nutrientes para as plantas (FERREIRA 1981), sendo este um dos processos mais perigosos (RIO GRANDE DO SUL, 1985). A erosão em sulco, segundo Bertoni e Lombardi Neto (1999), corresponde a pequenas irregularidades na declividade do terreno que já apresentam capacidade de favorecer o escoamento superficial com maior velocidade em determinados pontos, formando riscos mais ou menos profundos. As ravinas e voçorocas são estágios de erosão já mais avançados, tendo as ravinas fissuras de escoamento de profundidade e largura de tamanho inferior a $50 \mathrm{~cm}$, enquanto as voçorocas já apresentam mais de $50 \mathrm{~cm}$ (OLIVEIRA, 1999).

Como consequência da erosão, em conjunto com a grande perda de solo, ocorre a perda de nutrientes, ocasionando queda da fertilidade e afetando a produtividade das culturas, bem como a exposição do horizonte $B$, que é mais argiloso e menos permeável, com consequente aumento da enxurrada devido a redução da infiltração (FERREIRA, 1981; BERTONI; LOMBARDI NETO, 1999). Os sequenciais processos de sedimentação e deposição do material erodido nas regiões mais baixas das bacias hidrográficas, por exemplo, também provocam redução da fertilidade e produtividade do ecossistema (BERTONI; LOMBARDI NETO, 1999). 
Os impactos dos processos erosivos, originados a partir do manejo incorreto do solo são variados, sendo destacados os impactos sobre os custos de produção, por razão da redução da fertilidade do solo, os quais tem sua fina camada superficial média de $15 \mathrm{~cm}$ erodida exigindo, assim, mais insumos agrícolas; problemas de ordem de inutilização de áreas devido a criação de erosões avançadas, como as voçorocas; o decréscimo da produtiva, que devido a perda de solo, nutrientes e também de matéria orgânica e da agregação do solo, sujeitam os agroecossistemas a um índice de produtividade cada vez menor; por fim, problemas ligados a poluição, assoreamento e até impactos na produção de energia, quando o transporte de partículas aumenta a turbidez da água, transporta nutrientes agroquímicos e se depositam no leito de rios, barragens e lagos, provocando impactos sobre a fauna e flora aquática, ao consumo humano da água e assoreando reservatórios para produção energética (RIO GRANDE DO SUL, 1985).

Além da necessidade cada vez maior de se procurar conhecer os ecossistemas e os diferentes usos dados a estes, através de diagnósticos biofísicos e socioeconômicos, é fundamental se ampliar o aparato de conhecimento técnico dos mecanismos do monitoramento e controle de áreas vulneráveis a processos erosivos. A presente tese busca explicitar duas ferramentas importantes ao monitoramento e controle ambiental, que compreende o estudo da dinâmica de mudança de uso e cobertura da terra e a modelagem hidrossedimentológica. Quanto ao controle, estas ferramentas podem auxiliar de maneira determinante na tomada de decisões, mas a adoção de tecnologias de manejo para proteção real do solo precisa ser efetiva, seja para prevenção quanto para correção. PRIMAVESI (2002) aponta que todas as medidas de proteção dos solos tropicais são diretamente medidas de combate aos processos erosivos, tais como a aração mínima, plantio direto, cobertura morta, culturas de proteção, sistemas agroflorestais, culturas consorciadas e adubações completas, incluindo microorganismos. Por conclusão, Salomão (1999) descreve várias classes de medidas de controle dos processos erosivos, como as práticas de caráter vegetativo (plantas de cobertura, culturas em faixas, cordões de vegetação permanente, alternância de capinas e quebra-ventos), práticas de caráter edáfico (controle do fogo, adubação verde, adubação química, adubação orgânica, rotação de culturas e 
calagem) e também práticas de caráter mecânico (plantio em contorno, terraceamento e canais escoadouros).

\subsection{MODELAGEM AMBIENTAL COMO FERRAMENTA DE GESTÃO E PLANEJAMENTO AMBIENTAL DE BACIAS HIDROGRÁFICAS NÃO MONITORADAS.}

Estudar os diferentes processos naturais e antropogênicos que ocorrem em nível de bacia hidrográfica é bastante complexo, devido ao elevado número de compartimento e fluxo existentes dentro dos diferentes ecossistemas, em especial na análise de perda de solo. Segundo REICHARDT e TIMM (2004) ${ }^{2}$ apud MINOTI (2006), a principal razão do aumento do interesse de pesquisadores pela utilização de modelos de avaliação de erosão está ligado à dificuldade técnica e ao custo de se fazer medições diretas. Em nível de bacia hidrográfica, existe certo consenso de que a aplicação da modelagem hidrológica para qualificar e quantificar o balanço hídrico se mostra uma ferramenta capaz de melhorar o grau de entendimento (LI et al., 1992 ${ }^{3}$ apud CUl et al, 2015). Isto se esclarece também por razão dos modelos permitirem fazer avaliações mais complexas, avançadas e organizadas, sendo capaz de prever o comportamento de vários compartimentos e fluxos ecossistêmicos, bem como estudar os fenômenos de maneira dinâmica na interface espaço-temporal (PESSOA et al., 1997).

Os modelos tem se tornado importantes ferramentas, pois estão sendo desenvolvidos na perspectiva de integrarem diferentes indicadores dos processos ecossistêmicos, permitindo avaliar de maneira mais integrada o conjunto de fatores envolvidos na geração de possíveis impactos ambientais, sejam eles positivos ou negativos. A avaliação de impactos ambientais, como uma ferramenta importante do processo de planejamento e gestão ambiental, tanto do aspecto legal como técnico, é

\footnotetext{
${ }^{2}$ REICHARDT, K.; TIMM, L. C. Solo, planta e atmosfera: conceitos, processos e aplicações. Barueri: Manole. 2004. 478 p.

${ }^{3}$ ZHIJIA, L., JIREN, L. E CONGSHANG, H. A synthetic method for simulating both discharge and stage of flood in a channel. Yellow River, v. 2, p. 16-20, 1992.
} 
um instrumento de tomada de decisão, necessitando ser capaz de diagnosticar e predizer consequências de uma determinada ação (PESSOA et al., 1997; MINOTI, 2006). Além disso, os modelos permitem, probabilisticamente, avaliar os impactos em diferentes níveis de cenários, possibilitando predições de comportamentos futuros dos sistemas estudados em condições ainda não exploradas por experimentos reais, o que permite visualizar novos caminhos de análise, reduzindo o tempo e o custo da pesquisa (PESSOA et al., 1997).

Tendo em vista a necessidade de se utilizar um conjunto de técnicas específicas para se criar cenários e avaliar o impacto ambiental das diferentes atividades humanas, tais como experimentos e medições em campo, simulações de processos sistêmicos, avaliação de paisagem, modelos estatísticos e matemáticos, torna-se importante observar que os resultados gerados a partir de análise de cenários estão diretamente ligados a existência de um conjunto de informações básicas dos compartimentos e fluxos que compõem os ecossistemas estudados para rodar os modelos. Dessa forma, a criação de cenários futuros de uso e ocupação da terra, assim como os impactos das mudanças dos sistemas de uso e manejo da terra nas características hidrológicas e na perda de solos, exige a utilização de modelos capazes de integrar o máximo de informações e representarem as características e dinâmicas reais dos ecossistemas, contribuindo para o planejamento e gestão ambiental, em especial, em nível de bacias hidrográficas.

Na presente pesquisa serão utilizados os Modelos CLUE-S (Conversion of Land Use and its Effects at Small Regional Extent), com o objetivo de realizar avaliações de mudanças nos complexos padrões espaciais de uso da terra em virtude das interações entre dinâmica espacial e temporal de sistemas de uso da terra (VERBURG et al., 2002), e o Modelo SWAT (Soil and Water Assessment Tool) para prever o impacto das práticas de manejo do solo sobre a água e sedimentos em bacias hidrográficas com diferentes usos e coberturas da terra e condições de manejo durante longo período de tempo (NEITSCH et al., 2011). 


\subsubsection{Sistemas de Informação Geográfica aplicados a caracterização e análise ecossistêmica.}

O Sistema de Informações Geográficas (SIG) se constituem como um instrumento do Geoprocessamento capaz de integrar em uma única plataforma de trabalho diferentes programas que utilizam dados geográficos para a realização de amplas tarefas de análise do espaço. Os SIG's desenvolvem de maneira sistêmica tarefas de entrada, armazenamento, recuperação, geração de produtos e análises descritivas (CHRITOFOLETTI, 1999; FITZ, 2008). Acrescenta-se, ainda, a possibilidade de realizar todas essas tarefas em grandes quantidades de dados espaciais ao mesmo tempo (BURROUGH, $1998^{4}$ apud KUHN, 2005). Fitz (2008) apresenta os SIG's como a união de sistemas associados, os quais são constituídos por outros programas que são aplicados conforme necessidade do usuário.

No caso do presente estudo, o qual busca modelar os processos hidrológicos e de perda de solo, os SIG's contribuem com a sua capacidade de analisar de maneira integrativa os dados de relevo, pedologia, uso e cobertura do solo, dados climáticos e outros para predizer as características da variabilidade espacial do potencial de erosão em uma micro-bacia (MACHADO et al., 2003). Especificamente com relação ao exemplo da produção de sedimentos, que é originária de fontes não pontuais, os SIG's tem desempenhado um importante papel nas pesquisas com modelagem dos recursos naturais e provando ser uma excelente ferramenta de quantificação da poluição (SRINIVASAN et al., 1998).

Os SIG's são direcionados especificamente para o trabalho de análise de dados espacialmente distribuídos e georreferenciados sendo, por isso, constituídos de procedimentos aplicados a análise espacial, porém, há um esforço na perspectiva de criação de programas capazes de analisar os dados espaciais em consonância com a análise dos dados de séries temporais (CHRISTOFOLETTI, 1999). Pedrosa e Câmara (2007) corroboram afirmando que é um desafio transformar os SIG's, que são

\footnotetext{
${ }^{4}$ BURROUGH, P. A. Principles of geographical information systems. New York: Oxford university, 1998.
} 
essencialmente de análise estática, em sistemas com ferramentas de análises para a representação realística de processos espaço-temporais, tornando-os capazes de representar processos dinâmicos de ordem física e socioeconômica.

O modelo SWAT, utilizado para a modelagem hidrossedimentológica, é um software que possui uma interface com os SIG's (ArcSwat), sendo este um complexo modelo matemático semidistribuído que opera em escala de tempo diária, objetivando avaliar impactos dos agroecossistemas e das técnicas de manejo sobre o balanço hídrico, sobre a qualidade dos recursos naturais e sobre o manejo de bacias e reservatórios (ARNOLD; ALLEN, 1996; ARNOLD et al., 1998; OLIVEIRA et al., 2006). Por ser um modelo contínuo no tempo e por ter o auxílio dessa poderosa ferramenta SIG, o modelo SWAT é capaz de simular realisticamente os componentes e fluxo individuais do sistema hidrológico (ARNOLD et al., 1998; OLIVEIRA et al., 2006).

O modelo CLUE-S, por sua vez, para ser uma ferramenta capaz de representar de maneira realística os processos espaço-temporais que determinam as mudanças geográficas ao longo do tempo, se fundamenta na utilização da teoria do Autômato Celular (CARNEIRO, 2006) em conjunto com um SIG para trabalhar com a simulação dinâmica do uso e cobertura da terra. Mas, isso só é possível porque a modelagem com o uso do Autômato Celular permite a análise dinâmica e discreta do sistema em estudo, integrando em uma mesma modelagem aspectos complexos e também subjetivos (COUCLELIS, 1997).

\subsubsection{Modelagem hidrossedimentológica utilizando o modelo SWAT (Soil and Water Assessment Tool).}

O SWAT corresponde a um modelo hidrossedimentológico desenvolvido para avaliar o solo e a água na escala de bacia hidrográfica (NEITSCH et al., 2011), caracterizando-se, dessa forma, como um modelo operacional ou conceitual que trabalha em uma escala de tempo diária (ARNOLD et al., 1998). Trata-se de um modelo com uma forte fundamentação física, o qual utiliza dados de fácil disponibilidade, sendo 
eficiente computacionalmente, pois é capaz de simular grandes bacias com usos diversificados do solo continuamente, permitindo assim, a simulação por longos períodos de tempo dos impactos das mudanças de uso e ocupação da terra (TIM, 1996; GASSMAN et al., 2007; NEITSCH et al., 2011).

Dessa forma, as vantagens do SWAT estão em permitir a modelagem de bacias não monitoradas, não exige grandes investimentos em dinheiro e tempo, os dados de entrada estão disponíveis nas agências governamentais e permite ao usuário um monitoramento de longo prazo. Outra grande vantagem, se não a principal, é que o SWAT possui seu código numérico aberto, permitindo ao usuário alterar e fazer ajustes que achar relevantes, bem como possui sua interface com o SIG. O modelo também não exige calibração, porém não é possível calibrar o SWAT caso a bacia em estudo não seja monitorada (ARNOLD et al., 1998; NEITSCH et al., 2011). Além disso, o modelo não foi desenvolvido com o intuito de predizer eventos isoladamente.

O Modelo SWAT foi criado no início da década de 90, a partir da fusão de características de outros modelos desenvolvidos pelo Agricultural Research Service (ARS) dos Estados Unidos da América, fundamentando-se, em especial, no modelo SWRRB (Simulator for Water Resources in Rural Basins) (GASSMAN et al., 2007). O objetivo central do modelo SWAT é a previsão de processos impactantes do manejo da água, produção e transporte de sedimentos, além de avaliar o rendimento do uso de insumos agrícolas em bacias hidrográficas não monitoradas (ARNOLD et al., 1998), as quais podem apresentar diferentes tipologias pedológicas, mosaicos de uso e cobertura da terra, bem como diferentes mecanismos de gestão (NEITSCH et al., 2011).

Para fazer simulações, o SWAT requer uma série de dados de entrada específicos sobre clima, pedologia, relevo, vegetação e os tipos de uso e ocupação da terra na bacia. Os processos físicos associados ao movimento da água, transporte de sedimentos, crescimento vegetal, ciclo de nutrientes dentre outros, são diretamente modelados pelo SWAT (NEITSCH et al., 2011). A organização sistemática de armazenamento e manipulação do banco de dados, bem como a aplicação das funções do modelo sobre o banco de dados é permitido pela facilitação que a interface integrativa entre SWAT e o ArcGis ${ }^{8}$, denominada de ArcSWAT, permite ao usuário (WINCHELL et al., 2013). 
Para fins de modelagem, uma bacia hidrográfica é dividida em uma série de subbacias (ARNOLD et al., 1998). O uso de sub-bacias em uma simulação pode ser benéfica para identificar as diferenças das características hidrológicas de cada subbacia de acordo com a predominância de determinados usos dos solos (NEITSCH et al., 2011). Informações de entrada para cada sub-bacia são agrupadas ou organizadas nas seguintes categorias: clima; unidades de resposta hidrológica; açudes/pântanos; águas subterrâneas; e o canal principal, ou alcance, de drenagem da sub-bacia. Unidades de resposta hidrológica agrupam áreas de terra dentro da sub-bacia que são compostos de cobertura vegetal, solos e combinações de gestão (NEITSCH et al., 2011).

Uma informação importante para a melhor compreensão do modelo é que, independentemente da aplicação dada ao modelo, o sistema hidrológico, representado na Figura 1, é a força motriz que conduz todos os processos, sendo determinante encontrar o equilíbrio do mesmo para se diagnosticar a bacia em estudo. Dessa forma, apresentam-se duas fases de simulação distintas e fundamentais para os trabalhos com o modelo SWAT. A Primeira é a fase terrestre do ciclo hidrológico, a qual é composta por 7 diferentes entradas e processos: Clima, Hidrologia, Cobertura Vegetal/Crescimento de plantas, Erosão, Nutrientes, Pesticidas e Manejo. A segunda é a fase canal, onde o modelo SWAT abrange diferentes fenômenos de propagação da água, sedimentos, nutrientes e pesticidas oriundos da fase terrestre pelo canal principal.

Amplas descrições teóricas, metodológicas, técnicas e de aplicações estão publicadas em uma já vasta literatura (ARNOLD et al. 1998; ABBASPOUR et al. 2004; ARNOLD et al., 2005; SCHUOL et al. 2008; ARNOLD et al., 2011; NEITSCH et al., 2011; ARNOLD et al. 2012; WINCHELL et al., 2013; GASSMAN et al., 2007; GARBOSA et al., 2011; BRESSIANI et al., 2015a; DOUGLAS-MANKIN et al., 2010). O grupo responsável pelo modelo disponibiliza um site próprio (swat.tamu.edu), onde é possível fazer o download das versões dos Softwares ArcSWAT e SWAT-CUP (software de calibração), Macros em Excell para auxiliar na montagem e cálculos de dados climáticos e de solo, bem como links para acessar bancos de dados climáticos, hidrológicos, solos e relevo, além da lista de artigos publicados utilizando o SWAT. 


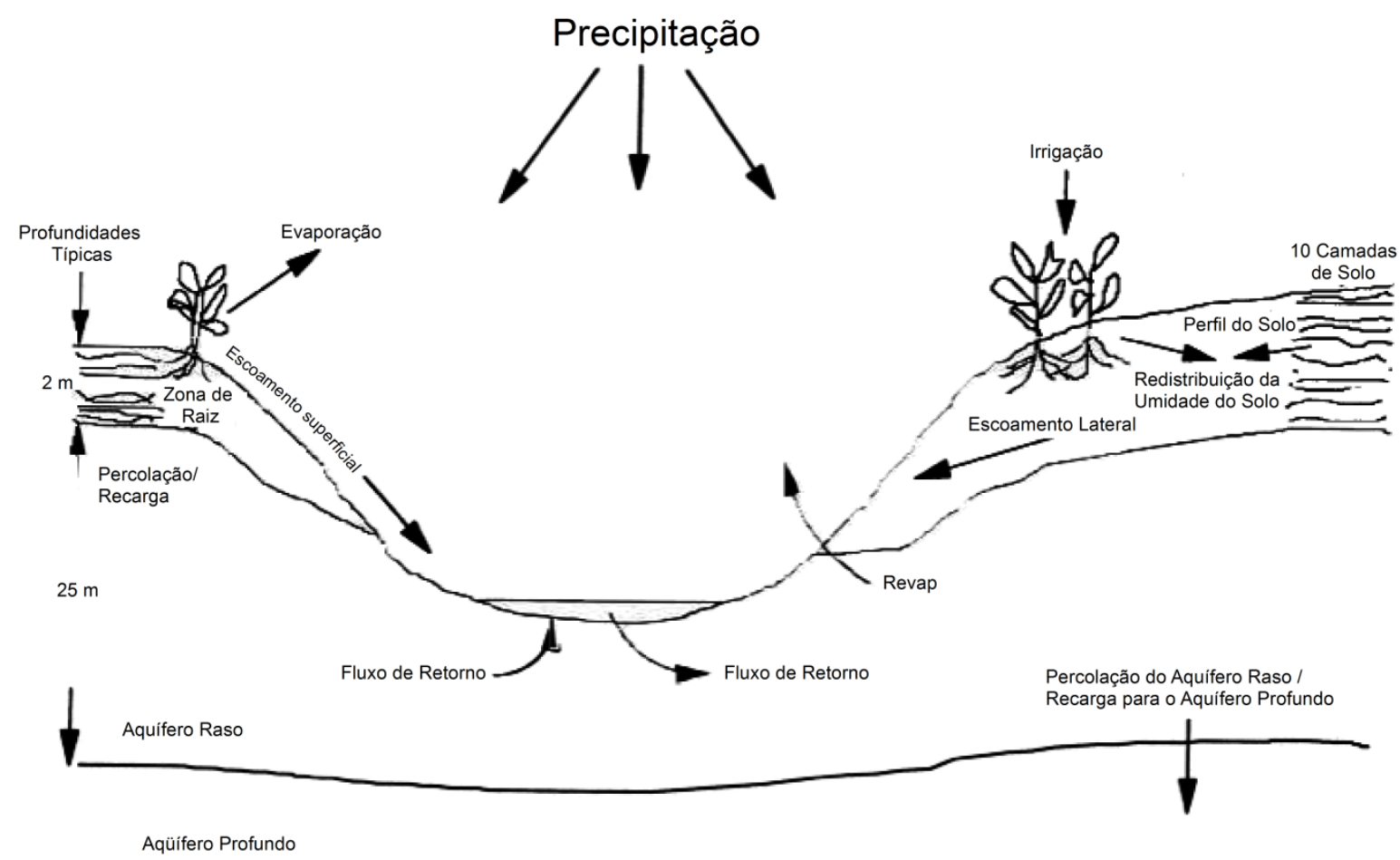

Figura 1: Componentes do balanço hídrico simulados nas sub-bacias do SWAT (Fonte: Adaptado de ARNOLD et al., 1998).

O modelo SWAT tem sido aplicado amplamente em diversos países como um instrumento importante de análise do impacto das mudanças de uso e cobertura do solo sobre aspectos biofísicos fundamentais dos ecossistemas. Pode-se destacar a aplicação do modelo com o objetivo de avaliar aspectos relacionados ao balanço hídrico (SOUSA et al., 2015), planejamento de uso da água (GUZHA et al 2013), processos erosivos (MEDEIROS et al., 2013), qualidade da água (BALTOKOSKI et al., 2010), impactos de dinâmica de uso e ocupação da terra (GALHARTE et al., 2014) e na gestão ambiental de áreas agrícolas (MACHADO et al., 2003).

Podem-se destacar algumas aplicações do modelo SWAT, como os trabalhos iniciais após a criação do Modelo SWAT. Arnoldo e Allen (1996) aplicaram o modelo SWAT sobre três bacias hidrográficas no estado de Illinois, com o objetivo de avaliar o balanço hídrico em áreas com diferenças geomorfológicas, mas com características climáticas semelhantes, focando, em especial, no escoamento superficial e subterrâneo, evapotranspiração e recarga do aquífero profundo. Os resultados mostraram que o modelo foi capaz de simular dentro dos limites aceitáveis todos os componentes do balanço, permitindo assim, uma avaliação da influência do uso e 
manejo do solo sobre características hidrológicas em larga escala, bem como orientar a tomada de decisão para adoção de melhoras práticas de manejo do solo.

Destaca-se também o trabalho de Srinivasan et al. (1998), que aplicou o modelo SWAT na bacia do rio Richland and Chambers Creeks, onde foi feita a calibração quanto aos dados de vazão e produção de sedimentos, mais especificamente, aplicou o modelo para estimar a produção de sedimentos em uma de suas sub-bacias denominada de Mill Creek, com cerca $283 \mathrm{~km}^{2}$, onde se validou a carga de sedimentos. Os resultados foram muito satisfatórios para vazão, sendo o teste de eficiência de Nash-Suttcliffe de 0,77 e 0,88, em duas estações estudadas na Bacia do rio Richland and Chambers Creeks, além de cargas de sedimentos real e simulada semelhantes na sub-bacia Mill Creek.

Outro trabalho influente quanto as aplicações do SWAT na sua década de início foi o de Arnold et al. (1999), o qual foi aplicado sobre 2100 grandes unidades hidrológicas delineadas pela USGS (United States Geological Survey) nos Estados Unidos da América, com a finalidade de compreender o comportamento do escoamento superficial, disponibilidade de água, transporte de sedimento e nutrientes para contribuir com o planejamento do uso da água na agricultura e municípios, tendências de cultivo e com o manejo de fertilizantes químicos e orgânicos; mesmo sem ser calibrado, o modelo encontrou resultados realísticos para escoamento superficial.

A adoção do modelo hidrossedimentológico SWAT em conjunto com o estudo de diferentes cenários de uso e ocupação do solo tem sido amplamente utilizada com o objetivo de avaliar os impactos na qualidade e disponibilidade de água de acordo com a mudança de uso e cobertura da terra. Nobert e Jeremiah (2012) trabalhando na Bacia do Rio Wami, Tanzânia, alertam que trabalhar o impacto de mudança de uso e cobertura da terra não é uma tarefa simplória, uma vez que há uma escassez de séries temporais de dados hidrológicos observados, uma grande variedade de ecossistemas envolvidos e uma dificuldade de se "controlar" as mudanças de uso do solo, bem como de monitorar essas áreas em campo. Constataram que o aumento da degradação dos ecossistemas florestais provocaram um aumento do escoamento superficial e redução do escoamento de base. 
Can et al. (2005), aplicaram o SWAT para estudar o impacto de cenários históricos e hipotéticos de uso e cobertura da terra, focando no aumento e redução da porcentagem de área com floresta e agricultura na bacia hidrográfica do Rio Fuhe, localizado na área de influência da bacia do lago Poyang, leste da China. Os autores identificaram que os plantios de arroz apresentaram maior escoamento superficial e que pequenos aumentos de áreas urbanas contribuíram para um aumento da produção de água, o que pode representar um possível aumento do perigo de contaminação ao rio. Gessesse et al. (2015) estudaram a bacia do rio Modjo, na Etiópia, a qual tem passado por profundas mudanças de uso e cobertura e erosão do solo; os autores identificaram de 1973 a 2007 um aumento de 55\% para 75\% da área da bacia coberta por áreas agrícolas em assentamentos rurais, redução das áreas de pastagem de 21,6\% para $5,5 \%$ e aumento da área urbana de 3,7\% para 5\%, o que implicou em um aumento de $14,2 \%$ no escoamento superficial e de $37 \%$ na produção de sedimentos.

No Brasil, o modelo SWAT tem sido cada vez mais utilizado como recurso aos estudos ambientais de bacias hidrográficas com forte relacionamento entre as instituições de pesquisa e ensino brasileiras com os responsáveis pelo constante desenvolvimento do Software. Segundo Garbosa et al. (2011) e Bressiane et al. (2015b), o trabalho mais antigo no Brasil que aplicou o modelo SWAT foi o de Oliveira e Medeiros (1999)*5. Garbosa et al. (2011) descreve o trabalho de Oliveira e Medeiros, o qual foi aplicado na bacia do rio Joanes, na Bahia, com $755,4 \mathrm{~km}^{2}$ da seguinte maneira:

Oliveira e Medeiros (1999) escreveram um dos primeiros artigos encontrados nos 12 anos de pesquisa com o modelo SWAT no Brasil. A bacia estudada está localizada na Região Nordeste. O objetivo principal foi avaliar o potencial da utilização do SWAT para a avaliação de bacias hidrográficas. Os autores concluíram que o modelo pode ser usado para planejamento e gestão de uma bacia hidrográfica brasileira.

Machado, Vettorazzi e Xavier (2003) aplicou o modelo SWAT na micro-bacia hidrográfica do Ribeirão dos Martins, afluente do rio Piracicaba-SP, cujo objetivo foi

${ }^{5}$ OLIVEIRA M. Q. C.; MEDEIROS, Y. D. P. Aplicação do modelo SWAT na avaliação de impactos decorrentes da modificação no uso do solo em bacias hidrográficas. In: XIII Simpósio Brasileiro de Recursos Hídricos, 1999, Belo Horizonte. ABRH, 1999. 
quantificar a produção de sedimentos no cenário de uso para o biênio 1999/2000, o qual apresentava alta degradação das áreas de preservação permanente, em comparação com cenários de atendimento ao código florestal brasileiro, como a manutenção da vegetação das áreas de bordas de rio, redores de nascente e encostas. Identificaram que os cenários com as áreas de preservação permanente respeitadas apresentaram redução de até $94 \%$ da produção de sedimentos em t.ha ${ }^{-1}$, apontando a necessidade de analisar a bacia hidrográfica unindo o diagnóstico de áreas mais sensíveis a processos erosivos e a recuperação de matas ciliares.

Crestana et al. (2010) publicou um trabalho importante quanto ao estudo de micro-bacias rurais aplicando o modelo SWAT. Em um primeiro estudo de caso, na micro-bacia do Rio Bonito $\left(223 \mathrm{~km}^{2}\right.$ ), Descalvado - SP, buscaram identificar possíveis áreas com maior suscetibilidade a processos de contaminação por dejetos de animais, tendo como premissa a avaliação da produção de sedimentos; no segundo estudo aplicaram o SWAT em micro-bacias da bacia hidrográfica do rio Mogi-Guaçu (São Paulo), agora com o objetivo de estimar os componentes hidrológicos. Os autores identificaram grande aporte de sedimentos no rio Bonito, o que eleva o risco de poluição por agroquímicos, fertilizantes e por dejetos animais. Observaram que baixos valores de escoamento superficial nas micro-bacias do Mogi-Guaçu e identificaram uma necessidade de dados de entradas mais robustos para o estudo destas micro-bacias.

Galharte et al. (2014) aplicaram o SWAT, combinado com o modelo de estudo de dinâmica espacial CLUE-S (Conversion of Land USE and its Effects at Small Region Extent), na micro-bacia do ribeirão das Guabirobas (SP) com o objetivo de estimar a produção de sedimentos em cenários futuros de expansão da cana-de-açúcar e laranja para o ano de 2025. O estudo constatou que a expansão da cana-de-açúcar promoveu maior produção de sedimentos nos cenários gerados pelo CLUE-S. Este trabalho experimentou, com sucesso, uma nova metodologia integrando ao SWAT cenários futuros de mudança de uso e cobertura da terra fundamentados em forçantes de mudanças biofísicas, climáticas, logísticas e socioeconômicas de diferentes escalas.

Creech et al. (2015) calibrou o modelo para a bacia do rio São Francisco ( $\approx$ $630.000 \mathrm{~km}^{2}$ ) com o objetivo de estimar o aporte de sedimento no cenário de $2005 \mathrm{e}$ também no pseudocenário histórico com vegetação nativa sem o impacto de atividades 
humanas, tais como a construção de barragens e irrigação. Trata-se de um estudo importante, uma vez que esta bacia engloba importantes estados brasileiros, como Minas Gerais, Bahia, Pernambuco, Alagoas e Sergipe, foca o trabalho na busca do entendimento do processo histórico de assoreamento do rio São Francisco e em contribuir para a adoção de melhores práticas de manejo da bacia, com intuito de reduzir o contínuo aumento do processo erosão da margem do rio, assim como o impacto sobre a navegabilidade do mesmo.

Bressiani et al. (2015a) desenvolveu um trabalho na região do semiárido brasileiro, na bacia do rio Jaguaribe, Ceará, no que diz respeito ao aprimoramento da aplicação do SWAT para esta região brasileira. O trabalho corrobora, em especial, para a discussão imediata da pouca disponibilidade de dados climáticos, hidrológicos e de qualidade da água e do solo na maioria das regiões brasileiras. O objetivo do trabalho foi verificar o impacto de diferentes resoluções temporais e espaciais de dados climáticos e diferentes métodos de evapotranspiração e tempo de aquecimento do modelo nas predições hidrológicas. A pesquisa aponta para um maior tempo de aquecimento como premissa de melhoramento do modelo; demonstrou que a aplicação da equação desenvolvida por Priestley-Taylor foi mais eficiente, conforme o teste de eficiência de Nash-Suttcliffe; e reafirma a importância da utilização de dados de precipitação e climáticos locais como uma informação fundamental ao desenvolvimento do modelo, mas também encaminha a utilização de dados originários da Reanálise do Sistema de Previsão Climática (Climate Forecast System Reanalysis, CFSR) como alternativa a regiões com baixa disponibilidade de dados.

Em termos de aplicação do modelo SWAT na região amazônica, ainda temos uma deficiência de trabalhos publicados em forma de artigos. Mas já vem ocorrendo uma série de aplicações na Bacia Amazônica de trabalhos de pesquisadores internacionais, os quais vêm sendo apresentados de maneira prévia durante as Conferências Internacionais organizadas pela equipe do Modelo SWAT de $2014 \mathrm{em}$ Pernambuco (Brasil) e em 2015 em Sardinia, Itália. Estes trabalhos têm focado no desenvolvimento e aprimoramento de dados de entrada necessários a modelagem hidrossedimentológica com o SWAT na região amazônica, a qual apresenta uma grande deficiência de dados climáticos e hidrológicos medidos, na calibração do modelo 
para estudos de relação de aspectos biofísicos e geomorfológicos com a hidrologia da região, estudo de impactos de mudanças climáticas, previsão de enchentes, produção de sedimentos, bem como as implicações da mudança de uso e cobertura do solo.

O importante trabalho desenvolvido na Amazônia por Sousa et al. $(2010,2015)$, na bacia do Rio Tocantins-Araguaia, mais especificamente sobre a sub-bacia do rio Lajeado, foca em um componente fundamental do ciclo hidrológico, a evapotranspiração, e busca acoplar a modelagem hidrológica do SWAT às estimativas de evapotranspiração a partir do modelo SEBAL (Surface Energy Balance Algorithms for Land - Bastiaanssena et al., 1998 ${ }^{\star 6}$ ), utilizando-se de estimativas dos componentes do balanço de energia e imagens orbitais. Os autores identificaram que a integração de dados de evapotranspiração obtidos por sensores remotos melhoraram significativamente os resultados do modelo quanto à simulação da vazão em bacias não monitoradas.

Nunes (2013) aplicou o Modelo SWAT, como escopo de sua dissertação de mestrado, sobre a grande bacia hidrográfica do Rio Capim $\left(37.199 \mathrm{~km}^{2}\right)$, que está localizada em sua grande porção no Estado do Pará. O objetivo da dissertação foi calibrar e validar o modelo, descrevendo o seu balanço hídrico em busca de contribuir com a gestão e planejamento hídrico. Os resultados do teste de eficiência de NashSuttcliffe foram 0,5 e 0,53 para duas estações calibradas, resultados de uma calibração manual com boa sensibilidade do operador sobre o comportamento da bacia e que segundo Moriasi et al. (2007) se mostram satisfatórios. Outra dissertação de mestrado desenvolvida no estado do Pará por Santos (2014), aplicou o modelo em uma pequena micro-bacia de cerca de $7,68 \mathrm{~km}^{2}$, correspondente ao rio Arapepó, cujo objetivo foi simular o balanço hídrico da bacia e comparar os resultados com o método direto de medição de vazão através do uso do molinete fluviométrico.

Por fim, Guzha et al. (2013) buscou compreender a influência da forte dinâmica de mudança de uso e cobertura da terra e a utilização de dados climáticos gerados por reanálise do National Center of Environmental Prediction (NCEP) obtido do site do SWAT (http://swat.tamu.edu/) sobre a modelagem dos componentes do balanço hídrico

\footnotetext{
${ }^{6}$ BASTIAANSSENA, W. G. M.; MENENTI, M; FEDDES, R. A.; HOLTSLAG, A. M. A remote sensing surface energy balance algorithm for land (SEBAL). 1. Formulation. Journal of Hydrology, v. 212, p. 198-212, 1998.
} 
da bacia do Rio das Mortes, Mato Grosso, onde há a predominância de agricultura de grão, com soja, milho e algodão. Os autores identificaram que nos cenários com expansão de áreas agrícolas com grão e algodão ocorreu aumento da produção de água de 4 a $7 \%$ e redução da evapotranspiração de 7 a $9 \%$. O trabalho reforça a importância de se avaliar cenários de uso e cobertura da terra e seus reflexos sobre a hidrologia a fim de contribuir para a compreensão da quantificação de serviços ambientais.

\subsubsection{Modelagem dinâmica utilizando o modelo CLUE-S (Conversion of land use and its effects at small regional extent.}

O CLUE-S é uma ferramenta de modelagem de dinâmica de mudança de uso e cobertura da terra, o qual integra a influência de diferentes processos de mudança através de simulações espacialmente explícitas (VERBUG et al., 2002). Soler (2010) explica que essas simulações espacialmente explícitas são fundamentais na análise empírica de probabilidades inerentes à alocação ou não de determinados usos ou coberturas de maneira dinâmica. Trata-se de um modelo voltado para simulação de alta resolução (VERBURG; VELDKAMP, 2004), apresentando o mesmo uma capacidade de resolução de trabalho entre 20 e 1000 metros (VERBURG; OVERMARS, 2007).

O modelo foi desenvolvido na Universidade de Wageningen, na Holanda, pelo Land Dynamics Group. O CLUE-S se originou a partir do modelo CLUE (Conversion of Land Use and its Effects), o qual leva em consideração o complexo arranjo de interações históricas e presentes entre os usos e coberturas do solo e os aspectos socioeconômicos e biofísicos para promover a alocação das mudanças de uso e cobertura, sendo voltado para áreas com grandes extensões, como nacional e continental (VELDKAMP; FRESCO, 1996; VERBURG et al., 1999). O CLUE-S corresponde a um aprimoramento da aplicabilidade do CLUE para um nível de análise regional e local, ou seja, de maior resolução espacial (VERBUG et al., 2002; SOLER, 2010; GALHARTE, 2011; PEREIRA, 2013). Mais detalhadamente, o CLUE-S opera 
simulações espaciais explícitas de mudanças de uso da terra fundamentadas na análise empírica da adequabilidade de alocação de um uso específico do solo, utilizando-se das interações e competições que caracterizam as dinâmicas espaciais e temporais dos sistemas de uso da terra (VERBUG et al., 2002; VERBURG; VELDKAMP, 2004).

Verbug et al. (2002) aponta que o CLUE-S possui a vantagem de fazer uma análise global do sistema em estudo, podendo fazer a simulação de diferentes usos e coberturas ao mesmo tempo, além da possibilidade de simular diferentes cenários. Pereira (2013) descreve o modelo como sendo de uso simples, sendo aplicável por usuários sem conhecimentos de programação e com conhecimentos básicos de SIG e estatística, o que permite uma fácil replicação da metodologia.

Valência (2008) explica que o CLUE-S possui seis características importantes para a compreensão do funcionamento do modelo: (i) É espacialmente explícito, uma vez que discretiza a área em estudo, utilizando um plano celular como base para que o modelo possa sincronizar informações oriundas de fontes, formatos e escalas diversas; (ii) Possui nível de aplicação regional, tendo como premissa e existência de um mapeamento de maior resolução, através da utilização de imagens de sensores com maior resolução espacial; (iii) A importante característica multifatorial, pois as mudanças de uso e cobertura ocorrem em função das forçantes de mudanças (driving forces); (iv) É um modelo multiescalar, sendo capaz de agregar um conjunto de informações de nível local, regional e até mesmo nacional e internacional para delineamento dos determinantes de mudanças e da demanda agregada do uso do solo; (v) possui uma resolução temporal em passo de ano, pois as simulações são realizadas a cada ano; (vi) por fim, o CLUE-S possui um enfoque estatístico, fundamentando sua análise de probabilidade de mudança de uso e cobertura na regressão logística, a qual é responsável por quantificar a influência das forçantes de mudança.

Atualmente para se ter acesso ao modelo é necessário se direcionar ao Institute for Environmental Studies da Universidade de Amsterdã (http://www.ivm.vu.nl/). No site, é possível encontrar a orientação teórica e técnica necessária para auxiliar na compreensão e aplicação do modelo CLUE e CLUE-S, sendo possível fazer o 
download do software em formato demonstrativo juntamente com o manual de uso e exercícios.

O modelo CLUE-S tem sido aplicado ao redor do mundo em lugares com diferentes características biofísicas e socioeconômicas. Podemos começar descrevendo o trabalho de Verburg e Veldkamp (2004), o qual apresenta uma aplicação do CLUE-S em duas diferentes escalas de atuação: em toda área do país Filipinas (Resolução de 2,5 X 2,5 km) e em uma de suas ilhas, denominada de Sibuyan (Resolução de $100 \times 100 \mathrm{~m}$ ). O objetivo do trabalho foi estudar a aplicação da modelagem de dinâmica espacial CLUE-S para avaliar aspectos ecológicos em relação às propriedades espaciais, o que orientou a escolha de duas áreas com escalas distintas para verificar o impacto da escala na definição do modelo, na formação do banco de dados e aplicabilidade dos resultados para a avaliação e gestão ecológica e ambiental. Os autores destacam que, apesar de se utilizar o mesmo modelo, a diferença entre as escalas de trabalho não permite a mesma interpretação. Isto se deve ao fato da escala grosseira apontar áreas principais de mudança de uso, o desflorestamento no caso, enquanto que a escala refinada permite uma análise mais profunda do impacto da mudança de cobertura sobre os processos ecológicos. Explicam também que o CLUE-S é aplicável nessas escalas por razão de permitir que o comportamento dos fatores locais e dos tipos de usos do solo sejam delineados conforme o objetivo da escala e que o estudo integrado de ambas escalas podem contribuir com o processo de planejamento e gestão, uma vez que a escala grosseira direciona a aplicação do modelo em escala mais refinada.

Verburg et al. (2006a), também nas Filipinas, desenvolveram a aplicação do CLUE-S no contexto de análise do impacto da mudança de uso e cobertura da terra sobre a biodiversidade como resultado da destruição da vegetação natural ou fragmentação ou isolamento de áreas naturais, de maneira a fornecer informações para o melhor planejamento e gestão de áreas protegidas. $O$ trabalho foi aplicado também em duas escalas diferentes: No Parque Natural Northern Sierra Madre $\left(485 \mathrm{~km}^{2}\right.$, com resolução $50 \times 50 \mathrm{~m}$ ) e no país inteiro (Resolução de $2,5 \times 2,5 \mathrm{~km}$ ). Os autores destacam que a modelagem em nível de paisagem, como é o caso de áreas protegidas, possibilita um modelo enriquecido em detalhes específicos dos processos de mudança, 
além de promover uma maior aproximação das unidades de uso com a influência direta dos tomadores de decisão. Dessa forma, o modelo agrega informações fundamentadas em pesquisas socioeconômicas dos tomadores de decisão, bem como fatores como a variedade de etnias nos vilarejos e a percepção de risco das mesmas.

Em uma aplicação na Europa, Vergurg et al. (2006b) estudaram as mudanças de uso e cobertura em toda Europa numa resolução de aproximadamente $16 \mathrm{~km}$ utilizando, para isso, um modelo de simulações de alta resolução, o CLUE-S, com o intuito de aferir análise em nível de paisagem. Dessa forma, o estudo analisa diferentes cenários fundamentados nos dados do IPCC (Intergovernmental Panel on Climate Change) e amplos objetivos econômicos, sociais e ambientais. Assim, o modelo utilizou dados adversos à demanda do modelo CLUE-S e, portanto, utilizando cenários construídos de acordo com as questões de uso da terra e as políticas agrícolas típicos para a Europa. O trabalho apresentou uma possibilidade de utilizar cenários de escala grosseira, permitindo análises semiquantitativas dos efeitos dos cenários baseados em estudos de economia global, mercados continentais, cooperações globais e comunidades regionais sobre aspectos de nível de paisagem. Os resultados mostraram também a importância de se buscar integrar forçantes de escalas diferentes para se compreender, em especial, fatores obscuros de mudança.

O modelo foi aplicado, também, como ferramenta para compreender os fatores preponderantes do processo de crescimento urbano em Dhaka, Bangladesh (AHMED et al., 2014). O trabalhou objetivou testar, através da regressão logística, um conjunto de forçantes e entender a capacidade destas de influenciarem na simulação urbana. Os autores identificaram bom desempenho do modelo (Kappa geral entre 0,4 e 0,7), fundamentado nas forçantes biofísicas, acesso a oportunidades (socioeconômicas) e variáveis de planejamento, sendo capaz de explicar as mudanças urbanas conforme outros resultados discutidos.

O CLUE-S tem sido utilizado, também, em estudos integrados com modelos hidrológicos. Gebere et al. (2015) utilizou o modelo CLUE-S em um estudo interessante, cujo objetivo foi analisar o impacto da mudança de uso e cobertura sobre a recarga de aquíferos subterrâneos, acoplado ao modelo de balanço hídrico WetSpass. O estudo foi aplicado na bacia hidrográfica do rio Haramaya, Etiópia, com cerca de 152,71 km², 
estudando cenários atuais e com melhores manejos de áreas sob aumento futuro da temperatura do ar. Os resultados demonstraram uma drástica mudança na paisagem da bacia, o que afetará negativamente os serviços ecossistêmicos, em especial a recarga de aquíferos, devido a contínua redução de áreas com vegetação natural.

Chu et al. (2010) desenvolveram um trabalho aplicando o modelo CLUE-S em um contexto interativo de modelagem, buscando aprimorar a modelagem dinâmica agregando outros métodos estatísticos de determinação da probabilidade de alocação, bem como métodos distintos de delineamento de demanda das mudanças. Os autores utilizaram o método da regressão logística e o Modelo ANN (PIJANOWSKI et al., 20027 para gerar as probabilidade de mudança, e agregaram ao estudo a elaboração das demandas através do modelo de cadeia de Markov e do modelo de autômato celular SELUTH (CHARKE; GAYDOS, 1998 ${ }^{\circ}$ ). Identificaram que a união dos diferentes métodos de projeção de demanda, bem como modelos empíricos funcionou como ferramenta de análise espacial e auxiliou no fornecimento de dados básicos para cálculos das propriedades métricas da paisagem da bacia.

O modelo já tem algumas aplicações no Brasil, seja utilizando a versão CLUE ou CLUE-S, bem como modelos adaptados a partir destes. Um dos primeiros trabalhos aplicados no Brasil com o CLUE foi a tese de doutorado desenvolvida por Aguiar (2006), cujo objetivo foi avaliar a influência de um grupo variado de fatores de mudança alternativos (ambientais, demográficas, de estrutura agrária, tecnológicos, políticas públicas e condições de mercado) sobre o processo de ocupação da Amazônia, a fim de compreender as diferenças intraregionais dos fatores determinantes de uso da terra. Para isso, Aguiar (2006) fez algumas alterações no código do modelo CLUE para inserir nele indicadores de níveis não uniformes de governança em toda a região, possibilitando assim explorar diferentes cenários de aplicação da lei. As principais razões da utilização do CLUE neste estudo foram por causa do modelo ser espacialmente explicito, incorporar uma ampla quantidade fatores determinantes, ser

\footnotetext{
${ }^{7}$ PIJANOWSKI, B.C.; BROWN, D.G.; SHELLITO, B.A.; MANIK, G.A. Using neural networks and GIS to forecast land use changes: a land transformation model. Comput. Environ. Urban, v. 26, n. 6, p. 553575, 2002.

${ }^{8}$ CLARKE, k. C.; GAYDOS, L. J. Loose-coupling a cellular automaton model and GIS: long-term urban growth prediction for San Francisco and Washington/Baltimore. International journal of geographical information science, v. 12, n. 7, p. 699-714, 1998.
} 
voltado para extensas áreas com exigências de dados de baixa resolução, por possibilitar a análise multiescalar, liberdade de interações entre as estatísticas com os fatores determinantes e as escalas, bem como por possuir aspectos temporais e espaciais das projeções de mudança bem definidos. De acordo com Aguiar (2007), é fundamental analisar um grupo variado de determinantes de mudança ligados à organização dos sistemas produtivos para se compreender o comportamento heterogêneo dos padrões de ocupação da Amazônia. Afirma ainda que essa heterogeneidade não se relaciona apenas aos aspectos ambientais e de acesso aos mercados, mas também aos atores do processo de ocupação e a estrutura agrária de toda a região.

Pimenta et al. (2008), por exemplo, fizeram uma adaptação do modelo CLUE-S, implementado a partir do ambiente de modelagem TerraME. As principais diferenças dessa adaptação é a possibilidade de expandir áreas de restrição sobre áreas de conversão permitida, a possibilidade de regionalização de parâmetros de elasticidade e forçantes de mudanças, além de não incluir restrições temporais de conversão. 0 modelo foi testado na região de Santarém, Pará, área de forte fronteira de expansão agrícola, com o objetivo de testar os fatores institucionais de posse da terra em um estudo de caso do mundo real contendo áreas de proteção ambiental, projetos de assentamento, projetos de desenvolvimento sustentável, agroextrativista e áreas de expansão. Coelho (2009) desenvolveu sua dissertação de mestrado utilizando o mesmo modelo adaptado do CLUE-S (PIMENTA et al., 2008), na mesma área de estudo, porém com o objetivo de estudar os processos de transformação da paisagem relacionando a expansão da agricultura capitalizada, em especial da monocultura da soja e do arroz. O estudo de COELHO (2009) identificou que ocorreu um processo de concentração fundiária primeiramente, um avanço sobre áreas de floresta em um segundo momento, bem como a entrada da agricultura de grão fortemente em áreas de assentamento rural, demonstrando a importância da metodologia para compreender os processos dinâmicos em áreas de fronteira agrícola.

O modelo CLUE-S também tem sido utilizado para estudar os impactos das mudanças de uso e cobertura sobre unidades de conservação, como é o caso do trabalho de Kuhn (2005), que avaliaram as tendências de uso do solo no Parque 
Nacional do Superagui, litoral norte do Estado do Paraná. O estudo descreve uma situação característica do Brasil, que é a forte presença populacional em unidades de conservação, acoplando também um mosaico de usos e cobertura interessantes. O estudo dá uma contribuição importante à área do planejamento e gestão de áreas protegidas, mostrando uma nova abordagem metodológica, com dados gerados importantes ao suporte de decisões públicas, bem como o esclarecimento de padrões de dinâmica de uso do solo na área.

Freitas e Santos (2011) apresentam um trabalho de formulação de metodologia de estudo de dinâmica da paisagem e entendimento de fatores condicionantes, tendo como base cenários fundamentados em histórico de uso e cobertura da terra, onde as espacializações das taxas de mudanças foram feitas por um método próprio, a abordagem de autômatos celulares determinísticos, comparando com os resultados do modelo CLUE-S. Os resultados mostraram que ambas as metodologias tiveram desempenho semelhantes, com grande aplicação tanto em escala regional como de paisagem.

Valência (2008) aplicou o modelo CLUE-S na micro-bacia hidrográfica do rio Coxim, na bacia do alto Taquari (Mato Grosso do Sul), avaliando duas técnicas para quantificar a influência dos impulsores de mudança sobre a probabilidade de alocação de um determinado uso, que foram a regressão logística e a regressão espacial, justificando que a regressão logística não considera a autocorrelação espacial presente nos processos espaciais da dinâmica de uso e cobertura do solo. Os dois enfoques apresentaram excelente acurácia de acerto, sendo que a regressão espacial não pode ser integrada ao CLUE-S.

Por fim, destacamos aqui duas teses de doutorado importantes quanto ao estudo da expansão da cana-de-açúcar no Brasil, em especial na região sudeste e centro sul do país, porém com enfoques e escalas diferentes. Primeiramente, o trabalho de Galharte (2011), também publicada como capítulo de livro (GALHARTE; CRESTANA, 2014), aplicou o CLUE-S em duas micro-bacias no estado de São Paulo (escala de paisagem) com o objetivo de gerar cenários futuros de expansão da cana e estimar a produção de sedimentos através de modelo hidrossedimentológico. O segundo trabalho é o de Pereira (2013), que objetivou elaborar um instrumento de análise estratégica da 
política de zoneamento para contribuir no ordenamento setorial rural, avaliando, assim, a influência dos resultados do Zoneamento Agroecológico da Cana na modelagem dinâmica da expansão da cana. Ambos os trabalhos se mostraram ser de grande importância na gestão ambiental rural, cada um em sua escala de análise, mas fornecendo instrumentos focados no aprimoramento do diagnóstico, avaliação e fundamentação biofísica, política e socioeconômica para o planejamento e gestão de áreas sob expansão da cana-de-açúcar.

O modelo CLUE-S tem sido, então, aplicado em regiões distintas quanto a seus aspectos socioeconômicos, políticos e biofísicos, desde a análise da intensificação da expansão agrícola, passando pelos estudos do desmatamento, até a compreensão dos processos de avanço da urbanização. Com isso, o CLUE-S se tornou um dos modelos de estudo de mudança de uso e cobertura da terra mais amplamente utilizado em vários ambientes (VERBURG; OVERMARS, 2007; VERBUG et al., 2002).

\subsubsection{Regionalização de vazão para sub-bacias não monitoradas.}

Um grande desafio da hidrologia está em compreender o comportamento dos processos hidrológicos, em especial quando as maiorias dos dados disponíveis são de caráter qualitativo e, por isso, quase sempre são inviáveis na aplicação do gerenciamento dos recursos hídricos de maneira sustentável (TUCCI, 2002). Goswami et al. (2007) vê as simulações em bacias não monitoradas como o atual grande desafio da hidrologia de águas de superfície. Tucci (2002) também explica que a quantificação dos fenômenos hidrológicos depende da mensuração destes ao longo do espaço e do tempo, sendo que estas variáveis possuem comportamento estocástico e necessitam de amostras confiáveis e representativas.

No entanto, em especial no Brasil, é complicado obter uma rede de monitoramento hidrológica que tenha uma cobertura mais ampla das regiões, dificultando assim o levantamento de um banco de dados robusto e que possibilite o entendimento do comportamento de um sistema hídrico, sobretudo em pequenas 
bacias (SILVEIRA et al., 1998). Muitas áreas de jusante não apresentam monitoramento, mesmo em países com extensas redes de estações, as quais na maioria das vezes não se localizam em regiões de real interesse para o planejamento hídrico (GOSWAMl et al., 2007). A rede hidrológica brasileira foi instalada pensando apenas nos aspectos energéticos, sendo, por isso, priorizadas bacias hidrográficas com área acima de $200 \mathrm{~km}^{2}$, o que também está ligado ao elevado custo de monitoramento de pequenas bacias e a dificuldade de se cobrir o território continental brasileiro (SILVA JÚNIOR. et al., 2003).

Uma técnica para auxiliar no estudo de regiões com pouco ou nenhum monitoramento é a de regionalização. Segundo Tucci (2002), "o termo regionalização tem sido utilizado em hidrologia para denominar a transferência de informações de um local para outro dentro de uma área com comportamento hidrológico semelhante". Assim, a regionalização objetiva estudar a viabilidade de se construir dados em locais sem ou com pouco monitoramento a partir de dados existentes em locais próximos com características espaciais semelhantes, considerando as incertezas do método (CUI et al., 2015).

Existe uma quantidade grande de variáveis que são utilizadas para caracterizar hidrologicamente uma região, como as condições climáticas e de precipitação, evapotranspiração, relevo, geologia, geomorfologia, pedologia, uso e cobertura da terra e manejo antrópico. Contudo, a definição de quais as melhores variáveis independentes a serem utilizadas para a determinação do valor da variável dependente deve ser criteriosa e fundamentada em conhecimentos prévios da região pelo hidrólogo ( $T U C C I$, 2002). Contudo, é importante ressaltar que essas variáveis explicativas devem ser facilmente determinadas, evitando-se métodos indiretos de determinação das mesmas, analisar com critério o uso de muitas variáveis, pois elas podem apresentar alta correlação, assim como devem auxiliar a regionalização a fornecer os níveis de incerteza da estimativa da variável dependente (TUCCI, 2002).

Em hidrologia, a regionalização de vazão pode ser aplicada para determinar variáveis dependentes como a vazão média, vazão média de cheia, vazões máximas e mínimas, tempo de concentração e curvas de permanência (ELETROBRÁS, 2000). A metodologia de regionalização é fundamentada em técnicas matemáticas e estatísticas, 
as quais são aplicadas para se estimar a probabilidade de ocorrerem valores máximos e mínimos de uma variável hidrológica e as técnicas de regressão e correlação aplicadas para compreender as relações entre variáveis dependentes e explicativas, que podem ser de caráter linear e não linear (TUCCI, 2002).

As equações de regressão, portanto, são estabelecidas entre a vazão média, se for o caso, e as características físicas e climáticas das bacias hidrográficas que possuem monitoramento de dados (TUCCl, 2013). As variáveis comumente utilizadas são a área de drenagem, precipitação, declividade, densidade de drenagem e comprimento do rio, sendo necessário se encontrar a melhor combinação que explique a variável desejada, uma vez que o melhor modelo, mais eficiente, deve apresentar o menor erro e o menor número de variáveis explicativas utilizadas na equação de regressão (TUCCl, 2013).

A escolha da melhor equação pode ser definida através das estatísticas de teste de significância $\mathrm{F}$ e do coeficiente de determinação, onde a primeira representa o teste de hipótese do modelo quanto à correlação com a variável independente, e a segunda explica o grau de correlação do modelo. Um fator que proporciona um melhor resultado dos modelos é a aplicação da regionalização em regiões homogêneas, o que significa que o hidrólogo procurou seguir alguns critérios fundamentais, como o agrupamento das bacias por tamanho da área, escolha de postos de monitoramento em rios principais, e principalmente buscou regiões biogeograficamente similares (GOSWAMI et al., 2007; TUCCI, 2013). A homogeneidade é determinada seguindo uma sequência de análise da curva de probabilidade adimensional para cada posto, escolher postos com tendências semelhantes como no caso do tempo de retorno, aplicar todos os critérios para definição das equações de regressão e, por fim, compatibilizar as regiões da curva de frequência com a região das equações de regressão (TUCCI, 2013).

A regionalização de vazão possui a vantagem de permitir 0 melhor aproveitamento das amostras pontuais existentes em uma região hidrográfica, sendo aplicada para melhorar as estimativas tanto das variáveis, como das funções, parâmetros e dos indicadores regionais hidrológicos (TUCCI, 2002). Em especial na região amazônica, os modelos de regionalização são ferramentas com grande possibilidade de contribuir, neste momento de grande escassez de dados, com a 
estimativa de dados de vazão para a região, dando suporte ao planejamento e gestão dos recursos hídricos (COSTA et al., 2012) e também tem apresentado resultados satisfatórios em regiões com déficit de postos de monitoramento em geral (ELETROBRÁS, 2000). Contudo, mesmo sendo uma ferramenta útil para o conhecimento hidrológico espacial, existem sérias limitações como a extrapolação de dados entre bacias com grande diferença de tamanho, o que gera incertezas na tomada de decisões, pois a regionalização não substitui dados monitorados em campo, dados reais, e por isso deve ser adotado todo o cuidado na extrapolação de resultados, em especial para bacias de menor porte, onde se observam os maiores erros (SILVA JUNIOR. et al., 2003).

No Brasil, muitos trabalhos têm aplicado a técnica da regionalização de vazão, que é amplamente utilizada para planejamento de energia hidroelétrica (ELETROBRÁS, 2000), com objetivos diversos, como: 1. estudos de vazão média de longo período para planejamento de suprimento hídrico (CHAVES et al., 2002; ALEXANDRE; MARTINS, 2005); 2. estudos de vazão média de longo período e vazão sazonal para quantificação do balanço hídrico em regiões de recarga de aquíferos (CURTARELLI, 2010); 3. bem como o estudo de vazões médias de longo período, vazões médias de cheia, curva de permanência e vazões mínimas com parâmetros transferidos de grandes bacias para bacias de pequeno porte sem nenhum tipo de monitoramento (SILVA Júnior. et al., 2003; PRUSKI et al., 2012). Na Amazônia, podemos destacar os trabalhos com a regionalização das curvas de permanência de Pessoa et al. (2011) e Costa et al. (2012), que objetivaram gerar dados para áreas não monitoradas, a fim de fornecer subsídios para contribuir com o planejamento e a gestão de recursos hídricos.

\subsection{ESTUDO DE CASO: ÁREAS SOB A EXPANSÃO DA PALMA DE ÓLEO NO NORDESTE PARAENSE.}

A Palma de Óleo popularmente conhecida com Dendezeiro, é a planta responsável pela produção do famoso óleo de dendê ou óleo de palma. É uma palmeira 
originária da costa africana (CORLEY; TINKER, 2008). Existem duas espécies de palma de óleo de valor econômico: 1. a Elaeis guineensis Jacq., de origem do continente africano, que é amplamente utilizada pelo setor agroindustrial; e 2. a espécie Elaeis oleifera (Kunth) Cortés, chamada de Caiaué, que é encontrada em países do continente americano (MONTEIRO; HOMMA, 2014).

As plantações dessa cultura estão prioritariamente localizadas em regiões tropicais, especificamente na África subsaariana, sudeste asiático e em alguns países da América Latina, sendo encontrada em muitos países na faixa do trópico úmido, como Indonésia, Malásia, Papua Nova Guiné, Filipinas, Camarões, Uganda, Costa do Marfim, Tailândia, Brasil, Colômbia, Equador, Peru, Guatemala, México, Nicarágua, Costa Rica e outros. A Palma de Óleo foi considerada a planta com maior taxa de produtividade de óleo vegetal no mundo em 2015, com cerca de 65,17 Mt anuais (USDA, 2015), com uma produção média de cerca de 4 toneladas por hectare (SERRÃO, $2000^{9}$ apud VILLELA, 2014), cerca de dez vez mais óleo por hectare em relação a soja, e ainda tem um ciclo de vida comercial de cerca de 25 anos (MÜLLER et al., 2006), iniciando sua produtividade por volta dos 3 anos. A Indonésia (35 Mt), Malásia (19,8 Mt) e a Tailândia (2 Mt) são os maiores produtores desse óleo no mundo, sendo a Ásia responsável por cerca de 85\% da produção mundial (USDA, 2015).

Seu óleo é amplamente utilizado nas indústrias químicas, de higiene e alimentícias, sendo este utilizado em cerca de $50 \%$ de todos os produtos industrializados encontrados nos supermercados. Atualmente, a produção de biocombustíveis é responsável pela demanda de $10 \%$ da produção mundial de óleo de palma e cerca de $13 \%$ de toda produção de óleo vegetal (MIN, $2013^{10}$ apud VILLELA, 2014).

De 2006 a 2014, período das simulações do presente estudo, a produção de óleo de palma no mundo teve um crescimento de $65 \%$, enquanto que o óleo de soja, que dominou o mercado no século $X X$, teve um crescimento duas vezes menor de $31 \%$. (USDA, 2010 e 2015). Com isso, para o ano de 2015, o óleo de palma, feito a partir da

\footnotetext{
${ }^{9}$ SERRÃO, E. Apresentação In: Viegas, I.; Muller, A. A Cultura do Dendezeiro na Amazônia Brasileira. 1 ed. Belém, Pará, 2000

${ }^{10}$ MIN, T. Asia Palm Sector: A year of two halves. Credit Suisse: Asia Pacific/Malaysia Equity Research Agricultural Products \& Agribusiness, 2013.
} 
polpa do fruto (mesocarpo) se tornou o óleo mais produzido do mundo $65,17 \mathrm{Mt}$, e o óleo palmiste, feito a partir da semente (endosperma) foi o quinto mais produzido $(7,55$ Mt) (USDA, 2015). Esse pico de crescimento da produção do óleo de palma no mundo está direcionado a fatores fundamentais como o baixo custo de produção, menor exigência de área plantada, os benefícios à saúde por ser livre de gordura trans (LIMA et al., 2002), que é uma demanda do mercado atual alimentício, aumento populacional e segurança alimentar (VILLELA, 2014). Além de mais produzido, o óleo de palma é também o mais exportado, chegando a um patamar de 57,6\% das exportações de óleo vegetais no mundo em 2013 (OILWORLD, 2013 ${ }^{11}$ apud VILLELA, 2014).

O Brasil, em especial, segundo os dados FAO (2013 ${ }^{12}$ apud VILLELA, 2014), é apenas $010^{\circ}$ maior produtor mundial de cachos de palma e $014^{\circ} \mathrm{em}$ total de área plantada, mas é o país com maior possibilidade de expansão dessa cultura devido a maior disponibilidade de áreas propícias a expansão da palma no mundo, com cerca de 116,652 Mha (FISCHER; SHAH, $2010^{13}$ apud VILLELA, 2014). Para a Amazônia, região com características mais favoráveis a expansão da palma, o Zoneamento Agroecológico da Palma de Óleo (ZAE-Palma) apresenta um total de área para plantio, somando as classes de aptidão Preferencial e Regular, de cerca de 29 Mha (Tabela 1), sendo que só o Estado do Pará detêm cerca de 12,5 Mha de área disponível com adequabilidade para a palma de óleo (Ramalho Filho, 2010).

Em aspectos gerais, a expansão da palma tem características diferentes quanto à demanda mundial, a qual prevê um crescimento de cerca de $30 \%$ da produção até 2020 (FAO, 2015; USDA, 2015), enquanto que no Brasil a expectativa de demanda chega a mais que dobrar a produção até 2020 (FAEPA, 2015; BRASIL-MAPA, 2015). Atualmente, o Brasil atende cerca de $50 \%$ da sua demanda interna, sendo prevista um aumento de demanda para 500.000 ha. Como o Brasil tinha cerca de 165.000 ha plantados em 2014 (MONTEIRO; HOMMA, 2014), sendo que mais de 95\% da produção nacional e das áreas cultivadas no país está concentrada no estado do Pará, logo a demanda de produção vai mais que triplicar a área plantada com palma de óleo no

\footnotetext{
${ }^{11}$ OILWORLD. 2012/13 is characterized by a pronounced slowdown of the production and the consumption growth of oils \& fats. Oil World Statistics Update, 2013.

${ }^{12}$ FAO. Organização das Nações Unidas para a Alimentação e Agricultura. FAOSTAT, 2013.

${ }^{13}$ FISCHER, G.; SHAH, M. Farmland Investments and Food Security. Laxenburg: IIASA - International Institute for Applied Systems Analysis. Report prepared under World Bank IIASA contract, 2010.
} 
Brasil para 2020. No entanto, tem-se uma perspectiva de expansão das indústrias do estado do Pará de até 355.000 ha (FAEPA, 2015) até 2020. Em 2014, o consumo interno do Brasil era de 820.000 t, sendo que nossa produção era de apenas 352.000 , com um déficit de 468.000 . Sendo que $97 \%$ da nossa demanda é basicamente para a indústria alimentícia.

Tabela 1: Resumo das áreas das classes do Zoneamento Agroecológico da Palma de Óleo nas áreas desmatadas da Amazônia Legal com adoção dos níveis de manejo B (nível tecnológico médio) e C (alto nível tecnológico).

\begin{tabular}{lccc}
\hline \multicolumn{4}{c}{ NÍVEL DE MANEJO B } \\
\hline CLASSE & hectare & $\mathbf{k m}^{\mathbf{2}}$ & \% da AM.L \\
\hline Preferencial & $\mathbf{7 . 3 3 7 . 4 2 6}$ & $\mathbf{7 3 . 3 7 4}$ & $\mathbf{1 , 4 5}$ \\
Regular & $\mathbf{2 2 . 3 1 7 . 7 0 7}$ & $\mathbf{2 2 3 . 1 7 7}$ & $\mathbf{4 , 4 2}$ \\
Marginal & 2.020 .879 & 20.209 & 0,40 \\
Inapta & 38.730 .565 & 387.306 & 7,67 \\
Subtotal $^{*}$ & 70.406 .577 & 704.066 & 13,94 \\
Área excluída ** & 434.565 .157 & 4.345 .652 & 86,06 \\
Total - AM.L & 504.971 .734 & 5.049 .717 & 100 \\
\hline
\end{tabular}

\begin{tabular}{lccc}
\multicolumn{4}{c}{ NíVEL DE MANEJO C } \\
\hline CLASSE & hectare & km $^{\mathbf{2}}$ & \% da AM.L \\
\hline Preferencial & $\mathbf{7 . 2 9 6 . 2 7 9}$ & $\mathbf{7 2 . 9 6 3}$ & $\mathbf{1 , 4 4}$ \\
Regular & $\mathbf{2 1 . 6 3 7 . 1 0 1}$ & $\mathbf{2 1 6 . 3 7 1}$ & $\mathbf{4 , 2 8}$ \\
Marginal & 2.299 .816 & 22.998 & 0,46 \\
Inapta & 39.173 .381 & 391.734 & 7,76 \\
Subtotal * $^{\text {Área excluída ** }}$ & 70.406 .577 & 704.066 & 13,94 \\
Total - AM.L & 434.565 .157 & 4.345 .652 & 86,06 \\
\hline
\end{tabular}

* Total da área do zoneamento, após os recortes: 704.066 $\mathrm{km}^{2}$, aproximadamente 13,94\% da Amazônia LegaL/

** Área de Proteção Ambiental, Terras Indígenas e Área não Desmatadas;

AM.L = Amazônia Legal;

Fonte: Adaptado de Ramalho Filho (2010).

O estudo feito pelo ZAE-Palma, avaliou a aptidão agrícola e climática de áreas desmatadas na Amazônia Legal brasileira para o uso agrícola pela palma de óleo, sendo definida quatro classes de aptidão: Preferencial, Regular, Marginal e Inapta. Para isso, o trabalho verificou a influência de dois cenários de expansão, sendo um denominado de Cenário $\mathrm{B}$, com baixa tecnificação no manejo, e o cenário $\mathrm{C}$, com emprego de alta tecnologia (RAMALHO FILHO, 2010). Os resultados não encontraram diferenças significativas entre a aplicação dos dois cenários, mas o trabalho identificou que os maiores limitantes do solo na discretização das classes de aptidão foram a 
deficiência de fertilidade, a suscetibilidade à erosão e os impedimentos à mecanização (RAMALHO FILHO, 2010). Estes aspectos são fundamentais ao presente estudo, pois caracterizam essa ausência de diferença significativa entre os resultados dos dois cenários de manejo, por razão da palma, em nível de produção considerada no estudo de 3.5 t/ha não exigir grandes quantidades de fertilizantes, mesmo sendo uma cultura de elevada exportação de nutrientes com a produção, por ser também uma cultura que não se baseia na mecanização intensa, bem como por ser uma cultura perene, que oferece proteção ao solo, não concorrendo para o aumento da exposição do solo.

Importante ressaltar que o ZAE-Palma nasce no contexto de grande demanda mundial por óleo de palma, o que impulsionou o Brasil a tomar medidas que promovam a expansão sustentável, socialmente inclusiva e que gere divisas ao país (MONTEIRO, 2013). Essas medidas são descritas no Programa de Produção Sustentável da Palma de Óleo no Brasil (Brasil-MAPA, 2010), o qual apresenta como principais diretrizes a preservação da floresta e da vegetação nativa, a expansão da produção integrada com a agricultura familiar e o respeito às áreas prioritárias definas no ZAE-Palma.

Outros trabalhos também reforçam a região nordeste do estado do Pará como uma região importante ao cenário de dinâmica de expansão da Palma, além de já oferecer uma estrutura agroindustrial consolidada (Tabela 2). Trata-se do Zoneamento de Riscos Climáticos para a Cultura do Dendezeiro no estado do Pará (BASTOS et al., 2001) e para o Brasil (MACEDO JUNIOR et al., 2009). Os resultados do mapeamento no Brasil demonstram a região Amazônica como a região climaticamente favorável ao desenvolvimento desta cultura, levando em consideração parâmetros climáticos como temperatura média anual do ar, precipitação média anual e deficiência hídrica. Em especial, o zoneamento do estado do Pará (BASTOS et al., 2001) descreveu três classes de aptidão ou potencialidades agroclimáticas: a primeira classe $(0,13 \%$ do Estado), denominada de Boa, evidencia ausência de estação seca e deficiência hídrica anual menor que $100 \mathrm{~mm}$; a segunda classe se chama Moderada (72,05\% do Estado), evidenciando presença de estação seca de curta duração e deficiência hídrica moderada entre 100 e 350 mm; A terceira classe, Restrita, abrange 27,82\% do Estado, com estação seca marcante e deficiência hídrica acentuada acima de $350 \mathrm{~mm}$. A quase 
totalidade das áreas plantadas no estado está situada em regiões de classe Boa e Moderada.

Hoje existem várias empresas que investem na palma de óleo no estado do Pará, sendo a Vale/Biopalma, Petrobras/Galp, Agropalma, ADM e a Denpasa as maiores produtoras (Tabela 2), sendo que cada vez mais a expansão da cultura exigirá a expansão das agroindústrias no estado, demandando mais áreas e também mais tecnologias envolvidas (MONTEIRO, 2013).

Tabela 2: Principais agroindústrias de extração de óleo de palma presentes no estado do Pará até o ano de 2013.

\begin{tabular}{|c|c|c|c|c|}
\hline Empresa & Município & $\begin{array}{c}\text { Área } \\
\text { Plantada } \\
\text { (ha) }\end{array}$ & $\begin{array}{l}\text { Metas de expansão } \\
2015-2018 \text { (ha) }\end{array}$ & $\begin{array}{c}\text { Usinas de } \\
\text { Processamento }\end{array}$ \\
\hline ADM & $\begin{array}{c}\text { São Domingos do } \\
\text { Capim }\end{array}$ & $>5.000$ & 24.000 & 0 \\
\hline Agropalma & Tailândia & 42.000 & 51.000 & 5 \\
\hline Dentauá & $\begin{array}{c}\text { Santa Isabel do } \\
\text { Pará }\end{array}$ & 5.546 & 5.600 & 2 \\
\hline Denpasa & $\begin{array}{c}\text { Santa Bárbara do } \\
\text { Pará }\end{array}$ & 1.750 & 10.000 & 1 \\
\hline Palmasa & Igarapé-Açu & 4.200 & 5.000 & 1 \\
\hline Marborges & Moju & 4.671 & 5.500 & 1 \\
\hline Mejer & Bonito & 6.500 & 5.000 & 0 \\
\hline Petrobras/Galp & Tailândia/Mocajuba & $>5.000$ & 70.000 & 0 \\
\hline Vale/Biopalma & Moju & $>60.000$ & 80.000 & 1 \\
\hline
\end{tabular}

Fonte: Adaptado de Monteiro (2013).

Conforme alguns estudos (MONTEIRO, 2013; MONTEIRO; HOMMA, 2014; HOMMA et al., 2014), a cultura da palma de óleo tem contribuído significativamente com a recuperação de áreas alteradas e com a inclusão socioeconômica de agricultores familiares, o que tem demonstrado a capacidade desta cultura ser uma boa alternativa de investimento e diversificação produtiva na Amazônia (MONTEIRO; HOMMA, 2014). Da mesma forma, estudos têm alertado para os possíveis impactos negativos da expansão da palma de óleo, tais como o amarelecimento fatal, desmatamento e o arrefecimento dos ganhos com políticas ambientais (BECKER, 2010; ALMEIDA; VIEIRA, 2014; LAMEIRA et al., 2015a; LAMEIRA et al., 2015b).

Dentro deste contexto, o presente trabalho tem como objetivo contribuir com informações quantitativas, através da aplicação da modelagem ambiental em nível de bacia hidrográfica, para que se possa cada vez mais entender os impactos da 
expansão da palma de óleo na Região Nordeste do estado do Pará. Busca também auxiliar na elaboração de planos de manejo e gestão ambiental através da apresentação de alguns métodos de monitoramento dos recursos naturais de regiões com pouco ou quase nenhum monitoramento, que é o caso das principais regiões onde a palma de óleo vem se expandido. Assim, espera-se contribuir com o entendimento do seguinte problema: Qual o impacto da expansão da palma de óleo sobre a dinâmica de mudança de uso e cobertura da terra da região nordeste do estado do Pará em relação aos aspectos hidrossedimentológicos de bacias hidrográficas não monitoradas? 


\section{METODOLOGIA}

Sinteticamente, após a definição do problema de pesquisa, o trabalho se divide em duas etapas: 1. modelagem com o CLUE-S e 2. modelagem com o SWAT. Na Etapa 1, o modelo CLUE-S foi utilizado para gerar cenários futuros de mudanças do uso e cobertura do solo para o ano de 2023 nas sub-bacias não monitoradas dos rios Bujaru e Mariquita. Na Etapa 2, o modelo SWAT foi calibrado através de dois métodos: I. geração de séries regionalizadas de vazão, medidas de vazão com molinete para avaliar o acerto da regionalização e utilização do software de calibração SWAT-CUP, tendo como base de calibração as séries de vazão estimadas pela regionalização; II. o segundo método de calibração se fundamentou na transferência de parâmetros calibrados da modelagem da bacia monitorada do rio Capim para as sub-bacias não monitoradas dos rios Bujaru e Mariquita. Após os experimentos de calibração das subbacias não monitoradas, o resultado do cenário de 2023, que foi produto da modelagem com o CLUE-S, foi inserido no SWAT. Assim, estimou-se o escoamento superficial e a produção de sedimentos nas modelagens para o ano de 2008 (com pouca ou nenhuma área de palma de óleo), para o ano de 2013 (com grande expansão da palma de óleo) e no cenário projetado de 2023 (com a duplicação da área de palma de óleo em relação a 2013).

$\mathrm{Na}$ Figura 2 é explicado o percurso metodológico aplicado na tese a fim de auxiliar na compreensão das ferramentas e suas interações no processo de desenvolvimento da pesquisa até atingir os objetivos da tese.

\section{1. ÁREA DE ESTUDO.}

O estudo foi aplicado em duas sub-bacias hidrográficas, sendo a primeira do Rio Bujaru (SBRB) (38.300 hectares $/ 383 \mathrm{~km}^{2}$ ), afluente da Margem esquerda do Rio Guamá, e a segunda do Rio Mariquita (SBRM) (15.994 hectares $/ 159,94$ km²), o qual é 
afluente do Rio Acará-Mirim (Figura 3). Ambas as sub-bacias se localizam na mesoregião do nordeste do estado do Pará, micro-região de Tomé-Açu (Acará, Moju, Tailândia, Tomé-Açu e Concórdia do Pará) (IBGE, 1990). Estas sub-bacias estão inseridas na Macrorregião Hidrográfica do Tocantins, conforme divisão federal definida pelo Conselho Nacional de Recursos Hídricos (BRASIL-CNRH, 2003). Porém, com relação à classificação estadual, essas bacias encontram-se inseridas na Macrorregião Hidrográfica Costa Atlântica - Nordeste (PARÁ, 2012).

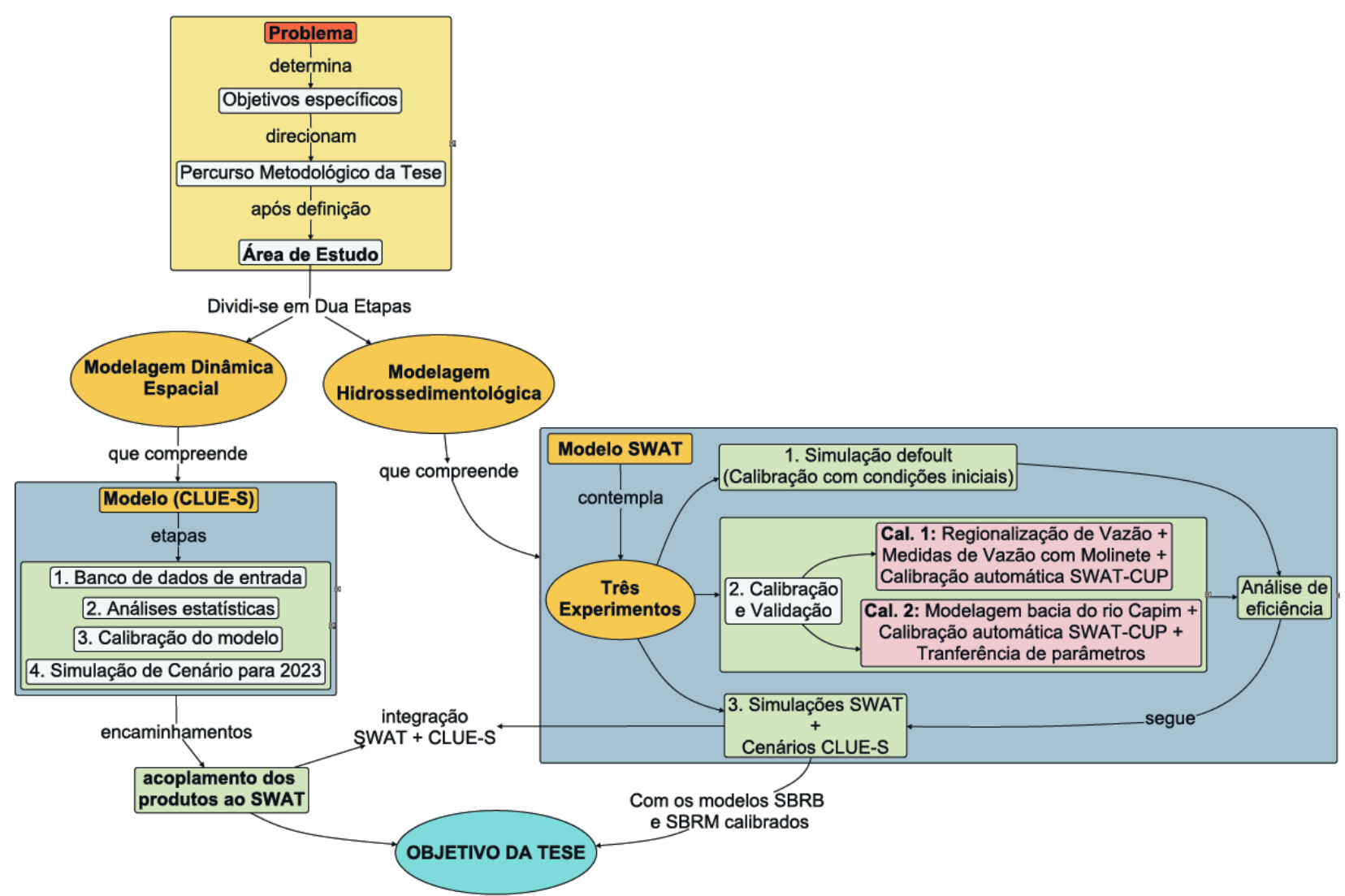

Figura 2: Mapa conceitual do percurso metodológico da tese.

A maior parte da sub-bacia do rio Bujaru está inserida dentro do município de Concórdia do Pará entre as coordenadas geográficas $47^{\circ} 52^{\prime} 55^{\prime \prime} \mathrm{W}, 1^{\circ} 48^{\prime} 21^{\prime \prime} \mathrm{S}$ e $48^{\circ}$ 04' 21" W, $2^{\circ}$ 06' 29" (Tabela 3). O clima é classificado como Am de acordo com a classificação de Köppen, $26,5^{\circ} \mathrm{C}$ é a temperatura média, com uma precipitação média anual de $2.286 \mathrm{~mm}$ e umidade do ar acima de $80 \%$, demonstrando um clima tropical úmido com abundância de chuvas no verão e escassez no inverno (Figura 4) (SILVA 
JUNIOR et al., 2012). O solo na sub-bacia é predominantemente classificado como LATOSSOLO AMARELO Distrófico, contendo manchas de ARGISSOLO AMARELO e VERMELHO-AMARELO Distrófico, PLINTOSSOLO PÉTRICO Concrecionário e NEOSSOLO QUARTZARÊNICO Órtico (EMBRAPA, 2006) (Quadro 1 no ANEXO A). Este município possuía estimativa de cerca de 31.352 habitantes em 2015, sendo contabilizado 28.216 habitantes pelo Censo 2010, área de $690,947 \mathrm{~km}^{2}$ e densidade populacional de 40,84 hab/km² (IBGE, 2010). Tem como atividade econômica principal a agropecuária, com destaque para a pimenta do reino e as lavouras de mandioca, sendo que a Palma de óleo tem se expandido fortemente na região (CORREA et al., 2012). Mas também, segundo o Censo Agropecuário de 2006, o município possuía 15.067 cabeças de gado (174 estabelecimentos produtores), 2.099 de suíno (229 estabelecimentos produtores) e cerca de 54 mil aves (635 estabelecimentos produtores).

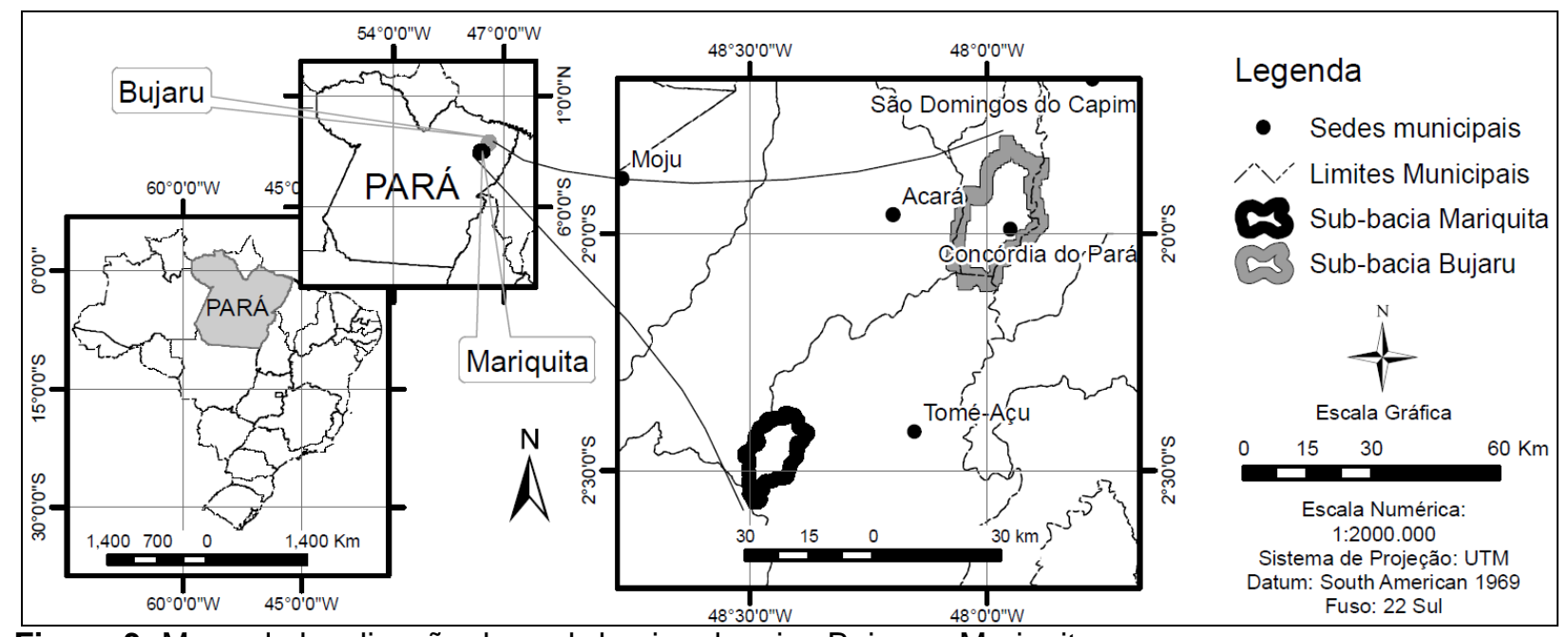

Figura 3: Mapa de localização das sub-bacias dos rios Bujaru e Mariquita.

Tabela 3: Municípios de localização da sub-bacia do rio Bujaru (SBRB).

\begin{tabular}{lcc}
\hline Município & Area $\mathbf{( k m 2 )}$ & $\mathbf{( \% )}$ \\
\hline Concórdia do Pará & 359,9 & 94,4 \\
São Domingo do Capim & 10,5 & 2,8 \\
Tomé-Açu & 8,0 & 2,1 \\
Acará & 2,7 & 0,7 \\
\hline
\end{tabular}




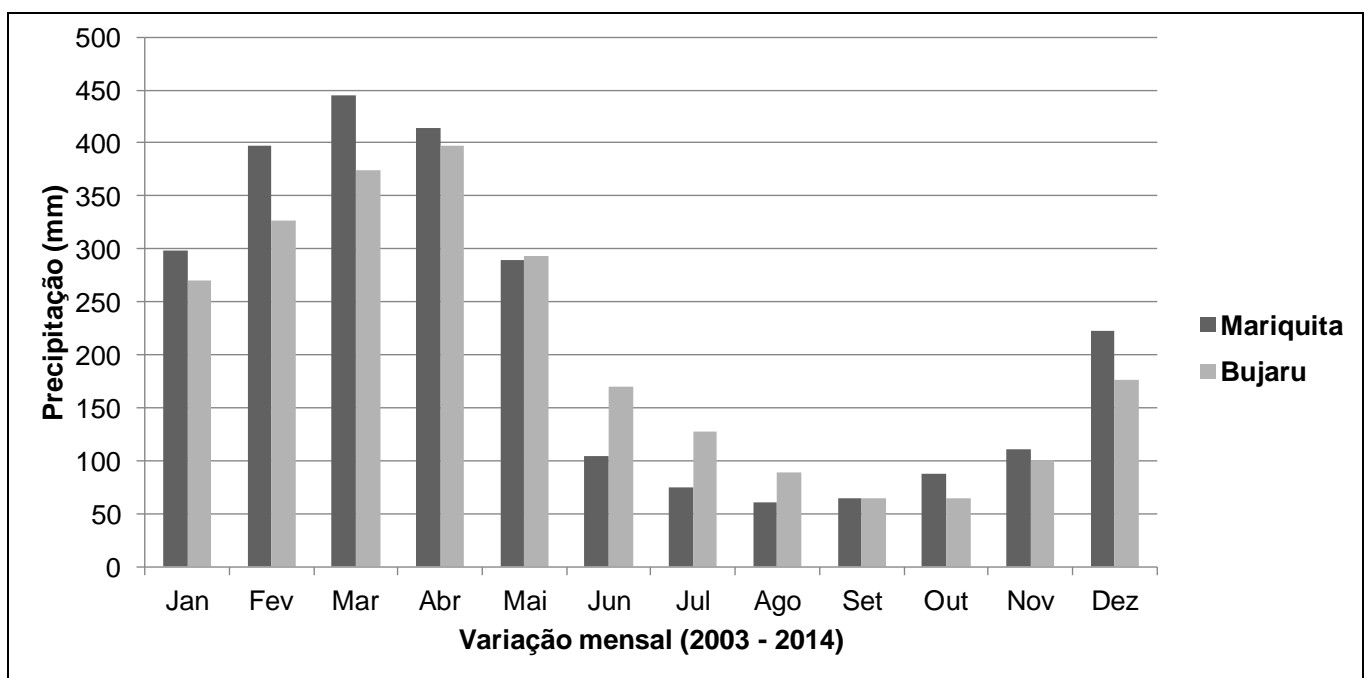

Figura 4: Média do acumulado mensal de longo período da série de 2003 a 2014 das estações da ANA (SBRM - 248001 / 248003 / 248006; SBRB - 148009 / 247003 / 148017) (Fonte: ANA, 2015).

A sub-bacia do rio Mariquita está inserida em sua quase totalidade dentro do município de Tomé-Açú (Tabela 4) entre as coordenadas geográficas $48^{\circ} 22^{\prime} 38^{\prime \prime} \mathrm{W}, 2^{\circ}$ $22^{\prime} 41^{\prime \prime} \mathrm{S}$ e $48^{\circ} 30^{\prime} 42^{\prime \prime} \mathrm{W}, 2^{\circ} 34^{\prime} 08^{\prime \prime} \mathrm{S}$. A classificação do clima é Am, segundo a classificação de Köppen, com temperatura média de $27,9^{\circ} \mathrm{C}$, precipitação média anual de $2.500 \mathrm{~mm}$ e umidade do ar acima de $80 \%$, sendo irregular a distribuição mensal da precipitação, tendo um período (novembro a junho) com maior intensidade de chuvas (Figura 4) (BAENA; FALESI, 1999). O solo na sub-bacia é predominantemente classificado como LATOSSOLO AMARELO Distrófico, contendo manchas de ARGISSOLO AMARELO Distrófico e PLINTOSSOLO PÉTRICO Concrecionário (EMBRAPA, 2009) (Quadro 1 no ANEXO A). Este município possui a estimativa de cerca de 60.456 habitantes em 2015, sendo contabilizados 56.518 habitantes pelo Censo 2010; possui área de 5.145,361 $\mathrm{km}^{2}$, com densidade populacional de 10,98 $\mathrm{hab} / \mathrm{km}^{2}$. O município tem como principais atividades a agropecuária, a pimenta do reino, árvores frutíferas em sistemas agroflorestais e consorciadas, como o cacau, açaí e o cupuaçu, tendo também forte área de expansão da Palma de óleo. Em relação à atividade pecuária, o município de Tomé-Açu apresenta maior produtividade, sendo estimado em 2006 cerca de 82.151 cabeças de gados (388 estabelecimentos produtivos), 5.069 de suínos (405 estabelecimentos produtivos) e 52 mil aves (1.198 estabelecimentos produtivos). 
Tabela 4: Municípios de localização da sub-bacia do rio Mariquita (SBRM).

\begin{tabular}{lcc}
\hline Município & Area $\mathbf{( k m 2 )}$ & $\mathbf{( \% )}$ \\
\hline Tomé-Açu & 154,2 & 96,4 \\
Acará & 5,7 & 3,6 \\
\hline
\end{tabular}

Uma forçante importante na escolha das sub-bacias SBRB e SBRM está ligada ao fato delas estarem inseridas em áreas de forte expansão da cultura da palma de óleo na região nordeste do estado do Pará. Conforme o Zoneamento Agroecológico da Palma de Óleo para regiões desmatadas da Amazônia (RAMALHO FILHO, 2010), a SBRB está localizada em sua quase totalidade dentro de áreas de aptidão edafoclimáticas da Classe Preferencial (Potencial alto - terras sem limitação a produção da palma de óleo), enquanto que a SBRM está inserida totalmente na Classe de aptidão Regular (Potencial médio a alto - terras com limitação moderada à produção da palma de óleo), excluindo-se as áreas de floresta (Figura 5).

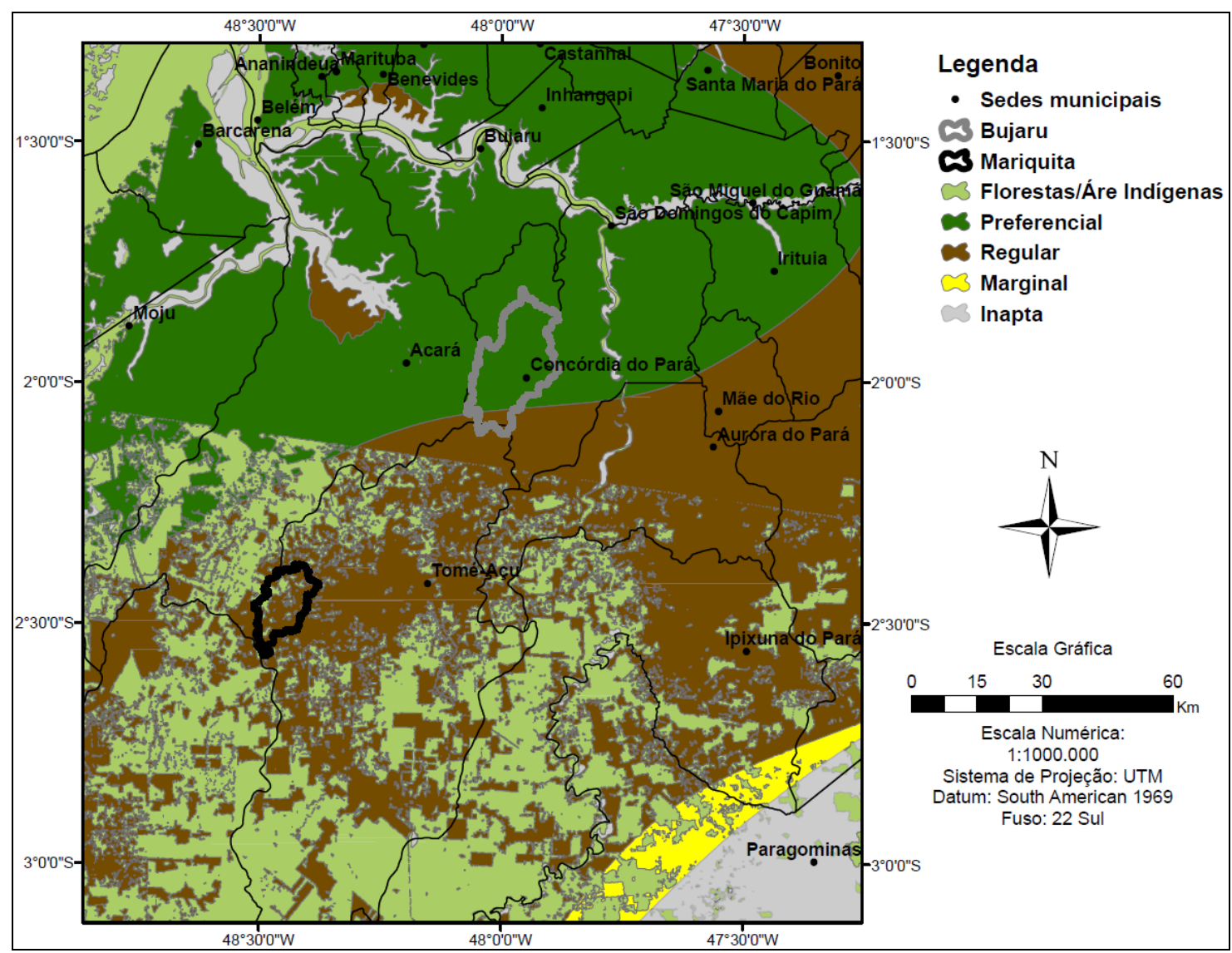

Figura 5: Localização das sub-bacias dos rios Bujaru e Mariquita sobre as classes de aptidão edafoclimáticas do Zoneamento Agroecológico da Palma de Óleo para o estado do Pará (Fonte: Ramalho Filho, 2010). 


\subsection{LEVANTAMENTO DE DADOS E MAPEAMENTO DO USO E COBERTURA DA TERRA NAS SUB-BACIAS.}

Para atender o objetivo do trabalho de comparar áreas com padrões de uso e cobertura da terra diferentes, em especial com relação à quantidade de área plantada com a palma de óleo, o SWAT foi aplicado para o ano de 2008, período de ausência ou pouca área plantada com palma de óleo, e em 2013, quando se tem uma presença maior dessa cultura em ambas sub-bacias. Para o ano de 2008, utilizou-se os mapas disponibilizados pelo Projeto TerraClass ${ }^{14}$, dados estes considerados adequados ao desenvolvimento do trabalho, pois se apresentam totalmente livres de nuvens durante 0 processo de classificação. Porém, houve um problema na escolha do segundo mapa, o qual representaria o mapa com presença da Palma de óleo, pois o TerraClass disponibiliza dados de uso e cobertura da terra apenas para os anos de 2008, 2010 e 2012. No entanto, os mapas de 2010 e 2012 estavam praticamente tomados pela classificação "área não observada" (áreas cobertas por nuvens ou sombra no momento da aquisição da imagem, ou ainda áreas recentemente queimadas) em nossas subbacias. Para solucionar o problema, foram produzidos mapas de uso e cobertura da terra para o ano de 2013 nas duas sub-bacias, conforme sub-item a seguir.

\subsubsection{Classificação semiautomática das imagens do LandSat.}

Para o ano de 2013, utilizamos imagens do satélite Landsat 8, sensor OLI (Operational Land Imager), composição colorida 6R, 5G e 4B, com projeção geográfica e datum WGS 84. As Cenas escolhidas para a classificação do ano de 2013 foram as seguintes órbitas e pontos: 223/61 para a sub-bacia do Bujaru e 223/62 para a sub-

\footnotetext{
${ }^{14}$ Cooperação entre o Instituto Nacional de Pesquisas Espaciais - Centro Regional da Amazônia (INPE/CRA), a Empresa Brasileira de Pesquisa Agropecuária - Embrapa Amazônia Oriental (CPATU), ambas localizadas em Belém - PA, além da Embrapa Informática Agropecuária (CNPTIA), situada em Campinas - SP.
} 
bacia do rio Mariquita. As imagens foram obtidas gratuitamente no The USGS Global Visualization Viewer (GloVis), disponibilizadas já em formato georreferenciado.

Com o intuito de manter a coerência com a metodologia dos dados TerraClass de 2008, trabalhamos nesta classificação com o mesmo software usado no TerraClass, o TerraAmazon, versão 4.5.1, tendo como base de discriminação de área com Floresta e áreas desmatadas o mapeamento do Projeto PRODES, o qual realiza o monitoramento por satélites do desmatamento por corte raso na Amazônia Legal e produz, desde 1988, as taxas anuais de desmatamento na região, que são usadas pelo governo brasileiro para o estabelecimento de políticas públicas (INPE, 2012). Os dados de saída foram gerados em UTM/SAD 69 Zona 22s, projeção base da tese. Primeiramente, foi realizado o recorte da imagem de acordo com a área com buffer de $500 \mathrm{~m}$ das sub-bacias e, em seguida, feito a segmentação utilizando o método de crescimento de regiões, com parâmetros de 6 para distância euclidiana e 18 para área de pixels. Este processo gerou os polígonos que foram classificados de acordo com as classes finais utilizadas na tese, com a exceção dos polígonos da palma de óleo, que correspondem a medidas em campo feitas pelos agricultores e cedidas gentilmente pelo Dr. Adriano Venturieri, pesquisador da Embrapa Amazônia Oriental. Por fim, utilizou-se o software ArcGis 10.3 da ESRI (Environmental Systems Research Institute) para fazer as edições nos mapas de uso e cobertura da terra classificados no Software TerraAmazon.

Para a retirada de áreas classificadas como "Nuvem" no mapa para 2013, utilizaram-se imagens de alta resolução do satélite RAPIDEYE, cujas cenas foram adquiridas pelo Ministério do Meio Ambiente (MMA) e disponibilizadas pelo sistema Geocatálogo do MMA (BRASIL-MMA, 2015), sendo escolhidas as seguintes cenas apresentadas na Tabela 5 . Os critérios adotados na escolha da imagem foram: a disponibilidade, a qualidade e a cena ser de 2012, de 2013 ou 2014. Foram gerados também mapas de uso e cobertura da terra das sub-bacias em estudo para os anos de 2000 e de 2004, seguindo a metodologia descrita acima, porém utilizando imagens do sensor ETM+ (Enhanced Thematic Mapper Plus) a bordo do satélite LandSat 5. 
Tabela 5: Relação de cenas do satélite RapidEye utilizadas e suas datas.

\begin{tabular}{|c|c|c|}
\hline Sub-bacia & Cena & Data \\
\hline \multirow{10}{*}{ SBRB } & $23381012012-09-13 \top 143222$ & 13/09/2012 \\
\hline & 2338201_2012-09-13Т143218 & $13 / 09 / 2012$ \\
\hline & 2338301_2012-09-13Т143215 & $13 / 09 / 2012$ \\
\hline & 2338301_2013-10-17T142638 & $17 / 10 / 2013$ \\
\hline & $2238128-2012-08-02 T 143214$ & 02/08/2012 \\
\hline & 2238128_2014-11-25Т142512 & $25 / 11 / 2014$ \\
\hline & $2238228 \quad 2012-08-02 T 143211$ & 02/08/2012 \\
\hline & $22382282013-08-01 \mathrm{~T} 142814$ & $01 / 08 / 2013$ \\
\hline & 2238328_2013-08-01T142810 & 01/08/2013 \\
\hline & 2238328_2014-08-17Т142516 & $17 / 08 / 2014$ \\
\hline \multirow{12}{*}{ SBRM } & 2237826_2012-08-03Т143021 & 03/08/2012 \\
\hline & $22378262013-08-01 T 142828$ & $01 / 08 / 2013$ \\
\hline & 2237926 2012-08-02Т 143222 & 02/08/2012 \\
\hline & 2237926_2013-08-01T142825 & 01/08/2013 \\
\hline & $22380262012-08-03 T 143014$ & 03/08/2012 \\
\hline & 2238026_2013-08-01T142822 & 01/08/2013 \\
\hline & $22378272012-08-02 T 143225$ & $02 / 08 / 2012$ \\
\hline & 2237827_2013-08-01T142828 & 01/08/2013 \\
\hline & 2237927_2013-08-01T142824 & 01/08/2013 \\
\hline & $2237927 \quad 2014-11-01 T 142134$ & $01 / 11 / 2014$ \\
\hline & 2238027_2012-08-03Т143014 & 03/08/2012 \\
\hline & 2238027_2013-08-01T142821 & 01/08/2013 \\
\hline
\end{tabular}

\subsubsection{Avaliação da exatidão do Mapeamento}

Esta avaliação foi feita através da geração de 50 pontos aleatórios nos mapas das sub-bacias (CONGALTON, 1991), utilizando a ferramenta create random points do software ArcGis 10.3, que gera pontos aleatórios sobre a área em classificação. A avaliação do acerto da classificação foi feita através da comparação entre as imagens classificadas do LandSat e as imagens de Alta Resolução do Satélite RAPIDEYE. A verificação foi feita através do cálculo da Exatidão Global (BRITES et al., 1996) e do Coeficiente de Concordância Kappa (HUDSON; RAMM, 1987), métodos estes explicados em detalhe no Ítem 5.6.4. 


\subsection{PRINCIPAIS CARACTERÍSTICAS GEOLÓGICAS E GEOMORFOLÓGICAS DAS SUB-BACIAS DOS RIOS BUJARU E MARIQUITA E DO COMPLEXO HIDROGRÁFICO GUAMÁ-CAPIM NO NORDESTE DO ESTADO DO PARÁ.}

De acordo com os dados geológicos e geomorfológicos disponibilizados pelo IBGE, são descritos a seguir características fundamentais das regiões em estudo que embasam a aplicação das metodologias de regionalização de vazão e de transferências de parâmetros calibrados de bacias monitoradas para bacias não monitoradas.

Quanto aos aspectos geológicos, a SBRB é constituída pela unidade geológica Cobertura Detrito-laterítica Neogênica, em sua nascente, pela Cobertura Detritolaterítica Pleistocênica na região nordeste da bacia e, em sua grande totalidade, pelo Grupo Barreiras, enquanto que a SBRM está totalmente inserida na Cobertura Detritolaterítica Pleistocênica. A porção média da Bacia do Rio Capim, utilizada na etapa de transferência de parâmetros calibrados para a SBRB e SBRM e na regionalização de vazão está inserida, principalmente, nas unidades de Cobertura Detrito-Laterítica Pleistocênica, Formação Ipixuna e Cobertura Detrito-laterítica Paleogênica. A porção alta do Rio capim, utilizada apenas na regionalização de vazão, está inserida nas classes Formação Itapecuru, Cobertura Detrito-Laterítica Pleistocênica e Cobertura Detrito-laterítica Paleogênica, principalmente. Outra bacia utilizada, também, apenas para o cálculo da regionalização de vazão, foi a bacia do Rio Guamá, inserida principalmente nas unidades Cobertura Detrito-laterítica Paleogênica, Formação Ipixuna, Formação Itapecuru e Grupo Barreiras.

Em relação à geomorfologia, todas as sub-bacias estão inseridas, predominantemente, na unidade dos Tabuleiros Paraenses, com a exceção da porção alta do rio Capim, que está predominante sobre as unidades do Planalto Dissecado do Gurupi (Grajaú) e Patamar Dissecado Capim (Moju).

As bacias do Bujaru, Mariquita e da porção média do rio Capim apresentam-se semelhantes quanto ao padrão principal subdendrítico. Porém, elas apresentam padrões secundários diferentes que denotam organização tectônica-estrutural diferenciada, mas que thes confere tropias semelhantes (NE-SW e NW-SE), 
diferenciando apenas na bacia do Bujaru que inclui a direção N-S e esta é a principal. Suas assimetrias fortes corroboram o controle estrutural nas bacias (LIMA; PONTE, 2012). A densidade dos elementos de drenagem variando de média a alta é resultado do terreno constituído por rochas com porosidade e permeabilidade variando de média a ruim, o que é confirmado pela variação dos solos nas referidas áreas. Em especial à bacia da porção média do rio Capim, isso se explica melhor por razão da formação Ipixuna compreender argilitos caulínicos e arenitos finos a grossos (VASQUEZ; COSTA, 2008).

A porção alta do rio Capim é estruturada sobre os sedimentos detrito-lateríticos e os arenitos e siltitos da formação Itapecuru (VASQUEZ; COSTA, 2008), com forte controle estrutural e predominância das direções principais SE-NW e SW-NE (LIMA; PONTE, 2012). A região da bacia do rio Guamá apresenta, em síntese, características geológicas semelhantes da região do alto e do médio Capim, por apresentar as unidades Cobertura Detrito-laterítica Paleogênica, Formação Ipixuna e Formação Itapecuru, porém apresenta, também, grande parte da sua bacia sobre a formação Barreiras (Grupo Barreiras), que é composto por uma sequência de sedimentos detríticos e siliciclásticos, pouco ou não consolidados, variando de areias finas a grossa, além de procedências de coberturas lateríticas, que é um material bastante intemperizado (NUNES et al, 2011).

Quanto à morfologia, tanto a SBRB, SBRM, Médio Capim e Guamá estão em feições tabulares, o que determina uma velocidade de escoamento semelhante. Resumidamente, as três bacias devem ter a mesma capacidade de erodir e transportar sedimentos devido à sua organização estruturada semelhante, com atenção especial à defluência NE-SW observada na parte sudeste da bacia do Mariquita, que deve, por isso, apresentar anomalias nestes aspectos. Os aspectos geológicos só reafirmam a interpretação supracitada, por apresentarem características de intemperismo e erosão semelhantes, mudando suas intensidades sazonalmente. 


\subsection{CARACTERIZAÇÃO DO SOLO EM ALGUNS PERFIS NA FAZENDA IPIRANGA.}

Para contribuir com os dados de solo na modelagem com o SWAT, realizou-se uma caracterização física e química de solo na propriedade "Fazenda Ipiranga", localizada no município de Tomé-Açu, Pará. A escolha dessa propriedade se deu por razão de estar numa região de solos característicos dos tipos LATOSSOLO AMARELO Distrófico e ARGISSOLO AMARELO Distrófico, e também por possuir diferentes usos e coberturas da terra como remanescente florestal, vegetação secundária, pastagem, palma de óleo e sistemas agroflorestais próximos uns dos outros para facilitar a logística do trabalho de campo, sendo estes os agroecossistemas escolhidos como áreas de estudo. A propriedade está localizada nas coordenadas geográficas 48 26' 04" W e 232 ' 08" S, próximo à sub-bacia do rio Mariquita (Figura 6).

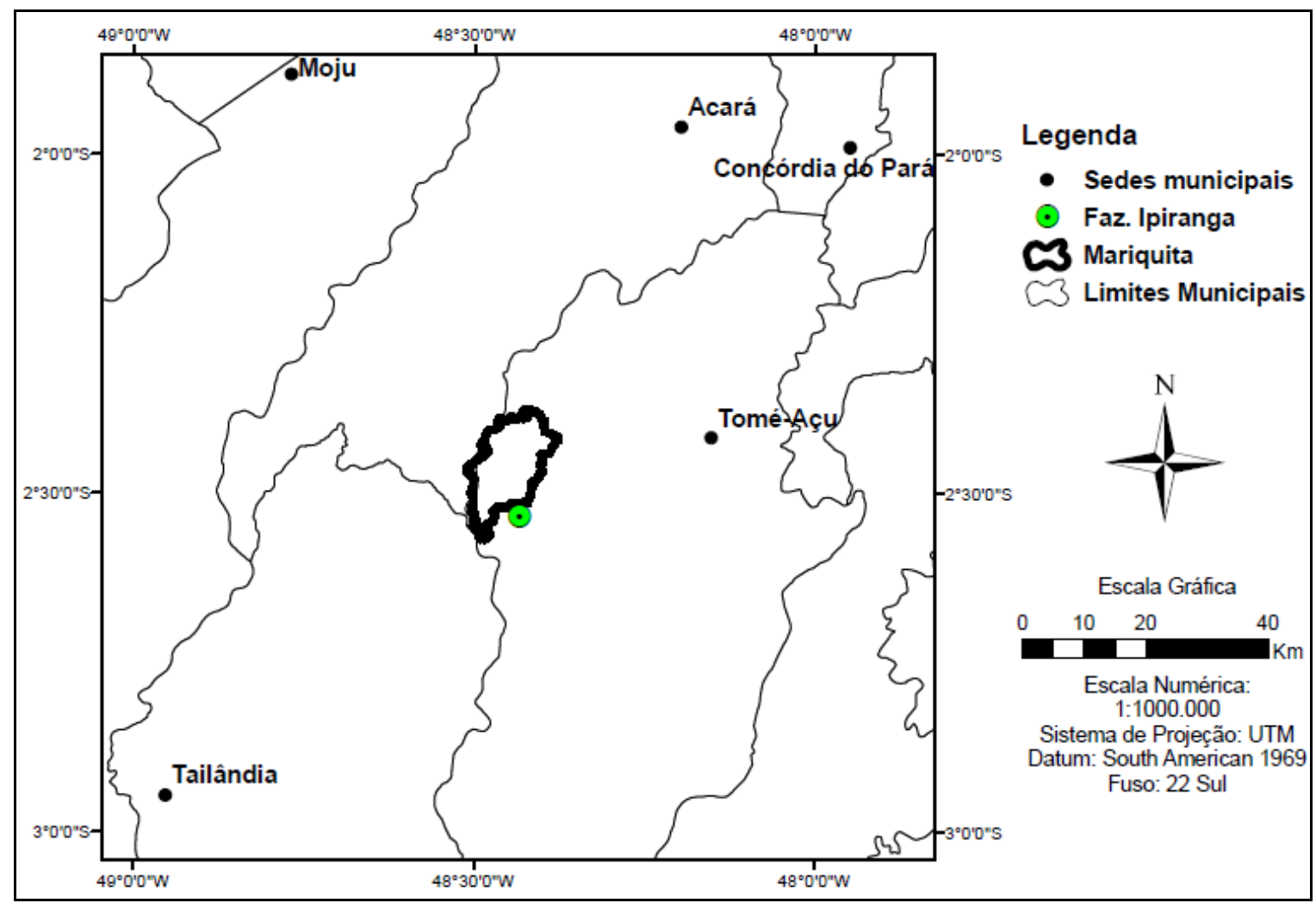

Figura 6: Localização da Fazenda Ipiranga. 
Foram abertas em cada área três trincheiras de $2 \times 1 \mathrm{~m}$ de área e 1,3 $\mathrm{m}$ de profundidade para coleta de solo para análise física, química e, especificamente, de densidade do solo (Figura 7 no APÊNDICE A). Ao redor de cada trincheira, com o auxílio de um trado holandês, foram feitos 7 aberturas no solo com a finalidade de coletar amostras compostas de solo nas profundidades de 0-10, 10-20, 20-30, 30-40, 40-60, 60-80 e 80-100 cm para análise física e química do solo no Laboratório de Solos da Embrapa Amazônia Oriental (Belém-PA). Nestas mesmas profundidades, porém em 3 faces da trincheira, foram coletadas amostras indeformadas de solo para medição de densidade, utilizando anéis volumétricos com volume conhecido, de aço inox, de 4 a 5,5 $\mathrm{cm}$ de diâmetro e 5 a $6 \mathrm{~cm}$ de altura. Nos mesmos locais de coleta da densidade foram coletadas amostras deformadas de solo para análise de estoque carbono total e índice de humificação. Foi realizado também o levantamento do histórico de uso e ocupação das áreas, por meio de entrevista com o proprietário Sr. Ribamar Braga.

Os resultados desse trabalho de campo foram utilizados em diferentes momentos. Na presente tese foram aproveitados os dados de granulometria e matéria orgânica medidas no Laboratório de Solos da Embrapa Amazônia Oriental (Belém-PA). Os resultados de estoque de carbono e índice de humificação não fizeram parte do presente estudo, compondo outra publicação relativa aos resultados do projeto Rede PECUS. No APÊNDICE A são apresentadas as fotografias deste trabalho de campo.

\subsection{SOIL AND WATER ASSESSMENT TOOL (SWAT).}

\subsubsection{Componentes do modelo SWAT.}

Fundamentado nos trabalhos de Arnold et al., (1998), Machado (2002), Minoti (2006), Oliveira et al. (2006), Lubtz (2009), Sousa (2010), Arnold et al. (2011), Neitsch et al. (2011), Arnold et al. (2012), Nunes (2013), Winchell et al. (2013) e Villela (2015), serão descritos, sinteticamente, os principais componentes das duas fases do ciclo 
hidrológico simuladas pelo modelo SWAT, que influenciam diretamente no objetivo do trabalho que é a simulação do escoamento superficial e do transporte de sedimentos.

\subsubsection{Fase Terrestre.}

$\mathrm{Na}$ fase terrestre do ciclo hidrológico, as simulações são feitas baseadas na equação do balanço hídrico (Eq. 1):

$$
S W_{t}=S W_{0}+\sum_{i=1}^{t}\left(R_{i}-Q_{i}-E t_{i}-P_{i}-Q R_{i}\right)
$$

Onde:

$S W t=$ quantidade final de água no solo $\left(\mathrm{mm} \mathrm{H}_{2} \mathrm{O}\right)$;

$S W_{0}=$ quantidade inicial de água no solo no dia i $\left(\mathrm{mm} \mathrm{H}_{2} \mathrm{O}\right)$;

$t=$ tempo (dias);

$R_{i}=$ quantidade de precipitação no dia i $\left(\mathrm{mm} \mathrm{H}_{2} \mathrm{O}\right)$;

$Q_{i}=$ quantidade de escoamento superficial no dia i $\left(\mathrm{mm} \mathrm{H}_{2} \mathrm{O}\right)$;

$E t_{i}=$ quantidade de evapotranspiração no dia i $\left(\mathrm{mm} \mathrm{H}_{2} \mathrm{O}\right)$;

$P_{i}=$ quantidade de água que percola da camada simulada para a camada inferior no dia i $\left(\mathrm{mm} \mathrm{H}_{2} \mathrm{O}\right)$;

$Q R_{i}=$ quantidade de água que retorna ao curso d'água no dia i devido ao escoamento sub-superficial $\left(\mathrm{mm} \mathrm{H}_{2} \mathrm{O}\right)$.

A subdivisão da bacia hidrográfica em Unidades de Resposta Hidrológicas (HRU, do inglês hydrologic response units) favorece uma análise mais refinada das diferenças de evapotranspiração para diferentes tipos de usos e características do solo. O escoamento superficial é medido para cada $\mathrm{HRU}$ e, em seguida, é quantificado o total para a bacia inteira, melhorando a análise do balanço hídrico da bacia. A Figura 8 mostra a sequência de processos realizados pelo SWAT na fase terrestre do ciclo hidrológico. 
$\mathrm{Na}$ fase terrestre, o SWAT divide sua modelagem em sete módulos: 1. clima, 2. hidrologia, 3. cobertura vegetal/crescimento de plantas, 4. erosão, 5. nutrientes, 6. pesticidas e 7. práticas de manejo. Os componentes "nutrientes" e "pesticidas" não serão apresentados, por não fazerem parte do escopo do presente trabalho.

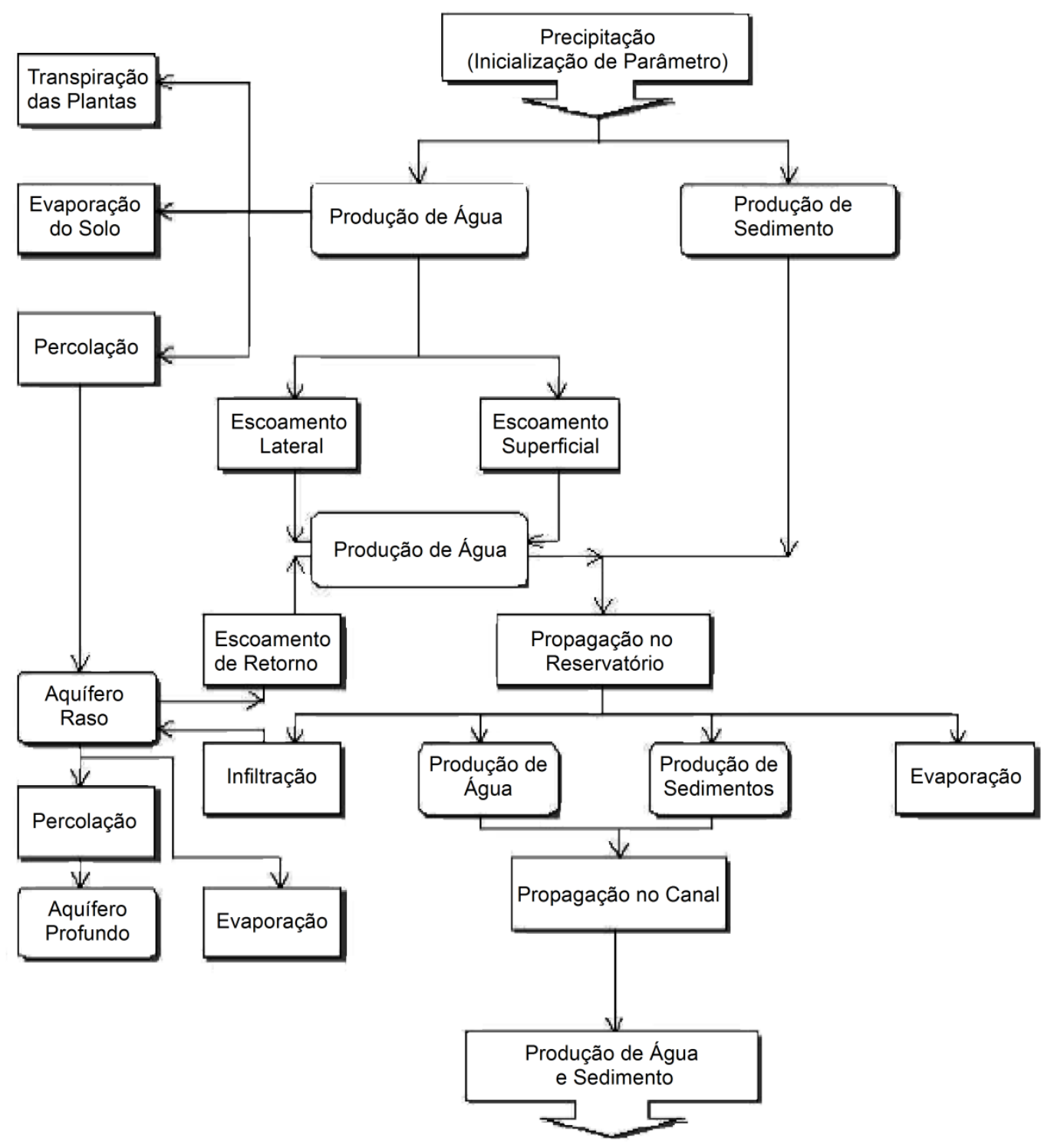

Figura 8: Fluxograma de comandos do SWAT para cada HRU (Fonte: Adaptado de King et al., $1996^{15}$ apud Machado, 2002).

${ }^{15}$ KING, K. W.; ARNOLD J. G.; WILLIAMS, J. R.; SCRINIVASAN R. Soil and Water Assessment Tool SWAT. USDA, Agricultural Research Service, 1996. 450 p. 


\section{A) Clima}

As informações climáticas a serem observadas nas bacias hidrográficas são dependentes da umidade e da entrada de energia no sistema, fatores estes que controlam o balanço hídrico. O modelo SWAT solicita a entrada de algumas variáveis, tais como dados diários de precipitação, temperaturas mínima e máxima do ar, radiação solar, velocidade do vento e umidade do ar.

Estes dados devem ser observados, mas também podem ser simulados pelo modelo. Essa tarefa é de responsabilidade de uma ferramenta inserida no modelo denominada de gerador climático (Weather Generator), a qual gera valores diários dos parâmetros necessários ao modelo: (i) a simulação da precipitação é criada a partir do método da cadeia de Markov, fundamentado na probabilidade de ocorrências de dias úmidos e secos (NICKS, $1974^{16}$ apud NEITSCH et al., 2011); (ii) Temperatura do ar e radiação solar é estimada por uma equação da continuidade que contabiliza, de acordo com a quantidade de dia seco e chuvoso, as variações das temperaturas e radiação solar; (iii) A velocidade do vento é gerada a partir de uma equação exponencial modificada ajustada através de dados de velocidade média mensal; (iv) a umidade relativa do ar é simulada através de distribuição triangular relativa à média mensal da umidade.

\section{B) Hidrologia}

\section{B1) Escoamento Superficial}

A estimativa do escoamento superficial é realizada pelo Método da Curva Número do Soil Conservation Service (SCS), representado pela Equação 2:

\footnotetext{
${ }^{16}$ Nicks, A. D. Stochastic generation of the occurrence, pattern, and location of maximum amount of daily rainfall. In Proceedings Symposium on Statistical Hydrology. Tucson, p. 154-171, 1974.
} 
$Q_{\text {surf }}=\frac{\left(R_{\text {day }}-I_{a}\right)^{2}}{\left(R_{\text {day }}-I_{a}+S\right)}$

Onde:

Qsurf = quantidade de escoamento superficial acumulado ou excesso de chuva $(\mathrm{mm})$;

Rday = precipitação diária;

$l_{a}=$ perdas iniciais que incluem acumulação superficial, interceptação e infiltração anterior ao escoamento superficial $(\mathrm{mm})$;

$S$ = parâmetro de retenção.

O parâmetro de retenção é em função: 1. do tipo e uso, 2. do manejo, 3. da inclinação do solo e 4. da permeabilidade, além de 5. ser temporalmente dependente das variações da quantidade de água no solo. O Parâmetro de retenção é dado por (Eq. 3):

$$
S=25,4\left(\frac{1000}{C N}-10\right)
$$

Onde $\mathrm{CN}$ é a curva número para o dia. $l_{a}$ é normalmente indicado como $0.2 S$, resultando na seguinte equação (Eq. 4):

$$
\begin{aligned}
& Q s=\frac{(R-0,2 S)^{2}}{(R+0,8 S)}, \mathrm{R}>0,2 . s \\
& Q=0, R \leq 0,2 . s
\end{aligned}
$$

O parâmetro $\mathrm{CN}$ é fundamental ao estudo do escoamento superficial, sendo dependente da relação de informações de uso e cobertura do solo, das características pedológicas e das condições de umidade antecedentes da área em estudos. Dessa forma, o CN é função da combinação dos diferentes grupos hidrológicos do solo, conforme suas características físicas e de infiltração, com os diversos usos e manejos 
do solo (SARTORI et al., 2005a). CN varia não linearmente entre 1 (murchamento) e 100 (saturação). Esta não linearidade da $\mathrm{CN}$, bem como a representação desses extremos, onde 1 corresponde a uma cobertura permeável e 100 a uma cobertura impermeável, o SWAT explica os valores da Curva Número através de três condições antecedentes de umidade: I - $\mathrm{CN}_{1}$, que corresponde a condições de solo seco; II - $\mathrm{CN}_{2}$, corresponde a condições de capacidade de campo; III - $\mathrm{CN}_{3}$, representa condições de solo saturado.

\section{B2 - Evapotranspiração (Etp)}

Evapotranspiração é um fluxo ecossistêmico composto pelos processos de evaporação da copa das árvores, transpiração das plantas, sublimação e pela evaporação da água do solo. O SWAT calcula a evaporação do solo e da planta separadamente. A evaporação potencial da água do solo e a transpiração das plantas estão diretamente relacionadas à Evapotranspiração Potencial (Etp) e do índice de área foliar (IAF).

\section{Evapotranspiração Potencial:}

O modelo SWAT oferece três métodos para o cálculo da Etp: Penman-Monteith (MONTEITH, $1965^{17}$ apud NEITSCH et al. 2011), Priestley-Taylor (PRIESTLEY and TAYLOR, $1972^{18}$ apud NEITSCH et al. 2011) e Hargreaves (HARGREAVES et. al., $1985^{19}$ apud NEITSCH et al. 2011).

Para o estudo, vamos utilizar o método de Penman-Monteith, pois requer um maior número de variáveis, como radiação solar (RS), temperatura $(T)$, umidade relativa

\footnotetext{
${ }^{17}$ MONTEITH, J. L. Evaporation and Environment. In: The State and Movement of Water in Living Organisms, XIXTh Symposium, 19., 1965, Swansea. Cambridge University Press, 1965. p. 205-234.

${ }_{18}$ PRIESTLEY, C. H. B.; TAYLOR, R. J. On the assessment of surface heat flux and evaporation using large-scale parameters. Mon. Weather. Rev., v. 100, p. 81-92, 1972.

${ }^{19}$ HARGREAVES, G. L.; HARGREAVES, G. H.; RILEY, J.P. Agricultural benefits for Senegal River Basin. J. Irrig. and Drain. Engr., v. 111, n. 2, p. 113-124, 1985.
} 
do ar (UR) e velocidade do vento (VV), devendo ser ressaltado que o cálculo da Etp pelo método escolhido nos traz estimativas melhores quando utilizamos dados horários, pois médias diárias podem não refletir a real distribuição diurna desses parâmetros.

O método de Penman-Monteith é expresso pela equação (Eq. 6):

$$
\lambda E=\frac{\Delta \cdot\left(H_{n e t}-G\right)+\rho_{\text {air }} \cdot C_{p} \cdot\left[\frac{e_{Z}^{0}-e_{Z}}{r_{a}}\right]}{\Delta+\gamma \cdot\left(1+\frac{r_{\mathrm{c}}}{\mathrm{r}_{\mathrm{a}}}\right)}
$$

Onde:

$\lambda E=$ é a densidade do fluxo de calor latente $\left(\mathrm{MJ} \mathrm{m}^{2} \mathrm{~d}^{-1}\right)$;

$E$ = é a taxa de evaporação profunda $\left(\mathrm{mm} \mathrm{d}^{-1}\right)$;

$\Delta=$ é a rampa da curva pressão-temperatura do vapor de saturação;

$\mathrm{de} / \mathrm{dT}=\left(\mathrm{Kpa}^{\circ} \mathrm{C}^{-1}\right)$;

$H_{\text {net }}=$ é a radiação líquida $\left(\mathrm{MJ} \mathrm{m}^{-2} \mathrm{~d}^{-1}\right)$;

$\rho_{\text {air }}=$ é a densidade do $\operatorname{ar}\left(\mathrm{Kg} \mathrm{m}^{-3}\right)$;

$C_{p}=$ é o calor específico à pressão constante $\left(\mathrm{MJ} \mathrm{Kg}^{-1}{ }^{\circ} \mathrm{C}^{-1}\right)$;

$e_{Z}^{0}=$ é a pressão do vapor de saturação do ar a altura $Z\left(\mathrm{Kpa}^{\circ} \mathrm{C}^{-1}\right)$;

$e_{z}=$ é a pressão do vapor do ar a altura Z (Kpa);

$\gamma=$ é a constante psicrométrica $\left(0,062 \mathrm{Kpa}^{\circ} \mathrm{C}^{-1}\right)$;

$r_{c}=$ é a resistência do dossel vegetativo $\left(\mathrm{s} \mathrm{m}^{-1}\right)$;

$r_{a}=$ é a resistência de difusão da camada de $\operatorname{ar}\left(\mathrm{s} \mathrm{m}^{-1}\right)$.

Iremos utilizar, também, o método de Priestley e Taylor, o qual é uma versão simplificada de equações combinadas, onde a componente aerodinâmica foi removida e a componente de energia foi multiplicada por um coeficiente, $\alpha_{\text {pet }}=1.28$, quando as áreas, em geral ao redor, são úmidas ou estão sob condições úmidas. Esta equação fornece a estimativa de evapotranspiração potencial para condições de baixa advecção. Por exemplo, em áreas semiáridas ou áridas onde a componente de advecção do 
balanço de energia é significante, a equação de Priestley-Taylor irá subestimar a evapotranspiração potencial.

O método de Priestley-Taylor é expresso pela equação (Eq. 7):

$$
\lambda E_{o}=\alpha_{p e t} \cdot \frac{\Delta}{\Delta+\gamma} \cdot\left(H_{n e t}-G\right)
$$

Onde:

$\lambda=$ é o calor latente de vaporização $\left(\mathrm{MJ} \mathrm{kg}^{-1}\right)$;

$E_{o}=$ Evapotranspiração Potencial $\left(\mathrm{mm} \mathrm{d}^{-1}\right)$;

$\alpha_{\text {pet }}=$ é o coeficiente;

$\Delta$ = é a rampa da curva pressão-temperatura do vapor de saturação;

$\mathrm{de} / \mathrm{d} T=\left(\mathrm{kpa}^{\circ} \mathrm{C}^{-1}\right)$;

$\gamma=$ é a constante psicrométrica $\left(\mathrm{Kpa}^{\circ} \mathrm{C}^{-1}\right)$;

$H_{\text {net }}=$ é a radiação líquida $\left(\mathrm{MJ} \mathrm{m}^{-2} \mathrm{~d}^{-1}\right)$;

$G=$ densidade do fluxo de calor para o solo $\left(\mathrm{MJ} \mathrm{m}^{-2} \mathrm{~d}^{-1}\right)$.

Evapotranspiração Real:

Após a determinação da evapotranspiração potencial, calcula-se a evapotranspiração real, sendo considerada pelo modelo SWAT, inicialmente, a evaporação da água interceptada pelas plantas primeiramente e, em seguida, a quantidade de água transpirada pelas plantas e evaporada do solo.

O modelo considera que, se a evapotranspiração potencial for inferior à quantidade de água livre nas plantas:

$$
E_{a}=E_{0} \rightarrow R_{I N T(f)}=R_{I N T(i)}-E_{a}
$$


Se superior:

$$
E_{\text {can }}=R_{I N T(i)} \rightarrow R_{I N T(f)}=0
$$

Onde:

$E_{a}=$ evapotranspiração real diária $(\mathrm{mm})$;

$E_{c a n}=$ a quantidade de evaporação diária livre nas plantas $(\mathrm{mm})$;

$E_{0}=$ evapotranspiração potencial diária $(\mathrm{mm})$;

$R_{I N T(i)}=$ a quantidade inicial diária da água livre nas plantas $(\mathrm{mm})$;

$R_{I N T(f)}=$ a quantidade final diária da água livre nas plantas em um dia $(\mathrm{mm})$.

Outras equações são utilizadas pelo modelo SWAT para o cálculo de processos específicos relativos às determinações da evaporação da água interceptada pela vegetação, transpiração, sublimação e evaporação do solo, as quais podem ser acessadas detalhadamente consultando a descrição dos cálculos de evapotranspiração na documentação teórica do SWAT, versão 2009 (NEITSCH et al., 2011).

\section{B3 - Infiltração / água no solo}

Com o método da CN (que trabalha em tempo diário), usado para cálculo do escoamento superficial, não é possível modelar a infiltração de forma direta. Logo, com este método, assume-se que a água que infiltra é dada pela diferença entre a precipitação e o escoamento superficial. Do total que infiltra, parte evapora ou é destinada ao metabolismo das plantas e a outra porção escoa lateralmente até alcançar o curso d'água. A água pode ainda percolar até uma camada mais profunda e recarregar o aquífero.

No SWAT o parâmetro que controla a quantidade de água disponível para as plantas é dado por (Eq. 10):

$$
A W C=F C-W P
$$


Onde:

$A W C=$ é a capacidade de água disponível para as plantas $(\mathrm{mm})$;

$F C=$ é a quantidade de água relativa à capacidade de campo (para o SWAT é a quantidade de água encontrada quando o solo está totalmente úmido e persiste drenado por cerca de dois dias);

$W P=$ é a quantidade de água no ponto de murchamento permanente.

Ponto de murchamento permanente é a quantidade de água encontrada quando as plantas murcham e não se recuperam mais. Isto é devido as suas folhas serem mantidas em umidades atmosféricas relativamente altas durante o período da noite, atingindo um murchamento irreversível, mesmo quando colocada em atmosfera saturada com vapor de água.

\section{B4) Percolação}

Quando há uma camada do solo em que a quantidade de água ultrapassa a capacidade de campo, ocorre a percolação. A percolação é estimada pela Equação 11:

$$
W_{\text {perc }, l y}=S W_{l y, \text { excess }} \cdot\left[1-\exp \left(\frac{-\Delta t}{T T_{\text {perc }}}\right)\right]
$$

Onde:

$W_{\text {perc,ly }}=$ é a quantidade de água que percola para uma camada inferior em um determinado dia $(\mathrm{mm})$;

$S W_{l y, e x c e s s}=$ é o volume drenável de água no solo em um determinado dia $(\mathrm{mm})$;

$\Delta t=$ é a extensão do passo de tempo (h);

$T T_{\text {perc }}=$ é a duração da percolação $(\mathrm{h})$. 


\section{B5) Escoamento lateral}

O Escoamento Lateral e caracterizado a partir do momento em que a água percolada verticalmente acha uma camada impermeável, acumula-se, e pela formação de uma zona saturada dá origem ao escoamento lateral. O cálculo desta componente é feito a partir do modelo de armazenamento cinemático, através da Equação 12.

$$
Q_{\text {lat }}=0.024 \cdot\left(\frac{2 . S W_{\text {ly,excess }} \cdot K_{\text {sat }} . s l p}{\phi_{d} \cdot L_{\text {hill }}}\right)
$$

Onde:

$Q_{l a t}=$ é a descarga de água da rampa de saída $\left(\mathrm{mm} \mathrm{dia}^{-1}\right)$;

$S W_{l y, e x c e s s}=$ é o volume drenável da água armazenada na zona saturada da rampa por unidade de área $(\mathrm{mm})$;

$K_{\text {sat }}=$ é a condutividade hidráulica saturada $\left(\mathrm{mm} \mathrm{h}^{-1}\right)$;

$s / p=$ é a declividade da rampa $\left(\mathrm{m} \mathrm{m}^{-1}\right)$;

$\phi_{d}=$ é a porosidade drenável da camada de solo $\left(\mathrm{mm} \mathrm{mm}^{-1}\right)$;

$L_{\text {hill }}=$ é o comprimento da rampa $(\mathrm{m})$.

Do mesmo modo que ocorre com o escoamento superficial, é possível aplicar um atraso para o escoamento lateral no caso de sub-bacias com tempo de concentração maior que 1 dia através da alteração do parâmetro LAT_TTIME, caso haja necessidade.

\section{B6) Águas subterrâneas}

As águas subterrâneas são classificadas como aquelas localizadas em camadas saturadas, onde a pressão é maior que a atmosférica. Utilizando o SWAT, é possível modelar tanto o sistema de aquífero raso, como o aquífero profundo. A água oriunda do aquífero raso contribui com o escoamento do canal, porém a água percolada até 0 aquífero profundo é eliminada do sistema. A Equação 13 descreve o balanço de água do aquífero raso: 
$a q_{s h, i}=a q_{s h, i-1}+w_{r c h r g, s h}-Q_{g w}-w_{\text {revap }}-w_{\text {pump }, s h}$

Onde:

$a q_{s h, i}=$ é a quantidade de água armazenada no aqüífero raso no dia i (mm), $a q_{s h, i-1}=$ é a quantidade de água armazenada no aqüífero raso no dia i-1 (mm);

$w_{\text {rchrg,sh }}=$ é a quantidade de recarga entrando no aqüífero raso no dia i $(\mathrm{mm})$ $Q_{g w}=$ é o escoamento de base ao canal no dia i $(\mathrm{mm})$

$w_{\text {revap }}=$ é a quantidade de água indo para a zona não saturada do solo em resposta às deficiências de água no dia i $(\mathrm{mm})$;

$w_{\text {pump,sh }}=$ é a quantidade de água retirada do aquífero raso por bombeamento no dia i (mm).

O Modelo SWAT permite a simulação do possível atraso entre o momento que a água sai do perfil e alcança o aquífero raso, o que está relacionado às características geomorfológicas da região em estudo. Este atraso não pode ser medido, apenas estimado, sendo controlado pelo parâmetro GW_DELAY. Outro parâmetro importante neste contexto é o RCHRG_DP, que responde pela determinação da quantidade de recarga que alcançará o aquífero profundo e deixará o sistema.

Com relação ao escoamento de base, para que este alcance o canal, é necessário que a água armazenada no aquífero raso exceda a um limiar préestabelecido, o qual é definido pelo parâmetro GWQMIN. Se ocorrer esse processo, o escoamento de base será calculado através da Equação 14:

$$
Q_{g w, i}=Q_{g w, i-1} \cdot \exp \left[-\alpha_{q w} \cdot \Delta t+w_{r c h r g, s h} \cdot\left(1-\exp \left(-\alpha_{g w} \cdot \Delta t\right)\right)\right]
$$

Onde:

$Q_{g w, i}=$ é o escoamento de base ao canal no dia i $(\mathrm{mm})$;

$Q_{g w, i-1}=$ é o escoamento de base ao canal no dia i-1 $(\mathrm{mm})$;

$\alpha_{g w}=$ é a constante de recessão do escoamento de base;

$\Delta t=$ é o passo de tempo (1 dia); 
$W_{\text {rchrg,sh }}=$ é a quantidade de recarga entrando no aqüífero raso no dia i $(\mathrm{mm})$.

A constante de recessão do escoamento de base $\left(\alpha_{\mathrm{gw}}\right)$, que no SWAT corresponde ao ALPHA_BF, pode ser obtida mais precisamente fundamentada nos dados medidos de vazão, através da Equação 15:

$$
\alpha_{q w}=\frac{2.3}{B F D}
$$

Onde:

$B F D=$ é o número de dias de escoamento de base para a bacia.

A água que chega ao aquífero raso pode retornar à zona não saturada por capilaridade ou, também, através da ação de raízes profundas de algumas plantas. Este fenômeno é denominado de revap pelo SWAT. Contudo, esse processo terá seu início apenas caso a quantidade de água do aquífero raso ultrapasse o limite definido pelo usuário no parâmetro REVAP_MN. Ocorrendo isto, o modelo calcula a quantidade de água removida através da Equação 16:

$$
w_{\text {revap }, m x}=\beta_{\text {rev }} \cdot E_{0}
$$

Onde:

$W_{\text {revap,mx }}=$ é a máxima quantidade de água movendo para a zona não saturada em resposta a deficiências de água $(\mathrm{mm})$;

$\beta_{\text {rev }}=$ é o coeficiente revap (GW_REVAP no SWAT);

$E_{0}=$ é a evapotranspiração potencial para o dia $(\mathrm{mm})$. 
C) Cobertura do terreno e Crescimento vegetal

O SWAT tem o potencial de diferenciar em suas simulações se a planta é de natureza perene ou anual, considerando o crescimento baseado na quantidade de energia interceptada e na eficiência de conversão de energia em biomassa pela planta. A partir do conhecimento de informações como a quantidade de radiação solar e a área foliar, absorção de nutrientes e transpiração, o modelo é capaz de estimar a interceptação de energia. Para isso, o SWAT utiliza uma versão simplificada do modelo EPIC (Environmental Policy Integrated Climate Model). A característica fundamental desse modelo está no fato de estimar o desenvolvimento fenológico em função de unidades de calor, assumindo que as plantas possuem uma temperatura ideal que determina um ótimo desenvolvimento e limiares máximos e mínimos que, quando ultrapassados, determinam o cessar de crescimento.

A teoria da unidade de calor postula que as plantas necessitem de determinadas quantidades de calor, as quais podem ser quantificadas e estão diretamente ligadas ao tempo de maturação. Como as plantas não se desenvolvem abaixo da temperatura de base, a porção de temperatura média diária que contribui para o desenvolvimento da planta é a quantidade que excede a temperatura de base. Dessa forma, o SWAT determina como índice de calor cada grau na temperatura média diária acima da temperatura de base, o qual é determinado como uma unidade de calor. Este método assume que a taxa de crescimento é proporcional ao aumento da temperatura, tendo como limite a linha de corte de temperatura máxima determinada pelo usuário.

O modelo SWAT ainda aplica outros índices e equações para calcular biomassa retirada do sistema após uma colheita, simular variações do crescimento em função da variabilidade da disponibilidade de nutrientes e água, além de variações nas temperaturas extremas. 
D) Erosão

A erosão e a produção de sedimentos são estimadas através da Equação Universal da Perda de Solos Modificada (MUSLE - Modified Universal Soil Loss Equation) para cada HRU (Equação 17). Enquanto a Equação Universal da Perda de Solos (USLE) trabalha com a precipitação como indicador de energia erosiva, a MUSLE utiliza o escoamento superficial para simular a erosão e o transporte de sedimentos, o que tem aumentado a eficiência dos resultados do modelo.

$$
\text { sed }=11.8 \cdot\left(\mathrm{Q}_{\text {surf }} \cdot \mathrm{q}_{\text {peak }} \cdot \text { area }_{\text {hru }}\right)^{0.56} \cdot \mathrm{K} \cdot \mathrm{C} \cdot \mathrm{P} \cdot \mathrm{LS} \cdot \mathrm{CFRG}
$$

Onde:

sed $=$ produção de sedimeto em um dia (tonelada métrica);

Qsurf = lâmina de escoamento superficial $(\mathrm{mm} / \mathrm{ha})$;

qpeak = vazão de pico $\left(\mathrm{m}^{3} / \mathrm{s}\right)$;

areahru = área da HRU (ha);

KUSLE $=$ fator erodibilidade da USLE;

CUSLE = fator cobertura e manejo da USLE;

PUSLE = fator práticas conservacionistas da USLE;

LSUSLE $=$ fator topografia da USLE;

$\mathrm{CFRG}=$ fator fragmentos grosseiros.

Para calcular a vazão de pico, a qual corresponde à taxa de escoamento superficial máxima em um determinado evento, o modelo SWAT utiliza uma expressão modificada do método racional:

$$
q_{\text {peak }}=\frac{\alpha_{\text {tc }} \cdot Q_{\text {surf }} \cdot \text { Area }}{3,6 \cdot t_{\text {conc }}}
$$

Onde:

qpeak = Taxa de escoamento de pico $\left(\mathrm{m}^{3} / \mathrm{s}\right)$; 
$\alpha_{t c}=$ Parcela de chuva diária que ocorre durante o tempo de concentração;

$Q_{\text {surf }}=$ é o escoamento superficial $(\mathrm{mm})$;

Area $=$ é a área da sub-bacia $\left(\mathrm{km}^{2}\right)$;

$t_{c o n c}=$ é o tempo de concentração da sub-bacia (h).

Para o cálculo do tempo de concentração, o qual corresponde ao tempo necessário para que toda a sub-bacia esteja contribuindo com o escoamento no exutório, faz-se a soma dos tempos de concentração de ambas as fases, terrestre e canal, sendo dado pela seguinte equação:

$t_{\text {conc }}=\frac{L_{s l p^{0,6} \cdot n^{0,6}}}{18 \cdot s p^{0,3}}+\frac{0,62 \cdot L \cdot n_{c h}{ }^{0,75}}{\operatorname{Area}^{0,125} \cdot \operatorname{slp}_{c h}{ }^{0,375}}$

Onde:

$L_{s / p}=$ comprimento de rampa da sub-bacia $(\mathrm{m})$

$n=$ coeficiente de rugosidade de Manning para a sub-bacia;

$s / p=$ declividade média da sub-bacia $\left(\mathrm{m} \mathrm{m}^{-1}\right)$;

$L=$ comprimento do canal do ponto mais distante da sub-bacia até o seu exutório $(\mathrm{km})$;

$n_{c h}=$ coeficiente de rugosidade de Manning para o canal;

Area $=$ área da sub-bacia $\left(\mathrm{km}^{2}\right)$;

$s / p_{c h}=$ declividade do canal $\left(\mathrm{m} \mathrm{m}^{-1}\right)$.

O fator de erodibilidade $(K)$ do solo foi calculado de acordo com a Equação 20 alternativa proposta por Williams (1995) ${ }^{20}$ apud Neitsch (2011):

$$
K=f_{\text {csand }} \cdot f_{\text {cl-si }} \cdot f_{\text {orgc }} \cdot f_{\text {hisand }}
$$

\footnotetext{
${ }^{20}$ WILLIAMS, J. R. Sediment-yield prediction with universal equation using runoff energy factor. In: Present and prospective technology for predicting sediment yield and sources. Proceedings of the sediment-yield workshop, 1975. Oxford: USDA Sedimentation lab., 1975.
} 
Onde:

$f_{\text {csand }}=$ é um fator que dá baixos fatores de erodibilidade do solo para solos com teores elevados de areia grossa e valores altos para solos com pouca areia;

$f_{c l-s i}=$ é um fator que dá baixos fatores de erodibilidade do solo para solos com alta relação argila/silt;

$f_{\text {orgc }}=$ é um fator que reduz a erodibilidade de solos com alto teor de carbono orgânico;

$f_{\text {hisand }}=$ fator que reduz a erodibilidade do solo quando há quantidades extremamente altas de areia.

Estes fatores são calculados pelas seguintes equações:

$$
\begin{aligned}
& f_{\text {csand }}=\left(0,2+0,3 \cdot \exp \left[-0,256 \cdot m_{s} \cdot\left(1-\frac{m_{\text {silt }}}{100}\right)\right]\right) \\
& f_{c l-s i}=\left(\frac{m_{\text {silt }}}{m_{c}+m_{\text {silt }}}\right)^{0,3} \\
& f_{\text {orgc }}=\left(1-\frac{0.25 \cdot \text { org } C}{\text { orgC } \exp [3,72-2,95 \cdot \text { orgC }]}\right) \\
& f_{\text {hisand }}=\left(1-\frac{0,7 \cdot\left(1-\frac{m_{s}}{100}\right)}{\left(1-\frac{m_{s}}{100}\right)+\exp \left[-5,51+22,9 \cdot\left(1-\frac{m_{s}}{100}\right)\right]}\right)
\end{aligned}
$$

Onde:

$m_{s}=$ é o percentual de areia;

$m_{\text {silt }}=$ é o percentual de silte;

$m_{c}=$ é o percentual de argila;

$\operatorname{org} C=$ é o percentual de carbono orgânico na camada. 
Por razão de ocorrer variação da cobertura vegetal durante o ciclo de crescimento das plantas, o SWAT calcula o fator de manejo e cobertura do solo $(C)$ diariamente através da Equação 25.

$$
\mathrm{C}=\exp \left(\left[\ln (0,8)-\ln \left(\mathrm{C}_{\mathrm{mn}}\right)\right] \cdot \exp \left[-0,00115 \cdot \operatorname{rsd}_{\mathrm{surf}}\right]+\ln \left[\mathrm{C}_{\mathrm{mn}}\right]\right)
$$

Onde:

$C_{m n}=$ é o valor mínimo da fator para determinada cobertura do solo;

$r s d_{\text {surf }}=$ quantidade de resíduos na superfície do solo $\left(\mathrm{kg} \mathrm{ha}^{-1}\right)$.

$C_{m n}$ é dado por:

$\mathrm{C}_{\mathrm{mn}}=1,463 \ln \left[\mathrm{C}_{\mathrm{aa}}\right]+0,1034$

Onde:

$C_{a a}$ é a média anual do fator de manejo e cobertura do solo.

O fator práticas conservacionistas $(\mathrm{P})$ trata da relação da taxa de perda de solo ligada ao uso de práticas específicas de suporte a conservação do solo com a declividade da área. Práticas como o plantio direto, cultivo em faixa, intercalando espécies vegetais diferentes e sistemas de terraceamento, são exemplos de métodos conservacionistas que podem reduzir os processos erosivos. Os valores de $P$ são sugeridos para cada prática e declividade.

O fator topográfico (LS) corresponde à relação entre a perda de solo em uma área com comprimento de rampa de $22,1 \mathrm{~m}$ e declividade de $9 \%$ com outra área sob as mesmas condições, sendo calculado através da seguinte equação:

$$
\mathrm{LS}=\left(\frac{\mathrm{L}_{\text {hill }}}{22,1}\right)^{\mathrm{m}} \cdot\left(65,41 \cdot \sin ^{2}\left(\alpha_{\text {hill }}\right)+4,56 \cdot \sin \alpha_{\text {hill }}+0,065\right)
$$


Onde:

$L_{\text {hill }}=$ comprimento de rampa $(\mathrm{m})$;

$m=$ termo exponencial;

$\alpha_{\text {hill }}$ é o ângulo da rampa.

O termo exponencial é dado por (Eq. 28):

$m=0,6 \cdot(1-\exp [-35.835 \cdot s l p])$

O fator de partículas grossas do solo é calculado através da Equação 29:

$C F R G=\exp (-0,053 \cdot$ rock $)$

Onde:

rock $=$ percentual de rochas na primeira camada do solo (\%).

Um ponto importante de ser mencionado ainda neste tópico é o fato do SWAT calcular a produção de sedimentos através do fluxo lateral subsuperficial e do escoamento de base, através da equação 30 :

$$
\operatorname{sed}_{\text {lat }}=\frac{\left(Q_{\text {lat }}+Q_{\text {gw }}\right) \cdot \text { area }_{\text {hru }} \cdot \text { conc }_{\text {sed }}}{1000}
$$

Onde:

$S_{l a t}=$ carga de sedimentos no escoamento lateral e de base (ton);

$Q_{l a t}=$ escoamento lateral para um dado dia $(\mathrm{mm})$;

$Q_{g w}=$ escoamento de base para um dado dia $(\mathrm{mm})$;

area $a_{\text {hru }}=$ área da $\mathrm{HRU}\left(\mathrm{km}^{2}\right)$;

conc $_{\text {sed }}=$ concentração de sedimentos nos escoamentos lateral e de base $\left(\mathrm{mg} \mathrm{L}^{-}\right.$ $\left.{ }^{1}\right)$. 


\section{E) Práticas de Gestão}

O SWAT apresenta também a especialidade de inserir operações de manejo como diferentes cultivos na mesma área em rotação, épocas de plantio e colheita, especificar prazos e quantidades da aplicação de fertilizantes, pesticidas e irrigação. Outras operações como pastagem, fertilização automática, aplicações detalhadas do uso da água, além de rotinas para calcular a carga de sedimentos oriundos de áreas urbanas. Estes procedimentos são todas possíveis de serem manejadas pelo usuário em nível de HRU's.

\subsubsection{Fase Canal.}

$\mathrm{Na} 2^{\circ}$ fase, as perdas podem ocorrer por evaporação, transmissão através do leito ou pela captação de água para uso humano ou agrícola. As entradas são propiciadas através da precipitação direta sobre o curso d'água e por descargas pontuais. Para este estudo, consideraram-se desprezíveis as contribuições por descargas pontuais e as remoções para quaisquer usos.

O SWAT utiliza dois métodos para simular a propagação do escoamento. Um método que usa um coeficiente de armazenamento variável e o método aqui utilizado que é o de "Muskingum", que modela o volume ao longo do canal através da combinação dos armazenamentos. O volume total é dado por (Eq. 31):

$$
V_{\text {stored }}=K \cdot\left(X \cdot q_{\text {in }}+(1-X) \cdot q_{\text {out }}\right)
$$

Onde:

$V_{\text {stored }}=$ volume de armazenamento $\left(\mathrm{m}^{3}\right)$;

$q_{\text {in }}=$ taxa de entrada do escoamento $\left(\mathrm{m}^{3} \mathrm{~s}^{-1}\right)$;

$q_{\text {out }}=$ taxa de descarga $\left(\mathrm{m}^{3} \mathrm{~s}^{-1}\right)$;

$K=$ constante de armazenamento para o canal (s); 
$X=$ fator de ponderação, que pode variar entre 0 e 0,5 , sendo comum o uso de 0,2 para rios.

Ké calculado pela seguinte equação (Eq. 32):

$$
K=\frac{1000 \cdot L_{c h}}{C_{k}}
$$

Onde:

$L_{c h}=$ comprimento do canal $(\mathrm{km})$;

$c_{k}=$ celeridade, que corresponde ao escoamento para uma profundidade específica $\left(m \cdot \mathrm{s}^{-1}\right)$.

A celeridade é definida como sendo (Eq. 33):

$C_{k}=\frac{5}{3} \cdot\left(\frac{R_{c h}^{2 / 3} \cdot s l p_{c h}^{1 / 2}}{n}\right)$

Onde:

$R_{c h}=$ raio hidráulico para uma determinada profundidade de escoamento $(\mathrm{m})$;

$s / p_{c h}=$ declividade ao longo do comprimento do canal $\left(\mathrm{m} \mathrm{m}^{-1}\right)$;

$n=$ coeficiente de Manning para o canal.

O SWAT calcula as perdas relacionadas a processos de transmissão em períodos secos, quando a água de escoamento profundo não chega ao canal. A Equação 34 representa esse cálculo:

$t_{\text {loss }}=K_{c h} \cdot T T \cdot P_{c h} \cdot L_{c h}$

Onde:

tloss = perdas por transmissão no canal $\left(\mathrm{m}^{3}\right)$;

$K_{c h}=$ condutividade hidráulica efetiva do canal $\left(\mathrm{mm} \mathrm{h}^{-1}\right)$; 
$T T=$ tempo de escoamento $(\mathrm{h})$;

$P_{c h}=$ perímetro molhado $(\mathrm{m})$;

$L_{c h}=$ comprimento do canal $(\mathrm{km})$.

As perdas por evaporação são calculadas através da Equação 35:

$E_{c h}=\operatorname{coef}_{e v} \cdot E_{0} \cdot L_{c h} \cdot W \cdot f r_{\Delta t}$

Onde:

$E_{c h}=$ evaporação do canal para o dia $\left(\mathrm{m}^{3}\right)$;

coef $_{e v}=$ coeficiente de evaporação que varia de 0 a 1 e pode ser alterado pelo usuário;

$E_{0}=$ evaporação potencial;

$L_{c h}=$ comprimento do canal $(\mathrm{km})$;

$W=$ largura do canal ao nível da água $(\mathrm{m})$;

$f r_{\Delta t}=$ fração do passo de tempo na qual a água está escoando no canal.

\subsubsection{Banco de dados de entrada do modelo SWAT.}

Os cálculos dos fenômenos hidrológicos pelo modelo SWAT dependem de um banco de dados de entrada (Figura 9) com informações sobre o clima, hidrologia, qualidade do solo, topografia, vegetação, hidrologia e práticas de gestão de terras que ocorrem na bacia, dividindo-se o banco de dados em dois tipos: 1. dados especializados (Planos de Informação) e 2. dados tabulares. 


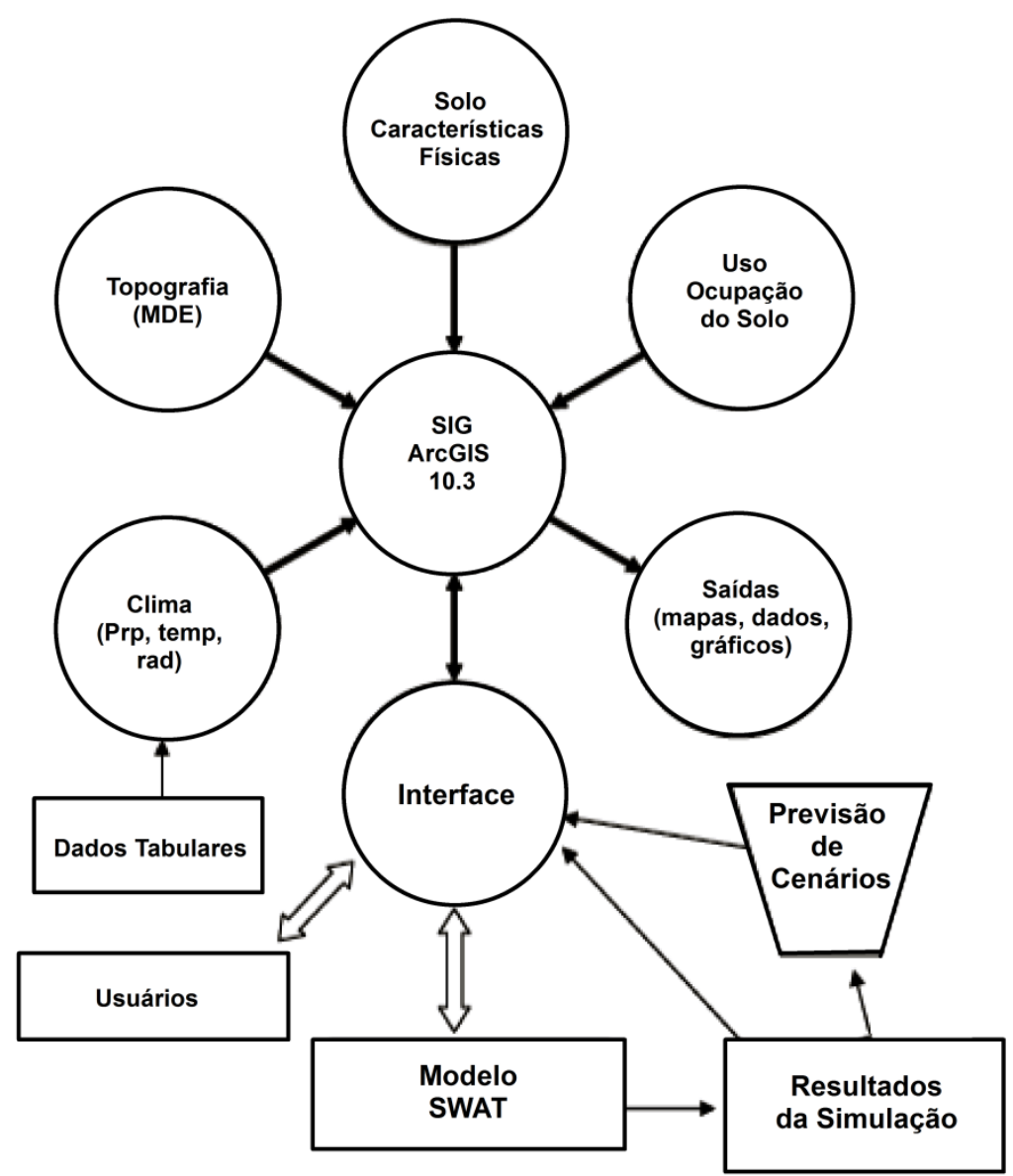

Figura 9: Processo de funcionamento do Modelo SWAT na Interface SIG (Fonte: adaptado de Machado, 2002).

5.5.2.1 Dados espacializados - Planos de Informação.

Mapa de uso e cobertura da terra.

Os anos base de uso e cobertura da terra são 2008 e 2013. O Mapa de 2008 representa o estado inicial de simulação praticamente sem a presença de palma de óleo, o qual foi elaborado pelo Projeto TerraClass (INPE, 2014). O mapa de 2013 representa o estado com forte presença de palma de óleo e foi elaborado conforme descrito no item 5.2.1. Aplicou-se ao SWAT, também, os mapas de uso e cobertura do solo dos cenários futuros de 2023 gerados com o modelo CLUE-S (ítem 5.6). 
$\mathrm{Na}$ modelagem com o SWAT, foram consideradas as seguintes classe de uso e cobertura: 1. palma de óleo, 2. agricultura geral, 3. pastagem, 4. remanescente florestal, 5. área urbana e 6 . água. Adota-se que as áreas de vegetação secundária tenham comportamento hidrossedimentológico semelhantes às áreas de remanescente florestal que, por essa razão, foram agrupadas em uma única classe denominada de "remanescente florestal".

Modelo Digital de Elevação do Terreno (MDE).

Foram utilizadas imagens de SRTM (Shuttle Radar Topography Mission) para a elaboração do Modelo de Elevação Digital das bacias em estudo, fundamental a delimitação das redes hidrográficas e sub-bacias. As cartas utilizadas são as seguintes: SA-22-X-D / SA-22-Z-B / SA-23-V-C / SA-23-Y-A. Estes dados estão disponíveis em sistema de coordenadas geográficas e Datum WGS84, com resolução de 90 metros e em uma escala de 1:250.000 (MIRANDA, 2005). O MDE foi utilizado para elaborar a carta de declividade (clinográfica) das sub-bacias em estudos.

\section{Mapa Pedológico.}

Para a elaboração do mapa pedológico das bacias, foi aplicado o dado disponibilizado pelo Zoneamento Ecológico Econômico do estado do Pará (ZEE-PA) na escala de 1:250.000 (ZEE-PA, 2010). Especialmente nas simulações com o SWAT, por razão de não haver um mapeamento mais refinado das classes de uso e cobertura do solo e com a intenção de contribuir com o objetivo do trabalho através da retirada de possíveis erros sistêmicos promovidos pela inserção de dados não validados em um modelo, adotou-se a classe de solo tida como predominante pelo ZEE-PA nas duas sub-bacias em estudo, que é a classe do LATOSSOLO AMARELO Distrófico (Quadro 1 no ANEXO A). 


\subsubsection{Dados Tabulares}

\section{Dados climáticos}

Foram organizados dados diários em arquivos de formato "txt" para precipitação $(\mathrm{mm})$, temperatura máxima e mínima do $\operatorname{ar}\left({ }^{\circ} \mathrm{C}\right)$, umidade relativa do ar $(\%)$, velocidade do vento $(\mathrm{m} / \mathrm{s})$ e radiação solar $\left(\mathrm{MJ} / \mathrm{m}^{2} \mathrm{dia}\right)$. Para precipitação foram utilizadas séries diárias das estações disponibilizadas pela Agência Nacional de Água (ANA), sendo utilizadas as estações 148009-Acará; 148017-Bujaru; 247003-Fazenda Jauará para a SBRB e as estações 248001-Fazenda Urucure, 248003-Tomé-Açu e 248006-PA256/Rio Acará Mirim para a SBRM (Tabela 6). O preenchimento de falhas dos dados diários em falta foi realizado através da média aritmética diária interanual por estação. Para os outros parâmetros climáticos, as séries diárias variaram de acordo com a disponibilidade de dados das estações automáticas utilizadas do Instituto Nacional de Meteorologia (INMET) (Tabela 6), sendo o preenchimento de falhas destes parâmetros realizados pelo gerador climático Weather Generator (WGEN_user), através da inserção do valor -99 onde há ausência de dados na série de entrada.

Além das séries diárias, o modelo requer a constituição do gerador climático WGEN_user, que é composto de um conjunto de parâmetros mensais calculados a partir do dados de precipitação, temperatura máxima e mínima, radiação solar, temperatura do ponto de orvalho e velocidade do vento para cada estação selecionada. O objetivo do gerador climático é fornecer informações ao SWAT para realizar o preenchimento de falhas. Os cálculos dos parâmetros que compõem as 3 WGEN_user utilizadas neste estudo, que correspondem as estações do INMET (Tabela 6), foram realizados través da tabela de cálculos meteorológicos disponibilizadas pelo Laboratório de Modelagem HidroClimático da Amazônia (LabHCam) da Universidade Federal Rural da Amazônia (UFRA). 
Tabela 6: Código, nome, localização e usos e séries das estações de precipitação (ANA) e de dados climáticos (INMET) disponíveis utilizados na tese (ANA, 2015; INMET, 2014).

\begin{tabular}{|c|c|c|c|c|c|}
\hline Fonte & Código & Nome & Município & Uso & Série \\
\hline \multirow{19}{*}{$\begin{array}{l}\text { ANA - } \\
\text { Estações } \\
\text { convencionais }\end{array}$} & 349002 & Goianésia & Goianésia do Pará & Regionalização & 2003-2014 \\
\hline & 447003 & Ligação do Pará & Dom Eliseu & Regionalização & 2003-2014 \\
\hline & 448000 & Rondon do Pará & Rondon do Pará & Regionalização & 2003-2014 \\
\hline & 348001 & $\begin{array}{l}\text { Fazenda } \\
\text { Maringa }\end{array}$ & Ipixuna do Pará & $\begin{array}{l}\text { SWAT-Capim / } \\
\text { Regionalização }\end{array}$ & 2003-2014 \\
\hline & 347000 & Paragominas & Paragominas & $\begin{array}{l}\text { SWAT-Capim / } \\
\text { Regionalização }\end{array}$ & 2003-2014 \\
\hline & 247006 & $\begin{array}{l}\text { PA 256-Rio } \\
\text { Capim }\end{array}$ & Ipixuna do Pará & $\begin{array}{l}\text { SWAT-Capim / } \\
\text { Regionalização }\end{array}$ & 2003-2014 \\
\hline & 247000 & Badajos & Ipixuna do Pará & $\begin{array}{l}\text { SWAT-Capim / } \\
\text { Regionalização }\end{array}$ & 2003-2014 \\
\hline & 248003 & Tomé-Açú & Tomé-Açú & $\begin{array}{l}\text { SWAT-SBRM/ } \\
\text { Regionalização }\end{array}$ & 2003-2014 \\
\hline & 248006 & $\begin{array}{l}\text { PA-256 / Rio } \\
\text { Acará Mirim }\end{array}$ & Tomé-Açu & $\begin{array}{l}\text { SWAT-SBRM / } \\
\text { Regionalização }\end{array}$ & 2003-2014 \\
\hline & 148017 & Bujaru & Bujaru & $\begin{array}{l}\text { SWAT-SBRB / } \\
\text { Regionalização }\end{array}$ & 2003-2014 \\
\hline & 247003 & Faz. Jauará & Aurora do Pará & $\begin{array}{l}\text { SWAT-SBRB / } \\
\text { Regionalização }\end{array}$ & 2003-2014 \\
\hline & 247004 & $\begin{array}{l}\text { Fazenda São } \\
\text { Raimundo }\end{array}$ & Ipixuna do Pará & $\begin{array}{l}\text { SWAT-Capim / } \\
\text { Regionalização }\end{array}$ & 2003-2014 \\
\hline & 248001 & $\begin{array}{l}\text { Fazenda } \\
\text { Urucuré }\end{array}$ & Acará & $\begin{array}{l}\text { SWAT-SBRM / } \\
\text { Regionalização }\end{array}$ & 2003-2014 \\
\hline & 148009 & Acará & Acará & $\begin{array}{l}\text { SWAT-SBRB / } \\
\text { Regionalização }\end{array}$ & 2003-2014 \\
\hline & 146005 & Tarauá - Ponte & Viseu & Regionalização & 2003-2014 \\
\hline & 147011 & $\begin{array}{l}\text { Colônia Santo } \\
\text { Antonio }\end{array}$ & Irituia & Regionalização & 2003-2014 \\
\hline & 147018 & $\begin{array}{c}\text { Santa Maria do } \\
\text { Pará }\end{array}$ & $\begin{array}{c}\text { Santa Maria do } \\
\text { Pará }\end{array}$ & Regionalização & 2003-2014 \\
\hline & 147016 & Ourem & Ourem & Regionalização & 2003-2014 \\
\hline & 146011 & $\begin{array}{c}\text { Santa Luzia do } \\
\text { Pará }\end{array}$ & $\begin{array}{c}\text { Santa Luzia do } \\
\text { Pará }\end{array}$ & Regionalização & 2003-2014 \\
\hline \multirow{3}{*}{$\begin{array}{l}\text { INMET - } \\
\text { Estações } \\
\text { automáticas }\end{array}$} & A202 & Castanhal & Castanhal & SWAT & 2003-2014 \\
\hline & A213 & Tomé-Açu & Tomé-Açu & SWAT & 2008-2014 \\
\hline & $\mathrm{A} 212$ & Paragominas & Paragominas & SWAT & 2008-2014 \\
\hline
\end{tabular}


Dados de solo

O SWAT requer um banco de dados tabulares preenchido com valores para os seguintes parâmetros: número de camadas do solo, grupo hidrológico, máxima profundidade da raiz no perfil do solo, fração de porosidade, textura, profundidade das camadas, densidade, capacidade de água disponível, condutividade hidráulica saturada, conteúdo de carbono orgânico, conteúdos de argila, silte, areia e fragmentos de rochas, albedo e fator erodibilidade do solo (fator K da MUSLE).

Fundamentado nas pesquisas bibliográficas dos dados físicos e químicos de perfis de solo disponibilizados pelo ZEE-PA, pelo Programa de Estudos e Pesquisas nos Vales Amazônicos (PROVAM, 1988) e na coleta de solo em campo, selecionou-se perfis de solo condizentes com a qualidade da classe descrita pelo ZEE-PA para cada bacia hidrográfica em estudo. Destes perfis, foram obtidas informações de número de camadas do solo, carbono orgânico, areia, silte, argila e rocha, os quais serviram de base para estimar todos os outros parâmetros de solo necessários ao SWAT através de funções de pedotransferência descritas por (SAXTON; RAWLS, 2006). O Grupo hidrológico de cada solo foi definido conforme os trabalhos de Sartori et al. (2005a; 2005b). Em especial com relação aos parâmetros de condutividade hidráulica e disponibilidade de água dos solos da região em estudo, tomou-se como base de verificação dos dados gerados por pedotransferência os trabalhos publicados por Oliveira Junior et al. (1997, 1998a, 1998b, 1999).

A inserção dos dados é feita manualmente no banco de dados do SWAT, através da plataforma ArcSWAT, onde é inserido as informações de todos os parâmetros dentro de uma nova classe com um novo nome. Com isso, o SWAT associará o nome da classe de solo no mapa espacializado com a respectiva tabela de atributos.

Outros parâmetros específicos para culturas e manejo

O SWAT disponibiliza de um amplo banco de dados de parâmetros específicos de diferentes classes de uso e cobertura da terra, o qual fornece todos os parâmetros 
necessários à modelagem. Contudo, alguns parâmetros necessitam de adaptação à região em estudo. Dessa forma, foram selecionados alguns parâmetros fundamentais dos usos relevantes ao estudo para serem alterados dentro do modelo, sendo: coeficiente de rugosidade de Manning ( $\left.\mathrm{OV} \_\mathrm{N}\right)$; altura máxima da copa das árvores (CHTMX), índice máximo de área foliar (BLAl) e profundidade máxima das raízes (RDMX). Para OV_N os valores foram obtidos de McCuen (1998) e Neitsch et al. (2011). Para CHTMX, BLAI e RDMX foram utilizados os dados dos seguintes estudos: Leite et al. (1997), Silva (2006), Silva (2008), Squire e Corley (1987) ${ }^{21}$ apud Punnuri e Singh (2013), Lai (2001), Lubtz (2009), COCK et al. ${ }^{22}$ (1979) apud Aguiar, E. (2003), Alves et al. (2001), Alves Júnior et al. (2010), Otsubo et al. (2012), Silva 1981, Embrapa 2004, Ramalho Filho (2010). Especialmente com relação à categoria "Agricultura Geral", utilizada como um dos usos e cobertura do presente estudo, teve seus parâmetros compostos por média de parâmetros das culturas do milho, feijão, soja e mandioca.

Os parâmetros do componente do modelo SWAT denominado de parâmetros gerais de manejo (Initial Pant Growth paramters), sendo eles o índice de área foliar inicial (LAI_INIT), peso da biomassa seca inicial $(\mathrm{kg} / \mathrm{ha})(\mathrm{BIO} I \mathrm{NIT})$ e o número total de unidades de calor necessários para levar a planta à maturidade (PHU_PLT), foram determinados, também, através de pesquisa bibliográfica e da indicação de especialistas no modelo em trabalho na Texas A \& M University, sob orientação do Dr. Raghavan Srinivasan, e aplicado unicamente às culturas de grande porte e perenes como floresta, palma de óleo e eucalipto.

\footnotetext{
${ }^{21}$ SQUIRE, G. R.; CORLBY, R. H. V. Oil palm. In: Sethuraj, M. R.; Raghavendra, A.S. Tree Crop Physiology. Amsterdam: Elsevier Science, p. 141-167, 1987.

${ }^{22}$ COCK, J. H.; FRANKLIN, D.; SANDOVAL, G.; JURI, P. The ideal cassava planting for maximum yield. Crop Science, v. 19, p. 271-279, 1979.
} 


\subsubsection{Medidas diretas de vazão em campo utilizando o molinete hidrométrico ou correntômetro de hélice.}

As duas sub-bacias em foco deste trabalho não são monitoras, o que nos levou a adotar um trabalho de campo com o objetivo de fazer medições de vazão no final do período chuvoso (Maio) e final do período menos chuvoso (Dezembro) do ano de 2014 para se conhecer a dimensão do comportamento das descargas líquidas e então poder contribuir com a verificação da coerência da regionalização de vazão (próximo tópico) e com a calibração do modelo SWAT.

Para o presente trabalho, utilizou-se o método convencional do molinete hidrométrico ou correntômetro de hélice, universalmente utilizado para medir a vazão em cursos de água naturais e artificiais, consistindo o mesmo em determinar a área da seção em estudo de determinado ponto e a velocidade média do fluxo de água que passa na mesma (ANA, 2014). O molinete é um velocímetro com formato de torpedo, cujo objetivo é medir a velocidade corrente da água em um ponto específico da seção, sendo sua medida expressa em metros por segundo (m/s) (CARVALHO, 2008) (Figura 10). Ele possui uma hélice acoplada na ponta do torpedo, que fica em sentido horizontal, onde cada rotação emite um pulso elétrico que é contabilizado por um contador de rotações (COELHO, 2011) (Figura 10). O contador digital é um componente fundamental do processo de medição, pois é responsável por captar o pulso elétrico do giro da hélice e contabilizar o número total em um determinado intervalo de tempo (BACK, 2006).

Para isso, foram escolhidas duas seções de medição no exutório de cada subbacia (Bujaru e Mariquita). Importante ressaltar que a Sub-bacia do Bujaru, por sofrer influência de maré, pode induzir a medição a alguma sub ou superestimação das medições, as quais serão confrontadas com os resultados da regionalização e da comparação com o balanço hídrico característico da região descrita na literatura. 


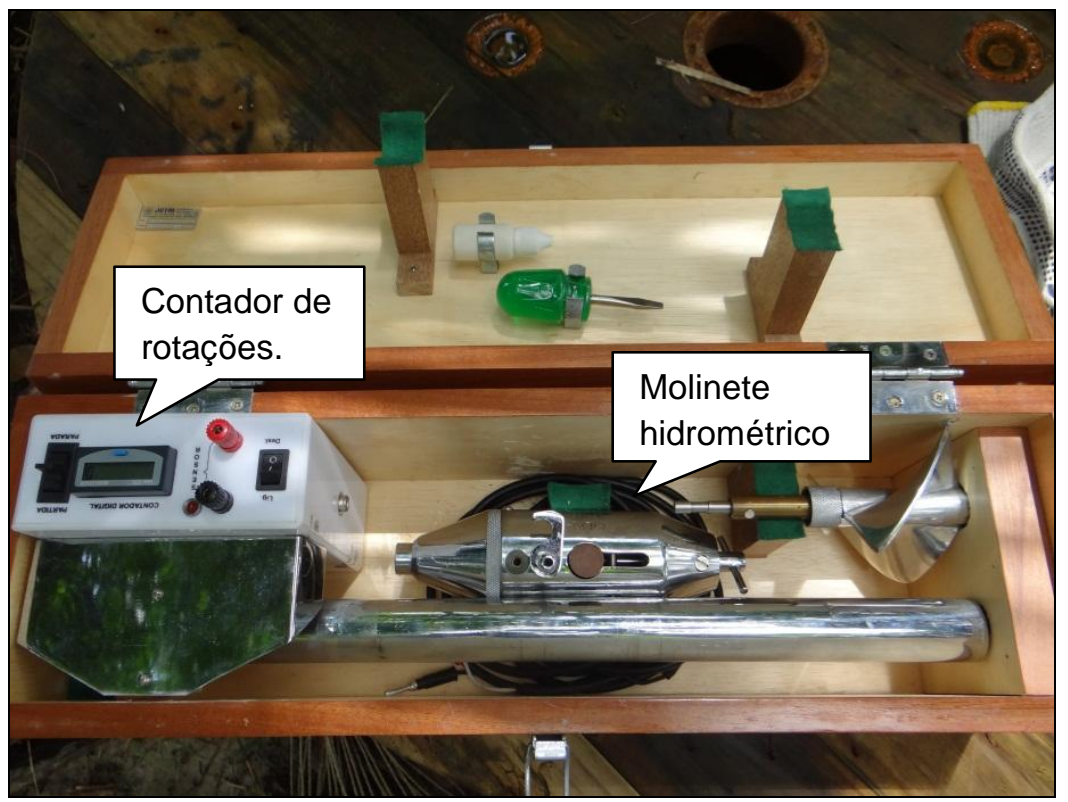

Figura 10: Equipamento de medição da velocidade do fluxo de água que passa por uma sessão do rio.

Para fazer o cálculo da vazão, além da velocidade do fluxo, é necessário se conhecer a largura e medir as profundidades que compõem a seção do rio. Para a medição da largura foi utiliza uma corda, e em seguida, utilizando uma trena para verificar o comprimento da corda em ambas as sub-bacias. A profundidade foi medida utilizando o método do barco ancorado na sub-bacia do rio Bujaru, devido a sua maior largura e profundidade, onde se mediu várias verticais dentro do alinhamento entre um ponto inicial de uma margem $(\mathrm{PI})$ até o ponto final, do outro lado da margem, utilizando uma corda com um peso amarrado na ponta (ANA, 2014). Na sub-bacia do rio Mariquita, utilizou-se o método de medição a vau, onde se caminha dentro do rio com uma haste metálica graduada. Este método, apesar de ser indicado para rios de largura pequena de profundidade inferior a $1 \mathrm{~m}$ e velocidade inferior a $1 \mathrm{~m} / \mathrm{s}$, aplicou-se ao Mariquita que tem profundidade superior a $1 \mathrm{~m}$.

Com o molinete atrelado a uma haste metálica graduada metricamente e conectado ao contador digital de rotações, o molinete foi ajustado para fazer medidas na faixa de $60 \%$ da profundidade de cada perfil, a contar do leito para a superfície do rio. Em cada perfil, o contador registrava o número total de giros da hélice num intervalo de 60 segundos.

O número de rotações por segundo foi calculado através da seguinte equação: 
$N=\frac{n}{i}$

Onde:

$N$ = Número de rotação por segundo;

$n=$ Número de rotações registradas durante intervalo de tempo;

$i=$ Intervalo de tempo de medição da velocidade (s).

O cálculo da velocidade é feito através da equação específica do molinete utilizado no presente estudo, a qual converte o número de rotações em velocidade. Esta equação é fornecida pelo fabricante do equipamento e é calibrada para cada molinete devendo, a mesma, ser aplicada unicamente para o aparelho calibrado (CARVALHO, 2008). A equação de calibração é determinada em laboratório especializado (BACK, 2006), sendo genericamente expressa pela seguinte equação:

$V=a \cdot N+b$

Onde:

$V=$ Velocidade;

$a=$ Passo da hélice;

$b=$ Inércia da hélice;

$N=$ Número de rotação por segundo.

O cálculo final da vazão média na seção em estudo foi realizado através do método da meia seção (Figura 11), o qual é o mais utilizado por entidades operadoras da rede hidrometereológica (ANA, 2014). O método calcula cada perfil através da multiplicação da vazão média na vertical pela área do retângulo, formado a partir da profundidade na vertical e das semidistâncias às verticais adjacentes, ou seja, determina-se a vazão média sobre as áreas de influência de cada vertical. 


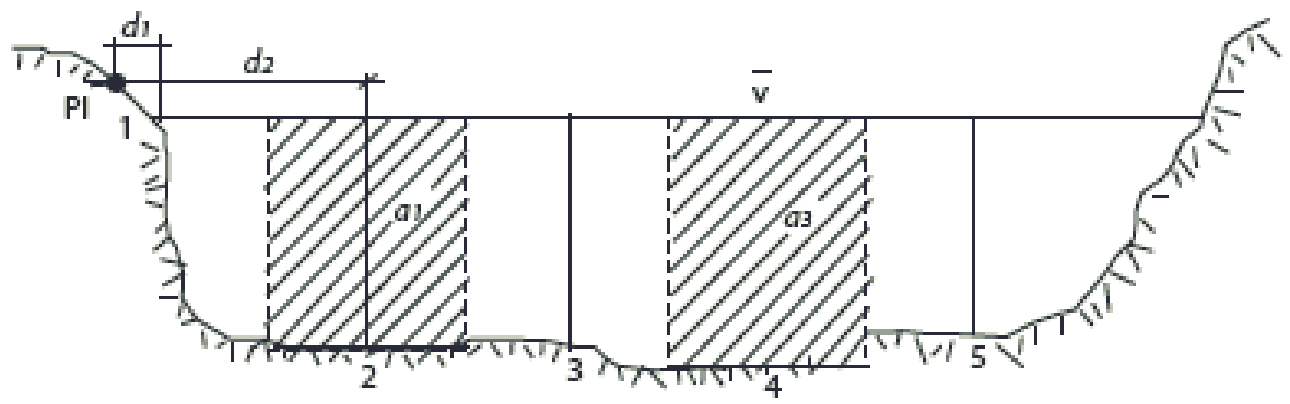

Figura 11: Cálculo da meia seção e verificação da área de influência de cada vertical (Fonte: ANA, 2014).

A equação da vazão parcial é a seguinte:

$q_{i}=v_{i} \cdot h_{i} \cdot\left(\frac{d_{i+1}-d_{i-1}}{2}\right)$

Onde:

$q_{i}=$ Vazão na seção i $\left(\mathrm{m}^{3} / \mathrm{s}\right)$;

$v_{i}=$ Velocidade média na vertical i $(\mathrm{m} / \mathrm{s})$;

$h_{i}=$ Profundidade da vertical $\mathrm{i}(\mathrm{m})$;

$d_{i+1}=$ Distância a partir do PI até a vertical posterior $(\mathrm{m})$;

$d_{i-1}=$ Distância a partir do PI até a vertical anterior $(\mathrm{m})$.

A vazão média é definida por:

$Q=\sum_{i}^{n} q_{i}$

(Eq. 39) 


\subsubsection{Estimativas de vazão através da regionalização de vazão das bacias hidrográficas do complexo Guamá-Capim.}

5.5.4.1 Área de estudo, objetivos e dados disponíveis.

Com o objetivo de estimar uma série de vazões regionalizadas entre os anos de 2006 a 2014 para as sub-bacias não monitoradas dos rios Bujaru e Mariquita, aplicouse o método de regionalização de vazão desenvolvido por Tucci (2002). Primeiramente, aplicou-se a regionalização para estimar a vazão média mensal de longo período, a qual servirá de base para validação do modelo SWAT. Porém, a fim de possibilitar o processo de calibração do modelo SWAT, aplicou-se a técnica de regionalização para cada ano de 2006 a 2014 gerando, assim, uma série regionalizada que foi utilizada diretamente na calibração automática com a ferramenta SWAT-CUP.

Para este estudo de regionalização, foram utilizados como variáveis independentes, os dados de área de drenagem das bacias $\left(\mathrm{km}^{2}\right)$ e precipitações médias $(\mathrm{mm})$ para estimar a variável dependente vazão média. A área de estudo abrange o complexo hidrográfico Guamá-Capim (Figura 12), de onde foram utilizados os dados de 4 estações fluviométricas (Tabela 7), sendo duas na bacia do rio Guamá, abrangendo uma área total de contribuição de $5.005,1 \mathrm{~km}^{2}$, e duas na bacia do rio Capim abrangendo uma área total de contribuição de $33.384,3 \mathrm{~km}^{2}$.

Todas as bacias em estudo na presente tese, Guamá, Capim, Bujaru (Afluente do Guamá) e Mariquita (Afluente do rio Acará-Mirim) estão localizadas na região nordeste do estado do Pará e inseridas na macrorregião hidrográfica brasileira chamada de Tocantins-Araguaia. Para se amenizar o erro inerente à utilização de bacias tão diferentes, inseriu-se 17 estações sintéticas (Tabela 7), as quais representam uma determinada sub-bacia, com o objetivo de melhorar a regressão e permitir, assim, a validação das funções sobre as estações reais (PESSOA et al., 2011; COSTA et al., 2012). Essas sub-bacias foram delineadas utilizando o próprio modelo SWAT e a escolha destas seguiu dois critérios: 1. as sub-bacias deveriam representar 
os diferentes tamanhos de áreas e 2. estarem inseridas na região com características pluviométricas semelhantes as das sub-bacias dos rios Bujaru e Mariquita.

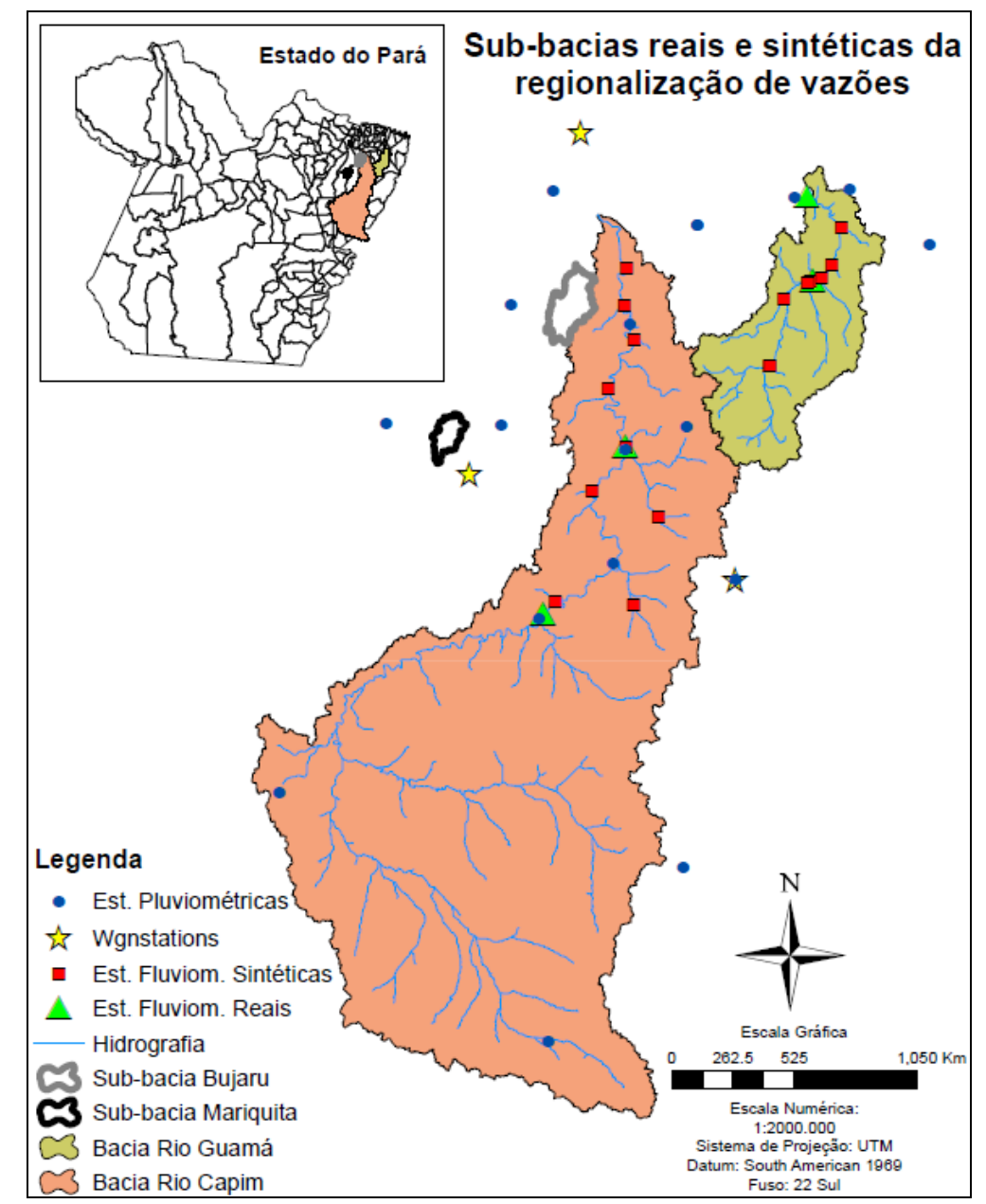

Figura 12: Distribuição das estações reais e sintéticas utilizadas na regionalização de vazão.

Apesar de o presente estudo utilizar parâmetros de bacias tão diferentes em proporções de tamanho quando comparados com as sub-bacias dos rios Bujaru e Mariquita, justifica-se isto por três razões básicas: primeiramente, é o que há disponível na região em termos de dados fluviométricos; em segundo, é que um dos objetivos da tese é discutir instrumentos que auxiliem no planejamento e gestão ambiental da região, tendo como foco as sub-bacias do Bujaru e Mariquita, num contexto de déficit de monitoramento ambiental; e a terceira razão se fundamenta na constatação de que a região apresenta comportamento climático e propriedades geomorfológicas semelhantes em sua maior parte (ver item 5.3). 
Tabela 7: Estações fluviométricas e características morfoclimáticas das bacias utilizadas na regionalização de vazão.

\begin{tabular}{|c|c|c|c|c|c|}
\hline Código & Rio & $\begin{array}{l}\text { Estações reais } \\
\text { e sintéticas }\end{array}$ & $\begin{array}{c}\text { A }(\mathrm{Km} 2) \text { - Área } \\
\text { de drenagem }\end{array}$ & $\begin{array}{c}P(\mathrm{~mm}) \text { - } \\
\text { Precipitaçao } \\
\text { média annual }\end{array}$ & $\begin{array}{c}\text { Extensão da } \\
\text { série } \\
\text { utilizada } \\
\text { (anos) }\end{array}$ \\
\hline 31700000 & Rio Capim & Badajós & 33384.3 & 1819.3 & 2003 a 2014 \\
\hline 31680000 & Rio Capim & $\begin{array}{l}\text { Fazenda } \\
\text { Maringá }\end{array}$ & 26598.3 & 1736.1 & 2003 a 2014 \\
\hline 31520000 & Rio Guamá & Bom Jardim & 5005.1 & 2235.4 & 2003 a 2014 \\
\hline 31490000 & Rio Guamá & Vila Capoeira & 3448.0 & 2255.4 & 2003 a 2014 \\
\hline Sintética & Rio Palheta & ESC-2-2 & 173.4 & 2275.1 & 2003 a 2014 \\
\hline Sintética & Rio Pirajoara & ESC-6-2 & 425.1 & 2278.1 & 2003 a 2014 \\
\hline Sintética & Rio Caratateua & ESC-8-2 & 243.5 & 2277.9 & 2003 a 2014 \\
\hline Sintética & Rio Maracaxi & ESC-12-2 & 455.6 & 2253.0 & 2003 a 2014 \\
\hline Sintética & Rio Candiru-Miri & ESC-15-2 & 422.2 & 2297.4 & 2003 a 2014 \\
\hline Sintética & $\begin{array}{l}\text { Ig. Amanaí ou } \\
\text { Goiabal }\end{array}$ & ESC-24-2 & 199.8 & 2191.5 & 2003 a 2014 \\
\hline Sintética & Não Identificado & ESC-27-2 & 294.0 & 2531.9 & 2003 a 2014 \\
\hline Sintética & $\begin{array}{c}\text { Rio Caratauá- } \\
\text { açu }\end{array}$ & ESC-36-2 & 243.8 & 1649.7 & 2003 a 2014 \\
\hline Sintética & Rio Potiritá & ESC-49-2 & 489.5 & 2327.4 & 2003 a 2014 \\
\hline Sintética & Rio Sujo & ESG-5-1 & 423.3 & 2074.7 & 2003 a 2014 \\
\hline Sintética & Igarapé lacaiacá & ESG-6-1 & 346.6 & 2259.5 & 2003 a 2014 \\
\hline Sintética & Não Identificado & ESG-7-1 & 563.8 & 2191.6 & 2003 a 2014 \\
\hline Sintética & Rio Jacamim & ESG-9-1 & 720.3 & 2276.0 & 2003 a 2014 \\
\hline Sintética & Rio Guamá & ESG-10-1 & 913.3 & 2276.0 & 2003 a 2014 \\
\hline Sintética & Não Identificado & ESG-10-2 & 224.7 & 2185.4 & 2003 a 2014 \\
\hline Sintética & Não Identificado & ESG-17-2 & 109.8 & 2154.2 & 2003 a 2014 \\
\hline Sintética & Induá & ESG-21-2 & 203.0 & 2241.8 & 2003 a 2014 \\
\hline
\end{tabular}

De acordo com a divisão hidrográfica do estado do Pará (PARÁ, 2012), a qual discretiza 7 macrorregiões conforme a homogeneidade de suas características geofisiográficas (geomorfologia, geologia, hidrografia, solos e fator hidroclimático), sendo elas denominadas de Costa Atlântica-Nordeste, Tocantins-Araguaia, Xingu, Portel-Marajó, Tapajós, Baixo Amazonas e Calha Norte, as sub-bacias em estudos estão todas inseridas dentro da mesma macrorregião hidrográfica Costa AtlânticaNordeste. A região apresenta também características semelhantes quanto ao uso e cobertura do solo, apresentando elevada fragmentação de áreas de remanescente florestal, pastagem, agricultura geral, vegetação secundária e plantios perenes como palma de óleo (dendê), eucalipto, mogno, teca, entre outras culturas. 
A vazão média de longo período é definida como a média das vazões médias diárias anuais. Esta variável permite quantificar, preliminarmente, o recurso hídrico disponível da bacia e é a máxima vazão possível de ser regularizada, abstraindo-se as perdas por evaporação e infiltração. A vazão média é resultado da precipitação na bacia, das condições de evaporação, cobertura do solo e do tamanho da bacia. A experiência hidrológica tem mostrado que a área de drenagem é o fator de maior peso no cálculo da vazão média (TUCCI, 2002). Por essa razão, as variáveis utilizadas foram precipitação e área das bacias, por serem também as mais comumente utilizadas.

5.5.4.2 Equações básicas de regressão.

A função matemática que relaciona a variável dependente y com as variáveis independentes $x i$, para $i=1,2,3 \ldots n$ pode ser linear:

$$
y=a_{1} \cdot x_{1}+a_{2} \cdot x_{2}+\cdots a_{n} \cdot x_{n}+b
$$

Quando $n=1$ a equação é dita linear simples, já que tem somente uma variável independente. Quando $n>1$ é dita linear múltipla. Quando a função matemática é não linear, procura-se, por um artifício, transformar esta equação numa expressão linear. Uma das funções usadas normalmente em hidrologia tem a seguinte forma:

$$
y=C x_{1}^{a 1} \cdot x_{2}^{a 2} \cdots x_{n}^{a n}
$$

Onde C, a1, a2, ....an são parâmetros. Transformando a equação por logarítmicos fica:

$$
\ln y=\ln C+a_{1} \cdot \ln x_{1}+a_{2} \cdot \ln x_{2}+\cdots+a_{n} \cdot \ln x_{n}
$$


Esta equação é semelhante a Eq. 40, onde os termos em logaritmo são transformados em:

$$
z=a_{1} \cdot w_{1}+a_{2} \cdot w_{2}+\cdots+a_{n} \cdot w_{n}+b
$$

Onde:

$$
\begin{aligned}
& z=\ln \mathrm{y} ; \\
& w_{i}=\ln \mathrm{x}_{\mathrm{i}} .
\end{aligned}
$$

Como a equação de regressão original é não linear, o erro padrão, calculado para a expressão linearizada pelo operador logarítmico, refere-se aos logarítmicos da variável dependente, havendo necessidade de se estabelecer uma expressão para o intervalo de variação da estimativa da vazão e não para o seu logaritmo. Para isso, utiliza-se o erro padrão fatorial que é dado por:

$$
\delta_{f}=e^{s}
$$

Onde s é o erro padrão dos logarítmicos de y. Desta forma, o intervalo de um desvio padrão com relação ao valor estimado fica:

$$
\frac{\bar{y}}{\delta_{\mathrm{f}}} \leq \overline{\mathrm{y}} \leq \overline{\mathrm{y}} \delta_{\mathrm{f}}
$$

O coeficiente de determinação não tendencioso é o seguinte:

$$
R^{2}=1-\frac{s^{2}}{s_{y}^{2}}
$$




\subsubsection{Análise da variância - ANOVA.}

Através da análise de variância é possível avaliar a correlação entre cada variável independente $e$ as possíveis combinações das demais variáveis independentes, ampliando o estudo da colinearidade. O resultado apresentado conterá os maiores coeficientes de correlação encontrados para cada variável, bem como a combinação das demais variáveis independentes que gerou tal correlação.

O resultado da regressão linear múltipla contém a análise da variância e outras opções, sendo:

1. gl: graus de liberdade;

2. SQ: soma quadrática;

3. MQ: variância quadrática média (Eq. 47);

$$
M Q=S Q / g l
$$

4. F: estatística F;

$$
F=M Q \text { regressão/MQerro }
$$

5. p: probabilidade de significância para $F$ ou para a equação de regressão múltipla linear como um todo. Utiliza a função da distribuição $F$ do Microsoft Excel para retornar os valores de probabilidade de significância. 
5.5.4.4 Procedimentos com os dados e construção de equações:

\section{A) Dados pluviométricos}

Foram utilizadas efetivamente 13 estações pluviométricas (Figura 13 e Tabela 6). As falhas nas séries diárias dos dados de precipitação foram preenchidas através da média diária interanual por estação. Em seguida, foi calculado o acumulado mensal por estação para os anos de 2003 a 2014. A precipitação média de cada mês que representou cada bacia, seja real ou sintética, foi calculada utilizando o método do polígono de Thiessen, tendo como ferramenta o software ArcGis 10.3 (Figura 13) para traçar os polígonos de Thiessen, conforme equação a seguir:

$$
P=\frac{\sum\left(A_{i} \cdot P_{i}\right)}{A}
$$

Onde:

$A_{i}$ é área de influência da estação pluviométrica i;

$P_{i}$ é precipitação registrada na estação pluviométrica i;

$A$ é área total da bacia.

\section{B) Dados de Vazão}

Utilizou-se séries de dados de vazão de 2003 a 2014 de 4 estações fluviométricas reais. A partir destes dados foram criadas 17 estações sintéticas (Tabela 7).

$$
Q_{1}=\frac{A_{1}}{A_{2}} \cdot Q_{2}
$$

A1 - área de drenagem do local do aproveitamento, em $\mathrm{km}^{2}$; 
A2 - área de drenagem do posto existente, em $\mathrm{km}^{2}$;

Q1 - vazão do local do aproveitamento, em $\mathrm{m}^{3} / \mathrm{s}$;

Q2 - vazão do posto existente, em $\mathrm{m}^{3} / \mathrm{s}$.

Quanto às séries mensais de 2003 a 2014 das estações sintéticas, estas foram elaboradas exclusivamente pelo método da correlação direta utilizando apenas a vazão específica relativa à média entre as vazões específicas das estações Bom Jardim e Capoeira (rio Guamá), uma vez que todas as estações pluviométricas que influenciam as estações sintéticas apresentam comportamento qualitativo e quantitativo semelhantes a região destas duas estações reais.

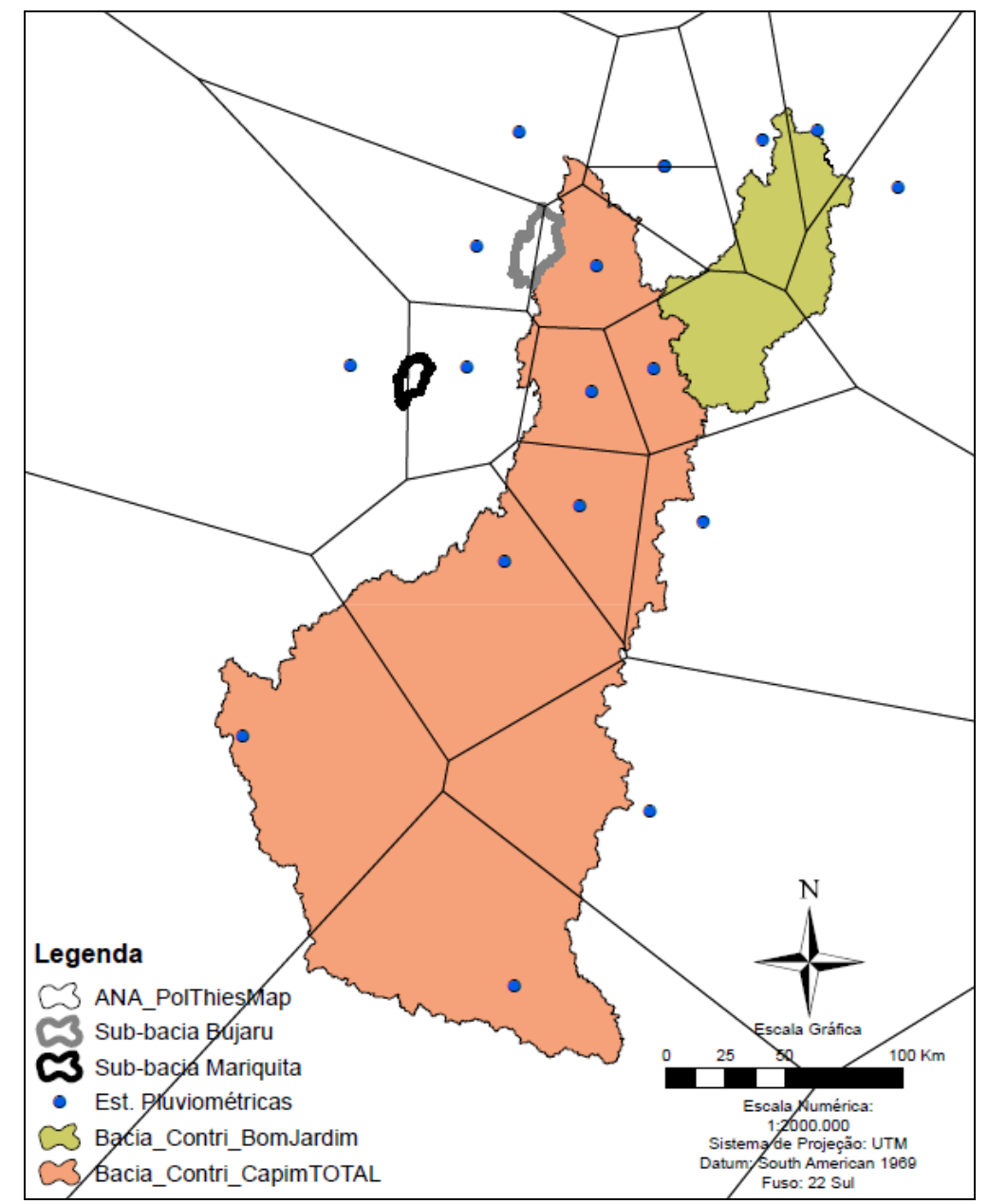

Figura 13: Distribuição dos polígonos de Thiessen e das estações utilizadas na regionalização de vazão. 
C) Cálculo e verificação do acerto da vazão média de longo período (QMMLP)

Com as variáveis independentes (precipitação e área das bacias) organizadas, aplicou-se a regressão não linear proposta por Tucci (2002), primeiramente para estimar a QMMLP. O procedimento foi realizado de maneira alternada com 3 estações reais e as 17 sintéticas, ou seja, fez-se a regressão utilizando a estação Badajós, Maringá e Jardim, sem a estação Capoeira, por exemplo, em conjunto com todas as 17 sintéticas, com o intuito de verificar o acerto da equação gerada sobre a estação real não incluída, que no exemplo é a estação Capoeira. O passo foi repetido para todas as estações reais seguindo este método para evitar colinearidade e estimativas tendenciosas. A verificação do acerto foi feita através dos métodos do Coeficiente de Nash-Sutcliffe (NSE), coeficiente de determinação $\left(R^{2}\right)$, a razão entre a raiz quadrada da média com o desvio padrão dos dados observados (RSR) e o percentual de tendências (PBIAS), descritos no item 5.5.7 explicado nas páginas seguintes.

Após a validação e verificação da capacidade de geração de estimativas no mínimo satisfatórias, segundo a estatística aplicada, em relação à média mensal de longo período das 4 estações reais, o método de regionalização aqui em estudo foi aplicado com o objetivo de gerar séries de 2006 a 2014. Para isso, foi feito o cálculo de regionalização de vazão para cada ano, da mesma forma como foi feita com a QMMLP.

Por fim, a relação testada neste estudo tem a seguinte forma:

$$
Q=a \cdot A^{b} \cdot P^{c}
$$

Sendo posteriormente logaritmizada e obtendo a seguinte forma:

$$
\ln Q=\ln a+b \cdot \ln A+c \cdot \ln P
$$

Onde:

$Q=$ é a vazão média de longo período $\left(\mathrm{m}^{3} / \mathrm{s}\right)$;

$A=$ é área das bacias $\left(\mathrm{km}^{2}\right)$;

$P=$ é a precipitação média $(\mathrm{mm})$; 
$a, b$ e $c=$ são parâmetros a serem ajustados.

\subsubsection{Análise de sensibilidade, calibração e validação.}

Foram realizadas etapas de análise de sensibilidade, calibração e validação do modelo com o objetivo de ajustar as curvas de vazão para as bacias em estudo. Esse processo é importante, uma vez que o modelo SWAT utiliza uma ampla variedade de parâmetros para descrever fisicamente os processos que muitas vezes não respondem e não condizem com o comportamento da Bacia, sendo fundamental a parametrização do modelo de acordo com a realidade do sistema (CHRISTOFOLETTI, 1999; ARNOLD et al., 2012).

A partir do exposto, vê-se a necessidade de identificar técnicas de calibração, bem como mecanismos para buscar resultados mais robustos quanto à comparação do resultado observado com o simulado. Arnold et al. (2012) coloca que os parâmetros de entrada do modelo SWAT são fundamentados em processos e devem representar a realidade do sistema através dos ranges (intervalos) dos parâmetros, o que conduzirá ao usuário a buscar conhecimentos de sua bacia, a opinião de profissionais da área, bem como a utilização de uma análise de sensibilidade para definir parâmetros e ranges a serem aplicados no processo de calibração. Isso mostra ainda mais que a calibração é uma etapa importante, pois auxilia o modelo a fazer predições mais adequadas, tendo este processo, como objetivo, estabelecer parâmetros adequados de entrada no modelo e internalizar as condições ambientais do sistema (CHRISTOFOLETTI, 1999).

A calibração do modelo é possível com alguns mecanismos: 1. o usuário insere diretamente valores de parâmetros no modelo, de acordo com o componente que necessita de mudança e o seu processo correlacionado; 2 . ou utiliza algoritmos que auxiliam na escolha dos melhores valores para cada parâmetro. Arnold et al. (2012) classifica essas técnicas como calibração manual, autocalibração direta pelo modelo SWAT (não disponibilizada na versão 2012 do SWAT) e o uso do SWAT-CUP, que é 
um software com alguns algoritmos voltados para a realização de análise de sensibilidade, calibração, validação e análise de incertezas (ABBASPOUR et al., 2014).

No presente trabalho, utilizou-se o software SWAT-CUP, o qual está disponível para download no site do SWAT (http://swat.tamu.edu/software/swat-cup/), sendo o mesmo de livre acesso e manipulação com possibilidade do usuário modificar o sistema caso queira, pois possui código aberto. O programa é amplamente utilizado por usuários do modelo SWAT para a realização de análise de sensibilidade, calibração, validação e análise de incertezas, sendo seus procedimentos dirigidos por quatro tipos de algoritmos a serem usados de acordo com a necessidade do usuário: GLUE61 (Generalized Likelihood Uncertainty Estimation), ParaSol (Parameter Solution), SUFI2 (Sequential Uncetainty Fitting) e MCMC (Markov Chain Monte Carlo) (ABBASPOUR etal., 2014).

A calibração neste trabalho foi aplicada apenas aos resultados de vazão, uma vez que não há dados de produção de sedimentos disponíveis. Foram utilizados os dados da série regionalizada de vazão calculada para os anos de 2006 a 2014 para a calibração das bacias não monitoradas dos rios Bujaru e Mariquita. Inicialmente, foi aplicada a estratégia de verificar o comportamento das bacias, fundamentado nas suas características geomorfológicas e de paisagem, bem como comparando o comportamento da curva de vazão inicial simulada pelo SWAT e a curva de vazão regionalizada, em conjunto com a orientação de experts no assunto e na revisão de literatura aplicada conforme os trabalhos de Arnold et al. (2012), Abbaspour et al. (2015), Daggupati (2015, no prelo) e Bressiani et al. (2016, no prelo), com o objetivo de definir parâmetros e rangers iniciais de calibração.

Em seguida, foi aplicado o SWAT-CUP para fazer a análise de sensibilidade do modelo através do algoritmo Sequential Uncertainty Fitting (SUFI-2) (ABBASPOUR et al., 2004), o qual possibilita fazer análises de sensibilidade de maneira global e individual, sendo a global realizada após uma interação completa e a individual feita para cada parâmetro em separado (ABBASPOUR, 2014). No presente trabalho, utilizou-se apenas a análise global de sensibilidade dos parâmetros, cujo método determina a sensibilidade através de um sistema de regressões múltiplas sobre os parâmetros gerados pelo método de amostragem "Latin Hypercube" (do Latino 
Hipercúbico). A significância relativa de cada parâmetro analisado é determinada pelo test-t, onde sua influência ou sensibilidade é definida a partir das mudanças na função objetivo escolhida pelo usuário, em conjunto com a análise do $p$-value, para verificar se a hipótese nula pode ser rejeitada (ABBASPOUR etal., 2014). De modo geral, quanto maior o valor do test-t, maior é a sensibilidade do parâmetro em influenciar na mudança da função objetivo, e quanto mais próximo de zero for o $p$-value, maior a significância do parâmetro. Por fim, de maneira geral, a união entre os resultados da análise de sensibilidade, o conhecimento da região e as orientações de especialistas no assunto foram os critérios de definição dos parâmetros finais da calibração.

O modelo apresenta incertezas em suas simulações, as quais são de complexa identificação, uma vez que estas incertezas estão inseridas nas variáveis independentes de entrada, na quantificação do acerto do modelo simulado, no modelo conceitual, nos parâmetros e nos dados medidos em campo. Estas incertezas são representadas pela faixa de incertezas na predição a 95\% de probabilidade (95PPU). Assim, o acerto do modelo é verificado com a adoção das duas análises estatísticas: Pfactor, que indica a porcentagem de dados observados dentro da faixa 95PPU; e Rfactor, que indica a espessura da faixa 95PPU, variando de 0 a $+\infty$. Para o P-Factor é sugerido valores maiores que $70 \%$ e para R-factor valores em torno de 1 .

\subsubsection{Transferência dos parâmetros calibrados da modelagem da porção média da bacia do rio Capim.}

O trabalho aplicou, como teste, o mecanismo de modelar, calibrar e validar a porção média da bacia do rio Capim (Figura 14), um dos rios principais da bacia Guamá-Capim, e então fazer a transferência de parâmetros calibrados desta bacia para as sub-bacias do rios Bujaru e Mariquita. A escolha apenas da porção média, que apresenta uma área de contribuição de aproximadamente $6.786 \mathrm{~km}^{2}$, no presente estudo, está ligada à proximidade dessa área e de sua semelhança quanto às propriedades climáticas, de paisagem e geomorfológicas com relação às sub-bacias 
dos rios Bujaru e Mariquita. Este mecanismo é utilizado por usuários do SWAT para calibrar bacias não instrumentadas utilizando parâmetros calibrados de outras bacias que apresentem caraterísticas climáticas, de solo e de uso semelhantes (ARNOLD et al., 2012).

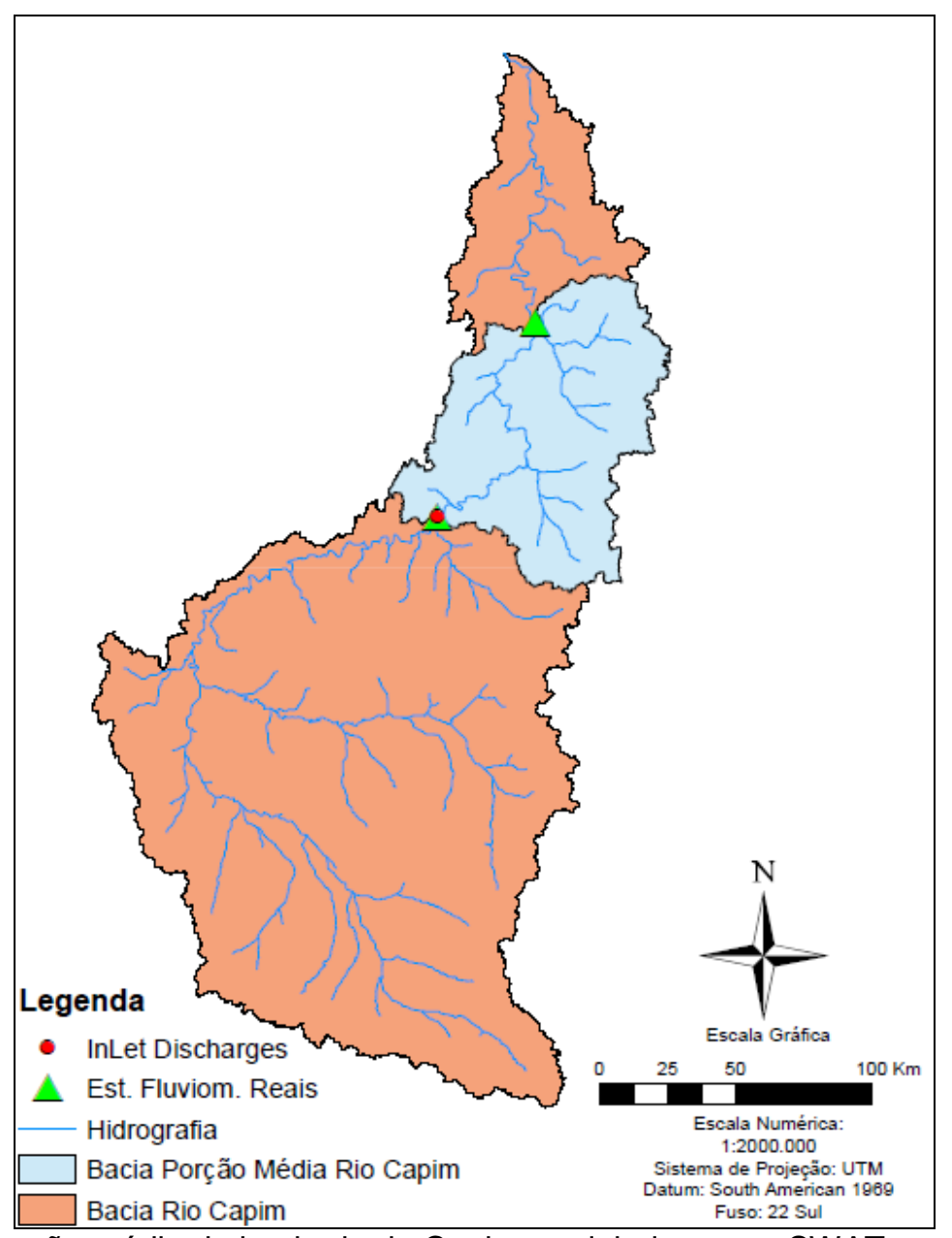

Figura 14: Área da porção média da bacia do rio Capim modelada com o SWAT.

Aplicaram-se os mesmos parâmetros considerados mais sensíveis utilizados nas sub-bacias dos rios Bujaru e Mariquita e seus respectivos rangeres. Inicialmente, não se levou em consideração a análise de sensibilidade, pois a intenção foi calibrar e validar a bacia da porção média do rio Capim com os mesmos parâmetros utilizados nas sub-bacias em estudo. Após a calibração e validação do modelo para o médio rio Capim, foi feita a transferência dos parâmetros calibrados para as sub-bacias dos rios Bujaru e Mariquita. O passo seguinte foi comparar os resultados entre os valores dos 
parâmetros calibrados e das curvas calibradas de vazão entre os métodos de calibração e validação utilizando a regressão não linear da regionalização de vazão como base de calibração em relação à transferência de parâmetros calibrados do rio Capim. Abaixo segue a descrição sintética dos dados de entrada do modelo para a porção média do rio Capim.

5.5.6.1 Os planos de informação.

MNT - Utilizou-se 10 cartas do SRTM: SA-22-X-D / SA-22-Z-B / SA-22-Z-D / SA23-V-C / SA-23-Y-A / SA-23-Y-C / SB-22-X-B / SB-22-X-D / SB-23-V-A / SB-23-V-C.

Uso e cobertura da terra - Utilizou-se o mapeamento do TerraClass 2010, pois apresentou menor área coberta por nuvens.

Tipos de solo - o mapeamento de solo é o do ZEE-PA, contendo os seguintes tipos de solo: GLEISSOLO HÁPLICO Distrófico (GXbd), LATOSSOLO AMARELO Distrófico (LAd), ARGISSOLO VERMELHO-AMARELO Distrófico (PVAd) e PLINTOSSOLO PÉTRICO Concrecionário (FFC).

\subsubsection{Os dados tabulares.}

A pesquisa, formatação e tabulação dos dados de clima, solo, vegetação e manejo seguiram os mesmos procedimentos explicados anteriormente no item 5.5.2. Neste modelo foram utilizados 5 estações pluviométricas (Tabela 6) e duas estações fluviométricas (Tebela 7). 
5.5.6.3 Procedimentos específicos.

Para modelar a porção média do rio Capim, foi inserido um InLet Discharges na estação de monitoramento fluviométrico Fazenda Maringá (31680000) (Figura 14). A parte média do rio Capim compreende a área de contribuição entre as estações Fazenda Maringá e Badajós (31700000), excluindo a porção a montante da bacia. Dessa forma, foi necessário inserir os dados diários de vazão em $\mathrm{m}^{3} /$ dia no Inlet da estação Fazenda Maringá. As medidas reais de vazão da estação Badajós foram utilizadas na calibração e validação, sendo utilizada uma série de 15 anos de dados fluviométricos (2000 a 2014).

A decisão de se utilizar a condição inicial no InLet é fundamental, pois isto fornece as condições iniciais do sistema em estudo, no caso a bacia do rio Capim. Os sistemas complexos são governados/representados por equações diferenciais parciais não lineares. A solução de equações diferenciais parciais não lineares não é única. As soluções dependem de dois fatores, que são as condições iniciais do problema e as condições de contorno do problema. Portanto, definido as condições de contorno do problema, resta informar as condições iniciais do problema para a devida solução (BUTKOV, 1973), que no caso é representado pela inserção do InLet Discharges.

\subsubsection{Avaliação da eficiência.}

A avaliação da eficiência do acerto das estimativas de vazão geradas pelo modelo SWAT foram determinadas através de 4 critérios estatísticos: coeficiente de Nash-Sutcliffe (NSE) (Eq. 53), coeficiente de determinação $\left(R^{2}\right)$ (Eq. 54), a razão entre a raiz quadrada da média com o desvio padrão dos dados observados (RSR) (Eq. 55) e o percentual de tendências (PBIAS) (Eq. 56) (LAPPONI, 2005; MORIASI et al., 2007; GUPTA et al., 2008; STRAUCH et al., 2012; BRESSIANI et al., 2015a). 


$$
\begin{aligned}
& N S E=1-\frac{\sum_{i=1}^{n}\left(o_{i}-S_{i}\right)^{2}}{\sum_{i=1}^{n}\left(o_{i}-o_{m e d}\right)^{2}} \\
& R^{2}=\left(\frac{\left(\sum_{i=1}^{n}\left(o_{i}-o_{\text {med }}\right) \cdot\left(S_{i}-S_{\text {med }}\right)\right)^{2}}{\sum_{i=1}^{n}\left(o_{i}-O_{\text {med }}\right)^{2} \cdot \sum_{i=1}^{n}\left(S_{i}-S_{\text {med }}\right)^{2}}\right) \\
& R S R=\frac{R M S E}{S T D E V_{o b s}}=\frac{\left[\sqrt{\sum_{i=1}^{n}\left(o_{i}-S_{i}\right)^{2}}\right]}{\left[\sqrt{\sum_{i=1}^{n}\left(o_{i}-o_{\text {med }}\right)^{2}}\right]} \\
& P B I A S=\frac{\sum_{i=1}^{n}\left(o_{i}-S_{i}\right)}{\sum_{i=1}^{n} o_{i}} \cdot 100 \%
\end{aligned}
$$

Onde:

$O_{i}=$ Dados observados num tempo $i$

$S_{i}=$ Dados simulados num tempo $i$

$\mathrm{O}_{\text {med }}=$ Média observada;

$\mathrm{S}_{\mathrm{med}}=$ Média simulada;

O NSE varia de $-\infty$ a 1 , sendo que quanto mais próximo de 1 , o evento simulado está mais próximo do observado (MORIASI et al., 2007). O $\mathrm{R}^{2}$ é um número positivo entre 0 e 1, sendo que quanto mais próximo de 1, melhor é a resposta da reta de regressão (LAPPONI, 2005). Tanto para o RSR e PBIAS, valores próximos de zero são ideais.

Todas as avaliações de acerto foram feitas para simulações mensais. A verificação da qualidade do resultado destas análises estatísticas foi baseada nos critérios definidos por Moriasi et al. (2007). As estatísticas foram aplicadas tanto na calibração como na validação. 


\subsubsection{Simulações hidrológicas por períodos e cenário.}

O foco das simulações foi aplicar o modelo SWAT para identificar a relação entre cenários diferentes de uso e cobertura do solo sobre o escoamento superficial e produção de sedimentos. Mas para tanto, as simulações objetivaram, especificamente, quantificar a vazão em ambos os cenários através dos modelos calibrados. Após essa etapa, fizeram-se as análises dos resultados de escoamento e produção de sedimentos.

Foram estudadas as modelagens de três mapas de uso e cobertura da terra, sendo: 1. para o ano de 2008 (TerraClass), 2. para ano de 2013 (classificação LandSat) e 3. para o cenário futuro de 2023 (simulação CLUE-S). A calibração foi aplicada apenas no ano de 2008 e os parâmetros calibrados foram replicados no modelo de 2013 e no cenário de 2023. O período de calibração foi de 2006 a 2010 e a validação de 2011 a 2014. Para isso, foram definidos 3 experimentos, onde em ambos foi feita a verificação do balanço hídrico, verificação estatística, e análise de resultados em escala mensal.

\subsubsection{Experimento 1.}

Nesta primeira etapa, o modelo foi abastecido com informações de clima, solo, relevo, vegetação e manejo reais das bacias em estudo, com a modificação de alguns parâmetros básicos, conforme explicados anteriormente. Porém, a grande maioria dos parâmetros foi mantida na opção de default. Então, o modelo foi rodado e, em seguida, foi aplicada a verificação estatística para analisar o comportamento inicial do modelo quanto às estimativas de vazão. Neste experimento, foi testado também qual dos dois métodos de evapotranspiração, Penman-Monteith ou Priestley-Taylor, foram mais eficientes na simulação da evapotranspiração na região em estudo. $O$ ano base desse primeiro experimento foi 2008. 


\subsubsection{Experimento 2.}

Nesta etapa foi feita a análise de sensibilidade, calibração e validação da modelagem para o mapa de uso e cobertura da terra do ano de 2008 , tendo como ferramenta de suporte a software SWAT-CUP. Este experimento objetivou trabalhar no melhoramento das simulações, buscando reduzir o volume escoado; aumentar a evapotranspiração e a infiltração; aumentar a perda de água para o aquífero profundo e aumentar a curva de recessão, por exemplo. Buscou-se também obter um valor do coeficiente de eficiência de Nash-Sutcliffe igual ou superior a 0,5 como critério base de qualidade da calibração, mas sem afetar as características gerais do balanço hídrico da região. A calibração aqui foi feita tendo como base a vazão regionalizada para as subbacias não monitoradas dos rios Bujaru e Mariquita, bem como a transferência dos parâmetros calibrados das simulações da porção média do Rio Capim. Por fim, os parâmetros calibrados do modelo do ano de 2008 foram aplicados na calibração dos modelos de 2013 e 2023.

\subsubsection{Experimento 3.}

Nesta fase de conclusão, os modelos calibrados para os anos de 2008 e 2013, assim como para o cenário futuro de 2023 gerado pelo modelo CLUE-S, foram aplicados para estimar o escoamento superficial e produção de sedimentos nas subbacias não monitoradas dos rios Bujaru e Mariquita. 


\subsection{MODELAGEM DINÂMICA DE MUDANÇA DE USO E COBERTURA DA TERRA UTILIZANDO O MODELO CLUE-S.}

\subsubsection{Componentes do modelo CLUE-S.}

Tendo como base fundamental teórica e metodológica os trabalhos de Verburg et al. (2002), Verburg; Veldkamp (2004); Verburg et al. (2002), Verburg e Overmars (2007), Valência (2008), Verburg (2010), Galharte (2011) e Pereira (2013), a seguir é descrita de maneira sintética a estrutura do modelo CLUE-S.

O modelo CLUE-S é subdividido em dois módulos distintos: um módulo não espacial de demanda e um módulo de alocação espacialmente explícita (Figura 15). O módulo não espacial calcula a variação de área para todos os tipos de uso da terra no nível agregado, onde um aumento em determinada área implicará na redução de área de outro uso. No módulo espacial, essas demandas determinam as mudanças de uso e cobertura da terra em diferentes locais dentro da região de estudo, através da utilização de um sistema de formatação de dados em raster (modelo matricial).

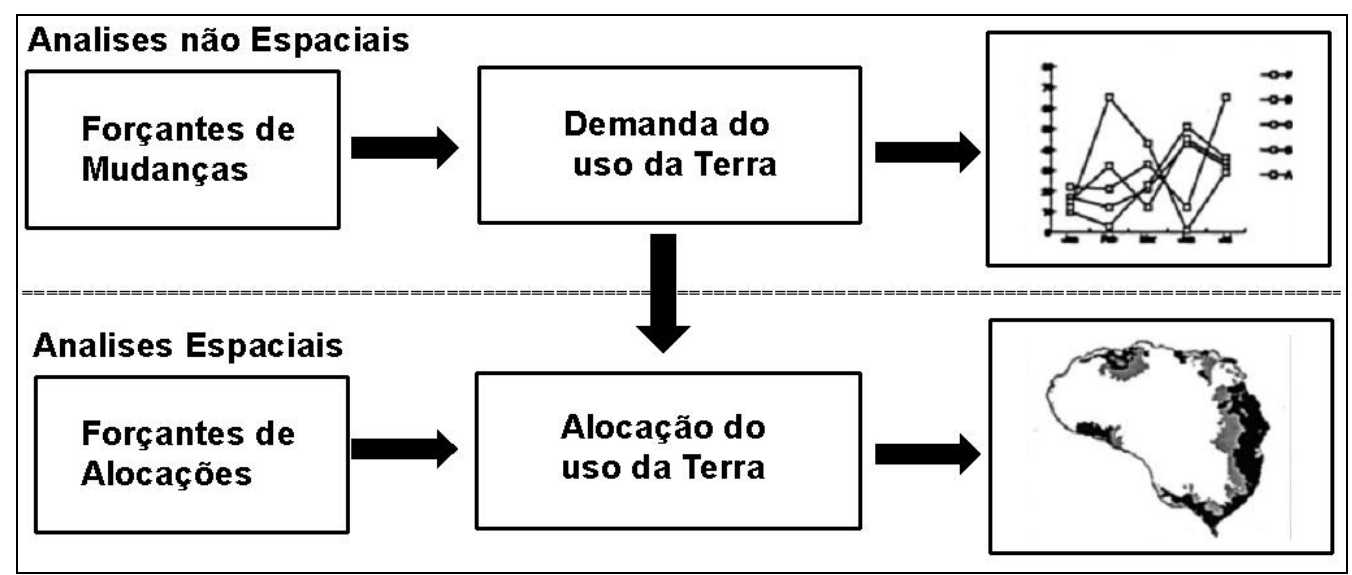

Figura 15: Procedimento de análise da dinâmica espacial através do CLUE-S (Fonte: adaptado de Verburg et al., 2010).

Nos processos de simulação, fundamentados nos componentes não espaciais e espaciais, o CLUE-S possui quatro subcomponentes necessários ao seu 
funcionamento: a) políticas e restrições de uso do espaço; b) parâmetros específicos de conversão; c) demanda de uso da terra; e d) características da área de estudo (Figura 16).

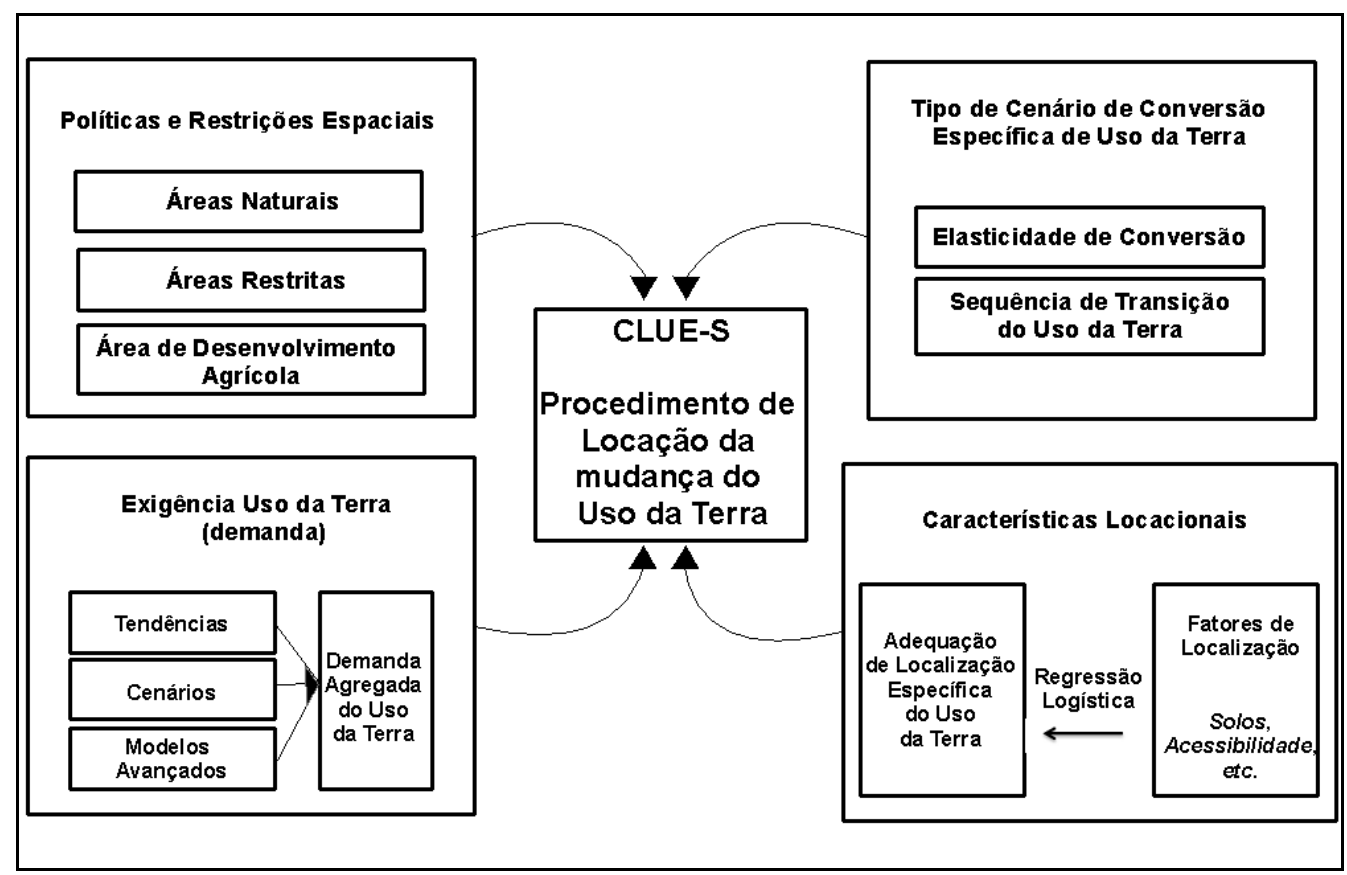

Figura 16: Visão geral do fluxo de informações dentro do modelo CLUE-S (Fonte: adaptado de Verburg et al., 2010).

5.6.1.1 Políticas e restrições de uso do espaço.

São parâmetros relevantes, pois além de influenciar os mecanismos e padrões de alteração da paisagem, são fortes limitadores legais de mudanças de usos e cobertura da terra nas suas regiões de influência. Nas simulações com o CLUE-S é necessário a elaboração de mapas que identifiquem essas áreas, sendo possível também representar as restrições de conversões de uso totais ou parciais no tempo através da matriz de conversão de uso. 
5.6.1.2 Parâmetros específicos de conversão.

São caracterizados pelos seguintes parâmetros: elasticidade de conversão e sequências de transição de uso e cobertura da terra, os quais influenciam na dinâmica temporal de mudança entres as classes de uso e cobertura do estudo.

A elasticidade de conversão de um determinado uso "u" é representado pelo parâmetro ELAS ${ }_{u}$, podendo assumir ou valor 0 , implicando numa maior possibilidade de conversão; ou o valor $0<$ ELASu $<1$, onde se tem um nível intermediário da elasticidade; ou o valor 1 , representando a impossibilidade de conversão.

A sequência de transição (Figura 17) dentro do modelo é representada pela Matriz de Conversão. Na matriz, o valor 1 indica que a conversão entre as clases é possível, e 0 indica a impossibilidade de conversão. É possível, ainda, na matriz de conversão, se inserir o máximo e o mínimo período de tempo que determinada classe deve permanecer sem mudança (Figura 18).

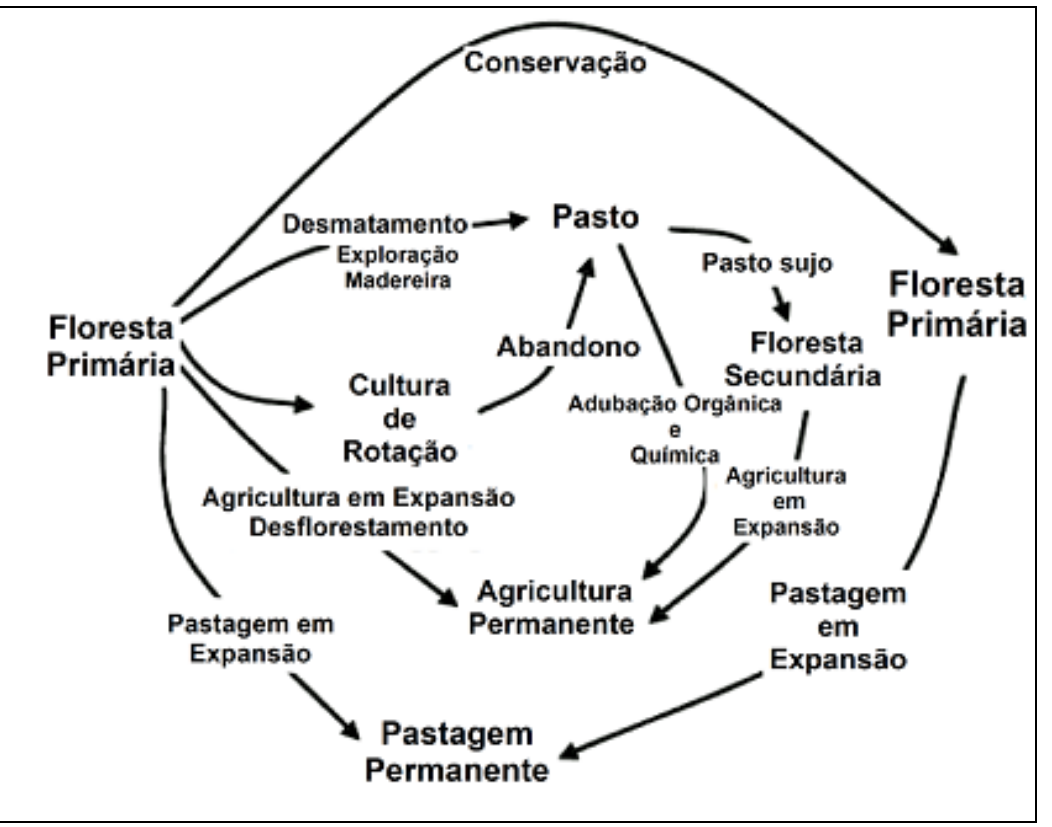

Figura 17: llustração de uma transição hipotética de mudança de uso e cobertura do solo (Fonte: adaptado de Soler, 2010). 


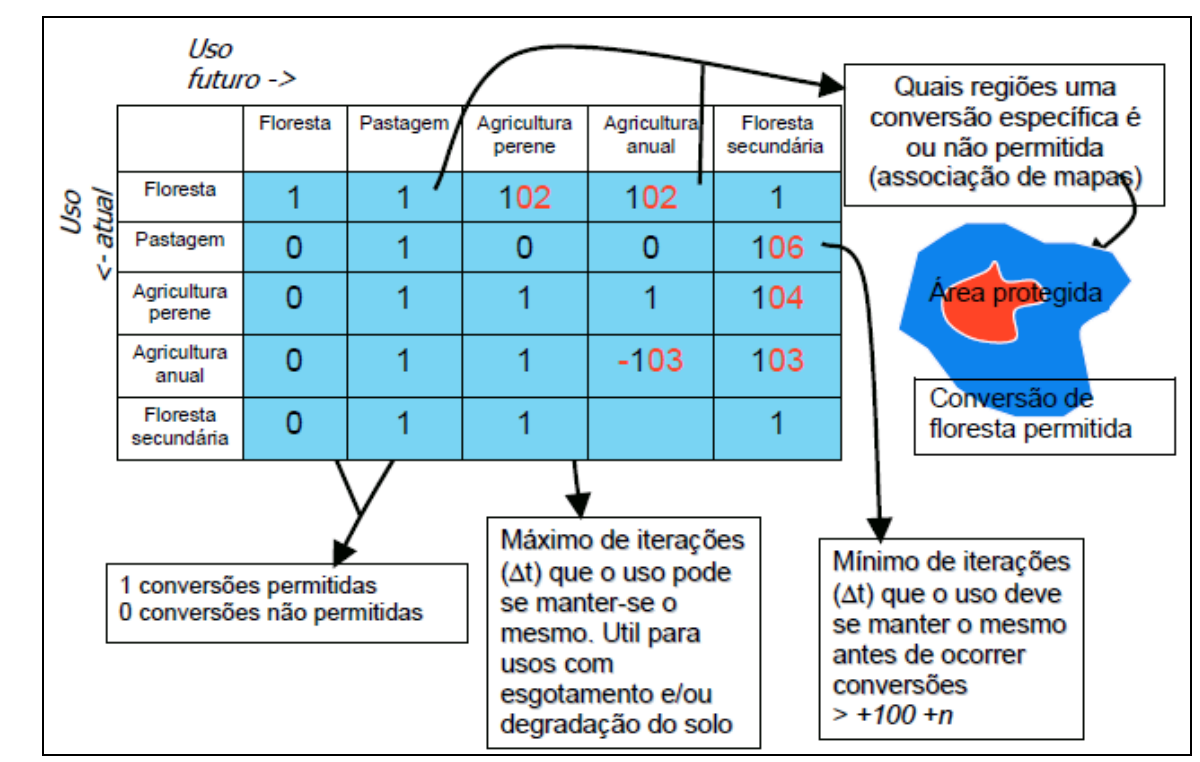

Figura 18: Exemplo de matriz de conversão utilizada no modelo CLUE-S (Fonte: Soler, 2010).

5.6.1.3 Demanda de uso da terra.

A demanda é responsável por determinar a quantidade de área a ser alocada para cada classe de uso e cobertura do solo. A elaboração da demanda pode ser feita através de diferentes métodos de acordo com o objetivo do estudo, podendo destacar a extrapolação de tendências de mudanças de uso e cobertura do solo baseada em histórico de uso, que é a técnica mais utilizada, as quais podem ser alteradas por razões de crescimento populacional e/ou escassez de recursos; a demanda também pode se fundamentar em modelos de mudança macroeconômicas, ligadas a interesses políticos e comerciais.

5.6.1.4 Características da área de estudo.

A relação entre o grupo de variáveis independentes (as forçantes de mudança) com a variável dependente em estudo (os usos em dinâmica de mudança) é 
responsável por direcionar o processo de alocação, o qual é determinado a partir de um modelo binominal logístico que irá determinar se uma célula se modificará ou não em um certo uso e cobertura da terra. A função que calcula a probabilidade de que cada tipo de uso e cobertura da terra terá em ocupar determinada região com características biofísicas, políticas, logísticas e socioeconômicas específicas é definida pelo seguinte modelo de regressão logística binária:

$$
\log \left[\frac{P_{i}}{1-P_{i}}\right]=\beta_{0}+\beta_{1} \cdot X_{1, i}+\beta_{2} \cdot X_{2, i}+\ldots+\beta_{n} \cdot X_{n, i}
$$

Onde $P_{i}$ é a probabilidade de uma célula de análise ser convertida em um tipo de uso do solo, $X n$ são os fatores e $i$ é a localização. Os coeficientes $(\beta)$ são estimados por meio de regressão logística utilizando o uso atual como variável dependente (VERBURG et al., 2002). Trata-se de um método aplicável em situações que se tem uma variável dependente dicotômica, ou seja, quando é possível prever a presença ou ausência de uma característica ou de um resultado (SOLER, 2010).

O método estatístico de regressão logística analisa a correlação entre os fatores indutores com as condicionantes das mudanças, o que irá qualificar e quantificar as relações entre variáveis dependentes, no caso os diferentes usos do solo, com as variáveis independentes, no caso os fatores explanatórios, que são os impulsionadores das mudanças de uso e cobertura nas bacias em estudo, por exemplo. O processo estatístico de regressão logística busca a representação de uma função matemática que seja capaz de relacionar uma variável dependente, a qual é de natureza dicotômica e por isso assume o valor binário 0 ou 1, a um grupo de variáveis independentes (MENARD, 2001).

Com base nos dados de entrada, o CLUE-S então calcula as mudanças mais prováveis na paisagem fundamentadas nas restrições e adequabilidades do local em estudo. Os procedimentos adotados são:

1. Determinação de todas as células com localização $i$ passíveis de serem alteradas, independentemente se forem com ou sem restrição de conversão.

2. Em seguida, é calculada a probabilidade total (TPROP $i, u)$ para cada uso $u$ conforme Equação 58: 


$$
\operatorname{TPROP}_{i, u}=P_{i, u}+E L A S_{u}+I_{T E R_{u}}
$$

Sendo $P_{i, u}$ a probabilidade da célula $i$ assumir o uso $u$ (conforme o modelo de regressão logística do fatores socioeconômicos e biofísicos); $E L A S_{u}$ é a elasticidade de mudanças específicas para cada uso; ITER $R_{u}$ é a variável de interação, a qual é específica a cada uso e indica a competitividade relativa do uso.

3. Faz-se uma alocação primária de ITER $R_{u}$ igual para todos os usos. Aloca-se nas células os usos de maior TPROP $i, u$, o que irá gerar mudanças em algumas células.

4. A área total alocada para cada uso é comparada com a demanda agregada quantificada previamente. Classes de uso que não apresentaram a quantidade de células suficientes à demanda terão seu valor de iteração aumentado. Classes de uso com número de células alocadas extrapolando a demanda terão seu ITER $R_{u}$ reduzido.

5. Os passos 2 e 4 são repetidos até que a demanda seja alocada corretamente. Quando a demanda é alocada corretamente, segue-se para o próximo incremento de tempo.

Na Figura 19 é descrito sinteticamente todos os procedimentos usados pelo modelo CLUE-S.

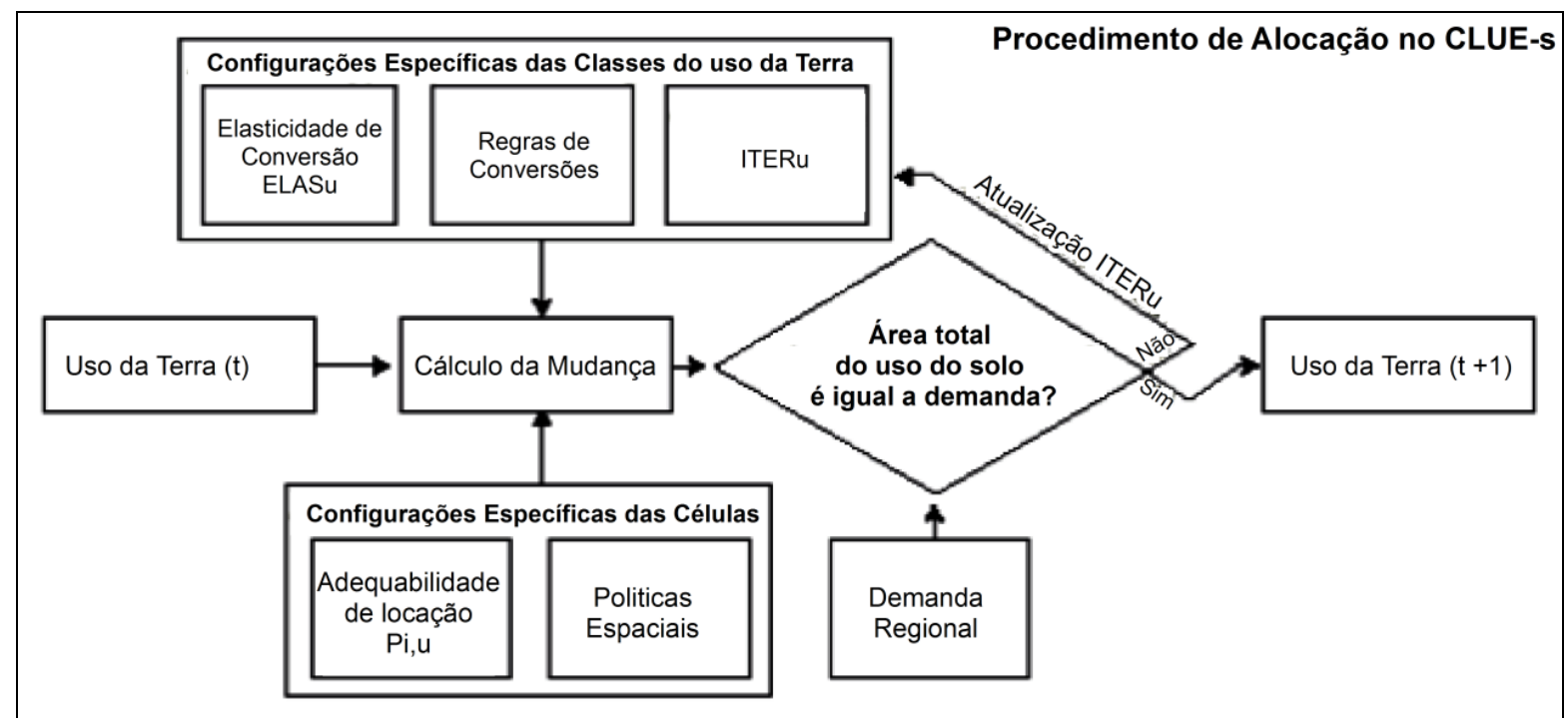

Figura 19: Fluxograma do módulo de alocação do modelo CLUE-S (Fonte: adaptado de VERBURG, 2010). 


\subsubsection{Banco de dados de Entrada do modelo CLUE-S.}

A realização das simulações da dinâmica de mudanças de uso e ocupação do solo através do modelo CLUE-S é dependente, primordialmente, da construção de um banco de dados georreferenciado, o qual deverá reunir informações qualitativas e quantitativas sobre aspectos do meio biofísico, socioeconômico, infraestrutural e geopolítico da área de estudo (SOLER, 2010). Todo o banco de dados utilizado neste modelo foi captado através da elaboração de pesquisa bibliográfica da região, dados de estudos já realizados nas bacias, dados do Instituto Brasileiro de Geografia e Estatística (IBGE), Agência Nacional de Água (ANA), Zoneamento Ecológico Econômico do estado do Pará (ZEE-PA), Instituto Nacional de Meteorologia (INMET), Instituto Nacional de Pesquisas Espaciais (INPE), Empresa Brasileira de Pesquisa Agropecuária (Embrapa), Agência Nacional de Transportes Aquaviários (ANTAQ), Zoneamento Agroecológico da Cultura da Palma de Óleo (ZAE-Palma), além de outras fontes bibliográficas citadas posteriormente.

Os dados que constituíram o arranjo de análise da presente tese estão divididos nos seguintes grupos: dados de uso e cobertura do solo, biofísicos, logísticos e socioeconômicos.

5.6.2.1 Dados de uso e cobertura da terra.

Foram utilizados os mapas 2008 e 2013 de uso e cobertura da terra, conforme descrição metodológica do item 5.5.2.1. 
5.6.2.2 Dados biofísicos.

Foram utilizados mapas do Modelo Digital de Elevação do Terreno e de pedologia, conforme descrição metodológica do item 5.5.2.1.

\subsubsection{Dados Socioeconômicos.}

Foram utilizados os dados de densidade populacional (habitante por $\mathrm{km}^{2}$ ) e renda per capita, espacializados por setor e obtidos do Censo demográfico do ano de 2010 do Instituto Brasileiro de Geografia e Estatística (IBGE).

5.6.2.4 Dados geográficos.

Mapa das rodovias federais e estaduais, localização das usinas de extração de óleo de palma, hidrografia, hidrovias e portos.

\subsubsection{Procedimentos da modelagem dinâmica com o CLUE-S.}

5.6.3.1 Identificação dos usos e coberturas da terra nas simulações.

As classes de uso e cobertura da terra utilizadas no CLUE-S foram Palma de Óleo, Agricultura Geral, Pastagem, Remanescente Florestal, Vegetação Secundária e Outros. A classe Outros corresponde à união das classes Área urbana e Água, sendo 
esta não modelada no presente estudo. Diferentemente da modelagem com o SWAT, no CLUE-S as classes Remanescente Florestal e Vegetação Secundária não foram unificadas para atender o objetivo de verificar a expansão da Palma de Óleo sobre áreas de Vegetação Secundária e restringir a expansão em áreas de Remanescente Florestal.

5.6.3.2 Identificação dos fatores explanatórios de mudança de uso e cobertura da terra.

Fundamentado no banco de dados apresentado anteriormente, foram construídos, conforme a disponibilidade de dados e no interesse do estudo, um banco de dados de fatores explanatórios ou explicativos das mudanças de uso e cobertura, ou seja, forçantes de mudança que são representados pelo conjunto de aspectos biofísicos, políticos e socioeconômicos que podem influenciar ou não na permanência ou mudança de classe em uma determinada região. Esses fatores explanatórios, segundo Soler (2010), podem ser estáticos, quando permanecem constantes ao longo do tempo, ou dinâmicos, quando se modificam ao longo do mesmo. Nesta tese todos são considerados estáticos.

5.6.3.3 Identificação das áreas de demandas para construção dos cenários de mudança.

No presente trabalho foram utilizados dois cenários de demandas, sendo um para calibração e outro para projeções futuras. Todos os cenários de demanda foram definidos de acordo com a escala do trabalho que corresponde a uma resolução de 100 $\mathrm{m}$, onde cada pixel tem área de 1 ha. 
a) Cenário 1- Cenário de demanda para a calibração de 2008 a 2013.

Neste, as demandas foram definidas tendo como base a diferença de área entre usos existentes nos mapas de 2008 a 2013. A variação da demanda entre os anos da calibração foi contabilizada conforme variação linear, sendo que cada área presente no mapa de 2008 foi ajustada através do acréscimo ou decréscimo de incremento anual. Este incremento de crescimento é calculado através da divisão igual para cada ano da área total que cresceu ou diminuiu entre os anos de 2008 e 2013 em cada uso e cobertura em estudo. Apesar de haver pequenas diferenças entre a classe Outros (Urbano e Água) entre os anos de 2008 (TerraClass) e 2013 (Classificação automática), a área desta classe no ano de 2008 foi mantida a mesma em todas as demandas de ambas sub-bacias.

b) Cenário 2- Cenário de demanda do ano base da simulação, 2013, para 0 cenário projetado de 2023.

Neste cenário, o objetivo central está em modelar a expansão da palma de óleo. Para isto, utilizou-se os mapas das sub-bacias de uso e cobertura da terra do ano de 2013, sendo aplicados neste os parâmetros calibrados do Cenário 1 relativos as regressões, matriz de conversão e elasticidade de cada classe de uso e cobertura. A área de demanda desta simulação foi elaborada a partir de revisões bibliográficas de documentos disponibilizados por órgãos nacionais e internacionais, bem como artigos, os quais foram compatibilizados de maneira a construírem cenários de mudança projetada para 2023.

O cenário global de expansão da palma de óleo seguiu o estabelecido por pesquisas fundamentadas no aumento do consumo internacional e do crescimento populacional por organizações reconhecidas por realizarem estes estudos e projeções para a produção de óleos vegetais, tais como a FAO (Food and Agriculture Organization of the United Nations) e a Oil World Data Base, que preveem um aumento de cerca de $30 \%$ das áreas de palma de óleo no mundo até 2023 . A demanda nacional 
foi elaborada a partir das projeções da Federação da Agricultura e Pecuária do Pará (FAEPA) da Confederação da Agricultura e Pecuária do Brasil (CNA) e do Ministéria da Agricultura, Pecuária e Abastecimento (MAPA), que projetam um crescimento de 100\% ou até mais das áreas de palma de óleo no Brasil.

As demandas agrícolas para Agricultura Geral e Pastagem se fundamentaram nos relatórios de projeção para o agronegócio brasileiro para 2023 do Ministério da Agricultura, Pecuária e Abastecimento (MAPA, 2013) e da Federação das Indústrias do Estado de São Paulo (FIESP, 2013). Os estudos apontam crescimento de cerca de $18 \%$ das áreas de Agricultura e redução de $3 \%$ das áreas de pastagens. A área agrícola vem crescendo essencialmente sobre as pastagens, exigindo da pecuária de corte um salto em termos de produtividade para assegurar a oferta brasileira.

Utilizou-se aqui, também, a análise qualitativa e quantitativa dos mapas classificados semiautomaticamente dos anos de 2000 e 2004, com o intuito de verificar o comportamento da mudança de uso e cobertura da terra num intervalo de tempo de 13 anos.

5.6.3.4 Preparo dos arquivos de entrada do modelo.

Os dados que foram pesquisados e produzidos em diferentes fontes, escalas e formatos, os quais foram utilizados neste modelo, primeiramente foram padronizados em formato raster (matricial), sendo que a resolução de análise está diretamente ligada à escala dos dados de entrada. Após convertidos em raster, as classes de uso e cobertura do solo dos mapas de 2008 e 2013 foram reclassificadas de acordo com o uso e cobertura nos seguintes valores: 0 - Palma de Óleo; 1 - Agricultura Geral; 2 Pastagem; 3 - Remanescente Florestal; 4 - Vegetação Secundária; e 5 - Outros (Área Urbana + Água). Estes arquivos raster de uso e cobertura foram, posteriormente, desmembrados em arquivos únicos para cada classe, sendo que em cada raster desmembrado o uso foi reclassificado com o valor 1 e os demais com valor 0 . 
$\mathrm{Na}$ sequência, os arquivos raster foram convertidos em formato ASCII, que é o formato utilizado no CLUE-S. É fundamental que os mapas tenham a mesma resolução espacial, o mesmo número de pixel, número de colunas e linhas iguais entre si, devem estar na mesma projeção/datum e as coordenadas do canto inferior esquerdo também são iguais para todos os arquivos de uma mesma área de estudo. Todos os dados possuem a projeção UTM SAD 1969, Datum South America, contendo o número de linhas e colunas iguais e resolução de $100 \mathrm{~m}$ x $100 \mathrm{~m}$ relativa às sub-bacias em estudo, Bujaru ou Mariquita.

Os procedimentos de preparo dos arquivos são adotados de maneira a representar todas as variáveis em estudo, sejam dependentes ou independentes, além de outros componentes fundamentais a modelagem, conforme os seguintes passos descritos por Pereira (2013):

I. Antes de começar os trabalhos, configurou-se o idioma do computador para inglês, uma vez que o CLUE-S trabalha apenas com o ponto como separador decimal;

II. O arquivo ASCII de uso e ocupação recebeu o nome de 'covall.0', com os usos da terra enumerados de 0 a $n(0,1,2,3,4, \ldots, n)$, sendo obrigado a começar com 0 ;

III. Preparou-se um arquivo ASCII para cada uso e ocupação, de modo que o uso que foi o nome do arquivo teve valor 1 e os demais usos receberam o valor 0 . Preparou-se este grupo de arquivos apenas para o ano de 2013, pois toda a análise de probabilidade de alocação da presente tese foi feita com base na correlação das classes de usos e cobertura presentes neste mapa de 2013 com os fatores explanatórios;

IV. Todos os fatores explanatórios também foram convertidos em formato ASCII, que receberam o nome de $\mathrm{Sc} 1 \mathrm{gr}^{*}$.fil (onde * varia de 0 até o número da última variável);

V. Utilizou-se o software CONVERT.EXE para preparar o pacote de tabelas para dar carga no programa de estatística SPSS Statistics 17.0. Para cada uso da terra, preparado conforme explicado no passo III, foi rodado o CONVERT.EXE com todos os fatores explanatórios utilizados em cada sub-bacia, quando foram gerados os arquivos 'stat.txt' para cada classe (stat_palmaoleo13; stat_agricultura13; stat_pastagem13; stat_remanescent13 e stat_secundaria13); A adoção das classes de 2013 para gerar os 
arquivos 'Stat' foi o método de calibração adotado na presente tese. Por não ser modelada neste trabalho, a classe Outros não foi avaliada na regressão logística.

VI. O trabalho com o programa de estatística, consistiu em 3 análises: a) A preparação da tabela de correlação de Pearson (bivariável), onde aplicou-se a linha de corte de 0,7 como critério de escolha entre variáveis com este nível de correlação, sendo estas variáveis consideradas como iguais e uma delas, somente uma delas, permaneceu no estudo; b) Elaboração da regressão logística binária, que forneceu as constantes para preparar o arquivo 'alloc.reg' do CLUE-S; c) cálculo da área sob a curva ROC (Receiver Operating Characteristics), sendo aceitável neste estudo valores acima de 0,7, mesmo sendo recomendável que seja superior a 0,8. Na realização da regressão logística, aplicou-se primeiramente o método 'Enter', incluindo todas as variáveis disponíveis. Em seguida, utilizou-se o método 'stepwise regression' com todas variáveis, mas nesse foram incluídos apenas os fatores explanatórios mais relevantes de acordo com a análise do SPSS. A sequência de testes para melhorar a Curva ROC foi baseada na combinação coerente de variáveis que expliquem a dinâmica de determinado uso, observando a linha de corte 0,7 da tabela de correlação bivariável;

VII. Preparou-se o arquivo 'alloc.reg' com os valores da regressão logística, o qual possui a seguinte estrutura e é melhor representada na Figura 20:

Linha 1: Código da classe de uso e cobertura do solo.

Linha 2: Constante da equação de regressão $\left(\beta_{0}\right)$.

Linha 3: Número de fatores explanatórios na equação de regressão.

Linha 4 em diante: Em cada linha, o coeficiente de regressão e o código numérico correspondente a cada fator explanatório. 


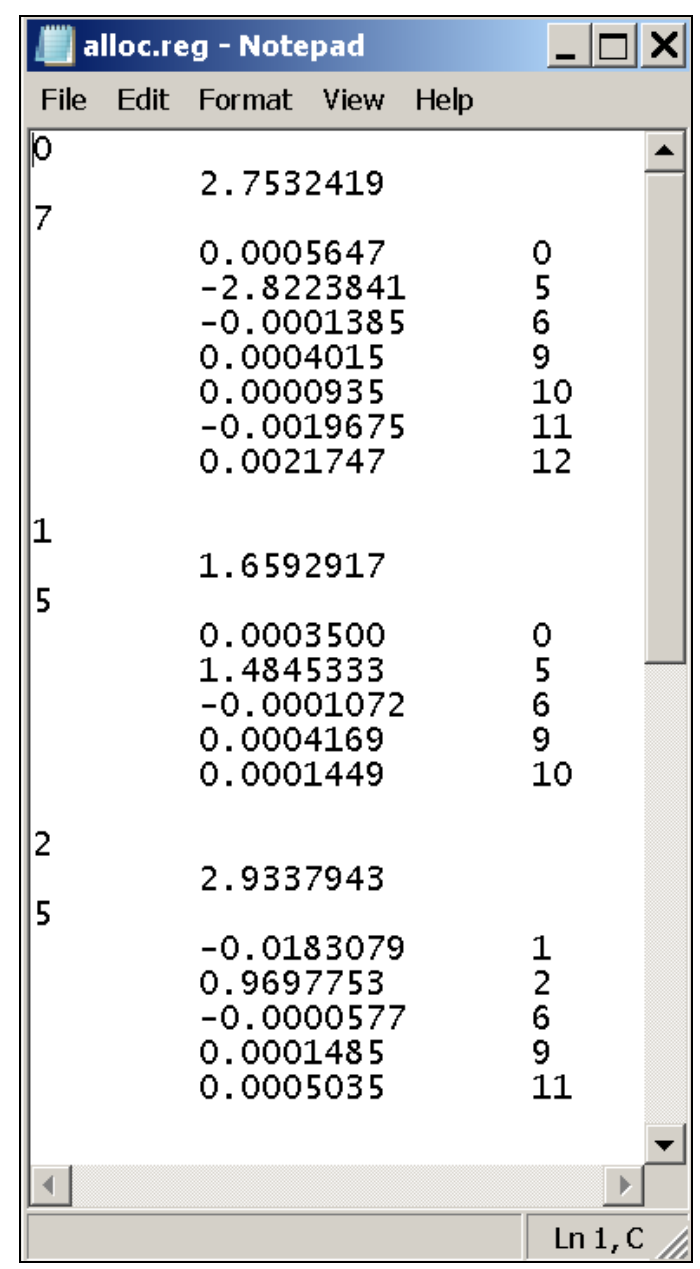

Figura 20: Exemplo de formato de um arquivo 'alloc.reg' utilizado na tese.

VIII. O passo seguinte foi elaborar a matriz de conversão, denominada de 'allow.txt', a qual indica se um uso pode mudar para outro ou não, e o tempo mínimo e máximo que um uso permanece fixo para poder mudar para outro uso, conforme exemplo aplicado na tese (Figura 21);

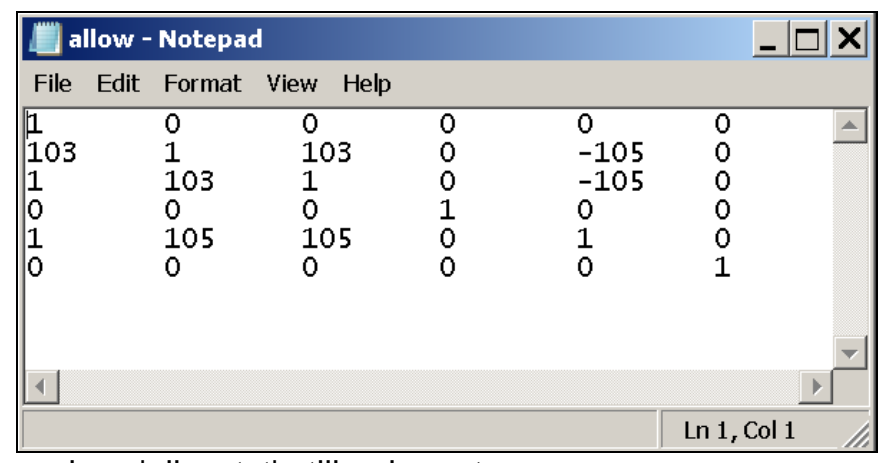

Figura 21: Exemplo de arquivos 'allow.txt' utilizado na tese. 
IX. Preparou-se, também em formato ASCII, o arquivo de restrição de área, denominado de 'region*.fil ( ${ }^{*}$ é alfanumérico e serve para identificar o tipo de restrição). Nesse arquivo, as células sem dados têm o valor (-9999) e as células que indicam restrição de área têm o valor (-9998), as demais células têm o valor 0;

X. Preparou-se o arquivo de demanda, o 'demand.in*' de cenários de demanda (* é numérico e usado para indicar diferentes demandas). Essa é uma tabela em txt, onde a primeira linha identifica o número de anos simulados e as demais linhas da tabela representam as demandas para cada ano (Linha) e para cada uso e cobertura (Coluna). A ordem de cada uso e cobertura deve ser a mesma especificada no arquivo de parâmetros principais.

XI. Outro arquivo importante é o de parâmetros principais 'main.1', o qual contêm todas as informações dos parâmetros importantes que determinam a configuração das simulações. Abaixo, segue a tabela que foi descrito este arquivo (Tabela 8):

Tabela 8: Arquivo de parâmetros principais ('main.1').

\begin{tabular}{llc}
\hline Linha & Descrição & Formato \\
\hline 1 & Número de classes de usos do solo. & Inteiro \\
2 & Número de regiões. & Inteiro \\
3 & Número máximo de variáveis independentes na equação de & Inteiro \\
& regressão. & \\
4 & Número máximo de impulsores de mudanças. & Inteiro \\
5 & Número de linhas do plano celular. & Inteiro \\
6 & Número de colunas do plano celular. & Inteiro \\
7 & Área da célula do plano celular em hectares. & Real \\
8 & Coordenada do eixo X no ponto inferior esquerdo do plano & Real \\
& celular. & \\
9 & Coordenada do eixo Y no ponto inferior esquerdo do plano & Real \\
& celular. & \\
10 & Códigos para as classes de uso do solo. & Inteiro \\
11 & Códigos para as elasticidades. & Real \\
12 & Variável de iteração. & Real \\
13 & Ano inicial e final da simulação. & Inteiro \\
14 & Número e código dos impulsores de mudanças dinâmicos. & Inteiro \\
15 & Tipo de arquivo de saída. & $0,1,-2$ ou 2 \\
16 & Escolha de regressões regionais. & 0,1 ou 2 \\
17 & Inicialização da história do uso do solo. & 0,1 ou 2 \\
18 & Escolha de função de vizinhança. & 0,1 ou 2 \\
19 & Adição de preferências locais & Inteiro \\
\hline
\end{tabular}

$\mathrm{Na}$ tabela exposta, podem-se explicar, destacadamente, as seguintes linhas importantes no presente trabalho: 
Linha 2 - Por default é 1, porém, se houver áreas com aspectos geomorfológicos e de uso e ocupação distintos, pode-se usar até 3 regiões;

Linha 10. Os códigos numéricos das classes de uso e cobertura do solo devem começar com 0 para a primeira classe, 1 para a segunda, e assim em diante.

Linha 11. Elasticidade de conversão é representada por códigos que expressam as mudanças permitidas e o comportamento das classes de uso e cobertura. Seguindo a linha 10, deve-se informar estes códigos para cada classe, tal que 0 $\leq X \geq 1$. Quando $X=0$, todas as possibilidades de mudanças são permitidas; entre 0 e 1 , as mudanças são permitidas, porém, quanto maior for $\circ X$, maior a possibilidade do uso atual ser mantido no mesmo local; quando $X=1$, significa que as mudanças nas células com determinado uso e cobertura não pode ser adicionada ou removida ao mesmo tempo.

Linha 12. Três números precisam ser especificados: 1) 0 , quando as convergências forem expressas em porcentagem; ou 1, quando forem expressas em hectares. 2) primeiro critério de convergência que corresponde ao desvio médio entre as mudanças na demanda e as mudanças alocadas na última iteração, sendo que por default para a opção em percentagem, o valor do desvio médio deve ser 0,35 e para a opção como valor absoluto, deve ser a área de uma célula dividida pelo número de classes de uso do solo. 3) segundo critério de convergência utiliza o desvio máximo entre as mudanças na demanda e no alocado na última iteração. Por default, para percentagem, o valor é de 3,0; para o caso do valor absoluto, dever ser pelo menos a área de uma célula.

XII. Com o modelo pronto para rodar, foi gerado arquivos de áreas de probabilidade de ocorrência para cada uso e cobertura do solo em função da demanda e das equações de regressão;

XIII. Por fim, rodaram-se as simulações. O produto destas, os arquivos 'cov_all.*' foram convertidos para raster, representado os resultados intermediários e finais das simulações ( ${ }^{*}$ varia de 0 a $n$, onde 0 é o 'covall.0', que é o primeiro ano gerado no início do trabalho, 1 foi o segundo ano, 2 o terceiro e assim por diante até o último ano de cada simulação). 
5.6.3.5 Análise dos fatores explanatórios utilizados.

$\mathrm{Na}$ presente tese, a análise da relação entre as classes de uso e cobertura do solo (variáveis dependentes) e os fatores explanatórios (variáveis independentes), foi realizada através de um programa estatístico e de planilha eletrônica (PEREIRA, 2013).

O software estatístico utilizado foi SPSS Statistic, versão 17.0, da IBM. Os arquivos gerados pelo CONVERT.EXE (Stat.txt) de cada uso e cobertura do solo foram importantes para o SPSS, onde foram geradas as tabelas de correlação bivariável, as regressões logísticas e o cálculo da área sob a curva ROC. Os resultados de interesse para constituir a análise de significância e importância dos fatores explanatórios, bem como a obtenção dos Betas que compuseram o arquivo 'alloc.reg', foram obtidos dos resultados da regressão logística (Figura 22).

\begin{tabular}{|ll|r|r|r|r|r|r||}
\hline \multicolumn{7}{|c|}{ Variables in the Equation } \\
\hline & \multicolumn{1}{|c|}{ B } & \multicolumn{1}{|c|}{ S.E. } & \multicolumn{1}{c|}{ Wald } & \multicolumn{1}{c|}{ df } & \multicolumn{1}{c|}{ Sig. } & \multicolumn{1}{|c|}{ Exp(B) } \\
\hline Step 1 ${ }^{\text {a }}$ & dlhidrografia & .417 & .052 & 63.296 & 1 & .000 & 1.517 \\
& sololad1 & -1.044 & .522 & 4.008 & 1 & .045 & .352 \\
sololad8 & -.788 & .514 & 2.347 & 1 & .126 & .455 \\
sololad39 & -3.516 & .725 & 23.522 & 1 & .000 & .030 \\
custodistant13 & .000 & .000 & 129.634 & 1 & .000 & 1.000 \\
dlportos & 5.928 & .700 & 71.624 & 1 & .000 & 375.461 \\
dlusinas70 & 1.266 & .276 & 21.091 & 1 & .000 & 3.548 \\
densetor2010 & .000 & .000 & 7.334 & 1 & .007 & .999 \\
Constant & -28.352 & 3.002 & 89.208 & 1 & .000 & .000 \\
\hline a. Variable(s) entered on step 1: dilhidrografia, sololad1, sololad8, sololad39, custodistant13, \\
diportos, dlusinas70, densetor2010.
\end{tabular}

Figura 22: Exemplo de resultado da regressão logística efetuada pelo SPSS.

As planilhas em Excel auxiliaram na análise das correlações entre as variáveis e também na formatação dos dados que compuseram os arquivos de entrada no modelo. 
5.6.3.6 Calibração e ajustes do modelo.

A calibração e validação do modelo requer um conjunto de dados de, pelo menos, dois anos distintos, separados entre si idealmente em pelo menos 10 anos (SOLER, 2010). No entanto, o presente trabalho faz o exercício de calibração utilizando dados que contabilizam um período de 5 anos entre os mapeamentos de uso e cobertura da terra. O processo de calibração e ajustes no modelo teve a seguinte rotina de trabalho: 1. Definição das entradas: foi calculado as constantes e Betas para um conjunto de variáveis para cada uso e cobertura da terra através da regressão logística (alloc1.reg), contrui-se a matriz de conversão (allow.txt) e foram determinados os valores de elasticidades para cada classe (main.1); 2. Aplicou-se os resultados das regressões, matriz de conversão elasticidade no modelo; 3 . Verificou-se 0 comportamento inicial do modelo e, em sequência, quando necessário, fizeram-se alterações das elasticidades, na matriz de conversão e retornou-se ao SPSS para testar novo agrupamento de variáveis explanatórias, conforme análise prévia de significância de cada variável e da correlação no limite mínimo da linha de corte de 0,7 , e recalcular as constantes e Betas; 4. Após seleção visual dos melhores resultados foi aplicado à estatística de verificação de acerto, conforme tópico seguinte.

\subsubsection{Aplicação do Modelo para cenários futuros}

Por fim, a etapa final nesta modelagem, foi selecionar o melhor resultado através de análise visual e estatística e aplicar o modelo com parâmetros calibrados para a projeção de cenários de mudança de uso e cobertura da terra para o ano de 2023. 


\subsubsection{Verificação do acerto dos resultados da calibração do modelo.}

Para testar o acerto do modelo, utilizou-se dois métodos amplamente utilizados em trabalhos de modelagem, inclusive com o CLUE-S e em trabalho de mapeamento de uso e cobertura do solo (BRITES et al., 1996; BOLFE et al., 2004; PEREIRA, 2013; RIBEIRO et al., 2011; VALENCIA, 2008; CRUZ et al., 2008), que foram a Acurácia Global (Exatidão Global) e o coeficiente de concordância Kappa (Índice Kappa). Os dois métodos foram aplicados para verificação quantitativa da concordância entre a quantidade de área estimada por sub-bacia (modelo) e a quantidade de área observada pelo mapeamento real, tendo como ano base de análise o ano de 2013. O resultado da estatística se deu levando em consideração o acerto pixel a pixel entre mapa real e simulado.

Aplicaram-se duas técnicas de verificação de acerto através do Índice Kappa: uma desenvolvida por Suchower e Copenhaver (1996), a qual foi aplicada para avaliar o percentual de acerto do modelo individualmente para cada uso e cobertura da terra (Equação 59); e o método descrito por Hudson \& Ramm (1987), o qual foi aplicado para avaliar o percentual de acerto do modelo de maneira total ou global (Equação 60). Foi aplicado também o cálculo da Exatidão Global (Equação 61), de maneira a avaliar os pontos corretamente classificados em relação ao total de pontos de referência de maneira individual e total (BRITES et al., 1996; HUDSON; RAMM, 1987). A partir da tabulação da área calculada e da área observada, elaborou-se a tabela de contingência, também denominada de matriz de erros ou matriz de confusão (Tabela 9). Todas as equações são descritas abaixo. 
Tabela 9: Tabela de contingência adaptada para a tese.

\begin{tabular}{|c|c|c|c|}
\hline \multirow{2}{*}{ Modelo X Real } & \multicolumn{2}{|c|}{ Mapa Real } & \multirow[b]{2}{*}{ TOTAL } \\
\hline & COM & SEM & \\
\hline \multirow[t]{2}{*}{ COM } & $\begin{array}{l}\text { Frequência total COM } \\
\text { O USO no Modelo e } \\
\text { COM O USO no Real }\end{array}$ & $\begin{array}{l}\text { Frequência total COM } \\
\text { O USO no modelo e } \\
\text { SEM O USO no Real }\end{array}$ & $\begin{array}{c}\text { Total de Área } \\
\text { cOM O USO pelo } \\
\text { modelo }\end{array}$ \\
\hline & $\begin{array}{l}\text { Porcentagem } \\
\text { COMxCOM }\end{array}$ & $\begin{array}{l}\text { Porcentagem } \\
\text { COMxSEM }\end{array}$ & Somatório \% \\
\hline \multirow[t]{2}{*}{ SEM } & $\begin{array}{l}\text { Frequência total SEM } \\
\text { O USO no modelo e } \\
\text { COM O USO no Real }\end{array}$ & $\begin{array}{l}\text { Frequência total SEM O } \\
\text { USO no modelo e SEM } \\
\text { O USO no Real }\end{array}$ & $\begin{array}{c}\text { Total de Área SEM } \\
\text { O USO pelo } \\
\text { modelo }\end{array}$ \\
\hline & $\begin{array}{l}\text { Porcentagem } \\
\text { SEMxCOM }\end{array}$ & $\begin{array}{l}\text { Porcentagem } \\
\text { SEMxSEM }\end{array}$ & Somatório \% \\
\hline \multirow[t]{2}{*}{ TOTAL } & $\begin{array}{c}\text { Total de Área COM O } \\
\text { USO pelo Real }\end{array}$ & $\begin{array}{c}\text { Total de Área SEM O } \\
\text { USO pelo Real }\end{array}$ & $\begin{array}{l}\text { Total de Área da } \\
\text { sub-bacia }\end{array}$ \\
\hline & Somatório \% coluna & Somatório \% coluna & $100 \%$ \\
\hline
\end{tabular}

(Fonte: Pereira, 2013)

$K=\frac{p_{0}-p_{e}}{1-p_{e}}$

Onde:

K - teste kappa;

$P_{0}$ - Probabilidade observada a partir dos resultados do modelo;

$P_{e}$ - Probabilidade esperada de acordo com observado em campo.

$K=\frac{n \cdot \sum_{i=1}^{c} X_{i i}-\sum_{i=1}^{c} X_{i l} \cdot X_{i c}}{n^{2}-\sum_{i=1}^{c} X_{i l} X_{i c}}$

Onde:

$X_{i i}=$ valor na linha i e coluna i da matriz de erros;

$X_{i l}=$ total da linha i;

$X_{i c}=$ total da coluna $\mathrm{i}$;

$n=$ total de observações;

$c=$ número total de classes.

$$
G=\frac{\sum_{i=1}^{M} n_{i i}}{N}
$$


Onde:

$N=$ número total de pixels contemplados pela matriz de erros;

$n=$ elemento da matriz de erros;

$M=$ número de categorias informacionais presentes na matriz de erros.

Os resultados destas estatísticas foram qualificados segundo a tabela de avaliação (Tabela 10) expressa por Fonseca (2000):

Tabela 10: Índice Kappa e o correspondente desempenho da classificação.

\begin{tabular}{lc}
\hline Índice Kappa & Desempenho \\
\hline$<0$ & Péssimo \\
$0<\mathrm{k} \leq 0,2$ & Ruim \\
$0,2<\mathrm{k} \leq 0,4$ & Razoável \\
$0,4<\mathrm{k} \leq 0,6$ & Bom \\
$0,6<\mathrm{k} \leq 0,8$ & Muito Bom \\
$0,8<\mathrm{k} \leq 1,0$ & Excelente \\
\hline
\end{tabular}

(Fonte: Fonseca, 2000)

\subsection{SISTEMAS COMPUTACIONAIS UTILIZADOS NA TESE}

Foram utilizados os seguintes sistemas computacionais para o desenvolvimento da presente pesquisa:

- ArcGis v. 10.3, desenvolvido pela Environmental Systems Research Institute, USA.

- SWAT v. 2012 - Soil and Water Assessment Tool, desenvolvido pelo Agricultural Research Service (ARS), Texas A\&M University System, Temple, Texas, USA.

- SWAT-CUP V. 2012 - SWAT Calibration and Uncertainty Programs, desenvolvido pela Swiss Federal Institute of Aquatic Science and Technology, Suíça.

- CLUE-S - Conversion of Land Use and its Effects at Small Region Extent, desenvolvido pelo grupo de pesquisa Land Dynamics Group na Universidade de Wageningen, Holanda. 
- Spring v. 5.2.7, desenvolvido pelo Instituto Nacional de Pesquisas Espaciais (INPE), Brasil.

- TerraAmazon v. 4.4.3, desenvolvido pelo Instituto Nacional de Pesquisas Espaciais (INPE), Brasil.

- SPSS - Statistical Package for the Social Sciences - PASW Statistic 18, desenvolvido na Universidade de Stanford e na Universidade de Chicago, USA. 


\section{RESULTADOS E DISCUSSÕES.}

\subsection{MAPAS DE USO E COBERTURA DA TERRA NAS SUB-BACIAS.}

\subsubsection{Mapa de uso e cobertura da terra de 2008.}

O mapa de 2008 utilizado na presente tese, o qual foi obtido do Projeto TerraClass (INPE / Embrapa), apresenta uma classificação ampla de usos e coberturas da terra, a qual foi simplicada de maneira a reduzir o número de classes através de um reagrupamento, ou reclassificação, e assim atender melhor o objetivo da tese. $O$ Quadro 2 mostra as reclassificações de acordo com modelagem, seja com o SWAT ou com o CLUE-S. Esse reagrupamento das classes foi realizado por razão de algumas classes poderem ser irrelevantes para modelagem hidrossedimentológica e por ocuparem áreas muito pequenas, como é o caso das classes água, pasto limpo, pasto sujo e área urbana.

Para o ano de 2008, o mapa final teve 7 classes espacializadas (Figura 23 e 24), sendo elas: Agricultura Geral, Palma de Óleo (Dendê), Pastagem, Remanescente Florestal, Vegetação Secundária, Água e Área Urbana. Áreas classificadas pelo TerraClass como Área Não Observada foram reclassifcadas como agricultura geral, sendo estas uma pequena porção da área do mapa (0,09 \% na sub-bacia do Mariquita e $0.04 \%$ na sub-bacia do rio Bujaru). As Tabelas 11 e 12 mostram a distribuição de área por uso e cobertura nas sub-bacias dos rios Bujaru e Mariquita, respectivamente.

Conforme Figura 23, na sub-bacia do rio Bujaru o predomínio é da pastagem (42,61\%), sendo que as áreas de Remanescente Florestal são poucas, ocupando apenas $10,36 \%$ da área da bacia. Porém, a sub-bacia do rio Mariquita apresenta 25,85\% de sua área coberta com Remanescente Florestal, tendo a predominância de sua área nesse período de Vegetação Secundária (37,31\%) e Pastagem (34,11\%) (Tabela 11 e 12). 
Quadro 2: Reclassificação dos usos e coberturas da terra do Projeto TerraClass 2008 para as áreas das sub-bacias dos rios Bujaru e Mariquita.

\begin{tabular}{lcc}
\hline Classe & \multicolumn{2}{c}{ Reclassificação } \\
\hline TerraClass & SWAT & CLUE-S \\
\hline Dende & Palma de Óleo & Palma de Óleo \\
Agricultura Anual & Agricultura Geral & $\begin{array}{c}\text { Agricultura Geral } \\
\text { Agropecuária }\end{array}$ \\
& Agricultura Geral & Agricultura Geral \\
Desflorestamento & Agricultura Geral & Agricultura Geral \\
& & \\
Mosaico de Ocupações & Agricultura Geral & Agricultura Geral \\
Outros & Agricultura Geral & Agricultura Geral \\
Não Floresta & Agricultura Geral & Agricultura Geral \\
Não Floresta & Agricultura Geral & Agricultura Geral \\
Pasto Limpo & Pastagem & Pastagem \\
Pasto sujo & Pastagem & Pastagem \\
Regeneração com Pasto & Pastagem & Pastagem \\
Pasto com solo exposto & Pastagem & Pastagem \\
Vegetação Secundária & Remanescente Florestal & Vegetação Secundária \\
Floresta & Remanescente Florestal & Remanescente Florestal \\
Floresta Sob Nuvem & Remanescente Florestal & Remanescente Florestal \\
Area não observada & --------------- & Outros \\
Área Urbana & Área Urbana & Outros \\
Hidrografia & Água & Outros \\
\hline
\end{tabular}




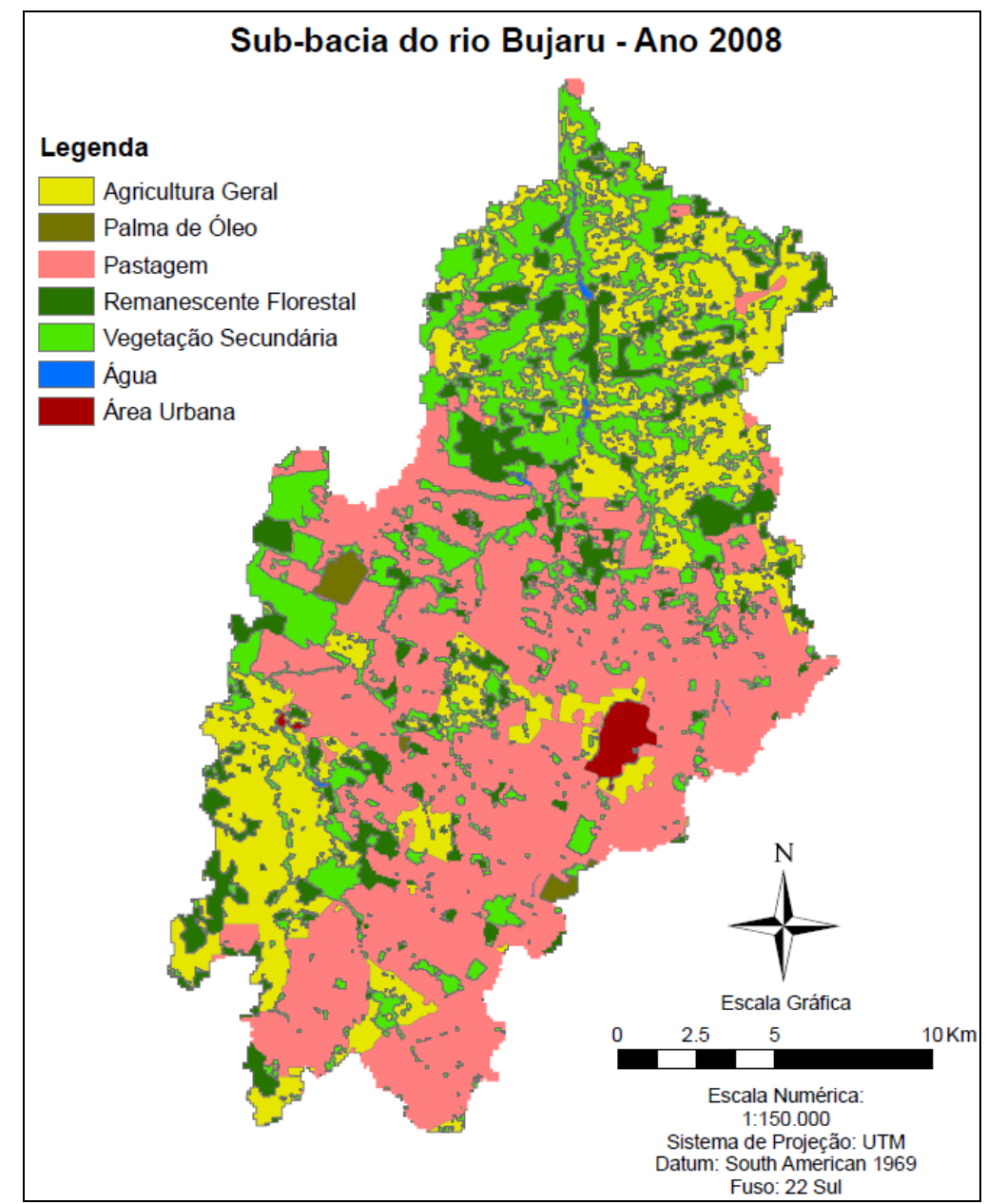

Figura 23: Mapa de uso e cobertura de 2008 para a sub-bacia do rio Bujaru.

Tabela 11: Distribuição de áreas para cada uso e cobertura da terra segundo reclassificação do TerraClass no ano de 2008 para a sub-bacia do rio Bujaru em hectares.

\begin{tabular}{lcc}
\hline Uso e Cobertura & Área (ha) & Área (\%) \\
\hline Agricultura Geral & $9.351,8$ & 24,53 \\
Palma de Óleo & 261,1 & 0,68 \\
Pastagem & $16.244,5$ & 42,61 \\
Remanescente Florestal & $3.949,6$ & 10,36 \\
Vegetação Secundária & $7.853,0$ & 20,60 \\
Água & 100,1 & 0,26 \\
Área Urbana & 361,8 & 0,96 \\
\hline TOTAL & $\mathbf{3 8 . 1 2 2 , 0}$ & $\mathbf{1 0 0 , 0 0}$ \\
\hline
\end{tabular}




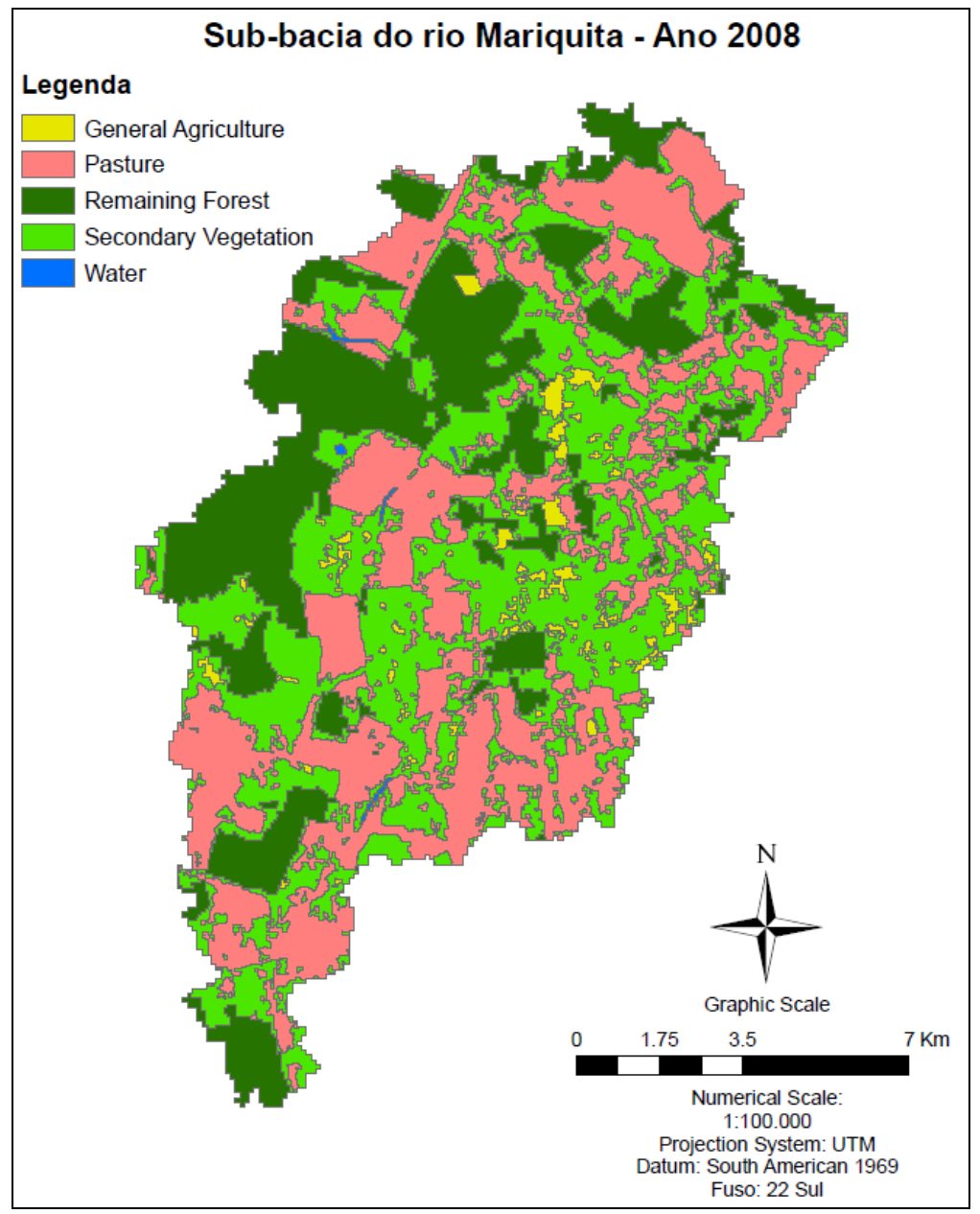

Figura 24: Mapa de uso e cobertura de 2008 para a sub-bacia do rio Mariquita.

Tabela 12: Distribuição de áreas para cada uso e cobertura da terra segundo reclassificação do TerraClass no ano de 2008 para a sub-bacia do rio Mariquita em hectares.

\begin{tabular}{lcc}
\hline Uso e Cobertura & Área (ha) & Área (\%) \\
\hline Agricultura Geral & 407,0 & 2,55 \\
Pastagem & $5.455,9$ & 34,11 \\
Remanescente Florestal & $4.134,2$ & 25,85 \\
Vegetação Secundária & $5.967,6$ & 37,31 \\
Água & 29,3 & 0,18 \\
\hline TOTAL & $\mathbf{1 5 . 9 9 3 , 9 9}$ & $\mathbf{1 0 0 , 0 0}$ \\
\hline
\end{tabular}




\subsubsection{Mapas classificados para os anos de 2000, 2004 e 2013.}

Os resultados das classificações para os anos de 2000, 2004 e 2013 estão definidas conforme as classes reagrupadas do mapa do TerraClass 2008 (Quadro 2). A partir das análises de Acurácia Global e do Coeficiente de Concordância Kappa aplicadas sobre os pontos aleatórios de verificação da exatidão da classificação para o mapa de 2013 (Figuras 25 e 26; Tabela 13 e 14), os resultados indicaram uma acurácia de $84 \%$ e $80 \%$, bem como um Kappa de 0,77 e 0,73, para as sub-bacias do Bujaru e Mariquita, respectivamente. De acordo com Tabela 10 no item 5.6.4, os resultados do índice Kappa global indicam uma classificação muito boa, de acordo com a escala do trabalho.

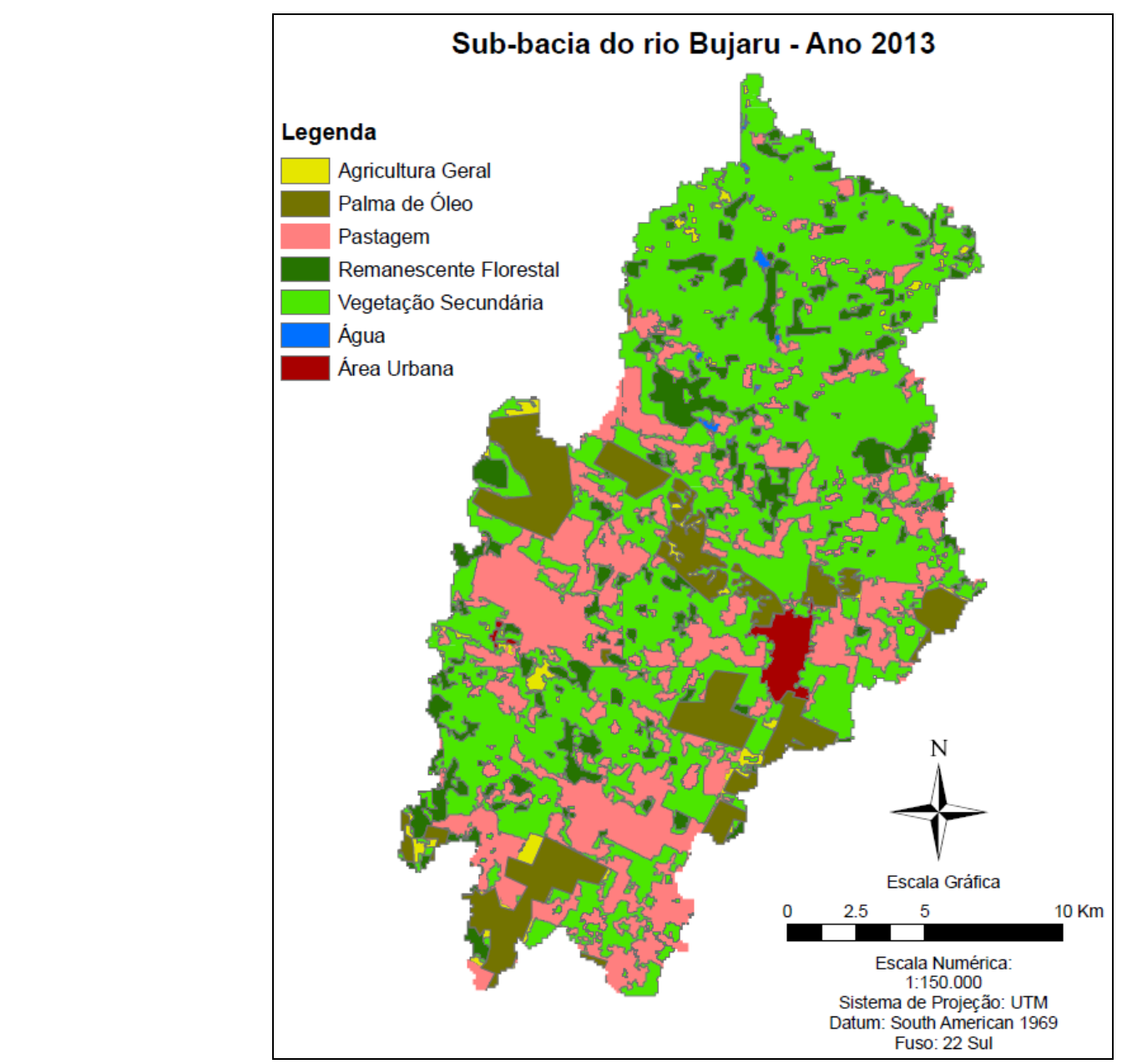

Figura 25: Mapas de uso e cobertura de 2013 para a sub-bacia do rio Bujaru. 
Tabela 13: Distribuição de áreas para cada uso e cobertura do mapa de 2013 para a sub-bacia do rio Bujaru em hectares.

\begin{tabular}{lcc}
\hline Uso e Cobertura & Área (ha) & Área (\%) \\
\hline Agricultura Geral & 726,0 & 1,90 \\
Palma de Óleo & $4.239,1$ & 11,12 \\
Pastagem & $9.168,6$ & 24,05 \\
Remanescente Florestal & $3.852,4$ & 10,11 \\
Vegetação Secundária & $1.9548,5$ & 51,28 \\
Água & 91,7 & 0,24 \\
Área Urbana & 495,8 & 1,30 \\
\hline TOTAL & $\mathbf{3 8 . 1 2 2 , 0}$ & $\mathbf{1 0 0 , 0 0}$ \\
\hline
\end{tabular}

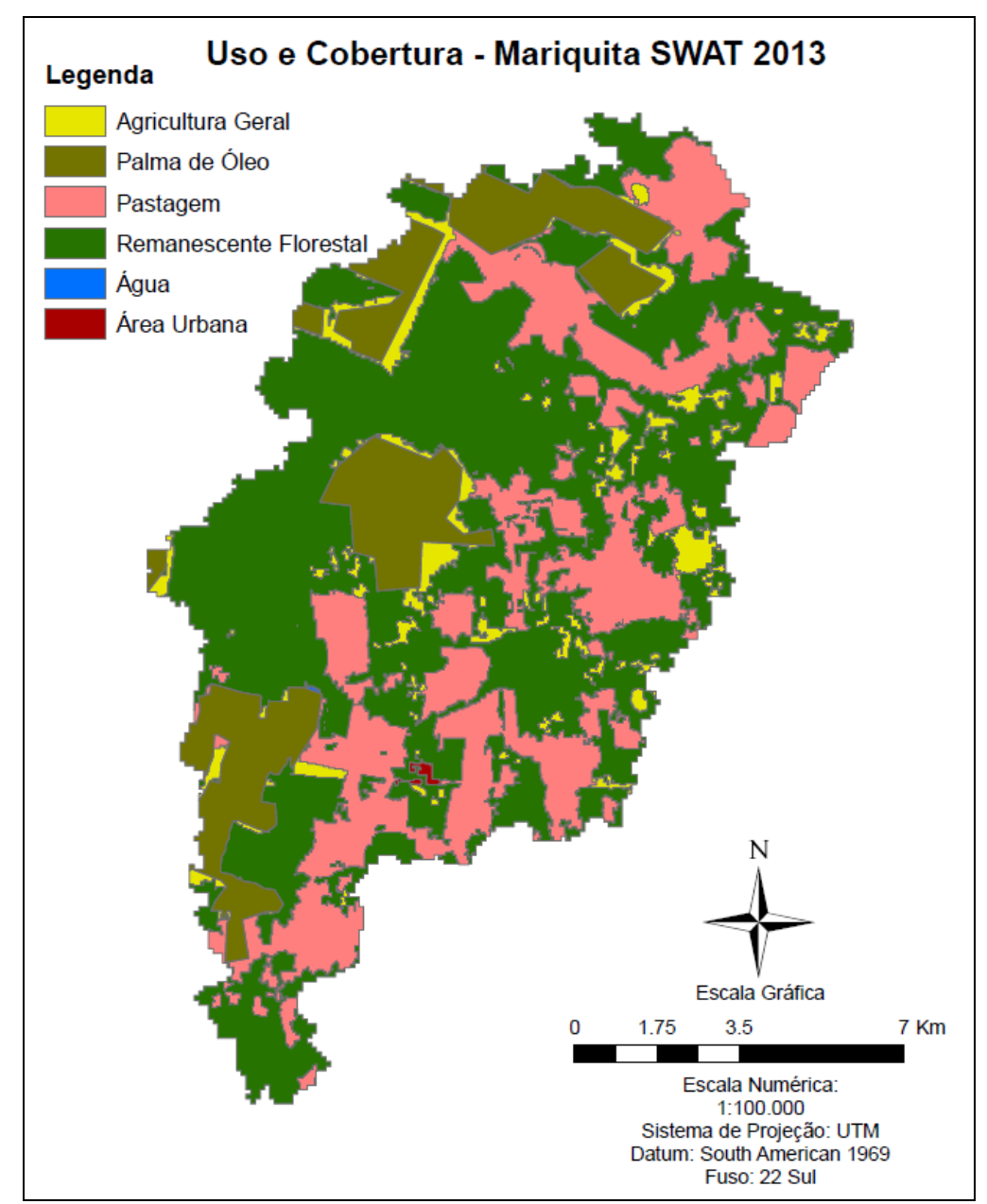

Figura 26: Mapas de uso e cobertura de 2013 para a sub-bacia do rio Mariquita. 
Tabela 14: Distribuição de áreas para cada uso e cobertura do mapa de 2013 para a sub-bacia do rio Mariquita em hectares.

\begin{tabular}{lcc}
\hline Uso e Cobertura & Área (ha) & Área (\%) \\
\hline Agricultura Geral & 916,4 & 5,73 \\
Palma de Óleo & $2.316,5$ & 14,48 \\
Pastagem & $4.222,7$ & 26,40 \\
Remanescente Florestal & $3.883,0$ & 24,28 \\
Vegetação Secundária & $4.634,3$ & 28,98 \\
Água & 2,7 & 0,02 \\
Área Urbana & 18,6 & 0,12 \\
\hline TOTAL & $\mathbf{1 5 . 9 9 3 , 9 9}$ & $\mathbf{1 0 0 , 0 0}$ \\
\hline
\end{tabular}

Abaixo seguem os mapas relativos aos anos de 2000 e 2004 para as sub-bacias dos rios Bujaru e Mariquita. Estes não foram submetidos à validação de verdade terrestre (Figura 27 e 28).

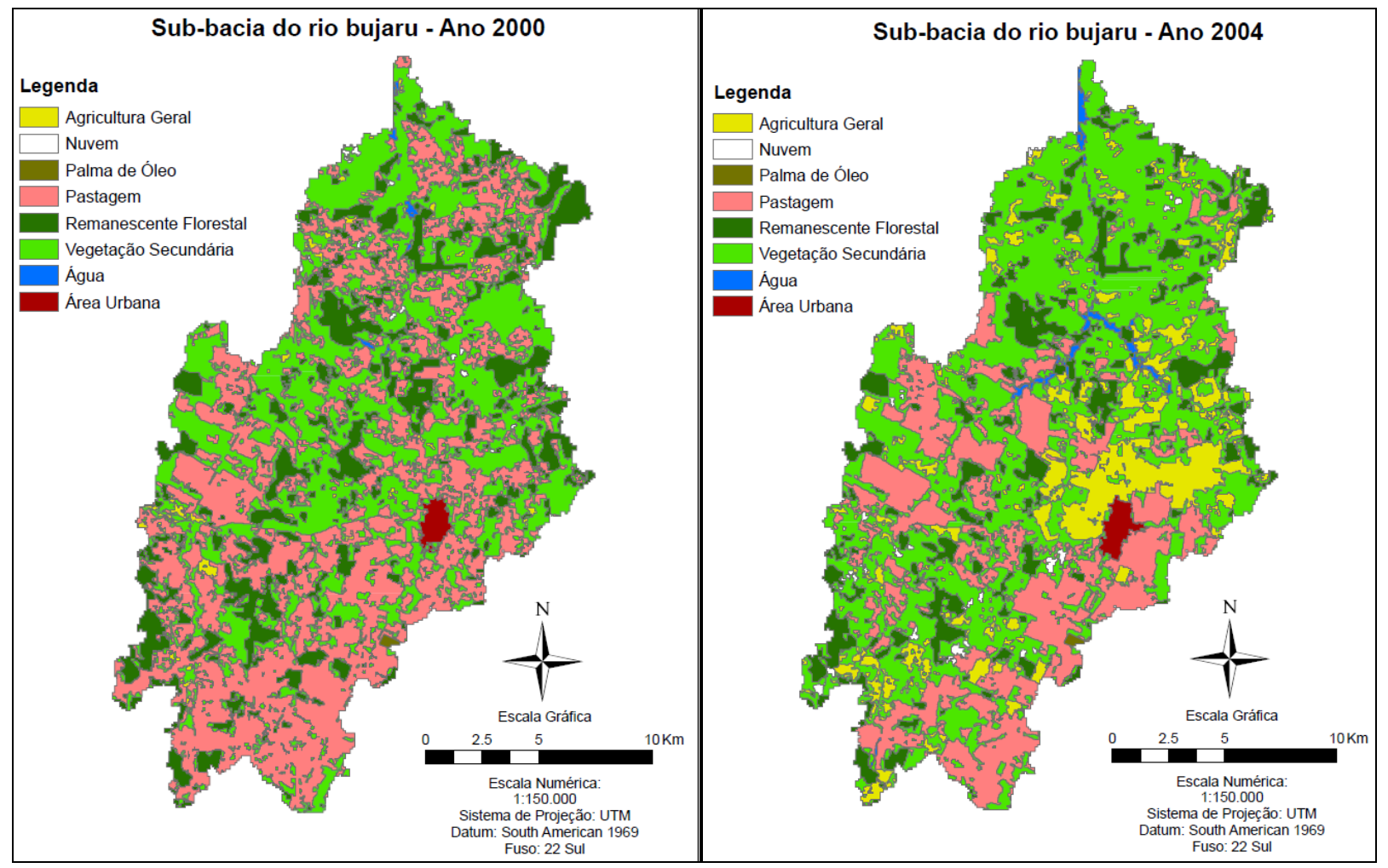

Figura 27: Mapas de uso e cobertura de 2000 e 2004 para a sub-bacia do rio Bujaru. 


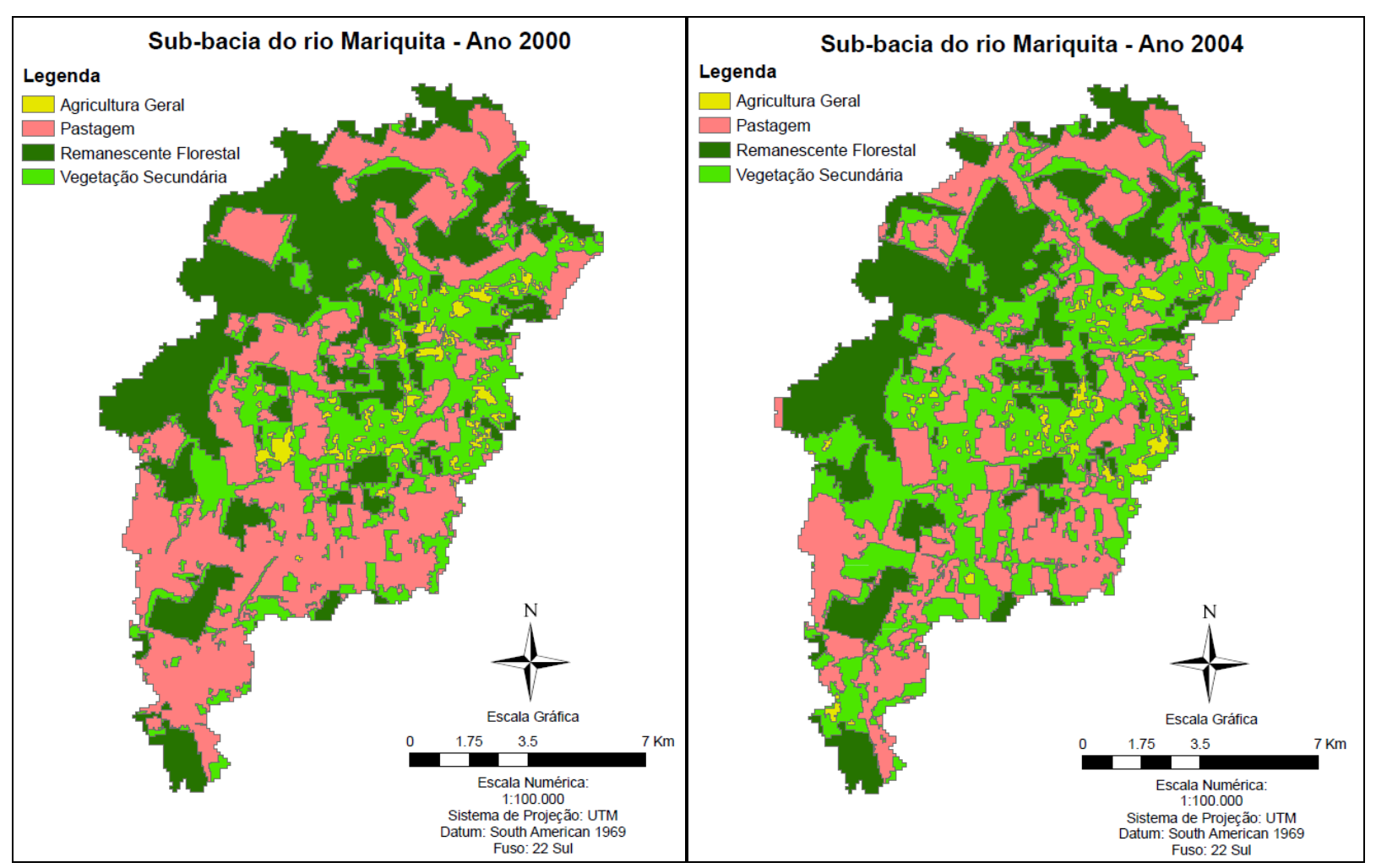

Figura 28: Mapas de uso e cobertura de 2000 e 2004 para a sub-bacia do rio Mariquita.

\subsubsection{Descrição das Mudanças de uso e cobertura de 2000 a 2013.}

$\mathrm{Na}$ Figura 29, relativa às mudanças de uso e cobertura da terra entre os anos de 2000, 2004, 2008 e 2013 na SBRB, observa-se uma característica cíclica das áreas de agropecuária (agricultura geral e pecuária) e das áreas de vegetação secundária, com aumento seguido de redução das áreas, o que é característico da região nordeste do estado do Pará. Esse efeito está diretamente relacionado à cultura de corte e queima da vegetação secundária para implantação de novas áreas de pastagem e agricultura geral, assim como ao abandono de áreas de pastagem degradadas e com solos exauridos por anos sequenciais de agricultura que são abandonas para entrarem em pousio (KATO et al., 2005). A Tabela 15 apresenta os valores das mudanças entre 2000 e 2013. 


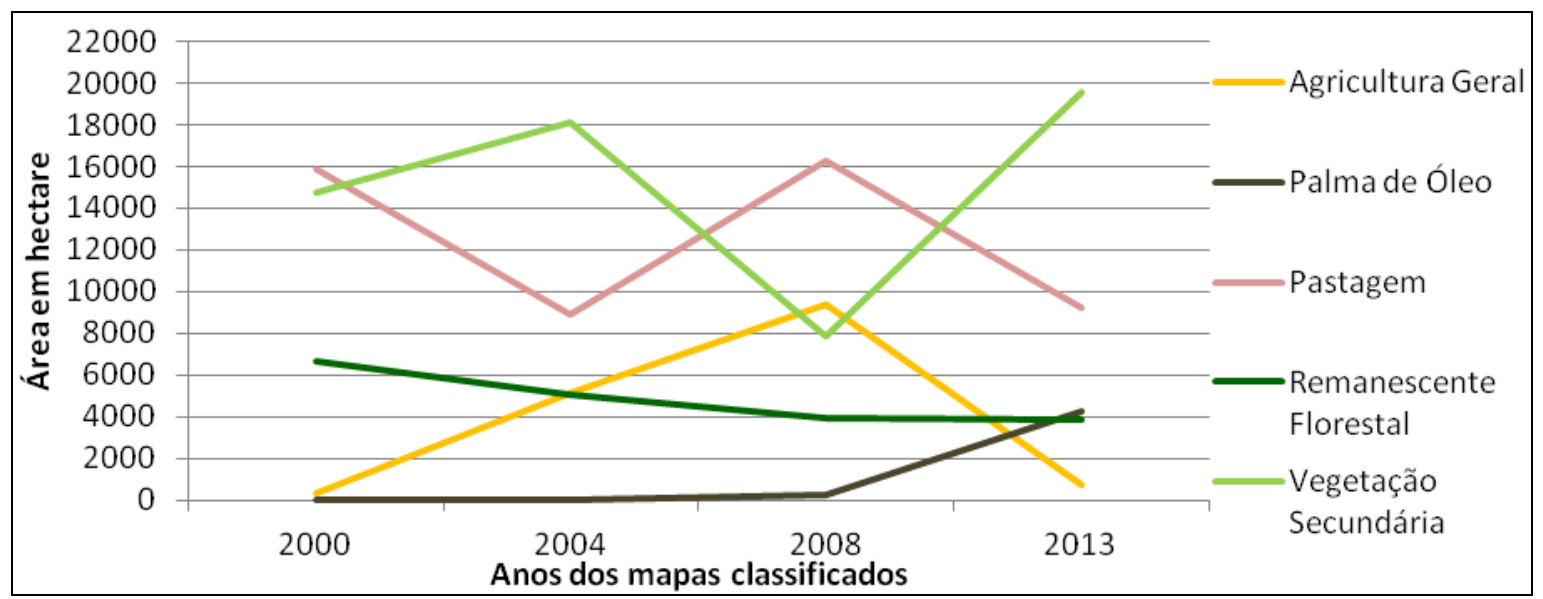

Figura 29: Gráfico de mudança de uso e cobertura da terra entre os anos de 2000, 2004, 2008 e 2013 na sub-bacia do rio Bujaru.

Tabela 15: Dinâmica da mudança do uso e cobertura da terra na sub-bacia do rio Bujaru entre os anos de 2000, 2004, 2008 e 2013.

\begin{tabular}{|c|c|c|c|c|c|c|c|c|}
\hline \multirow{2}{*}{$\begin{array}{l}\text { Classe de Uso } \\
\text { e Cobertura }\end{array}$} & \multicolumn{2}{|c|}{2000} & \multicolumn{2}{|c|}{2004} & \multicolumn{2}{|c|}{2008} & \multicolumn{2}{|c|}{2013} \\
\hline & Área (ha) & $\%$ & Área (ha) & $\%$ & Área (ha) & $\%$ & Área (ha) & $\%$ \\
\hline Palma de Óleo & 31 & 0,1 & 32 & 0,1 & 260 & 0,7 & 4.220 & 11,1 \\
\hline $\begin{array}{l}\text { Agricultura } \\
\text { Geral }\end{array}$ & 360 & 0,9 & 5.128 & 13,5 & 9.387 & 24,6 & 723 & 1,9 \\
\hline Pastagem & 15.889 & 41,7 & 8.882 & 23,3 & 16.263 & 42,7 & 9.188 & 24,1 \\
\hline $\begin{array}{l}\text { Remanescente } \\
\text { Florestal }\end{array}$ & 6.623 & 17,4 & 5.017 & 13,2 & 3.925 & 10,3 & 3.844 & 10,1 \\
\hline $\begin{array}{l}\text { Vegetação } \\
\text { Secundária }\end{array}$ & 14.773 & 38,8 & 18.100 & 47,5 & 7.833 & 20,5 & 19.569 & 51,3 \\
\hline Outros & 446 & 1,2 & 963 & 2,5 & 454 & 1,2 & 578 & 1,5 \\
\hline $\begin{array}{l}\text { Área total da } \\
\text { sub-bacia }\end{array}$ & \multicolumn{8}{|c|}{38.122} \\
\hline
\end{tabular}

Na SBRM (Figura 30 e Tabela 16), as áreas de agricultura geral são escassas nos 4 anos mapeados, sendo o seu território ocupado primordialmente por pastagens e vegetação secundária. Estes dois usos, em um primeiro momento tentem a seguir tendências inversas no gráfico, o que caracteriza um possível abandono de áreas com pastos degradados, mas que a partir de 2008 apresentam o mesmo comportamento de declínio de sua participação na área da sub-bacia.

Dessa forma, é importante ressaltar que a partir de 2010, têm-se um crescimento acelerado de palma de óleo em ambas sub-bacias, o que está relacionado diretamente aos investimentos feitos pelo governo brasileiro em 2010 para a expansão da cultura da palma de óleo (Dendê). Assim, a região começa a ter um aumento de áreas com a 
palma de óleo a partir de 2008, sendo este um movimento de expansão de uma cultura muito bem adaptada à região nordeste do Estado do Pará. De maneira geral a palma de óleo teve um crescimento expressivo na sub-bacia do rio Bujaru entre os anos de 2008 e 2013. Na sub-bacia do rio Mariquita a área passou de 0 ha para 2.308 ha. Esses números expressam bem o atual cenário de mudança de uso e cobertura da terra na região diante do potencial de expansão da palma de óleo.

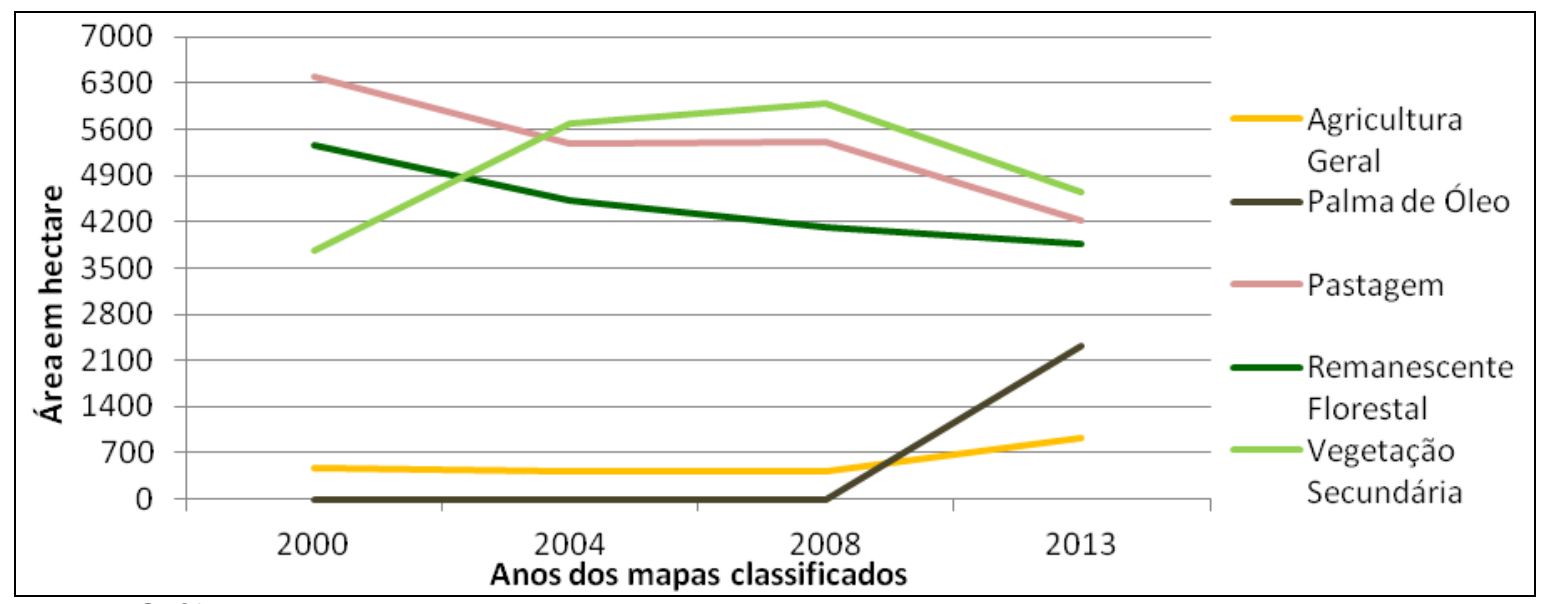

Figura 30: Gráfico de mudança de uso e cobertura da terra entre os anos de 2000, 2004, 2008 e 2013 na sub-bacia do rio Mariquita.

Tabela 16: Dinâmica da mudança do uso e cobertura da terra na sub-bacia do rio Mariquita entre os anos de 2000, 2004, 2008 e 2013.

\begin{tabular}{lcccccccc}
\hline $\begin{array}{l}\text { Classe de Uso } \\
\text { e Cobertura }\end{array}$ & \multicolumn{2}{c}{$\mathbf{2 0 0 0}$} & \multicolumn{2}{c}{$\mathbf{2 0 0 4}$} & \multicolumn{2}{c}{$\mathbf{2 0 0 8}$} & \multicolumn{2}{c}{$\mathbf{2 0 1 3}$} \\
\hline Área (ha) & $\%$ & Área (ha) & $\%$ & Área (ha) & $\%$ & Área (ha) & $\%$ \\
\hline $\begin{array}{l}\text { Agricultura } \\
\text { Geral }\end{array}$ & 0 & 0,0 & 0 & 0.0 & 0 & 0,0 & 2.308 & 14,4 \\
$\begin{array}{l}\text { Pastagem } \\
\text { Remanescente }\end{array}$ & 473 & 3,0 & 424 & 2,7 & 415 & 2,6 & 936 & 5,9 \\
$\begin{array}{l}\text { Florestal } \\
\text { Vegetação }\end{array}$ & 5.385 & 39,9 & 5.373 & 33,6 & 5.420 & 33,9 & 4.221 & 26,4 \\
$\begin{array}{l}\text { Secundária } \\
\text { Outros }\end{array}$ & 3.775 & 23,6 & 5.682 & 35,5 & 6.003 & 37,5 & 4.643 & 29,0 \\
\hline $\begin{array}{l}\text { Área Total da } \\
\text { sub-bacia }\end{array}$ & 0 & 0,0 & 0 & 0,0 & 25 & 0,2 & 19 & 0,1 \\
\hline
\end{tabular}


6.1.4 Mapa de uso e cobertura da terra do ano de 2010 utilizado na modelagem da porção média do rio Capim.

Na Figura 31 e na Tabela 17 seguem o mapa de uso e cobertura da terra utilizado na simulação da porção média da bacia do rio Capim com o modelo SWAT com a representatividade em hectares de cada classe. Todos os dados de entrada no modelo SWAT relativos à classe Reflorestamento foram obtidos de estudos sobre a árvore do Eucalipto.

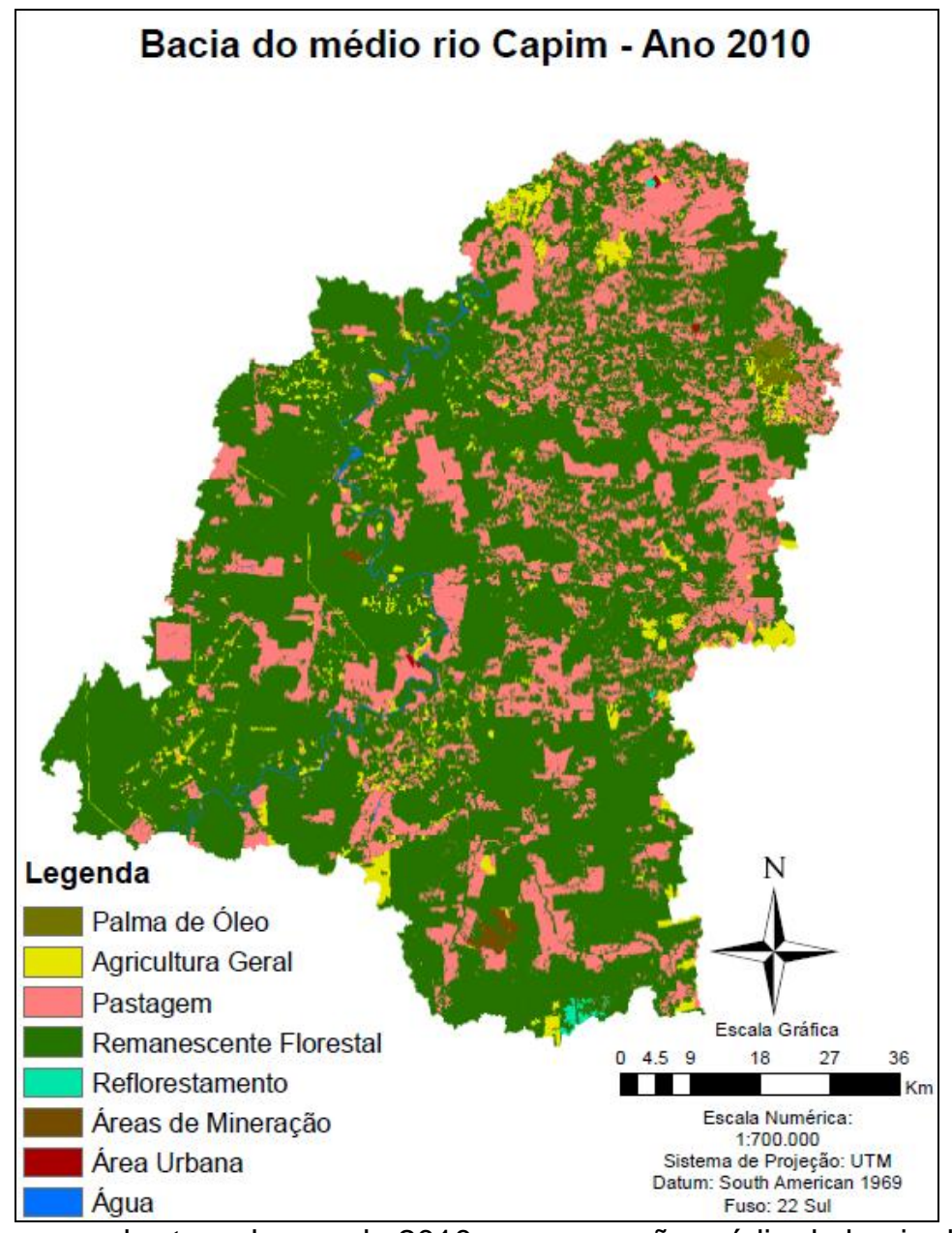

Figura 31: Mapa de uso e cobertura do ano de 2010 para a porção média da bacia do rio Capim. 
Tabela 17: Distribuição de áreas para cada uso e cobertura do mapa de 2010 para a porção média da bacia do rio Capim em hectares.

\begin{tabular}{lcc}
\hline Uso e Cobertura & Área (ha) & Área (\%) \\
\hline Palma de Óleo & 2.131 & 0,32 \\
Agricultura Geral & 22.883 & 3,38 \\
Pastagem & 162.363 & 24,1 \\
Remanescente Florestal & 480.927 & 71,27 \\
Reflorestamento & 1.009 & 0,14 \\
Áreas de Mineração & 2.061 & 0,30 \\
Área Urbana & 316 & 0,05 \\
Água & 3.009 & 0,44 \\
\hline TOTAL & $\mathbf{6 7 4 . 6 9 9}$ & $\mathbf{1 0 0 , 0 0}$ \\
\hline
\end{tabular}

\subsection{MODELO DIGITAL DE ELEVAÇÃO DO TERRENO (MDE).}

Nas Figuras 32 e 33 são apresentados os MDE's das SBRB e SBRM. O MDE do rio Bujaru apresenta altitude variando de $2 \mathrm{~m}$ no exultório até $76 \mathrm{~m}$ nas áreas de nascentes, com uma média de $39 \mathrm{~m}$. Na sub-bacia do rio Mariquita, a altitude variou de $16 \mathrm{~m}$ a $66 \mathrm{~m}$, com média de $42 \mathrm{~m}$. Em ambas as sub-bacias ocorre a predominância de declividade entre $0-3 \%$ (plano) e de $3-13 \%$ (suave a moderadamente ondulado), totalizando 99,9\%. Na sub-bacia do rio Bujarua, cerca de $51,9 \%$ é de relevo suave e $48,9 \%$ é moderado. Na sub-bacia do rio Mariquita estes valores correspondem a 66,2 e $33,7 \%$ para relevos suave e moderado, respectivamente.

Torna-se importante justificar as características do MDE da sub-bacia do rio Mariquita, pois o mesmo apresenta influência do Efeito Dossel do dado SRTM, que segundo Valeriano (2008), corresponde a identificação de objetos topográficos pelos sensores, como prédios e árvores. Por essa razão, no momento do delineamento da bacia do rio Mariquita foram adotadas algumas etapas a mais, como o delineamento manual da hidrografia para auxiliar na definição correta da sua área de contribuição. 


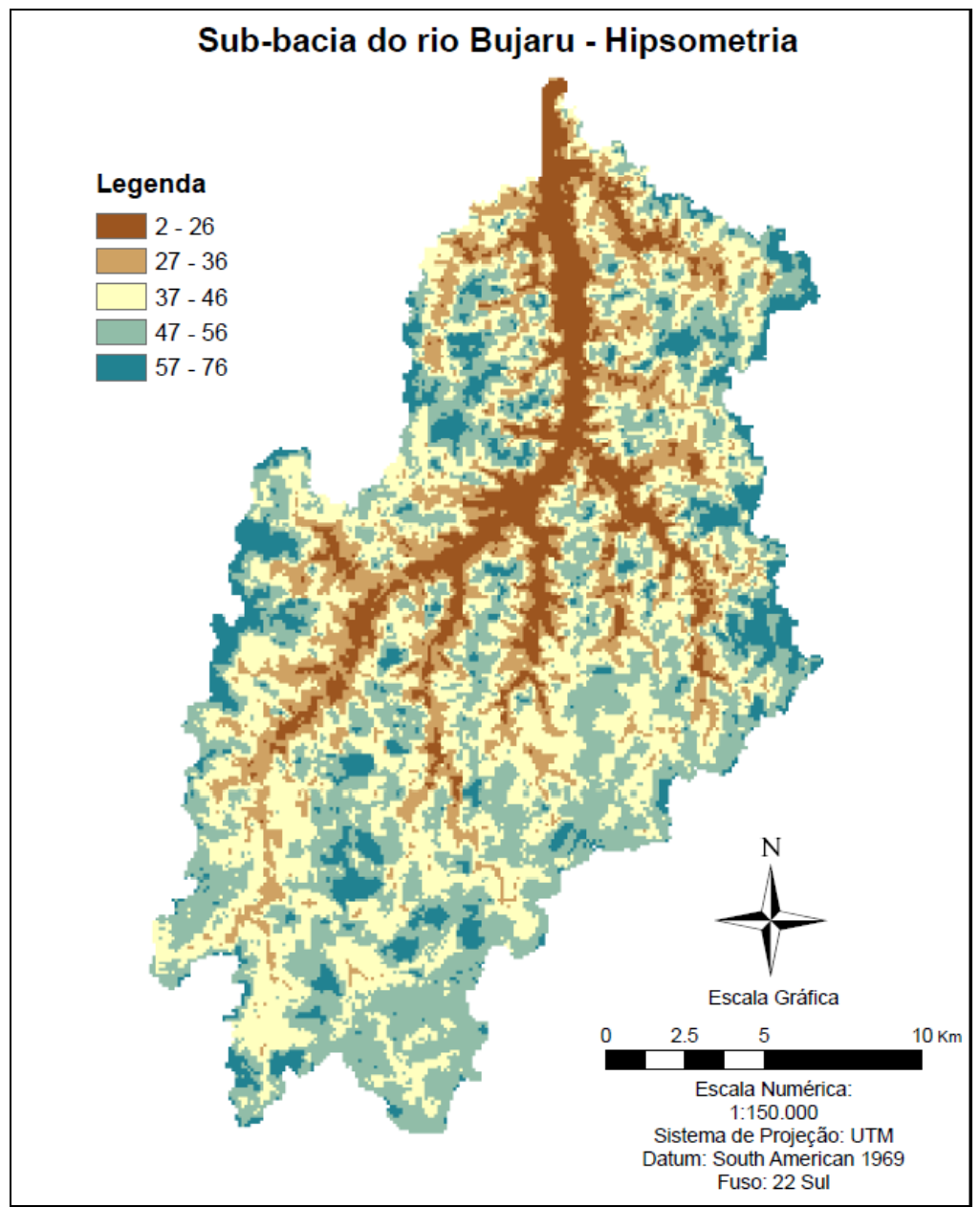

Figura 32: Modelo digital de elevação do terreno da sub-bacia do rio Bujaru. 


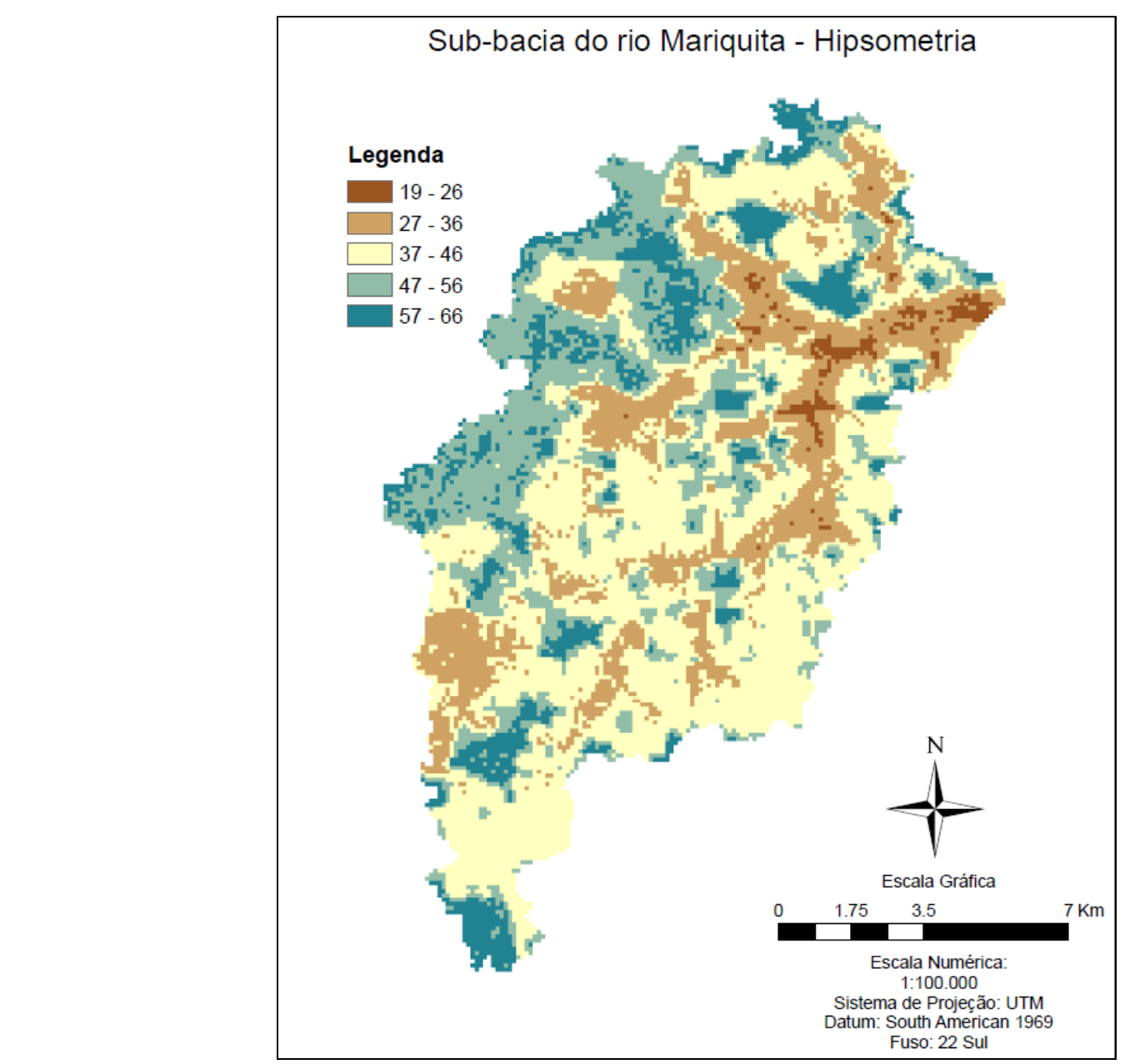

Figura 33: Modelo digital de elevação do terreno da sub-bacia do rio Mariquita.

Na Figura 34 é apresentado o MDE da porção média da bacia do rio Capim, dado base deste modelo. Este dado expressa que essa parte do rio Capim apresenta altitudes variando de $2 \mathrm{~m}$ a $208 \mathrm{~m}$, com média de $104 \mathrm{~m}$, também tendo predominância de declividade entre $0-3 \%$ (plano) e de $3-13 \%$ (suave a moderadamente ondulado), totalizando $97,5 \%$ da área total da bacia. 


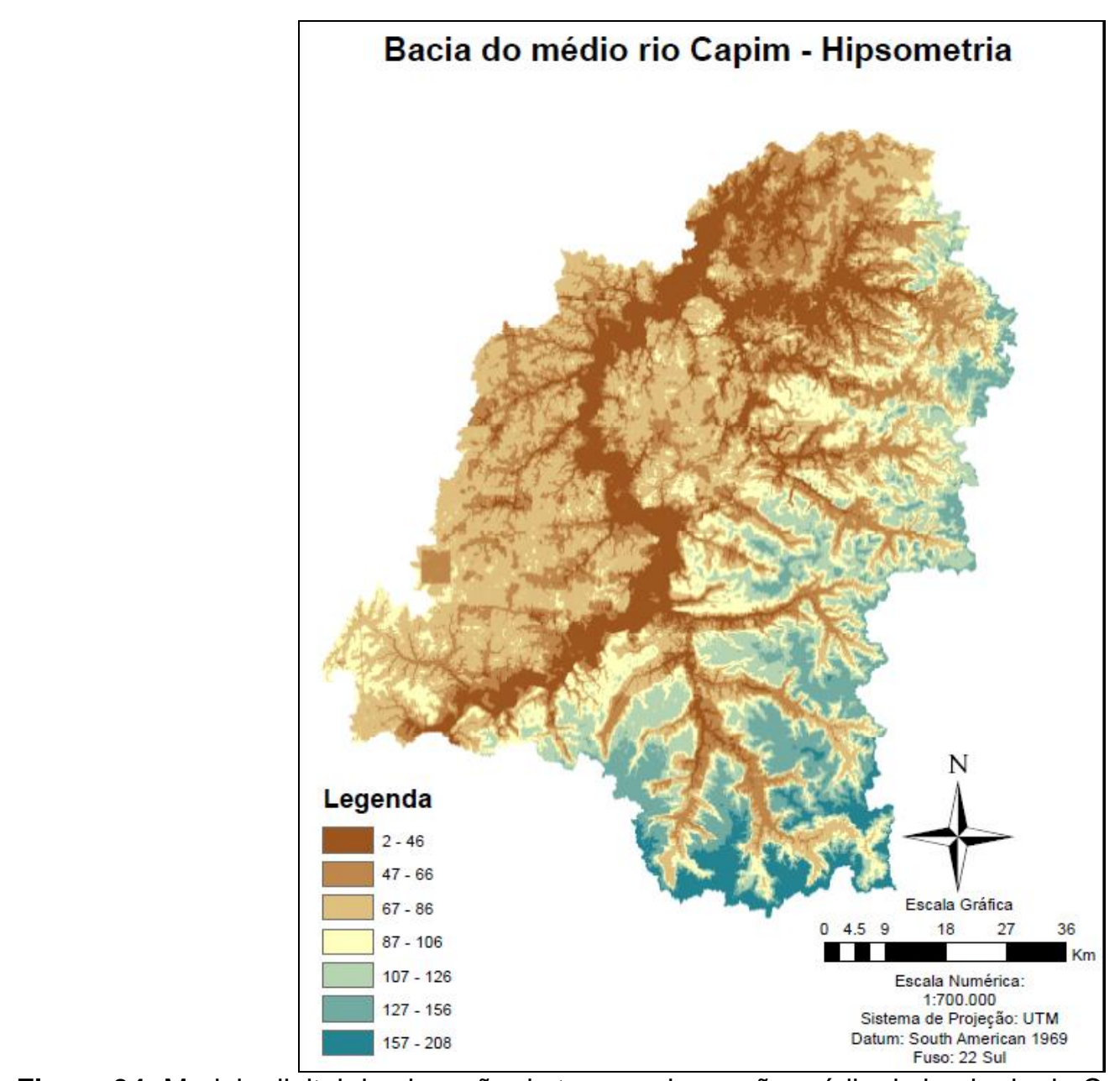

Figura 34: Modelo digital de elevação do terreno da porção média da bacia do rio Capim.

\subsection{MAPA PEDOLÓGICO.}

As Figuras 35 e 36 apresentam os mapas pedológicos das sub-bacias SBRB e SBRM utilizadas nas simulações com o Modelo SWAT, os quais foram compostos apenas da classe geral de LATOSSOLO AMARELO Distrófico, mas nas simulações com o CLUE-S foi utilizado os mapas conforme apresentados abaixo, uma vez que se optou por verificar se realmente há alguma influência dessas classes nas alocações de uso e cobertura do solo. Para a modelagem com o SWAT, optou-se por não usar estes mapas, devido não haver um mapeamento mais refinado da real distribuição geográfica das classes de solo não predominantes, sendo que a aplicação indevida deste mapa 
agregaria mais incertezas aos resultados simulados. Na Figura 37 é apresentado o mapa de solos da simulação do médio rio Capim.

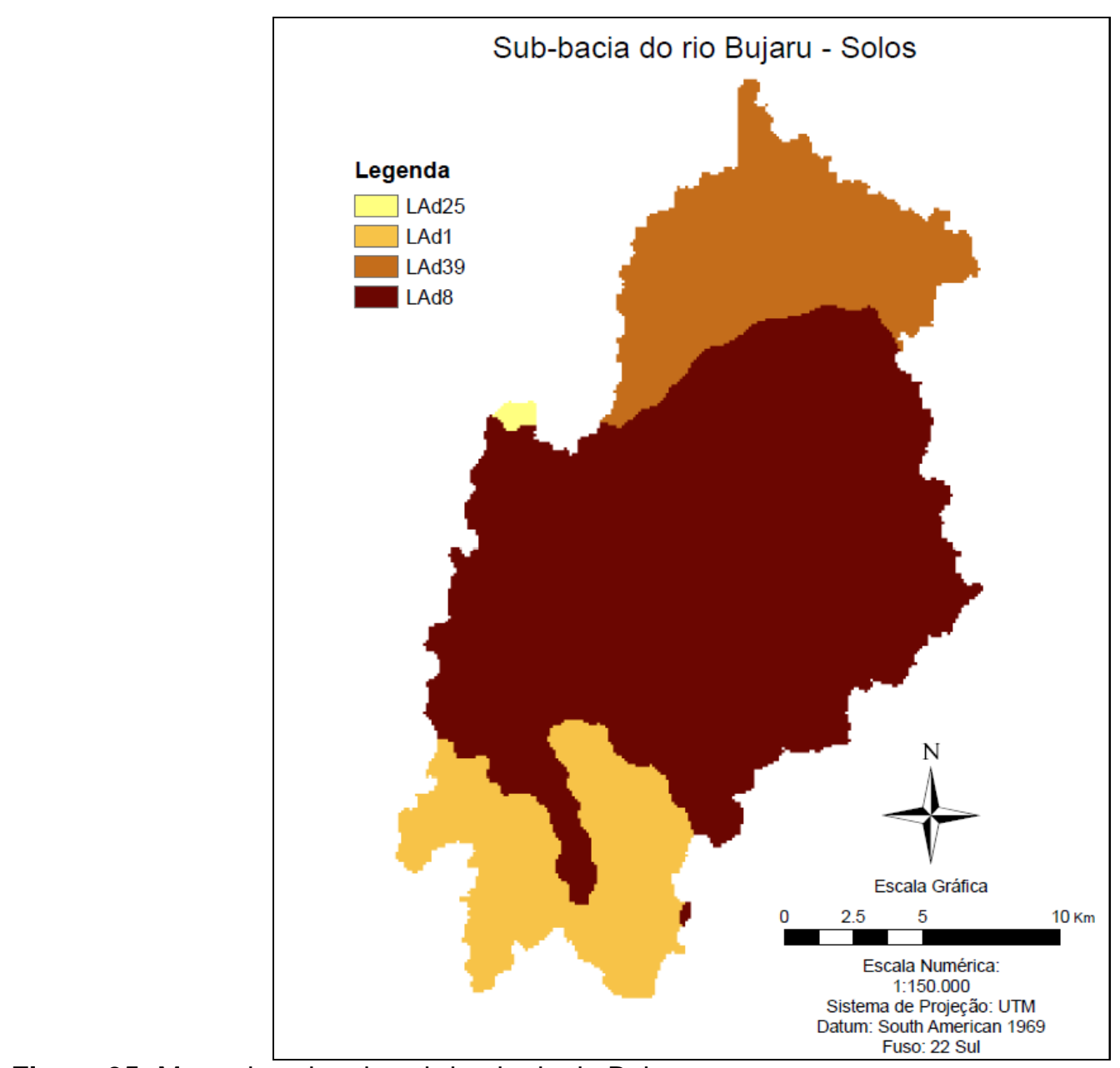

Figura 35: Mapa de solos da sub-bacia do rio Bujaru. 


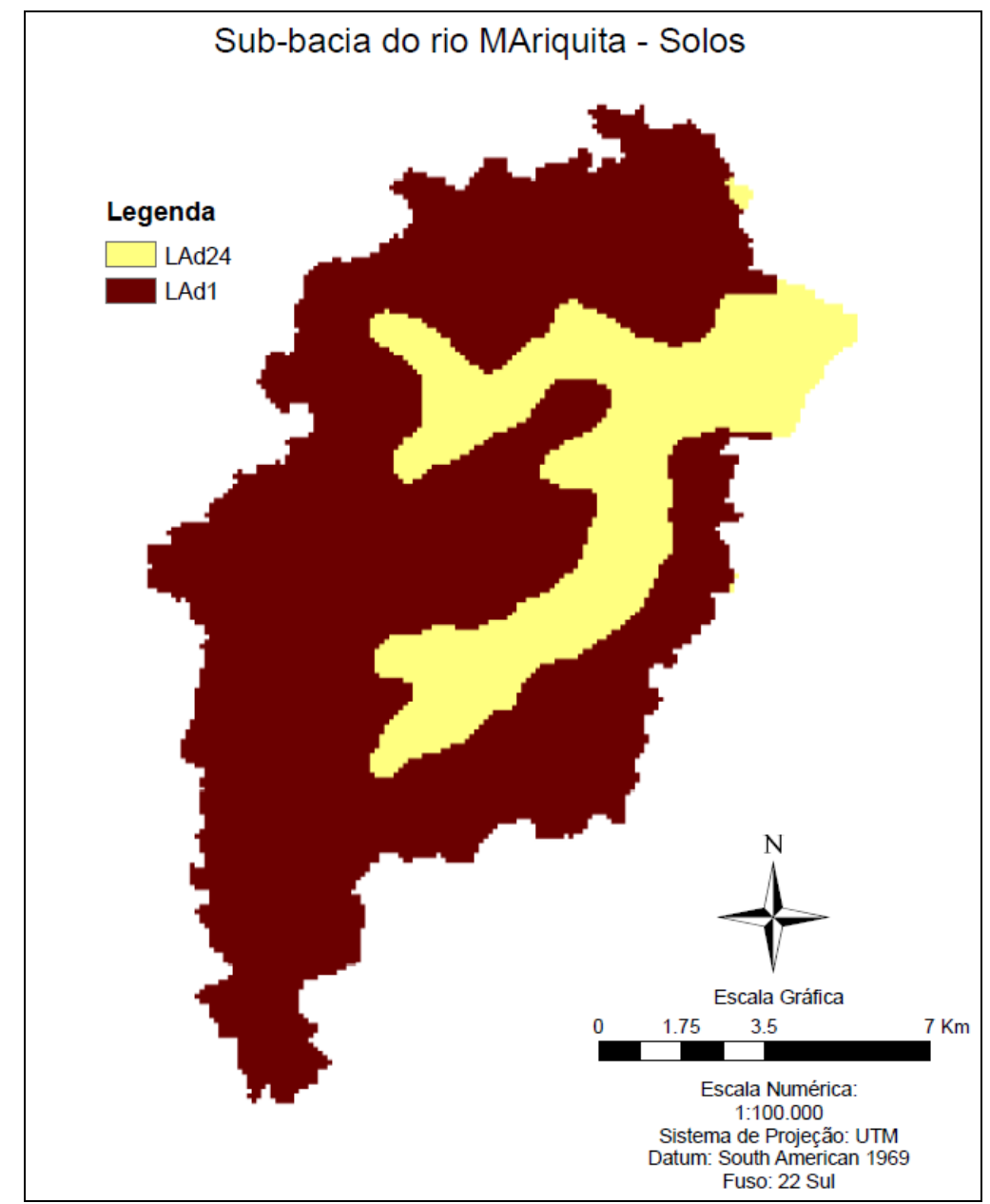

Figura 36: Mapa de solos da sub-bacia do rio Mariquita. 


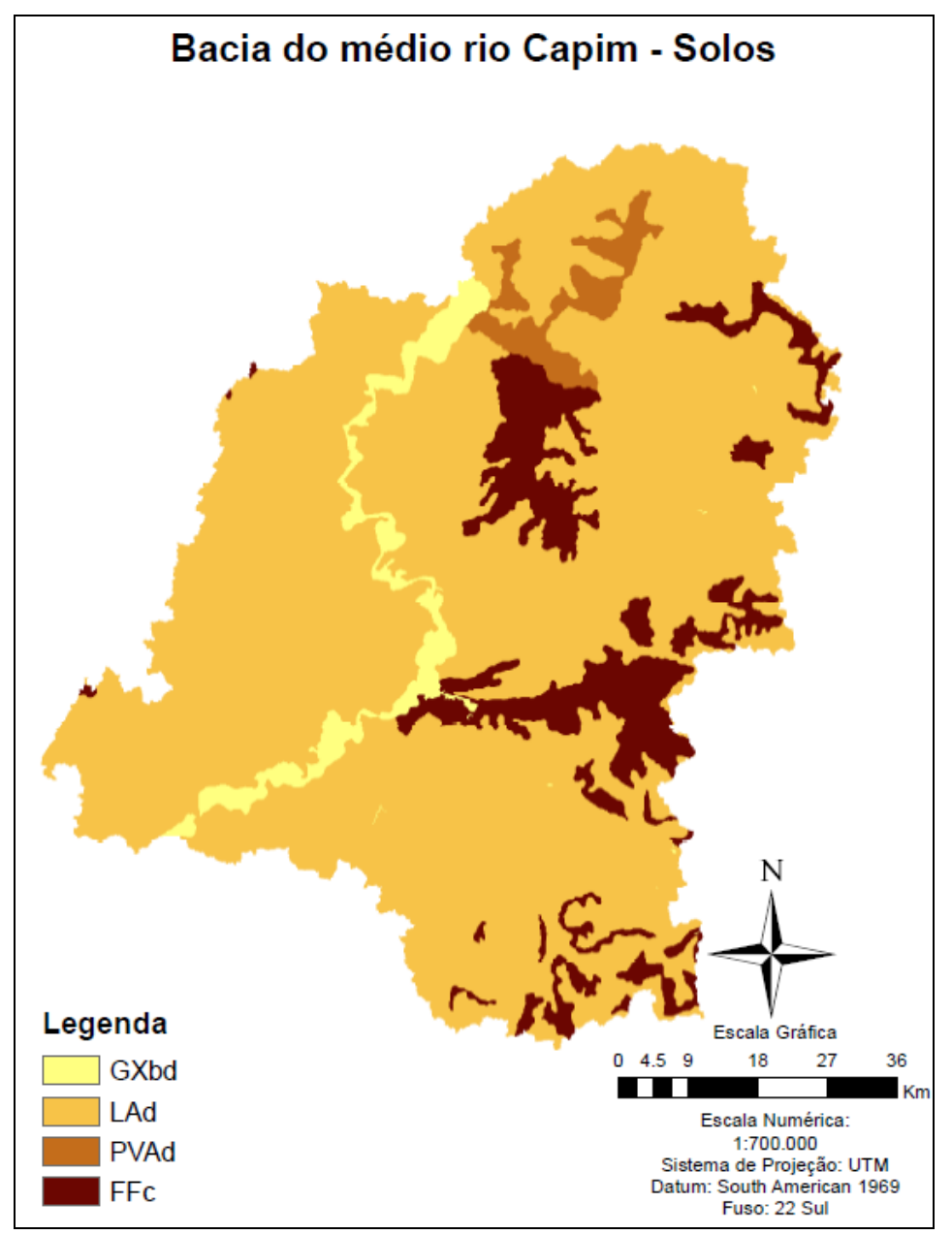

Figura 37: Mapa de solos da porção média da bacia do rio Capim.

\subsection{RESULTADOS DA APLICAÇÃO DO MODELO SWAT.}

\subsubsection{Delineamento automático das bacias.}

O processo de deliminação das bacias e sub-bacias foi o primeiro passo da modelagem com o SWAT, o qual foi realizado no Módulo Watershad Delineator do ArcSWAT (Figura 38). Em ambas sub-bacias em estudo, Bujaru e Mariquita, foi inserido o Modelo Digital de Elevação do Terreno (MDE), e a partir deste, iniciou-se os trabalhos. 


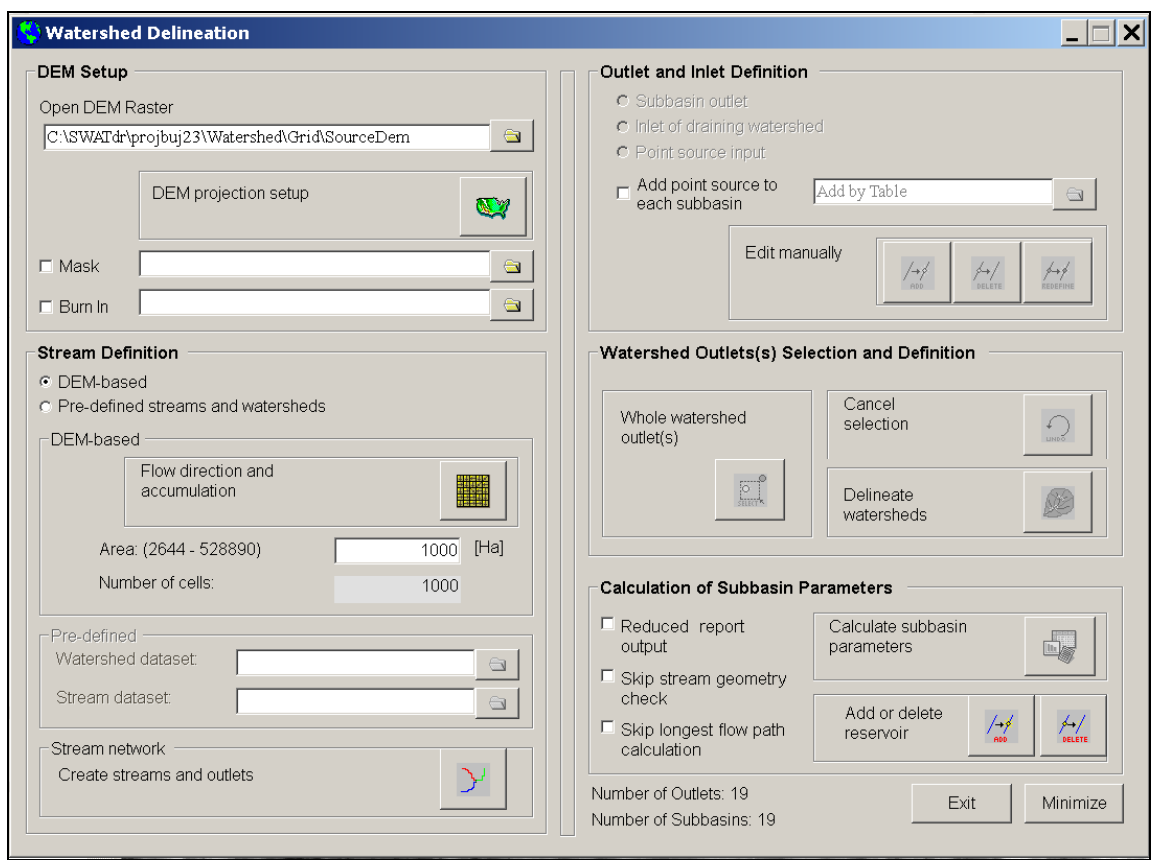

Figura 38: Interface do módulo Watershed Delineator do ArcSWAT 2009.

Em especial para a sub-bacia do rio Mariquita, cujo MDE SRTM apresentou problemas de influência do Efeito Dossel, o SWAT estava delineando incorretamente a bacia. Para solucionar o problema foi necessário adotar duas medidas técnicas para auxiliar o SWAT a delinear corretamente a hidrografia: primeiramente foi desenhada manualmente a rede hidrográfica através da vetorização sobre imagens do Google Earth, sendo esta rede hidrográfica inserida no SWAT em seguida para auxiliar a interface ArcSWAT a interpretar corretamente o caminho dos curso d'água; A segunda medida foi o ajuste manual no MDE, no ponto onde persistiu o erro de delineamento, através do aumento do valor da altitude para não ocorrer união de sub-bacias diferentes, o que vinha aumentando o tamanho real da bacia.

Feito os devidos ajustes, foram geradas as sub-bacias dos rios Bujaru e Mariquita, utilizando o limiar mínimo para geração das sub-bacias de 1000 ha (1000 células), que corresponde ao tamanho de referência para definição do tamanho de uma micro-bacia (FAUSTINO, 1996). Dessa forma, foi criado o número máximo de subbacias, dentro do limiar pré-definido, totalizando 19 sub-bacias para o rio Bujaru e 11 sub-bacias para o rio Mariquita, sendo o exutório de análise em ambas a sub-bacia de número 1 (Figura 39 e 40). Para o modelo do médio rio Capim, utilizou-se um limiar de 9000 ha, devido ao maior tamanho desta (Figura 41). 


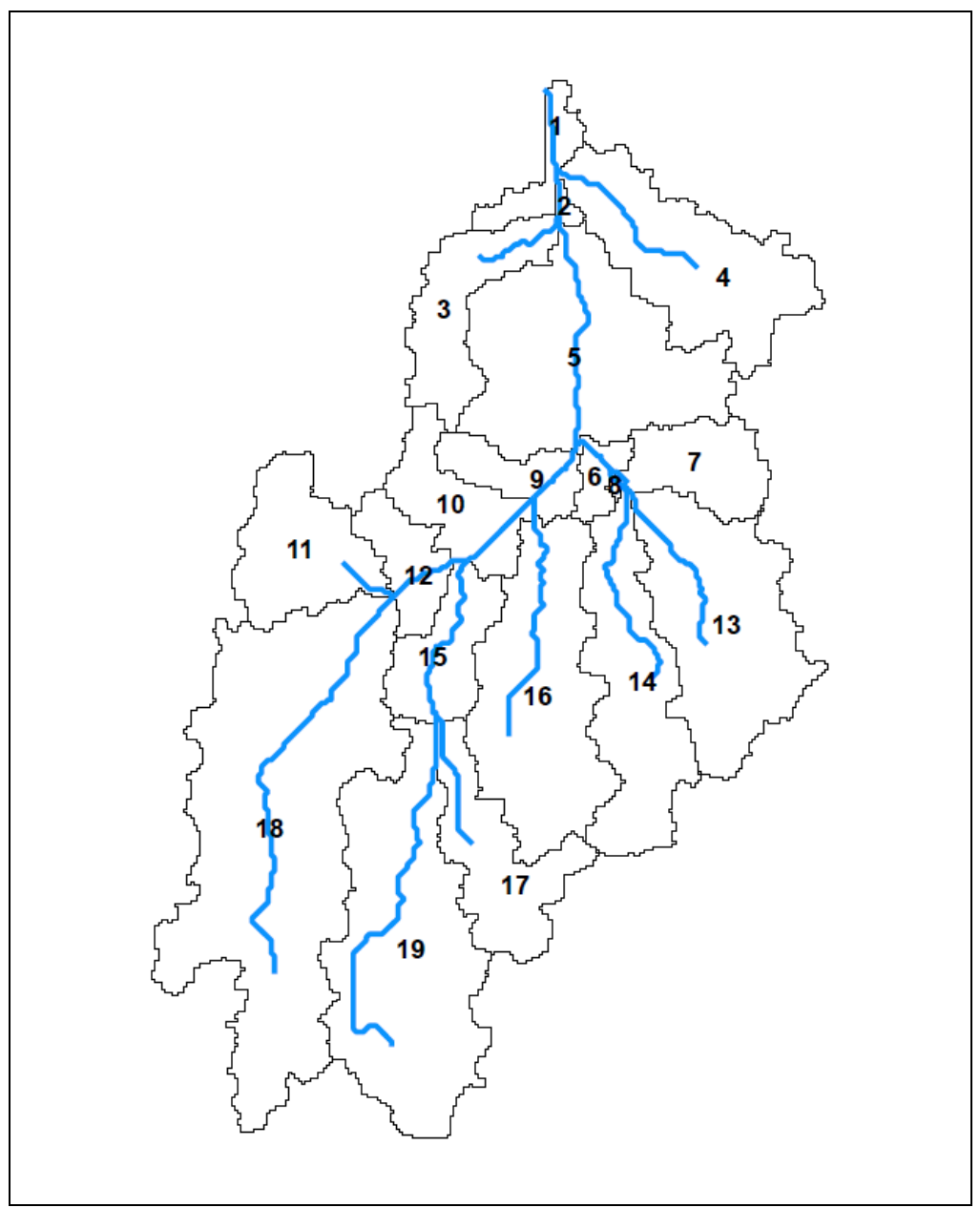

Figura 39: Sub-bacias e hidrografia delineadas pelo modelo SWAT para a sub-bacia do rio Bujaru. 


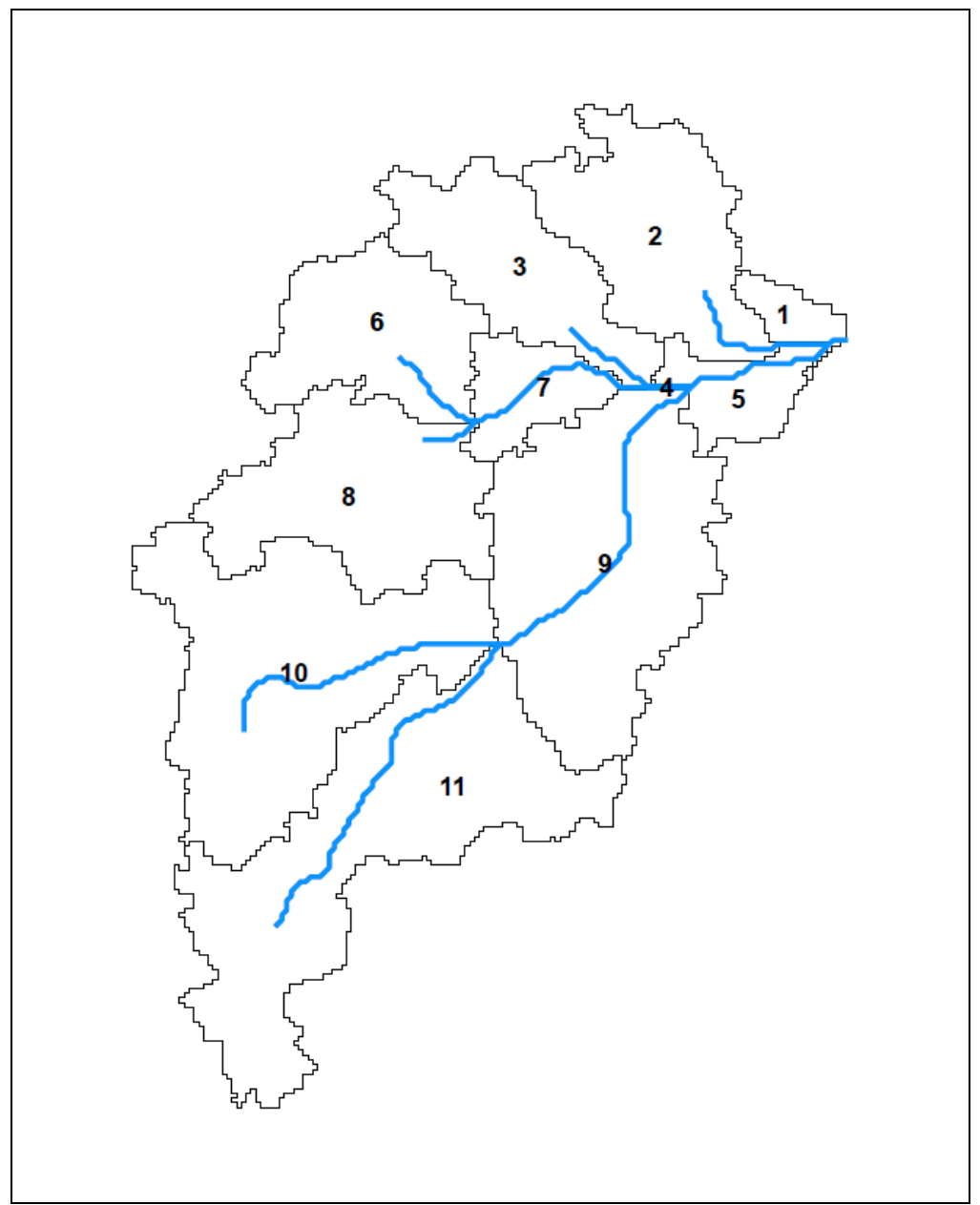

Figura 40: Sub-bacias e hidrografia delineadas pelo modelo SWAT para a sub-bacia do rio Mariquita. 


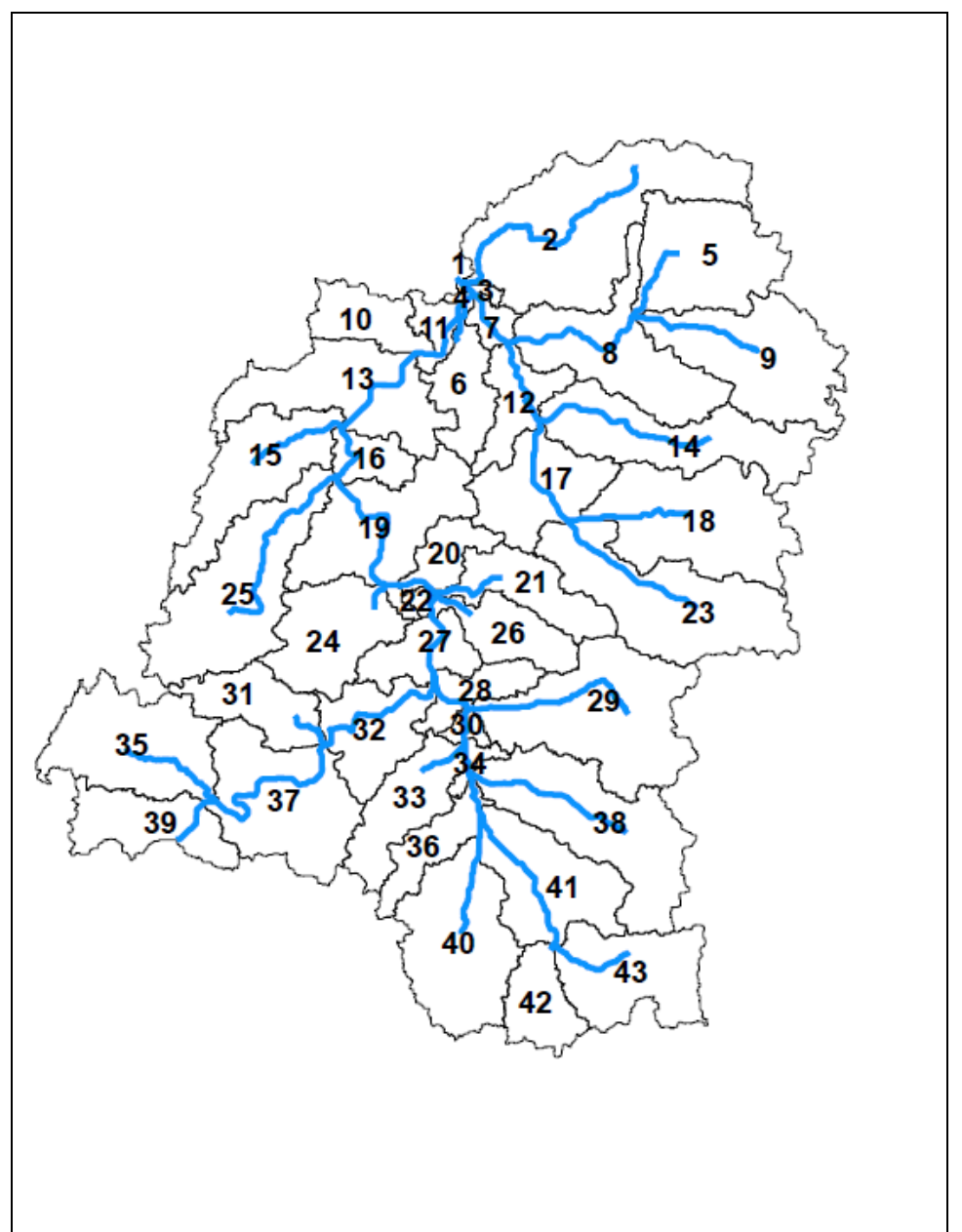

Figura 41: Sub-bacias e hidrografia delineadas pelo modelo SWAT para a porção média da bacia do rio Capim.

\subsubsection{Unidades de Resposta Hidrológica - HRU's.}

A definiçao das HRU's se iniciou pela inserção do mapa de uso e cobertura da terra adaptado para SWAT. Nas simulações com o SWAT, as classes "Remanescente Florestal" e "Vegetação Secundária" foram unificadas, permanecendo a nova classe com o nome de "Remanescente Florestal", conforme Quadro 2. Após a reclassificação feito no ArcSWAT, as classes ficaram com uma nova configuração, conforme Tabela 18. A classe "Reflorestamento" presente no mapa de uso e cobertura da terra da porção média da bacia do rio Capim foi reclassificada como eucalipto no SWAT (EUCA). Importante ressaltar, que foi inserido um pixel (1 ha) com Palma de Óleo na sub-bacia 
do rio Mariquita, objetivanto ter essa classe, mesmo que em uma pequena porção, no processo de calibração, mas prioritariamente por razão de que na calibração do CLUE$S$ de 2008 para 2013, todos os mapas devem ter alguma porcentagem de área com palma de óleo e no ano de 2008 não havia ainda palma de óleo.

Tabela 18: Classes de uso e cobertura representadas no SWAT.

\begin{tabular}{lc}
\hline Código SWAT & USO SUBBACIA \\
\hline AGRL & Agricultura Geral \\
OILP & Palma de Óleo \\
PAST & Pastagem \\
FRSE & Remanescente Florestal \\
WATR & Água \\
URMD & Área Urbana \\
EUCA & Reflorestamento \\
\hline
\end{tabular}

Quanto à coberta do tipo de solo, todas as sub-bacias estavam cobertas $100 \%$ com LATOSSOLO AMARELO Distrófico no presente estudo. No entando, as áreas foram discretizadas quanto às classes de rampa, sendo estas definidas de acordo com os graus de limitação por impedimento à mecanização na cultura da palma de óleo propostos no Zoneamento Agroecológico da Palma (RAMALHO FILHO, 2010). As classes foram divididas de 0-3\% (Grau Nulo); 3-13\% (Grau Ligeiro); 13-20\% (Grau Moderado); e de 20 em diante (Grau Forte e Muito Forte) (Tabelas 19, 20 e 21).

Tabela 19: Classes de rampa e suas respectivas representatividades de área para a sub-bacia do rio Bujaru.

\begin{tabular}{lcc}
\hline Rampa (\%) & Área (ha) & Área (\%) \\
\hline $0-3$ & 18.279 & 47,95 \\
$3-13$ & 19.811 & 51,97 \\
$13-20$ & 32 & 0,08 \\
$>20$ & 0 & 0 \\
\hline TOTAL & $\mathbf{3 8 . 1 2 2}$ & $\mathbf{1 0 0 , 0 0}$ \\
\hline
\end{tabular}

Tabela 20: Classes de rampa e suas respectivas representatividades de área para a sub-bacia do rio Mariquita.

\begin{tabular}{lcc}
\hline Rampa (\%) & Área (ha) & Área (\%) \\
\hline $0-3$ & 10.594 & 66,24 \\
$3-13$ & 5.399 & 33,76 \\
$13-20$ & 1 & 0,0063 \\
$>20$ & 0 & 0 \\
\hline TOTAL & $\mathbf{1 5 . 9 9 4}$ & $\mathbf{1 0 0 , 0 0}$ \\
\hline
\end{tabular}


Tabela 21: Classes de rampa e suas respectivas representatividades de área para a porção média da bacia do rio Capim.

\begin{tabular}{lcc}
\hline Rampa (\%) & Área (ha) & Área (\%) \\
\hline $0-3$ & 304.269 & 45,07 \\
$3-13$ & 354.276 & 52,48 \\
$13-20$ & 14.034 & 2,09 \\
$>20$ & 2.491 & 0,36 \\
\hline TOTAL & $\mathbf{6 7 5 . 0 7 0}$ & $\mathbf{1 0 0 , 0 0}$ \\
\hline
\end{tabular}

Por fim, após definidas as classes de uso e cobertura da terra, tipo e declividade do solo, foram criadas as HRU's aplicando o método de geração de "Múltiplas HRU's", onde não foi desconsiderada nenhuma combinação de uso e cobertura, tipo e declividade do solo. Assim, foi gerado um total de $146 \mathrm{HRU}$ 's para a sub-bacia do rio Bujaru, 62 HRU's para o Mariquita e 954 HRU's para a porção média da bacia do rio Capim.

\subsubsection{Dados Tabulares.}

\subsubsection{Clima.}

A inserção dos dados das estações climáticas, que correspondem as informações das Weather Genarator e as séries de 2003 a 2014 de precipitação, temperatura do ar, humidade relativa do ar, radiação solar e velocidade do vento, foi feita diretamente no ArcSWAT no módulo de simulação Weather Data Definition (Figura 42). Os dados inseridos em cada uma das três Weather Generator (WGN_user) utilizadas na tese estão expressos nas Tabelas 22, 23 e 24. 


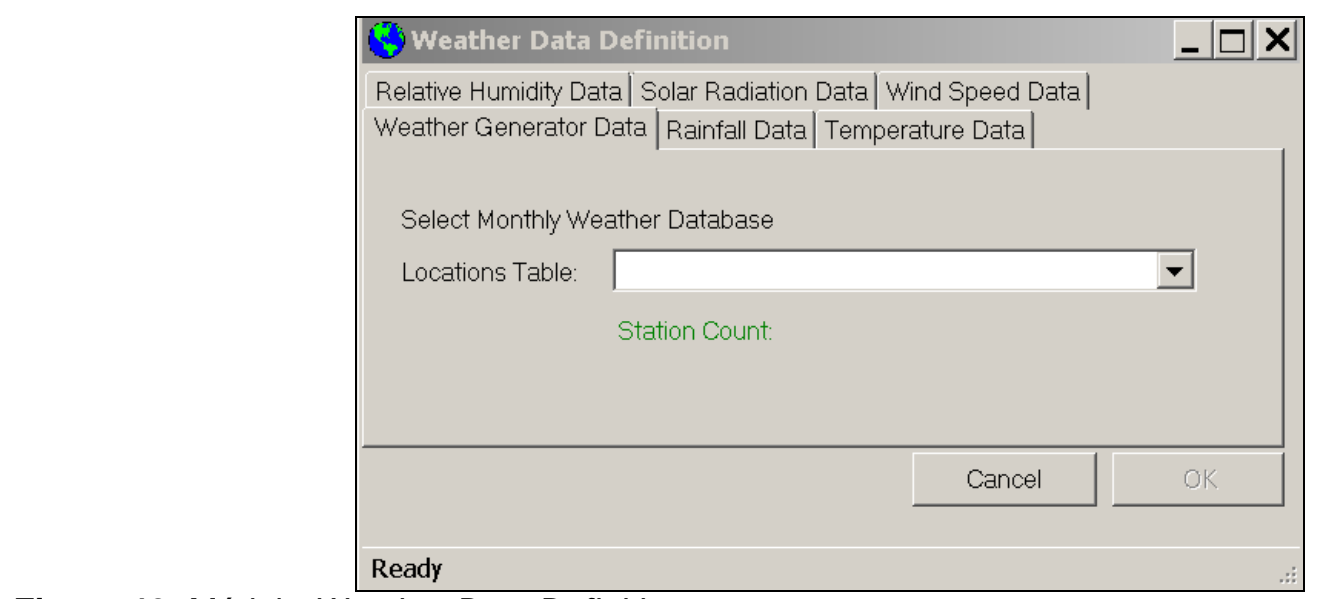

Figura 42: Módulo Weather Data Definition.

Tabela 22: Parâmetros climáticos inseridos na WGN_user INMET_A202, localizada no município de Castanhal, PA, calculados a partir da série de 2003 a 2014.

\begin{tabular}{lcccccccccccc}
\hline Parâmetros & Jan & Fev & Mar & Abr & Mai & Jun & Jul & Ago & Set & Out & Nov & Dez \\
\hline TMPMX & 31,9 & 31,1 & 31,1 & 31,3 & 31,7 & 31,9 & 32,0 & 32,6 & 33,2 & 33,7 & 33,8 & 33,1 \\
TMPMN & 23,2 & 23,2 & 23,2 & 23,1 & 22,9 & 22,5 & 22,6 & 22,8 & 22,8 & 22,6 & 22,8 & 23,0 \\
TMPSTDMX & 0,6 & 0,9 & 0,6 & 0,4 & 0,4 & 0,3 & 0,3 & 0,2 & 0,3 & 0,2 & 0,3 & 0,6 \\
TMPSTDMN & 0,3 & 0,3 & 0,3 & 0,1 & 0,2 & 0,2 & 0,2 & 0,2 & 0,2 & 0,3 & 0,3 & 0,3 \\
PCPMM & 289,5 & 319,1 & 367,2 & 393,3 & 290,6 & 169,9 & 120,8 & 79,2 & 60,5 & 66,2 & 94,1 & 184,4 \\
PCPSTD & 9,9 & 10,2 & 10,3 & 11,1 & 10,1 & 7,8 & 5,5 & 4,9 & 3,6 & 3,7 & 6,0 & 8,5 \\
PCPSKW & 1,7 & 1,5 & 1,5 & 1,3 & 1,9 & 3,3 & 2,3 & 3,2 & 2,5 & 2,9 & 3,3 & 2,3 \\
PR_W1 & 0,1 & 0,1 & 0,0 & 0,0 & 0,1 & 0,2 & 0,1 & 0,2 & 0,2 & 0,2 & 0,2 & 0,2 \\
PR_W2 & 0,8 & 0,8 & 0,9 & 1,0 & 0,8 & 0,6 & 0,5 & 0,4 & 0,2 & 0,3 & 0,4 & 0,6 \\
PCPD & 27,5 & 26,3 & 29,6 & 29,2 & 27,7 & 23,1 & 21,6 & 14,7 & 14,8 & 15,1 & 16,1 & 23,5 \\
RAINHHMX & 19,0 & 23,8 & 20,9 & 19,5 & 20,4 & 24,1 & 10,9 & 12,7 & 6,6 & 9,5 & 15,1 & 16,1 \\
SOLARAV & 14,1 & 13,4 & 13,9 & 14,7 & 15,6 & 16,5 & 16,2 & 16,2 & 17,3 & 16,5 & 16,7 & 15,4 \\
DEWPT & 23,3 & 23,6 & 23,7 & 23,6 & 23,5 & 23,0 & 22,5 & 22,6 & 22,3 & 22,1 & 22,1 & 22,5 \\
WNDAV & 2,1 & 2,0 & 1,8 & 1,6 & 1,7 & 1,8 & 2,0 & 2,3 & 2,6 & 2,6 & 2,6 & 2,3 \\
\hline
\end{tabular}

Tabela 23: Parâmetros climáticos inseridos na WGN_user INMET_A213, localizada no município de Tomé-Açu, PA, calculados a partir da série de 2008 a 2014.

\begin{tabular}{lcccccccccccc}
\hline Parâmetros & Jan & Fev & Mar & Abr & Mai & Jun & Jul & Ago & Set & Out & Nov & Dez \\
\hline TMPMX & 31,5 & 31,2 & 31,5 & 31,3 & 31,6 & 31,7 & 32,1 & 32,9 & 33,7 & 34,0 & 33,4 & 32,6 \\
TMPMN & 22,6 & 22,5 & 22,9 & 23,0 & 22,9 & 22,3 & 22,4 & 22,4 & 22,4 & 22,0 & 22,4 & 22,7 \\
TMPSTDMX & 0,7 & 0,8 & 0,5 & 0,4 & 0,4 & 0,3 & 0,4 & 0,4 & 0,4 & 0,4 & 0,4 & 0,5 \\
TMPSTDMN & 0,3 & 0,3 & 0,2 & 0,2 & 0,2 & 0,3 & 0,5 & 0,8 & 0,6 & 0,3 & 0,4 & 0,3 \\
PCPMM & 306,8 & 370,6 & 444,0 & 426,0 & 282,9 & 108,1 & 72,9 & 64,7 & 66,5 & 89,8 & 95,2 & 218,4 \\
PCPSTD & 11,0 & 11,8 & 12,9 & 12,9 & 10,7 & 5,9 & 4,5 & 4,6 & 5,0 & 6,9 & 7,6 & 10,7 \\
PCPSKW & 2,1 & 1,5 & 1,5 & 1,7 & 3,3 & 4,3 & 3,6 & 4,0 & 4,7 & 5,7 & 5,1 & 3,2 \\
PR_W1 & 0,1 & 0,1 & 0,0 & 0,0 & 0,1 & 0,1 & 0,1 & 0,2 & 0,2 & 0,2 & 0,2 & 0,1 \\
PR_W2 & 0,8 & 0,9 & 0,9 & 1,0 & 0,9 & 0,6 & 0,5 & 0,4 & 0,4 & 0,4 & 0,4 & 0,7 \\
PCPD & 28,0 & 27,0 & 30,0 & 29,0 & 29,0 & 22,0 & 18,0 & 15,0 & 18,0 & 18,0 & 17,0 & 25,0 \\
RAINHHMX & 24,3 & 21,0 & 23,6 & 25,4 & 34,5 & 18,4 & 11,2 & 12,9 & 12,9 & 25,6 & 24,0 & 29,4 \\
SOLARAV & 16,7 & 16,8 & 17,3 & 16,7 & 17,1 & 18,0 & 17,9 & 18,5 & 18,9 & 19,9 & 18,9 & 17,8 \\
DEWPT & 22,7 & 22,7 & 23,0 & 23,2 & 23,2 & 22,6 & 22,0 & 21,6 & 21,5 & 21,6 & 22,0 & 22,5 \\
WNDAV & 1,0 & 1,0 & 0,9 & 0,9 & 0,9 & 0,9 & 1,1 & 1,2 & 1,3 & 1,3 & 1,2 & 1,1 \\
\hline
\end{tabular}


Tabela 24: Parâmetros climáticos inseridos na WGN_user INMET_A212, localizada no município de Paragominas, PA, calculados a partir da série de 2008 a 2014.

\begin{tabular}{lcccccccccccc}
\hline Parâmetros & Jan & Fev & Mar & Abr & Mai & Jun & Jul & Ago & Set & Out & Nov & Dez \\
\hline TMPMX & 31,7 & 31,6 & 31,7 & 31,5 & 31,7 & 31,9 & 32,4 & 33,3 & 34,0 & 34,4 & 33,9 & 33,1 \\
TMPMN & 23,0 & 22,8 & 22,8 & 22,8 & 22,6 & 21,7 & 20,9 & 21,0 & 21,7 & 22,1 & 22,5 & 22,8 \\
TMPSTDMX & 0,6 & 0,6 & 0,4 & 0,4 & 0,4 & 0,3 & 0,3 & 0,4 & 0,4 & 0,4 & 0,4 & 0,7 \\
TMPSTDMN & 0,5 & 0,5 & 0,3 & 0,2 & 0,3 & 0,5 & 0,5 & 0,7 & 0,6 & 0,4 & 0,4 & 0,4 \\
PCPMM & 312,1 & 366,9 & 476,1 & 474,1 & 389,2 & 176,1 & 72,2 & 52,6 & 49,4 & 78,1 & 106,6 & 221,7 \\
PCPSTD & 16,5 & 16,6 & 16,8 & 18,7 & 17,4 & 11,6 & 6,2 & 4,4 & 4,9 & 7,6 & 10,6 & 13,2 \\
PCPSKW & 2,8 & 2,0 & 1,3 & 1,6 & 2,0 & 3,0 & 4,5 & 3,8 & 4,7 & 4,7 & 5,7 & 2,6 \\
PR_W1 & 0,1 & 0,1 & 0,0 & 0,0 & 0,1 & 0,2 & 0,1 & 0,2 & 0,2 & 0,2 & 0,2 & 0,2 \\
PR_W2 & 0,8 & 0,8 & 0,9 & 0,9 & 0,8 & 0,6 & 0,5 & 0,3 & 0,2 & 0,3 & 0,3 & 0,6 \\
PCPD & 27,5 & 26,3 & 29,6 & 29,2 & 27,7 & 23,1 & 21,6 & 14,7 & 14,8 & 15,1 & 16,1 & 23,5 \\
RAINHHMX & 40,2 & 33,1 & 27,3 & 32,4 & 32,2 & 25,2 & 17,7 & 9,7 & 13,1 & 19,5 & 35,8 & 26,9 \\
SOLARAV & 18,4 & 19,1 & 19,2 & 18,2 & 17,6 & 18,5 & 20,1 & 20,0 & 19,3 & 21,5 & 20,2 & 18,6 \\
DEWPT & 22,4 & 22,7 & 22,9 & 23,1 & 23,1 & 22,0 & 21,1 & 21,0 & 21,1 & 20,8 & 21,2 & 21,8 \\
WNDAV & 1,3 & 1,3 & 1,1 & 1,0 & 0,8 & 1,0 & 1,3 & 1,5 & 1,7 & 1,7 & 1,7 & 1,4 \\
\hline
\end{tabular}

Segue descrição desses parâmetros:

- TMPMX - média das tamperaturas máximas diárias a cada mês $\left({ }^{\circ} \mathrm{C}\right)$;

- TMPMN - média das tamperaturas míximas diárias a cada mês $\left({ }^{\circ} \mathrm{C}\right)$;

- TMPSTDMX - desvio padrão das temperaturas máximas diárias a cada mês $\left({ }^{\circ} \mathrm{C}\right)$;

- TMPSTDMN - desvio padrão das temperaturas mínimas diárias a cada mês $\left({ }^{\circ} \mathrm{C}\right)$;

- PCPMM - média da precipitação mensal total para o período $(\mathrm{mm})$;

- PCPSTD - desvio padrão das precipitações a cada mês;

- PCPSKW - coeficiente Skew para a precipitação diária a cada mês;

- PR_W1 - probabilidade de um dia úmido seguir um dia seco no mês;

- PR_W2 - probabilidade de um dia úmido seguir um dia úmido no mês;

- PCPD - média do número de dias com precipitação no mês;

- RAINHHMX - precipitação máxima para meia hora de chuva em todo o período mensal registrado.

- SOLARAV - média da radiação solar diária para cada mês $\left(\mathrm{MJ} / \mathrm{m}^{2}\right.$ dia).

- DEWPT - média das temperaturas diárias de ponto de orvalho a cada mês $\left({ }^{\circ} \mathrm{C}\right)$; 
- WNDAV - média das velocidades de vento diárias para cada mês $(\mathrm{m} / \mathrm{s})$;

\subsubsection{Solos.}

Na Tabela 25 são apresentados os parâmetros de cinco tipos de solos utililizados na tese, descrevendo as características físicas e hidrológicas da bacia fundamentais as simulações com o SWAT.

Tabela 25: Parâmetros das camadas de solo utilizadas nas simulações com o SWAT.

\begin{tabular}{|c|c|c|c|c|c|c|c|c|}
\hline SNAM & HYDGRP & NLAYERS & $\begin{array}{c}\text { SOL_Z } \\
(\mathrm{mm})\end{array}$ & $\begin{array}{c}\text { SOL_BD* } \\
\left(\mathrm{g} / \mathrm{cm}^{3}\right)\end{array}$ & $\begin{array}{c}\text { SOL_AWC* }_{(\mathrm{mm} / \mathrm{mm})} \\
\end{array}$ & $\begin{array}{c}\mathrm{SOL}_{(\mathrm{K} / \mathrm{K}}^{*} \\
(\mathrm{~mm} / \mathrm{h})\end{array}$ & $\begin{array}{c}\text { SOL_CBN } \\
(\%)\end{array}$ & $\begin{array}{l}\text { CLAY } \\
(\%)\end{array}$ \\
\hline & & 1 & 300 & 1,58 & 0,09 & 13,50 & 0,90 & 22,00 \\
\hline \multirow[t]{3}{*}{ LAd1M } & B & 2 & 1000 & 1,59 & 0,10 & 5,30 & 0,28 & 28,67 \\
\hline & & 3 & 2000 & 1,59 & 0,10 & 4,79 & 0,07 & 29,00 \\
\hline & & 1 & 300 & 1,59 & 0,07 & 24,12 & 0,87 & 17,70 \\
\hline \multirow[t]{3}{*}{ LAd1B } & B & 2 & 1000 & 1,61 & 0,08 & 14,46 & 0,46 & 21,70 \\
\hline & & 3 & 2000 & 1,61 & 0,09 & 9,54 & 0,29 & 24,50 \\
\hline & & 1 & 300 & 1,56 & 0,06 & 51,65 & 1,17 & 11,50 \\
\hline \multirow[t]{3}{*}{ PVAd } & C & 2 & 1000 & 1,62 & 0,08 & 9,96 & 0,39 & 25,00 \\
\hline & & 3 & 2000 & 1,62 & 0,08 & 7,04 & 0,21 & 27,50 \\
\hline & & 1 & 300 & 1,36 & 0,14 & 5,76 & 2,99 & 33,35 \\
\hline \multirow[t]{3}{*}{ FFC } & $\mathrm{D}$ & 2 & 1000 & 1,38 & 0,12 & 0,30 & 0,88 & 52,00 \\
\hline & & 3 & 2000 & 1,25 & 0,12 & 0,96 & 0,34 & 56,50 \\
\hline & & 1 & 300 & 1,16 & 0,13 & 7,09 & 3,94 & 50,00 \\
\hline \multirow[t]{2}{*}{ GXbd } & $\mathrm{D}$ & 2 & 1000 & 1,10 & 0,10 & 1,98 & 0,53 & 67,00 \\
\hline & & 3 & 2000 & 1,08 & 0,09 & 2,04 & 0,61 & 70,00 \\
\hline
\end{tabular}

* Valores estimados. NLAYER - Número de camadas; SOL_Z - profundidade da superfície do solo até o fundo da camada; SOL_BD - massa específica aparente; SOL_AWC - capacidade de água disponível na camada; SOL_CBN - carbono orgânico; SOL_K - condutividade hidráulica saturada; CLAY - teor de argila. 
Tabela 25 (continuação): Parâmetros das camadas de solo utilizadas nas simulações com o SWAT.

\begin{tabular}{|c|c|c|c|c|c|c|c|c|}
\hline SNAM & HYDGRP & NLAYERS & $\begin{array}{c}\text { SILT } \\
(\%)\end{array}$ & $\begin{array}{c}\text { SAND } \\
(\%)\end{array}$ & $\begin{array}{c}\text { ROCK } \\
(\%)\end{array}$ & $\begin{array}{c}\text { SOL_ALB* } \\
\text { (fraction) }\end{array}$ & USLE_K* & $\begin{array}{c}\text { SOL_EC* } \\
(\mathrm{dS} / \mathrm{m})\end{array}$ \\
\hline & & 1 & 13,50 & 64,50 & 0,00 & 0,25 & 0,14 & 1 \\
\hline \multirow[t]{3}{*}{ LAd1M } & $B$ & 2 & 14,33 & 57,00 & 0,00 & 0,25 & 0,14 & 0 \\
\hline & & 3 & 16,00 & 55,00 & 0,00 & 0,25 & 0,15 & 0 \\
\hline & & 1 & 9,15 & 73,15 & 0,00 & 0,25 & 0,13 & 1 \\
\hline \multirow[t]{3}{*}{ LAd1B } & B & 2 & 8,90 & 69,40 & 0,00 & 0,25 & 0,13 & 0 \\
\hline & & 3 & 11,50 & 64,00 & 0,00 & 0,25 & 0,14 & 0 \\
\hline & & 1 & 6,50 & 82,00 & 0,00 & 0,25 & 0,09 & 1 \\
\hline \multirow[t]{3}{*}{ PVAd } & C & 2 & 5,50 & 69,50 & 0,00 & 0,25 & 0,11 & 0 \\
\hline & & 3 & 5,00 & 67,50 & 0,00 & 0,25 & 0,11 & 0 \\
\hline & & 1 & 37,10 & 29,55 & 0,00 & 0,08 & 0,13 & 1 \\
\hline \multirow[t]{3}{*}{ FFC } & $D$ & 2 & 14,93 & 33,07 & 0,00 & 0,25 & 0,12 & 0 \\
\hline & & 3 & 30,40 & 13,10 & 0,00 & 0,25 & 0,17 & 0 \\
\hline & & 1 & 49,55 & 0,45 & 0,00 & 0,04 & 0,29 & 1 \\
\hline \multirow[t]{2}{*}{ GXbd } & $D$ & 2 & 30,30 & 2,70 & 0,00 & 0,25 & 0,27 & 0 \\
\hline & & 3 & 27,60 & 2,40 & 0,00 & 0,25 & 0,26 & 0 \\
\hline
\end{tabular}

* Valores estimados. SILT - teor de silte; SAND - teor de areia; ROCK - teor de pedregulhos e pedras; SOL_ALB - albedo; USLE_K - coeficiente de erodibilidade do solo; SOL_EC - condutividade elétrica. 6.4.3.3 Parâmetros específicos para as culturas e manejo.

$\mathrm{Na}$ Tabela 26 estão caracterizados os parâmetros relativos aos usos e conberturas do presente estudo, e que foram alterados para melhor adaptar os modelos às condições da região. $\mathrm{Na}$ Tabela 27 estão os resultados para as características iniciais de cada uso e cobertura da terra. No Experimento 3 da modelagem com 0 SWAT, o Índice de Área Foliar (LAI) inicial para a palma de óleo foi o de valor 5, já relativo a existência de plantas adultas em toda extensão das sub-bacias.

Tabela 26: Parâmetros adaptados a região de estudo relativos às culturas do SWAT.

\begin{tabular}{lcccc}
\hline USO SWAT & OV_N & BLAI & CHTMX (m) & RDMX (m) \\
\hline OILP & 0,19 & 5,0 & 12,0 & 2,0 \\
AGRL & 0,14 & 3,5 & 1,7 & 2,0 \\
PAST & 0,13 & 2,3 & 0,5 & 1,0 \\
FRSE & 0,4 & 6,0 & 20,0 & 3,5 \\
EUCA & 0,14 & 2,5 & 3,5 & 2,0 \\
\hline
\end{tabular}

Sendo: OV_N - Coeficiente de rugosidade de Manning; BLAI Índice máximo de área foliar; CHTMX - Altura máxima da copa das árvores; RDMX - Profundidade máxima das raízes 
Tabela 27: Parâmetros adaptados à região de estudo relativos ao Módulo de Manejo do SWAT.

\begin{tabular}{lccc}
\hline USO SWAT & LAI_INIT & BIO_INIT (kg/ha) & PHU \\
\hline FRSE & 6 & 1000 & 3000 \\
OILP & 3 & 1000 & 3000 \\
EUCA & 2,5 & 1000 & 3000 \\
\hline
\end{tabular}

Sendo: LAI_INIT - Índice de área foliar inicial; BIO_INIT

- Peso da biomassa seca inicial (kg/ha); PHU_PLT -

Número total de unidades de calor necessários para

levar a planta à maturidade.

\subsubsection{Resultados da regionalização de vazão.}

$\mathrm{Na}$ Figura 43 são apresentados os resultados do processo de cálculo e verificação do acerto da regionalização da vazão média de longo período entre os anos de 2003 a 2014 para as bacias de contribuição das estações Badajós, Fazenda Maringá, Bom jardim e Vila Capoeira, fundamentados na regressão não linear (TUCCI, 2002). Visualmente é possível observar uma boa aproximação entre as curvas simuladas através da regionalização e as curvas observadas. Na Tabela 28 , constatase o bom resultado do acerto das equações da regionalização através do teste com o coeficiente de Nash-Sutcliffe (NSE), caracterizando um resultado satisfatório para a estação Badajós e muito bom para as demais estações reais. Os resultados dos testes RSR e PBIAS apresentaram resultados satisfatórios, bom e muito bom de modo geral, com a excessão do RSR da estação Badajós, que foi o resultado com erro mais expressivo. 

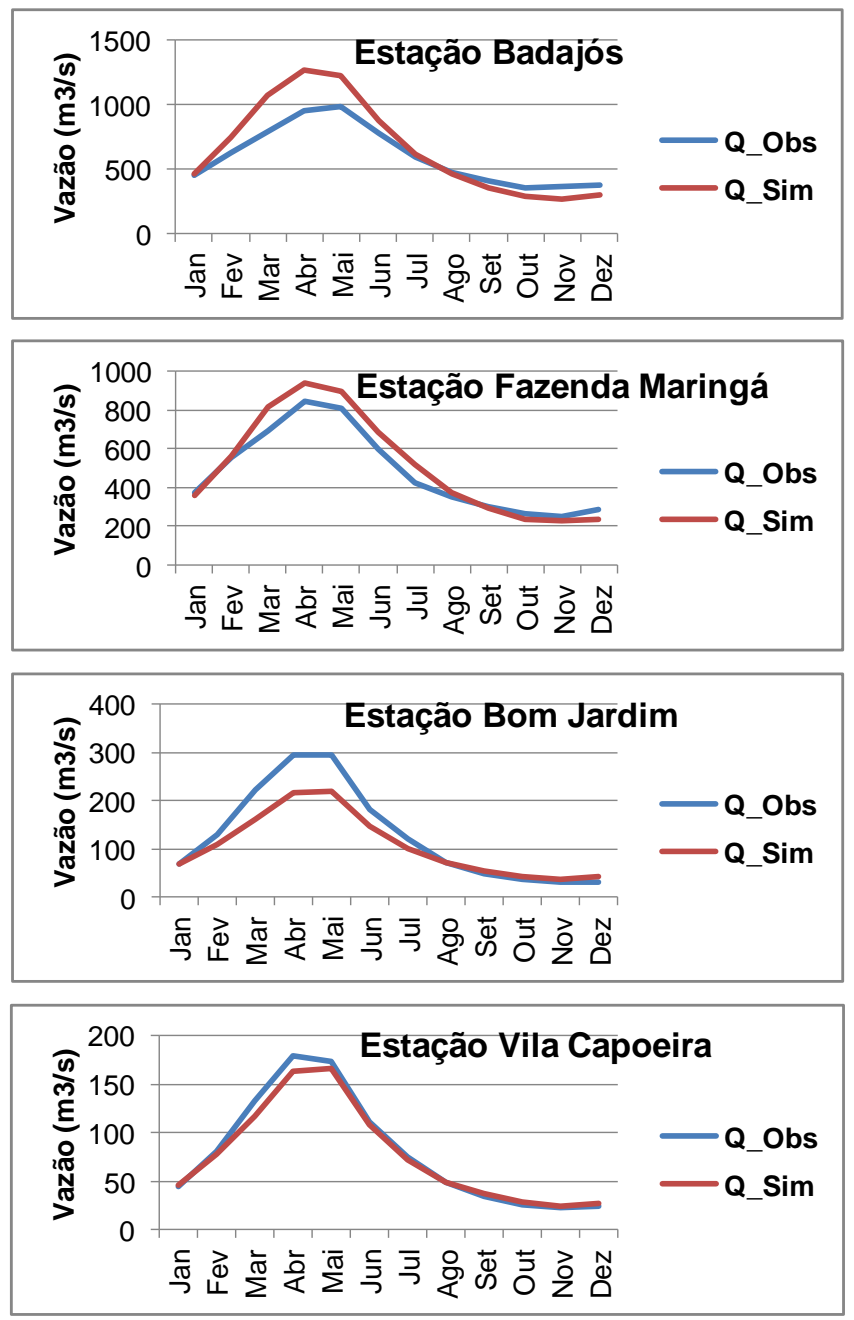

Figura 43: Vazões observadas e vazões simuladas da regionalização da vazão média mensal de longo período das 4 estações reais.

Tabela 28: Resultados dos índices de acertos da regionalização da vazão média de longo período sobre as bacias monitoradas em estudo.

\begin{tabular}{llll}
\hline Bacias & NSE & RSR & PBIAS \\
\hline Badajós & 0,52 & 0,69 & $-11,13$ \\
Faz. Maringá & 0,89 & 0,33 & $-6,93$ \\
Bom Jardim & 0,83 & 0,41 & 17,05 \\
Vila Capoeira & 0,98 & 0,13 & 3,44 \\
\hline
\end{tabular}

A Figura 44, a qual expressa o gráfico de dispersão dos valores simulados e observados, demonstra o bom desempenho das equações de regressão aplicadas na verificação do acerto dos modelos de regionalização, estando as equações geradas para esta verificação individual de cada estação real apresentadas na Tabela 29 no APÊNDICE A. No processo de calibração e validação sobre as estações reais, todas as 
equações apresentaram valor de probabilidade de significância baixo $(<0,05 \%)$, rejeitando-se assim a hipótese nula.
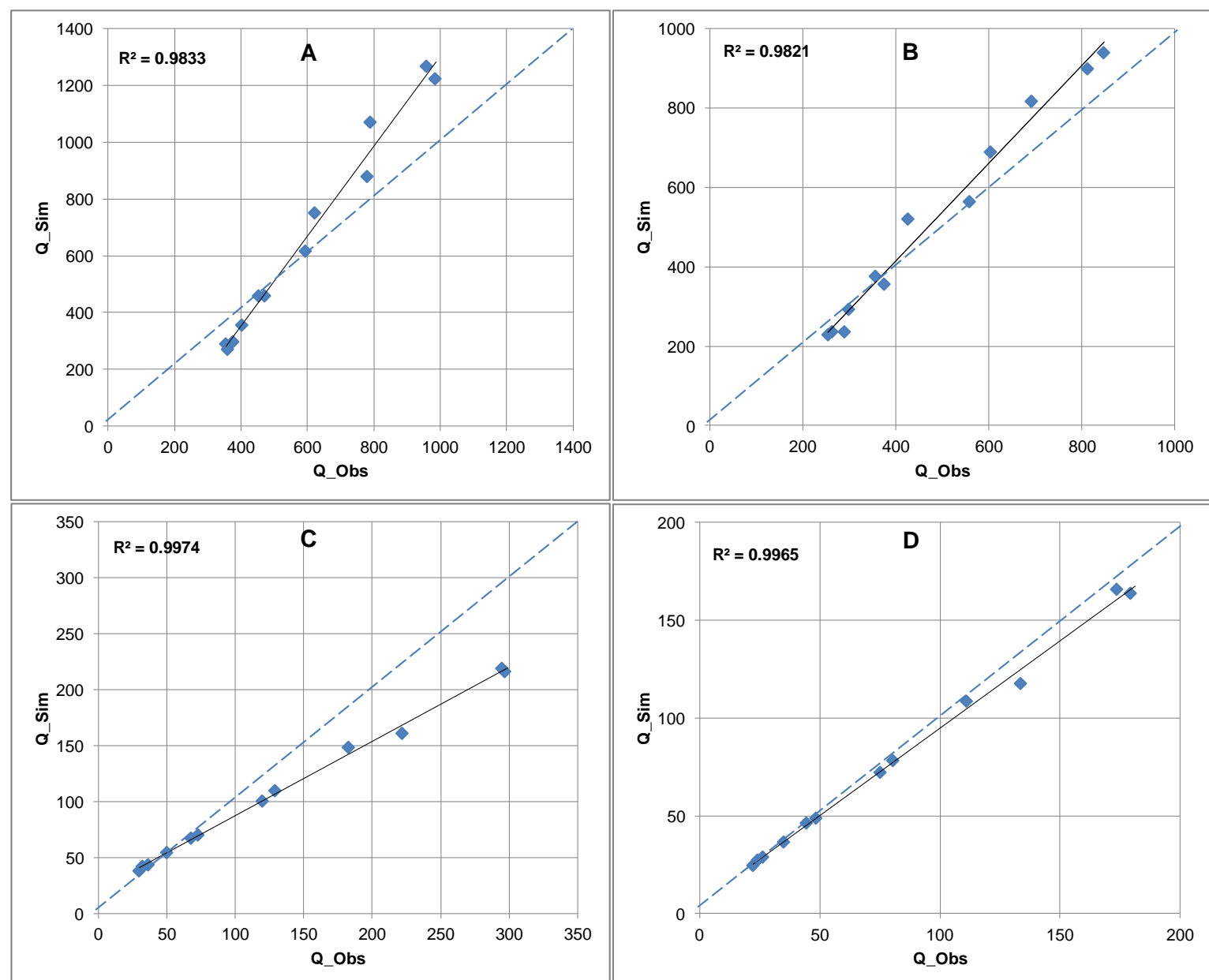

Figura 44: Diagrama de dispersão das vazões médias mensais de longo período observadas (Q_Obs) e simuladas (Q_Sim) através das equações de regionalização para o período de 2003 a 2014 nas Estações Badajós (A), Fazenda Maringá (B), Bom Jardim (C) e Vila Capoeira (D).

Tendo sido validado o estudo para as estações reais, aplicou-se o mesmo método para gerar as equações de regressão sazonal da vazão média mensal de longo período para as sub-bacias dos rios Bujaru e Mariquita. Abaixo, na Tabela 30, são apresentados os coeficientes das equações finais após verificação do acerto da regionalização, as quais foram elaboradas, neste caso, já tendo como variáveis dependentes as 4 estações reais e as 17 estações sintéticas, e a área de drenagem e precipitação mensal como variáveis independentes. Assim, estas equações foram aplicadas para geração das séries sazonais de vazão média mensal de longo período 
para as SBRB e SBRM. A Tabela 30 apresenta altos valores para o coeficiente de determinação $\left(R^{2}\right)$, indicando um elevado poder de explicação das equações de regressão, além de demonstrar que todas as equações apresentaram valor de probabilidade de significância baixo $(<0.05)$, rejeitando-se assim a hipótese nula.

Tabela 30: Coeficientes de regressão e estatísticas das equações finais para estimativa da Regionalização da Vazão Média Mensal de Longo Período das sub-bacias dos rios Bujaru e Mariquita.

Equação não linear $\gg Q=a A^{2} A^{b} P^{2} P^{c}$

\begin{tabular}{lcccccccccccc}
\hline & Jan & Feb & Mar & Apr & May & Jun & Jul & Aug & Sep & Oct & Nov & Dec \\
\hline $\mathrm{a}$ & 0,014 & 0,044 & 0,017 & 0,009 & 0,013 & 0,022 & 0,022 & 0,014 & 0,009 & 0,005 & 0,002 & 0,003 \\
$\mathrm{~b}$ & 1,008 & 0,967 & 0,922 & 0,912 & 0,929 & 0,961 & 0,963 & 0,997 & 1,023 & 1,051 & 1,076 & 1,079 \\
$\mathrm{c}$ & $-0,025$ & $-0,070$ & 0,228 & 0,382 & 0,330 & 0,134 & 0,051 & 0,009 & $-0,001$ & 0,024 & 0,121 & 0,092 \\
$\delta_{\mathrm{f}}^{*}$ & 1,013 & 1,048 & 1,102 & 1,098 & 1,088 & 1,063 & 1,056 & 1,012 & 1,030 & 1,063 & 1,088 & 1,094 \\
$\mathrm{R}^{2}$ & 0,999 & 0,999 & 0,996 & 0,996 & 0,997 & 0,998 & 0,999 & 0,999 & 0,999 & 0,999 & 0,998 & 0,997 \\
$\mathrm{~F}^{* *}$ & 0,000 & 0,000 & 0,000 & 0,000 & 0,000 & 0,000 & 0,000 & 0,000 & 0,000 & 0,000 & 0,000 & 0,000 \\
\hline
\end{tabular}

* Erro Padrão;

** Estatística F.

Importante destacar que o método, porém, só obteve sucesso por razão da criação das estações sintéticas (PESSOA et al., 2011; COSTA et al 2012), as quais contribuíram diretamente para a eliminação do efeito de colinearidade e assim permitiram a criação de equações capazes de gerar dados mensais de longo período validados com as séries de vazão reais para as bacias monitoradas e também poderem gerar séries de vazão médias mensais de longo período (QMMLP) mais confiáveis para as estações não monitoradas.

Tendo em vista os resultados obtidos na regionalização, seja no processo de verificação do acerto do método sobre as estações reais ou na elaboração das equações finais para as sub-bacias não monitoras em estudo, o método se mostrou de fácil aplicação e com resultados qualificados. Porém é fundamental ter em mente a importância de atender alguns procedimentos para um melhor funcionamento da regionalização. Dentre estes procedimentos, destacamos a necessidade de se verificar a homogeneidade quanto às características geofisiográficas das bacias em estudo, tais como geomorfologia, geologia, hidrografia, solos e fator hidroclimático (PARÁ, 2012). Goswami et al. (2007) apontam que as características hidrometeorológicas e 
topográficas são fortes auxiliares na triagem preliminar de bacias hidrográficas quanto a homogeneidade. Este critério foi levado em consideração, uma vez que nossas bacias estão todas localizadas dentro da macrorregião Hidrográfica Costa Atlântica-Nordeste.

Outro procedimento importante é a escolha das variáveis utilizadas para explicar o comportamento de parâmetros importantes no planejamento do uso dos recursos hídricos, como a vazão média, a vazão máxima de inundação, a curva de permanência, vazão mínima de acordo com a sua duração e tempo de retorno e coeficiente de escoamento. As variáveis mais utilizadas na literatura têm sido a área de drenagem, comprimento do rio, declividade e a precipitação (SIMMERS et al., 1984; CLAUSEN; PEARSON, 1995; TUCCI et al., 1995; POST et al., 1998; SILVA JÚNIOR. et al., 2003; WILKINSON et al., 2006; KULT et al., 2014). Segundo Silva Júnior et al. (2003), algumas variáveis como comprimento do rio e declividade acabam tendo forte correlação com a área de drenagem. Assim, é comum ver muitos trabalhos sempre tendo a área de drenagem como uma variável independente sempre presente e a que melhor tem explicado as variáveis hidrológicas (PILGRIM, 1983; SILVA JÚNIOR. et al., 2003).

Silva Júnior. et al. (2003), aplicou a regionalização nas bacias dos rios ljuí (Rio Grande do Sul) e Paraopeba (Minas Gerais) utilizando as regressões tendo como variável independente apenas a área de drenagem para estimar vazão média de longo período, vazão média de cheia, curva de permanência e vazão mínima. Os autores aplicaram a regionalização utilizando dados de estações fluviométricas com áreas de contribuição entre $469 \mathrm{~km}^{2}$ e $10.695 \mathrm{~km}^{2}$, e extrapolaram as equações para bacia superiores (104.162 e $\left.110.898 \mathrm{~km}^{2}\right)$ e para bacias inferiores $\left(0,125 \mathrm{~km}^{2}\right.$ a $\left.21,7 \mathrm{~km}^{2}\right)$. Para a regionalização da vazão média, as equações funcionaram muito bem, apresentando incertezas na extrapolação apenas para bacias inferiores a $10 \mathrm{~km}^{2}$. $\mathrm{O}$ estudo mostrou, assim, que a escala da bacia pode limitar a extrapolação de resultados, porém que algumas funções podem ser bem representadas na transição entre escalas superiores e inferiores, corroborando e dando um suporte a aceitabilidade da aplicação da regionalização de vazão nas condições da presente tese.

Um estudo desenvolvido por Wilkinson et al. (2006), avaliou a eficiência de dois modelos, sendo o primeiro fundamentado na equação de regressão, tendo como 
variáveis a área de drenagem e precipitação, e o segundo fundamentado na fórmula racional como produto da área de drenagem, precipitação e coeficiente de escoamento superficial. Os resultados mostraram uma maior eficiência do acerto para o modelo racional sobre a regressão. No entanto, é importante ressaltar que o modelo racional leva em consideração a influência da evapotranspiração no cálculo da regionalização da vazão média anual, e esse fator é um facilitador do acerto, uma vez que a área em estudo, a bacia do rio Murrumbidgee no sudeste da Austrália, apresenta uma forte variabilidade climática e influência de sistemas de chuva costeira. As equações de regressão possuem melhor desempenho em áreas homogêneas quanto a características geofisiográficas e de ecossistemas, que é o caso da presente tese.

Kult et al. (2014) desenvolveu um estudo de grandes proporções na bacia hidrográfica dos Grandes Lagos, a qual drena uma área de cerca de $500.000 \mathrm{Km}^{2}$ dos Estados Unidos da América e do Canadá, apresentando uma variada cobertura da terra, clima, características do subsolo e de atividades antrópicas. Os autores utilizaram os métodos de regressão linear múltipla e da árvore de regressão para regionalizar os coeficientes de escoamento mensal e média mensal. Um ponto bem interessante da pesquisa é que a árvore de regressão direcionou os resultados para um agrupamento das bacias com respostas hidrológicas similares, simplificando assim o modelo e evitando erros de ajustamento. As equações encontraram um ajuste razoável para as bacias em estudo, o que corrobora com o uso do método para a finalidade de estudar o escoamento em bacias não monitoradas.

Wagener e Montanari (2011) explicam que o real objetivo nos estudos hidrológicos em bacias hidrográficas não monitoradas deve ser o de compreender o comportamento característico da bacia. Estes autores ressaltam também que além da necessidade específica se fazer predições em bacias não monitoras com mais confiabilidade, há um forte apelo da comunidade científica que estuda hidrologia, ecologia e o recurso água por uma melhora da credibilidade das previsões hidrológicas em todos os sistemas ambientais. Dessa forma, entendem que os modelos de regionalização de bacias hidrográficas podem ser um dos maiores desafios dentro dos estudos hidrológicos. 
Dessa forma, a partir destes resultados, a presente tese busca aplicar esse método de regionalização para a geração de equações que possam ser utilizadas com o objetivo de construir séries de vazão de 2006 a 2014 para as sub-bacias não monitoradas dos rios Buajru e Mariquita, foco da tese. Essas séries são parte fundamental para o processo de calibração e validação do modelo SWAT, o qual faz parte do problema da presente tese testar uma metodologia capaz de contribuir com os estudos hidrossedimentológicos de bacias hidrográficas não monitoradas na Amazônia. Os resultados finais, tanto da regionalização sazonal (mensal) da vazão média de longo período, mas também da regionalização da vazão média mensal por ano são apresentados e discutidos nos itens relativos aos resultados dos experimentos com 0 modelo SWAT a seguir.

\subsubsection{Resultados dos experimentos de simulações com o SWAT.}

Aqui são explicados os resultados dos Experimentos 1 e 2. O Experimento 3 será explicado no Item 6.6. O objetivo destes dois primeiros experimentos é explicar todo o processo de simulação inicial, tendo como base dados reais medidos, revisados em bibliografias e estimados. Objetiva-se também explicar o processo de análise de sensibilidade dos modelos e o processo de calibração, validação e avaliação de eficiência dos resultados.

Dessa forma, os resultados perpassam pelo trabalho de modelagem da bacia monitorada do médio rio Capim e das duas sub-bacias não monitoradas dos rios Bujaru e Mariquita. Estes estudos objetivam especificamente gerar séries de vazões coerentes com a região e assim contribuir com a análise de escoamento e produção de sedimentos apresentados no Experimento 3. 
6.4.5.1. Experimento 1: Simulações em condições iniciais e Análise de sensibilidade.

Em todas as sub-bacias foram introduzidos os dados específicos de uso e cobertura da terra, relevo, solos, características climáticas e de vegetação, os quais serviram de condições iniciais para as simulações, representando assim as características biofísicas das áreas de estudo. Os demais parâmetros foram utilizados do "default".

Os dados de precipitação correspondem aos anos de 2003 a 2014, sendo utilizados 3 anos de aquecimento (2003 a 2005), 5 anos para a calibração (2006 a 2010) e 4 anos para a validação (2011 a 2014). De maneira geral, os modelos conseguiram simular bem a sazonalidade na etapa inicial, representando uma boa resposta qualitativa, porém os modelos subestimaram a evapotranspiração e superestimaram as vazões de pico, o que está ligado ao elevado escoamento superficial e de base, demonstrando uma ineficiência no acerto quantitativo. Outros trabalhos tem identificado a dificuldade inicial do modelo em obter um bom desempenho quando aplicado em outras regiões da Amazônia e no Brasil, em especial com relação às medidas de vazão, evapotranspiração e escoamento de base (LUBTZ, 2009; SOUZA, 2010; NUNES, 2013; OLIVEIRA, 2013).

\section{a) Sub-bacia do rio Bujaru}

A pesar de superestimar a vazão, o modelo Bujaru não apresentou atraso nem adiantamento na subida e descida da curva, além de representar bem os eventos de chuva (Figura 45). Identificou-se uma vazão média anual de longo período de $83,2 \%$ e $113,7 \%$ maiores que a vazão regionalizada, utilizando Preistley-Taylor e PenmanMonteith respectivamente. Quanto a evapotranspiração anual de longo período, a equação de Preistley-Taylor apresentou melhor comportamento dos resultados acumulados médios $(934,4 \mathrm{~mm})$ em relação a Penman-Monteith $(566,6 \mathrm{~mm})$, quando comparados aos dados conhecidos para a região, segundo o ZEE-PA (1.300-1.500 
$\mathrm{mm}$ ). Quanto aos períodos menos chuvosos, os resultados não obtiveram uma boa representatividade de acerto no geral, porém os valores mínimos foram semelhantes.

O eixo central de análise dos resultados está direcionado a avaliação do comportamento da vazão média mensal de longo período (QMMLP) simulada em relação à regionalizada, reduzindo assim o erro de análise e também por razão da vazão média ser a maior vazão que pode ser regularizada, permitindo a avaliação dos limites superiores do uso da água de um manancial para aplicação aos seus diferentes usos múltiplos (TUCCI, 2002).

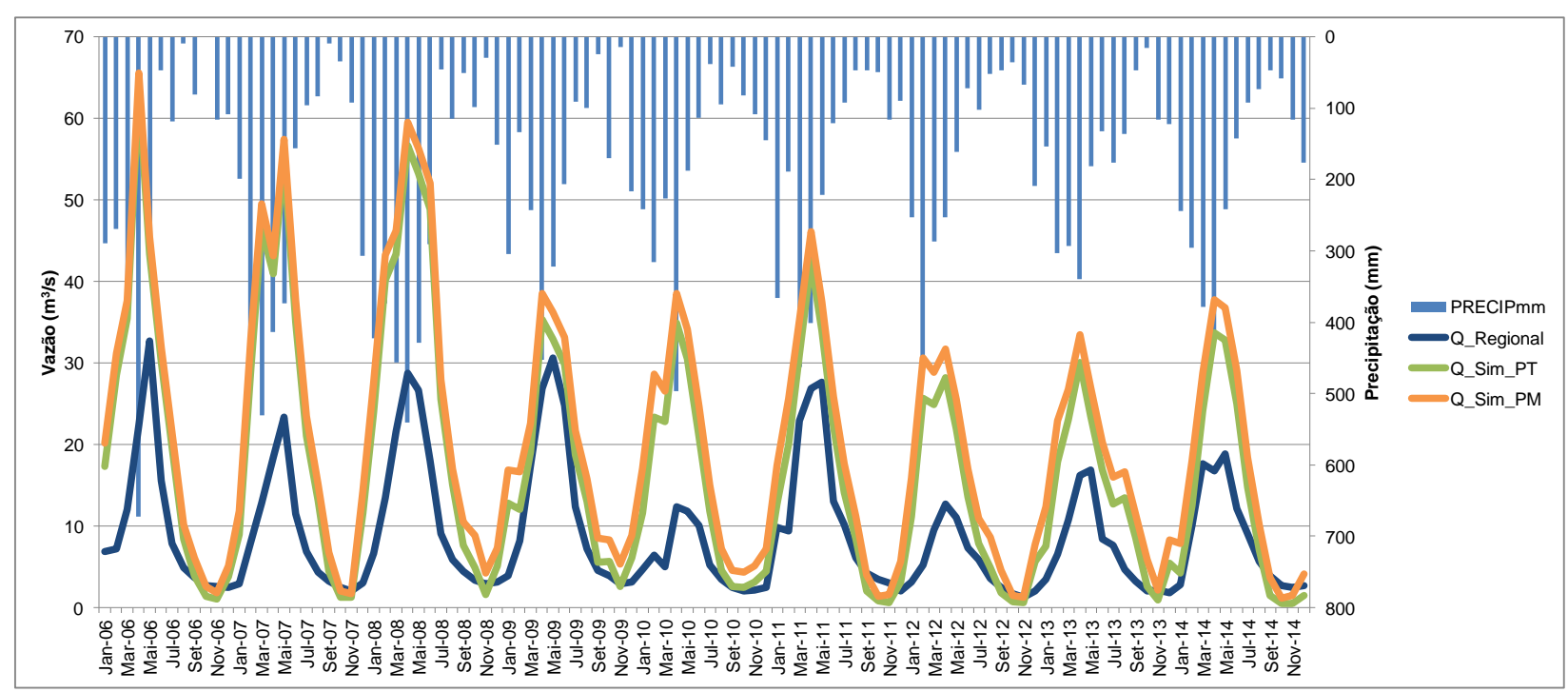

Figura 45: Vazões médias mensais simuladas e regionalizadas em comparação com a precipitação para a modelagem com condições iniciais da sub-bacia do rio Bujaru. Sendo PRECIPmm a precipitação, Q_Regional a vazão regionalizada, Q_Sim_PT a vazão mensal simulada com Preistley-Taylor, e Q_Sim_PM a vazão mensal simulada com Penman-Monteith.

$\mathrm{Na}$ Figura 46 estão os resultados relativos às vazões médias mensais de longo período simuladas e regionalizadas, demonstrando a necessidade de calibração, devido ao desempenho insatisfatório, segundo Moriasi et al., 2007, do modelo quanto aos testes estatísticos NSE, PBIAS, RSR e $\mathrm{R}^{2}$ aplicados as séries de vazões (Tabela $31 \mathrm{e}$ Figura 47). Demonstra também o melhor comportamento do modelo que utilizou a equação de evapotranspiração de Preistley-Taylor, conforme Tabela 31 e Figura 47. Outros trabalhos no Brasil e no mundo também aplicaram a equação de Preistley-Taylor na modelagem com o SWAT obtendo resultados a nível experimental e também com 
qualidade nas simulações da evapotranspiração (NEVES et al., 2005; WANG et al. 2006; SCHNEIDER et al., 2007 ; CAN et al., 2015; BRESSIANE et al. ,2016, no prelo).

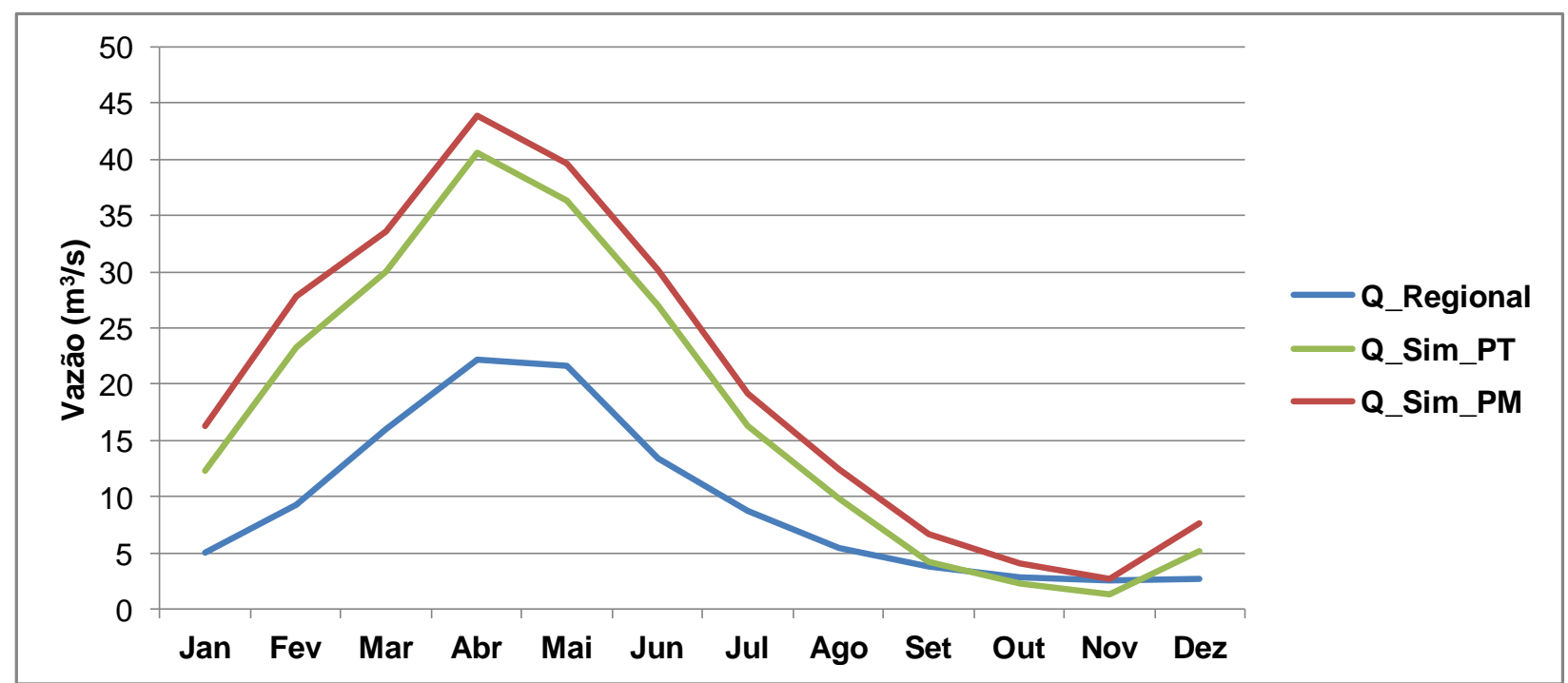

Figura 46: Vazões médias mensais de longo período simuladas e regionalizadas em condições iniciais para a sub-bacia do rio Bujaru entre os anos de 2006 a 2014. Sendo Q_Regional a vazão regionalizada, Q_Sim_PT a vazão mensal simulada com Preistley-Taylor e Q_Sim_PM a vazão mensal simulada com Penman-Monteith.
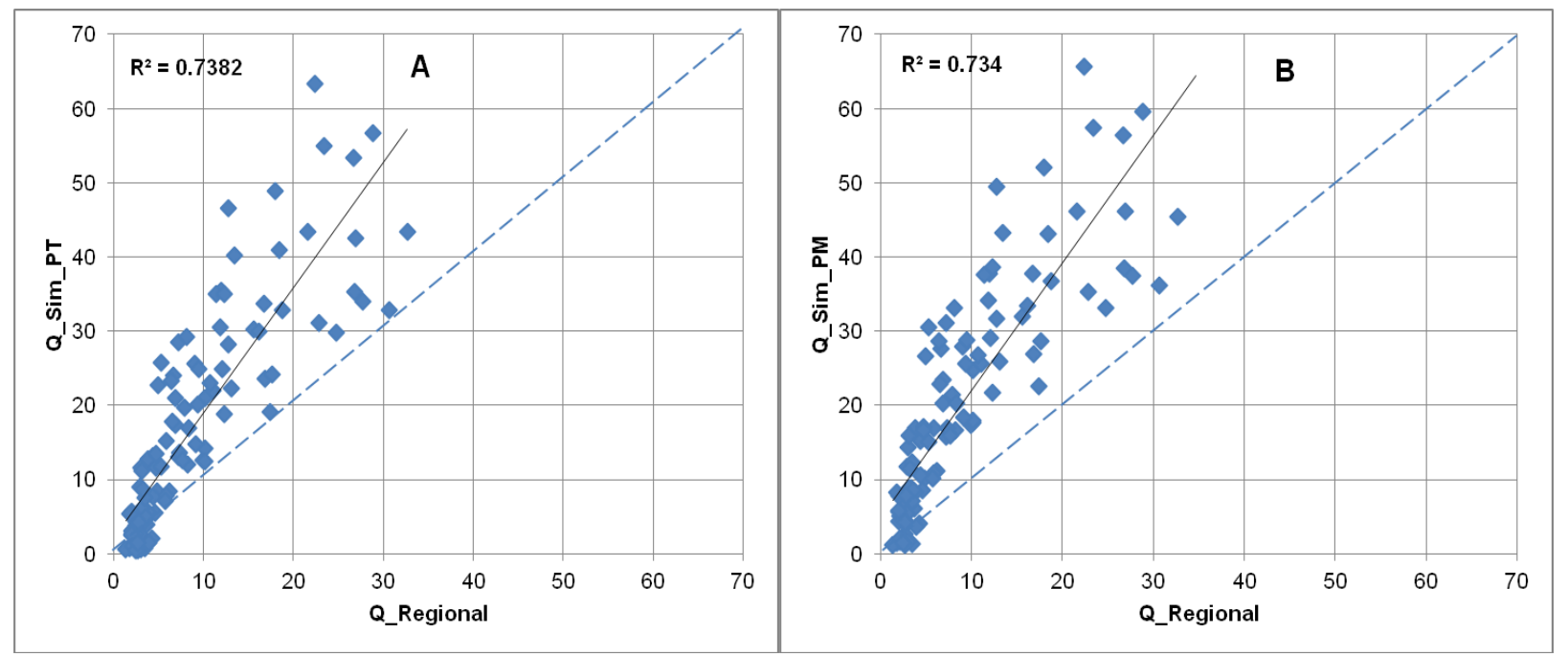

Figura 47: Diagrama de dispersão das vazões médias mensais regionalizadas e simuladas (sem calibração) para o período de 2006 a 2014 na sub-bacia do rio Bujaru. A - Modelo com Preistley-Taylor; B - Modelo com Penman-Monteith. 
Tabela 31: Avaliação da eficiência da simulação inicial usando Preistley-Taylor e Penman-Monteith para as sub-bacias dos rios Bujaru e Mariquita e para a porção média da bacia rio Capim.

\begin{tabular}{|c|c|c|c|c|c|c|}
\hline & \multicolumn{3}{|c|}{ Calibração (2006-2010) } & \multicolumn{3}{|c|}{ Validação (2011-2014) } \\
\hline & NSE & RSR & PBIAS & NSE & RSR & PBIAS \\
\hline & \multicolumn{6}{|c|}{ Bujaru } \\
\hline Preistley-Taylor & $-2,28$ & 1,81 & $-110,89$ & $-0,53$ & 1,24 & $-67,68$ \\
\hline \multirow[t]{2}{*}{ Penman-Monteith } & $-3,32$ & 2,08 & $-139,24$ & $-1,85$ & 1,69 & $-106,87$ \\
\hline & \multicolumn{6}{|c|}{ Mariquita } \\
\hline Preistley-Taylor & $-1,07$ & 1,44 & $-86,85$ & $-1,47$ & 1,57 & $-83,15$ \\
\hline \multirow[t]{2}{*}{ Penman-Monteith } & $-1,87$ & 1,69 & $-113,84$ & $-3,35$ & 2,09 & $-132,06$ \\
\hline & \multicolumn{6}{|c|}{ Capim } \\
\hline Preistley-Taylor & 0,07 & 0,96 & $-26,32$ & 0,22 & 0,88 & $-18,69$ \\
\hline
\end{tabular}

Após a analise das simulações iniciais, podem-se indicar algumas demandas de calibração do modelo Bujaru inicialmente, as quais podem ser ajustadas para a obtenção de um resultado mais adequado a região, sendo:

- Redução do volume total de escoamento, devido à superestimativa da vazão principalmente nos períodos chuvosos;

- Redução e regularização do escoamento de base e ajuste da curva de recessão;

- Aumento da evapotranspiração, para ajustar a vazão diminuindo a superestimativa principalmente nos períodos de cheia;

- Redução do escoamento superficial, para o ajuste da vazão de pico.

\section{b) Sub-bacia do rio Mariquita}

A sub-bacia do rio Mariquita também não apresentou atrasos ou adiantamentos com relação à curva regionalizada e representou bem a sazonalidade das vazões regionalizadas e respondeu bem ao comportamento da precipitação (Figura 48). As vazões médias anuais de longo período da simulação inicial superestimaram a regionalizada em $82,5 \%$ e $117,5 \%$ utilizando Preistley-Taylor e Penman-Monteith, respectivamente. Quanto à evapotranspiração anual de longo período, a equação de Preistley-Taylor apresentou melhor comportamento dos resultados médios anuais $(1.009,7 \mathrm{~mm})$ em relação à Penman-Monteith $(681,9 \mathrm{~mm})$, quando comparados aos 
dados conhecidos para a região, segundo o ZEE Pará (1.300-1.500 mm). Os resultados dos períodos de estiagem também não obtiveram uma boa representatividade de acerto no geral, porém os valores mínimos foram semelhantes.

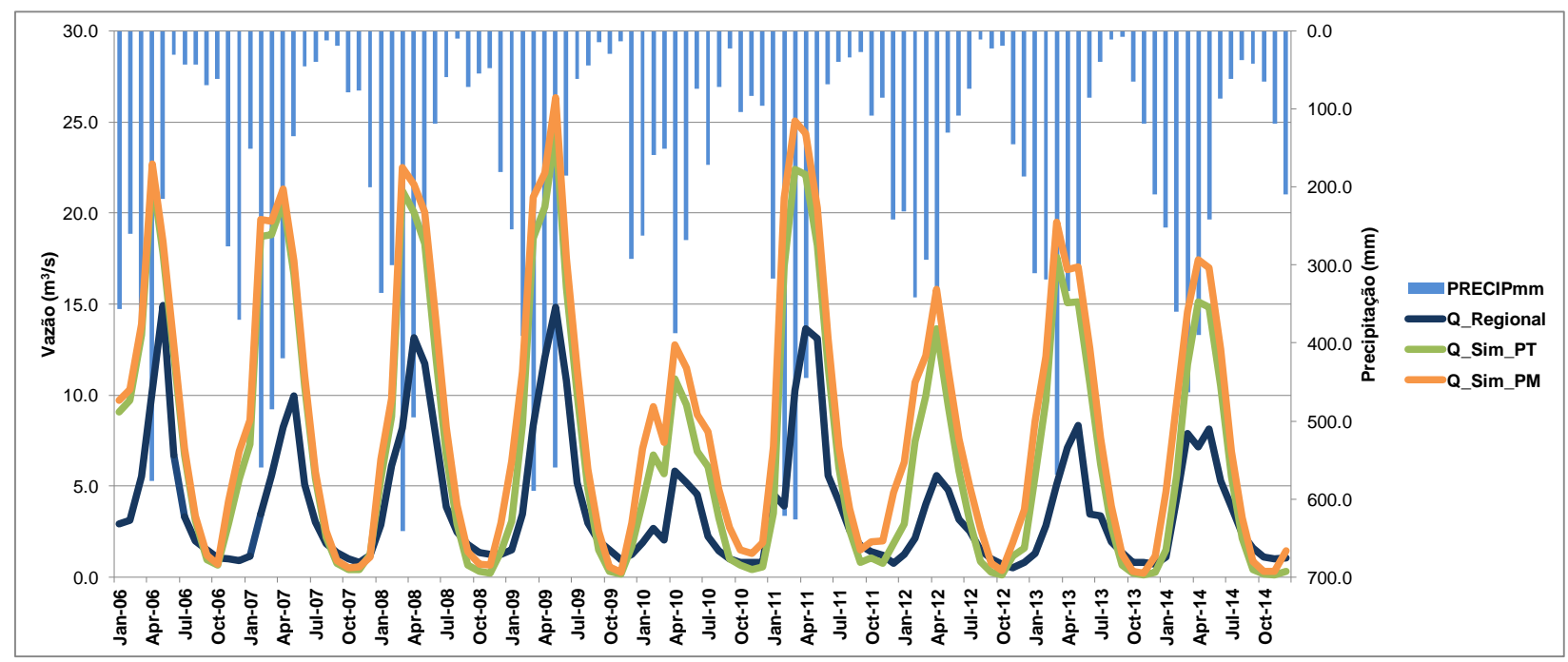

Figura 48: Vazões médias mensais simuladas e regionalizadas em comparação com a precipitação para a modelagem com condições iniciais da sub-bacia do rio Mariquita. Sendo PRECIPmm a precipitação, Q_Regional a vazão regionalizada, Q_Sim_PT a vazão mensal simulada com Preistley-Taylor, e Q_Sim_PM a vazão mensal simulada com Penman-Monteith.

$\mathrm{Na}$ Figura 49 estão os resultados relativos às vazões médias mensais simuladas e regionalizadas de longo período demonstrando também a necessidade de calibração, devido ao desempenho insatisfatório, segundo Moriasi et al., 2007, do modelo quanto aos testes estatísticos NSE, PBIAS e RSR aplicados aos resultados das séries de vazão de 2006 a 2014 (Tabela 31 e Figura 50). Assim como na sub-bacia do rio Bujaru, este modelo também apresentou o melhor comportamento dos resultados da simulação que utilizou a equação de evapotranspiração de Preistley-Taylor, conforme Tabela $31 \mathrm{e}$ Figura 50. 


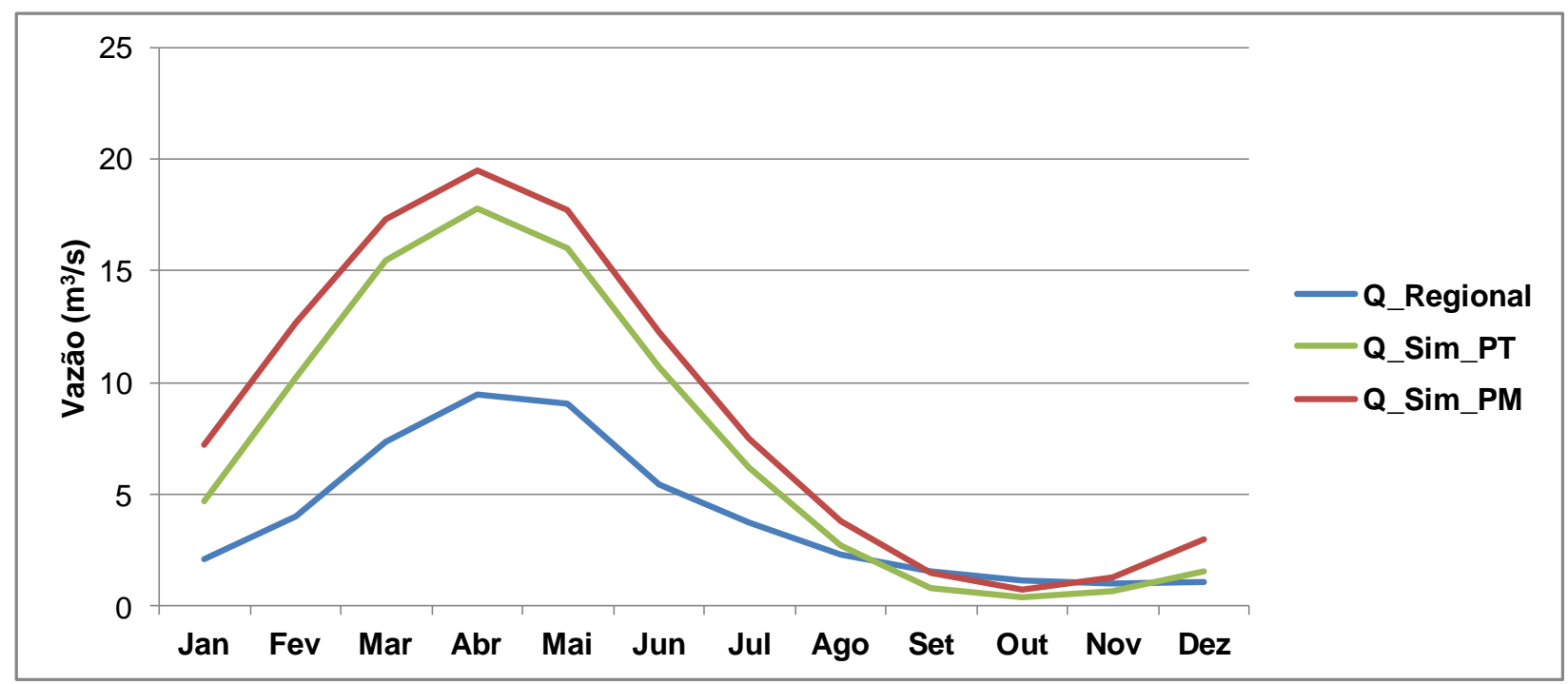

Figura 49: Vazões médias mensais de longo período simuladas e regionalizadas em condições iniciais para a sub-bacia do rio Mariquita entre os anos de 2006 a 2014. Sendo Q_Regional a vazão regionalizada, Q_Sim_PT a vazão mensal simulada com Preistley-Taylor e Q_Sim_PM a vazão mensal simulada com Penman-Monteith.
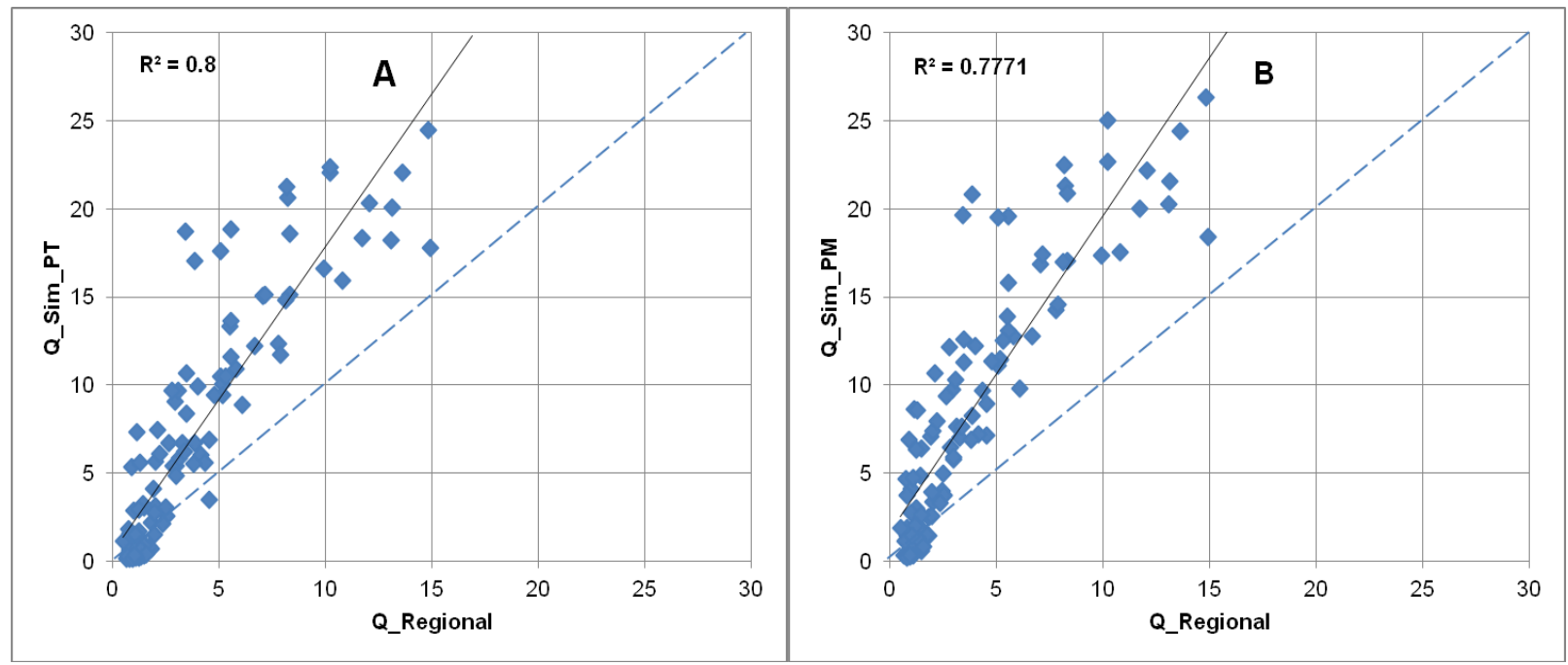

Figura 50: Diagrama de dispersão das vazões médias mensais regionalizadas e simuladas (sem calibração) para o período de 2006 a 2014 na sub-bacia do rio Mariquita. A - Modelo com PreistleyTaylor; B - Modelo com Penman-Monteith.

A caracterização do comportamento hidrológico entre Bujaru e Mariquita foi semelhante, identificando aqui as mesmas demandas de calibração para ajuste das curvas:

- Redução do volume total de escoamento, devido à superestimativa da vazão principalmente nos períodos chuvosos; 
- Redução e regularização do escoamento de base e ajuste da curva de recessão;

- Aumento da evapotranspiração, para ajustar a vazão diminuindo a superestimativa principalmente nos períodos de cheia;

- Redução do escoamento superficial, para o ajuste da vazão de pico.

\section{c) Porção média do rio Capim}

A bacia do rio Capim, cujas simulações são comparadas com dados reais de vazão, mesmo superestimando o volume total escoado representou bem a sazonalidade das vazões observadas e respondeu bem ao comportamento da precipitação, não sendo observadas visualmente grandes alterações de atraso ou adiantamento da curva simulada em relação à observada (Figura 51). A vazão média anual de longo período da simulação inicial superestimou a vazão observada em $23,2 \%$ utilizando a equação de Preistley-Taylor, a de melhor resultados para a região. Quanto à evapotranspiração anual de longo período, a bacia apresentou bom comportamento inicial $(1.133,2 \mathrm{~mm}$ ) em relação aos dados conhecidos para a região, segundo o ZEEPA (1.300-1.500 mm). Os resultados dos períodos de estiagem obtiveram uma boa representatividade de acerto no geral, apresentando uma leve subestimativa. Isso pode ser mais bem entendido uma vez que o modelo apresentou resultados razoáveis (MORIASI et al., 2007) quanto aos testes estatísticos aplicados para o período de calibração e validação, porém ainda em fase de simulação inicial (Tabela 31 e Figura 52). 


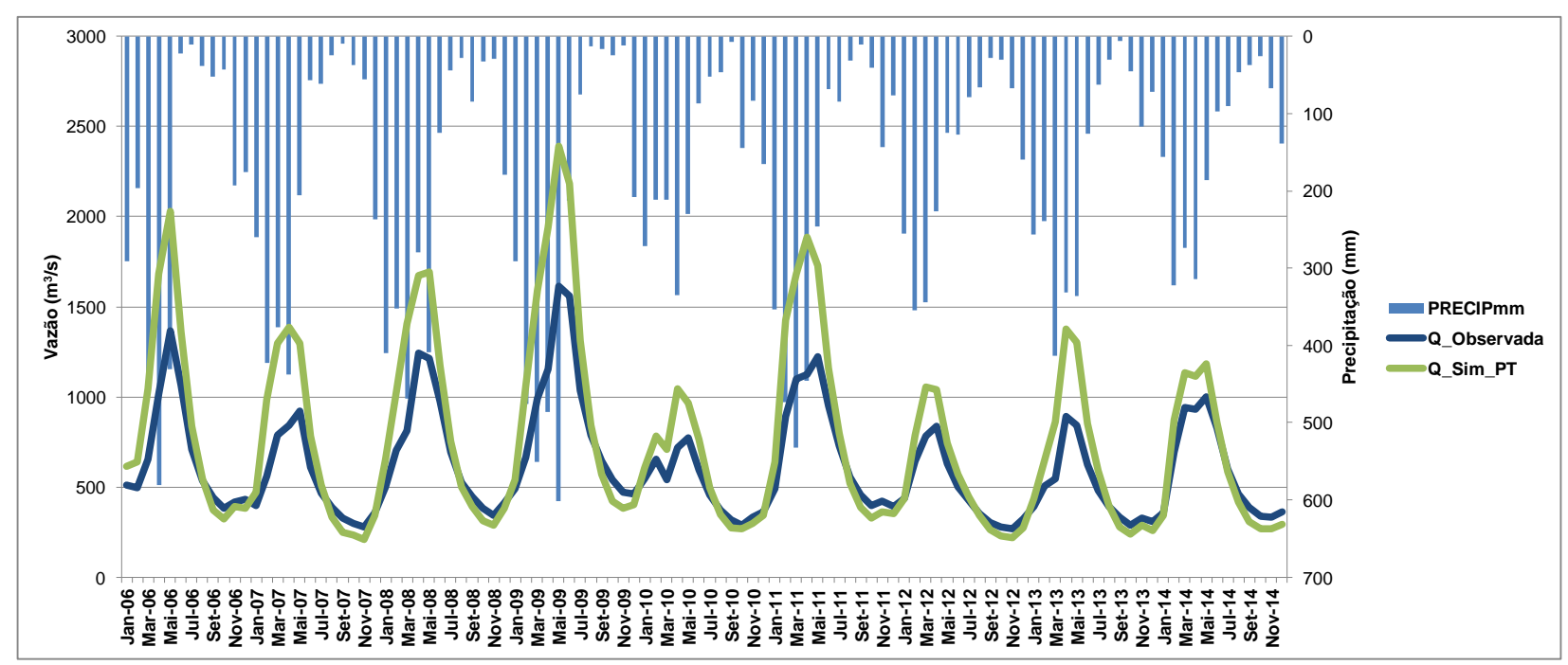

Figura 51: Vazões médias mensais simuladas (Q_Sim_PT é a vazão mensal simulada com PreistleyTaylor) e observadas (Q_Observada) em comparação com a precipitação (PRECIPmm) para a modelagem com condições iniciais da porção média da bacia do rio Capim.

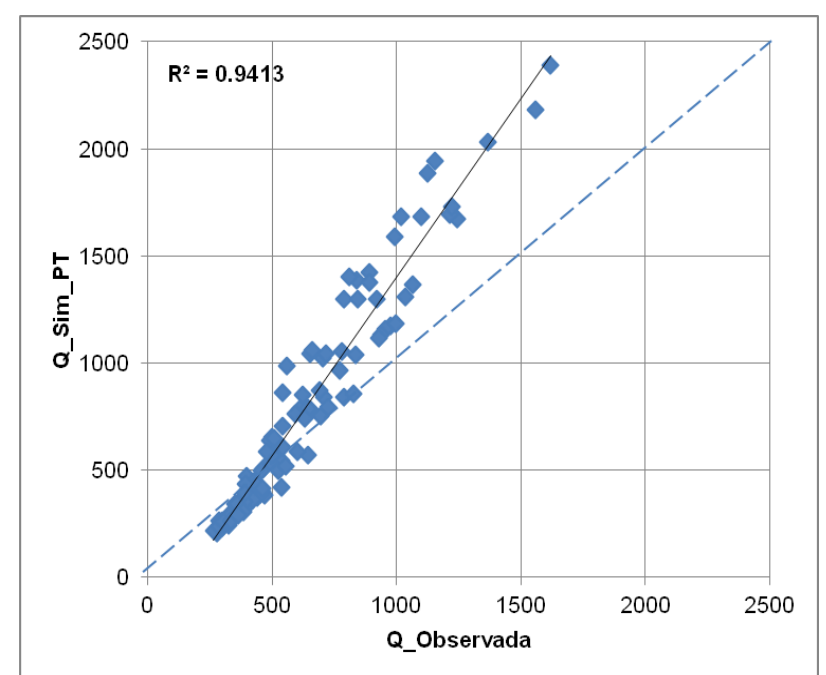

Figura 52: Diagrama de dispersão das vazões médias mensais observadas e simuladas (sem calibração) para o período de 2006 a 2014 na porção média da bacia do rio Capim.

A caracterização do comportamento hidrológico na porção média do rio Capim foi semelhante aos definidos por Nunes (2013), que estudou a bacia por completa, identificando-se assim as mesmas demandas de calibração para ajuste das curvas:

- Redução do volume total de escoamento, devido à superestimativa da vazão principalmente nos períodos chuvosos;

- Aumento do escoamento de base;

- Atraso (lag) no tempo do escoamento, para ajuste dos máximos e mínimos da vazão; 
- Aumento da evapotranspiração, para ajustar a vazão diminuindo a superestimativa principalmente nos períodos de cheia;

- Redução do escoamento superficial, para o ajuste da vazão de pico.

\section{d) Análise de Sensibilidade}

Inicialmente, o processo de calibração se dá com o estudo incial das bacias, realizado anteriormente. Em seguida aplicaram-se os procedimentos de seleção de parâmetros, análise de sensibilidade e calibração. Na Tabela 32 estão descritos todos os 15 parâmetros selecionados e os rangers (intervalos) utilizados inicialmente na análise de sensibilidade (ARNOLD et al., 2012). O modelo SWAT é sensível a mais de 100 parâmetros (ARNOLD et al. 1998), o que demonstra a importância de uma seleção de um grupo específico de variáveis. Os parâmetros aqui escolhidos correspondem às indicações de especialistas em calibração e da literatura conceitual e aplicada (MULETA, NICKLOW, 2005; WHITE et al., 2005; SOUSA, 2010; DOUGLAS-MANKIN et al., 2010, ARNOLD et al., 2012; NUNES, 2013; ARAGÃO et al.,2013; ABBASPOUR et al., 2015; BONUMA et al, 2015; BRESSIANE et al., 2016, no prelo).

Neste trabalho, a análise de sensibilidade foi aplicada unicamente aos modelos das sub-bacias não monitoradas, pois o objetivo foi definir parâmetros a serem ajustados a essas e então aplicar unicamente esses parâmetros escolhidos entre os 15 iniciais diretamente na calibração da porção média do rio Capim e assim poder verificar a aplicabilidade destes à calibração do modelo do rio Capim. Dessa forma, teremos em mãos valores calibrados destes parâmetros em uma bacia monitorada para então testar a eficiência desses parâmetros em calibrar as sub-bacias não monitoradas. Importante registrar que a calibração foi trabalhada apenas para ajustar as descargas líquidas e que os resultados de análise de sedimentos não foram calibrados no presente trabalho. 
Tabela 32: Parâmetros, descrições e ranges iniciais da análise de sensibilidade e calibração utilizados em todas as bacias estudadas.

\begin{tabular}{|c|c|c|}
\hline Parâmetros & Descrição & Intervalos Iniciais \\
\hline (v) ESCO.hru & Fator de compensação de evaporação do solo & 0,5 a 0,95 \\
\hline (r) CN2.mgt & Curva número inicial para a condição de umidade II & $-0,1$ a 0,1 \\
\hline (v) ALPHA_BF.gw & Constante de recessão do fluxo de retorno (dia) & 0,0 a 1,0 \\
\hline (a) GW_DELAY.gw & Tempo de atraso de águas subterrâneas (dia). & -30 a 60 \\
\hline (a) GWQMN.gw & $\begin{array}{l}\text { Profundidade limite de água no aquífero raso requerida para o } \\
\text { escoamento de retorno ocorrer }(\mathrm{mm})\end{array}$ & -1000 a 1000 \\
\hline (v) CANMX.hru & Armazenamento máximo no dossel (mm) & 0 a 30 \\
\hline (v) $\mathrm{CH} \_\mathrm{K} 2$. rte & Condutividade hidráulica efetiva no canal principal (mm/hr). & 0 a 10 \\
\hline (v) $\mathrm{CH}$ _N2.rte & Valor do Coeficiente de Manning "n" para o canal principal. & $-0,01$ a 0,2 \\
\hline (v) EPC̄O.bsn & Fator de compensação de absorção pelas plantas. & 0,01 a 1 \\
\hline (v) GW_REVAP.gw & $\begin{array}{l}\text { Coeficiente que controla a taxa de transferência de água do } \\
\text { aquífero raso para a zona de raízes. }\end{array}$ & 0,02 a 0,2 \\
\hline (a) REVAPMN.gw & $\begin{array}{l}\text { Profundidade limite de água no aqüífero raso para ocorrer revap } \\
(\mathrm{mm}) \text {. }\end{array}$ & -1000 a 1000 \\
\hline (r) SOL_AWC.sol & Capacidade de água disponível na camada de solo (mm/mm) & $-0,05$ a 0,05 \\
\hline (r) SOL_K.sol & Condutividade hidráulica saturada $(\mathrm{mm} / \mathrm{h})$ & $-0,05$ a 0,05 \\
\hline (v) SURLAG.bsn & Coeficiente de atraso do escoamento superficial (dia). & 0,01 a 24 \\
\hline (v) RCHRG_DP.gw & $\begin{array}{l}\text { Fração de percolação da zona de raízes que recarrega o } \\
\text { aquífero profundo (Fração). }\end{array}$ & 0 a 1 \\
\hline
\end{tabular}

O processo de análise de sensilbildiade através do SWAT-CUP foi realizada entre os anos de 2006 a 2010, sendo aplicadas 500 interações. Os parâmetros foram modificados utilizando três métodos: Multiplicação (r), Substituição (v) e por Soma (a) em relação ao valor definido na calibração. As Figuras 53 e 54 e as Tabelas 33 e 34 demonstram os resultados relativos à análise de sensibilidade, expressando os valores do $t$-stat e de $P$-Value para as SBRB e SBRM. 


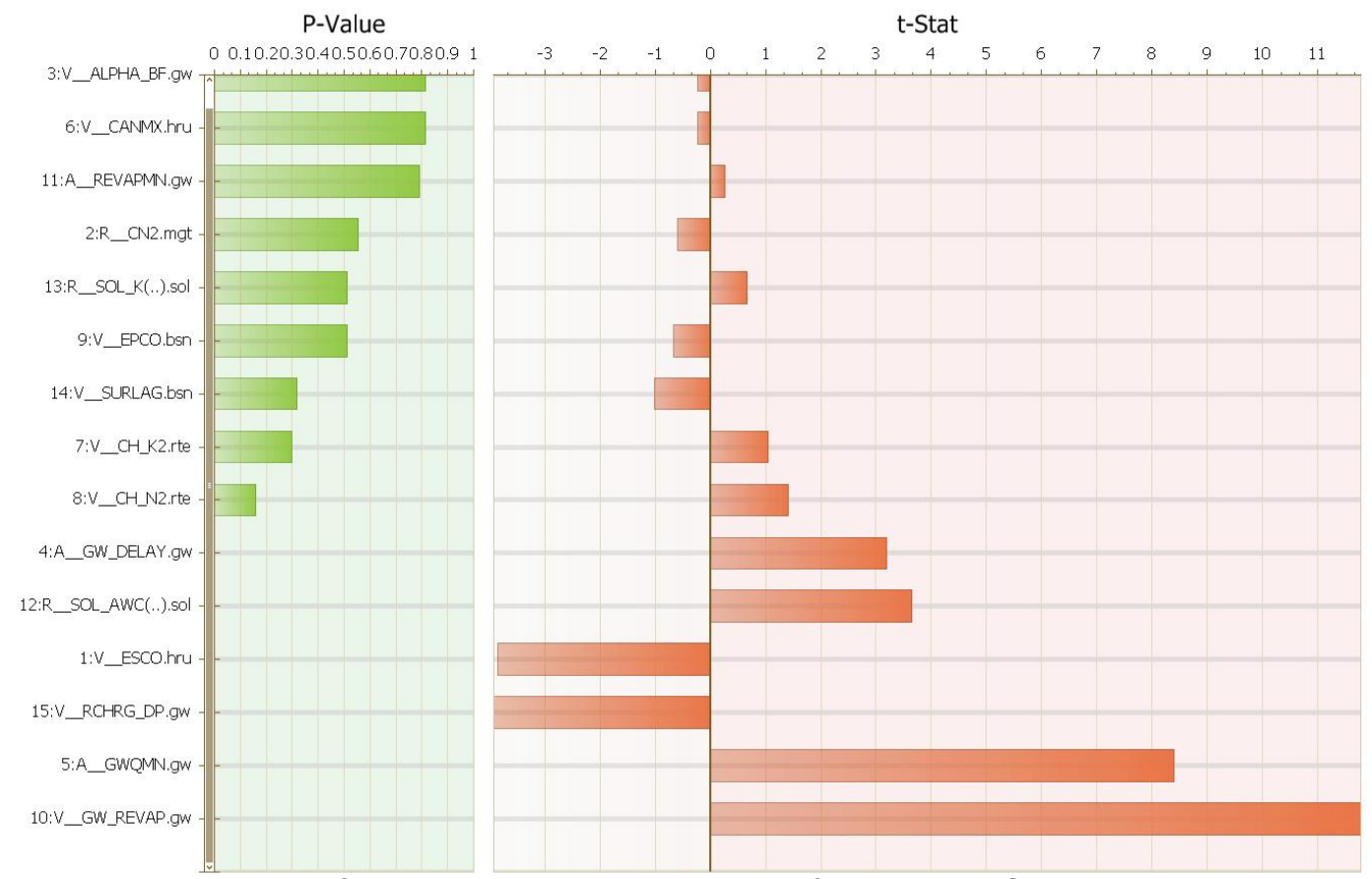

Figura 53: Resultado da análise de sensibilidade dos parâmetros do SWAT para a sub-bacia do rio Bujaru.

Tabela 33: Valores de $t$-stat e $P$-Value obtidos pela análise de sensibilidade dos parâmetros para a subbacia do rio Bujaru.

\begin{tabular}{lll}
\hline Parâmetros & t-Stat & P-Value \\
\hline 3:V_ALPHA_BF.gw & $-0,24$ & 0,81 \\
6:V_CANMX.hru & $-0,24$ & 0,81 \\
11:A_REVAPMN.gw & 0,27 & 0,79 \\
2:R_CN2.mgt & $-0,59$ & 0,55 \\
13:R_SOL_K(..).sol & 0,65 & 0,51 \\
9:V_EPCO.bsn & $-0,66$ & 0,51 \\
14:V_SURLAG.bsn & $-1,00$ & 0,32 \\
7:V_CH_K2.rte & 1,04 & 0,30 \\
8:V_CH_N2.rte & 1,41 & 0,16 \\
4:A_GW_DELAY.gw & 3,19 & 0,00 \\
12:R_SOL_AWC(..).sol & 3,65 & 0,00 \\
1:V_ESCO.hru & $-3,84$ & 0,00 \\
15:V_RCHRG_DP.gw & $-3,92$ & 0,00 \\
5:A_GWQMN.gw & 8,40 & 0,00 \\
10:V_GW_REVAP.gw & 11,78 & 0,00 \\
\hline
\end{tabular}




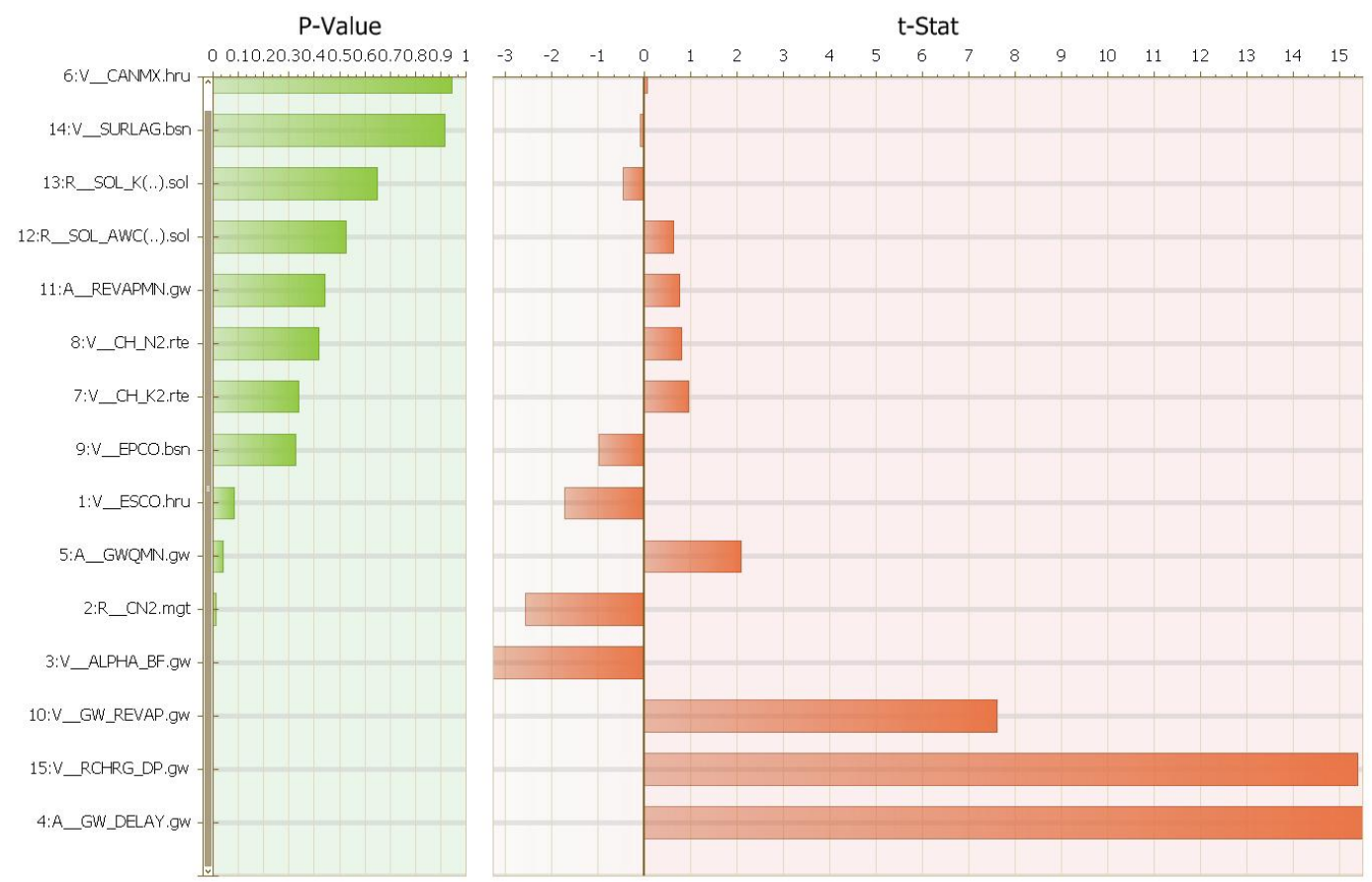

Figura 54: Resultado da análise de sensibilidade dos parâmetros do SWAT para a sub-bacia do rio Mariquita.

Tabela 34: Valores de $t$-stat e $P$-Value obtidos pela análise de sensibilidade dos parâmetros para a subbacia do rio Mariquita.

\begin{tabular}{lll}
\hline Parâmetros & t-Stat & P-Value \\
\hline 6:V_CANMX.hru & 0,07 & 0,94 \\
14:V__SURLAG.bsn & $-0,10$ & 0,92 \\
13:R__SOL_K(..).sol & $-0,46$ & 0,65 \\
12:R__SOL_AWC(..).sol & 0,63 & 0,53 \\
11:A_REVAPMN.gw & 0,77 & 0,44 \\
8:V_CH_N2.rte & 0,81 & 0,42 \\
7:V_CH_K2.rte & 0,95 & 0,34 \\
9:V_EPCO.bsn & $-0,98$ & 0,33 \\
1:V_ESCO.hru & $-1,72$ & 0,09 \\
5:A_GWQMN.gw & 2,08 & 0,04 \\
2:R_CN2.mgt & $-2,58$ & 0,01 \\
3:V_ALPHA_BF.gw & $-3,27$ & 0,00 \\
10:V_GW_REVAP.gw & 7,61 & 0,00 \\
15:V_RCHRG_DP.gw & 15,40 & 0,00 \\
4:A_GW_DELAY.gw & 15,50 & 0,00 \\
\hline
\end{tabular}


A partir das análises de sensibilidade sobre os modelos das sub-bacias não monitoradas, definiu-se 9 parâmetros finais para a calibração, sendo estes uma união entre os parâmetros mais sensíveis e alguns considerados importantes para o estudo. A Tabela 35 apresenta estes parâmetros e as demandas de modificações previstas para ajuste dos modelos dos rios Bujaru e Mariquita.

Tabela 35: Listagem dos 9 parâmetros selecionados de acorda com a demanda de ajuste dos modelos das sub-bacias dos rios Bujaru e Mariquita.

\begin{tabular}{|c|c|}
\hline Redução do volume de escoamento Total & $\begin{array}{c}\text { Redução e regularização do escoamento de } \\
\text { base e recessão da curva }\end{array}$ \\
\hline ESCO; CN2; CANMX; RCHRG_DP; SOL_AWC & ALPHA_BF; GWQMN; GW_REVAP; GW_DELAY \\
\hline
\end{tabular}

Parâmetros como ESCO, CN2, SOL_AWC, ALPHA_BF e CANMX apresentaram, em alguma das sub-bacias, uma baixa influência no modelo, porém em determinadas análises os parâmetros mesmo apresentando baixa sensibilidade podem ser fundamental no ajuste do modelo, uma vez que a literatura e o conhecimento da área de estudo sustentam a necessidade da manutenção do parâmetro (WHITE; CHAUBEY, 2005), o que fundamentou a permanência destes na calibração. Arnold et al (2012) evidenciam o amplo uso na literatura dos parâmetros CN2, ESCO e SOL_AWC em calibrações. A definição dos melhores parâmetros, que possam representar o ajuste do modelo e seus fenômenos com melhor acurácia é um passo fundamental na calibração e validação (DAGGUPATI et al., 2015, no prelo).

O parâmetro ESCO é importante, pois a aproximação das curvas simuladas e observadas reflete diretamente a variação desse parâmetro, uma vez que a redução da produção de água é reflexo da redução do valor deste (KANNAN et al., 2007). Sendo este um parâmetro importante para a simulação da evapotranspiração (MULETA; NICKLOW, 2004; WHITE; CAHUBEY, 2005; ARNOLD et al., 2012).

Kannan et al., (2007), identifica o parâmetro SOL_AWC com forte influência na calibração, uma vez que todos os componentes do balanço hídrico são sensíveis a este parâmetro, sendo que seu aumento influencia numa redução de componentes como escoamento de base, drenagem do solo e escoamento superficial, sendo este um parâmetro citado em trabalhos importantes (WHITE; CAHUBEY, 2005; ABBASPOUR et al., 2015). 
De fundamental importância para as simulações do escoamento superficial, o ajuste da Curva Número influencia diretamente na calibração mensal do escoamento superficial e nas características sazonais da bacia (ARNOLD et al., 2012). Esses autores apontam o CN2 como um dos primeiros passos de calibração, focado no ajuste da produção no sistema, mas apontam outras demandas sequenciais como necessárias, sendo estes os ajustes de parâmetros de escoamento subterrâneo (GW_REVAP e GW_DELAY), percolação (RCHRG_DP), recessão da curva de escoamento de base (ALPHA_BF), os quais são todos aplicados neste trabalho.

O parâmetro CANMX, em especial por razão de haver características diferenciadas da região amazônica em relação a outros ecossistemas florestais, foi utilizado na calibração, objetivando contribuir com o ajuste da vazão (MULETA; NICKLOW, 2004; WHITE; CAHUBEY, 2005)

Os 9 parâmetros selecionados após as análises de sensibilidade, revisão bibliográfica e, principalmente, após as orientações de especialistas no modelo SWAT (Tabela 35), são parâmetros amplamente utilizados na literatura internacional (DOUGLAS-MANKIN et al., 2010; TUPPAD et al., 2011; ARNOLD et al., 2012; ABBASPOUR et al., 2015), como citado acima, mas em especial na literatura brasileira também, o que fortalece a escolha destes (SOUSA, 2010; GARBOSSA et al., 2011; DURÃES et al., 2011; ROCHA et al., 2012; UZEIKA et al., 2012; NUNES, 2013; STRAUCH et al., 2013; PEREIRA et al., 2014a; CREECH et al., 2015; BRESSIANI et al., 2015a; FUKUNAGA et al., 2015; RODRIGUES et al., 2015).

\subsubsection{Experimento 2: Calibração e Validação.}

Assim como na análise de sensibilidade, a calibração com o SWAT-CUP foi realizada de forma automática através de 500 interações, mas com os 9 parâmetros escolhidos. A calibração foi feita no passo mensal de 2006 a 2010, totalizando 60 amostragens de vazão no exutório de cada bacia estudada. Dessa forma, abaixo são 
apresentados os resultados para as três bacias estudadas, sendo que os gráficos integram o resultado do período de calibração (2006-2010) e de validação (2011-2014).

\section{a) Calibração da porção média do Rio Capim}

$\mathrm{Na}$ bacia do rio Capim o experimento objetivou submeter esta bacia diretamente a calibração com os 9 parâmetros selecionados para as sub-bacias dos rios Bujaru e Mariquita. A Tabela 36 apresenta os resultados do melhor ajuste para estes parâmetros no período de calibração e validação. Observa-se que todos os parâmetros tiveram alguma alteração na calibração, que foi fundamental para a obtenção de um bom resultado, conforme apresentado na Figura 55 e comprovado através dos testes estatísticos (Figura 56 e Tabela 37), quando comparados com a classificação proposta por Moriasi et al. (2007) na Tabela 38, demonstrando bom acerto do modelo (NSE) e baixa super ou subestimativa (PBIAS), tanto na calibração como na validação.

Tabela 36: Parâmetros, métodos, intervalos e valores resultantes da calibração para a porção média da bacia do rio Capim.

\begin{tabular}{lccccccc}
\hline & \multicolumn{3}{c}{ SWAT-CUP } & & \multicolumn{2}{c}{ SWAT } \\
\cline { 2 - 3 } \cline { 6 - 7 } Parâmetros & $\begin{array}{c}\text { Valor } \\
\text { Mínimo }\end{array}$ & $\begin{array}{c}\text { Valor } \\
\text { Máximo }\end{array}$ & $\begin{array}{c}\text { Melhor } \\
\text { valor }\end{array}$ & & $\begin{array}{c}\text { Valor } \\
\text { Inicial }\end{array}$ & $\begin{array}{c}\text { Valor } \\
\text { Calibrado }\end{array}$ \\
\hline (V) ALPHA_BF.gw & 0 & 0,3 & 0,0075 & & 0,048 & 0,0075 \\
(V) ESCO.hru & 0,4 & 0,6 & 0,4046 & & 0,95 & 0,4046 \\
(R) CN2.mgt & $-0,1$ & 0,1 & $-0,089$ & & Varia & R: $-0,089$ \\
(A) GW_DELAY.gw & -30 & 60 & 14,730001 & & 31 & 45,730001 \\
(A) GWQMN.gw & -500 & 1300 & 664,599976 & & 1000 & 1664,599976 \\
(V) CANMX.hru* & 19 & 30 & 25,853001 & & 0 & $25,853001^{*}$ \\
(V) GW_REVAP.gw & 0,02 & 0,2 & 0,18794 & & 0,02 & 0,18794 \\
(R) SOL_AWC.sol & $-0,05$ & 0,1 & 0,04735 & & Varia & R: 0,047 \\
(V) RCHRG_DP.gw & 0 & 1 & 0,423 & & 0,05 & 0,423 \\
\hline
\end{tabular}

Nota: R: Mudanças relativas ao valor de Default (multiplicar o Default por $1+\mathrm{R}$ );

* Aplicado apenas aos usos FRSE e OILP. 


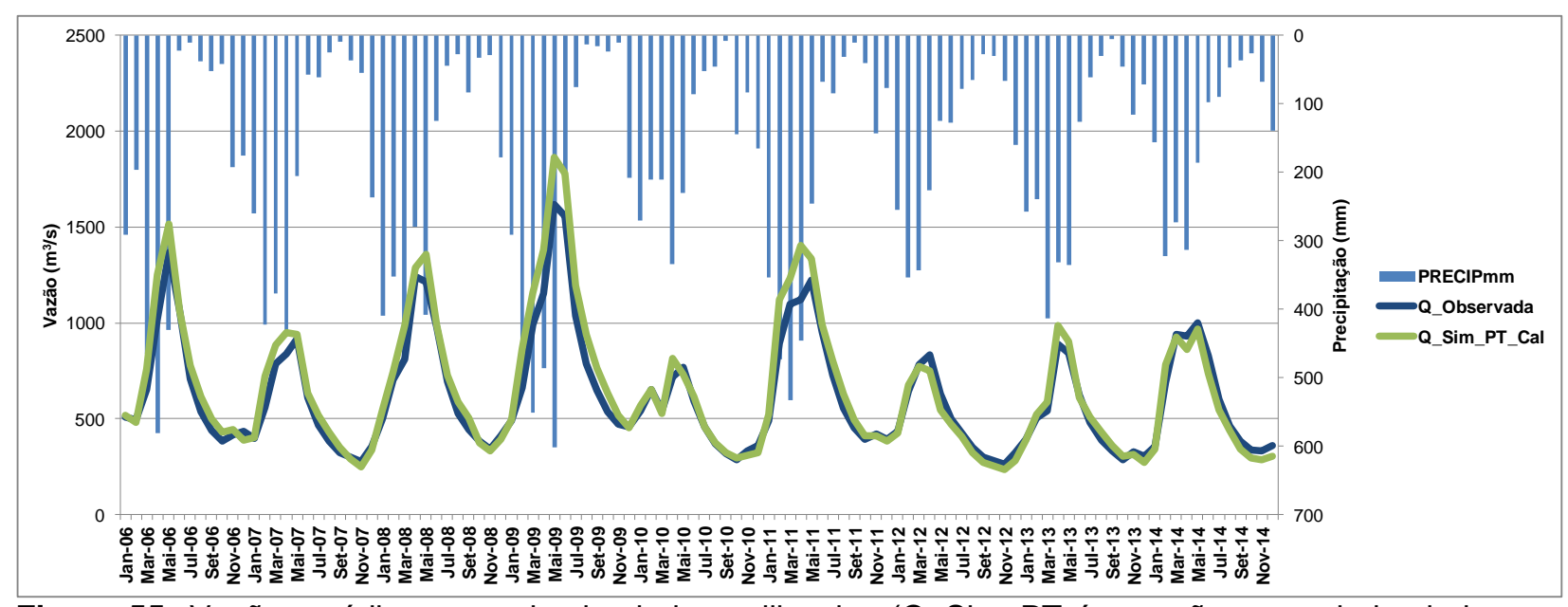

Figura 55: Vazões médias mensais simuladas calibradas (Q_Sim_PT é a vazão mensal simulada com Preistley-Taylor) e observadas (Q_Observada) em comparação com a precipitação (PRECIPmm) para o período de calibração (2006-2010) e validação (2011-2014) da porção média da bacia do rio Capim.

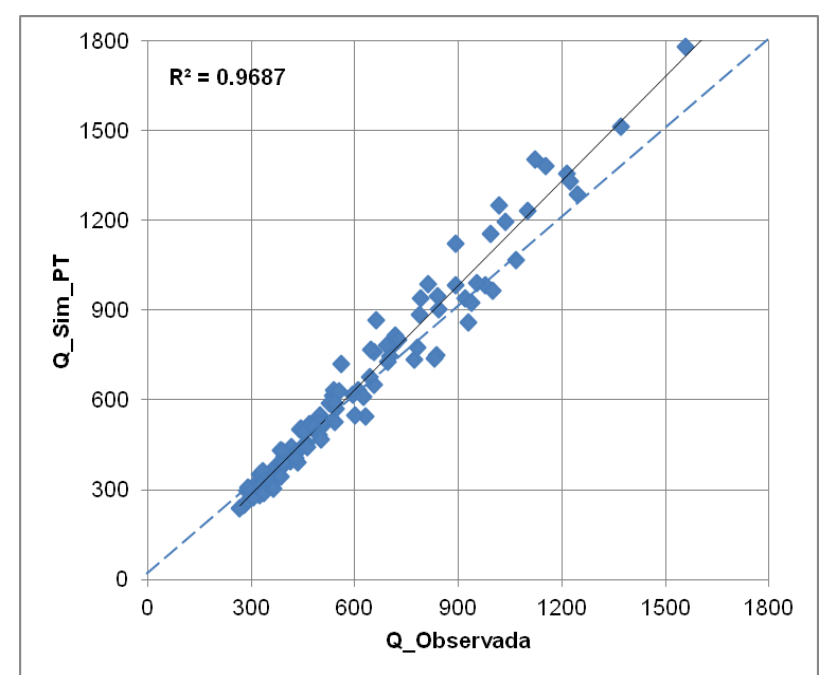

Figura 56: Diagrama de dispersão das vazões médias mensais observadas e simuladas calibradas para o período de 2006 a 2014 na porção média da bacia do rio Capim.

Importante observar que o modelo da bacia do rio Capim apresentou algumas demandas de calibração diferentes, em especial com relação à necessidade de aumentar o escoamento de base e ajustar, assim, a curva de recessão, bem como a necessidade de se atrasar um pouco alguns picos de vazão da curva simulada, Esse fator acabou exigindo alguns valores diferentes para os parâmetros GWQMN e GW_DELAY, em especial. Esses resultados tiveram forte influência no resultado final da transferência desses parâmetros para as sub-bacias não monitoradas SBRB e SBRM, como descrito mais a frente. 
Tabela 37: Avaliação da eficiência das simulações calibradas diretamente com a vazão regionalizada e calibradas com os parâmetros transferidos do modelo calibrado da porção média da bacia do rio Capim paras as sub-bacias não monitoradas dos rios Bujaru e Mariquita e da simulação para a porção média da bacia do rio Capim.

\begin{tabular}{|c|c|c|c|c|c|c|}
\hline \multirow{2}{*}{ Bacias } & \multicolumn{3}{|c|}{ Calibração (2006-2010) } & \multicolumn{3}{|c|}{ Validação (2011-2014) } \\
\hline & NSE & RSR & PBIAS & NSE & RSR & PBIAS \\
\hline & \multicolumn{6}{|c|}{ Calibração direta com a série regionalizada de vazão } \\
\hline Bujaru & 0,50 & 0,71 & $-27,59$ & 0,78 & 0,47 & 4,83 \\
\hline \multirow[t]{2}{*}{ Mariquita } & 0,73 & 0,52 & $-22,27$ & 0,76 & 0,49 & $-11,94$ \\
\hline & \multicolumn{6}{|c|}{ Calibração com os parâmetros do rio Capim } \\
\hline Bujaru & 0,03 & 0,98 & $-40,92$ & 0,38 & 0,79 & 10,13 \\
\hline Mariquita & 0,33 & 0,82 & $-32,50$ & 0,39 & 0,78 & $-10,86$ \\
\hline Capim & 0,91 & 0,30 & $-8,98$ & 0,92 & 0,28 & $-1,97$ \\
\hline
\end{tabular}

Tabela 38: Classificação do desempenho para as estatísticas NSE, PBIAS e RSR aplicadas a avaliação da vazão (MORIASI et al, 2007).

\begin{tabular}{lccc} 
Classificação & NSE & PBIAS $\%$ & RSR \\
\hline Muito bom & $0,75<$ NSE $\leq 1,00$ & PBIAS $< \pm 10$ & $0,00 \leq R S R \leq 0,50$ \\
Bom & $0,65<$ NSE $\leq 0,75$ & $\pm 10<$ PBIAS $< \pm 15$ & $0,50<R S R \leq 0,60$ \\
Satisfatório & $0,50<$ NSE $\leq 0,65$ & $\pm 15<$ PBIAS $< \pm 25$ & $0,60<R S R \leq 0,70$ \\
Insatisfatório & NSE $\leq 0,50$ & PBIAS $> \pm 25$ & $R S R>0,70$ \\
\hline
\end{tabular}

No presente trabalho, a modelagem e calibração da porção média da bacia do rio Capim tem o objetivo de verificar uma técnica usada por usuários do SWAT que é a transferência de parâmetros calibrados de bacias monitoradas para bacias sem monitoramento para predizer séries de vazão nas bacias não monitoradas (ARNOLD et al, 2012). A calibração de bacias não monitoradas é tópico importante de discussão recente na área da hidrologia (CUI et al., 2015), havendo mecanismos diferentes para implementar a técnica, como a calibração de um determinado número de bacias monitoradas e a transferência destes parâmetros de maneira direta de uma bacia monitora para uma não monitorada, através de regressão ou da composição de uma média global (GITAU; CHAUBEY, 2010; SELLAMI et al., 2014; ZARRINEH et al., 2015). Isto fortalece também a necessidade de se buscar o entendimento das similaridades de características entre as diferentes regiões hidrológicas para melhorar os resultados (PAGLIERO et al., 2014). A pesar de haver algumas aplicações desse método e com resultados positivos, segundo Daggupati et al. (2015, no prelo) ainda pouco se conhece 
a respeito da performance do modelo calibrado através de transferência de parâmetros, porém este pode ser um mecanismo de poupar tempo na modelagem sem sacrificar o desempenho do modelo.

\section{b) Sub-bacia do rio Bujaru}

Os resultados apresentados na Figura 57 são relativos ao método de calibração feito primeiramente com o SWAT-CUP, tendo como série "observada" no processo de calibração a vazão regionalizada através das equações de regressão não lineares, e são relativos também ao método de calibração fundamentada na transferência dos parâmetros calibrados da porção média da bacia do rio Capim para as sub-bacias não monitoradas, fundamentando-se, assim como na regionalização, na perspectiva de homogeneidade geofisiográfica e de uso e cobertura da terra.

Os resultados estatísticos demostram a relação de acerto entre os dois métodos de calibração com relação à vazão mensal regionalizada de 2006 a 2014 (Tabela 37 e Figura 59) e com relação ao gráfico da Figura 58 e Tabela 40, relativo às vazões médias mensais de longo período (QMMLP) regionalizadas, que é o escopo de análise para definição dos resultados finais do presente trabalho. Em ambas análises, o modelo calibrado diretamente com a regionalização de vazão apresentou os melhores resultados, quando comparados a série regionalizada (Tabela 37) e a QMMLP (Tabela 40), o que já era de se esperar (Figura 58). Porém, pode-se observar que existe um comportamento semelhante entre ambas as metodologias, o que fica mais claro ao analisarmos os resultados dos testes estatísticos para a QMMLP (Tabela 40), onde todos os modelos apresentaram bons resultados (MORIASE et al., 2007). A Tabela 39 apresenta os resultados finais dos parâmetros calibrados que forneceram o melhor ajuste do modelo Bujaru. 
Tabela 39: Parâmetros, métodos, intervalos e valores resultantes da calibração para a sub-bacia do rio Bujaru.

\begin{tabular}{lccccccc}
\hline & \multicolumn{3}{c}{ SWAT-CUP } & & \multicolumn{2}{c}{ SWAT } \\
\cline { 2 - 4 } \cline { 7 - 8 } Parâmetros & $\begin{array}{c}\text { Valor } \\
\text { Mínimo }\end{array}$ & $\begin{array}{c}\text { Valor } \\
\text { Máximo }\end{array}$ & $\begin{array}{c}\text { Melhor } \\
\text { valor }\end{array}$ & & $\begin{array}{c}\text { Valor } \\
\text { Inicial }\end{array}$ & $\begin{array}{c}\text { Valor } \\
\text { Calibrado }\end{array}$ \\
\hline (V) ALPHA_BF.gw & 0,003 & 0,2 & 0,189165 & & 0,048 & 0,189165 \\
(V) ESCO.hru & 0,4 & 0,6 & 0,5126 & & 0,95 & 0,5126 \\
(R) CN2.mgt & $-0,1$ & 0,05 & $-0,09745$ & & Varia & R: $-0,09745$ \\
(A) GW_DELAY.gw & -15 & 50 & $-13,895$ & & 31 & 17,105 \\
(A) GWQMN.gw & 100 & 1200 & 1194,5 & & 1000 & 2194,5 \\
(V) CANMX.hru* & 19 & 30 & 25,127001 & & 0 & $25,127001^{*}$ \\
(V) GW_REVAP.gw* & 0,02 & 0,2 & 0,16202 & & 0,02 & 0,16202 \\
(R) SOL_AWC.sol & 0 & 0,3 & 0,2385 & & Varia & R: 0,2385 \\
(V) RCHRG_DP.gw & 0,3 & 0,9 & 0,597 & & 0,05 & 0,597 \\
\hline
\end{tabular}

Nota: R: Mudanças relativas ao valor de Default (multiplicar o Default por $1+\mathrm{R}$ );

* Aplicado apenas aos usos FRSE e OILP.

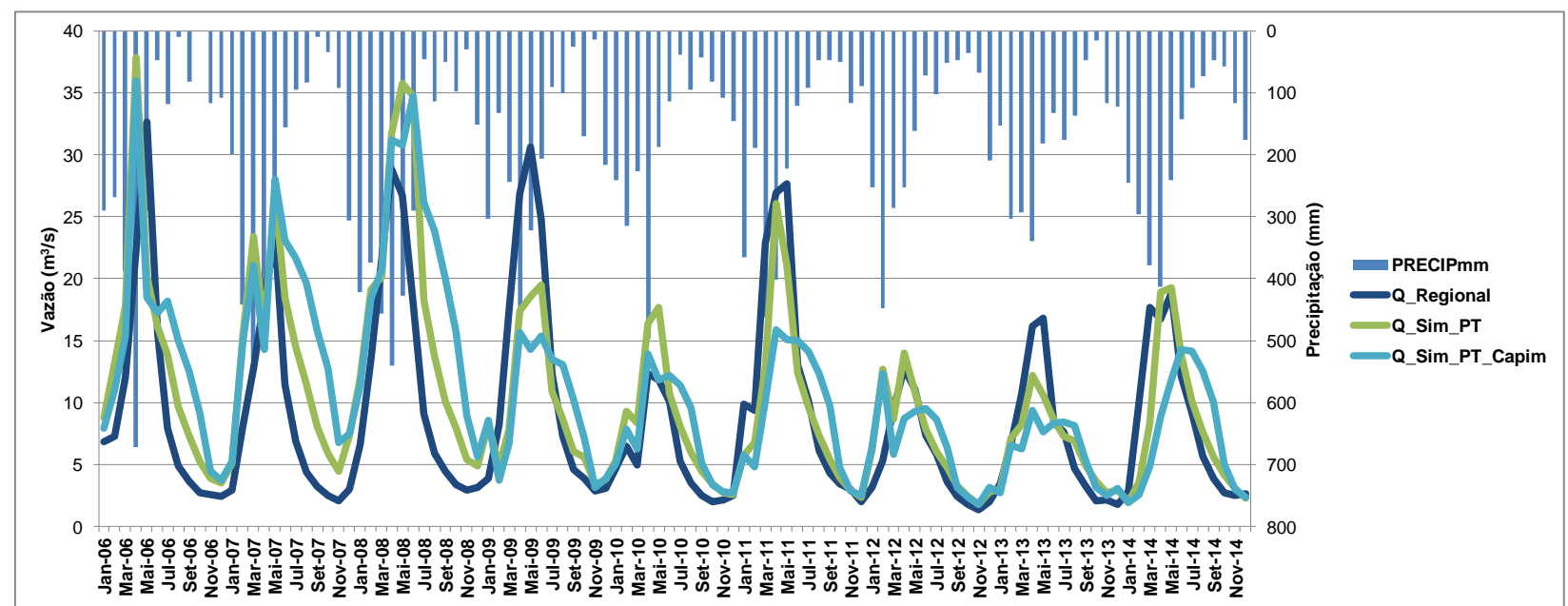

Figura 57: Comparação entre as vazões médias mensais simuladas calibradas diretamente com a regionalização (Q_Sim_PT), simuladas calibradas através dos parâmetros calibrados da porção média da bacia do rio Capim, vazões regionalizadas (Q_Regional) e a precipitação (PRECIPmm) para o período de calibração (2006-2010) e validação (2011-2014) da sub-bacia do rio Bujaru. 


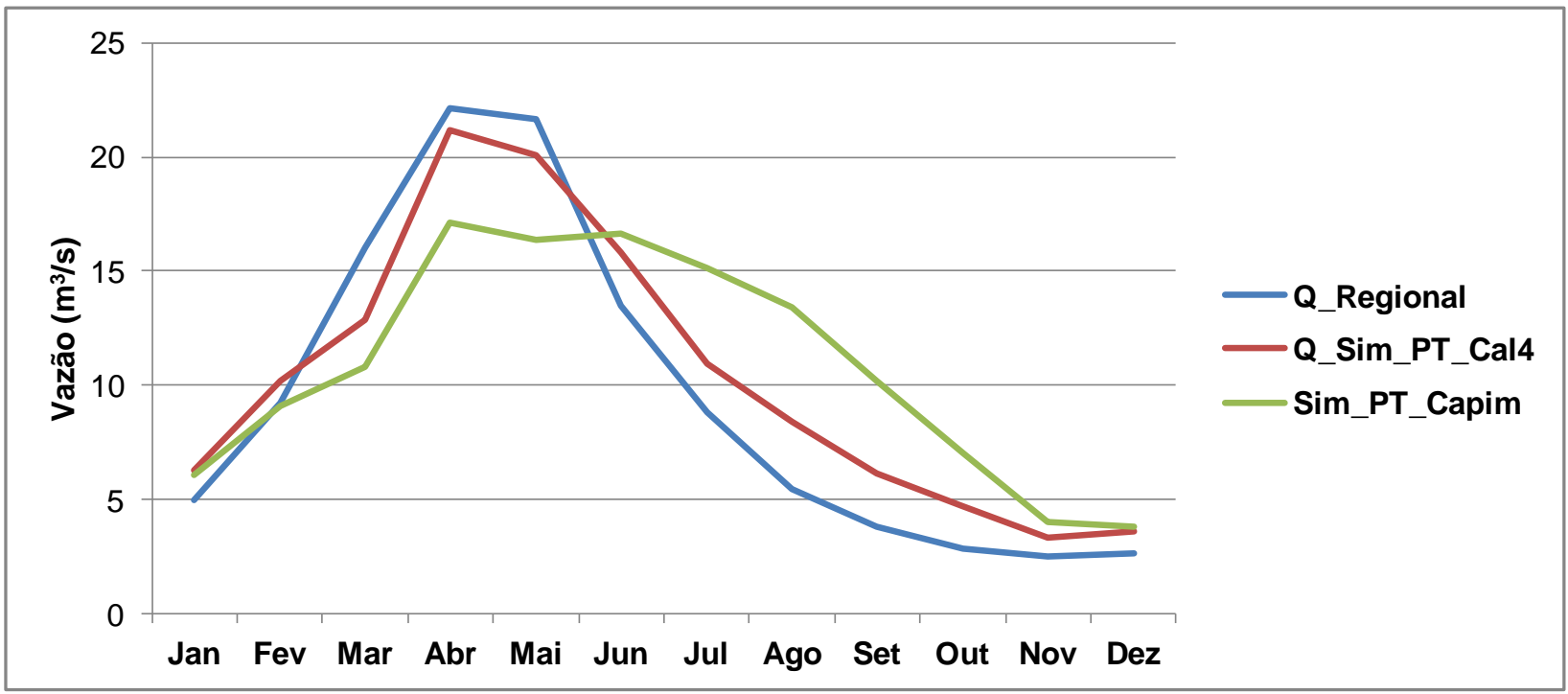

Figura 58: Vazões médias mensais de longo período simuladas calibradas (Q_Sim_PT_Cal4) e Regionalizadas (Q_Regional) para a sub-bacia do rio Bujaru entre os anos de 2006 a 2014.
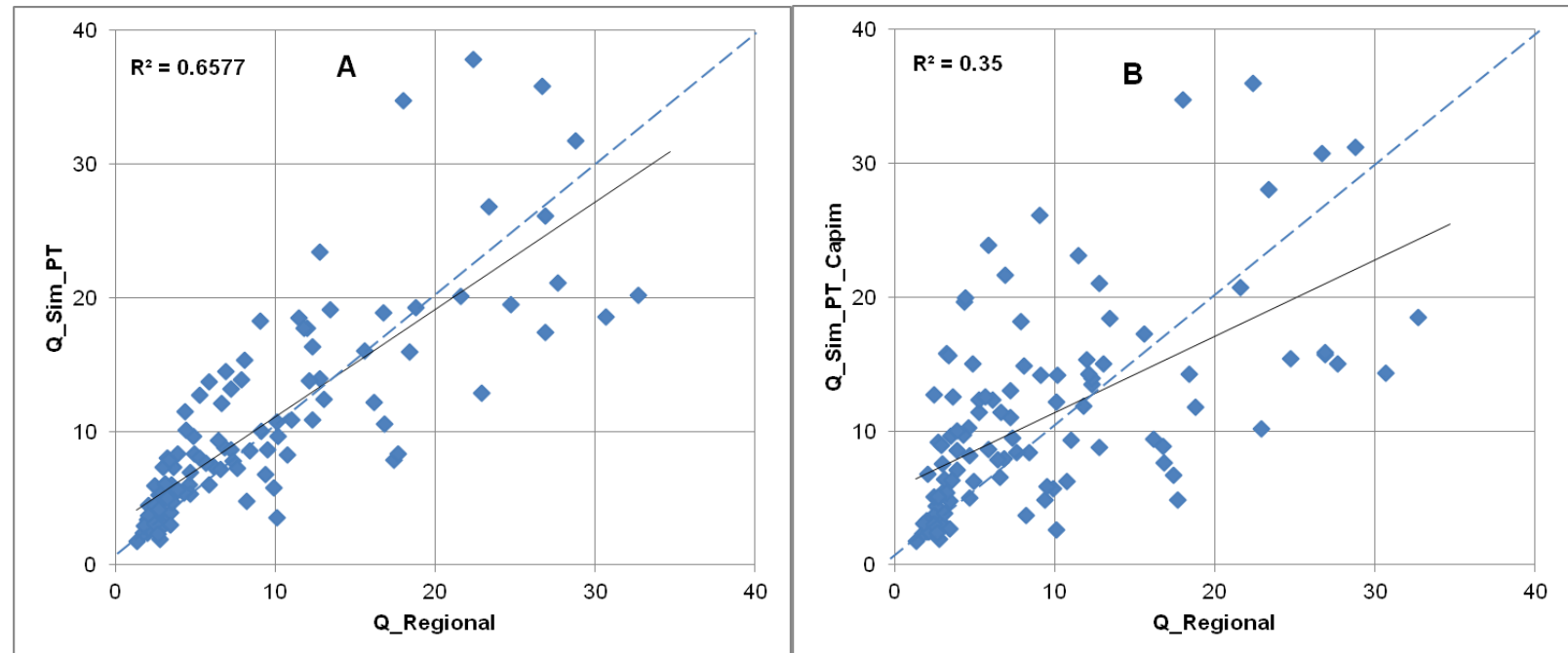

Figura 59: Diagrama de dispersão das vazões médias mensais regionalizadas e simuladas calibradas para o período de 2006 a 2014 na sub-bacia do rio Bujaru. A - Calibração direta com a regionalização; B Calibração com transferência de parâmetros. 
Tabela 40: Avaliação da eficiência das simulações calibradas diretamente com a vazão regionalizada e calibrada com os parâmetros transferidos do modelo calibrado da porção média da bacia do rio Capim paras as sub-bacias dos rios Bujaru e Mariquita.

\begin{tabular}{|c|c|c|c|c|c|c|}
\hline \multirow{2}{*}{ Sub-bacias } & \multicolumn{6}{|c|}{ Calibração QMMLP } \\
\hline & NSE & RSR & PBIAS & NSE & RSR & PBIAS \\
\hline & \multicolumn{3}{|c|}{ Calibração com a Regionalização } & \multicolumn{3}{|c|}{ Tranferência de parâmetros } \\
\hline Bujaru & 0,92 & 0,28 & $-8,72$ & 0,55 & 0,67 & $-14,22$ \\
\hline Mariquita & 0,93 & 0,26 & $-15,83$ & 0,55 & 0,67 & $-21,36$ \\
\hline
\end{tabular}

c) Sub-bacia do rio Mariquita

As análises dos resultados da calibração e validação do modelo da SBRM, relativas às séries mensais de 2006 a 2014 (Tabela 37, Figura 60 e Figura 62), seguem o mesmo padrão de análise da sub-bacia do rio Bujaru, diferenciando-se apenas por razão do modelo Mariquita ter obtido melhores resultados na calibração com os parâmetros do rio Campim, quando comparados com as séries de vazão regionalizada, do que o modelo Bujaru. A Tabela 41 apresenta os resultados finais dos parâmetros calibrados que forneceram o melhor ajuste do modelo. Os resultados da calibração da QMMLP também foram bons (Figura 61 e Tabela 40),

Tabela 41: Parâmetros, métodos, intervalos e valores resultantes da calibração para a sub-bacia do rio Mariquita.

\begin{tabular}{lccccccc}
\hline \multirow{2}{*}{ Parâmetros } & \multicolumn{3}{c}{ SWAT-CUP } & & \multicolumn{2}{c}{ SWAT } \\
\cline { 2 - 4 } \cline { 7 - 8 } & $\begin{array}{c}\text { Valor } \\
\text { Mínimo }\end{array}$ & $\begin{array}{c}\text { Valor } \\
\text { Máximo }\end{array}$ & $\begin{array}{c}\text { Melhor } \\
\text { valor }\end{array}$ & & $\begin{array}{c}\text { Valor } \\
\text { Inicial }\end{array}$ & $\begin{array}{c}\text { Valor } \\
\text { Calibrado }\end{array}$ \\
\hline (V) ALPHA_BF.gw & 0,003 & 0,2 & 0,152523 & & 0,048 & 0,152523 \\
(V) ESCO.hru & 0,4 & 0,6 & 0,5922 & & 0,95 & 0,5922 \\
(R) CN2.mgt & $-0,1$ & 0,03 & $-0,08765$ & & Varia & R: $-0,08765$ \\
(A) GW_DELAY.gw & -30 & 30 & $-8,700001$ & & 31 & 22,299999 \\
(A) GWQMN.gw & 300 & 1700 & 1141,40002 & & 1000 & 2141,400024 \\
(V) CANMX.hru & 19 & 30 & 19,385 & & 0 & $19,385^{*}$ \\
(V) GW_REVAP.gw & 0,07 & 0,2 & 0,19571 & & 0,02 & 0,19571 \\
(R) SOL_AWC.sol & $-0,05$ & 0,05 & 0,0419 & & Varia & R: 0,0419 \\
(V) RCHRG_DP.gw & 0,3 & 1 & 0,5247 & & 0,05 & 0,5247 \\
\hline
\end{tabular}

Nota: R: Mudanças relativas ao valor de Default (multiplicar o Default por $1+\mathrm{R}$ );

* Aplicado apenas aos usos FRSE e OILP. 


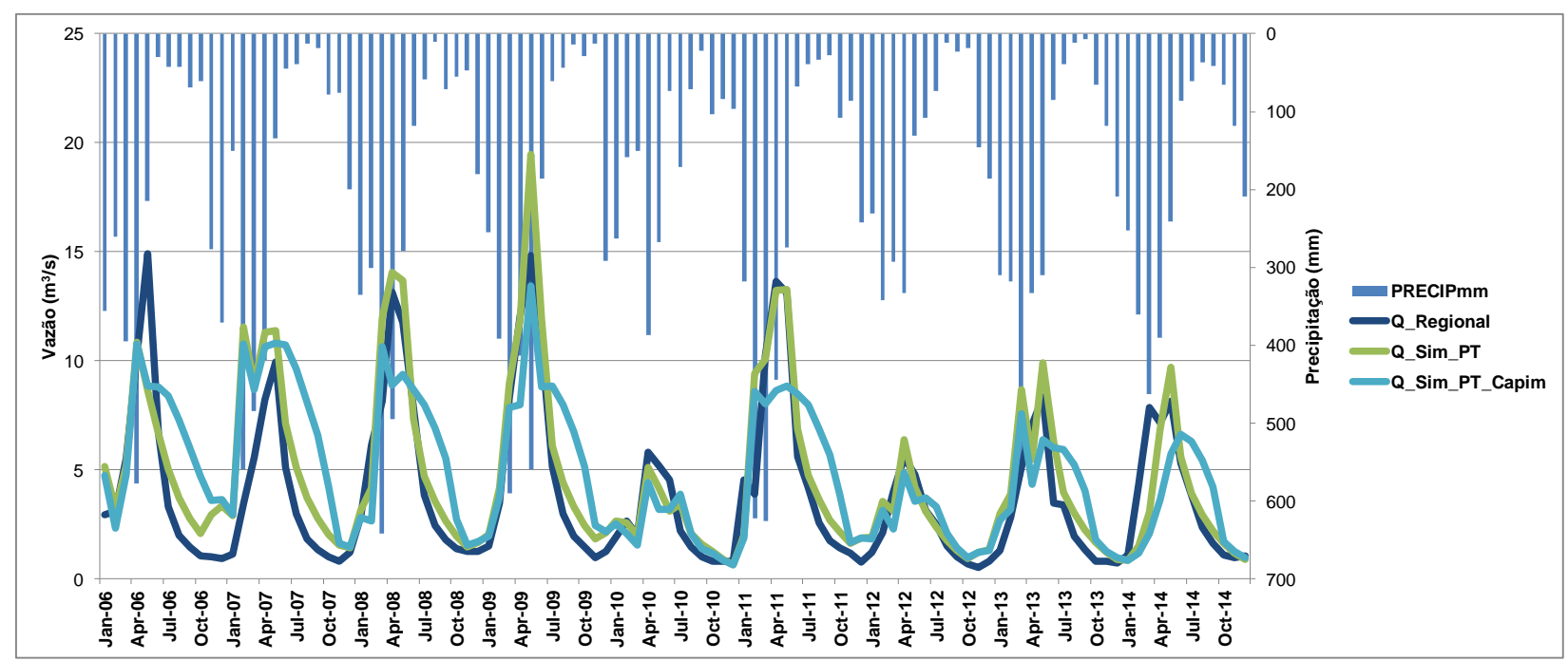

Figura 60: Comparação entre as vazões médias mensais simuladas calibradas diretamente com a regionalização (Q_Sim_PT), simuladas calibradas através dos parâmetros calibrados da porção média da bacia do rio Capim, vazões regionalizadas (Q_Regional) e a precipitação (PRECIPmm) para o período de calibração (2006-2010) e validação (2011-2014) da sub-bacia do rio Mariquita.

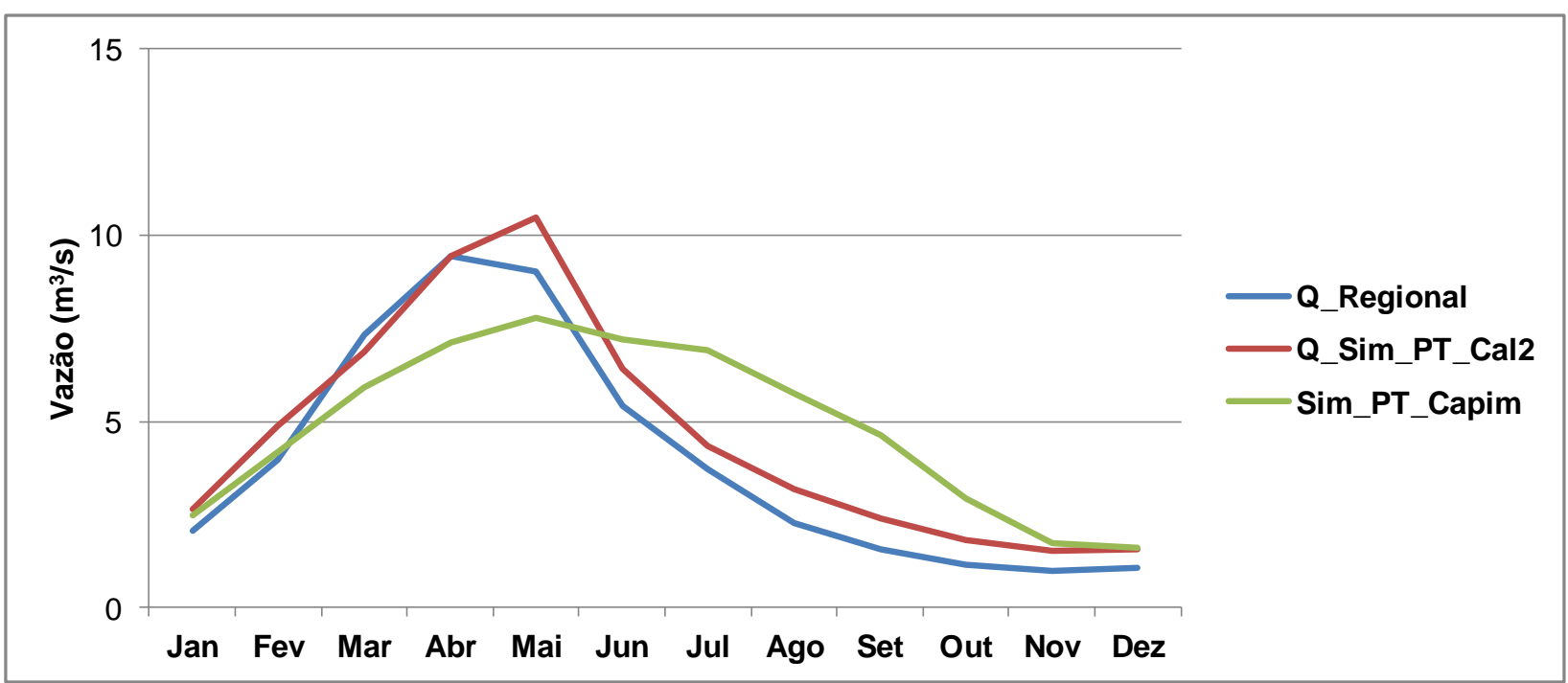

Figura 61: Vazões médias mensais de longo período simuladas calibradas (Q_Sim_PT_Cal2) e Regionalizadas (Q_Regional) para a sub-bacia do rio Mariquita entre os anos de 2006 a $201 \overline{4}$. 

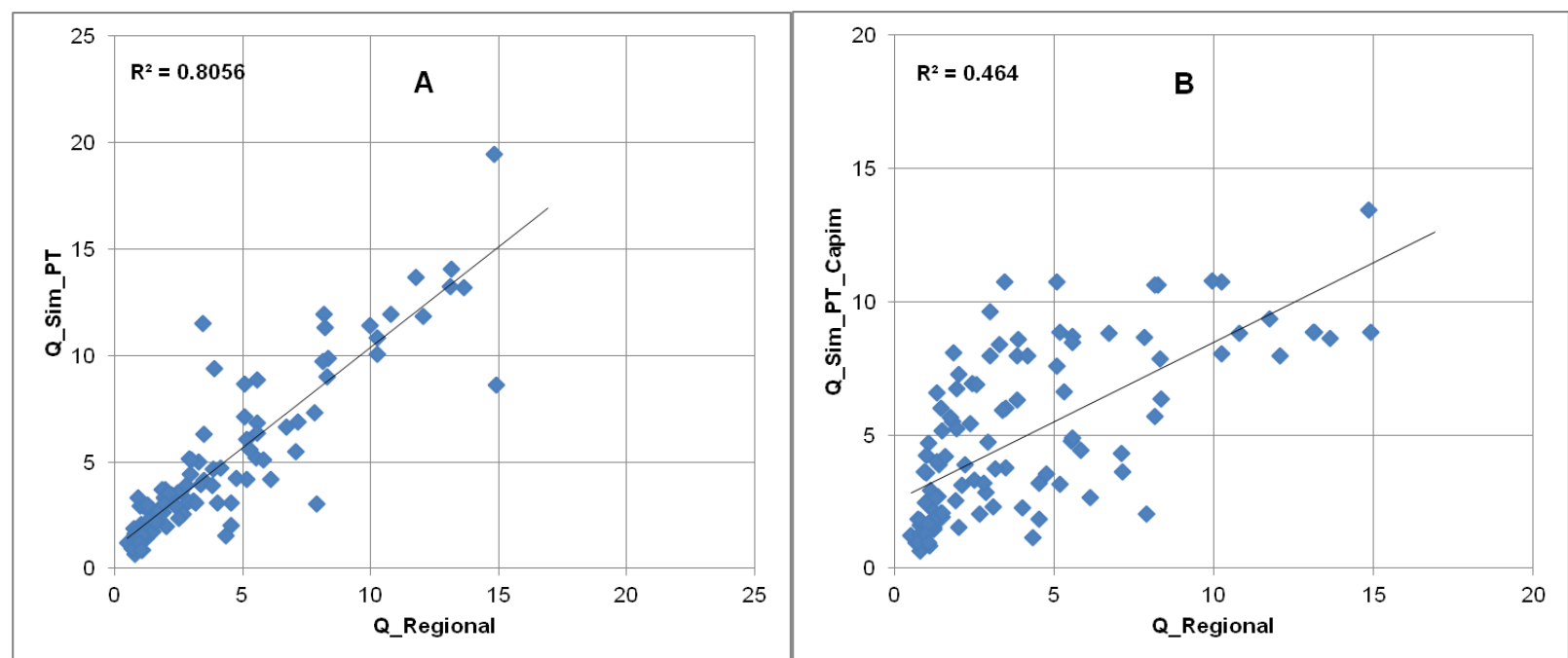

Figura 62: Diagrama de dispersão das vazões médias mensais regionalizadas e simuladas calibradas para o período de 2006 a 2014 na sub-bacia do rio Mariquita. A - Calibração direta com a regionalização; B - Calibração com transferência de parâmetros.

d) Balanço Hídrico no exultório das sub-bacias não monitoradas dos rios Bujaru e Mariquita.

De acordo com as Tabelas 42, 43, 44 e 45, o balanço hídrico, de maneira geral, foi muito semelhante em ambas sub-bacias em quase todos os parâmetros, com a exceção do escoamento subterrâneo, utilizando as duas metodologias de calibração. Isso pode ser observado quando comparamos alguns parâmetros fundamentais, como a média anual de longo período (Q_Sim), o acumulado médio de longo período da evapotranspiração real (ET), escoamento superficial (SURQ) e a produção total de água da sub-bacia que chega ao rio (WYLD). Observa-se também que a SBRB e SBRM apresentaram comportamento coerente com as características da região e no caso de alguns dados comparáveis, como evapotranspiração e coeficiente de escoamento, apresentaram comportamento padrão em ambas sub-bacias (ANA, 2015; ZEE-PA, 2010). Em especial a evapotranspiração, todos os modelos estão semelhantes aos dados disponibilizados pelo ZEE-PA $(1.300-1.500 \mathrm{~mm})$. Quanto ao coeficiente de escoamento, os resultados de 0,36 e 0,38 na SBRB e de 0,37 e 0,39 na SBRM, para a calibração direta com o SWAT-CUP e para a calibração com transferência de parâmetros do rio Capim respectivamente, também estão razoavelmente coerentes com 
os dados da região hidrográfica do Tocatins $(0,27)$, da qual fazem parte todas as áreas em estudo na presente tese. Mas também foram bem semelhantes ao coeficiente de escoamento da região hidrográfica do Atlântico Norte $(0,37)$, que é a região extremamente próxima da SBRB e SBRM e com características de precipitação parecidas.

Esses resultados demonstram semelhanças entres os dois métodos de calibração, demonstram a possibilidade de se utilizar a transferência de parâmetros calibrados de uma região para outra com características geofisiográficas semelhantes, bem como a possibilidade de se utilizar a regionalização de vazão como uma ferramenta de auxílio a calibração de modelos em bacias não monitoradas na Amazônia. Contudo, em relação à transferência de parâmetros de bacias monitoradas, talvez o melhor caminho seja criar modelos calibrados para um número maior de bacias monitoradas e então efetuar uma regionalização dos parâmetros calibrados, o que promoveria uma melhor distribuição das características regionais e consequentemente elevaria a qualidade da transferência de parâmetros.

Tabela 42: Balanço hídrico da sub-bacia do rio Bujaru calibrado com a regionalização de vazão.

\begin{tabular}{|c|c|c|c|c|c|c|c|c|c|c|c|}
\hline Mês & $\begin{array}{c}\text { Q_Reg. } \\
\left(\mathrm{m}^{3} / \mathrm{s}\right)\end{array}$ & $\begin{array}{c}\text { Q_Sim. } \\
\left(\mathrm{m}^{3} / \mathrm{s}\right)\end{array}$ & $\begin{array}{c}\text { PRP } \\
(\mathrm{mm})\end{array}$ & $\begin{array}{c}\text { ETP } \\
(\mathrm{mm})\end{array}$ & $\begin{array}{c}\text { ET } \\
(\mathrm{mm})\end{array}$ & $\begin{array}{c}\text { SW } \\
(\mathrm{mm})\end{array}$ & $\begin{array}{l}\text { PERC } \\
(\mathrm{mm})\end{array}$ & $\begin{array}{c}\text { SURQ } \\
(\mathrm{mm})\end{array}$ & $\begin{array}{c}\text { GW_Q } \\
(\mathbf{m m})\end{array}$ & $\begin{array}{c}\text { LAT_Q } \\
(\mathrm{mm})\end{array}$ & $\begin{array}{l}\text { WYLD } \\
(\mathrm{mm})\end{array}$ \\
\hline Jan & 5,0 & 6,3 & 274,5 & 111,8 & 94,6 & 221,6 & 103,6 & 20,9 & 0,0 & 0,8 & 39,9 \\
\hline Fev & 9,2 & 10,2 & 307,5 & 96,4 & 87,6 & 238,4 & 169,6 & 31,1 & 0,0 & 1,3 & 59,1 \\
\hline Mar & 16,0 & 12,8 & 362,8 & 106,3 & 101,5 & 246,9 & 210,9 & 35,4 & 1,1 & 1,8 & 86,3 \\
\hline Abr & 22,2 & 21,2 & 442,7 & 102,9 & 102,3 & 242,2 & 290,3 & 50,5 & 21,9 & 2,4 & 143,9 \\
\hline Mai & 21,7 & 20,1 & 267,3 & 117,4 & 116,1 & 234,0 & 138,3 & 21,5 & 32,4 & 2,4 & 148,5 \\
\hline Jun & 13,5 & 15,8 & 142,1 & 125,8 & 107,9 & 210,8 & 50,7 & 9,9 & 12,6 & 1,7 & 112,3 \\
\hline Jul & 8,8 & 10,9 & 94,3 & 131,6 & 87,3 & 202,4 & 13,0 & 2,2 & 1,2 & 1,1 & 80,9 \\
\hline Ago & 5,5 & 8,4 & 78,9 & 135,8 & 95,5 & 178,6 & 4,0 & 2,6 & 0,0 & 0,7 & 62,6 \\
\hline Set & 3,8 & 6,1 & 43,9 & 146,4 & 93,0 & 128,8 & 0,3 & 0,5 & 0,0 & 0,4 & 44,2 \\
\hline Out & 2,9 & 4,7 & 60,1 & 142,1 & 86,9 & 101,0 & 0,8 & 1,6 & 0,0 & 0,3 & 35,0 \\
\hline Nov & 2,5 & 3,4 & 85,9 & 133,2 & 86,4 & 97,2 & 0,4 & 0,4 & 0,0 & 0,2 & 24,4 \\
\hline Dez & 2,7 & 3,6 & 169,1 & 128,2 & 93,9 & 154,0 & 10,3 & 7,6 & 0,0 & 0,3 & 26,3 \\
\hline Média & 9,5 & 10,3 & 194,1 & 123,2 & 96,1 & 188,0 & 82,7 & 15,3 & 5,8 & 1,1 & 71,9 \\
\hline Total & --- & --- & $2.329,2$ & $1.477,9$ & $1.153,0$ & $2.256,0$ & 992,3 & 184,0 & 69,1 & 13,6 & 863,2 \\
\hline
\end{tabular}


Tabela 43: Balanço hídrico da sub-bacia do rio Bujaru calibrado com os parâmetros da porção média da bacia do rio Capim.

\begin{tabular}{|c|c|c|c|c|c|c|c|c|c|c|c|}
\hline Mês & $\begin{array}{c}\text { Q_Reg. } \\
\left(\mathrm{m}^{3} / \mathrm{s}\right)\end{array}$ & $\begin{array}{c}\text { Q_Sim. } \\
\left(\mathrm{m}^{3} / \mathrm{s}\right)\end{array}$ & $\begin{array}{c}\text { PRP } \\
(\mathrm{mm})\end{array}$ & $\begin{array}{c}\text { ETP } \\
(\mathrm{mm})\end{array}$ & $\begin{array}{c}\text { ET } \\
(\mathrm{mm})\end{array}$ & $\begin{array}{c}\text { SW } \\
(\mathrm{mm})\end{array}$ & $\begin{array}{l}\text { PERC } \\
(\mathrm{mm})\end{array}$ & $\begin{array}{c}\text { SURQ } \\
(\mathrm{mm})\end{array}$ & $\begin{array}{c}\text { GW_Q } \\
(\mathbf{m m})\end{array}$ & $\begin{array}{c}\text { LAT_Q } \\
(\mathrm{mm})\end{array}$ & $\begin{array}{l}\text { WYLD } \\
(\mathrm{mm})\end{array}$ \\
\hline Jan & 5,0 & 6,1 & 274,5 & 111,8 & 96,5 & 196,5 & 107,3 & 22,8 & 0,2 & 0,8 & 39,3 \\
\hline Fev & 9,2 & 9,1 & 307,5 & 96,4 & 88,3 & 208,7 & 171,2 & 33,5 & 1,8 & 1,2 & 53,5 \\
\hline Mar & 16,0 & 10,8 & 362,8 & 106,3 & 101,7 & 218,6 & 207,3 & 37,5 & 5,9 & 1,7 & 72,1 \\
\hline Abr & 22,2 & 17,1 & 442,7 & 102,9 & 102,4 & 213,3 & 288,1 & 53,5 & 18,8 & 2,1 & 112,5 \\
\hline Mai & 21,7 & 16,4 & 267,3 & 117,4 & 116,3 & 204,3 & 137,7 & 22,9 & 39,4 & 2,1 & 117,5 \\
\hline Jun & 13,5 & 16,6 & 142,1 & 125,8 & 108,3 & 180,5 & 50,5 & 10,6 & 50,1 & 1,5 & 119,1 \\
\hline Jul & 8,8 & 15,1 & 94,3 & 131,6 & 87,2 & 172,5 & 12,5 & 2,5 & 54,6 & 1,0 & 114,0 \\
\hline Ago & 5,5 & 13,4 & 78,9 & 135,8 & 94,8 & 149,2 & 3,8 & 2,9 & 50,2 & 0,7 & 102,1 \\
\hline Set & 3,8 & 10,2 & 43,9 & 146,4 & 91,6 & 100,8 & 0,3 & 0,6 & 36,9 & 0,4 & 76,2 \\
\hline Out & 2,9 & 7,0 & 60,1 & 142,1 & 79,2 & 80,7 & 0,8 & 1,8 & 22,2 & 0,3 & 55,4 \\
\hline Nov & 2,5 & 4,0 & 85,9 & 133,2 & 82,1 & 81,0 & 0,4 & 0,5 & 7,6 & 0,2 & 31,5 \\
\hline Dez & 2,7 & 3,8 & 169,1 & 128,2 & 92,6 & 137,1 & 11,2 & 8,7 & 0,7 & 0,3 & 28,0 \\
\hline Média & 9,5 & 10,8 & 194,1 & 123,2 & 95,1 & 161,9 & 82,6 & 16,5 & 24,0 & 1,0 & 76,8 \\
\hline Total & --- & --- & $2.329,2$ & $1.477,9$ & $1.140,9$ & $1.943,0$ & 991,1 & 197,8 & 288,2 & 12,2 & 921,2 \\
\hline
\end{tabular}

Tabela 44: Balanço hídrico da sub-bacia do rio Mariquita calibrado com a regionalização de vazão.

\begin{tabular}{|c|c|c|c|c|c|c|c|c|c|c|c|}
\hline Mês & $\begin{array}{c}\text { Q_Reg. } \\
\left(\mathbf{m}^{3} / \mathbf{s}\right)\end{array}$ & $\begin{array}{c}\text { Q_Sim. } \\
\left(\mathrm{m}^{3} / \mathrm{s}\right)\end{array}$ & $\begin{array}{l}\text { PRP } \\
(\mathrm{mm})\end{array}$ & $\begin{array}{c}\text { ETP } \\
(\mathrm{mm})\end{array}$ & $\begin{array}{c}\text { ET } \\
(\mathrm{mm})\end{array}$ & $\begin{array}{c}\text { SW } \\
(\mathrm{mm})\end{array}$ & $\begin{array}{l}\text { PERC } \\
(\mathrm{mm})\end{array}$ & $\begin{array}{c}\text { SURQ } \\
(\mathrm{mm})\end{array}$ & $\begin{array}{l}\text { GW_Q } \\
(\mathrm{mm})\end{array}$ & $\begin{array}{c}\text { LAT_Q } \\
(\mathrm{mm})\end{array}$ & $\begin{array}{l}\text { WYLD } \\
(\mathrm{mm})\end{array}$ \\
\hline Jan & 2,1 & 2,6 & 265,5 & 128,3 & 106,0 & 191,3 & 89,6 & 17,7 & 0,0 & 0,8 & 36,5 \\
\hline Fev & 4,0 & 4,9 & 368,3 & 113,6 & 101,8 & 197,8 & 220,1 & 37,4 & 0,0 & 1,2 & 63,4 \\
\hline Mar & 7,3 & 6,9 & 471,3 & 130,1 & 124,5 & 207,7 & 276,2 & 55,2 & 0,0 & 1,9 & 104,1 \\
\hline Abr & 9,5 & 9,5 & 424,7 & 118,9 & 117,6 & 202,3 & 265,2 & 42,9 & 29,5 & 2,1 & 141,7 \\
\hline Mai & 9,0 & 10,5 & 262,3 & 128,7 & 125,1 & 188,4 & 128,4 & 23,3 & 60,0 & 2,0 & 170,3 \\
\hline Jun & 5,4 & 6,4 & 86,0 & 134,8 & 105,5 & 152,2 & 18,6 & 1,2 & 18,6 & 1,4 & 101,7 \\
\hline Jul & 3,7 & 4,4 & 63,4 & 138,2 & 79,5 & 127,5 & 6,1 & 2,0 & 0,7 & 0,8 & 72,4 \\
\hline Ago & 2,3 & 3,2 & 26,2 & 148,3 & 90,1 & 63,5 & 0,0 & 0,0 & 0,0 & 0,5 & 53,3 \\
\hline Set & 1,6 & 2,4 & 28,3 & 148,3 & 63,5 & 28,2 & 0,0 & 0,0 & 0,0 & 0,3 & 38,6 \\
\hline Out & 1,1 & 1,8 & 63,2 & 162,4 & 58,6 & 32,9 & 0,0 & 0,3 & 0,0 & 0,2 & 29,8 \\
\hline Nov & 1,0 & 1,5 & 108,0 & 147,7 & 73,2 & 60,3 & 3,7 & 2,4 & 0,0 & 0,2 & 23,6 \\
\hline Dez & 1,1 & 1,6 & 221,6 & 134,8 & 112,3 & 129,9 & 33,1 & 6,1 & 0,0 & 0,3 & 23,3 \\
\hline Média & 4,0 & 4,6 & 199,1 & 136,2 & 96,5 & 131,8 & 86,7 & 15,7 & 9,1 & 1,0 & 71,6 \\
\hline Total & --- & --- & $2.389,0$ & $1.634,0$ & $1.157,6$ & $1.582,0$ & $1.041,0$ & 188,6 & 108,8 & 11,7 & 858,7 \\
\hline
\end{tabular}


Tabela 45: Balanço hídrico da sub-bacia do rio Mariquita calibrado com os parâmetros da porção média da bacia do rio Capim.

\begin{tabular}{|c|c|c|c|c|c|c|c|c|c|c|c|}
\hline Mês & $\begin{array}{c}\text { Q_Reg. } \\
\left(\mathrm{m}^{3} / \mathrm{s}\right)\end{array}$ & $\begin{array}{c}\text { Q_Sim. } \\
\left(\mathrm{m}^{3} / \mathrm{s}\right)\end{array}$ & $\begin{array}{l}\text { PRP } \\
(\mathrm{mm})\end{array}$ & $\begin{array}{c}\text { ETP } \\
(\mathrm{mm})\end{array}$ & $\begin{array}{c}\text { ET } \\
(\mathrm{mm})\end{array}$ & $\begin{array}{c}\text { SW } \\
(\mathrm{mm})\end{array}$ & $\begin{array}{c}\text { PERC } \\
(\mathrm{mm})\end{array}$ & $\begin{array}{c}\text { SURQ } \\
(\mathrm{mm})\end{array}$ & $\begin{array}{c}\text { GW_Q } \\
(\mathbf{m m})\end{array}$ & $\begin{array}{c}\text { LAT_Q } \\
(\mathbf{m m})\end{array}$ & $\begin{array}{l}\text { WYLD } \\
(\mathrm{mm})\end{array}$ \\
\hline Jan & 2,1 & 2,5 & 265,5 & 128,3 & 111,9 & 197,1 & 81,8 & 16,5 & 1,1 & 0,8 & 34,1 \\
\hline Fev & 4,0 & 4,2 & 368,3 & 113,6 & 104,8 & 206,4 & 215,7 & 35,9 & 2,5 & 1,2 & 56,8 \\
\hline Mar & 7,3 & 5,9 & 471,3 & 130,1 & 126,2 & 215,5 & 275,4 & 53,4 & 7,3 & 1,8 & 92,1 \\
\hline Abr & 9,5 & 7,1 & 424,7 & 118,9 & 118,6 & 212,0 & 263,8 & 41,2 & 21,4 & 2,1 & 107,7 \\
\hline Mai & 9,0 & 7,8 & 262,3 & 128,7 & 126,7 & 198,3 & 127,5 & 22,8 & 42,1 & 2,0 & 124,6 \\
\hline Jun & 5,4 & 7,2 & 86,0 & 134,8 & 111,3 & 158,6 & 17,9 & 1,1 & 52,2 & 1,4 & 114,5 \\
\hline Jul & 3,7 & 6,9 & 63,4 & 138,2 & 82,8 & 131,3 & 5,5 & 1,7 & 54,5 & 0,8 & 113,9 \\
\hline Ago & 2,3 & 5,8 & 26,2 & 148,3 & 90,5 & 66,9 & 0,0 & 0,0 & 46,5 & 0,5 & 94,8 \\
\hline Set & 1,6 & 4,6 & 28,3 & 148,3 & 65,7 & 29,3 & 0,0 & 0,0 & 36,6 & 0,3 & 74,0 \\
\hline Out & 1,1 & 2,9 & 63,2 & 162,4 & 59,2 & 33,8 & 0,0 & 0,2 & 19,3 & 0,2 & 49,5 \\
\hline Nov & 1,0 & 1,7 & 108,0 & 147,7 & 73,6 & 61,8 & 2,4 & 2,2 & 1,8 & 0,2 & 26,3 \\
\hline Dez & 1,1 & 1,6 & 221,6 & 134,8 & 114,5 & 130,0 & 32,0 & 5,7 & 0,0 & 0,3 & 23,6 \\
\hline Média & 4,0 & 4,9 & 199,1 & 136,2 & 98,8 & 136,8 & 85,2 & 15,1 & 23,8 & 1,0 & 76,0 \\
\hline Total & --- & --- & $2.389,0$ & $1.634,0$ & $1.185,8$ & $1.641,1$ & $1.021,9$ & 180,7 & 285,2 & 11,6 & 911,9 \\
\hline
\end{tabular}

Em sequência, por razão dos resultados da calibração direta com a vazão regionalizada terem obtido valores mais coerentes quando comparados aos resultados medidos em campo pelo método do molinete hidrométrico no ano de 2014 (Tabela 46), cujos perfis delineados para cada exutório, tanto no período chuvoso como no menos chuvoso, estão na Figura 63 do APÊNDICE A, assim como por razão da regionalização ter levado em consideração um número maior de sub-bacias e proporcionar, assim, a inserção mais completa das características regionais do que a transferência direta dos parâmetros calibrados de uma única bacia, no caso os da porção média do rio Capim, o presente trabalho aplicou nas análises de escoamento superficial e produção de sedimentos os dados relativos à calibração direta com a vazão regionalizada pelo método das equações de regressão.

Definido a calibração através das séries regionalizadas como base do presente estudo, as discussões continuam com a análise de um resultado importante para auxiliar a verificar se os comportamentos dos modelos aqui trabalhados estão coerentes com a realidade da região. Trata-se da análise comparativa da evapotranspiração entre as medidas com o modelo SWAT com os dados do ZEE-PA (2010), literatura sobre a Amazônia e sobre a palma de óleo. Isso é fundamental por razão de que o melhor entendimento e acerto das estimativas de evapotranspiração são de extrema 
importância para os estudos hidrológicos e dos recursos hídricos, bem com para o planejamento de irrigação (ALLEN, 1986). Contudo, a mensuração da evapotranspiração não é uma tarefa simples, sendo que os métodos são caros e demandam especialistas para o trabalho (ALLEN et al., 1998).

Tabela 46: Resultados da medição da vazão nos perfis dos exutórios das sub-bacias dos rios Bujaru e Mariquita.

\begin{tabular}{lccccc}
\hline \multirow{2}{*}{ Parâmetros } & \multicolumn{2}{c}{ Bujaru } & & \multicolumn{2}{c}{ Mariquita } \\
\cline { 2 - 3 } \cline { 5 - 6 } & Chuvoso & $\begin{array}{c}\text { Menos } \\
\text { chuvoso }\end{array}$ & & Chuvoso & $\begin{array}{c}\text { Menos } \\
\text { chuvoso }\end{array}$ \\
\hline Largura do rio & 22,0 & 21,0 & & 13,0 & 7,0 \\
Área & 87,0 & 23,8 & & 21,6 & 3,9 \\
Largura dos perfis & 3,0 & 3,0 & & 2,0 & 1,0 \\
Vazão & $\mathbf{2 4 , 8}$ & $\mathbf{3 , 7}$ & & $\mathbf{1 3 , 2}$ & $\mathbf{1 , 3}$ \\
\hline
\end{tabular}

Conforme resultados apresentados nas Tabelas 42 e 44, relativas ao balanço hídrico dos modelos calibrados com as séries regionalizadas de vazão, pode-se perceber o resultado satisfatório tanto da evapotranspiração potencial como da real quando comparadas aos resultados do ZEE-PA. Outros trabalhos desenvolvidos em áreas agrícolas e de floresta tropical, fundamentados no balanço de água, medidas micrometerológica, lisímetros e modelagem têm corroborado com o acerto do modelo por apresentarem resultados semelhantes (BRUIJNZEEL, 1990; COSTA et al., 2010; CHRISTOFFERSEN et al., 2014; LEIVAS et al., 2014).

Abaixo são apresentados em três tabelas (Tabelas 47, 48 e 49), os resultados relativos às medidas de evapotranspiração nas HRU's com palma de óleo, com o objetivo de contribuir com a qualidade da análise do acerto do modelo. A Tabela 47, primeiramente, apresenta o comportamento semelhante entre a evapotranspiração mensal e em especial da semelhança entre os resultados médios e acumulados de longo período entre as sub-bacias não monitoras que foram calibradas através da regionalização de vazão e os valores da bacia monitorada e calibrada do rio Capim. Estes apontam para um bom ajuste entre a calibração e as características regionais. 
Tabela 47: Precipitação (PCP), evapotranspiração potencial (PET) e evapotranpiração real (ET) médias mensais interanuais paras as sub-bacias não monitoradas dos rios Bujaru e Mariquita e para a porção média da bacia monitorada do rio Capim.

\begin{tabular}{|c|c|c|c|c|c|c|c|c|c|}
\hline \multirow[b]{2}{*}{ Mês } & \multicolumn{3}{|c|}{ Bujaru } & \multicolumn{3}{|c|}{ Mariquita } & \multicolumn{3}{|c|}{ Capim } \\
\hline & $\begin{array}{l}\text { PRECIP } \\
\text { (mm) }\end{array}$ & $\begin{array}{c}\text { PET } \\
(\mathrm{mm})\end{array}$ & $\begin{array}{c}\text { ET } \\
(\mathrm{mm})\end{array}$ & $\begin{array}{c}\text { PRECIP } \\
(\mathrm{mm})\end{array}$ & $\begin{array}{c}\text { PET } \\
(\mathrm{mm}) \\
\end{array}$ & $\begin{array}{c}\text { ET } \\
(\mathrm{mm})\end{array}$ & $\begin{array}{c}\text { PRECIP } \\
\text { (mm) }\end{array}$ & $\begin{array}{c}\text { PET } \\
(\mathbf{m m})\end{array}$ & $\begin{array}{c}\text { ET } \\
(\mathrm{mm})\end{array}$ \\
\hline 1 & 274,5 & 117,6 & 105,4 & 282,2 & 127,3 & 111,6 & 390,0 & 142,0 & 123,5 \\
\hline 2 & 307,5 & 102,7 & 95,9 & 367,9 & 113,2 & 105,1 & 331,7 & 136,0 & 129,1 \\
\hline 3 & 362,8 & 113,9 & 111,6 & 465,3 & 129,6 & 126,8 & 351,3 & 154,0 & 145,4 \\
\hline 4 & 442,7 & 107,9 & 107,9 & 418,7 & 118,6 & 118,5 & 558,1 & 143,3 & 139,7 \\
\hline 5 & 267,3 & 121,3 & 121,0 & 272,9 & 127,7 & 126,0 & 374,3 & 145,2 & 142,7 \\
\hline 6 & 142,1 & 128,5 & 106,0 & 91,3 & 132,9 & 97,8 & 131,4 & 142,3 & 85,0 \\
\hline 7 & 94,3 & 133,7 & 85,0 & 66,6 & 136,5 & 74,7 & 76,4 & 153,0 & 66,6 \\
\hline 8 & 78,9 & 139,8 & 75,9 & 33,7 & 145,9 & 57,9 & 39,6 & 160,2 & 53,1 \\
\hline 9 & 43,9 & 147,5 & 61,9 & 36,0 & 146,5 & 45,0 & 19,5 & 169,0 & 34,4 \\
\hline 10 & 60,1 & 149,0 & 59,6 & 66,2 & 160,1 & 57,7 & 53,8 & 179,9 & 43,2 \\
\hline 11 & 85,9 & 136,2 & 73,0 & 106,3 & 146,3 & 68,6 & 59,6 & 159,0 & 50,0 \\
\hline 12 & 169,1 & 131,9 & 86,0 & 219,8 & 134,0 & 103,5 & 92,5 & 154,1 & 66,9 \\
\hline MEDIA & 194,1 & 127,5 & 90,8 & 202,2 & 134,9 & 91,1 & 206,5 & 153,2 & 90,0 \\
\hline TOTAL & $2.329,2$ & $1.530,0$ & $1.089,2$ & $2.427,0$ & $1.618,6$ & $1.093,1$ & $2.478,3$ & $1.838,1$ & $1.079,8$ \\
\hline
\end{tabular}

Nas Tabelas 48 e 49, são apresentados os resultados mensais da evapotranspiração real de 2006 a 2014 em comparação as medidas preliminares de evapotranspiração cedidas gentilmente pelo Dr. Alessandro Carioca de Araújo, pesquisador da Embrapa Amazônia Oriental (Belém, Pará). Os dados correspondem a medidas de evapotranspiração real, obtidos através da técnica de covariância de vórtices turbulentos (eddy covariance) em torre de observação micrometeorológica em plantio de palma de óleo localizado na empresa Marborges Agroindustria S.A., na Vila Bacuriteua, município do Moju, Pará, com auxílio das seguintes instrumentações: anemômetro 3D ultrassônico e analisador de gás por infravermelho. Importante ressaltar que estes dados são relativos a uma área plantada com uma variedade (híbrido interespecífico - Elaieis guineensis x Elaeis oleifera) diferente da que se encontra em nossas sub-bacias em estudo (híbrido intraespecifico - Elaeis guineensis $x$ Elaeis guineensis, o Tenera), e que também apresentaram uma falha de $2 / 3$ dos dados relativos ao mês de agosto, que foram preenchidos através de médias. 
Tabela 48: Evapotranpiração real (ET) mensal de 2006 a 2014 em comparação as medidas mensais da Torre Micrometeorológica do município de Moju para a sub-bacia do rio Bujaru.

\begin{tabular}{lcccccccccc}
\hline \multicolumn{7}{c}{ ET Real } \\
\hline Mês & $\mathbf{2 0 0 6}$ & $\mathbf{2 0 0 7}$ & $\mathbf{2 0 0 8}$ & $\mathbf{2 0 0 9}$ & $\mathbf{2 0 1 0}$ & $\mathbf{2 0 1 1}$ & $\mathbf{2 0 1 2}$ & $\mathbf{2 0 1 3}$ & $\mathbf{2 0 1 4}$ & Torre \\
\hline $\mathbf{1}$ & 96,0 & 105,2 & 89,5 & 106,6 & 120,5 & 109,4 & 97,4 & 104,4 & 120,0 & 104,3 \\
$\mathbf{2}$ & 75,7 & 73,3 & 114,8 & 90,4 & 116,8 & 91,1 & 101,6 & 95,2 & 104,1 & 85,8 \\
$\mathbf{3}$ & 101,0 & 76,2 & 113,2 & 110,1 & 133,5 & 106,3 & 124,6 & 117,7 & 121,5 & 88,6 \\
$\mathbf{4}$ & 83,2 & 72,0 & 106,7 & 102,5 & 119,4 & 119,8 & 125,0 & 123,1 & 119,8 & 91,1 \\
$\mathbf{5}$ & 103,1 & 111,7 & 108,3 & 113,9 & 131,5 & 127,9 & 132,9 & 131,1 & 128,7 & 99,4 \\
$\mathbf{6}$ & 92,6 & 105,6 & 98,5 & 104,7 & 114,3 & 117,7 & 91,1 & 105,9 & 123,6 & 104,0 \\
$\mathbf{7}$ & 61,0 & 96,2 & 54,8 & 90,6 & 63,7 & 88,7 & 94,4 & 107,0 & 108,6 & 110,7 \\
$\mathbf{8}$ & 54,8 & 86,0 & 78,5 & 90,5 & 63,2 & 57,6 & 64,8 & 101,0 & 87,1 & 102,1 \\
$\mathbf{9}$ & 32,8 & 61,8 & 83,4 & 58,1 & 78,2 & 51,7 & 55,7 & 76,4 & 58,6 & 94,3 \\
$\mathbf{1 0}$ & 50,7 & 46,4 & 90,8 & 80,8 & 63,5 & 57,7 & 39,1 & 40,7 & 66,4 & 81,8 \\
$\mathbf{1 1}$ & 72,9 & 38,8 & 50,6 & 62,0 & 84,7 & 95,3 & 59,1 & 95,2 & 98,5 & 95,4 \\
$\mathbf{1 2}$ & 61,0 & 97,0 & 67,8 & 86,6 & 81,1 & 80,6 & 85,8 & 92,7 & 121,2 & 78,0 \\
\hline TOTAL & $\mathbf{8 8 4 , 8}$ & $\mathbf{9 7 0 , 1}$ & $\mathbf{1 0 5 6 , 9}$ & $\mathbf{1 0 9 6 , 8}$ & $\mathbf{1 1 7 0 , 4}$ & $\mathbf{1 1 0 3 , 7}$ & $\mathbf{1 0 7 1 , 6}$ & $\mathbf{1 1 9 0 , 2}$ & $\mathbf{1 2 5 8 , 1}$ & $\mathbf{1 1 3 5 , 7}$ \\
\hline
\end{tabular}

Tabela 49: Evapotranpiração real (ET) mensal de 2006 a 2014 em comparação as medidas mensais da Torre Micrometeorológica do município de Moju para a sub-bacia do rio Mariquita.

\begin{tabular}{lcccccccccc}
\hline \multicolumn{7}{c}{ ET Real } \\
\hline Mês & $\mathbf{2 0 0 6}$ & $\mathbf{2 0 0 7}$ & $\mathbf{2 0 0 8}$ & $\mathbf{2 0 0 9}$ & $\mathbf{2 0 1 0}$ & $\mathbf{2 0 1 1}$ & $\mathbf{2 0 1 2}$ & $\mathbf{2 0 1 3}$ & $\mathbf{2 0 1 4}$ & Torre \\
\hline $\mathbf{1}$ & 85,4 & 73,6 & 116,3 & 112,3 & 121,9 & 114,9 & 123,2 & 122,7 & 134,0 & 104,3 \\
$\mathbf{2}$ & 72,8 & 68,3 & 120,0 & 115,2 & 107,6 & 112,0 & 110,4 & 117,6 & 122,1 & 85,8 \\
$\mathbf{3}$ & 97,9 & 76,9 & 127,7 & 128,4 & 141,8 & 145,0 & 147,5 & 134,2 & 141,3 & 88,6 \\
$\mathbf{4}$ & 66,6 & 85,4 & 136,3 & 110,9 & 127,3 & 138,6 & 137,5 & 133,4 & 130,6 & 91,1 \\
$\mathbf{5}$ & 82,8 & 105,9 & 138,5 & 111,8 & 148,6 & 135,2 & 135,2 & 138,8 & 137,0 & 99,4 \\
$\mathbf{6}$ & 83,3 & 84,7 & 102,8 & 114,1 & 107,3 & 87,7 & 96,1 & 87,1 & 117,1 & 104,0 \\
$\mathbf{7}$ & 70,6 & 82,8 & 76,9 & 65,1 & 93,0 & 55,0 & 83,3 & 63,0 & 82,6 & 110,7 \\
$\mathbf{8}$ & 105,9 & 86,8 & 37,0 & 69,0 & 68,3 & 29,2 & 42,8 & 28,0 & 54,4 & 102,1 \\
$\mathbf{9}$ & 86,3 & 23,6 & 59,5 & 33,8 & 52,3 & 48,1 & 25,5 & 20,4 & 55,6 & 94,3 \\
$\mathbf{1 0}$ & 56,2 & 66,5 & 60,9 & 41,8 & 68,9 & 63,9 & 32,7 & 59,7 & 68,4 & 81,8 \\
$\mathbf{1 1}$ & 81,8 & 47,8 & 57,9 & 25,9 & 82,1 & 89,0 & 36,6 & 97,3 & 98,7 & 95,4 \\
$\mathbf{1 2}$ & 74,6 & 86,8 & 85,5 & 94,3 & 97,3 & 120,4 & 114,4 & 129,1 & 129,1 & 78,0 \\
\hline TOTAL & $\mathbf{9 6 4 . 1}$ & $\mathbf{8 8 9 . 2}$ & $\mathbf{1 1 1 9 . 4}$ & $\mathbf{1 0 2 2 . 6}$ & $\mathbf{1 2 1 6 . 3}$ & $\mathbf{1 1 3 8 . 9}$ & $\mathbf{1 0 8 5 . 2}$ & $\mathbf{1 1 3 1 . 2}$ & $\mathbf{1 2 7 0 . 9}$ & $\mathbf{1 1 3 5 . 7}$ \\
\hline
\end{tabular}

Preliminarmente, pode-se aferir das Tabelas 48 e 49 que os resultados, mesmo com algumas condições de análise expostas acima, fornecem uma visão de equiparação dos resultados de evapotranspiração real em áreas de palma de óleo modeladas e medidas em campo, corroborando de maneira positiva para afirmar que a calibração do modelo SWAT em bacias não monitoras e calibradas pelo método da regionalização de vazão podem fornecer dados de qualidade. De acordo com o Dr. 
Alessandro de Araújo e com o monitoramento disponibilizado pelo Climate Prediction Center do National Weather Service, orgão da National Oceanic and Atmospheric Administration (NOAA) dos Estados Unidos da América, o qual disponibiliza o monitoramento dos eventos de El Niño, apontam o ano de 2015, ano das medições da evapotranspiração na torre, como um ano de forte El Niño. Dessa forma, segundo a NOAA, os anos de 2006, 2009 e 2010 apresentaram eventos de El Niño e por isso são anos melhores para serem comparados com o de 2015, quanto à evapotranspiração. Mais uma vez, os resultados se mostraram semelhantes, corroborando ainda mais para os resultados dos modelos da SBRB e da SBRM por razão de apresentarem valores acumulados muito próximos $(2006=884,8 \mathrm{~mm} ; 2009=1.096,8 \mathrm{~mm} ; 2010=1.170,4$ $\mathrm{mm}$; e 2015 na torre $=1.135,7 \mathrm{~mm}$ ).

Outros trabalhos desenvolvidos em regiões da Ásia e da África, onde se encontram as maiores áreas plantadas com palma de óleo, representando a origem desta cultura, a qual é de grande importância e representatividade quanto aos aspectos socioeconômicos e ambientais dessas regiões, focam em estudar as implicações e demandas da cultura da palma de óleo sobre os recursos hídricos. Para isso, têm-se buscado aplicar diferentes técnicas para medir e estimar a evapotranspiração potencial e real, sendo que esses resultados tem sido semelhantes aos encontrados no presente trabalho (DUFRENE et al., 1993; KALLARACKAL et al., 2004; YUSOP et al., 2008; CARR, 2011; BAKOUME et al., 2013; ARSHAD, 2014; MEIJIDE et al., 2015; RÖLL et al., 2015). 


\subsection{RESULTADOS DAS SIMULAÇÕES COM O MODELO CLUE-S}

\subsubsection{Identificação do uso e cobertura de cada sub-bacia.}

No item 6.1 estão descritas todas as classes de uso e cobertura da terra que foram levadas em consideração na modelagem espacial com o CLUE-S para cada subbacia relativas aos anos de 2008 e 2013, sendo que nesta etapa da tese as classes de uso "Água" e "Área Urbana" foram unificadas em uma única classe denominada de "Outros", conforme Quadro 2. No CLUE-S, diferente do Modelo SWAT, utilizou-se a classe remanescente florestal separada da área de vegetação secundária, por razão de ser de interesse modelar as áreas de vegetação secundária (Tabelas 50 e 51).

Tabela 50: Uso e cobertura da terra para os anos de 2008 e 2013 para a sub-bacia do rio Bujaru.

\begin{tabular}{lccccc}
\hline \multirow{2}{*}{ Uso e Cobertura } & \multicolumn{2}{c}{$\mathbf{2 0 0 8}$} & & \multicolumn{2}{c}{$\mathbf{2 0 1 3}$} \\
\cline { 2 - 3 } \cline { 6 - 7 } & Area (ha) & $\%$ & & Area (ha) & $\%$ \\
\hline Palma de Óleo & 260 & 0,7 & & 4.220 & 11,1 \\
Agricultura Geral & 9.387 & 24,6 & & 723 & 1,9 \\
Pastagem & 16.263 & 42,7 & & 9.188 & 24,1 \\
Remanescente Florestal & 3.925 & 10,3 & & 3.844 & 10,1 \\
Vegetação Secundária & 7.833 & 20,5 & & 19.569 & 51,3 \\
Outros & 454 & 1,2 & & 578 & 1,5 \\
\hline Área Total da sub-bacia & \multicolumn{3}{c}{$\mathbf{3 8 . 1 2 2}$} \\
\hline
\end{tabular}

Tabela 51: Uso e cobertura da terra para os anos de 2008 e 2013 para a sub-bacia do rio Mariquita.

\begin{tabular}{lcccccc}
\hline \multirow{2}{*}{ Uso e Cobertura } & \multicolumn{2}{c}{2008} & & \multicolumn{2}{c}{$\mathbf{2 0 1 3}$} \\
\cline { 2 - 3 } \cline { 5 - 6 } & Area (ha) & \% & & Area (ha) & $\%$ \\
\hline Palma de Óleo & 0 & 0,0 & & 2.308 & 14,4 \\
Agricultura Geral & 415 & 2,6 & & 936 & 5,9 \\
Pastagem & 5.420 & 33,9 & & 4.221 & 26,4 \\
Remanescente Florestal & 4.130 & 25,8 & & 3.867 & 24,2 \\
Vegetação Secundária & 6.003 & 37,5 & & 4.643 & 29,0 \\
Outros & 25 & 0,2 & & 19 & 0,1 \\
\hline Área Total da sub-bacia & \multicolumn{3}{c}{$\mathbf{1 5 . 9 9 4}$} \\
\hline
\end{tabular}




\subsubsection{Identificação dos Fatores exploratórios e Aquisição de arquivos digitais.}

As variáveis independentes, que também podem ser denominadas de forçantes de mudança, selecionadas na presente tese seguiram orientação do material de treinamento do modelo CLUE-S (VERBURG, 2010) além de pesquisas bibliográficas sobre aplicações do modelo CLUE-S (VERBURG et al., 2002; KUHN, 2005; VERBURG et al., 2006b; VALENCIA, 2008, SOLER et al., 2009; LUO et al., 2010; GALHARTE, 2011; PEREIRA, 2013) e conversas com especialistas em agricultura da região nordeste do estado do Pará, em especial com relação a palma de óleo.

Mesmo alguns estudos tendo aplicado variáveis climáticas como precipitação e temperatura do ar como forçantes de mudança em estudos com o CLUE-S, tanto em macrobacia de $28.000 \mathrm{~km}^{2}$ (VALÊNCIA, 2008) como em pequenas bacias de cerca de $100 \mathrm{~km}^{2}$ (GALHARTE; CRESTANA, 2014), no presente trabalho não se utilizou essas variáveis por razão da precipitação e temperaturas serem homogêneas no interior da SBRB e SBRM (ZEE-PA, 2010). Outro dado disponível que não foi utilizado como variável foi o de aptidão edafoclimática para palma de óleo por razão das sub-bacias apresentaram características homogêneas também. Porém, em um estudo sobre a dinâmica da expansão da cana de açúcar realizado no estado de São Paulo e Goiás, Pereira (2013) identificou que as variáveis de aptidão da cana de açúcar, advindas das diretrizes e orientações técnicas do Zoneamento Agroecológico da cultura da Cana de Açúcar, são indicadas para o uso em estudos de dinâmica de mudança de uso e cobertura da terra.

No Quadro 3 são apresentadas todas as variáveis dependentes e independentes utilizadas conforme as categorias descritas. Os dados de uso e cobertura da terra e os dados biofísicos de hipsometria e tipo de solo já foram explicados anteriormente nos itens 6.1, 6.2 e 6.3, respectivamente. A seguir são apresentados os dados socioeconômicos, biofísicos e geográficos/logísticos. 
Quadro 3: Origem do dados utilizados nas simulações com CLUE-S para as sub-Bacias dos rios Bujaru e Mariquita.

\begin{tabular}{|c|c|c|c|}
\hline Parâmetros & Descrição & Origem & $\begin{array}{l}\text { Escala / Tipo / Ano } \\
\text { ref. }\end{array}$ \\
\hline \multicolumn{4}{|c|}{ Dados Uso e cobertura da terra } \\
\hline usocl2008 & $\begin{array}{l}\text { Mapas de uso e cobertura da } \\
\text { terra de } 2008\end{array}$ & $\begin{array}{l}\text { TerraClass } 2008 \\
(\text { Embrapa/INPE) }\end{array}$ & $\begin{array}{c}1: 100.000 / \text { Vetor / } \\
2013 \text { e } 2014\end{array}$ \\
\hline usocl2013 & $\begin{array}{l}\text { Mapas de uso e cobertura da } \\
\text { terra de } 2013\end{array}$ & $\begin{array}{c}\text { Classificação semi- } \\
\text { automática de imagens } \\
\text { LandSat. }\end{array}$ & $\begin{array}{c}1: 100.000 / \text { Vetor / } \\
2015\end{array}$ \\
\hline palmaoleo & $\begin{array}{c}\text { uso da terra com Palama de } \\
\text { Óleo }\end{array}$ & $\begin{array}{c}\text { Venturieri, } 2013 \\
\text { (Comunicação pessoal)* }^{*}\end{array}$ & ? / Vetor / 2013 \\
\hline \multicolumn{4}{|c|}{ Dados socioeconômicos } \\
\hline denssetor2010 & Densidade Polulacional & $\begin{array}{l}\text { Censo demográfico do } \\
\text { ano } 2010 \text { do Instituto } \\
\text { Brasileiro de Geografia } \\
\text { e Estatística (IBGE)* }\end{array}$ & $\begin{array}{c}1: 250.000 / \text { vetor / } \\
2010\end{array}$ \\
\hline rensetor2010 & $\begin{array}{l}\text { Valor do rendimento nominal } \\
\text { médio mensal das pessoas } \\
\text { responsáveis por domicílios } \\
\text { particulares permanentes } \\
\text { (com e sem rendimento) }\end{array}$ & $\begin{array}{l}\text { Censo demográfico do } \\
\text { ano } 2010 \text { do Instituto } \\
\text { Brasileiro de Geografia } \\
\text { e Estatística (IBGE). }{ }^{*}\end{array}$ & $\begin{array}{c}1: 250.000 / \text { vetor / } \\
2010\end{array}$ \\
\hline \multicolumn{4}{|c|}{ Dados geográficos/logísticos } \\
\hline costdist & $\begin{array}{l}\text { Custo da distância do } \\
\text { transporte da palma de óleo }\end{array}$ & $\begin{array}{c}\text { Embrapa Amazônia } \\
\text { Oriental** }\end{array}$ & ? / Raster / 2015 \\
\hline dehidrog /dloghidrog & $\begin{array}{l}\text { Distância Euclidiana e } \\
\text { logarítmica da hidrografia }\end{array}$ & SRTM (Embrapa) ${ }^{*}$ & $\begin{array}{c}1: 250.000 / \text { Vetor / } \\
2015 \\
\end{array}$ \\
\hline dehidrov /dloghidrov & $\begin{array}{c}\text { Distância Euclidiana e } \\
\text { logarítmica das hidrovias }\end{array}$ & ANTAQ $(2013)^{\star *}$ & ? / Vetor / 2009 \\
\hline deportos /dlogportos & $\begin{array}{l}\text { Distância Euclidiana e } \\
\text { logarítmica dos portos }\end{array}$ & ANTAQ $(2013)^{\star *}$ & ? / Vetor / 2009 \\
\hline deusin70/dlogusin70 & $\begin{array}{c}\text { Distância Euclidiana e } \\
\text { logarítmica das usinas de } \\
\text { extração de óleo de palma até } \\
70 \mathrm{Km} \text { de distância. }\end{array}$ & $\begin{array}{l}\text { Embrapa Amazônia } \\
\text { Oriental** }\end{array}$ & ? / Vetor / 2014 \\
\hline devias / dlogvias & $\begin{array}{c}\text { Distância Euclidiana e } \\
\text { logarítmica das rodovias } \\
\text { estaduais e federais }\end{array}$ & $\begin{array}{c}\text { Instituto Brasileiro de } \\
\text { Geografia e Estatística } \\
(\text { IBGE) }\end{array}$ & $\begin{array}{c}1: 250.000 / \text { vetor / } \\
2009\end{array}$ \\
\hline
\end{tabular}

\section{Dados Biofísicos}

\begin{tabular}{lccc}
\hline hipsometria & Mapa hipsométrico & SRTM (Embrapa) & $\begin{array}{c}\text { 1:250.000/ Raster / } \\
2013\end{array}$ \\
\hline $\begin{array}{l}\text { solo (lad1, lad8, lad25, } \\
\text { lad24 e lad39) }\end{array}$ & Classes de solos & $\begin{array}{c}\text { PARÁ TOTAL - } \\
\text { Econômento Ecológico } \\
\text { do Pará (2010) }\end{array}$ & $\begin{array}{c}1: 250.000 / \text { vetor / } \\
2009\end{array}$ \\
\hline
\end{tabular}

Notas: * obtido sob solicitação; ** obtido por download; ? - escala não informada na fonte. 


\section{a) Dados socioeconômicos.}

As informações de densidade populacional (habitantes $/ \mathrm{km}^{2}$ ) e a renda mensal familiar ( $\mathrm{R} \$ \mathrm{Mês})$ foram inseridas nos shapes de distribuição dos setores censitários para cada sub-bacia originando os mapas das Figuras 64.

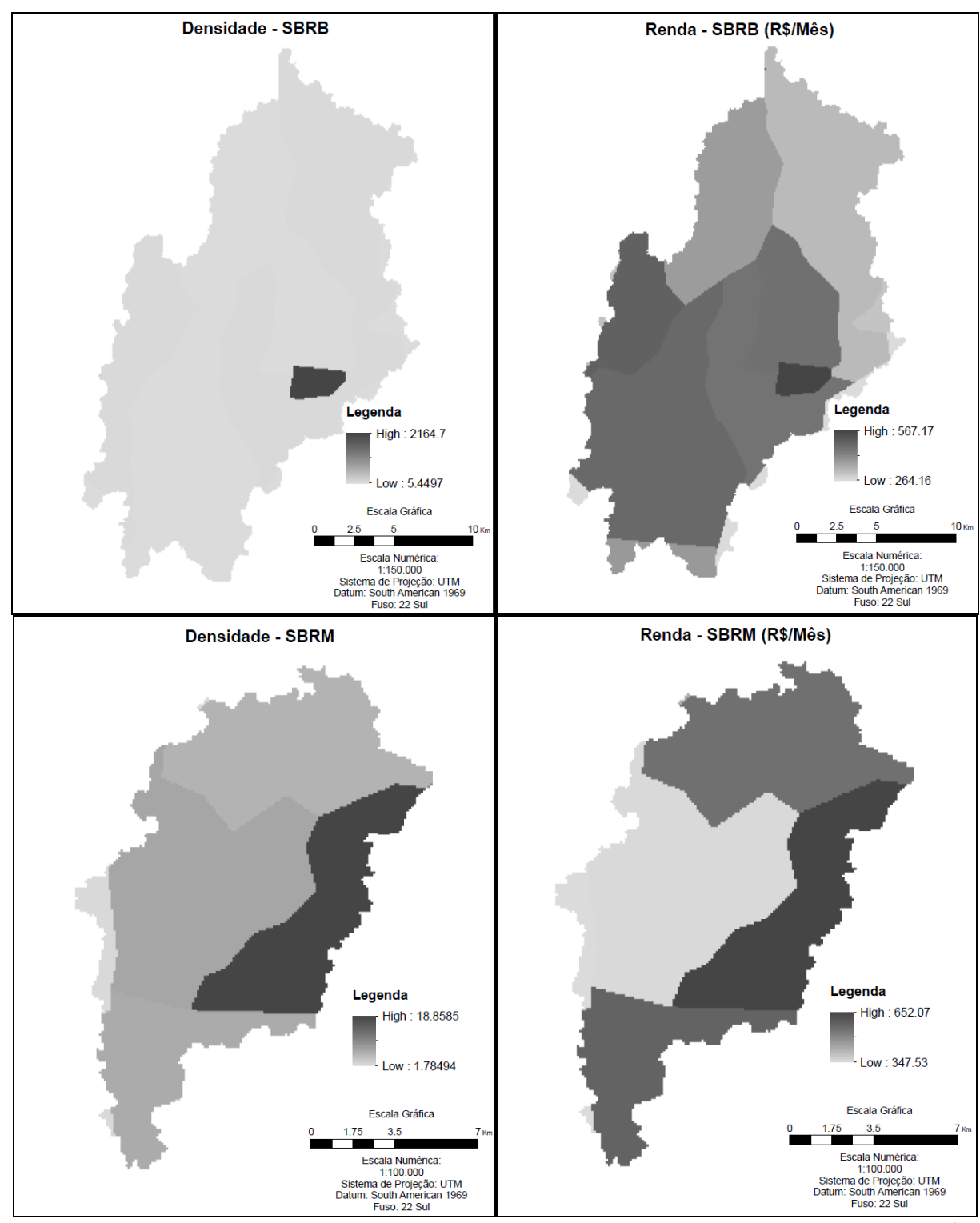

Figura 64: Mapas de distribuição da densidade populacional rural e da renda mensal familiar para as sub-bacias dos rios Bujaru e Mariquita. 


\section{b) Dados geográficos/logísticos.}

Os dados geográficos são: distância a hidrografia (Figura 65), hidrovias (Figura 66), portos (Figura 67), rodovias (Figura 68), usinas (Figura 69 e 70) e o mapa de custo da distância. O mapa de distância a usinas foi elaborado a partir das usinas que estavam a uma distância máxima de $70 \mathrm{~km}$ do limite das sub-bacias, sendo esta a distância ideal entre as áreas de cultivo e as usinas de extração do óleo da palma sem prejudicar a qualidade do produto ou onerar a logística.

Com a exceção do mapa de custo da distância, o cálculo desses planos celulares foi realizado através de dois métodos. O primeiro foi a distância euclidiana, calculada através da ferramenta Euclidean Distance do software ArcGis 10.3. O segundo método consistiu na aplicação do logaritmo natural sobre estes mapas de distância euclidiana, com o objetivo de tornar os mapas de distância mais simétricos (VALÊNCIA, 2008), realçando assim o efeito de proximidade e distância ao objeto (Ex.: rios). 


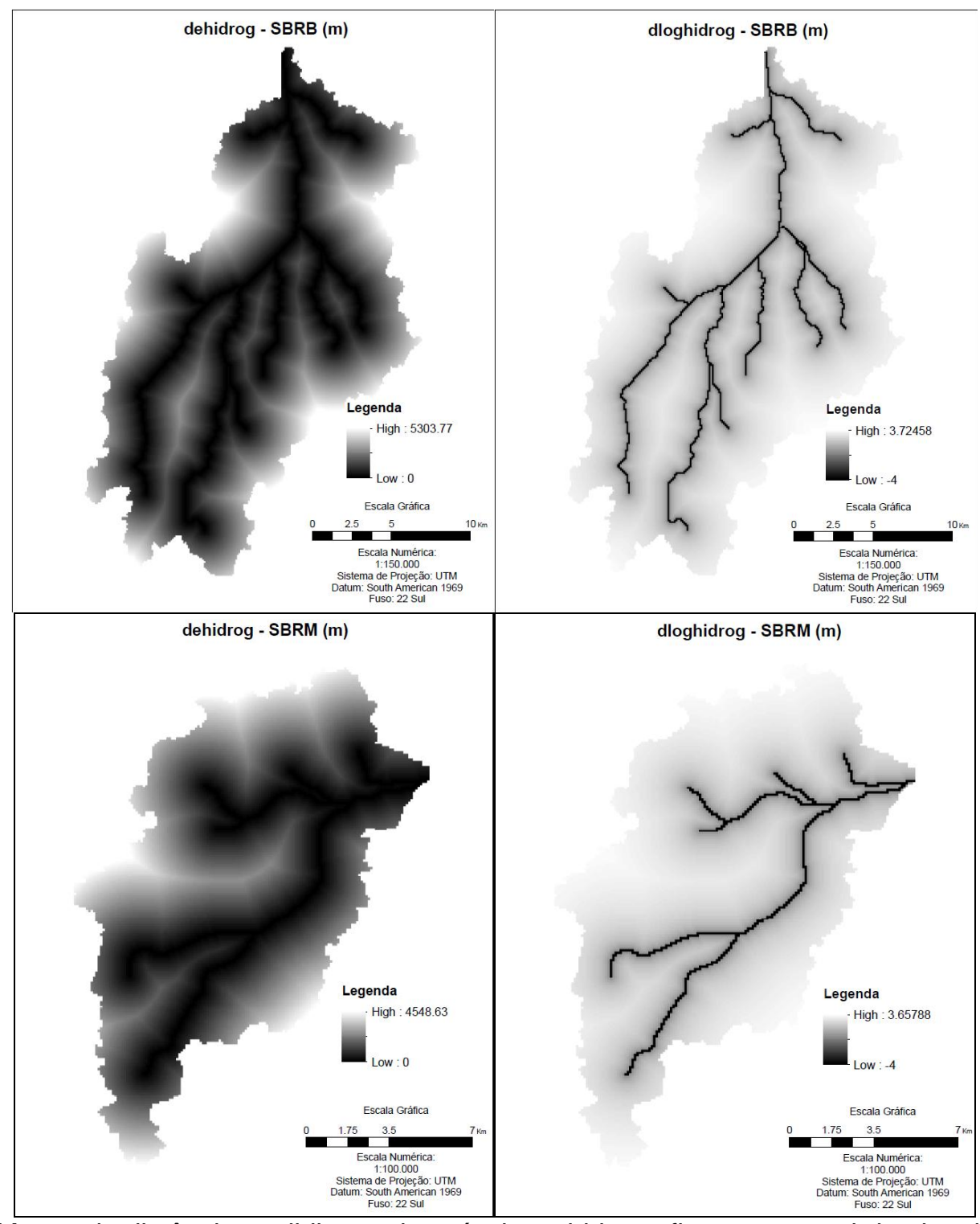

Figuras 65: Mapas de distância euclidiana e logarítmica a hidrografias para as sub-bacias dos rios Bujaru e Mariquita. 


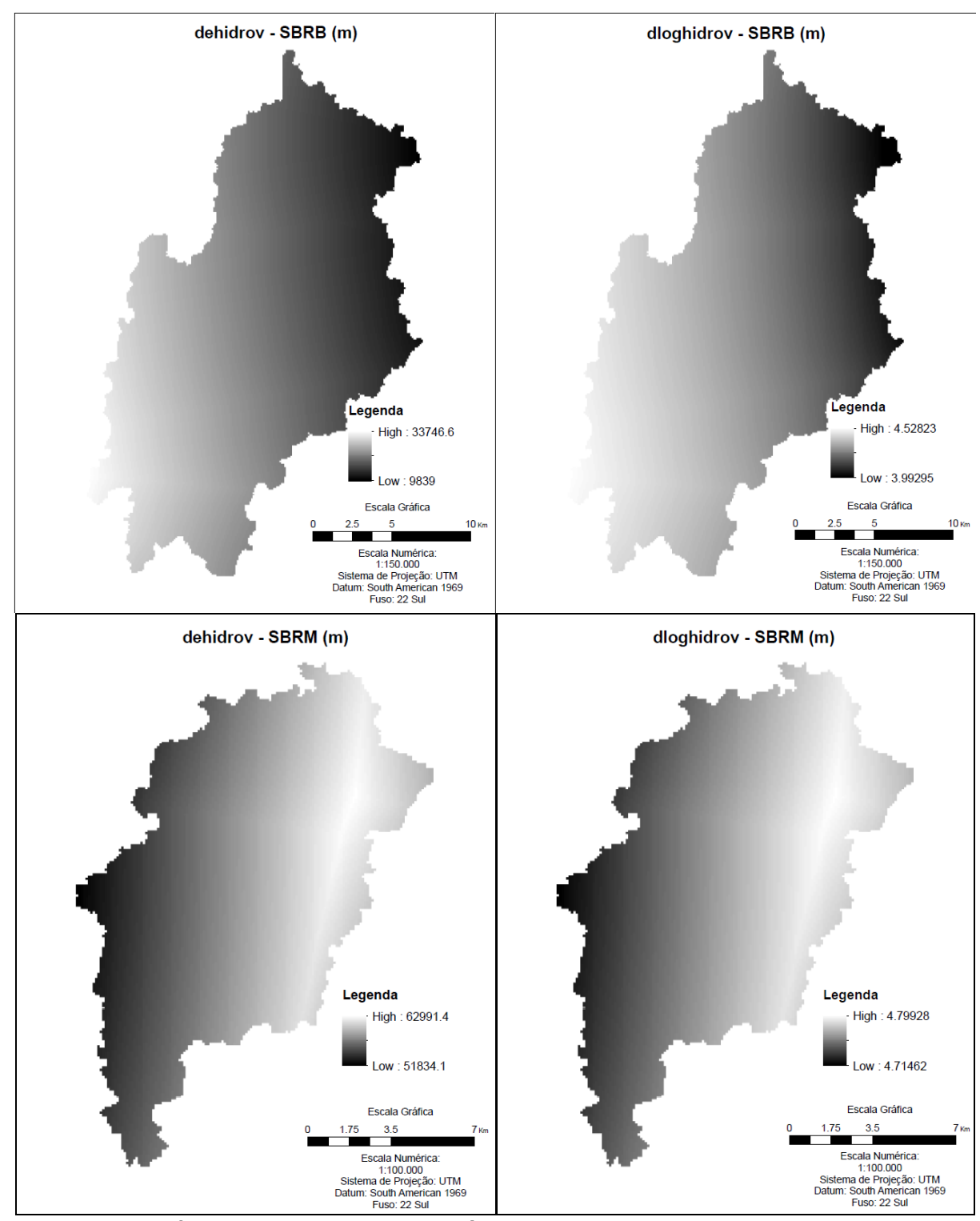

Figuras 66: Mapas de distância euclidiana e logarítmica a hidrovias para as sub-bacias dos rios Bujaru e Mariquita. 


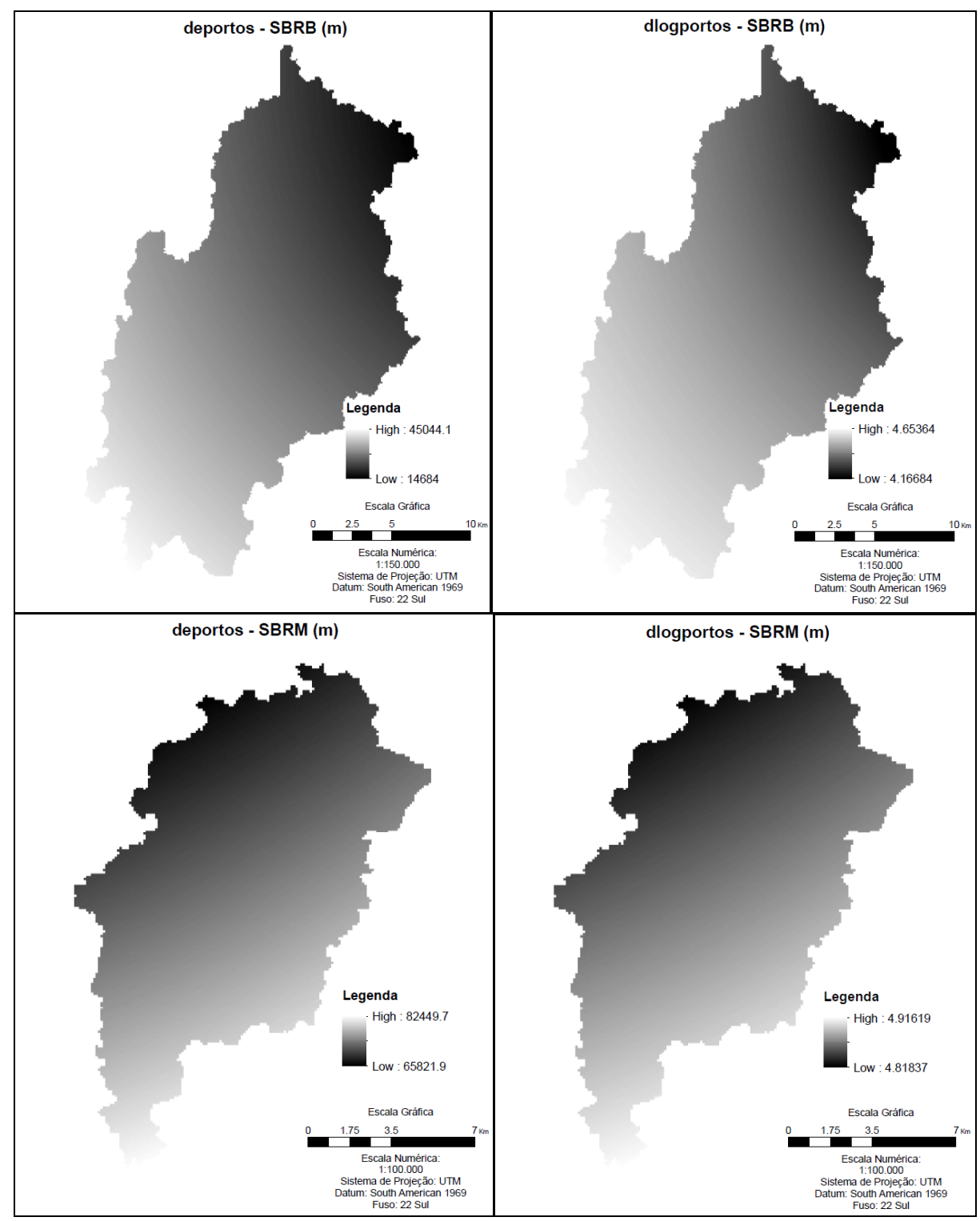

Figuras 67: Mapas de distância euclidiana e logarítmica a portos para as sub-bacias dos rios Bujaru e Mariquita. 


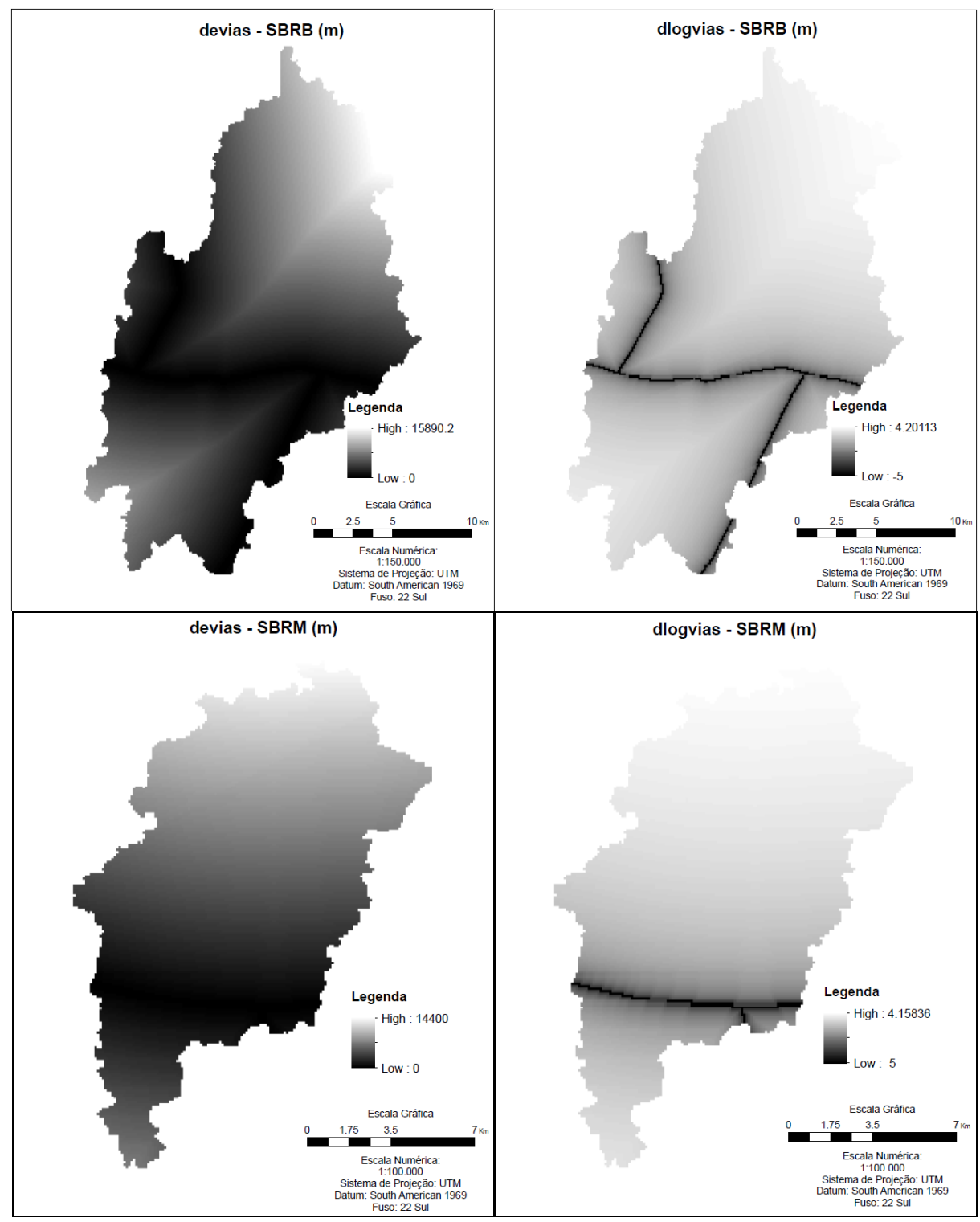

Figuras 68: Mapas de distância euclidiana e logarítmica a rodovias para as sub-bacias dos rios Bujaru e Mariquita. 


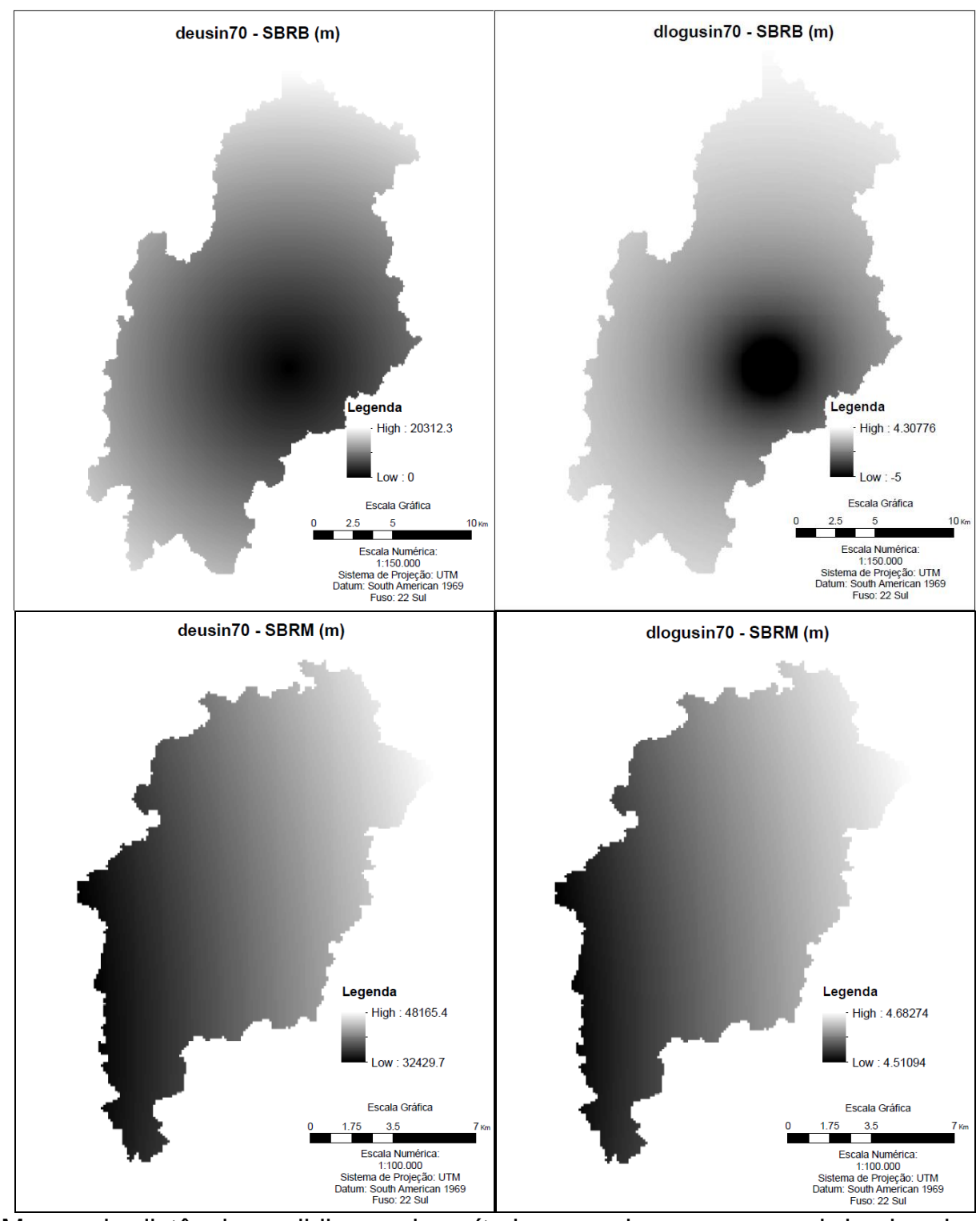

Figuras 69: Mapas de distância euclidiana e logarítmica as usinas para as sub-bacias dos rios Bujaru e Mariquita. 


\section{Sub-bacias e usinas de extração do óleo de palma}
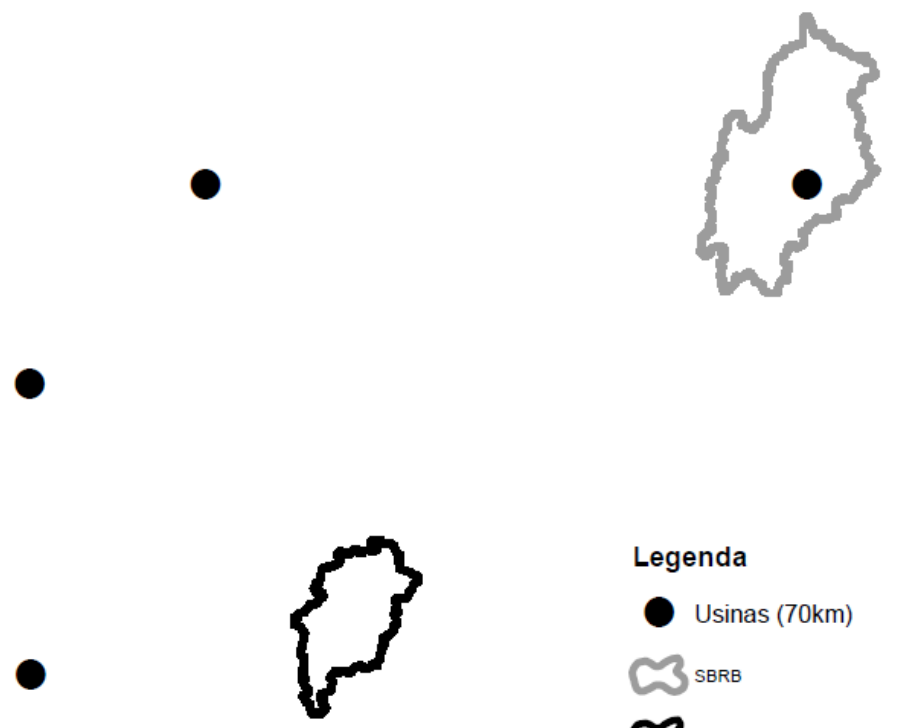

Legenda

Usinas $(70 \mathrm{~km})$

3 SBRB

$\mathcal{C}_{\text {sвRm }}$

Escala Gráfica

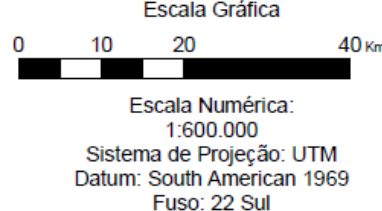

Fuso: 22 Sul

Figuras 70: Localização das usinas de extração do óleo de palma em relação as sub-bacias dos rios Bujaru e Mariquita.

Para a elaboração do mapa de custo da distância às usinas das SBRB e SBRM foi necessária a utilização de três produtos intermediários: os mapas de uso e cobertura do ano base de 2013, o mapa de rodovias federais e estaduais e a localização das usinas. Primeiramente foi unido o mapa de rodovias aos mapas de uso e cobertura. Em seguida, fundamentado no novo mapa de uso e cobertura somado as rodovias, elaborou-se uma superfície de fricção, a qual representa o custo relativo de atravessar uma unidade de célula, o qual está ligado ao uso específico da terra (SOARES FILHO, 2009). Essa superfície expressa os custos por pixel (por distância) para se levar um produto de um ponto a outro na bacia. Para se definir esse valor, tomou-se como base o custo da distância do transporte de um caminhão (um frete) cheio de cachos de palma de óleo (20t), que tem um custo de $20 R \$ / k m$ ou $2 R \$ / 100 m$, que é o tamanho do pixel do presente trabalho. 
Dessa forma a superfície de friç̧ão foi construída através da substituição (reclassificação) no novo raster de uso e ocupação do solo dos seguintes valores: 2 para a palma de óleo, representando o custo de $2 \mathrm{R} \$$ para cada $100 \mathrm{~m}$ percorrido por um frete capaz de transportar 20 toneladas de cachos de palma de óleo; 4 para agricultura geral e pastagem, simbolizando o dobro da dificuldade de se converter essas áreas para palma de óleo (GALHARTE, 2011); o valor de 500 para área de remanescente florestal, representando a total impossibilidade de conversão desse uso adotada na presente tese; valor 7 para áreas de vegetação secundária, as quais são mais complexas de conversão devido a demanda de investimento para suprimir essa vegetação; e por fim, adotou-se o valor de numero 2 paras as rodovias, objetivando evidenciar que quanto mais próximo das rodovias maior o benefício para a logística de escoamento da produção da palma de óleo (Figura 71).

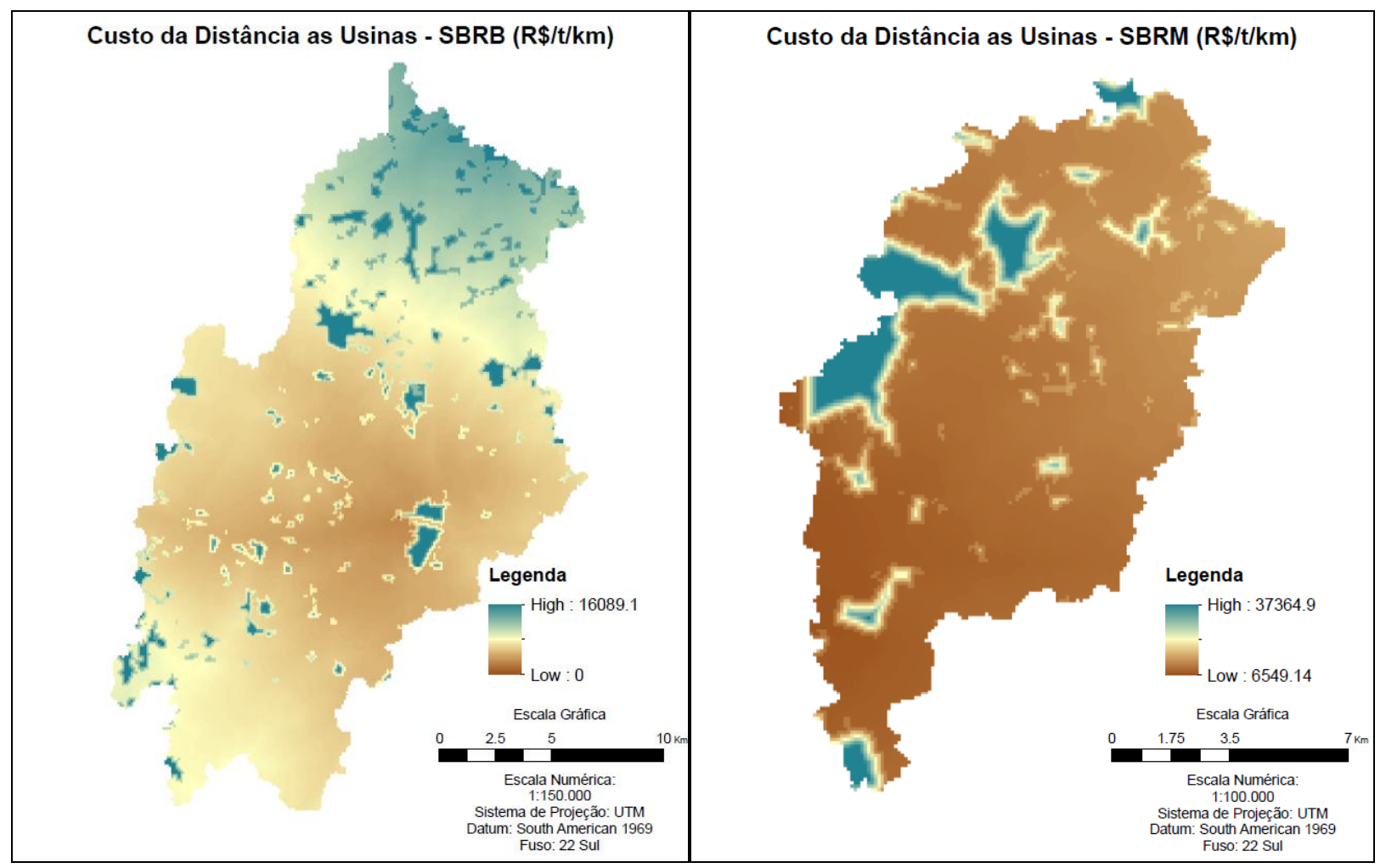

Figuras 71: Mapas de custo da distância as usinas de extração do óleo de palma para as sub-bacias dos rios Bujaru e Mariquita. 


\subsubsection{Identificação das demandas de mudança de uso e cobertura para cada sub- bacia.}

6.5.3.1 Cenário de demanda para a calibração de 2008 a 2013.

Seguem as Tabelas 52 e $53 \mathrm{com}$ as demandas de área para cada uso e cobertura por sub-bacia para o período de calibração de 2008 a 2013, as quais foram elaboradas fundamentadas apenas na mudança de uso entre 2008 e 2013.

Tabela 52: Demanda por uso entre os anos de 2008 e 2013 para a sub-bacia do rio Bujaru, considerando 6 classes de uso e de cobertura da terra, com as áreas em hectares e valores múltiplos de 1 ha (pixel de $100 \mathrm{~m})$.

\begin{tabular}{ccccccc}
\hline Ano & Palmaoleo & Agricultura & pastagem & remanes & secundaria & outros \\
\hline 2008 & 260 & 9.387 & 16.263 & 3.925 & 7.833 & 454 \\
2009 & 1.052 & 7.654 & 14.848 & 3.909 & 10.205 & 454 \\
2010 & 1.844 & 5.921 & 13.433 & 3.893 & 12.577 & 454 \\
2011 & 2.636 & 4.189 & 12.018 & 3.876 & 14.949 & 454 \\
2012 & 3.428 & 2.456 & 10.603 & 3.860 & 17.321 & 454 \\
2013 & 4.220 & 723 & 9.188 & 3.844 & 19.693 & 454 \\
\hline
\end{tabular}

Tabela 53: Demanda por uso entre os anos de 2008 e 2013 para a sub-bacia do rio Mariquita, considerando 6 classes de uso e de cobertura da terra, com as áreas em hectares e valores múltiplos de 1 ha (pixel de $100 \mathrm{~m}$ ).

\begin{tabular}{ccccccc}
\hline Ano & Palmaoleo & Agricultura & pastagem & remanes & secundaria & outros \\
\hline 2008 & 1 & 415 & 5.420 & 4.130 & 6.003 & 25 \\
2009 & 462 & 519 & 5.180 & 4.077 & 5.730 & 25 \\
2010 & 924 & 623 & 4.940 & 4.025 & 5.457 & 25 \\
2011 & 1.385 & 728 & 4.701 & 3.972 & 5.183 & 25 \\
2012 & 1.847 & 832 & 4.461 & 3.920 & 4.910 & 25 \\
2013 & 2.308 & 936 & 4.221 & 3.867 & 4.637 & 25 \\
\hline
\end{tabular}


6.5.3.2 Cenário de demanda para a projeção cenário de 2013 a 2023.

Seguem as Tabelas 54 e $55 \mathrm{com}$ as demandas de área para cada uso e cobertura por sub-bacia para o período de projeção de 2013 a 2023, utilizando como referência a demanda de crescimento nacional para a palma de óelo (FAEPA, 2013; MAPA, 2013) e as projeções da FIESP (2013) e MAPA (2013) para as projeções das áreas de Agricultura Geral e Pastagem.

Tabela 54: Demanda por área para projeção de 2013 e 2023 para a sub-bacia do rio Bujaru, considerando 6 classes de uso e de cobertura da terra, com as áreas em hectares e valores múltiplos de 1 ha (pixel de $100 \mathrm{~m}$ ).

\begin{tabular}{lccccccc}
\hline Anos & $\begin{array}{c}\text { Palma } \\
\text { de Óleo }\end{array}$ & $\begin{array}{c}\text { Agricultura } \\
\text { Geral }\end{array}$ & Pastagem & $\begin{array}{c}\text { Remanescente } \\
\text { Florestal }\end{array}$ & $\begin{array}{c}\text { Vegetação } \\
\text { Secundária }\end{array}$ & Outros & TOTAL \\
\hline 2013 & 4.220 & 723 & 9.188 & 3.844 & 19.569 & 578 & 38.122 \\
2014 & 4.642 & 735 & 9.160 & 3.844 & 19162 & 578 & 38.122 \\
2015 & 5.064 & 748 & 9.133 & 3.844 & 18.756 & 578 & 38.122 \\
2016 & 5.486 & 760 & 9.105 & 3.844 & 18.349 & 578 & 38.122 \\
2017 & 5.908 & 772 & 9.078 & 3.844 & 17.942 & 578 & 38.122 \\
2018 & 6.330 & 784 & 9.050 & 3.844 & 17.536 & 578 & 38.122 \\
2019 & 6.752 & 797 & 9.023 & 3.844 & 17.129 & 578 & 38.122 \\
2020 & 7.174 & 809 & 8.995 & 3.844 & 16.722 & 578 & 38.122 \\
2021 & 7.596 & 821 & 8.967 & 3.844 & 16.315 & 578 & 38.122 \\
2022 & 8.018 & 834 & 8.940 & 3.844 & 15.909 & 578 & 38.122 \\
2023 & 8.440 & 846 & 8.912 & 3.844 & 15.502 & 578 & 38.122 \\
\hline
\end{tabular}


Tabela 55: Demanda por área para projeção de 2013 e 2023 para a sub-bacia do rio Mariquita, considerando 6 classes de uso e de cobertura da terra, com as áreas em hectares e valores múltiplos de 1 ha (pixel de $100 \mathrm{~m}$ ).

\begin{tabular}{lccccccc}
\hline Anos & $\begin{array}{c}\text { Palma de } \\
\text { Óleo }\end{array}$ & $\begin{array}{c}\text { Agricultura } \\
\text { Geral }\end{array}$ & Pastagem & $\begin{array}{c}\text { Remanescente } \\
\text { Florestal }\end{array}$ & $\begin{array}{c}\text { Vegetação } \\
\text { Secundária }\end{array}$ & Outros & TOTAL \\
\hline 2013 & 2.308 & 936 & 4.221 & 3.867 & 4.643 & 19 & 15.994 \\
2014 & 2.539 & 952 & 4.208 & 3.867 & 4.409 & 19 & 15.994 \\
2015 & 2.770 & 968 & 4.196 & 3.867 & 4.175 & 19 & 15.994 \\
2016 & 3.000 & 984 & 4.183 & 3.867 & 3.941 & 19 & 15.994 \\
2017 & 3.231 & 1.000 & 4.170 & 3.867 & 3.707 & 19 & 15.994 \\
2018 & 3.462 & 1.016 & 4.158 & 3.867 & 3.473 & 19 & 15.994 \\
2019 & 3.693 & 1.031 & 4.145 & 3.867 & 3.239 & 19 & 15.994 \\
2020 & 3.924 & 1.047 & 4.132 & 3.867 & 3.005 & 19 & 15.994 \\
2021 & 4.154 & 1.063 & 4.120 & 3.867 & 2.771 & 19 & 15.994 \\
2022 & 4.385 & 1.079 & 4.107 & 3.867 & 2.537 & 19 & 15.994 \\
2023 & 4.616 & 1.095 & 4.094 & 3.867 & 2.303 & 19 & 15.994 \\
\hline
\end{tabular}

\subsubsection{Preparo dos arquivos para uso no modelo.}

As Tabelas 56 e 57 apresentam as denominações recebidas pelos arquivos em formato ASCII para a SBRB e SBRM, onde se observa os arquivos desmembrados de cada uso e cobertura da terra especificamente, bem como as denominações em código de cada variável explanatória utilizada na regressão logística. 
Tabela 56: Lista de fatores exploratórios para a sub-bacia do rio Bujaru.

\begin{tabular}{lc}
\hline Variável & Arquivo ASCII para o CLUE-s \\
\hline uso2008buj / uso2013buj & cov_all.0 \\
agricultura13 & agricultura13 \\
palmaoleo13 & palmaoleo13 \\
pastagem13 & pastagem13 \\
remanescent13 & remanescent13 \\
outros13 13 outros13 \\
secundaria13 & secundaria13 \\
dehidrografia/dlhidrografia & sc1gr0.fil \\
hipsometria & sc1gr1 \\
sololad1 & sc1gr2 \\
sololad8 & sc1gr3 \\
sololad25 & sc1gr4 \\
sololad39 & sc1gr5 \\
custodistant13 & sc1gr6 \\
dehidrovias/dlhidrovias & sc1gr7 \\
deportos/dlportos & sc1gr8 \\
deusinas70/dlusinas70 & sc1gr9 \\
derodovias/dlrodovias & sc1gr10 \\
densetor2010 & sc1gr11 \\
rensetor2010 & sc1gr12 \\
\hline
\end{tabular}

Tabela 57: Lista de fatores exploratórios para a sub-bacia do rio Mariquita.

\begin{tabular}{lc}
\hline Variável & Nome CLUE-s \\
\hline uso2008mar / uso2013mar & cov_all.0 \\
agricultura13 & agricultura13 \\
palmaoleo13 & palmaoleo13 \\
outros13 & outros13 \\
pastagem13 & pastagem13 \\
remanescent13 & remanescent13 \\
secundaria13 & secundaria13 \\
dehidrografia/dlhidrografia & sc1gr0.fil \\
hipsometria & sc1gr1 \\
sololad1 & sc1gr2 \\
sololad24 & sc1gr3 \\
custodistan13 & sc1gr4 \\
dehidrovias/dlhidrovias & sc1gr5 \\
deportos/dlportos & sc1gr6 \\
deusinas70/dlusinas70 & sc1gr7 \\
derodovias/dlrodovias & sc1gr8 \\
densetor2010 & sc1gr9 \\
rensetor2010 & sc1gr10 \\
\hline
\end{tabular}

Para 2008, o arquivo 'region*.fill' de restrição de uso (Figura 72) foi composto pelas classes Área Urbana e Água. Em 2013, foi adicionada ao mapa de restrição a classe Remanescente Florestal, além de Área Urbana e Água, com o objetivo de eliminar a supressão de áreas de floresta (Figura 72). 


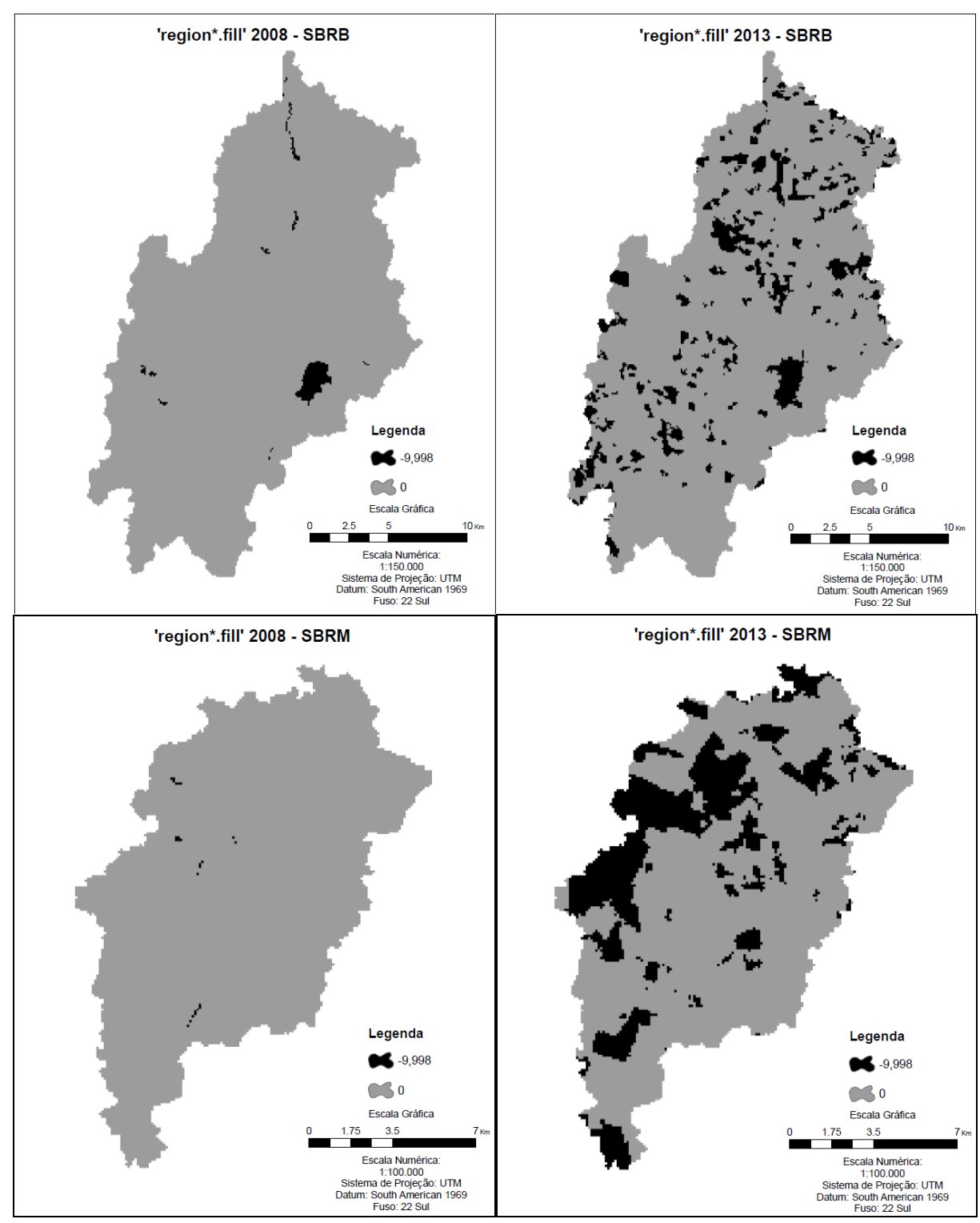

Figuras 72: Mapas de restrição de converção de 2008 e 2013 para as sub-bacias dos rios Bujaru e Mariquita.

A matriz de conversão apresentada na Tabela 58 para a calibração, inicialmente foi elaborada de maneira mais simples, uma vez que são apenas 6 anos de intervalo no período de calibração (2006 a 2013). Nesta matriz, as classes 'palmaoleo' e 'outros' são travadas e não se convertem e nenhuma outra, enquanto todas as classes restantes podem se converterem em todas as outras, incluindo para palma de óleo, mas não para a 'classe' outros. A exceção também é com relação a não conversão de áreas de agricultura geral para palma de óleo, por essa conversão ter sido mínima entre o período de 2008 a 2013. A classe 'remanescent', no período de calibração, foi permitida 
a conversão por razão de ter sido identificado entre os anos de 2000 e 2013 uma redução dessa classe em ambas sub-bacias.

Tabela 58: Matriz de conversão adotada para a calibração do modelo de 2008 para 2013 em ambas subbacias dos rios Buajru e Mariquita.

\begin{tabular}{lcccccc}
\hline Classes & palmaoleo & agricultura & pastagem & remanescent & secundaria & outros \\
\hline palmaoleo & 1 & 0 & 0 & 0 & 0 & 0 \\
agricultura & 0 & 1 & 1 & 0 & 1 & 0 \\
pastagem & 1 & 1 & 1 & 0 & 1 & 0 \\
remanescent & 1 & 1 & 1 & 1 & 0 & 0 \\
secundaria & 1 & 1 & 1 & 0 & 1 & 0 \\
outros & 0 & 0 & 0 & 0 & 0 & 1 \\
\hline
\end{tabular}

Na simulação de projeção de 2013 a 2023, a Matriz de conversão teve algumas mudanças (Tabela 59), onde as classes 'agricultura' (3 anos), 'pastagem' (3 anos) e 'secundaria' (5 anos) receberam tempos mínimos de permanência antes de serem convertidos, sendo que o tempo mínimo de 5 anos para Vegetação Secundária está ligado ao tempo médio de pousio da região nordeste do estados do Pará (KATO et al., 2005). Para se converterem em 'secundaria', as classes 'agricultura' e 'pastagem' devem permanecer no máximo 5 anos em atividade. Na matriz de projeção as áres de Remanescente Florestal são travadas para conversão para manuntenção desses ecossistemas. As áreas de palma de óleo continuam travadas por ser uma cultura de ciclo longo (25 a 30 anos).

Tabela 59: Matriz de conversão adotada para nas simulações de projeção de 2013 a 2023 em ambas sub-bacias dos rios Buajru e Mariquita.

\begin{tabular}{lcccccc}
\hline Classes & palmaoleo & agricultura & pastagem & remanescent & secundaria & outros \\
\hline palmaoleo & 1 & 0 & 0 & 0 & 0 & 0 \\
agricultura & 103 & 1 & 103 & 0 & -105 & 0 \\
pastagem & 1 & 103 & 1 & 0 & -105 & 0 \\
remanescent & 0 & 0 & 0 & 1 & 0 & 0 \\
secundaria & 1 & 105 & 105 & 0 & 1 & 0 \\
outros & 0 & 0 & 0 & 0 & 0 & 1 \\
\hline
\end{tabular}




\subsubsection{Análise dos fatores exploratórios do estudo de caso.}

Através da utilização de planilhas eletrônicas, os resultados da correlação bivariável foram tabulados e auxiliaram no processo manual de calibração das equações de regressão logística. O procedimento de busca pela melhora da Curva ROC (PONTIUS; SCHNEIDER, 2001), realizada após a escolha dos parâmetros pelo método Enter e Stepwise, com todos as variáveis explanatórias, fundamentou-se na identificação de parâmetros não significativos nesses primeiros métodos de regressão, bem como no corte de variáveis explanatórias com correlação $\geq 0,7$, conforme outros trabalhos (VALÊNCIA, 2008; SOLER et al., 2009; PEREIRA, 2013).

Os resultados dos modelos utilizando a distância logarítmica (VALÊNCIA 2008) no presente trabalho apresentaram qualidade inferior da Curva ROC e no acerto final do modelo CLUE-S em relação aos modelos utilizando a distância euclidiana, sendo estas últimas variáveis as escolhidas nas simulações finais.

Abaixo segue o gráfico da correlação bivariável entre o uso palma de óleo e as variáveis explanatórias aplicadas na SBRB e SBRM (Figura 73). No APÊNDICE B (Figuras 74, 75, 76 e 77), estão os gráficos das correlações bivariáveis relativas aos outros usos em estudo. Pode-se perceber que a variável 'custodistan13', em todos os modelos, foi a que se correlacionou mais expressivamente em quase todos os modelos, tanto que nos testes de regressão retirando esta variável explicativa, a qualidade da Curva ROC sempre foi inferior.

Em especial à palma de óleo, que é o grande objetivo dessa modelagem, as variáveis 'custodistan13', 'dehidrografia', 'sololad1', 'sololad24', 'sololad39', 'deusinas70' e 'rensetor2010', apresentaram forte correlação com o uso palma de óleo, sendo estas forçantes conceitualmente importantes para a cultura da palma, seja quanto ao aspecto logístico, mão de obra, assim como ambiental. Estes aspectos podem explicar a razão dessas forçantes terem sido escolhidas nas melhores regressões finais em ambas subbacias para modelar a palma de óleo.

Mesmo as SBRB e SBRM sendo ocupadas por uma única classe predominante de tipo de solo (LATOSSOLO AMARELO Distrófico - Lad), a utilização desmembrada 
destas sub-classes (Lad1, Lad8, Lad24, Lad25 e Lad39) apresentaram níveis de correlação diferenciadas com todos os usos e coberturas do presente estudo. No entanto, isto pode ou não indicar que há alguma diferença na influência da qualidade desses solos de interesse para a cultura da palma de óleo, por exemplo, mas o que realmente explicou a importância dessas variáveis no estudo foi que os testes de regressão logística sem esta discretização em sub-classes de solo reduziram consideravelmente a qualidade da Curva $R O C$ e do resultado final na calibração nas duas sub-bacias.

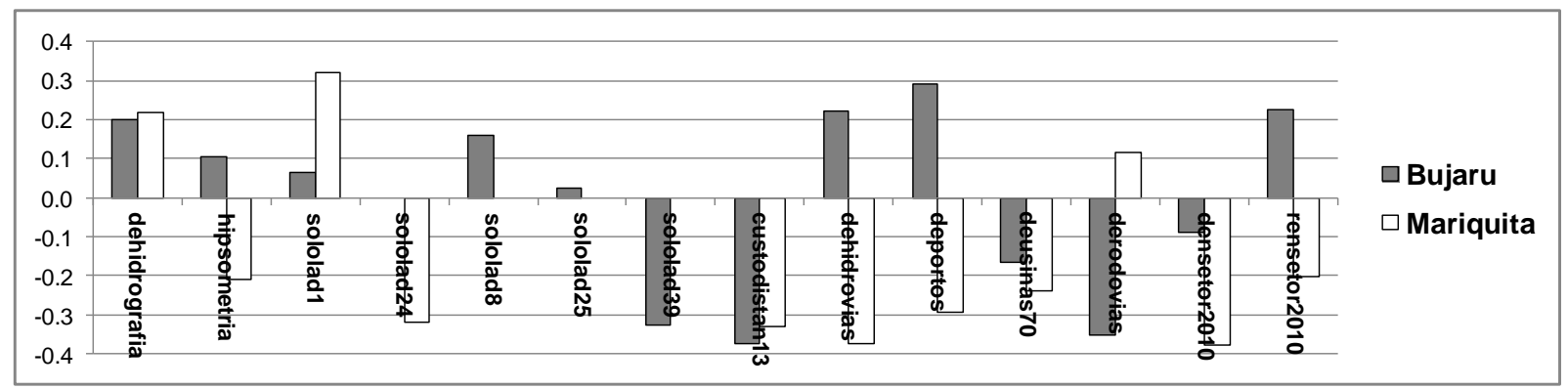

Figura 73: Correlação bivariável entre a classe palma de óleo e as variáveis explanatórias para o ano de 2013.

Os resultados da regressão logística com o SPSS para os Coeficientes de Regreção $\beta$, Significância, Exponencial do Coeficiente $\beta$ e da área sobre a Curve ROC são apresentados na Tabela 60 (SBRB) e na Tabela 61 (SBRM). Estes resultados são relativos às constantes da equação de regressão de cada uso e cobertura, bem como os valores dos betas de cada fator explanatório relacionado ao uso que influencia. Esses resultados serão os componentes do arquivo 'alloc.reg' que alimentará o modelo nas simulações e representam os melhores testes encontrados, os quais auxiliaram na obtenção dos melhores resultados visuais e estatísticos das simulações durante a etapa de calibração. Segundo Lesschen et al. (2005), para estudos de mudança de uso e cobertura da terra, o valor da curva ROC acima de 0,7 são normalmente considerados aceitáveis, mas os valores acima de 0,8 são considerados excelentes. O valor do exponencial do coeficiente $\beta$ da regressão logística indica a alteração nas probabilidades mediante a variação de uma unidade da variável independente. Ou seja, quando $\operatorname{Exp}(\beta)>1$, a probabilidade aumenta mediante o aumento do valor da variável 
independente, sendo que quando o $\operatorname{Exp}(\beta)<1$, a probablidade diminui (VERBURG et al., 2002).

Em ambas sub-bacias, as variáveis 'custodistan13' e 'deusinas70' foram as que estiveram mais presentes nos modelos, tanto na SBRB como na SBRM. Isso pode estar demonstrando a influência significante da estruturação do sistema produtivo da palma de óleo nessa região sobre as mudanças do uso e cobertura da terra (LAMEIRA et al., 2015a). A variável 'densetor2010' também esteve fortemente presente nos modelos das duas sub-bacias, sendo também uma variável importante conceitualmente, devido à necessidade de mão de obra da população próxima para trabalhar na cultura da Palma de Óleo (HOMMA, et al., 2000; BECKER, 2010).

Para as áreas de palma de óleo, em ambas sub-bacias, as variáveis biofísicas de solos e hipsometria foram as que tiveram maior contribuição na explicação dos modelos (Tabela 60 e 61), apresentando maiores valores dos coeficientes de regressão. Com relação às variáveis 'dehidrovias' e 'deportos', estas não apresentaram significância no modelo da SBRB, mas foram importantes no ajuste da curva do modelo da SBRM. Mesmo sendo variáveis de sentido semelhante, 'dehidrovias' e 'deportos' apresentaram coeficientes de regressão com sinais opostos, mas devido a contribuição na melhora do modelo, estas foram mantidas. Evento parecido, mas com outro sentido, aconteceu na SBRB, onde a variável 'deusinas70' deveria, teoricamente, ter um $\beta$ de valor negativo, representando que quanto mais próximo de usinas, maior a concentração de Palma. Entretanto, como a SBRB possui uma usina dentro de seus limites e a distância mínima de $70 \mathrm{~km}$ quase nunca é superada, a leitura bivariável feita pelo modelo pode indicar uma possível análise invertida, porém as áreas de Palma estão próximas da usina na realidade. Esse efeito de inversão de sinais de maneira oposta a aplicação teórica, podem estar alertando para necessidade de se rever a utilização de algumas variáveis explicativas que talvez funcionem melhor em escalas menos refinadas, em especial as variáveis de distância. Outros trabalhos em escalas mais grosseiras que o do presente trabalho encontraram resultados melhores com variáveis de distância parecidas (WASSENAAR et al., 2007; VALÊNCIA, 2008; PEREIRA, 2013).

Importante observar que a forçante distância a hidrografia expressou um uso incorreto ambientalmente do ecossistema na SBRM. Isso pode ser observado através 
do sinal do coeficiente de regressão dessa forçante em relação a classe pastagem (Tabela 61), sendo identificada uma relação inversamente proporcional em relação a distância da hidrografia. Quanto a hipsometria, as áreas de pastagens da SBRM tem respondido dinamicamente melhor as áreas de menor declive. Ao contrário, as áreas de remanescente florestal e vegetação secundária têm apresentado comportamentos esperados, sendo inversamente proporcional à distância a hidrografia e diretamente proporcional ao aumento da declividade (Tabela 60 e 61).

No presente estudo, em síntese, é possível observar a maior influência (maior valor do $\beta$ ) das forçantes biofísicas selecionadas para todos os usos da SBRB. $\mathrm{Na}$ SBRM, as forçantes biofísicas foram mais influentes apenas para os modelos da 'palmaole013', 'agricultura13' e 'remanescent13'. Quanto aos aspectos biofísicos é possível verificar lógica explicativa conceitual apenas para a variável explanatória 'hipsometria'. As forçantes logísticas explicaram melhor os modelos dos usos e coberturas da SBRM, apresentando maiores betas para o modelo 'palmaoleo13', mas não ficaram claras as relações específicas conceituais entre as variáveis dependentes e as variáveis independentes de logísticas, mais especificamente de distância a portos e hidrovias. Isso talvez seja explicado pela escala de trabalho aplicada na tese, ou seja, nível de meso-bacias de menor porte (150 a $400 \mathrm{~km}^{2}$ ) não serem capaz de apresentar um correlação mais clara, em especial com as forçantes de distância. As variáveis explanatórias socioeconômicas ('densetor2010' e 'rensetor2010') tiveram influências completamente diferentes quanto a explicação dos modelos nas duas sub-bacias, o que pode estar relacionado às características agrícolas diferenciadas de cada sub-bacia, uma vez que a SBRM tem a palma de óleo como uso consolidado e a SBRB como uso em expansão.

De maneira geral, na SBRB os resultados da Curva ROC foram excelentes para as áreas de palma de óleo e remanescente florestal $(>0,8)$ e satisfatórios para os modelos dos demais usos e coberturas $(>0,7)$. Na SBRM, os resultados excelentes foram identificados nos modelos da palma de óleo, pastagem e remanescente florestal, sendo satisfatórios os resultados dos modelos da agricultura geral e vegetação secundária. Importante observar que a Curva ROC da palma de óleo na SBRM $(0,95)$ foi consideravelmente melhor que a da $\operatorname{SBRB}(0,806)$, o que pode estar ligado a maior 
presença desse uso na SBRM e de maneira mais distribuída, favorecendo assim a leitura da correlação bivariável. A resposta de melhor qualidade da Curva ROC do modelo da SBRM reflete no melhor acerto desse uso na calibração, conforme apresentado mais a frente.

A partir dos resultados das regressões logísticas é possível calcular os mapas de probabilidade de alocação espacializados de um determinado uso e cobertura. Os resultados dos coeficientes de regressão $(\beta)$ são responsáveis por representar a influência que cada fator explanatório possui sobre a alocação da variável dependente através da criação de uma região no mapa com maior probabilidade para expansão, por exemplo, da cultura da palma de óleo. Fundamentado nestes coeficientes, o Modelo CLUE-S permite a elaboração desses mapas de distribuição das probabilidades, conforme apresentado nas Figuras 78 e 79 do APÊNDICE B, apontando para possíveis focos de expansão de cada uso e cobertura da terra do presente estudo, de acordo com as forçantes de mudanças aplicadas.

\subsubsection{Carga no modelo.}

Essencialmente, na hora de iniciar as simulações, o CLUE-S exige 4 arquivos básicos, além do 'Cov_all." e dos arquivos 'Sc1gr'.fil', que são os arquivos 'alloc.reg', 'allow.txt', 'demand.in1' e 'main.txt'.

Os resultados advindos dos melhores testes de regressão (Tabela 60 e 61 acima), serviram para comporem o arquivo 'alloc.reg'. Na realidade, durante todo o processo de calibração, foram construídos diferentes arranjos de variáveis explicativas para cada variável dependente em cada teste de simulação, fundamentados no melhor resultado da Curva ROC após a escolha de variáveis significativas, conceitualmente interessantes e após o corte de variáveis de correlação alta. 
Tabela 60: Resultados da regressão logística do melhor modelo de calibração (2008-2013) para a sub-bacia do rio Bujaru.

\begin{tabular}{|c|c|c|c|c|c|c|c|c|c|c|c|c|c|c|c|}
\hline \multicolumn{16}{|c|}{ Sub-bacia do rio Bujaru } \\
\hline \multirow{2}{*}{$\begin{array}{l}\text { Variáveis } \\
\text { Explanatórias }\end{array}$} & \multicolumn{3}{|c|}{ palmaoleo13 } & \multicolumn{3}{|c|}{ agricultura13 } & \multicolumn{3}{|c|}{ pastagem13 } & \multicolumn{3}{|c|}{ remanescent13 } & \multicolumn{3}{|c|}{ secundaria13 } \\
\hline & $\beta$ & Sig. & $\operatorname{Exp}(\beta)$ & $\beta$ & Sig. & $\operatorname{Exp}(\beta)$ & $\beta$ & Sig. & $\operatorname{Exp}(\beta)$ & $\beta$ & Sig. & $\operatorname{Exp}(\beta)$ & $\beta$ & Sig. & $\operatorname{Exp}(\beta)$ \\
\hline dehidrografia & 0,0006 & 0,0000 & 1,0006 & 0,0003 & 0,0000 & 1,0003 & & & & & & & $-0,0001$ & 0,0002 & 0,9999 \\
\hline hipsometria & & & & & & & $-0,0104$ & 0,0024 & 0,9897 & 0,0510 & 0,0000 & 1,0523 & & & \\
\hline sololad1 & $-0,4472$ & 0,0008 & 0,6394 & & & & & & & & & & $-0,9112$ & 0,0000 & 0,4020 \\
\hline \multicolumn{16}{|l|}{ sololad8 } \\
\hline sololad25 & & & & 2,0523 & 0,0009 & 7,7859 & & & & & & & & & \\
\hline sololad39 & $-3,0054$ & 0,0000 & 0,0495 & 1,5911 & 0,0000 & 4,9090 & & & & $-1,4618$ & 0,0000 & 0,2318 & 0,8324 & 0,0000 & 2,2988 \\
\hline custodistan13 & $-0,0001$ & 0,0000 & 0,9999 & $-0,0001$ & 0,0000 & 0,9999 & $-0,0001$ & 0,0000 & 0,9999 & 0,0001 & 0,0000 & 1,0001 & 0,0000 & 0,0000 & 1,0000 \\
\hline \multicolumn{16}{|l|}{ dehidrovias } \\
\hline \multicolumn{16}{|l|}{ deportos } \\
\hline deusinas70 & 0,0005 & 0,0000 & 1,0005 & 0,0004 & 0,0000 & 1,0004 & 0,0002 & 0,0000 & 1,0002 & $-0,0004$ & 0,0000 & 0,9996 & 0,0001 & 0,0000 & 1,0001 \\
\hline derodovias & 0,0001 & 0,0000 & 1,0001 & 0,0002 & 0,0000 & 1,0002 & & & & $-0,0001$ & 0,0000 & 0,9999 & 0,0003 & 0,0000 & 1,0003 \\
\hline densetor2010 & $-0,0020$ & 0,0291 & 0,9980 & & & & 0,0006 & 0,0002 & 1,0006 & $-0,0726$ & 0,0001 & 0,9300 & & & \\
\hline rensetor2010 & 0,0026 & 0,0007 & 1,0026 & & & & & & & 0,0050 & 0,0000 & 1,0050 & & & \\
\hline Constant & 2,6451 & 0,0000 & 14,0842 & 1,8966 & 0,0000 & 6,6630 & 2,7479 & 0,0000 & 15,6104 & $-9,7577$ & 0,0000 & 0,0001 & 0,9386 & 0,0000 & 2,5564 \\
\hline Curva ROC & \multicolumn{3}{|c|}{0,8060} & \multicolumn{3}{|c|}{0,7610} & \multicolumn{3}{|c|}{0,7050} & \multicolumn{3}{|c|}{0,9320} & \multicolumn{3}{|c|}{0,7320} \\
\hline
\end{tabular}


Tabela 61: Resultados da regressão logística do melhor modelo de calibração (2008-2013) para a sub-bacia do rio Mariquita.

\begin{tabular}{|c|c|c|c|c|c|c|c|c|c|c|c|c|c|c|c|}
\hline \multicolumn{16}{|c|}{ Sub-bacia do rio Mariquita } \\
\hline \multirow{2}{*}{$\begin{array}{l}\text { Variáveis } \\
\text { Explanatórias }\end{array}$} & \multicolumn{3}{|c|}{ palmaoleo13 } & \multicolumn{3}{|c|}{ agricultura13 } & \multicolumn{3}{|c|}{ pastagem13 } & \multicolumn{3}{|c|}{ remanescent13 } & \multicolumn{3}{|c|}{ secundaria13 } \\
\hline & $\bar{\beta}$ & Sig. & $\operatorname{Exp}(\beta)$ & $\bar{\beta}$ & Sig. & $\operatorname{Exp}(\beta)$ & $\bar{\beta}$ & Sig. & $\operatorname{Exp}(\beta)$ & $\beta$ & Sig. & $\operatorname{Exp}(\beta)$ & $\bar{\beta}$ & Sig. & $\operatorname{Exp}(\beta)$ \\
\hline dehidrografia & & & & & & & $-0,0008$ & 0,0000 & 0,9992 & $-0,0005$ & 0,0065 & 0,9995 & & & \\
\hline hipsometria & $-0,0779$ & 0,0000 & 0,9250 & $-0,0223$ & 0,0046 & 0,9779 & & & & 0,1487 & 0,0000 & 1,1604 & & & \\
\hline \multicolumn{16}{|l|}{ sololad1 } \\
\hline sololad24 & $-2,6805$ & 0,0000 & 0,0685 & & & & & & & & & & & & \\
\hline custodistan13 & $-0,0006$ & 0,0000 & 0,9994 & 0,0000 & 0,0000 & 1,0000 & $-0,0002$ & 0,0000 & 0,9998 & 0,0002 & 0,0000 & 1,0002 & 0,0000 & 0,0000 & 1,0000 \\
\hline dehidrovias & 0,0036 & 0,0000 & 1,0036 & $-0,0003$ & 0,0002 & 0,9997 & & & & & & & 0,0002 & 0,0000 & 1,0002 \\
\hline deportos & $-0,0017$ & 0,0000 & 0,9983 & $-0,0002$ & 0,0000 & 0,9998 & 0,0003 & 0,0000 & 1,0003 & & & & & & \\
\hline deusinas70 & $-0,0022$ & 0,0000 & 0,9978 & 0,0003 & 0,0000 & 1,0003 & 0,0008 & 0,0000 & 1,0008 & $-0,0006$ & 0,0000 & 0,9994 & & & \\
\hline derodovias & 0,0011 & 0,0000 & 1,0011 & & & & 0,0003 & 0,0000 & 1,0003 & & & & & & \\
\hline densetor2010 & & & & 0,1593 & 0,0000 & 1,1727 & $-0,0979$ & 0,0000 & 0,9068 & & & & 0,0738 & 0,0000 & 1,0765 \\
\hline rensetor2010 & & & & $-0,0029$ & 0,0000 & 0,9971 & & & & & & & $\begin{array}{c}- \\
0,0021\end{array}$ & 0,0006 & 0,9979 \\
\hline Constant & 83,4952 & 0,0000 & $1,8 \mathrm{E}+36$ & 26,7897 & 0,0000 & $4,3 \mathrm{E}+11$ & $-27,1548$ & 0,0000 & 0,0000 & $-13,4193$ & 0,0000 & 0,0000 & 3,9365 & 0,0058 & 0,0195 \\
\hline Curva ROC & & 0.9500 & & & 0.7290 & & & 0.8410 & & & 0.9900 & & & 0.7090 & \\
\hline
\end{tabular}


Os arquivos de 'allow.txt', que englobam os resultados das matrizes de conversão, foram os mesmos para a SBRB e SBRM, sendo aplicados dois modelos de arquivo, sendo um para o período de calibração (2008-2013) e outro para o período de projeção (2013-2023). O arquivo 'allow.txt', conforme necessário, pode ser modificado com o objetivo de auxiliar no ajuste da calibração. Os arquivos 'demand.in1', foram elaborados a partir das tabelas de demandas para os cenários de calibração e projeção, sendo que estes não foram alterados no processo de calibração.

Por fim, preparou-se o arquivo 'main.txt' (Tabela 62), unindo informações gerais do modelo, mas em especial as informações de elasticidades, que dentre todas as informações presentes no 'main.txt', foram as que sofreram constates alterações durante o processo de calibração.

\subsubsection{Ajustes do modelo de calibração 2008 - 2013 e projeção 2013 - 2023.}

Após a definição de todos os arquivos necessários para composição dos modelos, os quais se fundamentaram nas discussões dos usos e coberturas a serem estudados, na seleção das variáveis explicativas das mudanças espaciais e nas demandas de área para uso e cobertura, o trabalho prosseguiu com o processo de simulações da etapa de calibração, que correspondeu ao período de 2008 a 2013.

Os melhores resultados das regressões logísticas, que são consequência dos melhores arranjos entre as variáveis explicativas e, consequentemente, as melhores respostas das áreas sobre as Curvas ROC, foram então inseridas no modelo CLUE-S para geração dos testes de simulação e posterior análise visual. No entanto ainda foi necessário ajustar dois componentes fundamentais do processo de ajuste dos modelos, que são a matriz de conversão (explicadas anteriormente) e as elasticidades. 
Tabela 62: Parâmetros principais dos modelos na calibração e projeção.

\begin{tabular}{|c|c|c|c|c|}
\hline \multirow{2}{*}{$\begin{array}{l}\text { Parâmetros } \\
\text { Descrição de cada } \\
\text { linha }\end{array}$} & \multicolumn{2}{|c|}{ Bujaru } & \multicolumn{2}{|c|}{ Mariquita } \\
\hline & $2008-2013$ & $2013-2023$ & $2008-2013$ & $2013-2023$ \\
\hline $\begin{array}{l}\text { Número de } \\
\text { usos/coberturas da } \\
\text { terra }\end{array}$ & 6 & 6 & 6 & 6 \\
\hline Número de regiões & 1 & 1 & 1 & 1 \\
\hline $\begin{array}{l}\text { Máx. núm. de var. } \\
\text { independ. na eq. } \\
\text { de regre*. }\end{array}$ & 8 & 8 & 7 & 7 \\
\hline $\begin{array}{l}\text { Número total de } \\
\text { fatores } \\
\text { explanatórios }\end{array}$ & 13 & 13 & 11 & 11 \\
\hline Número de linhas & 334 & 334 & 211 & 211 \\
\hline Número de colunas & 213 & 213 & 150 & 150 \\
\hline $\begin{array}{l}\text { Área da célula de } \\
\text { grade - hectares }\end{array}$ & 1 & 1 & 1 & 1 \\
\hline $\begin{array}{l}\text { Coordenada x - } \\
\text { esquerda }\end{array}$ & 825670,177 & 825670,177 & 776715,299 & 776715,299 \\
\hline $\begin{array}{l}\text { Coordenada y - } \\
\text { inferior }\end{array}$ & 9766700,346 & 9766700,346 & 9715782,900 & 9715782,900 \\
\hline $\begin{array}{l}\text { Códigos dos usos } \\
\text { da terra }\end{array}$ & 012345 & 012345 & 012345 & 012345 \\
\hline $\begin{array}{l}\text { Códigos das } \\
\text { elasticidades dos } \\
\text { usos da terra }\end{array}$ & $10,50,20,90,71$ & $10,50,20,90,71$ & $10,50,20,90,51$ & $10,50,20,90,51$ \\
\hline $\begin{array}{l}\text { Variáveis de } \\
\text { iteração }\end{array}$ & 00,353 & 00,353 & 00,353 & 00,353 \\
\hline $\begin{array}{l}\text { Início e fim da } \\
\text { simulação (anos) }\end{array}$ & 20082013 & 20132023 & 20082013 & 20132023 \\
\hline $\begin{array}{l}\text { Fatores } \\
\text { explanatórios com } \\
\text { variação anual }\end{array}$ & 0 & 0 & 0 & 0 \\
\hline $\begin{array}{l}\text { Formato dos } \\
\text { arquivos de saída }\end{array}$ & 1 & 1 & 1 & 1 \\
\hline $\begin{array}{l}\text { Regiões com } \\
\text { diferentes } \\
\text { regressões }\end{array}$ & 0 & 0 & 0 & 0 \\
\hline Inicialização do & & & & \\
\hline $\begin{array}{l}\text { histórico de uso da } \\
\text { terra }\end{array}$ & 12 & 12 & 12 & 12 \\
\hline $\begin{array}{l}\text { Escolha do cálculo } \\
\text { de vizinhança }\end{array}$ & 0 & 0 & 0 & 0 \\
\hline $\begin{array}{l}\text { Adição específica } \\
\text { na preferência da } \\
\text { área }\end{array}$ & 0 & 0 & 0 & 0 \\
\hline
\end{tabular}

* Máximo número de variáveis independentes na equação de regressão. 
Tendo em mente que a elasticidade para cada classe varia de 0 a 1 e que quanto mais próximo de 1 forem os valores, menor é a possibilidade de conversão do uso e cobertura, no presente trabalho foram testados vários ajustes dos valores de elasticidades, sendo definidos como melhores ajustes os valores de 1 pra palma de óleo (OILP) e outros (Não se alteram), 0,5 para agricultura geral (AGRL) (grau médio de dificuldade de mudança); 0,2 para pastagem (PAST) (maior facilidade de mudança), 0,9 para áreas de remanescente florestal (FRSE_RF) (representando um pequena possibilidade de exploração de áreas de floresta nativa) e 0,7 para áreas de vegetação secundária (RFSE_VS) (demonstrando o custo ambiental, de tempo e mão de obra da conversão dessas áreas).

Abaixo são demonstrados os mapas de uso e cobertura da terra real de 2013 e o mapa da simulação calibrada de 2008 a 2013 para as sub-bacias. A avaliação do ajuste da calibração foi feita através da elaboração da tabela de contingência entre o mapa real e simulado de 2013, do Índice de Acurácia Global e do teste de Acerto Kappa.

Para a SBRB, a Figura 80 apresenta o melhor modelo quanto aos aspectos visuais e estatísticos (Tabela 65). A Tabela 63 demonstra a distribuição do acerto global entre os mapas reais e simulados, sendo possível identificar o erro global de cada uso. Como exemplo da OILP, que no modelo da SBRB obteve maior erro do que na SBRM, registrou-se uma Acurácia Global de 40\% e simulação errada de $27,6 \%$ e de $27,3 \%$ para as classes AGRL e FRSE_VS, respectivamente. Na Tabela 64 são apresentados os dados da análise da tabela de contingência base para o teste Kappa, o qual demonstra que o modelo da SBRB errou mais na indicação do acerto da presença de OILP do que da ausência. 


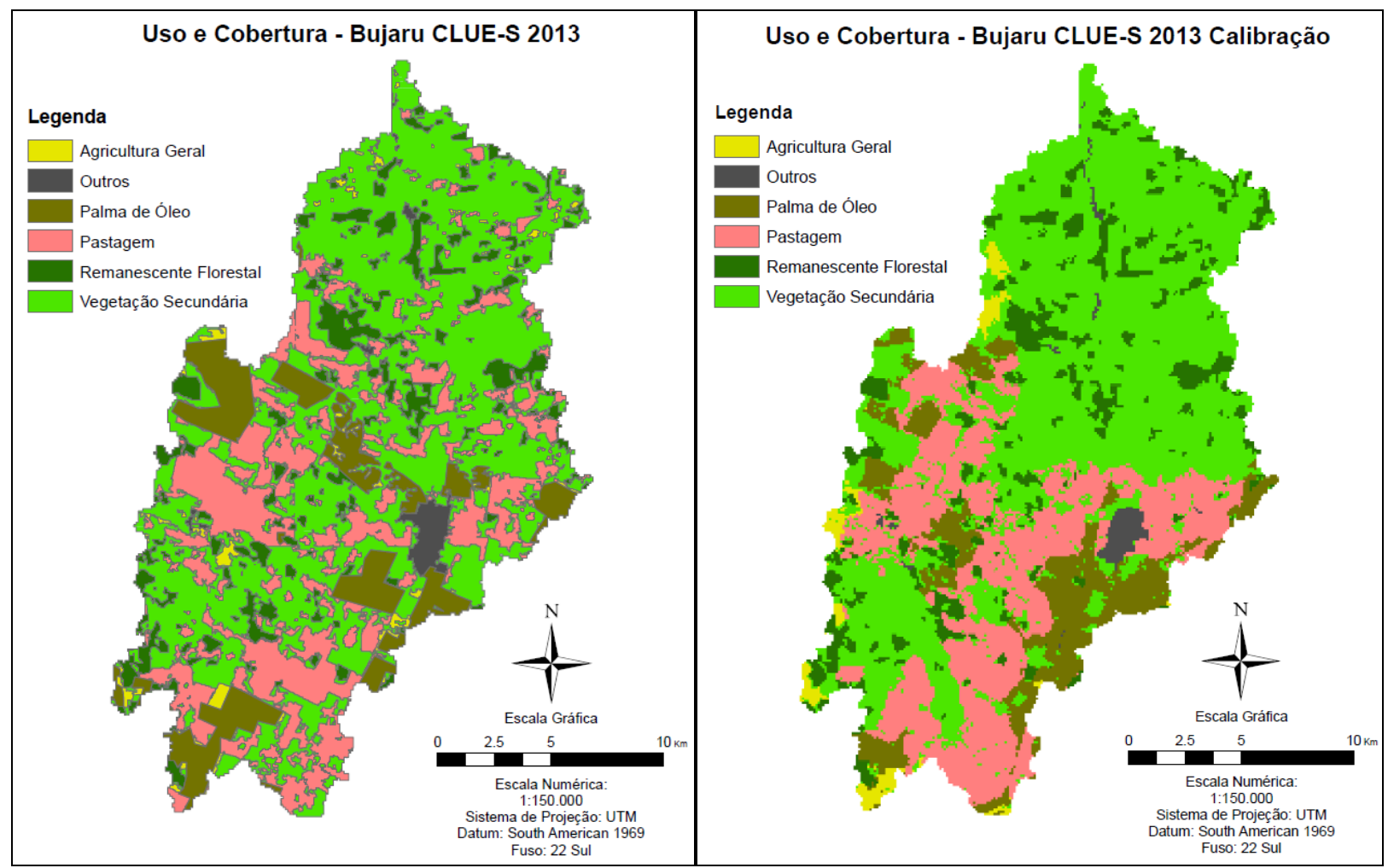

Figura 80: Mapa real (esquerda) e mapa da etapa de calibração do CLUE-S para a sub-bacia do rio Bujaru.

Tabela 63: Frequência de acerto na calibração do melhor modelo para a sub-bacia do rio Bujaru.

\begin{tabular}{|c|c|c|c|c|c|c|c|c|}
\hline & \multicolumn{6}{|c|}{ Mapa Simulado de 2013} & \multirow{2}{*}{$\begin{array}{l}\text { Total } \\
\text { pixels }\end{array}$} \\
\hline & & OILP & AGRL & PAST & FRSE_RF & FRSE_VS & OUTROS & \\
\hline \multirow{6}{*}{$\begin{array}{l}\frac{m}{0} \\
\text { N } \\
\frac{0}{0} \\
\frac{0}{\pi} \\
\mathbb{d} \\
\frac{\pi}{2} \\
\frac{0}{\pi} \\
\Sigma\end{array}$} & OILP & $\begin{array}{l}1.686 \\
(40,0)\end{array}$ & $\begin{array}{c}153 \\
(3,6)\end{array}$ & $\begin{array}{c}1166 \\
(27,6)\end{array}$ & $\begin{array}{c}59 \\
(1,4)\end{array}$ & $\begin{array}{c}1154 \\
(27,3)\end{array}$ & $\begin{array}{c}2 \\
(0,0)\end{array}$ & 4.220 \\
\hline & AGRL & $\begin{array}{c}149 \\
(20,6)\end{array}$ & $\begin{array}{c}61 \\
(8,4)\end{array}$ & $\begin{array}{c}167 \\
(23,1)\end{array}$ & $\begin{array}{c}12 \\
(1,7)\end{array}$ & $\begin{array}{c}332 \\
(45,9)\end{array}$ & $\begin{array}{c}2 \\
(0,3)\end{array}$ & 723 \\
\hline & PAST & $\begin{array}{r}1.112 \\
(12,1) \\
\end{array}$ & $\begin{array}{l}233 \\
(2,5)\end{array}$ & $\begin{array}{l}4.391 \\
(47,8) \\
\end{array}$ & $\begin{array}{c}51 \\
(0,6)\end{array}$ & $\begin{array}{l}3.353 \\
(36,5) \\
\end{array}$ & $\begin{array}{c}48 \\
(0,5)\end{array}$ & 9.188 \\
\hline & FRSE_RF & $\begin{array}{c}16 \\
(0,4)\end{array}$ & $\begin{array}{c}4 \\
(0,1)\end{array}$ & $\begin{array}{c}17 \\
(0,4)\end{array}$ & $\begin{array}{l}3.577 \\
(93,1)\end{array}$ & $\begin{array}{l}227 \\
(5,9)\end{array}$ & $\begin{array}{c}3 \\
(0,1)\end{array}$ & 3.844 \\
\hline & FRSE_VS & $\begin{array}{l}1.229 \\
(6,3)\end{array}$ & $\begin{array}{l}273 \\
(1,4) \\
\end{array}$ & $\begin{array}{l}3.398 \\
(17,4) \\
\end{array}$ & $\begin{array}{c}184 \\
(0,9) \\
\end{array}$ & $\begin{array}{c}14.389 \\
(73,5) \\
\end{array}$ & $\begin{array}{c}96 \\
(0,5)\end{array}$ & 19.569 \\
\hline & OUTROS & $\begin{array}{c}10 \\
(1,7)\end{array}$ & $\begin{array}{c}0 \\
(0,0)\end{array}$ & $\begin{array}{c}56 \\
(9,7)\end{array}$ & $\begin{array}{c}1 \\
(0,2)\end{array}$ & $\begin{array}{c}208 \\
(36,0)\end{array}$ & $\begin{array}{c}303 \\
(52,4)\end{array}$ & 578 \\
\hline
\end{tabular}

Sendo: OILP - Palma de óleo; AGRL - Agricultura geral; Past - Pastagem; FRSE_RF Remanescente florestal; FRSE_VS - Vegetação secundária. 
Tabela 64: Tabelas de contigência para o teste estatistico dos resultados da palma de óleo na sub-bacia do rio Bujaru.

\begin{tabular}{|c|c|c|c|c|c|}
\hline \multicolumn{6}{|c|}{ Palma de Óleo } \\
\hline & & & \multicolumn{2}{|c|}{ Mapa Real de 2013} & \multirow[b]{2}{*}{ Total } \\
\hline & & & $\begin{array}{c}\text { Com } \\
\text { Palma }\end{array}$ & $\begin{array}{c}\text { Sem } \\
\text { Palma }\end{array}$ & \\
\hline \multirow{6}{*}{ 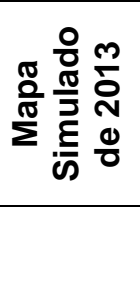 } & Frequência & \multirow{2}{*}{ Com Palma } & $1.686,0$ & $2.516,0$ & $4.202,0$ \\
\hline & Porcentagem & & 0,04 & 0,1 & 0,1 \\
\hline & Frequência & \multirow{2}{*}{ Sem Palma } & $2.534,0$ & $31.386,0$ & $33.920,0$ \\
\hline & Porcentagem & & 0,1 & 0,8 & 0,9 \\
\hline & Frequência & \multirow{2}{*}{ Total } & $4.220,0$ & $33.902,0$ & $38.122,0$ \\
\hline & Porcentagem & & 0,1 & 0,9 & 1,0 \\
\hline
\end{tabular}

Tabela 65: Resultados dos índices de acurácia global e kappa paras as sub-bacias.

\begin{tabular}{|c|c|c|c|c|}
\hline & \multicolumn{2}{|c|}{ Bujaru } & \multicolumn{2}{|c|}{ Mariquita } \\
\hline & Acurácia Global & Kappa Individual & Acurácia Global & Kappa Individual \\
\hline OILP & 40,0 & 0,33 & 62,0 & 0,56 \\
\hline AGRL & 8,4 & 0,07 & 12,8 & 0,07 \\
\hline PAST & 47,8 & 0,31 & 59,2 & 0,45 \\
\hline FRSE_RF & 93,1 & 0,92 & 95,1 & 0,94 \\
\hline \multirow[t]{3}{*}{ FRSE_VS } & 73,5 & 0,67 & 61,0 & 0,65 \\
\hline & \multicolumn{2}{|c|}{ Bujaru } & \multicolumn{2}{|c|}{ Mariquita } \\
\hline & Acurácia Global & Kappa Total & Acurácia Global & Kappa Total \\
\hline Mapa Total & 0,64 & 0,45 & 0,66 & 0,56 \\
\hline
\end{tabular}

Para a SBRM, a Figura 81 apresenta a comparação entre o melhor modelo simulado, quanto aos aspectos visuais e estatísticos (Tabela 65), e o modelo real para o ano de 2013. A Tabela 66 demonstra a distribuição do acerto global entre os mapas reais e simulados, sendo possível identificar que para a classe OILP, a Acurácia Global foi de $62 \%$ e o erro de simulação de 10,5\%, 12,8 e 12,8\% para as classes AGRL, PAST e FRSE_VS, respectivamente. $\mathrm{Na}$ análise da tabela de contingência, o modelo da SBRM errou mais na indicação do acerto da presença de OILP do que da ausência, assim como a SBRB (Tabela 67).

$\mathrm{Na}$ Tabela 65, têm-se os resultados do teste Kappa para a SBRB e SBRM. Em termos gerais, os resultados da calibração foram mais eficientes para a SBRM, apresentando Kappa Total superior $(0,56)$ em relação a SBRB $(0,45)$, sendo estes resultados classificados como de nível Bom (FONSECA, 2000). Especificamente com 
relação à OILP, foco deste estudo, os resultados para o teste Kappa da SBRB foram classificados como Razoável para a SBRB $(0,33)$ e como Bom para a SBRM $(0,56)$.

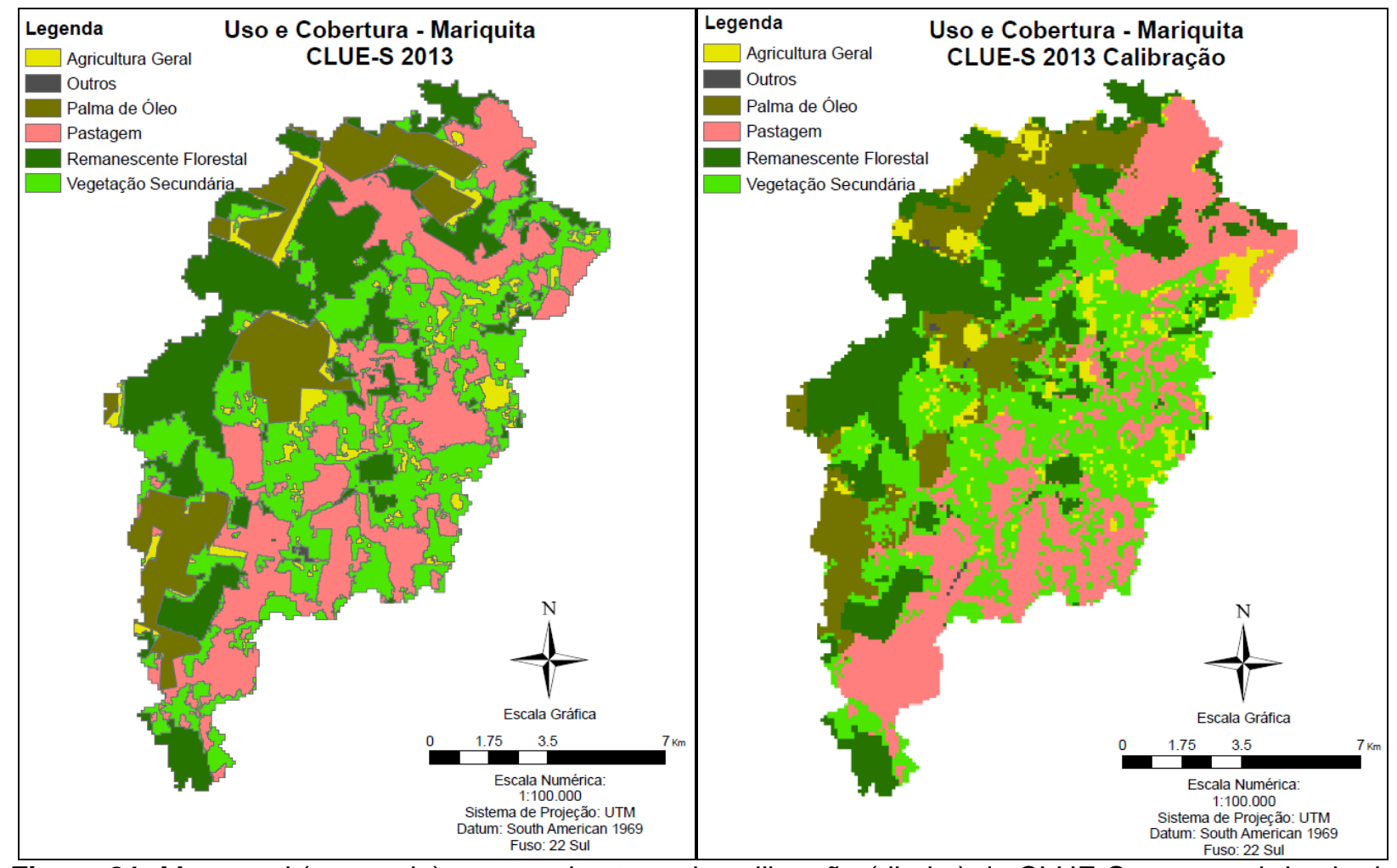

Figura 81: Mapa real (esquerda) e mapa da etapa de calibração (direita) do CLUE-S para a sub-bacia do rio Mariquita.

Tabela 66: Frequência de acerto na calibração do melhor modelo para a sub-bacia do rio Mariquita.

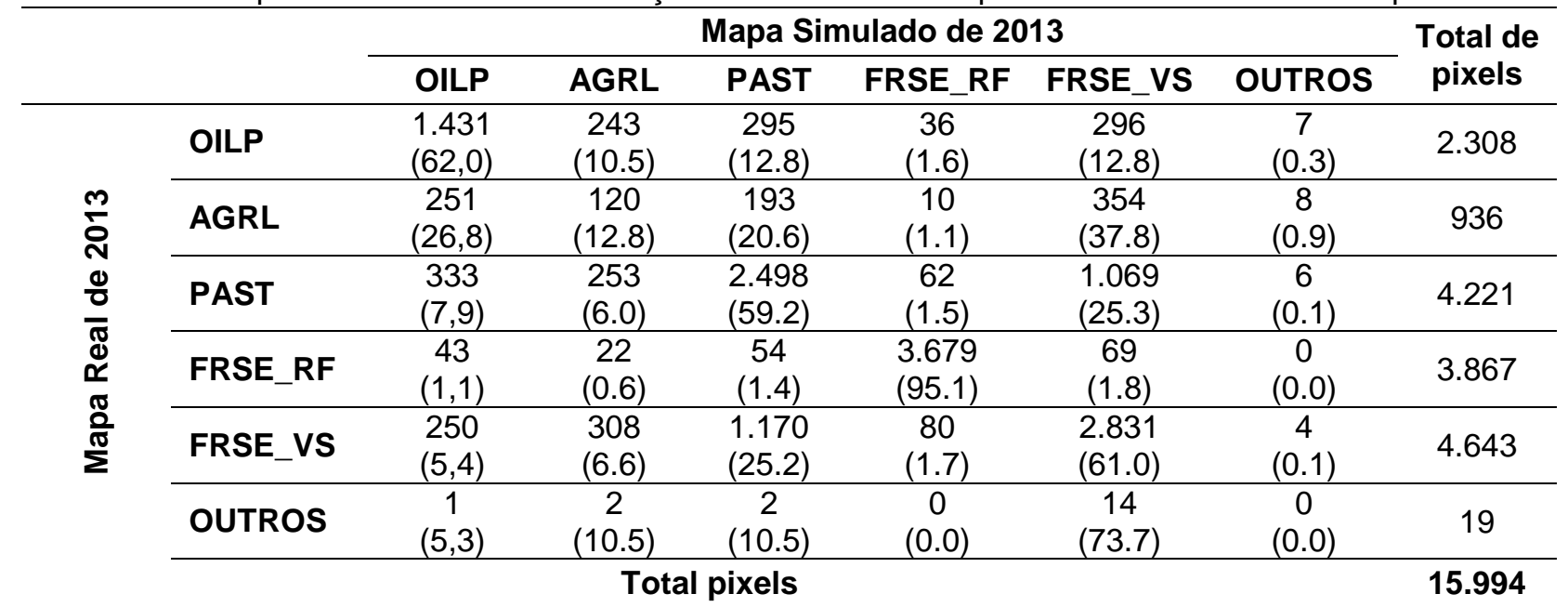

Sendo: OILP - Palma de óleo; AGRL - Agricultura geral; Past - Pastagem; FRSE_RF - Remanescente florestal; FRSE_VS - Vegetação secundária. 
Tabela 67: Tabelas de contigência para o teste estatístico dos resultados da palma de óleo na sub-bacia do rio Mariquita.

\begin{tabular}{|c|c|c|c|c|c|}
\hline \multicolumn{6}{|c|}{ Palma de Óleo } \\
\hline & & & \multicolumn{2}{|c|}{ Mapa Real de 2013} & \multirow[b]{2}{*}{ Total } \\
\hline & & & $\begin{array}{l}\text { Com } \\
\text { Palma }\end{array}$ & $\begin{array}{c}\text { Sem } \\
\text { Palma }\end{array}$ & \\
\hline \multirow{6}{*}{ 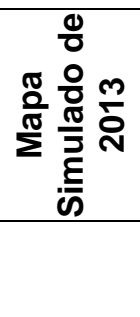 } & Frequência & Com Dolma & 1.431 & 878 & 2.309 \\
\hline & Porcentagem & Com ramra & 0,09 & 0,05 & 0,14 \\
\hline & Frequência & Som Dolma & 877 & 12.808 & 13.685 \\
\hline & Porcentagem & Sem Palma & 0,06 & 0,8 & 0,86 \\
\hline & Frequência & Tatal & 2.308 & 13.686 & 15.994 \\
\hline & Porcentagem & Iotal & 0,14 & 0,86 & 1 \\
\hline
\end{tabular}

Estes resultados apontam para uma avaliação razoável da modelagem para subbacia do rio Bujaru, e por isso aceitável para este estudo, porém foi obtido um bom acerto da modelagem para a sub-bacia do rio Mariquita. Um ponto importante a ser levado em consideração é a necessidade de se rever algumas variáveis explicativas, tais como a obtenção de um mapa de solo mais detalhado e inserção de novas variáveis, como a distância a centro urbanos, aos sitemas florestais e às vias de acesso a propriedades, por exemplo (SOLER; VERBURG, 2010; LUO et al., 2010). Talvez seja interessante, em especial ao estudo da expansão da palma de óleo, analisarem-se as interações entre a dinâmica dessa cultura com relação às forçantes de mudança em uma escala menor, onde seja possível identificar com mais detalhamento a influência de variáveis como distância a hidrovias e rodovias, por exemplo.

A partir dos resultados visuais e estatísticos dos melhores modelos para ambas sub-bacias, aplicou-se o arquivo de demanda de 2013 a 2023, conjuntamente com os arquivos calibrados da matriz de conversão, as regressões com melhor ajuste e as elasticidades de melhor reposta, para se elaborar o mapa projetado da mudança espacial para 2023, sendo estes resultados apresentados na Figura 84. Esses mapas projetados foram então aplicados ao modelo SWAT calibrado, conforme item seguinte, para prever os impactos futuros do avanço de palma de óleo, bem como a mudança dos outros usos e coberturas da terra, sobre alguns aspectos hidrossedimentológicos.

Alguns trabalhos tem referenciado a utilização conjunta entre o Modelo CLUE-S e SWAT, no intuito de fazer previsões de mudanças nos fluxos hidrológicos, processos erosivos e na contaminação dos recursos hídricos, sendo um trabalho no Brasil 
(GALHARTE et al., 2014) e três na China (LIU et al., 2014; ZHANG et al., 2013; ZHOU et al., 2013). Os resultados mostram ser adequada a utilização dos dois modelos em conjunto, sendo possível gerar bons resultados quanto ao monitoramento, controle, gestão e planejamento ambiental, assim como para a construção de políticas públicas. Os trabalhos apontam também que o acoplamento do dois modelos oferece um novo método de contribuir para os estudos ambientais de maneira mais ampla e com maior riqueza de informações, representando de maneira mais eficiente e próximo da realidade o padrão de mudanças espaciais ao mesmo tempo que identifica áreas vulneráveis a degradação ambiental, fornecendo dados multidisciplinares de ordem qualitativa como quantitativa.

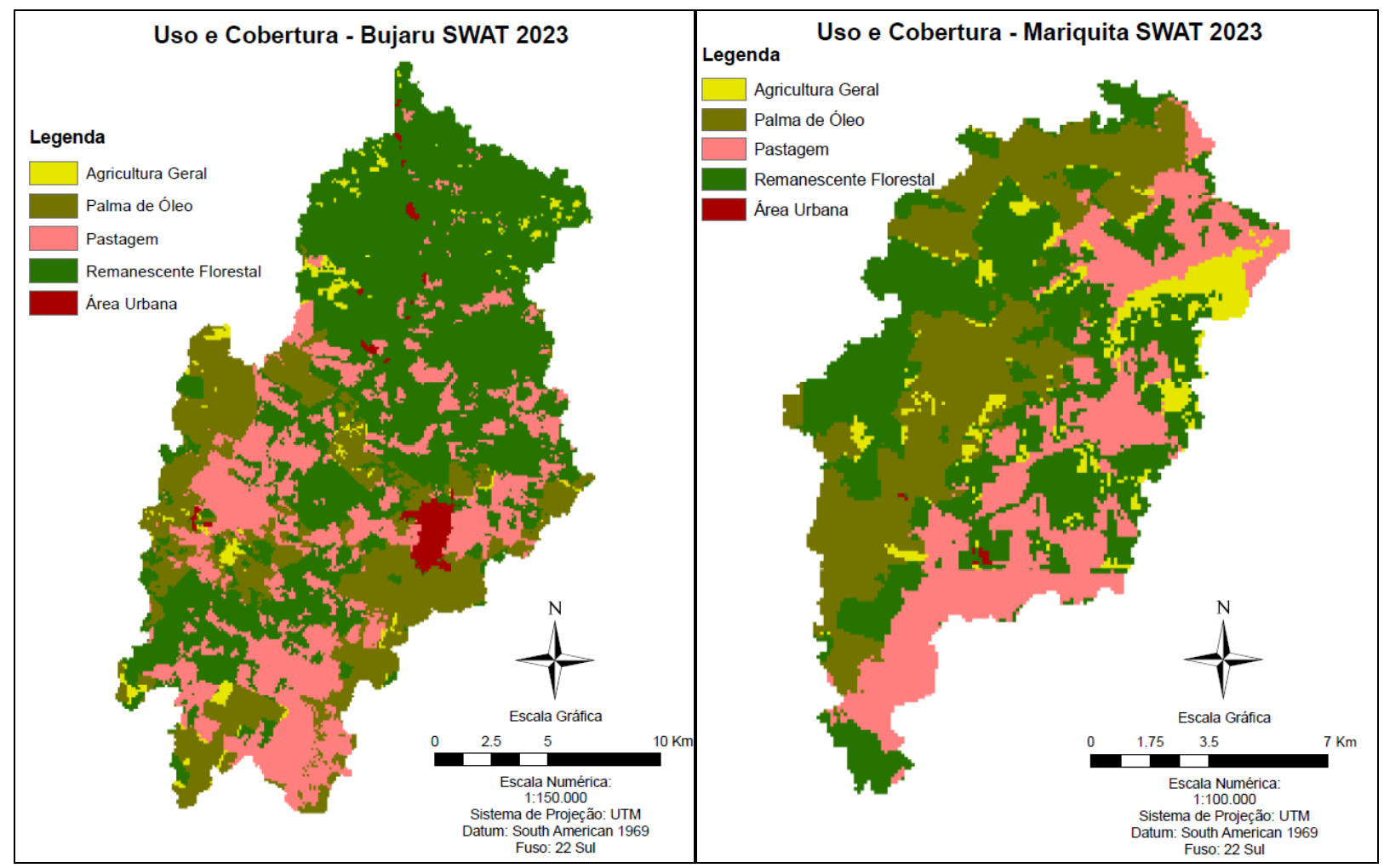

Figura 82: Mapa da projeção para 2023 com o CLUE-S das sub-bacias dos rios Bujaru e Mariquita. 


\subsection{EXPERIMENTO 3: ANÁLISE DE CENÁRIOS E INTEGRAÇÃO SWAT E CLUE-S.}

Incialmente são explicados os resultados de escoamento superficial, e em seguida os resultados de produção de sedimentos, sendo todos estes produtos da análise dos resultados médios das simulações entre os anos de 2006 a 2014 para o ano de $2008 \mathrm{com}$ pouca ou sem área de palma de óleo, para o ano de $2013 \mathrm{com}$ grande avanço da palma de óleo e o cenário projetado através do estudo de dinâmica espacial com o CLUE-S com o dobro de palma de óleo em relação a 2013 (2023). O presente trabalho discutiu os resultados das estimativas de produção de sedimento nos modelos, mas sem uma calibração específica para isto, porém levando em consideração que o modelo calibrado para vazão pode contribuir com resultados mais qualificados para a estimativa da produção de sedimentos.

As pesquisas têm aplicado de maneira integrada o estudo de dinâmica espacial com o uso de modelos para a geração de cenários futuros acoplados a modelagem hidrológica na perspectiva de predizer possíveis impactos nos serviços ecossistêmicos. Com o modelo CLUE-S integrado ao SWAT, tem-se o trabalho de Zhang et al. (2013) e Liu et al. (2014), direcionado para o estudo de dinâmica espacial sobre fontes não pontuais de poluição por macronutrientes na China; o trabalho de Galharte et al. (2014) aplicado para gerar cenários de expansão da cana e os impactos sobre escoamento superficial e produção de sedimentos em micro-bacias de São Paulo (Brasil); assim como a pesquisa de Zhou et al. (2013), que utilizou os dois modelos de forma integrada para avaliar as respostas hidrológicas da expansão de áreas urbanas na bacia do rio Yangtze na China. Molin (2014) utilizou o modelo de estudo de dinâmica espacial Dinâmica EGO em conjunto com o SWAT para avaliar respostas na produção de água do possível aumento de áreas de floresta de Mata Atlântica na bacia do rio Piracicaba, na região sudeste do Brasil.

Ressalta-se que o objetivo não é esgotar as possibilidades de análise da influência de mudança de cenário, e em especial da expansão da palma de óleo sobre estas sub-bacias, sobre o escoamento superficial e produção de sentimentos, mas sim contribuir com a análise de impacto ambiental, utilizando ferramentas como os modelos 
(CLUE_S e SWAT), o SIG e estatística. De modo geral visa contribuir com o estudo da gestão ambiental rural, especificamente em nível de bacias hidrográficas, colocando em discussão as ferramentas disponíveis, os dados e os resultados gerados, os quais podem contribuir na compreensão da influência dos diferentes usos e coberturas da terra nas estruturas e funções ecossistêmicas. Assim, pretende-se disponibilizar um conjunto de ferramentas para estimar alterações no regime de escoamento superficial e produção de sedimentos, contribuindo diretamente na gestão dos recursos naturais.

Observa-se a expansão considerável da palma de óleo (OILP), chegando a ocupar $11 \%$ da SBRB e $14 \%$ da SBRM, entre os anos de 2008 e 2013. A palma expande consideravelmente em toda a região nordeste do estado do Pará, chegando a quase triplicar sua área de cobertura entre 2008 e 2013 nas áreas de estudo da presente tese. Ocorre uma redução de áreas de agricultura geral (AGRL) (-92.2\%) e pastagem (PAST) (-43.5\%), entre 2008 e 2023 para a SBRB. Para o mesmo período, as áreas de remanescente florestal (FRSE_RF) sofrem leve redução nas duas subbacias, porém as áreas de vegetação secundária (FRSE_VS) aumentam consideravelmente na SBRB (149\%) e reduzem na SBRM (23\%). Para 2023, através do estudo de demanda, as áreas de OILP duplicam nas duas sub-bacias, as áreas de AGRL expandem $17 \%$ e a PAST reduz $3 \%$, resultando numa maior redução de áreas de vegetação secundária para SBRB (21\%) e SBRM (50\%), uma vez que as áreas de remanescente florestal permaneceram iguais de 2013 a 2023 (Tabela 68).

Torna-se importante destacar que na modelagem com o SWAT só existiu o uso "remanescente florestal" (FRSE), que aqui desmembramos em FRSE_RF e FRSE_VS, para melhor entendimento do contexto de mudança de uso e cobertura da terra nas sub-bacias dos rios Bujaru e Mariquita. Porém, a maior modificação se dá para FRSE_VS, mas quando for escrito apenas a sigla FRSE, isso quer dizer a classe de uso simulada no SWAT, integrando remanescente florestal e vegetação secundária. 
Tabela 68: Uso e cobertura da terra para os três períodos de modelagem.

\begin{tabular}{ccccccc}
\hline \multicolumn{7}{c}{ Bujaru } \\
\hline \multirow{2}{*}{ Classe de Uso e Cobertura } & \multicolumn{2}{c}{$\mathbf{2 0 0 8}$} & \multicolumn{2}{c}{$\mathbf{2 0 1 3}$} & \multicolumn{2}{c}{$\mathbf{2 0 2 3}$} \\
\cline { 2 - 7 } & Area (ha) & $\%$ & Area (ha) & $\%$ & Area (ha) & $\%$ \\
\hline Palma de Óleo & 260 & 0.7 & 4.220 & 11.1 & 8.441 & 22.1 \\
Agricultura Geral & 9.387 & 24.6 & 723 & 1.9 & 836 & 2.2 \\
Pastagem & 16.263 & 42.7 & 9.188 & 24.1 & 8.908 & 23.4 \\
Remanescente Florestal & 3.925 & 10.3 & 3.844 & 10.1 & 3.844 & 10.1 \\
Vegetação Secundária & 7.833 & 20.5 & 19.569 & 51.3 & 15.515 & 40.7 \\
Outros & 454 & 1.2 & 578 & 1.5 & 578 & 1.5 \\
\hline
\end{tabular}

Área Total da sub-bacia

38.122

Mariquita

\begin{tabular}{ccccccc}
\hline \multirow{2}{*}{ Classe de Uso e Cobertura } & \multicolumn{2}{c}{2008} & \multicolumn{2}{c}{$\mathbf{2 0 1 3}$} & \multicolumn{2}{c}{2023} \\
\cline { 2 - 7 } & Area (ha) & $\%$ & Area (ha) & $\%$ & Area (ha) & $\%$ \\
\hline Palma de Óleo & 0 & 0,0 & 2.308 & 14,4 & 4.619 & 28,9 \\
Agricultura Geral & 415 & 2,6 & 936 & 5,9 & 1.079 & 6,7 \\
Pastagem & 5.420 & 33,9 & 4.221 & 26,4 & 4.101 & 25,6 \\
Remanescente Florestal & 4.130 & 25,8 & 3.867 & 24,2 & 3.867 & 24,2 \\
Vegetação Secundária & 6.003 & 37,5 & 4.643 & 29,0 & 2.309 & 14,4 \\
Outros & 25 & 0,2 & 19 & 0,1 & 19 & 0,1 \\
\hline Área Total da sub-bacia & \multicolumn{7}{c}{$\mathbf{1 5 . 9 9 4}$} \\
\hline
\end{tabular}

Essas modificações expressivas de cenários, em especial a forte expansão da palma de óleo e forte redução das áreas de vegetação secundária, bem como a variação do tipo de solo, declividade e a distribuição das chuvas influenciarão diretamente nos processos de escoamento e produção de sedimentos. O comportamento de uma bacia em relação ao sedimento, por exemplo, está associado à geomorfologia, cobertura vegetal, regime de chuvas e outros fatores (MACHADO; VETTORAZZI, 2013).

$\mathrm{Na}$ Figura 83, são apresentados os dados de distribuição do escoamento superficial e da produção de sedimentos para a SBRB. É Possível observar a redução da produção de escoamento superficial e de sedimentos de 2008 a 2023. Esta subbacia possui apenas $10 \%$ de FRSE_RF, mas o aumento considerável de FRSE_VS de 2013 e 2023, em relação a 2008, implica numa redução de valores da curva número (CN) e consequente redução do escoamento superficial. A FRSE_VS, semelhante a um ecossistema de floresta primária, apresenta alta capacidade de manutenção de alguns 
serviços ecossistêmicos, como redução do impacto da chuva no solo, redução do escoamento superficial, manutenção da umidade, redução de perdas de água por evaporação direta e estocagem de carbono no solo, dando a este ecossistema características próximas das áreas de FRSE_RF (NEPSTAD et al., 2001). Por essa razão, a vegetação secundária foi simulada no SWAT com os mesmo parâmetros das áreas de remanescente florestal.

As bacias da montante $(13,14,15,16,18,19$, por exemplo) da SBRB foram as que apresentaram maior produção de escoamento em 2008 (189 a 264 mm), estando isso correlacionado com a maior presença de agropecuária (Figura 83). Mas passam a se caracterizar de maneira homogênea ao restante da sub-bacia nos cenários de 2013 e $2023 \mathrm{com}$ valores inferiores de escoamento superficial. Este processo coincide com a grande redução de áreas de PAST $(C N=62)$ e $A G R L(C N=69)$, assim como o aumento de área de FRSE_VS $(C N=49)$ e OILP $(C N=59)$. As sub-bacias da porção média e baixa apresentaram as menores faixas de escoamento (151 a $189 \mathrm{~mm}$ ), devido a forte presença da vegetação secundária e o avanço ainda maior deste uso em 2013 e 2023. Este comportamento se aplica também a produção de sedimentos que foi mais elevada na porção montante em 2008, homogeneizando-se as outras sub-bacias nos períodos seguintes.

O exemplo do efeito da mudança de uso e cobertura da terra sobre o escoamento superficial na SBRB é visualizado na sub-bacia 18, a qual passou em 2008 de uma representatividade quanto a OILP $(0,23 \%)$, AGRL $(37,78 \%)$, PAST $(35,05 \%)$ e FRSE (26,53\%) para uma paisagem fortemente alterada em 2013 (OPILP = 10,16\%; AGRL $=3,72 \% ;$ PAST $=35,78 \% ; \mathrm{FRSE}=49,97 \%$ ) e também no cenário projetado de 2023 (OPILP $=31,73 \% ;$ AGRL $=3,70 \% ;$ PAST $=32,00 \% ;$ FRSE $=32,20 \%$ ). Em especial com relação à substituição de áreas de AGRL por FRSE_VS de 2008 para 2013, assim como pelo avanço da OILP sobre a FRSE_VS de 2013 para 2023, tem-se uma redução do escoamento nessa sub-bacia. A sub-bacia 16, por sua vez, com $66.47 \%$ de PAST e ausência de OILP em 2008, passa a ter uma representatividade de $21,03 \%$ para OILP e $50,28 \%$ para FRSE em 2013 , e de $33,59 \%$ para OILP e $38,58 \%$ para FRSE em 2023. É interessante observar que em ambas sub-bacias, 18 e 16, apesar de uma redução de áreas com vegetação secundária, mantiveram-se na mesma 
faixa de escoamento (151 a $189 \mathrm{~mm}$ ), demonstrando um efeito positivo da palma de óleo em reduzir o impacto da chuva sobre o solo. Paralelamente, a produção de sedimentos teve uma queda de $53 \%$ na sub-bacia 18 e de $70 \%$ na sub-bacia 16 , relativo aos modelos de 2013 e 2023.

De maneira geral, a SBRB apresentou decréscimo no escoamento superficial e na produção de sedimentos em termos de acúmulo anual de longo período de 3.858,4 $\mathrm{mm}, 1.892,8 \mathrm{~mm}$ e $2.071 \mathrm{~mm}$ e de 5,7 t/ha, 1,6 t/ha e 1,6 t/ha (Tabela 69), para os modelos de 2008, 2013 e 2023, respectivamente, sendo o mesmo efeito visualizado no comportamento mensal para o acumulado médio da SBRB (Figura 84 e 85), em especial durante o período chuvoso (Janeiro a Junho). Quanto à produção de sedimentos, a dinâmica de redução das áreas de pastagens, em especial, bem como 0 avanço de áreas de palma de óleo e o aumento de áreas de vegetação secundária, possivelmente relacionado ao abandono de áreas agrícolas para o trabalho nas plantações de palma de óleo, tem favorecido a uma redução dos processos erosivos, sendo verificada uma redução de 109,2 t/ha, em 2008, para 29,8 em 2013 e 30,3 em 2023 (Tabela 69). 


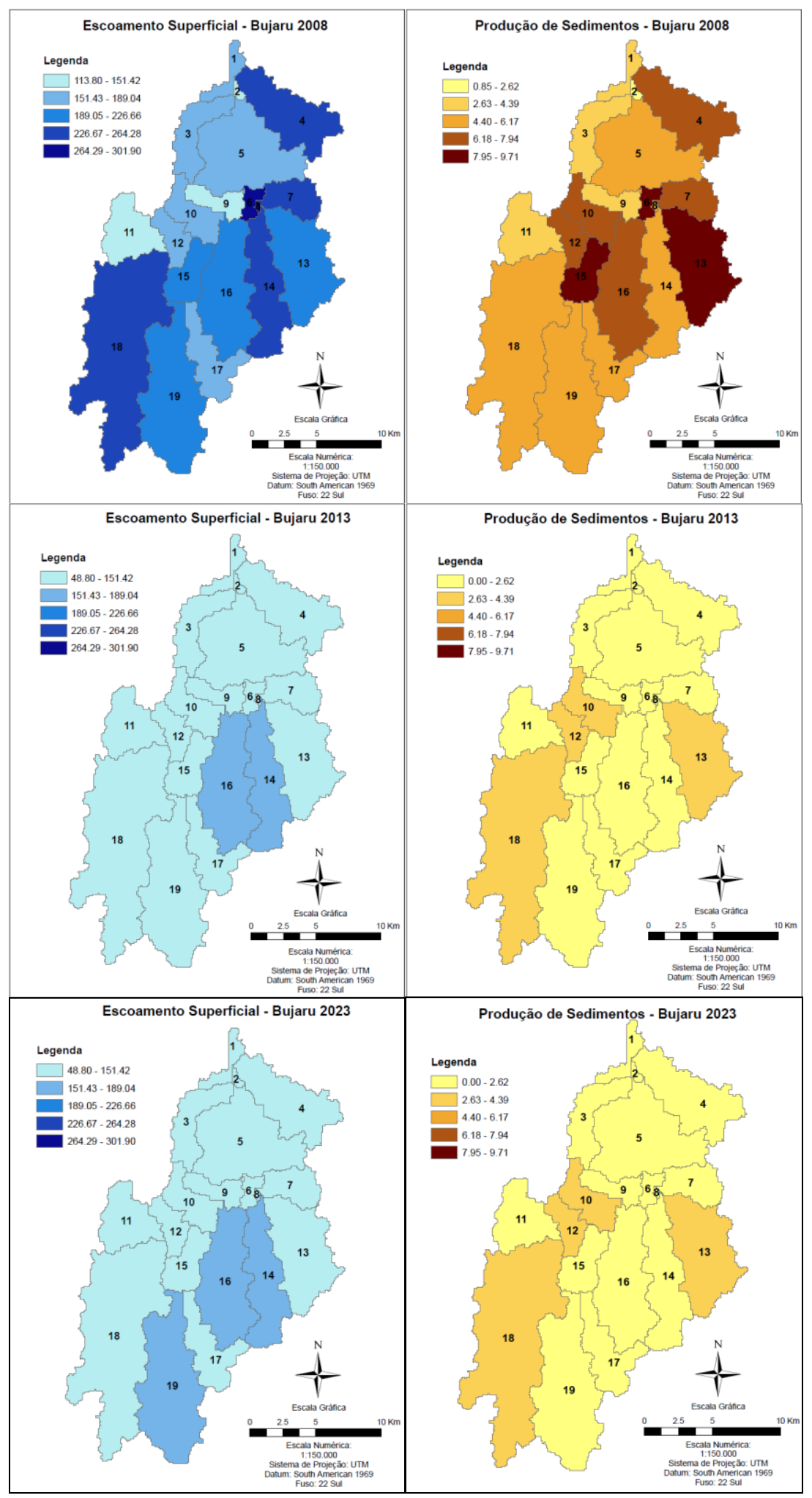

Figura 83: Distribuiação na sub-bacia do rio Bujaru do escoamento superficial $(\mathrm{mm})$ e da produção de sedimentos ( $\mathrm{t} / \mathrm{ha}$ ) para os modelos de 2008, 2013 e 2023. 


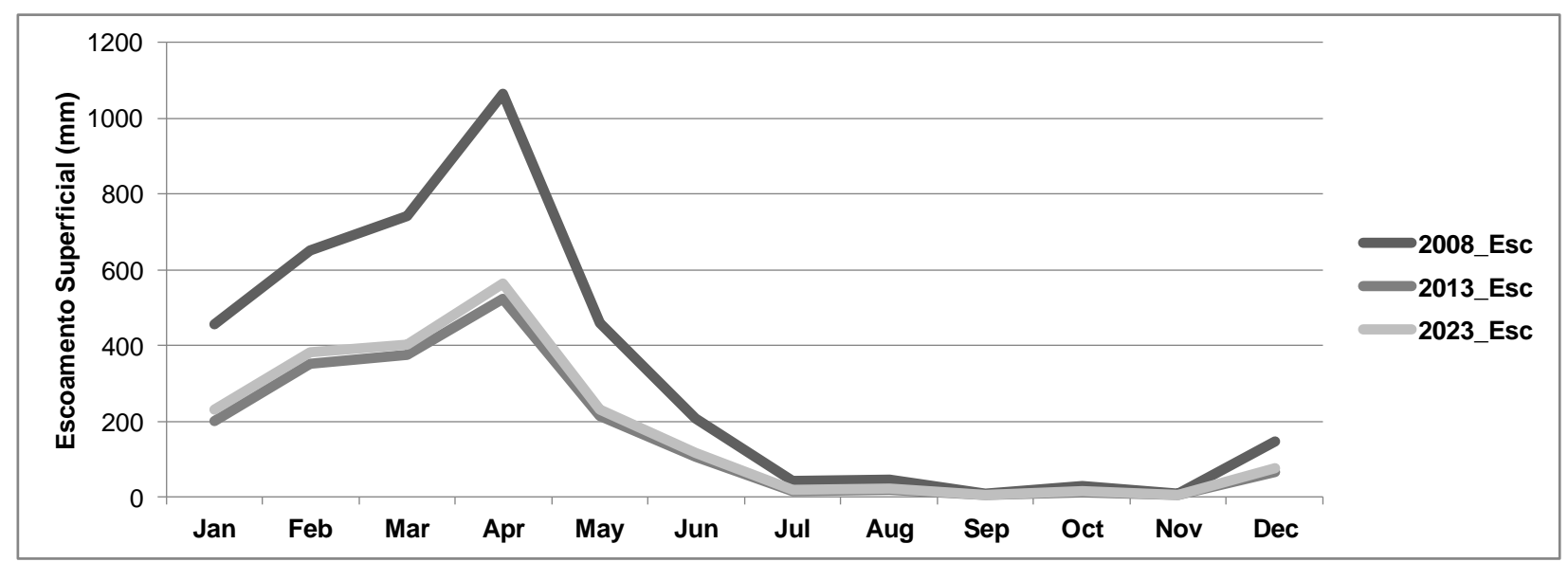

Figura 84: Comparação da variação temporal do escoamento superficial total mensal médio (mm) nos três modelos da sub-bacia do rio Bujaru.

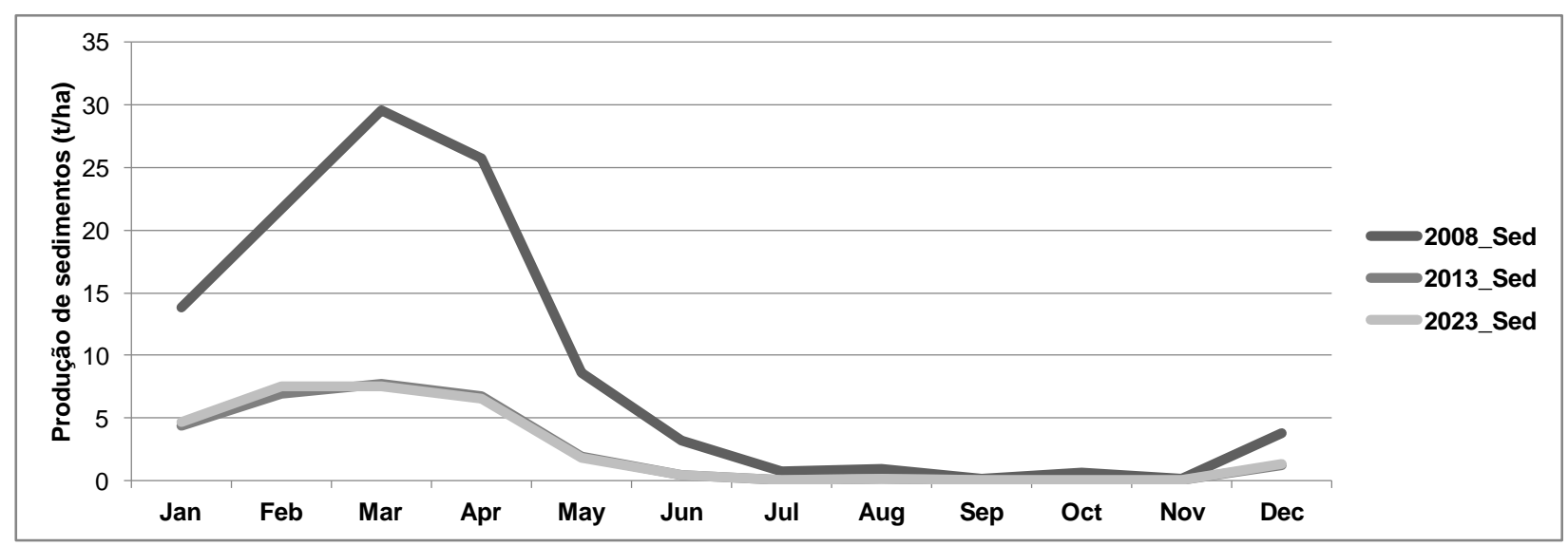

Figura 85: Comparação da variação temporal da produção de sedimentos total mensal média (t/ha) nos três modelos da sub-bacia do rio Bujaru.

Na sub-bacia do rio Mariquita (SBRM) a produção do escoamento superficial e de sedimentos, em quantidades totais, apresentou comportamento inverso a SBRB em relação aos cenários de 2008 (2.314,9 mm; 41,1 t/ha), $2013(2.752,0 \mathrm{~mm} ; 47,7$ t/ha) e 2023 (3.208,8 mm; 65,6 t/ha), sendo os maiores valores observados para o ano de 2023 (Tabela 70). Este aumento de escoamento e da produção de sedimentos de 2008 para 2013 e depois para 2023 é reflexo de uma dinâmica espacial diferenciada na SBRM, especialmente em relação à redução das áreas com FRSE_VS $(C N=50)$ e ao aumento de área de AGRL, o que ocorre de maneira inversa na SBRB (Figura 86). Os gráficos dos acumulados mensais de longo período também demonstram, mesmo que de maneira menos acentuada que na SBRB, o aumento do escoamento superficial e da produção de sedimentos na SBRM (Figura 87 e 88). 
Tabela 69: Escoamento superficial e produção de sedimentos nas 19 sub-bacias do rio Bujaru.

\begin{tabular}{|c|c|c|c|c|c|c|}
\hline \multirow{2}{*}{ Sub-bacias } & \multicolumn{3}{|c|}{ Escoamento Acumulado (mm) } & \multicolumn{3}{|c|}{ Produção de Sedimentos (t/ha) } \\
\hline & 2008_Esc & 2013_Esc & 2023_Esc & 2008_Sed & 2013_Sed & 2023_Sed \\
\hline 1 & 184.0 & 70.3 & 88.4 & 4.019 & 0.683 & 0.670 \\
\hline 2 & 113.8 & 48.8 & 48.8 & 0.851 & 0.005 & 0.005 \\
\hline 3 & 161.0 & 81.6 & 97.0 & 4.163 & 1.344 & 1.395 \\
\hline 4 & 245.8 & 67.2 & 63.2 & 6.285 & 0.714 & 0.491 \\
\hline 5 & 182.1 & 61.3 & 69.4 & 5.390 & 0.610 & 0.566 \\
\hline 6 & 274.2 & 81.4 & 81.4 & 8.984 & 1.471 & 1.471 \\
\hline 7 & 255.8 & 64.0 & 62.7 & 7.130 & 0.763 & 0.655 \\
\hline 8 & 301.9 & 48.9 & 48.9 & 4.741 & 0.003 & 0.003 \\
\hline 9 & 125.4 & 66.9 & 92.0 & 3.659 & 0.961 & 1.011 \\
\hline 10 & 185.6 & 132.2 & 136.6 & 7.340 & 3.066 & 2.884 \\
\hline 11 & 131.2 & 127.9 & 146.3 & 3.680 & 1.660 & 1.885 \\
\hline 12 & 159.5 & 119.0 & 128.4 & 6.196 & 2.657 & 2.733 \\
\hline 13 & 211.3 & 106.9 & 111.1 & 8.356 & 2.922 & 2.963 \\
\hline 14 & 258.4 & 162.0 & 179.0 & 5.945 & 1.719 & 1.966 \\
\hline 15 & 225.8 & 113.2 & 114.3 & 9.709 & 2.572 & 2.581 \\
\hline 16 & 226.2 & 160.0 & 170.2 & 6.463 & 1.837 & 1.971 \\
\hline 17 & 180.5 & 124.0 & 135.1 & 5.967 & 1.944 & 1.855 \\
\hline 18 & 228.0 & 127.8 & 141.1 & 5.830 & 2.780 & 2.731 \\
\hline 19 & 208.0 & 129.6 & 158.0 & 4.476 & 2.134 & 2.450 \\
\hline TOTAL & 3858.4 & 1892.8 & 2071.8 & 109.2 & 29.8 & 30.3 \\
\hline MÉDIA & 203.1 & 99.6 & 109.0 & 5.7 & 1.6 & 1.6 \\
\hline
\end{tabular}

As sub-bacias a montante da SBRM apresentaram praticamente os mesmos quantitativos de escoamento superficial e de produção de sedimentos, mas com algumas exceções. Por exemplo, a sub-bacia 8 apresentou estimativas reduzidas de 2008 para 2013 devido a substituição de quase 90\% das áreas de pasto e cerca de $40 \%$ das áreas FRSE por OILP, e por outra análise, a sub-bacia 11 que teve o domínio de PAST $(C N=63)$ na projeção para 2023 , assim como a sub-bacia 7 , com aumento da representatividade de áreas de PAST (22\%) e OILP (10\%) em substituição as áreas de vegetação secundária, que sofrem forte redução como um todo na SBRM.

As sub-bacias a jusante ( 1,3 e 5$)$ foram as que tiveram maior variação no aumento do escoamento superficial e produção de sedimentos, porém com forçantes diferentes para cada sub-bacia. A sub-bacia 1 teve a representação de área com FRSE de $78 \%$ em 2008, 86\% em 2013, mas no cenário projetado para 2023 apresentou uma forte queda em seus valores (23\%), além de uma redução em $79 \%$ na área de pasto 
em 2013 e um forte aumento em 2023, dominando cerca de 69\% da sub-bacia. Semelhante, a de número 5 sofreu uma redução de FRSE e aumento progressivo de PAST e AGRL. Já com relação à sub-bacia de número 3 , reduziu-se mais da metade de áreas de FRSE e ocorreu a expansão da OILP e das Áreas de AGRL. Contudo, essas mudanças são pequenas em relação SBRM como um todo, mas chamam a atenção para uma manutenção dos fenômenos hidrológicos, mesmo havendo um aumento intensivo de áreas de palma de óleo na SBRM, sendo que este uso de 2008, com nenhum hectare plantado, passa ocupar 14\% em 2013 e 28,9\% em 2023. A expansão da palma de óleo se dá em especial nas sub-bacias 3, 6 e 10. As sub-bacias 6 e 10, em especial, apresentam uma grande ocupação de ecossistemas de florestas (FRSE_RF e FRSE_VS) em 2008 e 2013 e a OILP avança sobre as áreas de PAST e AGRL nesse primeiro momento, avançando sobre áreas de vegetação secundária no cenário projetado de 2023. Contudo, a substituição de áreas de PAST e AGRL por palma de óleo não afetam negativamente a produção de escoamento superficial e sedimentos, apenas no ano de 2013 para o sub-bacia 3, e no cenário de 2023 para a sub-bacia 8, pois a palma avança sobre áreas de vegetação secundária, as quais promovem menor escoamento e menor produção de sedimentos do que as áreas de palma de óleo. 


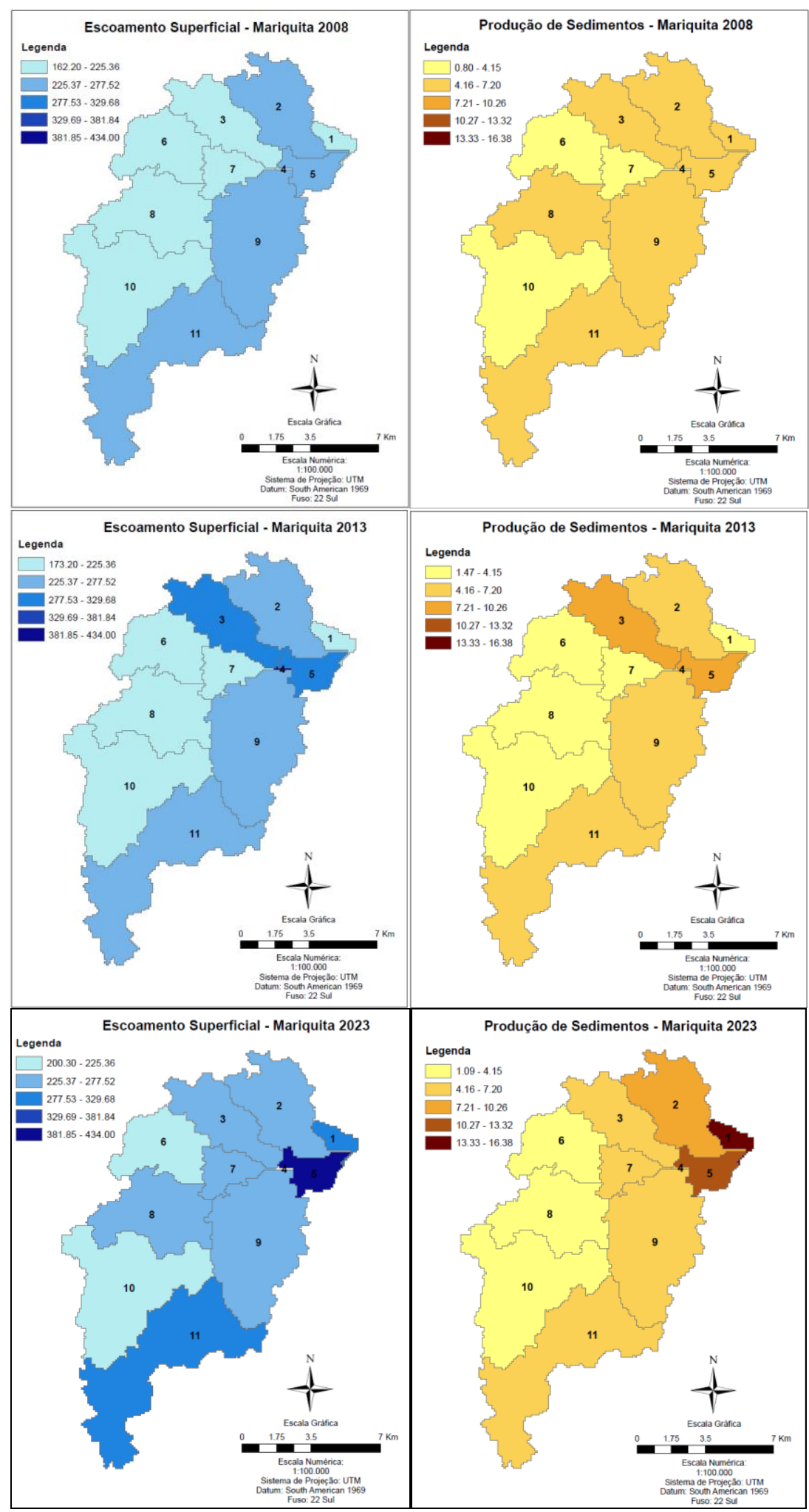

Figura 86: Distribuição na sub-bacia do rio Mariquita do escoamento superficial $(\mathrm{mm})$ e da produção de sedimentos (t/ha) para os modelos de 2008, 2013 e 2023. 


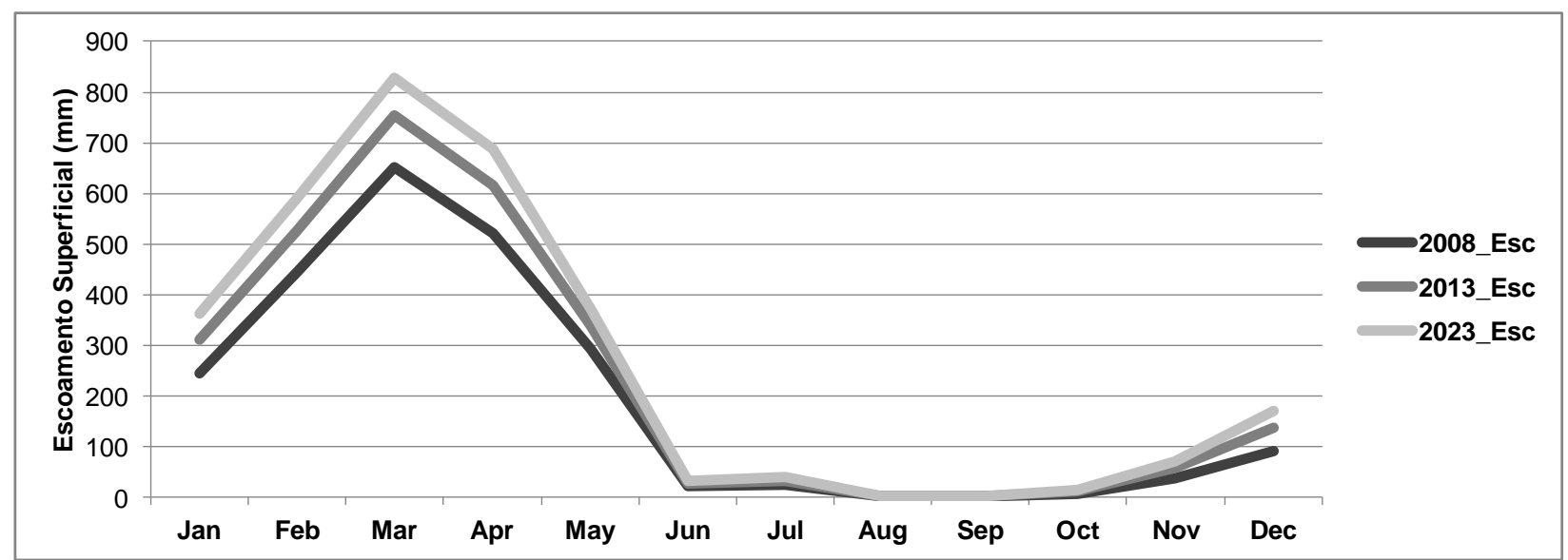

Figura 87: Comparação da variação temporal do escoamento superficial total mensal médio (mm) nos três modelos da sub-bacia do rio Mariquita.

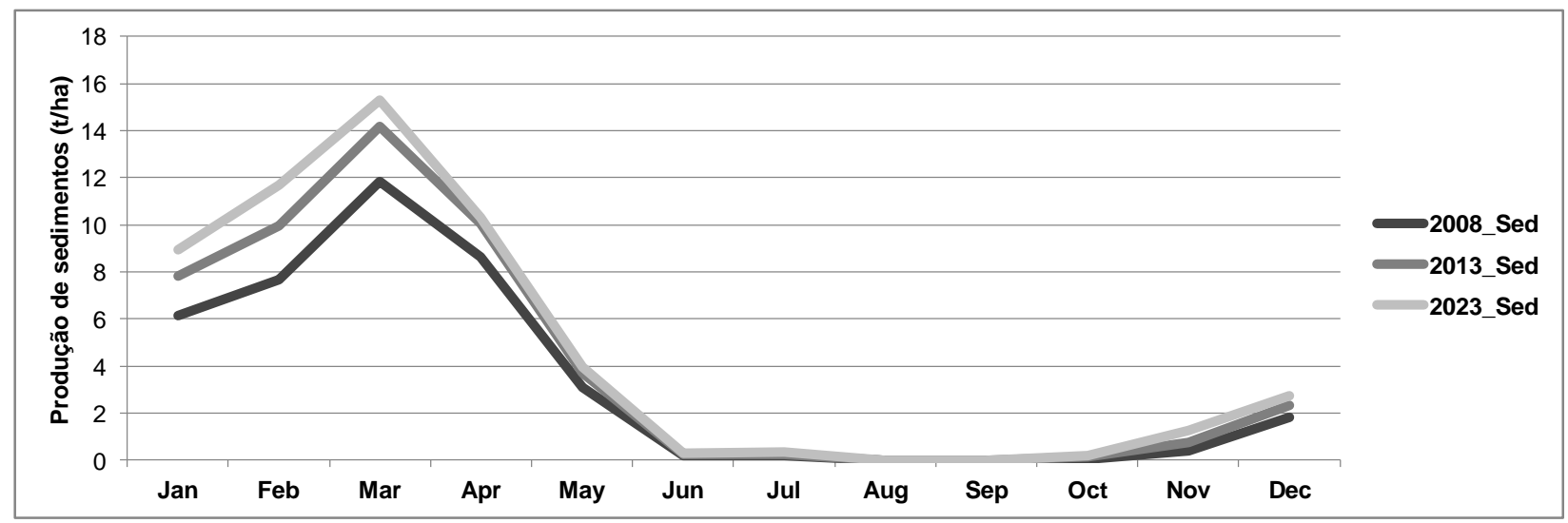

Figura 88: Comparação da variação temporal da produção de sedimentos total mensal média (t/ha) nos três modelos da sub-bacia do rio Mariquita.

Tabela 70: Escoamento superficial e produção de sedimentos nas 11 sub-bacias do rio Mariquita.

\begin{tabular}{lccccccc}
\hline & \multicolumn{2}{c}{ Escoamento Acumulado } & & \multicolumn{3}{c}{ Produção de Sedimentos } \\
\cline { 1 - 3 } Sub-bacias & 2008_Esc & 2013_Esc & 2023_Esc & & 2008_Sed & 2013_Sed & 2023_Sed \\
\hline $\mathbf{1}$ & 188.6 & 184.6 & 326.3 & & 4.662 & 2.521 & 16.381 \\
$\mathbf{2}$ & 250.8 & 267.2 & 276.8 & & 6.613 & 7.067 & 7.344 \\
$\mathbf{3}$ & 221.3 & 283.2 & 271.6 & & 4.158 & 8.599 & 5.320 \\
$\mathbf{4}$ & 162.2 & 434.0 & 474.5 & & 0.804 & 4.506 & 5.786 \\
$\mathbf{5}$ & 245.2 & 289.4 & 432.3 & & 5.704 & 7.659 & 10.275 \\
$\mathbf{6}$ & 185.5 & 202.6 & 201.9 & & 2.055 & 1.466 & 1.086 \\
$\mathbf{7}$ & 193.0 & 173.2 & 231.8 & & 2.086 & 2.082 & 5.283 \\
$\mathbf{8}$ & 207.8 & 220.0 & 227.5 & & 4.375 & 1.676 & 1.389 \\
$\mathbf{9}$ & 231.0 & 254.9 & 267.7 & & 4.456 & 5.669 & 5.338 \\
$\mathbf{1 0}$ & 169.8 & 181.1 & 200.3 & & 2.012 & 1.734 & 1.431 \\
$\mathbf{1 1}$ & 259.8 & 261.9 & 298.0 & & 4.167 & 4.695 & 5.961 \\
TOTAL & $\mathbf{2 3 1 4 . 9}$ & $\mathbf{2 7 5 2 . 0}$ & $\mathbf{3 2 0 8 . 8}$ & & $\mathbf{4 1 . 1}$ & $\mathbf{4 7 . 7}$ & $\mathbf{6 5 . 6}$ \\
MÉDIA & $\mathbf{2 1 0 . 4}$ & $\mathbf{2 5 0 . 2}$ & $\mathbf{2 9 1 . 7}$ & & $\mathbf{3 . 7}$ & $\mathbf{4 . 3}$ & $\mathbf{6 . 0}$ \\
\hline
\end{tabular}


A influência da mudança da $\mathrm{CN}$ sobre o escoamento superficial observado neste estudo é bem descrita no trabalho de Marchioro (2008), o qual identificou, após a calibração do modelo SWAT para a bacia do córrego Santa Maria com predominância de solos do tipo CAMBISSOLO Háplico, ARGISSOLO VERMELHO-AMARELO e NEOSSOLO, uma alteração considerável no aumento da percolação e na minimização do escoamento superficial, com consequente redução da produção média de sedimentos nas HRU's. Esse comportamento demonstra a importância desse parâmetro no ajuste do balanço de água. Peterson e Hamlett (1998) já haviam identificado as respostas da variabilidade da vazão e escoamento superficial em relação à $\mathrm{CN}$, em especial a redução desses componentes quando se tem a redução do valor de CN na sub-bacia Ariel Creek, na Pensilvânia (USA).

Mais recentemente na Corea do Sul, Kim et al. (2010) também apontaram a importância da calibração de CN para predição correta dos picos de vazão, reforçando que a vantagem do método está ligada a capacidade das sub-bacias do modelo levarem em consideração as características heterogêneas da bacia em que estão inseridas, tais como declividade, uso e cobertura da terra e tipo de solo. Em ambas subbacias SBRB e SBRM, a análise da influência da dinâmica de uso e cobertura da terra sobre os componentes hidrossedimentológicos é favorecida por razão das bacias apresentarem mesmo tipo de solo predominante e declividades planas e suavemente onduladas em sua maioria.

Compreender o componente escoamento superficial é importante para se verificar o impacto dos diferentes usos e coberturas sobre aspectos importantes como a perda de solos e contaminação da água. Chaubey et al. (2010) avaliaram os efeitos de diferentes práticas de manejo em áreas de pastagem sobre o processo de perdas de nutrientes e a relação com áreas de amortecimento, como as matas ciliares. Os autores apontam o carreamento da adubação pelo escoamento superficial, afetando em especial os primeiros $10 \mathrm{~mm}$ do solo, bem como demonstram a importância das áreas ripárias na proteção contra a perda desses nutrientes devido ao escoamento que vem de áreas de pastagens. Easton et al. (2010), estimaram o escoamento superficial e a perda de solo na bacia do Blue Nile, na Etiópia, em sub-bacias com área variando de 1,3 a $174,000 \mathrm{Km}^{2}$, identificando o aumento do escoamento relacionado aos eventos de 
chuva, às características do solo raso e ao aumento do tamanho da área de contribuição. Estes resultados implicaram ainda que a medição em sub-bacias menores pode auxiliar no controle de erosão e proteger os recursos hídricos. De maneira geral, assim como a percolação e o fluxo de água subterrânea, o escoamento é um fluxo dominante no sistema hídrico, totalmente dependente dos eventos de precipitação, sejam extremos ou normais (MIGLIACCIO; CHAUBEY, 2008). Costa et al. (2013) acrescenta ainda que os principais fatores que contribuem para o aumento do escoamento superficial são a quantidade, intensidade, duração e distribuição da precipitação, interceptação da cobertura vegetal, demanda atmosférica, impermeabilização do solo, desflorestamento, movimentação de terra, ocupação inadequada do solo e declividade.

Outros estudos têm avaliado os impactos de diferentes cenários de uso e cobertura nos fluxos de vazão, escoamento superficial, evapotranspiração e produção de sedimentos, porém sobre diferentes óticas de análise e utilizando o SWAT acoplado a diferentes metodologias (MACHADO; VETTORAZZI, 2003; NEVES; SILVA; CRESTANA et al., 2006; DURAES et. al., 2011; UZEIKA et al. 2012; ROCHA et al., 2012; STRAUCH et al. 2013; SILVA et al. 2013; PEREIRA et al., 2014a; PEREIRA et al., 2014b; BONUMA et al., 2014; GALHARTE et al., 2014; CREECH et al., 2015; SOUSA et al., 2015; FUKUNAGA et al, 2015, BRESSIANI et al., 2015b). Tais estudos tem buscado utilizar o modelo SWAT em algumas ocasiões acoplado a modelos e técnicas de análise climática e de dinâmica espacial e a cenários, com objetivos de compreender, avaliar e propor modelos de gestão dos recursos naturais através do aporte de informações importantes como a modelagem do balanço hídrico, em especial a vazão, evapotranspiração e o escoamento superficial, para determinar os impactos dos diferentes usos e coberturas da terra, bem como das diferentes técnicas de manejo do solo relacionado aos aspectos biofísicos das bacias, sobre os processos erosivos, contribuindo assim para a conservação do solo e da água.

Complementarmente a análise feita até aqui, as Figuras 89 e 90 apresentam os resultados específicos de variação do escoamento superficial e da produção de sedimentos para a SBRB e SBRM nos modelos de 2008, 2013 e 2023 de maneira proporcional. Fica claro, apesar da baixa variação de declividade, que as sub-bacias a 
montante apresentaram maiores valores de escoamento e sedimentos para a SBRB, porém não se observa o mesmo resultado para a SBRM, devido a uma maior homogeneidade da declividade. Porém, conforme discutido anteriormente, as características de uso e cobertura da terra em ambas sub-bacias, estão sendo as principais forçantes dessa distribuição do escoamento superficial e da produção de sedimentos. Ressalta-se também que ocorre a coincidência entre o crescimento e a redução do escoamento superficial e a produção de sedimentos, ou seja, há uma relação diretamente proporcional entre estes fluxos ecossistêmicos tanto na SBRB como na SBRM.

É importante ressaltar que de maneira geral, conforme Figura 89 e 90 e levando em consideração o domínio de LATOSSOLO AMARELO Distrófico na SBRB e SBRM, as sub-bacias delineadas pelo SWAT apresentaram resultados de produção de sedimentos bem abaixo do limite de tolerância de perda de solo de 12,15 t/ha.ano (VIEIRA; VIEIRA, 1990) e 12,7 t/ha.ano (NUNES et al., 2012), com a exceção da subbacia 1 da SBRM, a qual teve sua área ocupada por PAST em $68.81 \%$ em 2023. Sendo a tolerância de perda de solo a quantidade que é possível ser perdida de terra sem prejudicar o nível de produtividade da área (BERTONI; LOMBARDI NETO, 1999), é fundamental se compreender se as bacias em estudo excedem ou não esses limites, em especial para verificar se o avanço da Palma de Óleo pode ou não acarretar problemas maiores de erosividade com relação aos outros usos e coberturas da região. 


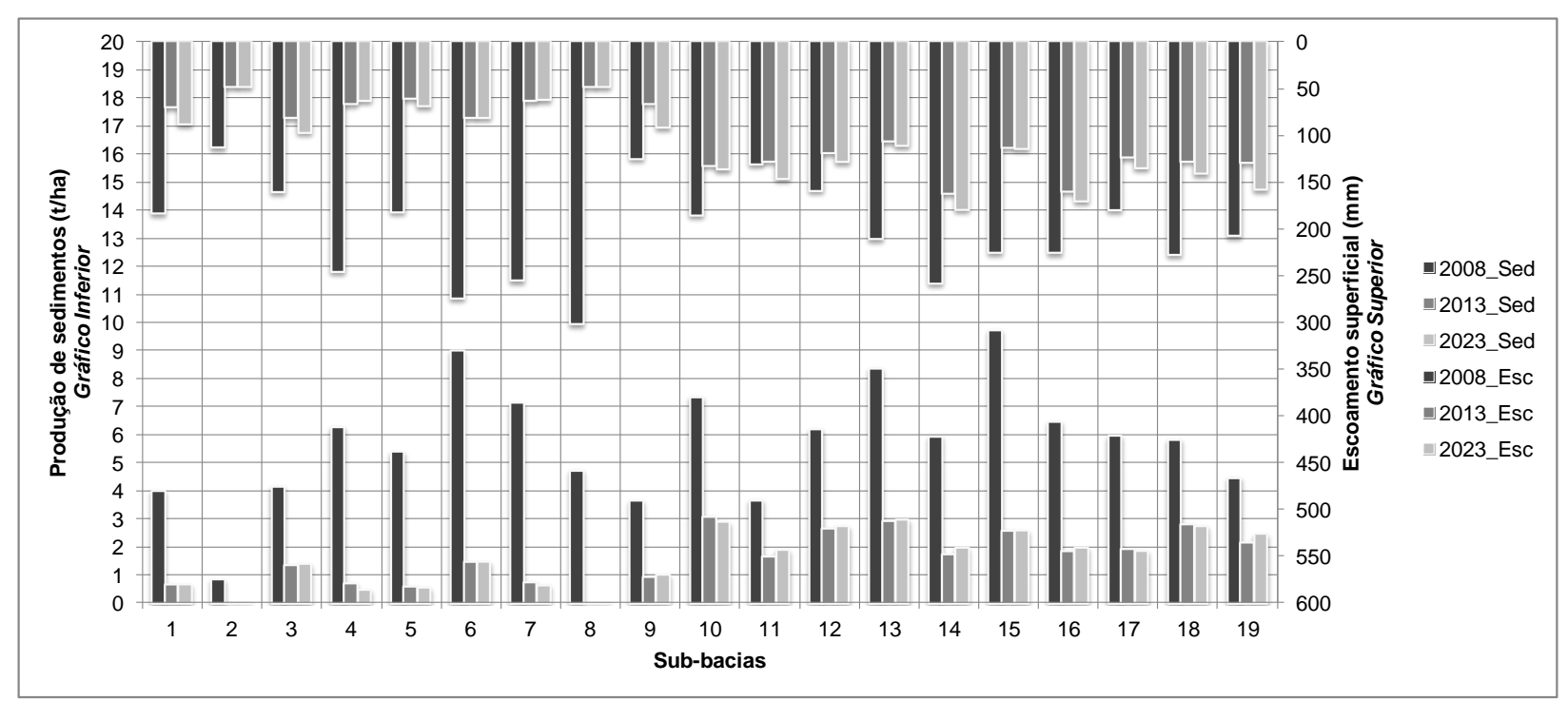

Figura 89: Escamento superficial e produção de sedimentos nas 19 sub-bacias do rio Bujaru.

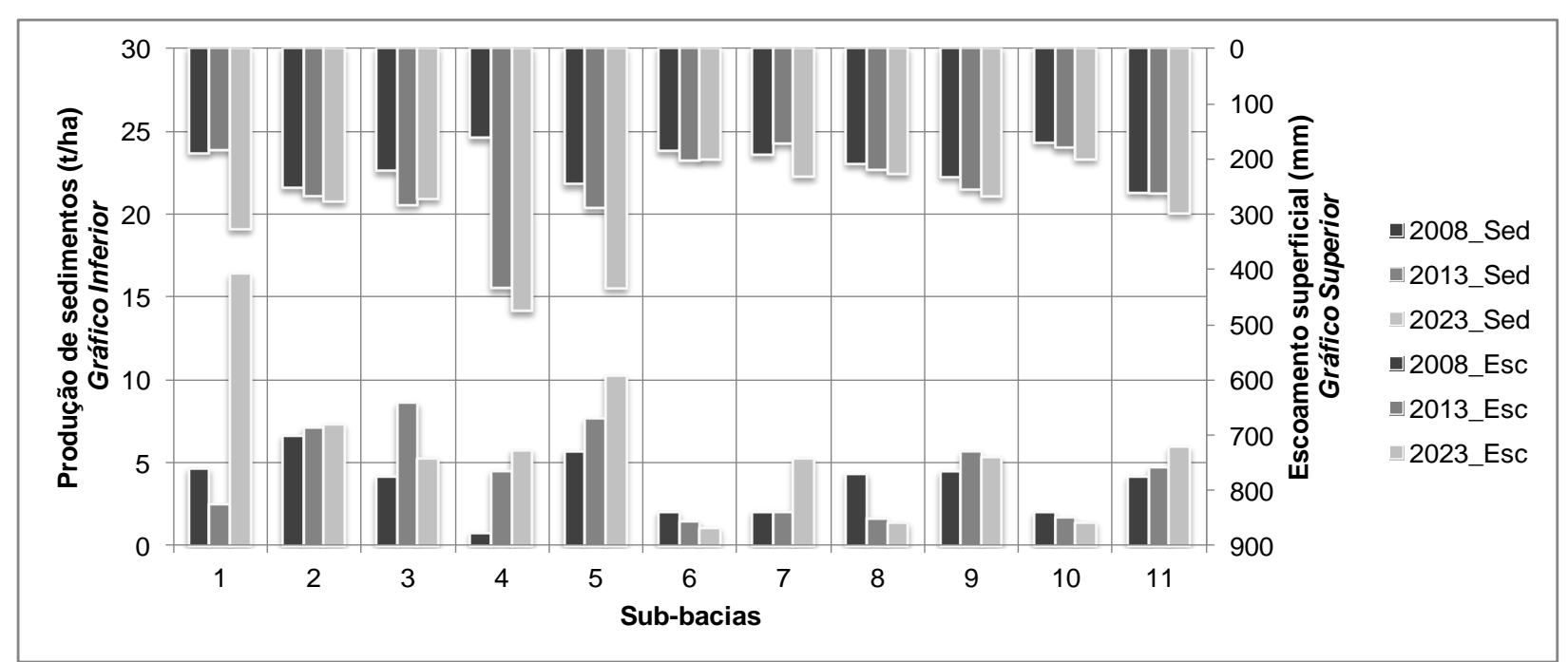

Figura 90: Escoamento superficial e produção de sedimentos nas 11 sub-bacias do rio Mariquita.

Especificamente, avaliaram-se os resultados da produção do escoamento superficial e de sedimentos para cada uso e cobertura da terra de interesse ao processo de dinâmica espacial deste estudo, que são as áreas de palma de óleo (OILP), agricultura geral (AGRL), pastagem (PAST) e remanescente florestal (FRSE). Lembrando que os resultados para FRSE correspondem aos resultados da união entre remanescente florestal e vegetação secundária, para as simulações com o SWAT.

Os resultados não identificaram, dentro de cada uso e cobertura, influência expressiva da variação da declividade, porém foi possível observar claramente que as áreas AGRL, seguida das áreas de PAST, foram as que mais produziram escoamento e 
consequentemente mais sedimentos nas duas sub-bacias em todos os cenários (Tabela 71 e 72). As áreas de palma de óleo, contrariamente, apresentaram menor produção de escoamento e sedimentos em relação à AGRL e PAST em todos os cenários. As áreas de FRSE apresentaram as menores estimativas. Um ponto importante é que a baixa estimativa da produção de sedimentos nas HRU's com palma de óleo foi muito próxima da FRSE, podendo está relacionado ao Fator C (CUSLE) da Equação Universal da Perda de Solos Modificada (MUSLE) semelhante entre essas duas classes, sendo este fator responsável por determinar a magnitude do impacto das características de manejo e cobertura da terra sobre a erosão.

Tabela 71: Média anual de longo período do escoamento superficial (Escoa) e da produção de sedimentos (Sedim) entre os anos de 2006 e 2014 para a sub-bacia do rio Bujaru nos três anos de uso e cobertura da terra por declividade.

\begin{tabular}{|c|c|c|c|c|c|c|}
\hline \multirow[b]{2}{*}{ Classes } & \multicolumn{2}{|c|}{2008} & \multicolumn{2}{|c|}{2013} & \multicolumn{2}{|c|}{2023} \\
\hline & $\begin{array}{c}\text { Escoa } \\
(\mathrm{mm})\end{array}$ & $\begin{array}{c}\text { Sedim } \\
\text { (t/ha) }\end{array}$ & $\begin{array}{c}\text { Escoa } \\
(\mathbf{m m})\end{array}$ & $\begin{array}{c}\text { Sedim } \\
\text { (t/ha) }\end{array}$ & $\begin{array}{c}\text { Escoa } \\
(\mathrm{mm})\end{array}$ & $\begin{array}{c}\text { Sedim } \\
\text { (t/ha) }\end{array}$ \\
\hline & \multicolumn{6}{|c|}{ Declividade 0-3 } \\
\hline OILP & 12,006 & 0,034 & 12,058 & 0,040 & 12,102 & 0,040 \\
\hline AGRL & 31,465 & 0,292 & 31,660 & 0,246 & 31,674 & 0,247 \\
\hline PAST & 18,179 & 0,273 & 18,072 & 0,234 & 18,071 & 0,233 \\
\hline \multirow[t]{2}{*}{ FRSE } & 4,700 & 0,000 & 4,055 & 0,000 & 4,018 & 0,000 \\
\hline & \multicolumn{6}{|c|}{ Declividade 3-13 } \\
\hline OILP & 11,972 & 0,125 & 12,036 & 0,158 & 12,081 & 0,167 \\
\hline AGRL & 31,432 & 1,080 & 31,642 & 0,917 & 31,646 & 0,848 \\
\hline PAST & 18,136 & 1,171 & 18,039 & 0,934 & 18,038 & 0,927 \\
\hline \multirow[t]{2}{*}{ FRSE } & 4,668 & 0,002 & 4,015 & 0,001 & 3,998 & 0,001 \\
\hline & \multicolumn{6}{|c|}{ Declividade 13-20 } \\
\hline OILP & 11,301 & 0,186 & 11,052 & 0,177 & 11,586 & 0,256 \\
\hline AGRL & 31,262 & 2,104 & - & - & - & - \\
\hline PAST & 17,665 & 1,874 & 17,456 & 1,580 & 17,456 & 1,580 \\
\hline FRSE & 4,514 & 0,003 & 3,861 & 0,001 & 3,852 & 0,001 \\
\hline
\end{tabular}


Tabela 72: Média anual de longo período do escoamento superficial (Escoa) e da produção de sedimentos (Sedim) entre os anos de 2006 e 2014 para a sub-bacia do rio Mariquita nos três anos de uso e cobertura da terra por declividade.

\begin{tabular}{|c|c|c|c|c|c|c|}
\hline \multirow[b]{2}{*}{ Classes } & \multicolumn{2}{|c|}{2008} & \multicolumn{2}{|c|}{2013} & \multicolumn{2}{|c|}{2023} \\
\hline & $\begin{array}{l}\text { Escoa } \\
(\mathrm{mm})\end{array}$ & $\begin{array}{c}\text { Sedim } \\
(\mathrm{t} / \mathrm{ha})\end{array}$ & $\begin{array}{l}\text { Escoa } \\
(\mathrm{mm})\end{array}$ & $\begin{array}{c}\text { Sedim } \\
\text { (t/ha) }\end{array}$ & $\begin{array}{l}\text { Escoa } \\
(\mathrm{mm})\end{array}$ & $\begin{array}{c}\text { Sedim } \\
\text { (t/ha) }\end{array}$ \\
\hline & \multicolumn{6}{|c|}{ Declividade 0-3 } \\
\hline OILP & 23,273 & 0,054 & 22,503 & 0,045 & 22,698 & 0,052 \\
\hline AGRL & 44,265 & 0,339 & 44,753 & 0,359 & 44,753 & 0,370 \\
\hline PAST & 30,303 & 0,467 & 30,304 & 0,422 & 30,247 & 0,511 \\
\hline \multirow[t]{2}{*}{ FRSE } & 11,315 & 0,001 & 11,286 & 0,001 & 11,286 & 0,001 \\
\hline & \multicolumn{6}{|c|}{ Declividade 3-13 } \\
\hline OILP & & & 22.449 & 0.293 & 22.715 & 0.287 \\
\hline AGRL & 44,221 & 1,442 & 44,647 & 1,716 & 44,642 & 1,878 \\
\hline PAST & 30,199 & 2,225 & 30,205 & 2,113 & 30,203 & 2,056 \\
\hline \multirow[t]{2}{*}{ FRSE } & 11,269 & 0,005 & 11,269 & 0,005 & 11,238 & 0,005 \\
\hline & \multicolumn{6}{|c|}{ Declividade 13-20 } \\
\hline FRSE & 11,303 & 0,008 & 11,30292 & 0,007593 & 11,30292 & 0,007593 \\
\hline
\end{tabular}

As áreas de AGRL apresentaram média anual de longo período entre todas as declividades e cenários para escoamento superficial e produção de sedimento, respectivamente, de 31,5 e 0,82 para SBRB e de 44,5 e 1,02 para a SBRM. Os valores médios da Pastagem, uso este reconhecido por causar degradação do solo se mal manejado, apresentaram valores médios de escoamento e produção de sedimentos, entre ambas declividades e períodos de modelagem, de 17,9 mm e 0,98 t/ha.ano para SBRB e de $30,2 \mathrm{~mm}$ e 1,29 t/ha.ano para a SBRM. Os maiores valores observados na SBRM podem estar relacionados aos maiores índices pluviométricos nesta bacia, assim como o maior valor do coeficiente de erodibilidade (Fator K) da SBRM $(0,138)$ em relação a SBRB $(0,125)$ (MACHADO, 2002; VILLELA, 2015), uma vez que a declividade entre as SBHB e SBRM são iguais e as classes de uso semelhantes, tendo influências próximas dos diferentes valores do Fator $\mathrm{C}$ da MUSLE.

Costa et al (2013) avaliaram a influência da densidade e declividade na lâmina de escoamento também em áreas de LATOSSOLO AMARELO Distrófico, assim como no presente trabalho, no município de Marapanim (nordeste do estado do Pará), sobre declividades e densidade do solo semelhantes a deste estudo. Avaliaram medidas in loco com coletores de escoamento em áreas de capoeira, pastagem com preparo de 
área com corte-e-queima, além de áreas de cultivo de mandioca e sistemas agroflorestais (SAF's), sendo esses dois últimos ambos em áreas com manejo de cortee-queima e corte-e-trituração. Os autores identificaram as áreas de pastagem como as que mais contribuíram para a produção de escoamento, sendo estas já bastante degradadas, devido ao pastoreio elevado. Apontam as áreas de capoeira como forte redutoras do escoamento superficial, em especial pela idade de 20 anos dessas áreas e a influência direta da interceptação da chuva pelo dossel florestal. Em relação às áreas de roça e SAF's, o estudo apontou para a forte influencia do manejo de preparo de área com corte-e-trituração da capoeira.

Outros estudos também mostram a importância da manutenção da cobertura morta e do não uso da queima como técnicas de manejo do solo que contribuem com a redução da lâmina de escoamento superficial e da erosão (BERTOL et al., 2011; SANTOS et al., 2007). De modo geral, os resultados de COSTA et al. (2013) apontaram para valores da média mensal entre os meses chuvosos da região (Janeiro a Maio) de 9,3 mm, 57,9 mm e 7,65 mm para Capoeira, Pastagem e Plantios de mandioca, respectivamente. Estes resultados são semelhantes às médias mensais dos meses mais chuvosos da SBRB e SBRM (Tabela 73 e 74). Estas duas tabelas apresentam os resultados anuais médios e acumulados de escoamento por uso e cobertura do solo e por cenário, entre os anos de 2006 a 2014, por ano completo e para os seis meses mais chuvosos. 
Tabela 73: Média e soma anual de longo período do escoamento superficial e da produção de sedimentos entre todos os meses e entre os meses mais chuvosos dos anos de 2006 e 2014 para a subbacia do rio Bujaru nos três anos de uso e cobertura da terra.

\begin{tabular}{|c|c|c|c|c|c|c|c|c|}
\hline \multicolumn{9}{|c|}{ Bujaru } \\
\hline & \multicolumn{4}{|c|}{ Média de todos os Meses } & \multicolumn{4}{|c|}{ Média dos 6 meses mais chuvosos } \\
\hline & $\begin{array}{c}\text { Média } \\
\text { ESC }\end{array}$ & $\begin{array}{l}\text { Média } \\
\text { SED }\end{array}$ & $\begin{array}{c}\text { Soma } \\
\text { ESC }\end{array}$ & $\begin{array}{c}\text { Soma } \\
\text { SED }\end{array}$ & $\begin{array}{c}\text { Média } \\
\text { ESC }\end{array}$ & $\begin{array}{l}\text { Média } \\
\text { SED }\end{array}$ & $\begin{array}{c}\text { Soma } \\
\text { ESC }\end{array}$ & $\begin{array}{c}\text { Soma } \\
\text { SED }\end{array}$ \\
\hline & \multicolumn{8}{|c|}{2008} \\
\hline OILP & 11.760 & 0.115 & 142.690 & 1.140 & 22.783 & 0.181 & 136.697 & 1.084 \\
\hline AGRL & 31.386 & 1.159 & 377.310 & 8.840 & 56.449 & 1.322 & 338.700 & 7.929 \\
\hline PAST & 17.993 & 1.106 & 217.000 & 10.730 & 34.370 & 1.741 & 206.222 & 10.446 \\
\hline \multirow[t]{2}{*}{ FRSE } & 4.627 & 0.002 & 56.010 & 0.010 & 9.336 & 0.002 & 56.014 & 0.013 \\
\hline & \multicolumn{8}{|c|}{2013} \\
\hline OILP & 11.716 & 0.125 & 144.040 & 1.230 & 21.893 & 0.184 & 131.356 & 1.104 \\
\hline AGRL & 31.651 & 0.581 & 379.800 & 7.130 & 55.202 & 1.031 & 331.212 & 6.191 \\
\hline PAST & 17.856 & 0.916 & 216.080 & 7.980 & 33.026 & 1.275 & 198.154 & 7.648 \\
\hline \multirow[t]{2}{*}{ FRSE } & 3.977 & 0.001 & 47.790 & 0.006 & 7.962 & 0.001 & 47.769 & 0.006 \\
\hline & \multicolumn{8}{|c|}{2023} \\
\hline OILP & 11.923 & 0.154 & 144.660 & 1.370 & 21.969 & 0.207 & 131.819 & 1.243 \\
\hline AGRL & 31.660 & 0.548 & 379.920 & 6.570 & 55.219 & 0.951 & 331.315 & 5.706 \\
\hline PAST & 17.855 & 0.913 & 216.070 & 7.930 & 33.023 & 1.267 & 198.136 & 7.604 \\
\hline FRSE & 3.956 & 0.001 & 47.800 & 0.006 & 7.964 & 0.001 & 47.783 & 0.006 \\
\hline
\end{tabular}

Tabela 74: Média e soma anual de longo período do escoamento superficial e da produção de sedimentos entre todos os meses e entre os meses mais chuvosos dos anos de 2006 e 2014 para a subbacia do rio Mariquita nos três anos de uso e cobertura da terra.

\begin{tabular}{|c|c|c|c|c|c|c|c|c|}
\hline \multicolumn{9}{|c|}{ Mariquita } \\
\hline & \multicolumn{4}{|c|}{ Média de todos os Meses } & \multicolumn{4}{|c|}{ Média dos 6 meses mais chuvosos } \\
\hline & $\begin{array}{c}\text { Média } \\
\text { ESC }\end{array}$ & $\begin{array}{l}\text { Média } \\
\text { SED }\end{array}$ & $\begin{array}{c}\text { Soma } \\
\text { ESC }\end{array}$ & $\begin{array}{c}\text { Soma } \\
\text { SED }\end{array}$ & $\begin{array}{c}\text { Média } \\
\text { ESC }\end{array}$ & $\begin{array}{c}\text { Média } \\
\text { SED }\end{array}$ & $\begin{array}{c}\text { Soma } \\
\text { ESC }\end{array}$ & $\begin{array}{c}\text { Soma } \\
\text { SED }\end{array}$ \\
\hline & \multicolumn{8}{|c|}{2008} \\
\hline OILP & 23.273 & 0.054 & 279.280 & 0.650 & 42.122 & 0.099 & 252.732 & 0.594 \\
\hline AGRL & 44.243 & 0.891 & 530.920 & 10.690 & 77.503 & 1.512 & 465.020 & 9.070 \\
\hline PAST & 30.251 & 1.346 & 363.040 & 15.650 & 54.336 & 2.459 & 326.019 & 14.757 \\
\hline \multirow[t]{2}{*}{ FRSE } & 11.296 & 0.004 & 135.510 & 0.034 & 22.039 & 0.006 & 132.234 & 0.034 \\
\hline & \multicolumn{8}{|c|}{2013} \\
\hline OILP & 22.476 & 0.169 & 269.710 & 2.030 & 40.503 & 0.306 & 243.019 & 1.835 \\
\hline AGRL & 44.700 & 1.037 & 536.430 & 12.060 & 78.349 & 1.705 & 470.091 & 10.232 \\
\hline PAST & 30.255 & 1.267 & 363.080 & 14.720 & 54.340 & 2.313 & 326.040 & 13.878 \\
\hline \multirow[t]{2}{*}{ FRSE } & 11.286 & 0.004 & 135.340 & 0.035 & 22.013 & 0.006 & 132.075 & 0.035 \\
\hline & \multicolumn{8}{|c|}{2023} \\
\hline OILP & 22.710 & 0.180 & 272.470 & 2.120 & 40.970 & 0.320 & 245.870 & 1.920 \\
\hline AGRL & 44.700 & 1.090 & 536.400 & 13.050 & 78.340 & 1.850 & 470.070 & 11.080 \\
\hline PAST & 30.220 & 1.280 & 362.700 & 15.400 & 54.280 & 2.420 & 325.680 & 14.530 \\
\hline FRSE & 11.260 & 0.003 & 135.160 & 0.036 & 21.980 & 0.006 & 131.900 & 0.036 \\
\hline
\end{tabular}


As áreas de pastagem, segundo o estudo de Moraes et al (2006) no município de Paragominas-PA, Amazônia Oriental, tiveram sua capacidade de infiltração ultrapassada em $75 \%$ dos eventos de precipitação média, quando comparadas as áreas de floresta, às quais quase não tiveram sua capacidade de infiltração ultrapassa. Este estudo foi em sistemas sobre solos plínticos, identificando valores de escoamento superficial acumulado médio de 2001 a 2003 para os meses mais chuvosos (Dezembro a Junho) de $71 \mathrm{~mm}$ e 261,6 $\mathrm{mm}$ e também valores médios mensais desses meses de $11,8 \mathrm{~mm}$ e $43,6 \mathrm{~mm}$ para floresta e pasto, respectivamente. Estes valores mais elevados para áreas de floresta e pastagem, em relação aos dados de Bujaru da presente tese (Tabela 73 e 74), podem estar ligados a diferença de solo, sendo os LATOSSOLOS AMARELOS Distrófico solos bem drenados, mais porosos e com alta taxa de infiltração, características totalmente inversas aos solos plínticos (Sartori et al., 2005a) estudados por Moraes et al. (2006), mesmo a região de Paragominas tendo menores índices pluviométricos.

A variabilidade climática e de ecossistema tem influência direta sobre as características de escoamento superficial e perda de solo, o que é demonstrado em trabalhos desenvolvido em outras regiões brasileiras. Em um trabalho no município de Aracruz sobre solos do tipo ARGISSOLO AMARELO e PLINTOSSOLO Háplico, Cardoso et al. (2004) encontrou valores maiores de escoamento superficial em áreas de floresta variando de 30 a $35 \mathrm{~mm}$ e a perda de solo variando entre 0,045 a 0,05 t/ha.ano, em média anual, o que está relacionado ao tipo de solo de menor drenagem, mas também a essa floresta ter características diferentes com a perda de folhas na estação seca. Youlton (2013) mediu o impacto da substituição de áreas de pastagem por cana de açúcar no município de Itirapina-SP, estimando escoamento e erosão do solo. O autor identificou um escoamento no primeiro ano $40,5 \mathrm{~mm}$ e $56,1 \mathrm{~mm}$ e no segundo ano de 30,4 mm e 11,8 mm, para pasto e Cana, respectivamente. Esses resultados do segundo ano com menor escoamento na cana estão ligados à disposição de matéria orgânica morta da palha sobre o solo no sistema cana-soca do segundo ano. O resultado semelhante foi observado na produção de sedimentos, onde a pastagem apresentou perda de solo de 0,26 t/ha.ano, a cana-planta de 2,58 t/ha.ano e a cana-soca de 0,43 t/ha.ano, refletindo a importância da cobertura morta. 
Aplicando o modelo SWAT calibrado para estimar escoamento e sedimentos, produzindo estimativas semelhantes ao presente trabalho, Lelis $(2011 ; 2012)$ identificou valores de produção total média entre os anos do estudo para escoamento e sedimentos comparando usos como café, Pastagem e Floresta em Viçosa - MG, onde os resultados também apontaram para uma maior produção de escoamento e sedimentos nas áreas de pastagem em LATOSSOLOS VERMELHO Amarelo, sendo de $117 \mathrm{~mm}$ e 0,288 t/ha.ano, enquanto que as áreas de floresta foram de $34 \mathrm{~mm}$ e 0,019 t/ha.ano. Estes dados demonstram a importância de se avaliar criteriosamente 0 avanço de novas culturas e se planejar, fundamentado em estudos ambientais, as melhores áreas e técnicas de manejo para evitar a perda de solo.

Especificamente com relação à Palma de Óleo, alguns trabalhos tem relatado o impacto da expansão da palma de óleo em conjunto com a mudança geral de cenários incluindo outras classes de uso e cobertura do solo com o objetivo de estimar impactos na produção de água e sedimentos, avaliações de pegada hídrica, impactos sobre represas de abastecimento e irrigação utilizando o modelo SWAT na Malásia, Indonésia e Tailândia (BABEL et al., 2011; HASAN et al., 2012; RUSLI; MAJID, 2012; MEMARIAN et al., 2014), bem como utilizando outros modelos (LAl et al., 2008; MEMARIAN et al., 2012).

Alansi et al. (2009) avaliando diferentes cenários de 1984 a 2006 e também cenário futuro de 2020, identificaram que ocorreu aumento expressivo de áreas com palma de óleo e área urbana, chegando a ocupar, respectivamente, 15,93\% e 6,46\% da áreas da bacia do rio Bernam na Malásia em 2006 e 18,4\% e 19,63\% no cenário projetado de 2020, acompanhado de uma redução de cerca de $20 \%$ das áreas de floresta. Assim, os autores identificaram redução do escoamento de $16 \%$ a $59 \%$ durante os meses chuvosos e de $3 \%$ a $32 \%$ no período de estiagem entre os cenários de 1984 a 2006, enquanto que a redução foi de $50 \%$ abaixo da demanda de água do período de estiagem. Resultados semelhantes ao do presente trabalho, como o de Babel et al. (2011) em um estudo do impacto sobre a produção de água e sedimentos da expansão de culturas biocombustíveis na Tailândia (palma de óleo, mandioca e cana de açúcar), apontaram que o cenário de expansão da palma de óleo apresentou insignificante alteração na evapotranspiração e na produção de água, mas com um 
aumento no aporte de nitrato, o que está ligado a maior aporte de adubo nitrogenado nesta cultura, quando comparada a cana de açúcar e a mandioca.

Por outro lado, dados preliminares dos autores Majid \& Rusli (2014) tem apontado um aumento do escoamento superficial quando se substitui áreas de floresta por plantios de seringueira e em sequencia se substitui por palma de óleo na bacia na porção superior da bacia do rio Muar, na Malásia, aumentando assim a magnitude de eventos de enchente na região e apontando para uma necessidade de implantação de técnicas de manejo que auxiliem no controle desses eventos extremos. Importante ressaltar que os dados de Majid \& Rusli (2014) identificam a palma de óleo com menor índice de área foliar em relação aos usos floresta e seringueira, o que corrobora para um maior escoamento nas áreas de palma. A tese desenvolvida por Lai (2001), apontou resultados não com objetivo direto em relação à palma de óleo na porção alta da bacia do rio Bernam, também na Malásia, onde ocorreu a expansão da palma de óleo de 1993 até 2008, ocupando cerca de 23\% da bacia neste último ano, porém acompanhado de aumento de áreas classificadas como solo exporto e áreas urbanas. Lai (2001) identificou assim, que o aumento no escoamento superficial está relacionado de maneira geral ao aumento de solo exposto e ao regime de precipitação fortemente diferenciado entre os anos de estudo. 


\section{CONCLUSÕES}

O trabalho de levantamento de dados para compor o complexo de informações necessárias ao desenvolvimento da modelagem com o SWAT e com o CLUE-S exigiu uma ampla rede de contatos institucionais para obtenção dos dados, bem como para trabalhar e analisar com os mesmos a fim de ajustar ao formato adequado de uso na tese. Isso se comprovou pela necessidade de classificar imagens para o ano de 2013, devido a inutilização dos dados do Projeto TerraClass de 2012 para essa modelagem. Cita-se também a necessidade de ajuste do Modelo de elevação Digital da sub-bacia do rio Mariquita para melhorar a qualidade do delineamento da mesma. Ao mesmo tempo criticasse a ausência de mapeamentos da terra mais refinados, sendo necessário utilizar dados em escalas de 1:250.000. A Tabela 6 e o Quadro 3 expressam bem a variedade de dados e origens de busca. Destaca-se o trabalho de campo para a abertura de trincheiras para análise granulométrica e de fertilidade, as medidas de vazão nos exutórios das duas sub-bacias e a ampla revisão bibliográfica para obtenção de dados de características hidrológicas do solo e de parâmetros morfológicos das diferentes classes de uso e cobertura da terra utilizadas.

A região estudada possui monitoramento fluviométrico apenas em grandes bacias hidrográficas, como é o caso da bacia dos rios Guamá e Capim. Porém para este estudo foi necessário a utilização desses dados para a regionalização de vazão para as bacias menores (Bujaru e Mariquita), uma vez que são os únicos dados disponíveis. A técnica de regionalização por equações não lineares aplicada, porém, só obteve sucesso por razão da criação das estações sintéticas que contribuíram efetivamente para a validação da regionalização da vazão média mensal de longo período das estações fluviométricas do rio Capim (Badajós e Fazenda Maringá) e do rio Guamá (Bom Jardim e Vila Capoeira), conforme Figura 43, Tabela 28 e Figura 44. 0 método se mostrou de fácil aplicação e com bons resultados, apontando para uma necessidade de se buscar uma maior homogeneidade quanto às características geofisiográficas das bacias estudadas na regionalização.

A utilização das séries de vazão regionalizadas de 2006 a 2014 (Figuras 45 e 48) e da vazão média mensal de longo período para a sub-bacia do rio Bujaru e Mariquita 
(Figuras 46 e 49), demostrou-se um procedimento inovador e importante para a calibração do modelo SWAT em bacias não monitoradas na Amazônia. As Figuras $57 \mathrm{e}$ 58, para a sub-bacia do rio Bujaru, e as Figuras 60 e 61, para a sub-bacia do rio Mariquita, mostram os resultados da calibração através do método de calibração direta com a série regionalizada através do software SWAT-CUP e da calibração através da transferência dos parâmetros calibrados da bacia do rio Capim (porção média). Os dois métodos utilizados demonstraram bons resultados na calibração do modelo SWAT, mas os resultados da calibração direta com a regionalização de vazão apresentaram resultados mais coerentes quando comparados aos resultados das medidas com 0 molinete hidrométrico, mesmo os resultados de ambas as metodologias terem apresentados resultados semelhantes quanto ao balanço hídrico (Tabelas 42, 43, 44 e 45). No entanto, para a metodologia de transferência de parâmetros de bacias monitoradas, como no caso do rio Capim, talvez o melhor caminho seja criar modelos calibrados para um número maior de bacias monitoradas e então efetuar uma regionalização dos parâmetros calibrados, o que pode melhorar o nível de confiança do resultado.

Quanto à evapotranspiração real, todos os modelos estão semelhantes aos dados disponibilizados pelo ZEE-PA (1.300-1.500 mm), assim como os coeficientes de escoamento foram coerentes com os das regiões hidrográficas do Tocatins $(0,27)$ e Atlântico Norte $(0,37)$. Com relação às áreas de palma de óleo, o modelo foi capaz de estimar com eficiência a evapotranspiração nestas unidades de resposta hidrológica (1.089,2 mm para SBRB e de $1.093,1 \mathrm{~mm}$ para SBRM), quando comparado a dados da literatura e de medidas feitas in loco através de torre de monitoramento micrometeorológico $(1.135,7 \mathrm{~mm})$, o que demonstrou a capacidade do modelo de simular o balanço hídrico em áreas de palma de óleo na região amazônica.

A aplicação do modelo CLUE-S para avaliar a dinâmica de mudança de uso e cobertura da terra nas sub-bacias dos rios Bujaru e Mariquita foi capaz de integralizar as variáveis explanatórias biofísicas, logísticas e socioeconômicas, com as demandas agregadas e as características de elasticidade de cada classe e gerou os mapas futuros de uso e cobertura da terra para o cenário de 2023 das sub-bacias estudadas. O processo de calibração do modelo CLUE-S entre os anos de 2008 e 2013 foi mais 
eficiente para a SBRM (Tabela 65), tanto para a bacia como um todo como especificamente para a modelagem da palma de óleo. Ocorreu maior influência das forçantes biofísicas selecionadas para todos os usos da SBRB. Na SBRM, as forçantes biofísicas foram mais influentes apenas para os modelos da 'palmaoleo13', 'agricultura13' e 'remanescent13'. As forçantes logísticas explicaram melhor os modelos dos usos e coberturas da SBRM, apresentando maiores betas para o modelo 'palmaole013', mas não ficaram claras as relações específicas conceituais entre as variáveis dependentes e as variáveis independentes de logísticas. Isso pode ser explicado pela escala de trabalho aplicada no estudo não ser capaz de apresentar uma correlação mais clara, em especial com as forçantes de distância. As variáveis explanatórias socioeconômicas tiveram influências completamente diferentes quanto à explicação dos modelos nas duas sub-bacias, o que pode estar relacionado às características agrícolas diferenciadas de cada sub-bacia, uma vez que a SBRM tem a palma de óleo como uso consolidado e a SBRB como uso em expansão, por exemplo.

Um ponto importante na modelagem do CLUE-S no presente trabalho foi a necessidade de se rever algumas variáveis explicativas e também acrescentar novas forçantes, sendo interessante verificar esse mesmo estudo da expansão da palma de óleo em uma escala menor. Talvez seja interessante se verificar também outro mecanismo de análise estatística de acerto, como por exemplo, a substituição da análise acerto por pixel para uma análise por sub-bacia. Contudo, os resultados de projeção para 2023 foram satisfatórios estatisticamente e foram utilizados como cenários de estudo do modelo SWAT para estimativas de escoamento superficial e perda de solos.

O acoplamento do resultado do CLUE-S ao modelo SWAT se mostrou importante para a representação e análise dos padrões de mudanças espaciais ao mesmo tempo em que contribui para a identificação de áreas vulneráveis a degradação ambiental, fornecendo dados multidisciplinares de ordem qualitativa e quantitativa. Tecnicamente o CLUE-S possui a vantagem de gerar um cenário com maior consistência, pois se fundamenta em fatores explicativos e demandas de área das mudanças reais, distribuindo de maneira estatística, conforme a probabilidade, os usos e coberturas no espaço com coerência. 
Os resultados das estimativas do escoamento superficial e da produção de sedimentos nas sub-bacias não monitoradas na Amazônia Oriental brasileira, tendo como mecanismo de calibração a construção de séries de vazão regionalizadas através de equações de regressão não linear se mostram importantes, pois geraram um arcabouço de informações ainda inexistente para a região. Tais estimativas apontaram para uma redução do escoamento superficial e da produção de sedimentos na SBRB e um aumento na SBRM entre os anos de 2008, 2013 e no cenário gerado pelo CLUE-S para 2023 (Figuras 83 e 86; Tabelas 69 e 70). Isto se deve, respectivamente, ao aumento de vegetação secundária na SBRB e redução dessa vegetação na SBRM, as quais promovem a manutenção de alguns serviços ecossistêmicos de maneira semelhante às áreas de remanescente florestal, como os menores valores de escoamento superficial. Assim, percebeu-se que a expansão da palma de óleo não foi a razão da redução (SBRB) e nem do aumento (SBRM) de escoamento superficial e produção de sedimentos nas sub-bacias em estudo. Porém, os resultados apontam que a palma de óleo pode impactar de maneira menos agressiva no escoamento superficial, no transporte de sedimentos e possivelmente de nutrientes, consequentemente. Isso é mais bem observado nos resultados que apresentaram as áreas de palma de óleo com menor escoamento superficial e produção de sedimentos média mensal do período mais chuvoso entre os anos de 2006 a 2014 com relação às áreas de agricultura geral e pastagem, conforme Tabelas 73 e 74 .

Os resultados do SWAT são fundamentais para a gestão ambiental rural no nível de bacia hidrográfica, pois apresentam um método com resultados eficientes na estimativa do balanço hídrico, proporcionando assim a possibilidade de se conhecer o comportamento hidrológico de bacias não monitoradas na Amazônia. O trabalho procurou aproveitar os dados existentes disponíveis para a região de uma forma mais ampla e ao mesmo tempo realçou a demanda científica de dados de base oriundos do monitoramento ambiental, bem como a necessidade de aumentar a rede de monitoramento de dados nessa região. Dessa forma, o conhecimento do impacto de cada uso e cobertura da terra sobre o escoamento superficial e produção de sedimentos, bem como a distribuição desses fluxos hidrossedimentológicos sobre as áreas das sub-bacias, é fundamental para o entendimento do comportamento 
hidrológico e sedimentológico das bacias não monitoradas na Amazônia e para o direcionamento de melhores práticas manejos do solo.

O estudo também contribui para que seja possível adotar melhores práticas de manejo do solo objetivando evitar o aumento do escoamento superficial e da produção de sedimentos e possível degradação do solo. Nesse contexto é importante se utilizar os resultados de cenários futuros advindos de um modelo de dinâmica espacial, como é - CLUE-S, para se obter resultados de maior probabilidade de ocorrência e confiáveis para cada região e, dessa forma, poder contribuir com a geração de políticas públicas e planejar o uso sustentável de bacias hidrográficas não monitoradas na Amazônia. 


\section{REFERÊNCIAS}

ABBASPOUR, K.C.; JOHNSON, C.; VAN GENUCHTEN, M.T. Estimating uncertain flow and transport parameters using a sequential uncertainty fitting procedure. Vadose Zone Journal, v. 3, p. 1340-1352, 2004.

ABBASPOUR, K. C.; ROUHOLAHNEJAD, E.; VAGHEFI, S.; SRINIVASAN, R.; YANG, H.; KLØVE, B. A. Continental-Scale Hydrology and Water Quality Model for Europe: Calibration and Uncertainty of a High-Resolution Large-Scale SWAT Model. Journal of Hydrology, v. 524, p. 733-752, 2015.

ABBASPOUR, K.C. SWAT-CUP 2012: SWAT Calibration and Uncertainty Programs - A User Manual. Duebendorf: Department of Systems Analysis, Integrated Assessment and Modelling (SIAM), Eawag, Swiss Federal Institute of Aquatic Science and Technology, 2014. $100 \mathrm{p}$.

AGUIAR, A. P. D.; CÂMARA, G.; ESCADA, M. I. S. Spatial statistical analysis of landuse determinants in the Brazilian Amazonia: Exploring intra-regional heterogeneity. Ecological Modelling, v. 209, n. 2, p. 169-188, 2007.

AGUIAR, A. P. D. DE. Modelagem de mudanças de Uso e Cobertura do Solo na Amazônia: Questões Gerais. In: Instituto de Pesquisas Espaciais. São José dos Campos: INPE, 2003. Disponível em: $<$ http://dpi.inpe.br/tutoriais/modelagem/cap4_modelos_LUC.pdf> Acesso em 03 de Março de 2016.

AGUIAR, A. P. D. DE. Modeling land use change in the Brazilian Amazon: exploring intra-regional heterogeneity. 2006. $173 \mathrm{f}$. Tese (Doctorate in Remote Sensing) - National Institute for Space Research (INPE), São José dos Campos, 2006.

AGUIAR, E. B. Produção e qualidade de mandioca de mesa (Manihot esculenta Crantz) em diferentes densidades populacionais e épocas de colheita. 2003. $101 \mathrm{f}$. Dissertação (Mestrado em Agricultura Tropical e Subtropical - Área de Concentração em Tecnologia da Produção Agrícola.) - Instituto Agronômico de Campinas, Campinas, 2003. 
AHMED, S. J.; BRAMLEY, G.; VERBURG, P. H. Key Driving Factors Influencing Urban growth: Spatial-Statistical Modelling with CLUE-S. in: Dewan, A.; Corner, R. Dhaka Megacity: Geospatial perspectives on urbanisation, environment and health. Springer Geography, 2014.

ALANSI, A. W.; AMIN, M. S. M.; ABDUL HALIM, G.; SHAFRI, H. Z. M.; AIMRUN, W. Validation of SWAT model for stream flow simulation and forecasting in Upper Bernam Humid Tropical River Basin, Malaysia. Hydrology and Earth System Sciences Discussions, v.6, n. 6, p. 7581-7609, 2009.

ALEXANDRE, A. M. B.; MARTINS, E. S. P. R. Regionalização de vazões médias de longo período para o Estado do Ceará. Rev Bras Recurs Hídr, v. 10, n. 3, p. 93-102, 2005.

ALLEN, R. G. A. Penman for all seasons. Journal of Irrigation and Drainage Engineering, v. 112, n, 4, p. 348-368, 1986.

ALLEN, R. G.; PEREIRA, L. S.; RAES, D.; SMITH, M. Crop Evapotranspiration Guidelines for Computing Crop Water Requirements - FAO. Roma: Irrigation and Drainage, paper 56, 1998. $318 \mathrm{p}$.

ALMEIDA, A. S. DE; VIEIRA, I. C. G. Conflitos no uso da terra em áreas de preservação permanente em um polo de produção de biodiesel no estado do Pará. Revista Ambiente \& Água, v. 9, n. 3, p. 476-487, 2014.

ALVES, D. R.; FRIZZONE, J. A.; DOURADO NETO, D. Repartição da lâmina de irrigação, aplicada via pivô central, na cultura do milho. Revista Brasileira de Engenharia Agrícola e Ambiental, v. 5, n. 1, p. 67-70, 2001.

ALVES JÚNIOR, J.; SILVEIRA, P. M. DA; STONE, L. F.; CUNHA, P. C. R. DA. Retenção de água pelo dossel do feijoeiro irrigado por aspersão. Irriga, Botucatu, v. 15, n. 1, p. 90-97, jan./mar. 2010.

ANA - Agência Nacional de Águas. Medição de Descargas Líquidas em Grandes Rios: Manual técnico. Brasília: ANA; SGH, 2014. 94 p. 
ANA - Agência Nacional de Águas. Sistema de Informações Hidrológicas. Brasília, 2015. Disponível em: <http://hidroweb.ana.gov.br>. Acesso em 02 Jan. de 2015.

ARAGÃO, R. DE; CRUZ, M. A. S.; AMORIM, J. R. A. DE; MENDONÇA, L. C.; FIGUEIREDO, E. E. DE; SRINIVASAN, V. S. Análise de sensibilidade dos parâmetros do modelo SWAT e simulação dos processos hidrossedimentológicos em uma bacia no agreste nordestino. Revista Brasileira de Ciência do Solo, v. 37, n. 4, p. 1091-1102, 2013.

ARNOLD, J. G.; ALLEN, P. M. Estimating hydrologic budgets for three illinois watersheds. Journal of Hydrology, v. 176, n. 1, p. 57-77, 1996.

ARNOLD, J. G.; FOHRER, N. SWAT2000: current capabilities and research opportunities in applied watershed modelling. Hydrological Processes, v. 19, n. 3, p. 563-572, 2005.

ARNOLD, J.G.; KINIRY, J.R.; SRINIVASAN, R.; WILLIAMS, J.R.; HANEY, E.B.; NEITSCH, S.L. Soil and Water Assessment Tool: Input/output File Documentation Version 2009. Temple: Grassland, Soil and Water Research Laboratory, Agricultural Research Service, 2011. 662 p.

ARNOLD, J. G.; MORIASI, D. N.; GASSMAN, P. W.; ABBASPOUR, K. C.; WHITE, M. J.; SRINIVASAN, R.; SANTHI, C.; HARMEL, R. D.; VAN GRIENSVEN, A.; VAN LIEW, M. W.; KANNAN, N.; JHA, M. K. SWAT: model use, calibration, and validation. American Society of Agricultural and Biological Engineers, Transactions of the ASABE, v. 55, n. 4, p. 1491-1508., 2012.

ARNOLD, J. G.; SRINIVASAN, R.; MUTTIAH, R. S.; ALLEN, P. M. Continental scale simulation of the hydrologic balance1. J. Am. Water Resour. Assoc, v. 35, n. 5, 1999.

ARNOLD, J.G.; SRINIVASAN, R.; MUTTIAH, R.S.; WILLIAMS, J.R. Large area hydrologic modeling and assessment. Part I: model development. J. Am. Water Resour. Assoc, v. 34, p. 73-89, 1998.

ARSHAD, A. M. Crop evapotranspiration and crop water requirement for oil palm in Peninsular Malaysia. Journal of Biology, Agriculture and Healthcare, v. 4, n.16, p. 23-28, 2014. 
BABEL, M. S.; SHRESTHA, B.; PERRET, S. R. Hydrological impact of biofuel production: a case study of the khlong Phlo watershed in Thailand. Agricultural Water Management, v. 101, n. 1, p. 8-26, 2011.

BACK, A. J. Hidráulica e hidrometria aplicada: com programa hidrom para cálculo. Florianópolis: EPAGRI, 2006. 299 p.

BAENA, A. R. C.; FALESI, I. C. Avaliação do Potencial Químico e Físico dos Solos sob Diversos Sistemas de Uso da Terra na Colônia Agrícola de Tomé-Açu, Estado do Pará. Belém: Embrapa Amazônia Oriental - Boletim de pesquisa Nº 18. 1999.

BAKOUMÉ, C.; SHAHBUDIN, N.; SHAHRAKBAH, Y.; CHEAH, S. S.; NAZEEB, M. A. T. Improved method for estimating soil moisture deficit in oil palm (Elaeis guineensis Jacq.) areas with limited climatic data. Journal of Agricultural Science, v. 5, n. 8, p. 57, 2013.

BALTOKOSKI, V.; TAVARES, M. H. F.; MACHADO, R. E.; OLIVEIRA, M. D. Calibração de modelo para a simulação de vazão e de fósforo total nas sub-bacias dos rios Conrado e Pinheiro-Pato Branco (PR). Revista Brasileira de Ciência do Solo, v. 34, n. 1, p. 253-261, 2010.

BASTOS, T. X.; MULLER, A. A.; PACHECO, N. A.; SAMPAIO, M. N.; ASSAD, A. D.; MARQUES, A. F. S. Zoneamento de riscos climáticos para a cultura do dendezeiro no Estado do Pará. Revista Brasileira de Agrometeorologia, Passo Fundo, v. 9, n. 3, p. 564-570, 2001.

BECKER, B. K. Geopolítica da Amazônia. Estudos Avançados [online], v. 19, n. 53, 2005. ISSN 1806-9592.

BECKER, B. K. Recuperação de áreas desflorestadas da Amazônia: será pertinente o cultivo da palma de óleo (Dendê)?. Confins [online], v. 10, n. 10, 2010. DOI: $10.4000 /$ confins.6609.

BERTOL, I.; GOBBI, E.; BARBOSA, F. T.; PAZ-FERREIRO, J.; GEBLER, L.; RAMOS, J. C.; WERNER, R. D. S. Erosão hídrica em campo nativo sob diversos manejos: perdas de água e solo e de fósforo, potássio e amônio na água de enxurrada. Revista Brasileira de Ciência do Solo, v. 35, n. 4, p. 1421-1430, 2011.

BERTONI, J.; LOMBARDI NETO, F. Conservação do Solo. 2.ed. São Paulo: Ícone, 1999. 355p. 
BOLFE, E. L.; PEREIRA, R. S.; MADRUGA, P. R. A.; FONSECA, E. L. D. Avaliação da classificação digital de povoamentos florestais em imagens de satélite através de índices de acurácia. Revista Árvore, v. 28, n. 1, p. 85-90, 2004. ISSN: 0100-6762.

BONUMÁ, N. B.; ROSSI, C. G.; ARNOLD, J. G.; REICHERT, J. M.; MINELLA, J. P.; ALLEN, P. M.; VOLK, M. Simulating landscape sediment transport capacity by using a modified SWAT model. Journal of Environmental Quality, v. 43, n. 1, p. 55-66, 2014.

BONUMÁ, N. B.; REICHERT, J. M.; RODRIGUES, M. F.; MONTEIRO, J. A. F.; ARNOLD, J. G.; SRINIVASAN, R. Modeling surface hydrology, erosion, nutrient transport, and future scenarios with the ecohydrological SWAT model in brazilian watersheds and river easins. Tópicos em Ciência do. Solo, v. 9, p. 241-290, 2015.

BRASIL. CNRH - Conselho Nacional de Recursos Hídricos. Resolução no 30, de 11 de dezembro de 2002. Diário Oficial da União, Brasília, DF, 19 mar. 2003.

BRASIL. Lei $\mathbf{n}^{\circ} 9.433$ de 8 de janeiro de 1997. Institui a Política Nacional de Recursos Hídricos (PNRH), cria o Sistema Nacional de Gerenciamento de Recursos Hídricos, regulamenta o inciso XIX do art. 21 da Constituição Federal, e altera o art. $1^{\circ}$ da Lei $n^{\circ}$ 8.001, de 13 de março de 1990, que modificou a Leu $n^{\circ} 7.990$, de 28 de dezembro de 1989. Brasília, DF.

BRASIL. MAPA - Ministéria da Agricultura, Pecuária e Abastecimento. Câmera Setorial Produtiva da Palma de Óleo: Biodiesel e Palma. Brasília, DF, 2012. Disponível em: $<$ http://www.agricultura.gov.br/arq_editor/file/camaras_setoriais/Palma_de_oleo/3RE/Ap p_Aprobio_Palma.pdf>. Acesso em: 20 dez. 2015.

BRASIL. MAPA - Ministéria da Agricultura, Pecuária e Abastecimento. Programa de Produção Sustentável da Palma de Óleo no Brasil (PPSPO). Brasília, DF, 2010. 9 p.

BRASIL. MMA - Ministério do Meio Ambiente. Brasília, DF, 2015. Disponível em: <http://www.geocatalogomma.com.br/index.jsp>. Acesso em 27 Set. 2015.

BRESSIANI, D. DE A.; GASSMAN, P. W.; FERNANDES, J. G.; GARBOSSA, L. H. P.; SRINIVASAN, R.; BONUMÁ, N. B.; MENDIONDO, E. M. A. Review of soil and water assessment tool (SWAT) applications in Brazil: challenges and prospects. Int $\mathbf{J}$ Agric \& Biol Eng, v. 8, n. 3, p. 1-27, 2015b. 
BRESSIANI, D. DE. A.; SRINIVASAN, R.; JONES, C. A.; MENDIONDO, E. M. Effects of spatial and temporal weather data resolutions on streamflow modeling of a semi-arid basin, northeast Brazil. International Journal of Agricultural and Biological Engineering, v. 8, n. 3, p. 125-139, 2015a.

BRESSIANI, D. DE A.; SRINIVASAN, R.; MENDIONDO, E. M.; SAUVAGE, S.; PEREZ, J. M. S. Systematic Procedure for Calibrating a Complex Watershed: case study in Southeast Brazil. 2016. No prelo.

BRIASSOULIS, H. Analysis of Land Use Change: Theoretical and Modeling Approaches. Lesvos: University of the Aegean, 1999. 152 p. Disponível em: <http://www.rri.wvu.edu/WebBook/Briassoulis/contents.htm>. Acesso em: 23 Mai. 2015.

BRIASSOULIS, H. Land-use, Land-cover Changes and Global Aggregate Impacts. In: Verheye, W. H. Encyclopedia Land use, land cover and soil sciences: Encyclopedia of Life Support Systems. EOLSS-UNESCO, 2009, p. 192-208. Disponível em: <http://www.eolss.net/sample-chapters/c19/E1-05-01-07.pdf>. Acesso em: 02 Abr. 2015.

BRITES, R. S.; SOARES, V. P.; RIBEIRO, C. A. A. S. Verificação da exatidão em classificação de uma imagem orbital mediante a utilização de três índices. Revista Árvore, Viçosa, v. 20, n. 3, p. 415-424, 1996.

BRUIJNZEEL, L. A.; SAMPURNO, S. P. Hydrology of Moist Tropical Forests and Effects of Conversion: a state of knowledge review. Amsterdam: Free University, 1990.

BUTKOV, E. Mathematical Physics. London: Addison Wesley, 1973.

BUTLER R. A.; LAURENCE W. F. Is oil palm the next threat to the Amazon? Tropical Conservation Science, v. 2, n. 1, p. 1-10, 2009.

CAN, T.; XIAOLING, C.; JIANZHONG, L.; GASSMAN, P. W.; SABINE, S.; JOSÉMIGUEL, S. P. Assessing impacts of different land use scenarios on water budget of Fuhe river, China using SWAT model. International Journal of Agricultural and Biological Engineering, v. 8, n. 3, p. 95-109, 2015. 
CARDOSO, D. P.; SILVA, M. L. N.; CURI, N.; SÁFADI, T.; FONSECA, S.; FERREIRA, M. M.; MARTINS, S. G.; MARQUES, J. J. G. S. M. Erosão hídrica avaliada pela alteração na superfície do solo em sistemas florestais. Sci. For, n. 66, p. 25-37, 2004.

CARNEIRO, T. G. C. NESTED-CA: A foundation for multiscale modelling of land use and land cover change. 2006. $109 \mathrm{f}$. Tese (Doutorado) - Instituto Nacional de Pesquisas Espaciais (INPE), São José do Campos, 2006.

CARR, M. K. V. The water relations and irrigation requirements of oil palm (Elaeis guineensis): a review. Experimental Agriculture, v. 47, n. 04, p. 629-652, 2011.

CARVALHO, T. M. DE. "Técnicas de medição de vazão por meios convencionais e não convencionais." Revista Brasileira de Geografia Física, v. 1, n. 1, p. 73-85, 2008.

CHAUBEY, I.; CHIANG, L.; GITAU, M. W.; MOHAMED, S. Effectiveness of best management practices in improving water quality in a pasture-dominated watershed. Journal of Soil and Water Conservation, v. 65, n. 6, p. 424-437, 2010.

CHAVES, H. M. L.; ROSA, J. W. C.; VADAS, R. G.; OLIVEIRA, R. V. Regionalização de vazões mínimas em bacias através de interpolação em sistemas de informação geográfica. Revista Brasileira de Recursos Hídricos, v. 7, n. 3, p. 43-51, 2002.

CHRISTOFFERSEN, B. O.; RESTREPO-COUPE, N.; ARAIN, M. A.; BAKER, I. T.; CESTARO, B. P.; CIAIS, P.; FISHER, J. B.; GALBRAITH, D.; GUAN, X.; GULDEN, L.; VAN DEN HURK, B.; ICHII, K.; IMBUZEIRO, H.; JAIN, A.; LEVINE, N.; MIGUEZMACHO, G.; POULTER, B.; ROBERTI, D. R.; SAKAGUCHI, K.; SAHOO, A.; SCHAEFER, K.; SHI, M.; VERBEECK, H.; YANG, Z.; ARAÚJO, A. C.; KRUIJT, B. MANZI, A. O.; ROCHA, H. R. DA; VON RANDOW, C.; MUZA, M. N.; BORAK, J.; COSTA, M. H.; GONÇALVES, L. G. G. DE; ZENG, X.; SALESKA, S. R. Mechanisms of water supply and vegetation demand govern the seasonality and magnitude of evapotranspiration in Amazonia and Cerrado. Agricultural and Forest Meteorology, v. 191, p. 33-50, 2014.

CHRISTOFOLETTI, A. Modelagem de Sistemas Ambientais. São Paulo: Edgard Blücher, 1999. 236 p. 
CHU, H. J.; LIN, Y. P.; WU, C. F. Forecasting space-time land use change in the Paochiao watershed of Taiwan using demand estimation and empirical simulation approaches. In: TANYA, D.; GERVASI, O.; MURGANTE, B.; PARDEDE, E.; APDUHAN, B. O. Computational Science and its Applications - ICCSA. Fukuoka: Springer, 2010. p. 116-130.

CLAUSEN, B.; PEARSON, C. P. Regional frequency analysis of annual maximum streamflow drought. Journal of Hydrology, v. 173, n. 1, p. 111-130, 1995.

COELHO, A. Modelagem de dinâmica do uso da terra e cobertura vegetal na região de Santarém, Oeste do Pará. 2009. 128 p. Dissertação (Mestrado) - Instituto de Geociências Programa de pós-graduação em Ciências Ambientais, Universidade Federal do Pará, 2009.

COELHO, B. Z. Avaliação de técnicas e métodos de hidrometria na estação fluviométrica São Ludgero, SC. 2011. 85 f. TCC (Engenharia Ambiental) Universidade do Extremo Sul Catarinense (UNESC), Criciúma, 2011.

CONGALTON, R. G. A Review of assessing the accuracy of classifications of remotely sensed data. Remote Sensing of Environment, v. 37, n. 1, p. 35-46, 1991.

CORLEY, R.H.V.; TINKER, P.B. The Oil Palm. 5th ed. Wiley Blackwell, 2008. 592 p.

CORREA, D. L.; FREITAS, B. W.; SILVA MELO, M. R. DA; MACIEL, M. D. N. M.; SOARES, J. A. C. Avaliação da Produtividade do Dendê (Elaeisguineensis) Através de Técnicas de Sensoriamento Remoto e Geoprocessamento do Município de Concórdia do Pará, 10., 2012, Belém. Anais do 10 Seminário Anual de Iniciação Científica da UFRA. Belém: UFRA, 2012.

COSTA, M. H.; BIAJOLI, M. C.; SANCHES, L.; MALHADO, A.; HUTYRA, L. R., ROCHA, H. R. DA; AGUIAR, R. G.; ARAÚJO, A. C. DE. Atmospheric versus vegetation controls of Amazonian tropical rain forest evapotranspiration: are the wet and seasonally dry rain forests any different?. Journal of Geophysical Research: Biogeosciences, v. 115, p. $1-9,2010$.

COSTA, A. S.; CARIELLO, B. L.; BLANCO, C. J. C.; PESSOA, F. C. L. Regionalização de curvas de permanência de vazão de regiões hidrográficas do Estado do Pará. Revista Brasileira de Meteorologia, v. 27, n. 4, p. 413-422, 2012. 
COSTA, C. F. G.; FIGUEIREDO, R. D. O.; OLIVEIRA, F. D. A.; SANTOS, I. P. O. Escoamento superficial em latossolo amarelo distrófico típico sob diferentes agroecossistemas no nordeste paraense. Revista Brasileira de Engenharia Agrícola e Ambiental, v. 17, n. 2, p. 162-169, 2013.

COUCLELIS, H. From cellular automata to urban models: New principles for model development and implementation. Environ. Plann. B Plan. Des., v. 24, n. 2, p. 165174, 1997.

CREECH, C. T.; SIQUEIRA, R. B.; SELEGEAN, J. P.; MILLER, C. Anthropogenic impacts to the sediment budget of São Francisco river navigation channel using SWAT. International Journal of Agricultural and Biological Engineering, v. 8, n. 3, p. 140157, 2015.

CRESTANA, S.; MINOTI, R. T. ; NEVES, F. F. . Modelagem e simulação aplicadas à avaliação dos impactos da perda de solo e dos dejetos de suínos na qualidade da água de microbacias. In: GOMES, M. A. F.; PESSO, M. C. P. Y. Planejamento ambiental do espaço rural com ênfase para microbacias hidrográficas: manejo de recursos hídricos, ferramentas computacionais e educação ambiental. Brasília: Embrapa Informação Tecnológica, 2010, p. 167-199.

CRUZ, E. S.; CARVALHO, D. F. D.; VARELLA, C. A.; SILVA, L. D.; SOUZA, W. J.; PINTO, F. A. Comparação de classificadores de imagens digitais na determinação da cobertura do solo. Engenharia Agrícola, v. 28, n. 2, p. 237-244, 2008.

CUI, X.; SUN, W.; TENG, J.; SONG, H.; YAO, X. Effect of length of the observed dataset on the calibration of a distributed hydrological model. Remote Sensing and GIS for Hydrology and Water Resources, 2015.

CURTARELLI, M. P.; SILVA, D. J. D.; FERREIRA, C. M. Estudo do balanço hídrico na bacia do rio Canoas em Urubici, SC, Brasil: subsídio à proteção da zona de recarga direta do Sistema Aquífero Guarani. Revista Ambiente e Água, v. 5, n. 3, p. 108-121, 2010.

DAGGUPATI P.; PAI N.; ALE S.; DOUGLAS-MANKIN K. R.; ZECKOSKI R.; JEONG J.; PARAJULI P. B.; SARASWAT D.; YOUSSEF M. A. A recommended calibration and validation strategy for hydrologic and water quality models. American Society of Agricultural and Biological Engineers, 2015. No prelo. 
DEBELE B.; SRINIVASAN R.; PARLANGE J. Y. Coupling upland watershed and downstream waterbody hydrodynamic and water quality models (SWAT and CE-QUALW2) for better water resources management in complex river basins. Environ Model Assess, v. 13, n. 1, p. 135-153, 2008. doi:10.1007/s10666-006-9075-1.

DOUGLAS-MANKIN K. R.; SRINIVASAN R.; ARNOLD J. G. Soil and water assessment tool (SWAT) model: current developments and applications. Transactions of the ASABE, v. 53, n. 5, p. 1423-1431, 2010.

DUFRÊNE, E.; DUBOS, B.; REY, H.; QUENCEZ, P.; SAUGIER, B. Changes in evapotranspiration from an oil palm stand (Elaeis guineensis Jacq.) exposed to seasonal soil water deficits. Oléagineux, Paris, v. 48, n. 3, p. 105-120, 1993.

DURÃES, M. F.; MELLO, C. R. D.; NAGHETTINI, M. Applicability of the SWAT model for hydrologic simulation in Paraopeba River Basin, MG. Cerne, v. 17, n. 4, p. 481-488, 2011.

EASTON, Z. M.; FUKA, D. R.; WHITE, E. D.; COLLICK, A. S.; BIRUK ASHAGRE, B.; MCCARTNEY, M.; AWULACHEW, S. B.; AHMED, A. A. STEENHUIS, T. S. A multi basin SWAT model analysis of runoff and sedimentation in the Blue Nile, Ethiopia. Hydrology and Earth System Sciences, v. 14, n. 10, p. 1827-1841, 2010.

ELETROBRAZ. Diretrizes para estudos e projetos de pequenas centrais hidrelétricas. Rio de Janeiro: Eletrobraz. 2000. 458 p.

EMBRAPA - EMPRESA BRASILEIRA DE PESQUISA AGROPECUÁRIA. Centro Nacional de Pesquisa de Solos. Sistema brasileiro de classificação de solos. 2. ed. Rio de Janeiro: EMBRAPA - SPI, 2000. 412 p.

EMBRAPA - EMPRESA BRASILEIRA DE PESQUISA AGROPECUÁRIA. Produção de sementes sadias de feijão comum em várzeas tropicais. Santo Antônio de Goiás: Embrapa Arroz e Feijão, 2009. (Embrapa Arroz e Feijão. Sistemas de Produção, n. 4) Disponível em <https://sistemasdeproducao.cnptia.embrapa.br/FontesHTML/Feijao/FeijaoVarzeaTropic al/disposicao_fertilizante.htm>. Acesso em: 24 Jun. 2014.

FAEPA - FEDERAÇÃO DA AGRICULTURA E PECUÁRIA DO PARÁ. A cadeia produtiva da palma de óleo no Estado do Pará: Uma avaliação crítica. 2015. 
FAO. AGRICULTURAL OUTLOOK 20015-2024. Disponível em: <www.oecd.org>. Acesso em: 30 Mai. 2015.

FAUSTINO, J. Planificación y gestión de manejo de cuencas. Turrialba: CATIE, 1996. 90p.

FERREIRA, P. H. DE M. Princípios de manejo e conservação do solo. 2. ed. São Paulo: Nobel, 1981.

FIESP. Outlook Brasil 2023. Projeções para o agronegócio. São Paulo: FIESP/ICONE, 2013. 116 p.

FILIZOLA, H. F.; ALMEIDA FILHO, G. S. DE; CANIL, K.; SOUZA, M. D. DE; GOMES, $M$. A. F. Controle dos processos erosivos lineares, ravina e voçorocas, em área de solos arenosos. Jaguariúna: EMBRAPA Meio Ambiente, Circular técnica n. 22, 2011. 7 p.

FITZ, P. R. Geoprocessamento sem complicação. São Paulo: Oficina de textos, 2008.

FONSECA, L. M. G. Processamento Digital de Imagens. Instituto Nacional de Pesquisas Espaciais (INPE), 2000. 105 p.

FREITAS, M. W. D. DE; SANTOS, J. R. DOS. Esboço de modelagem da dinâmica da paisagem no município de Lages-SC. In: Simpósio Brasileiro de Sensoriamento Remoto, 15., 2011, Curitiba. INPE - Instituto Nacional de Pesquisas Espaciais, 2011.

FUKUNAGA, D. C.; CECÍLIO, R. A.; ZANETTI, S. S.; OLIVEIRA, L. T.; CAIADO, M. A. C. Application of the SWAT hydrologic model to a tropical watershed at Brazil. Catena, v. 125, p. 206-213, 2015.

GALHARTE, C. A.; CRESTANA, S. Os impactos das atividades agrícolas nos recursos hídricos. In: PALHARES, J. C. P.; GEBLER, L. Gestão ambiental na agropecuária. Brasília: Embrapa Informação Tecnológica, 2014. p.457 490. 
GALHARTE, C. A. Estimativa do escorrimento superficial e da produção de sedimentos em áreas de atividades agrossilvopastoris, no Estado de São Paulo, em função da mudança de uso e cobertura do solo. Tese (doutorado) - Escola de Engenharia de São Carlos, Universidade de São Paulo, São Carlos, 2011.

GALHARTE, C. A.; VILLELA, J. M.; CRESTANA, S. Estimativa da produção de sedimentos em função da mudança de uso e cobertura do solo. Revista Brasileira de Engenharia Agrícola e Ambiental, v. 18, n. 2, p. 188-193, 2014.

GARBOSSA, L. H. P.; VASCONCELOS, L. R. C.; LAPA, K. R.; BLAINSKI, É.; PINHEIRO, A. The use and results of the Soil and Water Assessment Tool in Brazil: A review from 1999 until 2010. In: 2011 INTERNATIONAL SWAT CONFERENCE, 2011, Spain. SWAT, 2011. $150 \mathrm{p}$.

GASSMAN, P.W.; REYES, M.; GREEN, C. H.; ARNOLD, J. G. The Soil and water assessment tool: historical development, applications, and future research directions. Transactions of the American Society of Agricultural and Biological Engineers, St. Joseph, v. 50, p. 1211-1250, 2007.

GEBERE, S. B.; ALAMIREW, T.; MERKEL, B. J.; MELESSE, A. M. Land use and land cover change impact on groundwater recharge: The case of lake haramaya watershed, Ethiopia. In: MELESSE, A.; ABTEW, W. Landscape Dynamics, Soils and Hydrological Processes in Varied Climates. Spring Geography, 2015. 839 p.

GESSESSE, B.; BEWKET, W.; BRÄUNING, A. Model-based characterization and monitoring of runoff and soil erosion in response to land use/land cover changes in the Modjo watershed, Ethiopia. Land Degradation \& Development, v. 26, n. 7, p. 711-724, 2015.

GITAU, M. W.; CHAUBEY, I. Regionalization of SWAT model parameters for use in ungauged watersheds. Water, v. 2, n. 4, p. 849-871, 2010.

GOSWAMI, M.; O'CONNOR, K. M.; BHATTARAI, K. P. Development of regionalisation procedures using a multi-model approach for flow simulation in an ungauged catchment. Journal of Hydrology, v. 333, p. 517-531, 2007. 
GUERRA, A. J. T.; Botelho, R. G. M. Características e propriedades dos solos relevantes para os estudos pedológicos e análise dos processos erosivos. Anuário do Instituto de Geociências, v. 19, p. 93-114, 1996.

GUERRA, A. J. T. "Experimentos e monitoramentos em erosão dos solos." Revista do Departamento de geografia, v. 16, p. 32-37, 2005.

GUERRA, A. J. T. O início do processo erosivo. In: GUERRA et al. Erosão e conservação do solo: conceitos, temas e aplicações. Rio de Janeiro: Bertrand Brasil, 1999. p. $17-55$

GUIMARÃES, J. C. C.; ALMEIDA, W. F. DE; PAIS, P. S. M.; ANDRADE, M. L. DE C. A Abordagem de Práticas Conservacionista na Recuperação de Voçorocas. Enciclopédia Biosfera, Goiânia, v.8, n.14, p. 997-989, 2012.

GUPTA, H. V.; WAGENER, T.; LIU, Y. Reconciling theory with observations: elements of a diagnostic approach to model evaluation. Hydrological Processes, v. 22, n. 18, p. 3802-3813, 2008.

GUZHA, A. C.; NOBREGA, R.; KOVACS, K.; AMORIM, R. S. S.; GEROLD, G. Quantifying impacts of agro-industrial expansion in Mato Grosso, Brazil, on watershed hydrology using the Soil and Water Assessment Tool (SWAT) model. In: 20th International Congress on Modelling and Simulation, Adelaide, 2013.

HASAN, Z. A.; HAMIDON, N.; YUSOF, M. S.; GHANI, A. A. Flow and sediment yield simulations for Bukit Merah Reservoir catchment, Malaysia: a case study. Water Science and Technology, v. 66, n. 10, p. 2170-2176, 2012.

HERNANI, L. C.; PRUSKI, F.; DE-MARIA, I. C.; CASTRO FILHO C.; FREITAS, P. L. DE; LANDERS, J. A erosão e seu impacto. In: MANZATTO, C. V.; FREITAS JUNIOR, E. DE; PERES, J. R. Uso agrícola dos solos brasileiros. Rio de Janeiro: Embrapa Solos, 2002. p. 47-60.

HOMMA, A. K. O.; FURLAN JÚNIOR, J.; CARVALHO, R. A.; FERREIRA, C. A. P. Bases para uma política de desenvolvimento da cultura do dendezeiro na Amazônia. In: VIEGAS, I. DE J. M., MÜLLER, A. A. A cultura do dendezeiro na Amazônia Brasileira. Belém: Embrapa Amazônia Oriental/Manaus: Embrapa Amazônia Ocidental, 2000. p.11-30. 
HOMMA, A. K. O.; MENEZES, A. J. E. A. DE; MONTEIRO, K. F. G.; SANTOS, J. C. DOS; REBELLO, F. K.; COSTA, D. H. M.; GOMES JÚNIOR, R. A.; SENA, A. L. DOS SANTOS; MOTA JÚNIOR, K. J. A. Integração Grande Empresa e Pequenos Produtores de Dendezeiro: o Caso da Comunidade de Arauaí, Município de Moju, Pará. Belém: Embrapa Amazônia Oriental. Boletim de Pesquisa e Desenvolvimento, 2014. $42 \mathrm{p}$.

HUDSON, W. D.; RAMM, C. W. Correct formulation of the kappa coefficient of agreement. Photogrammetric Engineering and Remote Sensing, v. 53, n. 4, p. 421422, 1987.

IBGE - INSTITUTO BRASILEIRO DE GEOGRAFIA E ESTATÍSTICA. Divisão Regional do Brasil em mesorregiões e microrregiões geográficas. Rio de Janeiro: IBGE, 1990. $137 \mathrm{p}$.

IBGE - INSTITUTO BRASILEIRO DE GEOGRAFIA E ESTATístiCA -. Censo Demográfico: Brasil, 2010. Rio de Janeiro: IBGE, 2010.

INMET - INSTITUTO NACIONAL DE METEOROLOGIA. Rede de Estações Meteorológicas Automáticas e Convencionais do INMET. Brasília, 2014. Disponível em: <http://inmet.gov.br>. Acesso em 27 Jul. 2014.

INPE - INSTITUTO NACIONAL DE PESQUISAS ESPACIAIS. Projeto PRODES: Monitoramento da Floresta Amazônica Brasileira por Satélite. 2012. Disponível em: <http://www.obt.inpe.br/prodes/index.php>. Acesso em 27 Fev.2015.

INPE - INSTITUTO NACIONAL DE PESQUISAS ESPACIAIS. Projeto TerraClass. 2014. Disponível em <http://www.inpe.br/cra/projetos_pesquisas/terraclass2010.php>. Acesso em 01 Jun. 2014.

KALLARACKAL, J.; JEYAKUMAR, P.; GEORGE, S. J. Water use of irrigated oil palm at three different arid locations in Peninsular India. Journal of Oil Palm Research, v. 16, p. $45-53,2004$.

KANNAN, N.; WHITE, S. M.; WORRALL, F.; WHELAN, M. J. Sensitivity analysis and identification of the best evapotranspiration and runoff options for hydrological modelling in SWAT-2000. Journal of Hydrology, v. 332, n. 3, p. 456-466, 2007. 
KATO, O.; Kato, M. S. A.; CARVALHO, C. R. DE; FIGUEIREDO, R.; SÁ, T. D. DE A.; VIELHAUER, K.; DENICH, M. Manejo de vegetação secundária na Amazônia visando ao aumento da sustentabilidade do uso agrícola do solo. In: Congresso Brasileiro de Ciência do Solo: Solos, sustentabilidade e qualidade ambiental, 30., 2005, Recife. Anais... Recife, 2005.

KIM, N. W.; LEE, J. W.; LEE, J.; LEE, J. E. SWAT application to estimate design runoff curve number for South Korean conditions. Hydrological Processes, v. 24, n. 15, p. 2156-2170, 2010.

KUHN, C. Uma análise sistêmica das transformações de uso do solo como suporte à decisão para o planejamento de Unidades de Conservação. 2005. $163 \mathrm{f}$. Dissertação (Mestrado em Planejamento Urbano e Regional) - Universidade Federal do Rio Grande do Sul, Porto Alegre, 2005.

KULT, J. M.; FRY, L. M.; GRONEWOLD, A. D.; CHOI, W. Regionalization of hydrologic response in the Great Lakes basin: Considerations of temporal scales of analysis. Journal of Hydrology, v. 519, p. 2224-2237, 2014.

LAI, S. H.; AMIN, M.; SOOM, M.; LAW, P. L.; MAH, D. Y. S. Applications of GIS and remote sensing in the hydrological study of the upper Bernam river Basin, Malaysia. Journal The Institution of Engineers, Malaysia, v. 69, n.1, 2008.

LAI, S. H. Application of Swat Hydrological Model with GIS Interface to Upper Bernam River Basin. 2001. 122 f. Dissertation (Master of Science in the Faculty of Engineering) - Universiti Putra Malaysia, 2001.

LAMBIN, E. F.; TURNER, B. L.; GEIST, H. J.; AGBOLA, S. B.; ANGELSEN, A.; BRUCE, J. W.; GEORGE, P. S. The causes of land-use and land-cover change: moving beyond the myths. Global environmental change, v. 11, n. 4, p. 261-269, 2001.

LAMEIRA, W. J. DE M.; VIEIRA, I. C. G. Análise da expansão do cultivo da palma de óleo no Nordeste do Pará. Novos Cadernos NAEA, v. 18, n. 2, p. 185-197, jun-set. 2015a. ISSN 1516-6481 / 2179-7536.

LAMEIRA, W. J. DE M.; VIEIRA, I. C. G.; TOLEDO, P. M. DE. Panorama da Sustentabilidade na Fronteira Agrícola de Bioenergia na Amazônia. Sustentabilidade em Debate,v. 6, n. 2, p. 193-210, 2015b. 
LAPPONI, J. C. Estatística usando Excel. Rio de Janeiro: Elsevier, 2005.

LEIVAS, J. F.; TEIXEIRA, A. D. C.; ANDRADE, R. G. Estimativa dos fluxos evapotranspiratórios na floresta nacional do tapajós e entorno a partir de imagens de satélite. In: INOVAGRI International Meeting, 2., 2014, Fortaleza.

LESSCHEN, J.-P.; VERBURG, P. H.; STAAL, S. J. Statistical methods for analysing the spatial dimension of changes in land use and farming systems. Wageningen: ILRI \& Wageningen University, 2005.

LEITE, F. P.; BARROS, N. D.; NOVAIS, R. D.; SANS, L. M. A.; FABRES, A. S. Crescimento de Eucalyptus grandis em diferentes densidades populacionais. Revista Árvore, v. 21, n. 3, p. 313-321, 1997.

LELIS, T. A.; CALIJURI, M. L.; FONSECA, A. S. DA; LIMA, D. C. DE. Impactos causados pelas mudanças climáticas nos processos erosivos de uma bacia hidrográfica: Simulação de cenários. Revista Ambiente \& Água, v. 6, n. 2, p. 282-294, 2011.

LELIS, T. A.; CALIJURI, M. L.; SANTIAGO, A. F.; LIMA, D. C.; ROCHA, E. O. Análise de sensibilidade e calibração do modelo SWAT aplicado em bacia hidrográfica da região sudeste do Brasil. Revista Brasileira de Ciência do Solo, v. 36, p. 623-634, 2012.

LIMA, A. M. M. DE; PONTE, M. X. Dinâmica da paisagem da bacia do rio Capim-PA (The Capim-Pa River Basin Landscape Dynamics). Revista Brasileira de Geografia Física, v. 5, n. 1, p. 127-142, 2012.

LIMA, A. M. M. DE. Sistema de informação de recursos hídricos como subsídio a elaboração do plano diretor da bacia do Rio Capim - Pa. In: Simpósio Brasileiro de Sensoriamento Remoto, 12., 2005, Goiânia. Anais XII, 2005. p. 3789-3796.

LIMA, S. M. V.; FREITAS FILHO, A.; CASTRO, A. M. G.; SOUZA, H. R. Desempenho da cadeia produtiva do dendê na Amazônia Legal. Belém: Sudam (extinta)/Fundação de Apoio ao Desenvolvimento da UFPE, 2002. 164 p. 
LIU, M.; LI, C.; HU, Y.; SUN, F.; XU, Y.; CHEN, T. Combining CLUE-S and SWAT models to forecast land use change and non-point source pollution impact at a watershed scale in Liaoning Province, China. Chinese Geographical Science, v. 24, n. 5, p. 540-550, 2014.

LUBITZ, E. Avaliação da aplicação do modelo hidrológico SWAT à bacia do Ribeirão Concórdia - Lontras, SC. 2009. 86 p. Dissertação (Mestrado em Engenharia Ambiental) - Universidade Regional de Blumenau, Blumenau, 2009.

LUO, G.; YIN, C.; CHEN, X.; XU, W.; LU, L. Combining system dynamic model and CLUE-S model to improve land use scenario analyses at regional scale: a case study of sangong watershed in Xinjiang, China. Ecological Complexity, v. 7, n. 2, p. 198-207, 2010.

MCCUEN, R. H. Hydrologic analysis and design. New Jersey: Prentice-Hall, 1998.

MACEDO JUNIOR, C.; ASSAD, E. D.; MARIN, F. R. Zoneamento de riscos climáticos para a dendeicultura no Brasil. In: CONGRESSO BRASILEIRO DE AGROMETEOROLOGIA, 16., 2009, Belo Horizonte. Anais... Viçosa: UFV; 2009.

MACHADO, R. E. Simulação de escoamento e de produção de sedimentos em uma microbacia hidrográfica utilizando técnicas de modelagem e geoprocessamento. 2002. $152 \mathrm{f}$. Tese (Doutorado em Agronomia) - Escola Superior de Agricultura Luiz de Queiroz, Universidade de São Paulo, Piracicaba, 2002.

MACHADO, R. E.; VetTORAZZI, C. A.; XAVIER, A. C. Simulação de cenários alternativos de uso da terra em uma microbacia utilizando técnicas de modelagem e geoprocessamento. Revista Brasileira de Ciência do Solo, v. 27, n. 4, p. 727-733, 2003.

MACHADO, R. E.; VETTORAZZI, C. A. Simulação da produção de sedimentos para a microbacia hidrográfica do Ribeirão dos Marins (SP). Revista Brasileira de Ciência do Solo, v. 27, n. 4, p. 735-741, 2003.

MAJID, M. R.; RUSLI, N. Hydrological impact of large scale conversion of rubber to oil palm plantation. In: 2014 International SWAT Conference, 2014, Pernambuco. 2014. 
MARCHIORO, E. Modelagem hidrossedimentológica na bacia do córrego Santa Maria: Subsídios à aplicação de práticas de conservação de água e solo no noroeste fluminense. 2008. 218 f. Tese (Doutorado em Geografia) - Universidade Federal do Rio de Janeiro, Rio de Janeiro, 2008.

MARCHIORO, E.; FERNANDES, N. F.; MACEDO, J. R. DE; BHERING, S. B.; GONÇALVES, A. O.; PRADO, R. B. Modelagem da produção de sedimentos usando cenário ambiental alternativo no noroeste do Rio de Janeiro-Brasil. Geografias (UFMG), v. 10, n. 1, p. 54-70, 2014.

MEDEIROS, I. C.; XAVIER, A. P. C.; SILVA, A. M.; SANTOS, C. A. G.; SILVA, R. M. Simulação da produção de sedimentos utilizando dados de entrada de alta resolução espacial no modelo SWAT. In: Simpósio Brasileiro de Recursos Hídricos, 20., 2013, Bento Gonçalves, Anais... Bento Gonçalves, 2013.

MEIJIDE, A.; RÖLL, A.; NIU, F.; JUNE, T.; HÖLSCHER, D.; KNOHL, A. Evapotranspiration components determined by eddy covariance and sap flux measurements in oil palm plantations in Sumatra, Indonesia. In: EGU - General Assembly Conference, Abstracts, 17, 2015.

MENARD, S. Applied logistic regression analysis. Sage: Sage University Papers. 2001.

MEMARIAN, H.; BALASUNDRAM, S. K.; ABBASPOUR, K. C.; TALIB, J. B.; BOON SUNG, C. T.; SOOD, A. M. SWAT-based hydrological modelling of tropical land-use scenarios. Hydrological Sciences Journal, v. 59, n. 10, p. 1808-1829, 2014.

MEMARIAN, H.; BALASUNDRAM, S. K.; TALIB, J. B.; TEH BOON SUNG, C.; MOHD SOOD, A.; ABBASPOUR, K. C. KINEROS2 application for land use/cover change impact analysis at the Hulu Langat Basin, Malaysia. Water and Environment Journal, v. 27, n. 4, p. 549-560, 2012.

MINOTTI, R.T. Abordagens qualitativa e quantitativa de micro-bacias hidrográficas e áreas alagáveis de um compartimento do Médio Mogi-Superior/SP. 2006. 203 p. Tese (Doutorado em Ciências da Engenharia Ambiental) - Escola de Engenharia de São Carlos, Universidade de São Paulo, São Carlos, 2006. 
MIRANDA, E. E. DE; (Coord.). Brasil em Relevo. Campinas: Embrapa Monitoramento por Satélite, 2005. Disponível em: <http://www.relevobr.cnpm.embrapa.br>. Acesso em: 17 fev. 2013.

MIGLIACCIO, K. W.; CHAUBEY, I. Spatial distributions and stochastic parameter influences on SWAT flow and sediment predictions. Journal of hydrologic engineering, v. 13, n. 4, p. 258-269, 2008.

MOLIN, P. G. Dynamic modeling of native vegetation in the Piracicaba River basin and its effects on ecosystem services. 2014. $148 \mathrm{f}$. Doctoral Thesis - Escola Superior de Agricultura Luiz de Queiroz, Universidade de São Paulo (USP), Piracicaba, 2014.

MONTEIRO, K. F. G. Análise de indicadores de sustentabilidade socioambiental em diferentes sistemas produtivos com palma de óleo no Estado do Pará. 2013. 198 f. Tese (Doutorado em Ciências Agrárias/Agroecossistemas da Amazônia) Universidade Federal Rural da Amazônia/Embrapa Amazônia Oriental, Belém, 2013.

MONTEIRO, K. F. G.; HOMMA, A. K. O. Diferentes sistemas de produção com Palma de Óleo (Elaeis Guineensis Jaq.) e a participação do Brasil no cenário internacional. Observatorio de la Economía Latinoamericana, 2014.

MORAES, J. M. DE.; SCHULER, A. E.; DUNNE, T.; FIGUEIREDO, R. D. O.; VICTORIA, R. L. Water storage and runoff processes in plinthic soils under forest and pasture in Eastern Amazonia. Hydrological Processes, v. 20, n. 12, p. 2509-2526, 2006.

MORIASI, D.N; ARNOLD, J. G; VAN LIEW, M. W; BINGER, R. L; HARMEL, R. D; VEITH, T. Model evaluation guidelines for systematic quantification of accuracy in watershed simulations. Trans ASABE, v. 50, n. 3, p. 885-900, 2007.

MULETA, M. K.; NICKLOW, J. W. Sensitivity and uncertainty analysis coupled with automatic calibration for a distributed watershed model. Journal of Hydrology, v. 306, n. 1, p. 127-145, 2005.

MÜLLER, A. A.; FURLAN JÚNIOR, J.; CELESTINO FILHO, P. A Embrapa Amazônia Oriental e o agronegócio do dendê no Pará. Belém: Embrapa Amazônia Oriental, 2006. 68 p. (Embrapa Amazônia Oriental. Documentos, 257). 
NEITSCH, S. L.; ARNOLD, J. G.; KINIRY, J. R.; WILLIAMS, J. R. Soil and Water Assessment Tool: Theoretical Documentation Version 2009. Temple: Grassland, Soil and Water Research Laboratory, Agricultural Research Service, 2011. 618 p.

NEPSTAD, D. C.; MOUTINHO, P. R. S.; MARKEWITZ, D. The recovery of biomass, nutrients stocks, and deep soil functions in secondary forests. In: MCCLAIN, M.; VICTORIA, R.; RICHEY, J. Biogeochemistry of the Amazon. London: Oxford University Press, 2001. 416 p.

NEVES, F. F.; SILVA, F. DAS G. B. DAS; CRESTANA, S. Comparação entre três métodos de evapotranspiração potencial aplicados a duas sub-bacias hidrográficas de Descalvado-SP. In: Simpósio Brasileiro de Recursos Hídricos, 16., 2005.

NEVES, F. F.; SILVA, F. DAS G. B. DAS; CRESTANA, S. Uso do modelo AVSWAT na avaliação do aporte de nitrogênio $(N)$ e fósforo $(P)$ aos mananciais de uma microbacia hidrográfica contendo atividade avícola. Eng. Sanit. Ambient, v. 11, n. 4, p. 311-317, 2006.

NOBERT, J.; JEREMIAH, J. Hydrological response of watershed systems to land use/cover change. a case of Wami River Basin. Open Hydrology Journal, v.6, p. 7887, 2012.

NUNES, H. G. G. C. Modelagem hidrológica na bacia do rio capim. 2013. $99 \mathrm{f}$. Dissertação (Mestrado em Ciências Florestais) - Universidade Federal Rural da Amazônia, Belém, 2013.

NUNES, J. G.; CAMPOS, M. C. C.; OLIVEIRA, F. P.; NUNES, J. C. Tolerância de perda de solo por erosão na região sul do Amazonas. Ambiência Guarapuava (PR), v. 8, n. 3, p. 859-868, 2012.

NUNES, F. C.; SILVA E. F. DA; VILAS-BÔAS, G. S. Grupo Barreiras: características, gênese e evidências de neotectonismo. Rio de Janeiro: Embrapa Solos, 2011. 30 p. (Embrapa Solos. Boletim de Pesquisa e Desenvolvimento, 194).

OLIVEIRA, W. N. DE. Avaliação da qualidade ambiental da paisagem da bacia hidrográfica e do reservatório do ribeirão João Leite. 2013. 179 f. Dissertação (Mestrado em Engenharia do Meio Ambiente) - Universidade Federal de Goiás, Goiânia, 2013. 
OLIVEIRA, M. A. T. DE. Processos erosivos e preservação de áreas de risco de erosão por voçorocas. In: GUERRA et al. Erosão e conservação do solo: conceitos, temas e aplicações. Rio de Janeiro: Bertrand Brasil, 1999.

OLIVEIRA, F.; VALENZUELA, R.; SRINIVASAN, J. C.; CHO, H.; KOKA, S.; AGRAWAL, A. Arcgis-swat: a geodata model and gis interface for swat. Journal of the american water resources association. 2006, p. 295-309.

OLIVEIRA JUNIOR, R. C. DE; RODRIGUES, T. E.; VALENTE, M. A.; SILVA. J. M. L. DA. Caracterização físico-hídrica de quatro perfis de solos da região Transamazônica, trecho Altamira-Itaituba. Belém: Embrapa-CPATU, 1998a. 29p. (Embrapa-CPATU, Boletim de Pesquisa, 206).

OLIVEIRA JUNIOR, R. C. DE; RODRIGUES, T. E.; SILVA, J. M. L. DA; VALENTE, M. A. Caracterização físico-hídrica dos principais solos da região de Marabá-Carajás, Estado do Pará. Belém: Embrapa-CPATU, 1998b. 43 p. (Embrapa-CPATU. Boletim de Pesquisa, 205).

OLIVEIRA JUNIOR, R. C. DE; VALENTE, M. A.; RODRIGUES, T. E.; SIL VA, J. M. L. DA. Caracterização físico-hídrica de cinco perfis de solos do nordeste paraense. Belém: Embrapa Amazônia Oriental, 1997. 27 p. (Embrapa Amazônia Oriental. Boletim de Pesquisa, 177).

OLIVEIRA JUNIOR, R. C. DE; VALENTE, M. A.; RODRIGUES, T. E. Caracterização físico-hídrica de solos do sudeste paraense. Belém: Embrapa Amazônia Oriental, 1999. 35 p. (Embrapa Amazônia Oriental. Boletim de Pesquisa, 20).

OTSUBO, A .A.; BRITO, O. R.; PASSOS, D. P.; ARAÚJO, H. S. DE; MERCANTE, F. M.; OTSUBO, V. H. N.. Formas de preparo de solo e controle de plantas daninhas nos fatores agronômicos e de produção da mandioca. Semina: Ci. Agr., Londrina, v. 33, n. 6, p. 2241-2246, 2012.

PAGLIERO, L.; BOURAOUI, F.; WILLEMS, P.; DIELS, J. Large-scale hydrological simulations using the soil water assessment tool, protocol development, and application in the Danube Basin. Journal of Environmental Quality, v. 43, n. 1, p. 145-154, 2014. 
PARÁ. Secretaria de Meio Ambiente do Estado do Pará. Política de Recursos Hídricos do Estado do Pará: Lei Estadual n 6.381, de 25 de julho de 2001. Belém: SEMA-PA, 2012. $117 \mathrm{p}$.

PEDROSA, B. M; CAMARA, G. Modelagem dinâmica e sistemas de informação geográfica. In: MEIRELLES, M.S.P.; CAMARA,G., ALMEIDA, C.M. Geomática: modelos e aplicações ambientais. Brasília: Embrapa SCT, 2007. p. 237-280.

PEREIRA, S. E. M. Análise estratégica do zoneamento agroecológico como instrumento de ordenamento territorial setorial rural e sua aplicação em modelos de mudança de uso e cobertura da terra. 2013. $166 \mathrm{f}$. Tese (Doutorado em Meio Ambiente) - Universidade do Estado do Rio de Janeiro (UERJ), Rio de Janeiro, 2013.

PEREIRA, D. D. R.; MARTINEZ, M. A.; ALMEIDA, A. Q. D.; PRUSKI, F. F.; SILVA, D. D. D.; ZONTA, J. H. Hydrological simulation using SWAT model in headwater basin in Southeast Brazil. Engenharia Agrícola, v. 34, n. 4, p. 789-799, 2014 a.

PEREIRA, D. D. R.; ALMEIDA, A. Q. D.; MARTINEZ, M. A.; ROSA, D. R. Q. Impacts of deforestation on water balance components of a watershed on the Brazilian East Coast. Revista Brasileira de Ciência do Solo, v. 38, n. 4, p. 1350-1358, 2014 b.

PESSOA, F. C. L.; BLANCO, C. J. C.; MARTINS, J. R. Regionalização de curvas de permanência de vazões da região da calha Norte no Estado do Pará. RBRH Revista Brasileira de Recursos Hídricos, v. 16, n. 2, p. 65-74, 2011.

PESSOA, M. C. P. Y.; LUCHIARI JUNIOR, A.; FERNANDES, E, N.; LIMA, M. A. Principais modelos e simuladores utilizados para análise de impactos ambientais das atividades agrícolas. Jaguariúna: Embrapa, 1997. 91 p.

PETERSON, J. R.; HAMLETT, J. M. Hydrologic calibration of the Swat model in a watershed containing fragipan soils. Journal of The American Water Resources Association, v. 34, n. 3,p. 531-544, 1998.

PILGRIM, D. H. Some problems in transferring hydrological relationships between small and large drainage basins and between regions. Journal of Hydrology, v. 65, n. 1, p. 49-72, 1983. 
PIMENTA, P. et al. Land change modeling and institutional factors: heterogeneous rules of territory use in the Brazilian Amazonia. In: Simpósio Brasileiro de Geoinformática, 10., 2008, Rio de Janeiro. Anais... Disponível em: $<$ http://www.dpi.inpe.br/gilberto/papers/pimenta_geoinfo2008.pdf>. Acesso em: 08 Out. 2014.

PONTIUS, R. G.; SCHNEIDER, L. C. Land-cover change model validation by an ROC method for the Ipswich watershed, Massachusetts, USA. Agriculture, Ecosystems \& Environment, v. 85, n. 1, p. 239-248, 2001.

POST, D. A.; JONES, J. A.; GRANT, G. E. An improved methodology for predicting the daily hydrologic response of ungauged catchments. Environmental Modelling \& Software, v. 13, n. 3, p. 395-403, 1998.

PRIMAVESI, A. Manejo ecológico do solo: a agricultura em regiões tropicais. São Paulo: Nobel, 2002.

PROVAM - PROGRAMA DE ESTUDOS E PESQUISAS NOS VALES AMAZÔNICOS. SUPERINTENDÊNCIA DO DESENVOLVIMENTO DA AMAZÔNIA. Belém: SUDAM/OEA, 1990. $189 \mathrm{p}$.

PRUSKI, F. F.; NUNES, A.; REGO, F. S.; SOUZA, M. Extrapolação de equações de regionalização de vazões mínimas: Alternativas para atenuar os riscos. Water Resources and Irrigation Management, Cruz das Almas, v. 1, n. 1, p. 51-59, set-dez. 2012.

PUNNURI, S. M.; SINGH, B. P.. Oil Palm. In: BHARAT, P. Singh. Biofuel Crops: Production, Physiology and Genetics. Fort Valley State University, Fort Valley, Georgia, UDA. 2013.

RAMALHO FILHO, A. Zoneamento agroecológico, produção e manejo da cultura de palma de óleo na Amazônia. Rio de Janeiro: Embrapa Solos, 2010. 216 p.

RIBEIRO, B. M. G.; FONSECA, L. M. G.; KUX, H. J. H. Mapeamento da cobertura do solo urbano utilizando imagens Worldview-ii e o sistema interimage. Revista Brasileira de Cartografia, v. 63, p. 51-63, 2011. 
RIO GRANDE DO SUL, Secretaria da Agricultura. Manual de conservação do solo e água: uso adequado e preservação dos recursos narurais renováveis. 3 ed. Porto Alegre, 1985. $287 \mathrm{p}$.

ROCHA, E. O.; CALIJURI, M. L.; SANTIAGO, A. F.; ASSIS, L. C. DE; ALVES, L. G. S. The contribution of conservation practices in reducing runoff, soil loss, and transport of nutrients at the watershed level. Water Resources Management, v. 26, n. 13, p. 38313852, 2012.

RODRIGUES, E. L.; ELMIRO, M. A. T.; BRAGA, F. DE A.; JACOBI, C. M.; ROSSI, R. D. Impact of changes in land use in the flow of the Pará River Basin, MG. R. Bras. Eng. Agríc. Ambiental, v. 19, n. 1, p. 70-76, 2015.

RÖLL, A.; NIU, F.; MEIJIDE, A.; HARDANTO, A.; KNOHL, A.; HÖLSCHER, D. Transpiration in an oil palm landscape: effects of palm age. Biogeosciences, v. 12, n. 19, p. 5619-5633, 2015.

RUSLI, N.; MAJID, M. R. Investigating leaf area index of palm oil and rubber on hydrologic response: a research methodology. In: International Technical Conference, 2012, Kuala Lumpur. 2012. p. 1-7.

SALOMÃO, F. X. DE T. Controle e prevenção dos processos erosivos. In: GUERRA et al. Erosão e conservação do solo: conceitos, temas e aplicações. Rio de Janeiro: Bertrand Brasil, 1999.

SANTOS, J. T. S. dos. Aplicação do modelo hidrológico swat para a sub-bacia do rio arapepó (Salinópolis/PA). 2014. 84 f. Dissertação (Mestrado em Ciências Florestais) - Universidade Federal Rural da Amazônia, Belém, 2014.

SANTOS, C. A. G.; SILVA, R. M. DA; SRINIVASAN, V. S. Análise das perdas de água e solo em diferentes coberturas superficiais no semi-árido da Paraíba. OKARA: Geografia em debate, v. 1, n. 1, p. 16-32, 2007.

SARTORI, A.; GENOVEZ, A. M.; LOMBARDI NETO, F. Classificação Hidrológica de Solos Brasileiros para a Estimativa da Chuva Excedente com o Método do Serviço de Conservação do Solo dos Estados Unidos Parte 2: Aplicação. Revista Brasileira de Recursos Hídricos, v. 10, n. 4, p. 19-29, 2005b. 
SARTORI, A.; LOMBARDI NETO, F.; GENOVEZ, A. M. Classificação hidrológica de solos brasileiros para a estimativa da chuva excedente com o método do serviço de conservação do solo dos Estados Unidos. Parte 1: Classificação. Revista Brasileira de Recursos Hídricos, v. 10, n. 4, p. 05-18, $2005 a$.

SAXTON K E; RAWLS W. J. Soil water characteristic estimates by texture and organic matter for hydrologic solutions. Soil Science Society of Agronomy Journal, v. 70, n. 5, p. 1569-1578, set-out. 2006. doi: 10.2136/sssaj2005.0117.

SCHNEIDER, K.; KETZER, B.; BREUER, L.; VACHÉ, K. B.; BERNHOFER, C.; FREDE, $\mathrm{H}$. G. Evaluation of evapotranspiration methods for model validation in a semi-arid watershed in northern China. Advances in Geosciences, v. 11, p. 37-42, 2007.

SCHUOL, J.; ABBASPOUR, K. C.; SRINIVASAN, R.; YANG, H. Estimation of freshwater availability in the West African sub-continent using the SWAT hydrologic model. Journal of Hydrology, v. 352, n. 1, p. 30-49, 2008.

SELLAMI, H.; LA JEUNESSE, I.; BENABDALLAH, S.; BAGHDADI, N.; VANCLOOSTER, M. Uncertainty analysis in model parameters regionalization: a case study involving the SWAT model in Mediterranean catchments (Southern France). Hydrology and Earth System Sciences, v. 18, p. 2393-2413, 2014.

SIMMERS, I. A systematic problem-oriented approach to hydrological data regionalisation. Journal of Hydrology, v. 73, n. 1, p. 71-87, 1984.

SINGH, V. P.; WOOLHISER, D. A. "Mathematical modeling of watershed hydrology." Journal of Hydrologic Engineering, v. 7, n. 4, p. 270-292, 2002.

SILVA, F. S. M DA. Estudo dos potenciais impactos das mudanças climáticas e de alterações na cobertura vegetal nos recursos hídricos na região central da Amazônia. 2008, 99 f. Dissertação (Mestrado em Ciências Ambientais), Universidade Federal do Pará (UFPA), Belém, 2008.

SILVA, H. T. DA. Caracterização morfológica, agronômica e fenológica de cultivares de feijão (Phaseolus vulgaris L.) comumente plantado em diversas regiões do Brasil. Goiânia: Embrapa/CNPAF, 1981. (Embrapa/CNPAF. Circular técnico, 15). 
SILVA, J. S. DE O. Produtividade de óleo de palma na cultura do dendê na Amazônia Oriental: influência do clima e do material genético. 2006. 81. f. Dissertação (Mestrado em Fitotecnia) - Universidade Federal de Viçosa (UFV), Viçosa, 2006.

SILVA JÚNIOR, O. B.; BUENO, E. O.; TUCCI, C. E. M.; CASTRO, N. M. R. Extrapolação espacial na regionalização da vazão. Revista Brasileira de Recursos Hídricos, v. 8, n. 1, p. 21-37, 2003.

SILVA JUNIOR, C. A. DA; BOECHAT, C. L.; CARVALHO, L. A. DE.. Atributos químicos do solo sob conversão de floresta Amazônica para diferentes sistemas na região Norte do Pará, Brasil. Biosci. J., Uberlândia, v. 28, n. 4, p. 566-572, Jul-Ago. 2012.

SILVA, R. M. DA.; SANTOS, C. A. G.; SILVA, V. C. DE L.; SILVA, L. P. E. Erosivity, surface runoff, and soil erosion estimation using GIS-coupled runoff-erosion model in the Mamuaba catchment, Brazil. Environmental Monitoring and Assessment, v. 185, n. 11, p. 8977-8990, 2013.

SILVEIRA, G. L. DA; TUCCI, C. E.; SILVEIRA, A. L. DA. Quantificação de vazão em pequenas bacias sem dados. RBRH - Revista Brasileira de Recursos Hídricos, v. 3, n. 3, p. 111-131, jul-set. 1998.

SOARES-FILHO, B. S.; RODRIGUES, H. O.; COSTA, W. L. S. Modeling environmental dynamics with Dinamica EGO. Minas Gerais: Centro de Sensoriamento Remoto. Universidade Federal de Minas Gerais, 2009. 115 p.

SOLER, L. S. Modelagem espacial de uso da terra utilizando o CLUE-S. Conceito e aplicações para estudos de dinâmica de uso da terra. Material de apoio. São Carlos SP: Embrapa CNPDIA, 2010. 49 p.

SOLER, L. DE S; ESCADA, M. I. S.; VERBURG, P. H. Quantifying deforestation and secondary forest determinants for different spatial extents in an Amazonian colonization frontier (Rondonia). Applied Geography, v. 29, p. 182-193, 2009.

SOLER, L. DE S.; VERBURG, P. H. Combining remote sensing and household level data for regional scale analysis of land cover change in the Brazilian Amazon. Regional Environmental Change, v. 10, n. 4, p. 371-386, 2010. 
SOUZA, E. R.; FERNANDES, M. R. Sub-bacias hidrográficas: unidades básicas para o planejamento e a gestão sustentáveis das atividades rurais. Informe Agropecuário, Belo Horizonte, v. 21, n. 207, p. 15-20, 2000.

SOUSA, A. M. L. Estimativa dos fluxos de calor a partir de imagens orbitais e aplicação na modelagem hidrológica. 2010. 129 f. Tese (Doutorado em Recursos Hídricos e Saneamento Ambiental) - Instituto de Pesquisas Hidráulicas, Universidade Federal do Rio Grande do Sul, Porto Alegre, 2010.

SOUSA, A. M. L. D.; VITORINO, M. I.; CASTRO, N. M. D. R.; BOTELHO, M. D. N.; SOUZA, P. J. O. P. D. Evapotranspiration from Remote Sensing to Improve the Swat Model in Eastern Amazonia. Floresta e Ambiente, v. 22, n. 4, p. 456-464, 2015.

SRINIVASAN, R.; RAMANARAYANAN, T. S.; ARNOLD, J. G.; BEDNARZ, S. T. Large area hydrologic modeling and assessment part II: Model application1. Journal of The American Water Resources Association, v. 34, n. 1, p. 91-101, 1998.

SUCHOWER, L. J.; COPENHAVER, M. D. Using the SAS® system to perform McNemar's test and calculate the kappa statistic for matched pairs of data. In: NORTHEAST SAS USERS GROUP CONFERENCE, 1996, Boston. Proceedings... Boston: NESUG, 1996. p. 686-693.

STRAUCH, M.; BERNHOFER, C.; KOIDE, S.; VOLK, M.; LORZ, C.; MAKESCHIN, F. Using precipitation data ensemble for uncertainty analysis in SWAT streamflow simulation. Journal of Hydrology, v. 414, p. 413-424, 2012.

STRAUCH, M.; LIMA, J. E.; VOLK, M.; LORZ, C.; MAKESCHIN, F. The impact of best management practices on simulated streamflow and sediment load in a Central Brazilian catchment. Journal of Environmental Management, v. 127, p. S24-S36, 2013.

TIM, U.S. Emerging technologies for hydrologic and water quality modeling research. Transactions of the ASAE, v.39, n. 20, p. 465-476, 1996.

TUCCI, C. E. M. Hidrologia: Ciência e Aplicação. Porto Alegre: Editora UFRGS, 2013. $943 \mathrm{p}$. 
TUCCI, C. E. M. Regionalização de Vazões. Porto Alegre: Editora da Universidade / UFRGS, 2002. $256 \mathrm{p}$.

TUCCI, C.; Silveira, A.; Sanchez, J.; Albuquerque, F. Flow regionalization in the upper Paraguay basin, Brazil. Hydrological Sciences Journal, v. 40, n. 4, p. 485-497, 1995.

TUNDISI, J.G.; STRASKRABA, M. Strategies for building partnerships in the context of river basin management: the role of ecotechnology and ecological engineering. Lakes \& Reservoirs: Research and Management, Blackwell Publishing, v. 1, p. 31-38, 1995.

TUPPAD, P.; DOUGLAS-MANKIN, K. R.; LEE, T.; SRINIVASAN, R.; ARNOLD, J. G. Soil and water assessment tool (SWAT) hydrologic/water quality model: extended capability and wider adoption. Transactions of the ASABE, v. 54, n. 5, p. 1677-1684, 2011.

USDA - United States Department of Agriculture. Oilseeds: World Markets and Trade. Circular Series, 2010. 33 p.

USDA - United States Department of Agriculture. Oilseeds: World Markets and Trade. Circular Series, 2015. 36 p.

UZEIKA, T.; MERTEN, G. H.; MINELLA, J. P.; MORO, M. Use of the SWAT model for hydro-sedimentologic simulation in a small rural watershed. Revista Brasileira de Ciência do Solo, v. 36, n. 2, p. 557-565, 2012.

VALENCIA, L. I. O. Enfoque da estatística espacial em modelos dinâmicos de mudança do uso do solo. 2008. 93 f. Dissertação (Mestrado em Engenharia da Computação) - Faculdade de Engenharia, Universidade do Estado do Rio de Janeiro, Rio de Janeiro.2008.

VALERIANO, M. DE M. TOPODATA: guia para utilização de dados geomorfológicos locais. INPE, p. 0-72, 2008.

VASQUEZ, M. L.; ROSA-COSTA, L. T. Geologia e recursos minerais do estado do Pará. SIG: texto explicativo dos mapas geológico e tectônico e de recursos minerais do estado do Pará. 2008. 
VELDKAMP, A.; FRESCO, L. O. CLUE: a conceptual model to study the conversion of land use and its effects. Ecological Modelling, v. 85, n. 2, p. 253-270, 1996.

VERBURG, P. H.; KONING, G. H. J. DE; KOK, K.; VELDKAMP, A.; BOUMA, J. A spatial explicit allocation procedure for modelling the pattern of land use change based upon actual land use. Ecological Modelling, v. 116, n. 1, p. 45-61, 1999.

VERBURG, P. H; OVERMARS, K. P. Dynamic simulation of land-use change trajectories with the CLUE-S model. In: KOOMEN, E.; STILLWELL, J.; BAKEMA, A.; SCHOLTEN, H. J. Modelling land-use change: Progress and applications. Netherlands: Springer, 2007. cap. 18. p. 321-338.

VERBURG, P. H.; OVERMARS, K. P.; HUIGEN, M. G.; GROOT, W. T. DE; VELDKAMP, A. Analysis of the effects of land use change on protected areas in the Philippines. Applied Geography, v. 26, n. 2, p. 153-173, 2006a.

VERBURG, P. H.; SCHOT, P. P.; DIJST, M. J.; VELDKAMP, A. Land use change modelling: current practice and research priorities. GeoJournal, v. 61, n. 4, p. 309-324, 2004.

VERBURG, P. H.; SCHULP, C. J. E.; WITTE, N.; VELDKAMP, A. Downscaling of land use change scenarios to assess the dynamics of European landscapes. Agriculture, Ecosystems \& Environment, v. 114, n. 1, p. 39-56, 2006b.

VERBURG, P.H.; SOEPBOER, W.; VELDKAMP, A.; LIMPIADA, R.; ESPALDON, V. Modeling the spatial dynamics of regional land use: the CLUE-S model. Environmental Management, v 30, n. 3, p. 391-405, 2002.

VERBURG, P. H. The CLUE Modeling Framework: The conversion of land use and its effects. University Amsterdam: Institute for Enviromantal Studies, 2010. 49 p.

VERBURG, P. H.; VELDKAMP, A. Projecting land use transitions at forest fringes in the Philippines at two spatial scales. Landscape Ecology, v. 19, n. 1, p. 77-98, 2004.

VIEIRA, M. M. F.; VIEIRA, L. S. Tolerância de perdas de terras para alguns solos amazônicos. B. FCAP, Belém, v. 19, p. 69-77, dez.1990. 
VILLELA, A. A. Expansão da palma na amazônia oriental para fins energéticos. 2014. 388 f. Tese (Doutorado em Planejamento Energético) - Universidade Federal do Rio de Janeiro, Rio de Janeiro, 2014.

VILLELA, J. M. V. Avaliação da influência da expansão da cana-de-açúcar no regime hidrossedimentológico na microbacia do córrego Cana do Reino, Votuporanga - SP. 2015. 146 f. Dissertação (Mestrado em Ciências da Engenharia Ambiental), Universidade de São Paulo, São Carlos, 2015.

WAGENER, T.; MONTANARI, A. Convergence of approaches toward reducing uncertainty in predictions in ungauged basins. Water Resources Research, v. 47, n. 6, p. 1-8, 2011.

WANG, X.; MELESSE, A. M.; YANG, W. Influences of potential evapotranspiration estimation methods on SWAT's hydrologic simulation in a northwestern Minnesota watershed. Transactions of the ASABE, v. 49, n. 6, p. 1755-1771, 2006.

WASSENAAR, T.; GERBER, P.; VERBURG, P. H.; ROSALES, M.; IBRAHIM, M.; STEINFELD, $\mathrm{H}$. Projecting land use changes in the Neotropics: The geography of pasture expansion into forest. Global Environmental Change, v. 17, n. 1, p. 86-104, 2007.

WHITE, K. L.; CHAUBEY, I. Sensitivity analysis, calibration, and validations for a multisite and multivariable swat model. JAWRA, p. 1077-1089, 2005.

WILKINSON, S. N.; YOUNG, W. J.; DEROSE, R. C. Regionalizing mean annual flow and daily flow variability for basin-scale sediment and nutrient modelling. Hydrological Processes, v. 20, n. 13, p. 2769-2786, 2006.

WINCHEL, M; SRINIVASAN, R; DI LUZIO, M; ARNOLD, J. ArcSWAT Interface for SWAT 2012: User's Guide. Texas, USA: Texas AgriLife Research, USDA Agricultural Research Service. 2013. 464 p.

WISCHMEIER, W. H.; SMITH, D. D. Predicting rainfall erosion losses: a guide to conservation planning. Washington: USDA, 1978. $58 \mathrm{p}$. 
YANG, Q; MENG, F. R.; ZHAO, Z; CHOW, T. L.; BENOY, G; REES H. W.; BOURQUE C. P. A. Assessing the impacts of flow diversion terraces on stream water and sediment yields at a watershed level using SWAT model. Agric Ecosyst Environ, v. 132, p. 23-31, 2009. doi:10.1016/j.agee.2009.02.012.

YOULTON, C. Quantificação experimental da alteração no balanço hídrico e erosão em um Neossolo Quartzarênico devido à substituição de pastagem por cana-de-açúcar. 2013. 62 f. Tese (Doutorado em Ciências) - Escola de Engenharia de São Carlos, Departamento de Hidráulica e Saneamento, Universidade de São Paulo, São Carlos, 2013.

YUSOP, Z.; HUI, C. M.; GARUSU, G. J.; KATIMON, A. Estimation of evapotranspiration in oil palm catchment by short-time period water-budget method. Malays $\mathbf{J}$ Civ Eng, $v$. 20, p. 160-174, 2008.

ZEE-PA. Zoneamento Ecológico-Econômico da Zona Leste e Calha Norte do Estado do Pará. Diagnóstico do Meio Físico-Biótico. 1. ed. Belém: PARÁ RURAL, 2010. 326 p.

ZARRINEH, N.; VAN GRIENSVEN, A.; SENNIKOVS, J.; BEKERE, L.; PLUNGE, S. Regionalisation of parameters of a large-scale water quality model in Lithuania using PAIC-SWAT. In: EGU General Assembly Conference Abstracts, 17., 2015, 607 p.

ZHANG, P.; LIU, Y.; PAN, Y.; YU, Z. Land use pattern optimization based on CLUE-S and SWAT models for agricultural non-point source pollution control. Mathematical and Computer Modelling, v. 58, n. 3, p. 588-595, 2013.

ZHANG, X.; Srinivasan, R.; Bosch, D. Calibration and uncertainty analysis of the SWAT model using Genetic Algorithms and Bayesian Model Averaging. J Hydrol, v. 374, n. 3, p. 307-317, 2009. doi:10.1016/ j.jhydrol.2009.06.023

ZHOU, F.; XU, Y.; CHEN, Y.; XU, C. Y.; GAO, Y.; DU, J. Hydrological response to urbanization at different spatio-temporal scales simulated by coupling of CLUE-S and the SWAT model in the Yangtze River Delta region. Journal of Hydrology, v. 485, p. 113-125, 2013. 


\section{APÊNDICE A - Informações extras do modelo SWAT.}

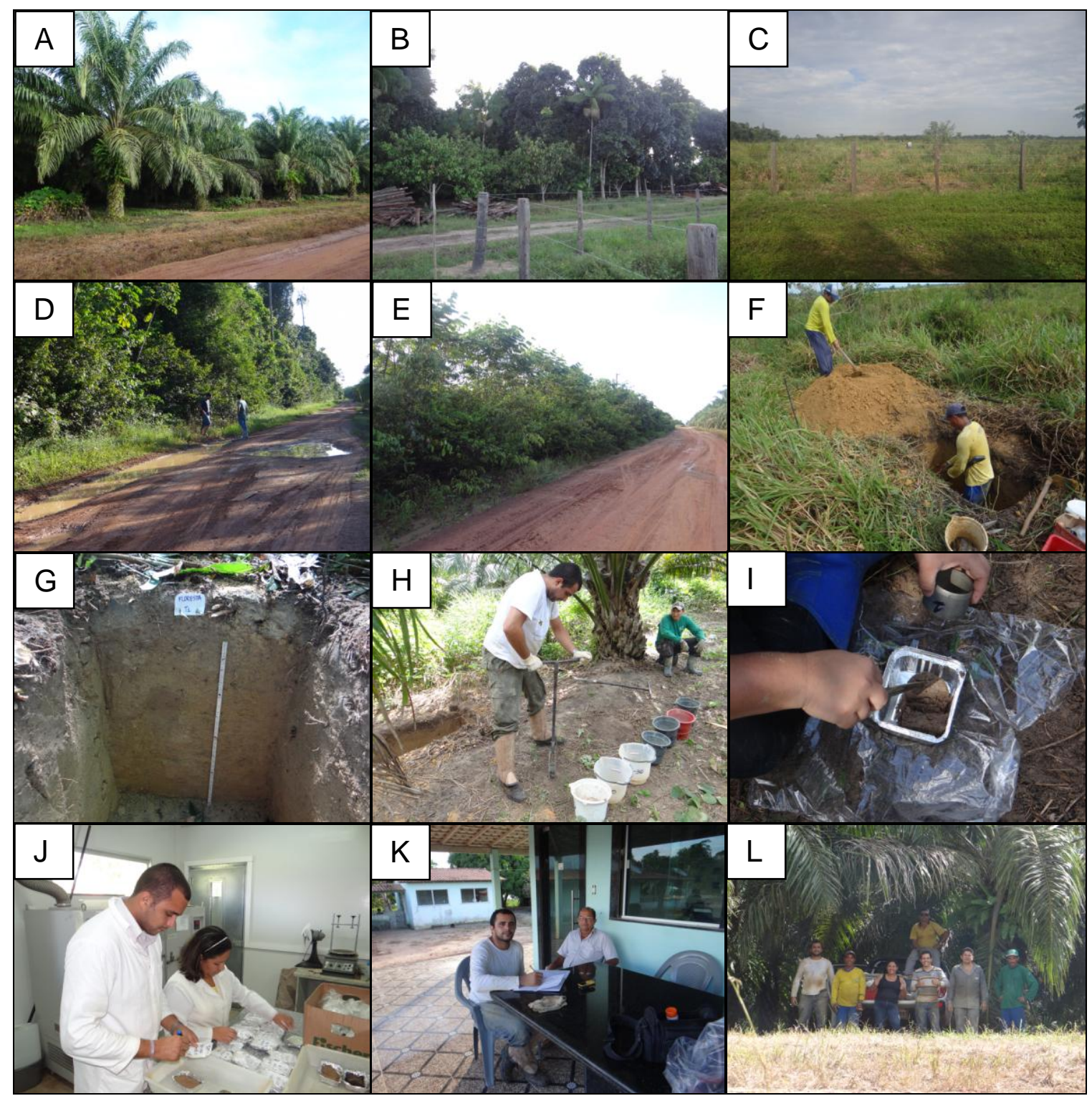

Figura 7: Fotografias dos usos e coberturas da terra e dos trabalhos de coleta e análise dos solos da Fazenda Ipiranga. Onde: A - Plantio de palma de óleo; B - Sistema Agroflorestal; C - Pastagem; D Remanescente florestal; E - Vegetação secundária; F - Abertura da trincheira; G - Perfil da trincheira aberta; $\mathrm{H}$ - Coleta de solo para análise de fertilidade; I - Amostra indeformada para análise da densidade; $\mathrm{J}$ - Pesagem da densidade; K - Entrevista com o proprietário; L - Equipe de trabalho. 
Tabela 29: Coeficientes de regressão e estatísticas das equações finais para estimativa da Regionalização da Vazão Média Mensal de Longo Período das 4 estações reais de monitoamento fluviométrico.

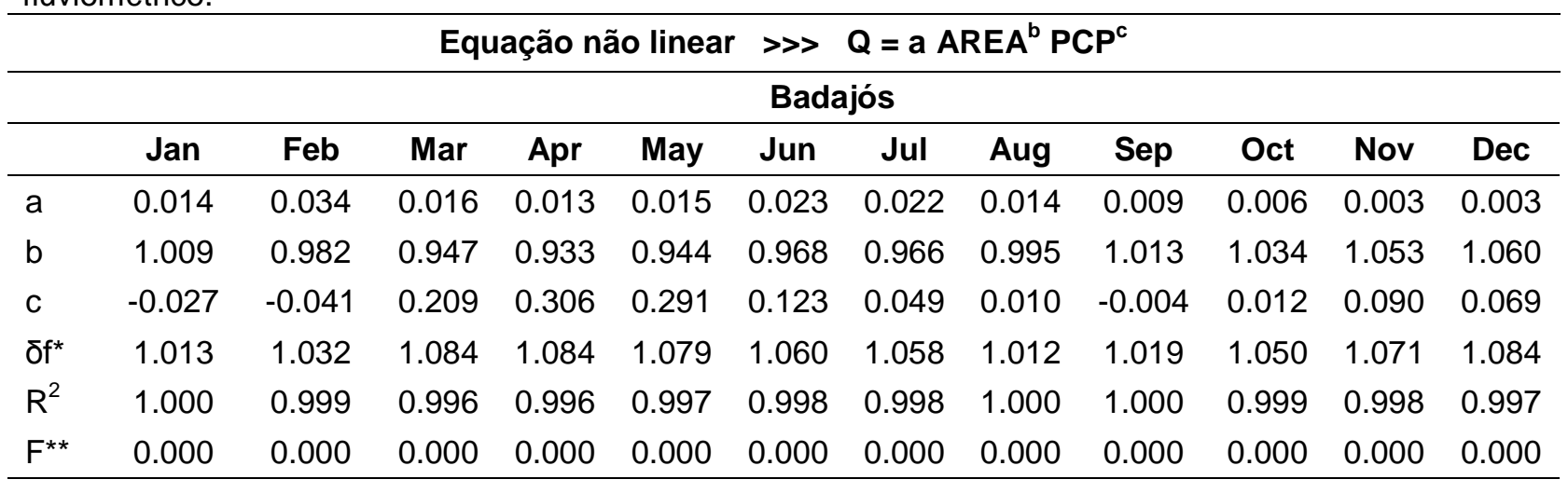

Maringá

\begin{tabular}{lcccccccccccc}
\hline & Jan & Feb & Mar & Apr & May & Jun & Jul & Aug & Sep & Oct & Nov & Dec \\
\hline $\mathrm{a}$ & 0.014 & 0.044 & 0.024 & 0.012 & 0.016 & 0.026 & 0.023 & 0.014 & 0.009 & 0.005 & 0.003 & 0.003 \\
$\mathrm{~b}$ & 1.005 & 0.968 & 0.934 & 0.920 & 0.934 & 0.965 & 0.974 & 0.999 & 1.022 & 1.043 & 1.068 & 1.064 \\
$\mathrm{c}$ & -0.016 & -0.068 & 0.159 & 0.342 & 0.290 & 0.102 & 0.029 & 0.002 & 0.000 & 0.022 & 0.108 & 0.075 \\
$\mathrm{\delta f}^{*}$ & 1.009 & 1.049 & 1.099 & 1.098 & 1.088 & 1.060 & 1.042 & 1.006 & 1.031 & 1.062 & 1.089 & 1.087 \\
$\mathrm{R}^{2}$ & 1.000 & 0.999 & 0.995 & 0.995 & 0.996 & 0.998 & 0.999 & 1.000 & 1.000 & 0.998 & 0.997 & 0.997 \\
$\mathrm{~F}^{* *}$ & 0.000 & 0.000 & 0.000 & 0.000 & 0.000 & 0.000 & 0.000 & 0.000 & 0.000 & 0.000 & 0.000 & 0.000 \\
\hline
\end{tabular}

Bom jardim

\begin{tabular}{lcccccccccccc}
\hline & Jan & Feb & Mar & Apr & May & Jun & Jul & Aug & Sep & Oct & Nov & Dec \\
\hline $\mathrm{a}$ & 0.014 & 0.030 & 0.026 & 0.016 & 0.023 & 0.032 & 0.027 & 0.015 & 0.008 & 0.005 & 0.003 & 0.003 \\
$\mathrm{~b}$ & 1.008 & 0.959 & 0.908 & 0.897 & 0.911 & 0.943 & 0.951 & 0.994 & 1.029 & 1.059 & 1.087 & 1.091 \\
$\mathrm{c}$ & -0.025 & 0.006 & 0.170 & 0.303 & 0.245 & 0.080 & 0.024 & 0.003 & 0.013 & 0.032 & 0.078 & 0.054 \\
$\mathrm{\delta f}^{*}$ & 1.013 & 1.033 & 1.072 & 1.068 & 1.060 & 1.048 & 1.044 & 1.011 & 1.024 & 1.048 & 1.070 & 1.072 \\
$\mathrm{R}^{2}$ & 1.000 & 1.000 & 0.998 & 0.998 & 0.998 & 0.999 & 0.999 & 1.000 & 1.000 & 0.999 & 0.999 & 0.998 \\
$\mathrm{~F}^{* \star}$ & 0.000 & 0.000 & 0.000 & 0.000 & 0.000 & 0.000 & 0.000 & 0.000 & 0.000 & 0.000 & 0.000 & 0.000 \\
\hline
\end{tabular}

Vila Capoeira

\begin{tabular}{lcccccccccccc}
\hline & Jan & Feb & Mar & Apr & May & Jun & Jul & Aug & Sep & Oct & Nov & Dec \\
\hline a & 0.014 & 0.042 & 0.019 & 0.012 & 0.014 & 0.023 & 0.023 & 0.014 & 0.009 & 0.005 & 0.003 & 0.003 \\
b & 1.010 & 0.966 & 0.918 & 0.909 & 0.927 & 0.959 & 0.961 & 0.997 & 1.025 & 1.054 & 1.080 & 1.084 \\
c & -0.018 & -0.061 & 0.212 & 0.351 & 0.316 & 0.129 & 0.047 & 0.010 & 0.002 & 0.020 & 0.102 & 0.074 \\
$\delta^{*}$ & 1.008 & 1.049 & 1.101 & 1.098 & 1.090 & 1.065 & 1.057 & 1.012 & 1.029 & 1.060 & 1.087 & 1.091 \\
$\mathrm{R}^{2}$ & 1.000 & 0.999 & 0.996 & 0.996 & 0.997 & 0.998 & 0.999 & 1.000 & 1.000 & 0.999 & 0.998 & 0.998 \\
$\mathrm{~F}^{* *}$ & 0.000 & 0.000 & 0.000 & 0.000 & 0.000 & 0.000 & 0.000 & 0.000 & 0.000 & 0.000 & 0.000 & 0.000 \\
\hline
\end{tabular}



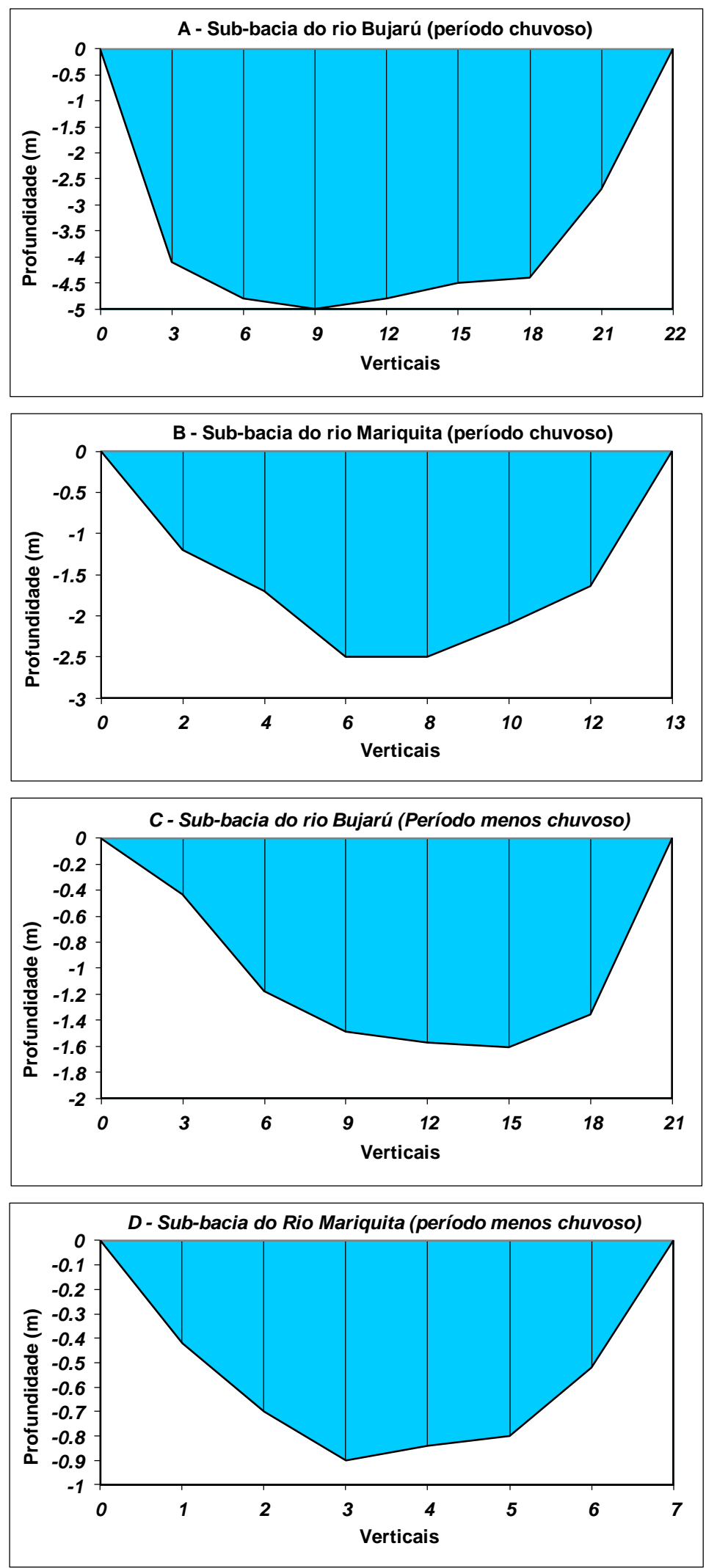

Figura 63: Perfis delineados nos exutoríos das sub-bacias dos rios Bujaru e Mariquita para medição de vazão com molinete hidrométrico. 


\section{APÊNDICE B - Informações extras do modelo CLUE-S.}

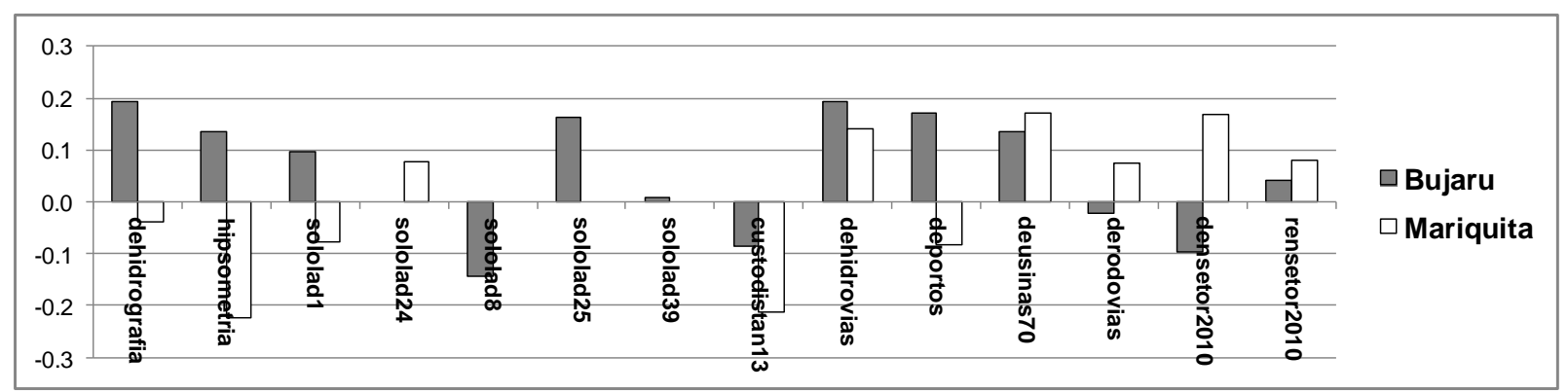

Figura 74: Correlação bivariável entre a classe agricultura geral e as variáveis explanatórias para o ano de 2013.

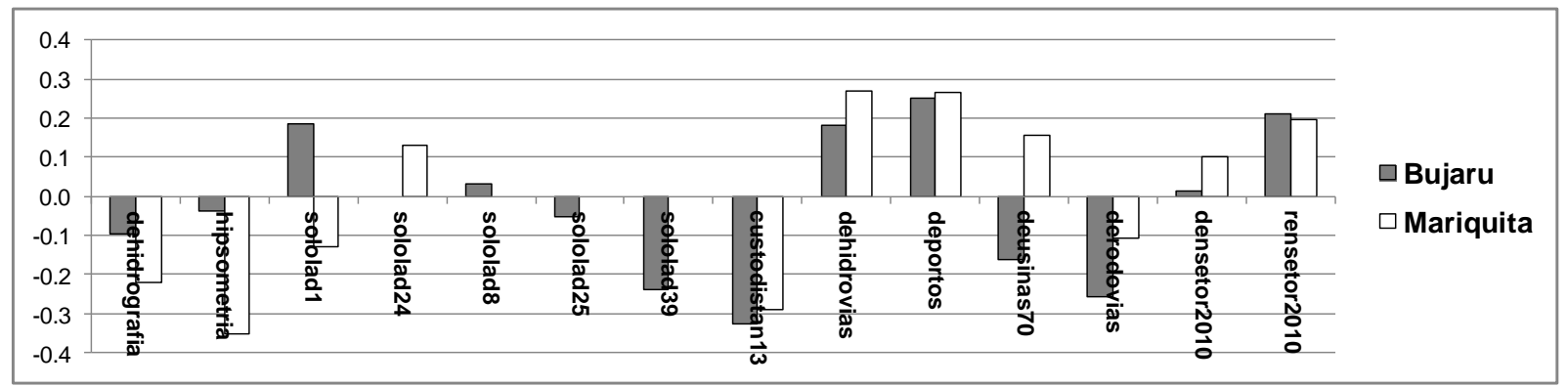

Figura 75: Correlação bivariável entre a classe pastagem e as variáveis explanatórias para o ano de 2013.

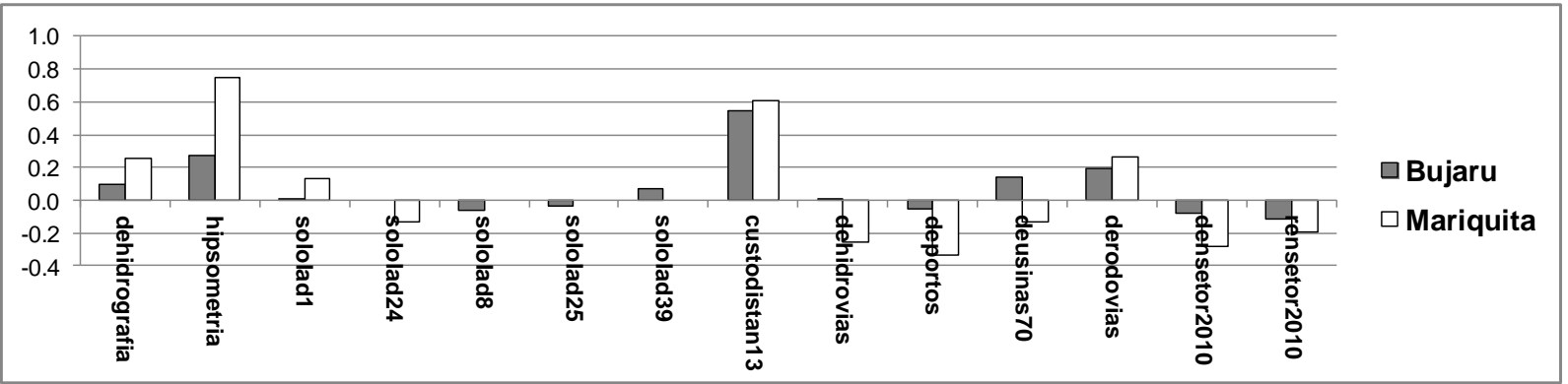

Figura 76: Correlação bivariável entre a classe remanescente florestal e as variáveis explanatórias para o ano de 2013. 


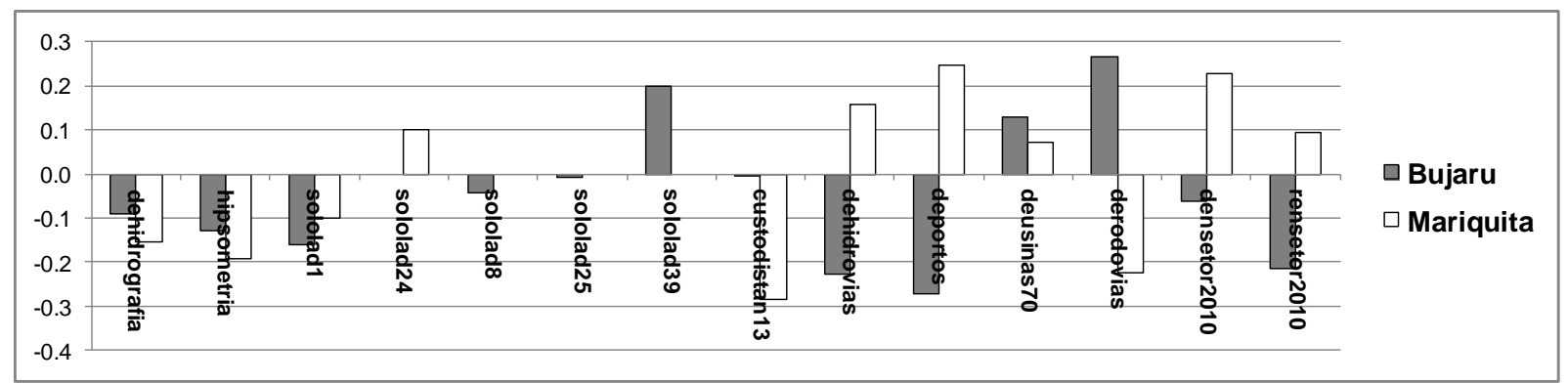

Figura 77: Correlação bivariável entre a classe vegetação secundária e as variáveis explanatórias para o ano de 2013.

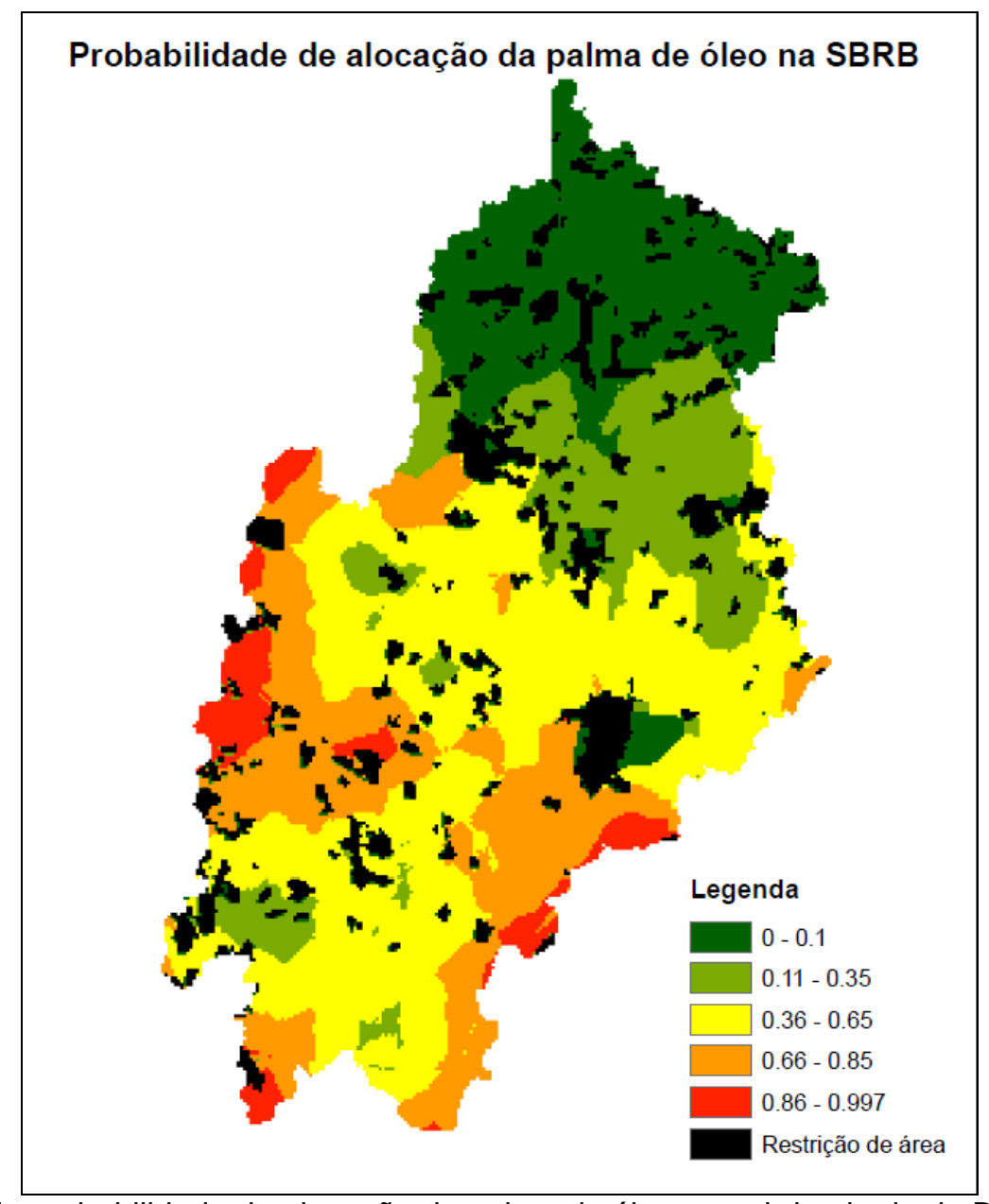

Figura 78: Mapa de probabilidade de alocação da palma de óleo na sub-bacia do rio Bujaru. 
Probabilidade de alocação da palma de óleo na SBRM

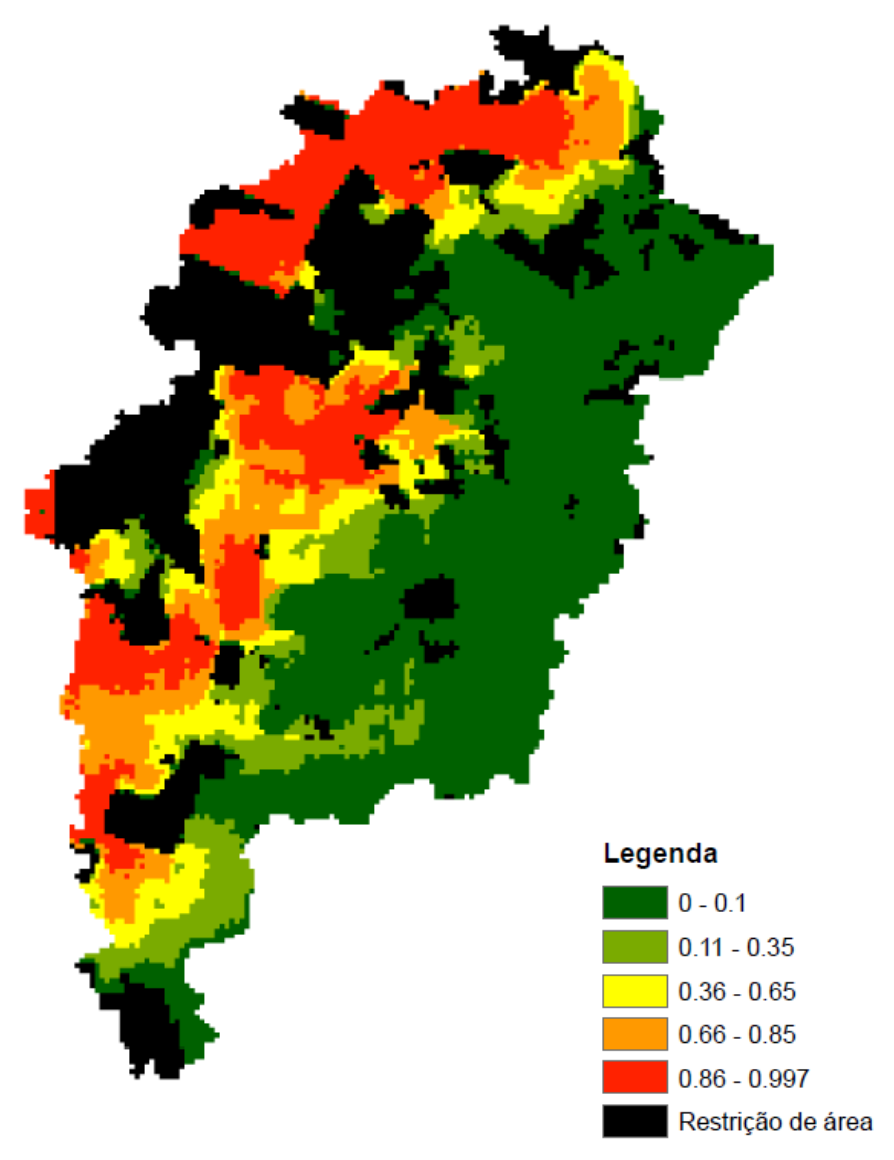

Figura 79: Mapa de probabilidade de alocação da palma de óleo na sub-bacia do rio Mariquita. 


\section{ANEXO A - Informações gerais à Tese.}

Quadro 1: Variedades de LATOSSOLO AMARELO Distrófico (LAd) encontradas nas sub-bacias em estudo (ZEE-PA, 2010).

Sub-bacia do Rio Bujaru
LAd1 - LATOSSOLO AMARELO Distrófico típico, média, A moderado, plano e suave ondulado.

Lad8 - LATOSSOLO AMARELO Distrófico típico, média e argilosa + ARGISSOLO AMARELO e VERMELHO-AMARELO Distrófico típico, média/argilosa + PLINTOSSOLO PÉTRICO Concrecionário típico, argilosa, todos A moderado, plano e suave ondulado.

Lad25 - LATOSSOLO AMARELO Distrófico típico e petroplíntico, média e argilosa + ARGISSOLO AMARELO Distrófico típico e petroplíntico, média/argilosa + PLINTOSSOLO PÉTRICO Concrecionário latossólico, média muito cascalhenta (LATOSSOLO VERMELHO Distrófico argissólico e petroplíntico, média/argilosa muito cascalhenta), todos $\mathrm{A}$ moderado, suave ondulado e ondulado.

LAd39 - LATOSSOLO AMARELO Distrófico argissólico, arenosa/média, plano e suave ondulado + PLINTOSSOLO PÉTRICO Concrecionário argissólico, arenosa muito cascalhenta/média muito cascalhenta e arenosa muito cascalhenta/argilosa muito cascalhenta, suave ondulado e ondulado + NEOSSOLO QUARTZARÊNICO Órtico típico, plano e suave ondulado, todos A moderado (ESPODOSSOLO FERRIHUMILÚVICO Hidromórfico espessarênico, A moderado, plano).

\section{Sub-bacia do Rio} Mariquita
LAd1 - LATOSSOLO AMARELO Distrófico típico, média, A moderado, plano e suave ondulado.

LAd24 - LATOSSOLO AMARELO Distrófico típico, média + LATOSSOLO AMARELO Distrófico petroplíntico, média muito cascalhenta + ARGISSOLO AMARELO Distrófico típico, média/argilosa + PLINTOSSOLO PÉTRICO Concrecionário argissólico, média muito cascalhenta/argilosa muito cascalhenta, todos A moderado, plano e suave ondulado. 